\title{
Development of a Dynamic Modeling and Control System Design Methodology for Gas Turbines
}

by

\author{
Shaun R. Gaudet \\ B.Eng. (Aerospace) \\ A thesis submitted to \\ the Faculty of Graduate Studies and Research \\ in partial fulfillment of the requirements \\ for the degree of

\section{Master of Applied Science} \\ in \\ Aerospace Engineering \\ Ottawa-Carleton Institute For \\ Mechanical and Aerospace Engineering \\ Department of Mechanical and Aerospace Engineering \\ Carleton University \\ Ottawa, Ontario, Canada \\ December 2007 \\ (C) 2007 \\ Shaun R. Gaudet
}




$\begin{array}{ll}\begin{array}{l}\text { Library and } \\ \text { Archives Canada }\end{array} & \begin{array}{l}\text { Bibliothèque et } \\ \text { Archives Canada }\end{array} \\ \begin{array}{l}\text { Published Heritage } \\ \text { Branch }\end{array} & \begin{array}{l}\text { Direction du } \\ \text { Patrimoine de l'édition }\end{array} \\ \begin{array}{l}\text { 395 Wellington Street } \\ \text { Ottawa ON K1A 0N4 } \\ \text { Canada }\end{array} & \begin{array}{l}\text { 395, rue Wellington } \\ \text { Ottawa ON K1A 0N4 } \\ \text { Canada }\end{array}\end{array}$

Your file Votre référence ISBN: 978-0-494-40639-7

Our file Notre référence

ISBN: 978-0-494-40639-7

NOTICE:

The author has granted a nonexclusive license allowing Library and Archives Canada to reproduce, publish, archive, preserve, conserve, communicate to the public by telecommunication or on the Internet, loan, distribute and sell theses worldwide, for commercial or noncommercial purposes, in microform, paper, electronic and/or any other formats.

The author retains copyright ownership and moral rights in this thesis. Neither the thesis nor substantial extracts from it may be printed or otherwise reproduced without the author's permission.
AVIS:

L'auteur a accordé une licence non exclusive permettant à la Bibliothèque et Archives Canada de reproduire, publier, archiver, sauvegarder, conserver, transmettre au public par télécommunication ou par l'Internet, prêter, distribuer et vendre des thèses partout dans le monde, à des fins commerciales ou autres, sur support microforme, papier, électronique et/ou autres formats.

L'auteur conserve la propriété du droit d'auteur et des droits moraux qui protège cette thèse. $\mathrm{Ni}$ la thèse ni des extraits substantiels de celle-ci ne doivent être imprimés ou autrement reproduits sans son autorisation.
In compliance with the Canadian Privacy Act some supporting forms may have been removed from this thesis.

While these forms may be included in the document page count, their removal does not represent any loss of content from the thesis.
Conformément à la loi canadienne sur la protection de la vie privée, quelques formulaires secondaires ont été enlevés de cette thèse.

Bien que ces formulaires aient inclus dans la pagination, il n'y aura aucun contenu manquant.

\section{Canada}




\section{Abstract}

A dynamic modeling and control system design methodology was developed to aid in the off-design performance analysis and control system design process. This capability was developed primarily to assist engine designers during the preliminary design stage, i.e., early in the gas turbine design process.

This thesis describes the dynamic modeling method developed; including all the thermodynamic and mathematical calculations for each section of the gas turbine. This model was then used to simulate engine-startup-to-design-point steady-state and transient performance. The resulting dynamic model was also used as a virtual test bed to assess engine performance at its operating limits.

The control system design methodology laid out a roadmap to control system design, which relied on a minimal amount of data available early in the gas turbine design process. Starting with the controller selection, the method then detailed how to translate control system requirements into engine protection limiters and fuel schedules. The resulting control system design was comprised of two sections: startup sequencing and engine control, which allowed gas turbine control throughout the entire operating regime.

A test case was conducted through the dynamic modeling and control system design for a 1-MW gas turbine marine application. The resulting dynamic model was then validated against GasTurb 10. Also, the proposed control system design was tested virtually with the help of the dynamic model to verify if the control system design requirements were met. Overall, the results showed excellent agreement with the GasTurb benchmark and it was found that the control system design method produced a useful preliminary design of the controls system. 


\section{Acknowledgments}

I would like to acknowledge the endless support and guidance of Dr. J.E.D Gauthier in his efforts to make this body of work possible. I would also like to give special thanks to my colleagues at Rolls-Royce Canada and the Department of Mechanical and Aerospace Engineering for their valuable assistance. Finally, I would like to thank all my friends and family for their endless support both academically and personally. 


\section{Table of Contents}

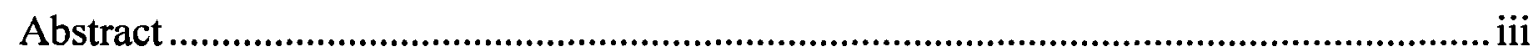

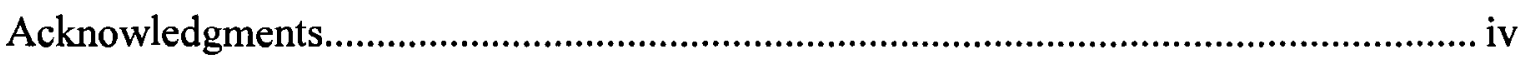

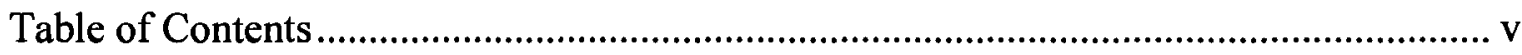

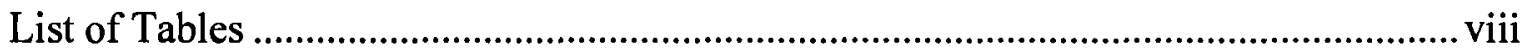

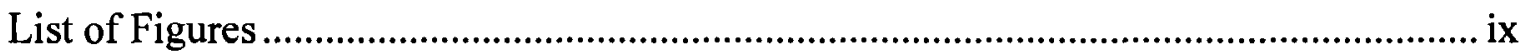

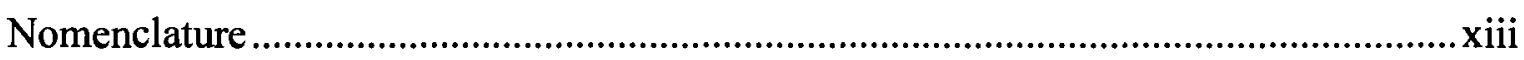

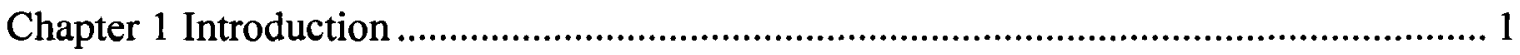

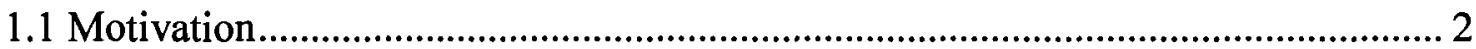

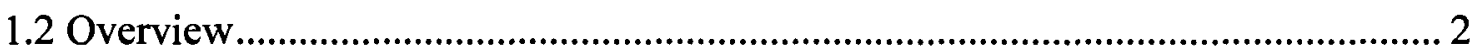

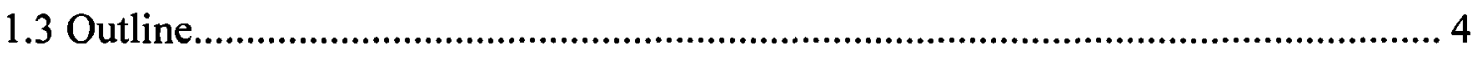

Chapter 2 Literature Review .............................................................................. 5

2.1 Dynamic Modeling of Gas Turbine Performance.............................................. 5

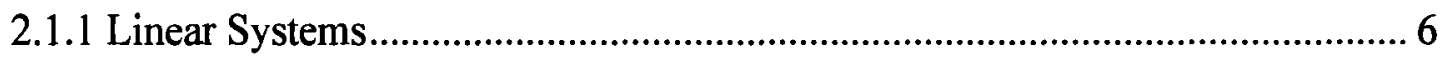

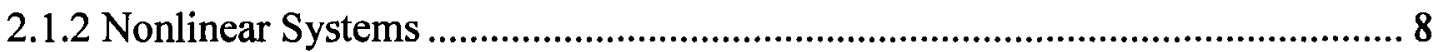

2.2 Dynamic Modeling of Sub-idle Gas Turbine Performance .................................. 19

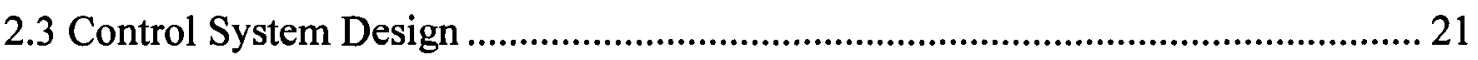

2.3.1 Control System Design Requirements ...................................................... 24

2.3.2 Basic Control Concepts and Design Methodologies ..................................... 30

Chapter 3 Gas Turbine Dynamic Modeling Method ................................................ 42

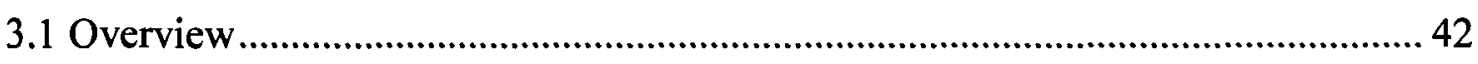

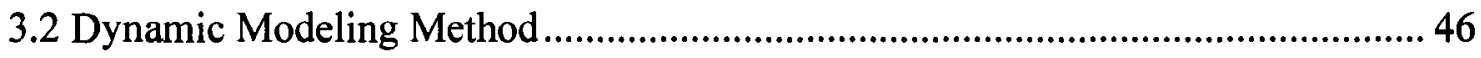

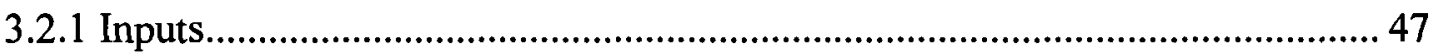

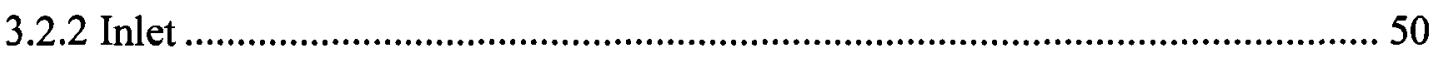

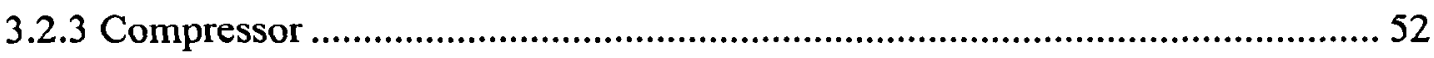

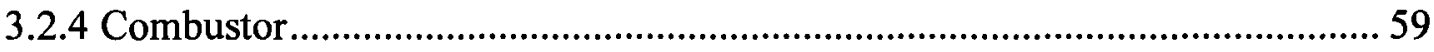

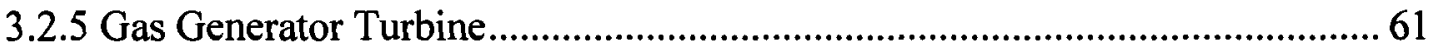

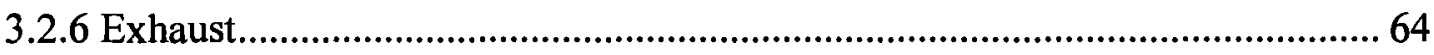

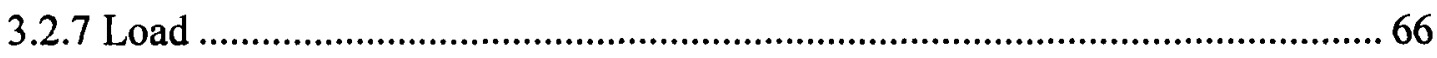




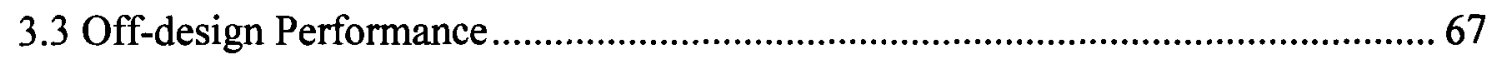

3.3.1 Steady-State Performance Calculations ..........................................................67

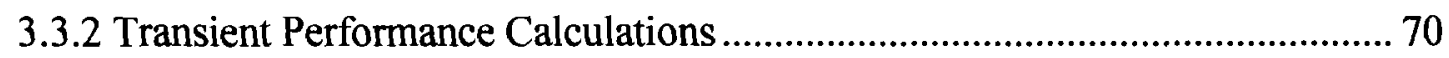

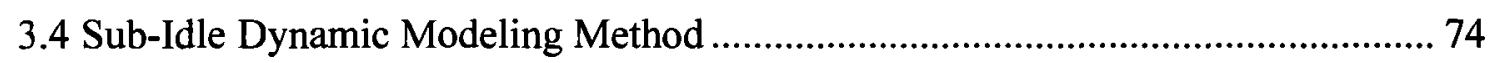

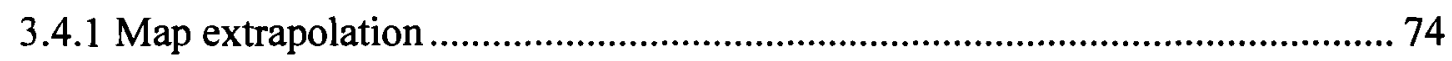

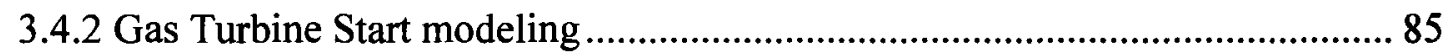

Chapter 4 Gas Turbine Control System Design Method ................................................... 88

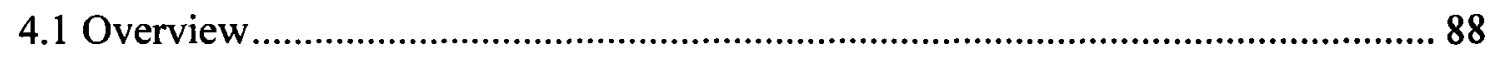

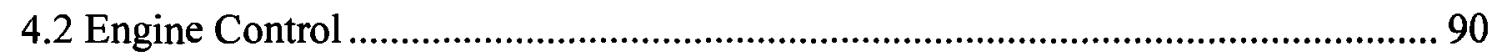

4.2.1 Gain Scheduling (Prime Control) ……………………..................................... 92

4.2.2 Performance Limiters (Protective Control) .................................................... 99

4.2.3 Maximum and Minimum Fuel Schedule (Protective Control) ....................... 102

4.3 Startup Sequencing …....................................................................................... 107

4.3.1 Startup Fuel Scheduling (Prime Control) ........................................................ 107

4.3.2 Performance Limiters (Protective Control) ………….................................. 110

Chapter 5 Dynamic Modeling and Control System Design........................................... 112

5.1 Gas Turbine Dynamic Modeling ............................................................................ 112

5.1.1 Gas Turbine Design Point Requirements....................................................... 112

5.1.2 Geometrical Characteristics .......................................................................... 114

5.1.3 Dynamic Model Inputs ............................................................................... 114

5.1.4 Design Point Performance Data.................................................................... 116

5.1.5 Component Map Scaling............................................................................ 117

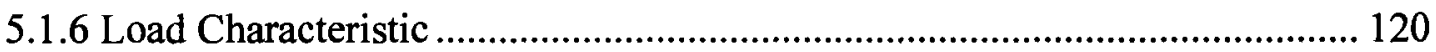

5.1.7 Dynamic Model Assembly .......................................................................... 121

5.2 Gas Turbine Sub-Idle Dynamic Modeling....................................................... 121

5.2.1 Component Map Extrapolation................................................................... 121

5.2.1 Starter Torque Characteristics...................................................................... 124

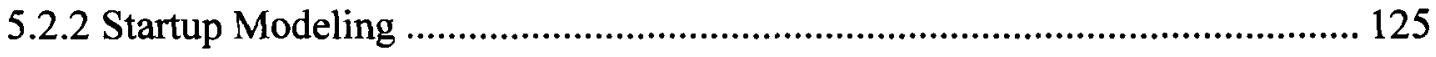

5.3 Control system design.................................................................................. 126

5.3.1 Control System Requirements - Engine Control........................................... 126

5.3.2 Controller Selection .................................................................................... 128 
5.3.3 Acceleration and Deceleration Gain Schedules............................................ 129

5.3.4 Performance Limiters.................................................................................. 134

5.3.5 Maximum and Minimum Fuel Schedule (Protective Control) ....................... 138

5.3.6 Control System Requirements - Startup Sequencing...................................... 144

5.3.7 Startup Fuel Scheduling............................................................................ 145

5.3.8 Startup Performance Limiters ........................................................................ 147

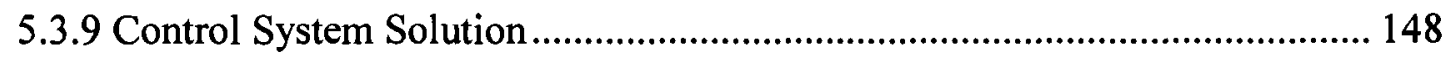

Chapter 6 Results and Discussion................................................................................... 153

6.1 Gas Turbine Dynamic Model Validation............................................................. 153

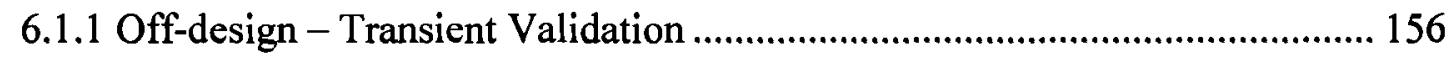

6.2 Sub-idle Dynamic Model Validation ............................................................... 164

6.2.1 Extrapolated Component Map ........................................................................ 169

6.3 Control System Design Analysis and Validation.................................................... 174

6.3.1 Acceleration Fuel Schedule Selection ........................................................... 174

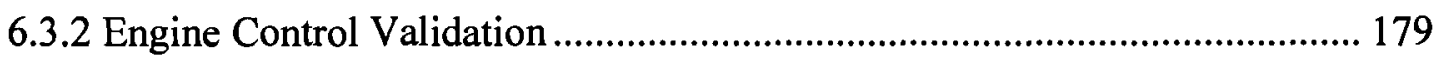

6.3.3 Startup Sequencing Validation ..................................................................... 184

Chapter 7 Conclusions and Recommendations............................................................. 188

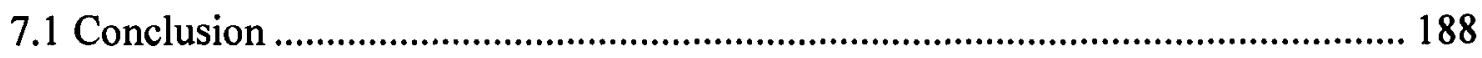

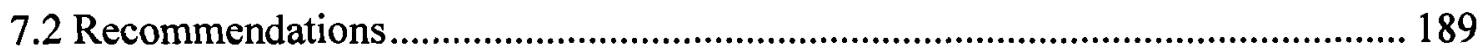

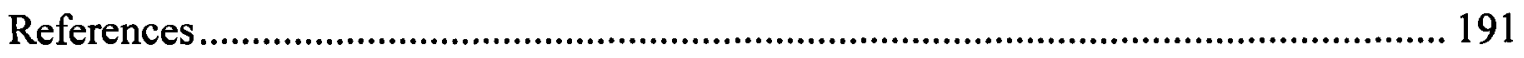

Appendix A - Newton-Raphson Method ................................................................. 194

Appendix B - GasTurb 10 Component Maps .................................................................... 196

Appendix C -Design Point and Off-Design Steady-State Validation ............................. 204

C.1 Design Point Validation ...................................................................................... 204

C.2 Off-design - Steady-State Validation ................................................................. 205

Appendix D - Dynamic Model and Control System In-house Code............................... 213 


\section{List of Tables}

Table 2.1: Effects of independent $K_{p}, K_{i}$ and $K_{d}$ tuning (Ang et al., 2005).................... 39

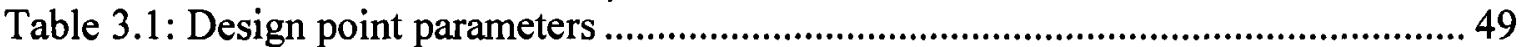

Table 3.2: Gas turbine geometrical characteristics .................................................... 50

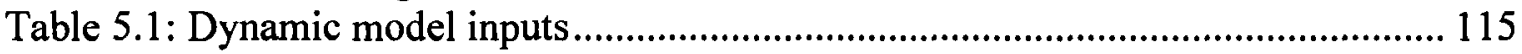

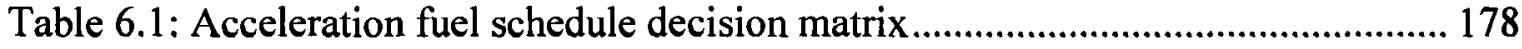

Table 6.2: Control system response summary ......................................................... 181

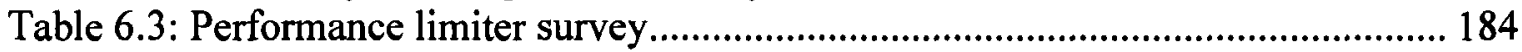

Table C.1: Design point validation results............................................................. 204 


\section{List of Figures}

Figure 2.1: (a) Iteration procedure for gas generator (b) Overall iteration procedure for free power turbine unit (Saravanamuttoo et al., 2001)

Figure 2.2: (a) Turbine characteristic independent of non-dimensional speed (b) Realistic

turbine characteristic (Saravanamuttoo et al., 2001)

Figure 2.3: Simple turbojet component matching procedure using a Newton-Raphson

Iteration (adapted from Kurzke, 1995)

Figure 2.4: Variation in relative flow range (adapted from Saravanamuttoo and MacIsaac, 1983)

Figure 2.5: Generalized compressor characteristic (adapted from Saravanamuttoo and

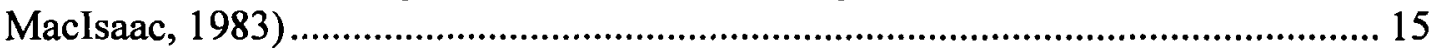

Figure 2.6: Operating trajectories for different computing methods (Fawke and

Saravanamuttoo, 1971) .................................................................................. 18

Figure 2.7: Control system components (Saravanamuttoo et al., 2001) ........................... 21

Figure 2.8: Functional process diagram of a simple engine control system (Jaw and Garg, 2005)

Figure 2.9: Hydromechanical system: (a) Computing section (b) Fuel metering section (adapted from Saravanamuttoo et al., 2003) .............................................................. 23

Figure 2.10: Control system requirements roadmap.................................................... 24

Figure 2.11: Gas turbine control limiters (adapted from Sawyer, 1966) ........................... 26

Figure 2.12: Temperature modulating curve (adapted from Sawyer, 1966)...................... 27

Figure 2.13: Gas turbine control limiters with tolerance margins (adapted from Sawyer, 1966)

Figure 2.14: Typical fuel schedule (adapted from GasTOPS, 1990)............................... 29

Figure 2.15: Open-loop control (adapted from Saravanamuttoo, 2003)........................... 30

Figure 2.16: "Human in the loop control (adapted from Saravanamuttoo, 2003)............. 31

Figure 2.17: Closed-loop control (adapted from Saravanamuttoo, 2003) ......................... 31

Figure 2.18: Proportional control (adapted from Ogata, 2002) ......................................... 32

Figure 2.19: Typical proportional-controlled step response ................................................ 33

Figure 2.20: Isochronous control (adapted from Saravanamuttoo, 2003) .......................... 33

Figure 2.21: Typical isochronous-controlled step response ................................................ 34

Figure 2.22: PID control (adapted from Ogata, 2002) .......................................................... 35

Figure 2.23: Typical step response: PID controller compared to isochronous governor.. 36

Figure 2.24: Unit-step response curve showing performance specifications (adapted from

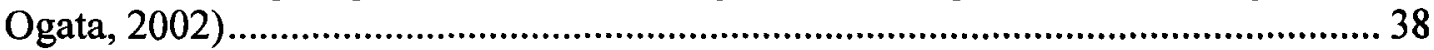

Figure 2.25: Closed-loop control with gain scheduling (Adapted from Qi et al., 1992).. 40

Figure 3.1: Typical gas turbine design procedure (adapted from Saravanamuttoo, 2001)43

Figure 3.2: Dynamic modeling method ........................................................................ 44

Figure 3.3: Single spool gas turbine component breakdown (GasTOPS, 1990) ............... 45

Figure 3.4: Dynamic modeling tool application ................................................................. 46

Figure 3.5: Engine layout: turboshaft engine with power turbine and handling bleed..... 48

Figure 3.6: Inlet modeling............................................................................................... 51

Figure 3.7: Compressor modeling.................................................................................... 53 
Figure 3.8: Beta line mapping (adapted from Kurzke, 2004a) ....................................... 54

Figure 3.9: Tabulated compressor maps (adapted from Walsh and Fletcher, 1998) ........ 55

Figure 3.10: Combustor modeling ............................................................................. 59

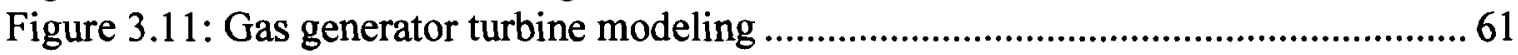

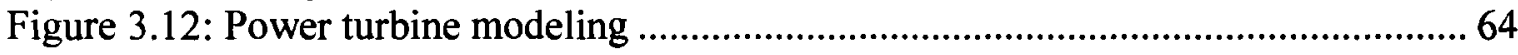

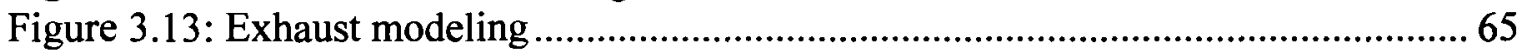

Figure 3.14: Load characteristics (Adapted from Saravanamuttoo et al., 2001) ............... 66

Figure 3.15: Off-design steady-state component matching ............................................... 69

Figure 3.16: Transient performance calculation procedure ……………............................. 72

Figure 3.17: Off-design transient component matching ..................................................... 73

Figure 3.18: Generic compressor map (adapted from Kurzke (2004b))............................ 81

Figure 3.19: Intersection points used to calculate similarity law exponents ..................... 82

Figure 3.20: Extrapolated compressor map .................................................................... 83

Figure 3.21: Generic turbine map (adapted from Kurzke (2004b) ..................................... 84

Figure 3.22: Extrapolated turbine map …………………................................................ 85

Figure 4.1: Control system design method overview …………......................................... 89

Figure 4.2: Isochronous control .................................................................................. 92

Figure 4.3: Engine response and time constant ........................................................... 93

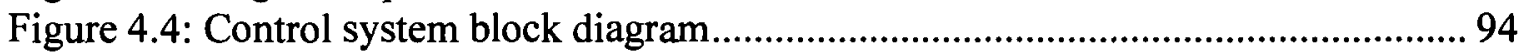

Figure 4.5: Acceleration step response analysis ......................................................... 97

Figure 4.6: Deceleration step response analysis ................................................................ 98

Figure 4.7: Isochronous control with gain scheduling................................................... 99

Figure 4.8: Generic modulating curve ........................................................................ 100

Figure 4.9: Isochronous control with gain scheduling and engine protection limiters... 101

Figure 4.10: Isochronous control with gain scheduling, engine protection limiters and engine operation limiters.................................................................................... 102

Figure 4.11: Typical fuel boundaries ............................................................................ 104

Figure 4.12: Isochronous control with gain scheduling, engine protection limiters, engine operation limiters and fuel schedules.................................................................. 106

Figure 4.13: Startup sequencing prime control........................................................ 108

Figure 4.14: Sketching the first leg of the start fuel schedule ......................................... 109

Figure 4.15: Generating the second leg of the start fuel schedule ................................... 110

Figure 4.16: Startup sequencing prime and protective controls ..................................... 111

Figure 5.1: Sketch of the turboshaft engine .............................................................. 116

Figure 5.2: Design point performance data.................................................................... 117

Figure 5.3: Scaled compressor map ....................................................................... 118

Figure 5.4: Scaled gas generator turbine map................................................................ 119

Figure 5.5: Scaled power turbine map ……………............................................119

Figure 5.6: Load characteristic .............................................................................. 120

Figure 5.7: Extrapolated compressor map .................................................................... 122

Figure 5.8: Extrapolated gas generator turbine map ........................................................ 123

Figure 5.9: Extrapolated power turbine map .................................................................. 123

Figure 5.10: Starter torque characteristic (adapted from Agrawal and Yunis, 1982)..... 125

Figure 5.11:Isochronous controller with additional proportional gains.......................... 128

Figure 5.12: Inputted fuel step changes ...................................................................... 129

Figure 5.13: Power turbine spool speed step response .................................................. 130 
Figure 5.14: Controller proportional gain schedules .................................................... 131

Figure 5.15: Controller integral gain schedules.......................................................... 131

Figure 5.16: $\mathrm{K}_{1}$ gain schedules ........................................................................... 133

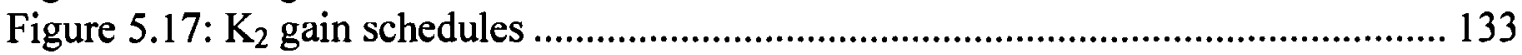

Figure 5.18: $\mathrm{K}_{3}$ gain schedule ...................................................................................... 134

Figure 5.19: Over-temperature engine protection........................................................... 135

Figure 5.20: Gas generator over-speed protection..................................................... 135

Figure 5.21: Power turbine over-speed protection.......................................................... 136

Figure 5.22: Gas generator minimum spool speed limiter................................................ 137

Figure 5.23: Minimum fuel to air ratio limiter ...................................................... 137

Figure 5.24: Referred fuel flow boundaries............................................................ 139

Figure 5.25: Fuel flow boundaries..................................................................... 140

Figure 5.26: Acceleration fuel schedules.................................................................. 141

Figure 5.27: Deceleration fuel schedule ................................................................... 142

Figure 5.28: Control system with reference fuel flow ................................................ 143

Figure 5.29: Reference fuel flow ............................................................................. 144

Figure 5.30: First leg of the startup fuel schedule ....................................................... 146

Figure 5.31: Complete startup fuel schedule …………........................................... 147

Figure 5.32: Power turbine spool speed demand as a function of PLA setting .............. 149

Figure 5.33: Overall start sequencing system solution .................................................... 149

Figure 5.34: Overall engine control system solution...................................................... 150

Figure 5.35: Control system startup procedure ................................................................. 151

Figure 6.1: GasTurb 10 pre-defined turboshaft engine layout........................................... 154

Figure 6.2: GasTurb 10 design point inputs for a turboshaft engine ............................. 155

Figure 6.3: Transient manoeuvres plotted on compressor map ........................................ 157

Figure 6.4: Transient operating line error ........................................................................ 158

Figure 6.5: Gas generator spool speed transient response comparison ........................... 159

Figure 6.6: Compressor exit pressure transient response comparison ............................. 160

Figure 6.7: Gas generator turbine inlet temperature transient response comparison...... 160

Figure 6.8: Fuel flow transient response comparison ....................................................... 161

Figure 6.9: Fuel-to-air ratio transient response comparison ............................................. 161

Figure 6.10: Transient percen error - engine parameters linked to the control system .. 163

Figure 6.11: Sub-idle steady-state operating points........................................................ 165

Figure 6.12: Transient fuel step ................................................................................. 166

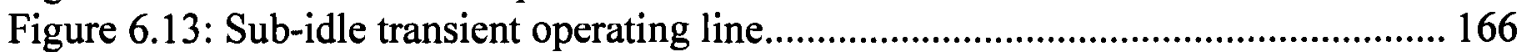

Figure 6.14: Sub-Idle gas generator spool speed transient response ............................... 167

Figure 6.15: Sub-idle compressor exit pressure transient response................................. 167

Figure 6.16: Sub-idle gas generator turbine inlet temperature transient response.......... 168

Figure 6.17: Steady-state fuel-to-air ratio ......................................................................... 169

Figure 6.18: Compressor map speed line comparison .................................................... 170

Figure 6.19: Compressor map extrapolation error ............................................................... 171

Figure 6.20: Gas generator turbine map extrapolation error............................................. 172

Figure 6.21: Power turbine map extrapolation error.......................................................... 172

Figure 6.22: Off-design steady-state power turbine beta line variation............................ 173

Figure 6.23: Transient operating line for each fuel schedule......................................... 175

Figure 6.24: Transient operating lines surge margin ........................................................ 176 
Figure 6.25: Gas generator turbine inlet temperature transient response

Figure 6.26: Power turbine spool speed response.................................................... 178

Figure 6.27: Power lever angle setting step changes .............................................. 180

Figure 6.28: Control system power turbine spool speed response................................ 181

Figure 6.29: Power turbine spool speed response - propeller partially out of the water 182

Figure 6.30: Transient fuel-to-air ratio - propeller partially out of water ..................... 183

Figure 7.31: Gas generator spool speed response during startup................................ 185

Figure 7.32: Startup torques............................................................................. 186

Figure 6.33: Gas generator turbine inlet temperature response during startup............... 187

Figure C.1: Off-design steady-state operating line comparison .................................. 206

Figure C.2: Off-design steady-state operating line comparison (at constant $\mathrm{N}_{\mathrm{pt}}$ ) ......... 207

Figure C.3: Steady-state operating line error ............................................................. 208

Figure C.4: Error - engine parameters linked to the control system .............................. 209

Figure C.5: Combustion efficiency comparison ................................................. 210

Figure C.6: Power turbine steady-state operating line (constant $\mathrm{N}_{\mathrm{pt}}$ ) ........................ 211

Figure C.7: Power turbine steady-state operating line (with load characteristic)........... 212 


\section{Nomenclature}

$\begin{array}{ll}\% \text { N } & \text { Relative spool speed in percent } \\ \text { B } & \text { Bleed fraction } \\ c_{p} & \text { Specific heat at constant pressure } \\ \text { G } & \text { Torque } \\ \text { G(s) } & \text { Laplace transfer function } \\ \text { h } & \text { Specific enthalpy } \\ \text { HV } & \text { Heating value } \\ \text { I } & \text { Polar moment of inertia } \\ \text { K } & \text { Gain } \\ \text { Load } & \text { Combustor loading } \\ \dot{m} & \text { Mass flow rate } \\ \text { Mp } & \text { Maximum overshoot } \\ \text { N } & \text { Spool speed } \\ \text { p } & \text { Mass flow relationship exponent } \\ \text { P } & \text { Pressure } \\ \text { PLA } & \text { Power lever angle } \\ \text { PR } & \text { Pressure Ratio } \\ \text { q } & \text { Work relationship exponent } \\ \text { Q } & \text { Non-dimensional mass flow } \\ \text { r } & \text { Power relationship exponent } \\ \text { R } & \text { Gas constant } \\ \text { s } & \text { Entropy } \\ \text { SM } & \text { Surge Margin } \\ \text { t } & \text { Time } \\ \text { T } & \text { Temperature } \\ \text { TIT } & \text { Turbine inlet temperature } \\ \text { V } & \text { Velocity } \\ \text { V } & \text { Volume } \\ \text { W } & \text { Specific Work } \\ \text { W } & \text { Work } \\ \dot{\text { W }} & \text { Power } \\ \text { X(s) } & \text { Laplace transform of the input } \\ \text { Y(s) } & \text { Laplace transform of the output } \\ & \end{array}$




\section{Greek Symbols}

$\Delta$
$\beta$
$\delta$
$\varepsilon$
$\zeta$
$\gamma$
$\psi$
$\theta$
$\eta$
$\omega$
$\tau$

\section{Subseripts}

a
amb
b
bleed
c
calc
d
D
delay
des
exhaust
f
gear
gg
guess
i
ideal
ign
inlet
isen
last
map
max
mech
min

Change or difference

Beta value

Corrected pressure $=\mathrm{P}_{\mathrm{o}} / 101.325 \mathrm{kPa}$

Time delay (transport lag)

Damping ratio

Specific heat ratio

Specific entropy

Corrected temperature $=\mathrm{T}_{0} / 288.15 \mathrm{~K}$

Efficiency

Frequency

Time constant
Air

Ambient

Combustor

Bleed

Compressor

Calculated

Derivative

Demand

Delay

Design point

Exhaust

Fuel

Gearbox

Gas generator

Guess

Integral

Ideal

Ignition

Inlet

Isentropic

Last

Component map

Maximum

Mechanical

Minimum 


$\begin{array}{ll}\text { n } & \text { Natural } \\ \text { new } & \text { New point } \\ \text { now } & \text { Now } \\ \text { o } & \text { Stagnation or total } \\ \text { old } & \text { Old } \\ \text { operating line } & \text { Operating line } \\ \text { p } & \text { Proportional } \\ \text { peak } & \text { Peak } \\ \text { poly } & \text { Polytropic } \\ \text { prop } & \text { Propeller } \\ \text { pt } & \text { Power turbine } \\ \text { ref } & \text { Reference point } \\ \text { rise } & \text { Rise } \\ \text { s } & \text { Ideal } \\ \text { set } & \text { Settling } \\ \text { start } & \text { Starter } \\ \text { std } & \text { Standard } \\ \text { surgeline } & \text { Surge line } \\ \text { x } & \text { Extrapolation } \\ \text { t } & \text { Turbine } \\ 1,2,3,4,5,6 & \text { Station numbering }\end{array}$




\section{Chapter 1 Introduction}

The gas turbine is known to be a versatile power plant. Its ability to produce large amounts of power or thrust for its size and weight rendered the gas turbine as the obvious choice as a prime mover for the aircraft industry. Also, since gas turbines have low emissions and multi-fuel capability, the power generation industry and industrial installations see the gas turbine as a cost-effective solution to growing environmental restrictions. The engine's versatility comes from the manufacturers' capability to design and produce highly efficient engines of various sizes and configurations, which are catered to specific applications. However, due to the high cost of production of efficient engines, manufacturers limit their production to profitable applications such as aircraft engines or large industrial engines. As for other applications, the manufacturers adapt their design to fit performance requirements of a given application without changing the underlying design of the engine. These are known as aero-derivative engines. The costeffectiveness of this type of engine is greatly reduced, as the operator does not necessarily require the high-end performance available in an aircraft engine.

The overall goal of this project was to design a low-cost gas turbine engine for a marine application. The idea was to show that a gas turbine engine could be produced at low-cost when the design specifications are catered to a specific application. The design task was given to a small team of graduate students at Carleton University in Ottawa, Ontario, Canada. Every student was asked to produce a comprehensive design tool for a specific component of the engine. Once assembled the design tools became a roadmap to follow when designing the low-cost gas turbine engine. 


\subsection{Motivation}

High performance powerboat manufacturers have been using gas turbine engines for a few years. Having a greater power-to-weight ratio than any inboard or outboard motor, the gas turbine allows powerboat manufacturers to design lighter and faster boats. Conventionally, gas turbine engines installed in these powerboats were overhauled helicopter engines. These turboshaft engines equipped with a power turbine provided adequate power but at a very expensive cost. Since the marine application does not have the same weight requirements as a helicopter, major cost reductions can be achieved by designing a gas turbine specifically for the marine application.

The purpose of the thesis was to provide a comprehensive methodology to assist gas turbine dynamic modeling and control system design. The development of a dynamic modeling tool based on thermodynamic principles will be highlighted. The tool will produce key information required for control system design and transient performance analyses. The goal of the thesis was to produce a simple comprehensive procedure that can be used early in the preliminary design phase or as part of an optimizing iterative process. The resulting model will provide a virtual testing environment with the ability to run the engine to its performance limits. This will allow designers to analyze and optimize, in a cost-effective manner, the gas turbine without the risk of damaging a real engine.

\subsection{Overview}

The overall project consisted of the development of a low-cost 1-MW turboshaft engine with a power turbine for a powerboat application. The design team, which consists of seven graduate students, three co-supervisors and one sponsor, was responsible for the design of the compressor, combustion chamber, the gas generator turbine, the power turbine, the shafts and the control system. The scope of this thesis focused mainly on the dynamic modeling of the complete engine and the elaboration of a comprehensive control 
design method used to alleviate the burden of control system design faced during the early stages of gas turbine design.

Dynamic models are mathematical representations of dynamic systems. To design a control system, the designer must understand every detail relevant to the dynamic system (Ogata, 2002). The dynamic model gives an insight on how the dynamic system would respond to specific inputs or situations. A gas turbine dynamic model consists of mathematical and thermodynamic representations of engine components. Key information required to build such a model is available at an early stage of the design. As a result, the designer has the opportunity to see how the engine would react under specific conditions and make, if required, modifications to the design without incurring costs increase. Control system designers can also use the gas turbine dynamic model as a virtual test bed. Its capability to model transient performance allows the designer to study situations that would normally destroy a real life engine.

Gas turbine control systems have three fundamental functions: 1) startup and shutdown sequencing, 2) steady-state control when the engine is in operation and 3) protection (Boyce, 2001). During startup the controller ensures that the engine accelerates safely to idle speed. From idle speed to maximum speed the controller reacts to user inputs. The engine response depends on the type of protection imbedded in the controller. Protection against high turbine temperatures, surge and over-speed limits the amount of fuel the controller sends to the combustion chamber and therefore alters the engine time response. Rapid accelerations and deceleration could push the engine to its maximum allowable limits. With these limiters in mind the designers must layout a protective roadmap called fuel schedules to ensure the engine will run safely under any circumstances. These fuel schedules are tested virtually using a dynamic model to ensure adequate and safe transient response. 


\subsection{Outline}

To provide a comprehensive methodology to gas turbine dynamic modeling and control system design, many tasks must be completed. The summary of these tasks will be used as an outline for this thesis. Included in the thesis is a literature review, an overview of the theory used in the development of a dynamic modeling and control system design methodology, validation, analysis and discussion of the results and a conclusion containing recommendations for future work. 


\section{Chapter 2 Literature Review}

This chapter provides an overview to gas turbine dynamic modeling and control system design theory. It provides a roadmap for the reader by highlighting key principles and theories used in the elaboration of the comprehensive dynamic modeling and control system design methodology discussed in subsequent chapters.

A discussion on the types of dynamic systems and the underlying mathematical and thermodynamic modeling principles will be presented. Steady-state and transient performance modeling procedures and sub-idle performance extrapolation techniques will also be discussed. This chapter also emphasizes key steps found in the control system design procedure, more specifically controller selection based on performance requirements, identification of engine limiters and a discussion on a controller performance enhancing technique called gain scheduling.

\subsection{Dynamic Modeling of Gas Turbine Performance}

As explained previously, the need for means of exploring dynamic behaviours early during the design phase of a gas turbine increases proportionally to the rise of development costs of modern engines. According to Walsh and Fletcher (1998), control system design and transient performance are inseparable. Therefore the design of an adequate controller depends greatly on the capability to study and understand transient performance accurately. Since gas turbine transient response can only be determined experimentally once the engine is fully assembled, the need for a dynamic modeling tool is apparent. Saravanamuttoo and Fawke (1970) list the following requirements for the implementation of a successful dynamic simulator:

- Flexibility. The simulation must be able to represent all modes of transient behaviour. 
- Credibility. The simulation must be readily understandable and accurately represent the dynamic behaviour over the complete running range.

- Availability. The simulation once proved in operation, must be capable of being brought into use whenever required.

- Reliability. A high degree of reliability and repeatability is clearly essential.

Throughout the years many methods were developed to predict engine dynamic response. According to Fawke and Saravanamuttoo (1971), investigating gas turbine dynamic behaviours started around the early $50 \mathrm{~s}$ and has evolved from hand-written calculations to complex highly accurate digital computer simulations. Based on their summary of modeling methods, it is possible to see that all models have one thing in common: they are represented mathematically by sets of equations. These sets of equations may be modeled to reflect linear or nonlinear dynamic systems. There are advantages and disadvantages to both modeling techniques as will be discussed in the following sub-sections.

\subsubsection{Linear Systems}

A system is said to be linear if the principle of superposition applies (Ogata, 2002). Therefore it is possible to model dynamic responses of complex systems by treating multiple inputs as individuals and then adding their individual responses together. Even though gas turbines are considered nonlinear in nature, according to Fawke and Saravanamuttoo (1971), the simplest representation of a gas turbine is obtained by assuming that the engine can be represented approximately by a linear system. They state that based on this first-order approximation, the engine dynamic response can be modeled using simple mathematical expression containing time constants and partial derivatives. Once converted to the Laplace domain these equations take the form of Eqn 2.1.

$$
\mathrm{Y}(\mathrm{s})=\mathrm{X}(\mathrm{s}) \frac{\mathrm{K}}{(\tau \mathrm{s}+1)} \mathrm{e}^{-\mathrm{s} \varepsilon}
$$


where $\mathrm{X}(\mathrm{s})$ is the Laplace transform of the input and represents in most case the input fuel flow, $\mathrm{Y}(\mathrm{s})$ is the Laplace transform of the output and may represent such variables as the gas generator spool speed, turbine inlet temperature, compressor discharge pressure, etc. $\mathrm{K}$ is known as the proportional gain, $\tau$ as the time constant and $\varepsilon$ as the time delay of the system . The accuracy of this model is acceptable for small performance variations and can be used to assess engine stability and response near a steady-state condition (GasTOPS, 1990). Time constants can be obtained experimentally or estimated analytically. As explained previously, dynamic models are cost-effective when available early in the design process, as they allow for design optimization and validation prior to hardware production. For this reason, the capability of estimating accurately time constants before experimental testing is available becomes a priority. To solve this problem, Lucas Co. developed an approximation method (Eqn 2.2) that provides time constants based on information available early in the design process (GasTOPS, 1990).

$$
\tau=\frac{1.05 \times 10^{-8} \mathrm{I} \times \mathrm{N}}{\left(1-\frac{\mathrm{T}_{4}}{\mathrm{~T}_{3}}\right)\left(\frac{\mathrm{dm}_{\mathrm{f}}}{\mathrm{dN}}\right)}
$$

In this equation, the variable I corresponds to the polar moment of inertia of the engine and the variable $\mathrm{N}$ represents the engine spool speed. $\left(\mathrm{dm}_{\mathrm{f}} / \mathrm{dN}\right)$ is used to represent the slope of the steady state fuel flow curve.

Even though many engine control systems were successfully designed using the time constant approach, one major drawback to linear dynamic modeling is the fact that it does not provide information about the physical operation of the engine (Maclsaac, 1975). This is because the linearization process requires all engine variables to be lumped into one relationship. As shown by Eqn 2.1, only the effect of the input variable on the output can be studied as all other variables are lumped into time constants or time delays. As a result, it is not possible to assess if the engine is operating safely during transient 
operation because engine limiters such as compressor surge or over-temperature cannot be recognized through this linearized representation (MacIsaac, 1975).

\subsubsection{Nonlinear Systems}

A system is said to be nonlinear if the principle of superposition does not apply. Thus for nonlinear systems, the response to two inputs cannot be calculated by treating individually and adding the results (Ogata, 2002). This is the case for gas turbine engines operating under large transients. Therefore since the linearization process discussed previously is not valid for large variations, a new modeling technique is required. According to Saravanamuttoo and Fawke (1970), to satisfy the list of requirements highlighted in Section 2.1, it is necessary to approach the problem from the viewpoint of the engineering thermodynamicist by using compressor and turbine characteristics. In the mid 1950s, Dugan and Fillipi pioneered a nonlinear dynamic modeling procedure that applied necessary matching conditions to component characteristics (Fawke and Saravanamuttoo, 1971). From these matching conditions, a series of operating points where found based on the assumption of flow compatibility but not work compatibility. The engine speed response was then calculated based on the acceleration rate produced by the resulting torque imbalance between the compressor and turbine.

Since the core of Dugan and Fillipi's nonlinear dynamic modeling procedure consisted of component matching, the focus of the discussion will now be placed on this part of the procedure. MacIsaac (1975) stated that the key to interpretation of the transient operation lies in a thorough understanding of the steady-state componentmatching problem. In other words, thermodynamic steady-state component-matching methods are the foundation of transient models. Therefore, building an accurate transient model depends on the accuracy of the component characteristics and the steady-state matching process involved. While summarizing the evolution of the steady-state component matching procedures, he concluded that the most comprehensive treatment of

component matching and steady-state off-design operation belongs to Saravanamuttoo, Roger and Cohen. Using identities of non-dimensional parameters, Saravanamuttoo et al. 
(2001) were able to develop a straightforward component-matching method for singleshaft and twin-spool gas turbine engines. The component-matching procedure relies on the fact that compatibility of flow and compatibility of work must be satisfied at all time to ensure steady-state operation. Based on these requirements an iterative process is used to determine the engine running line. The procedure is summarized in the flowchart of Figure 2.1. 


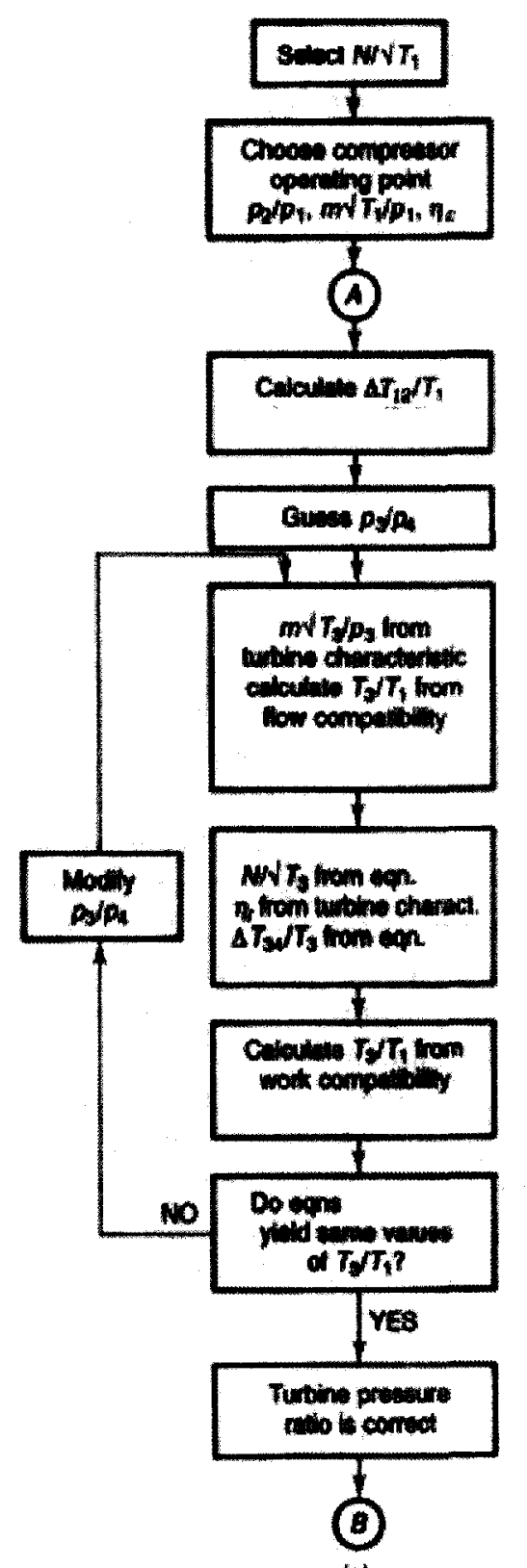

(a)

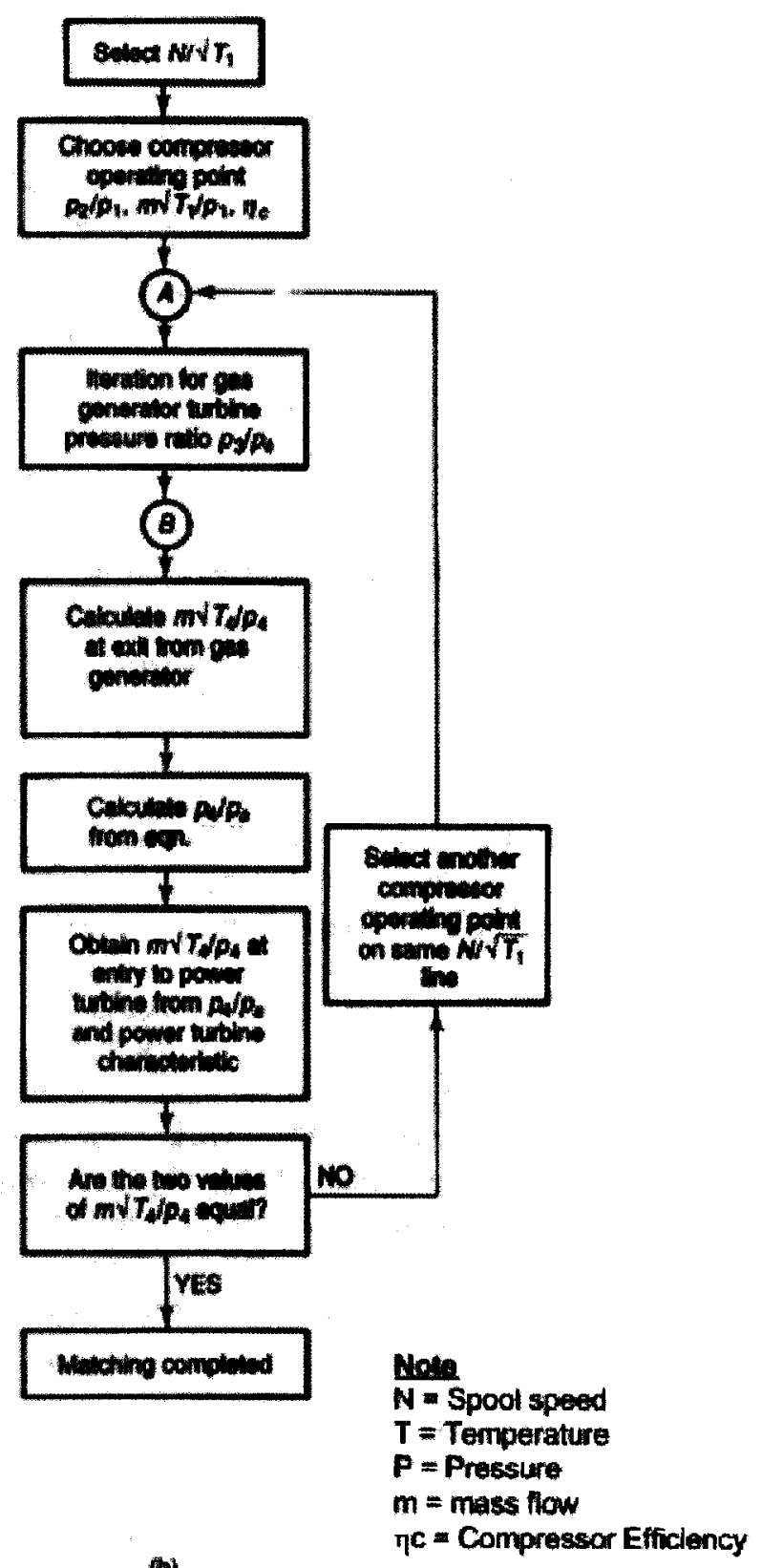

(b)

Figure 2.1: (a) Iteration procedure for gas generator (b) Overall iteration procedure for free power turbine unit (Saravanamuttoo et al., 2001)

Saravanamuttoo et al. (2001), developed their component-matching procedure at a time when digital computation was in its infancy. Due to the fact that component matching required an iterative solution, simplifying assumptions were applied. The matching procedure was developed based on the assumption that turbines had a non-dimensional 
mass flow rate independent of non-dimensional speed and therefore only a function of pressure ratio. However, as seen in Figure 2.2, this is not always the case. One can see that this assumption does not hold when the turbine is operating under unchoked conditions at low speeds. As a result, to ensure accurate dynamic modeling under unchoked conditions, an extra variable in the form of turbine inlet temperature must be added to the iterative loop.

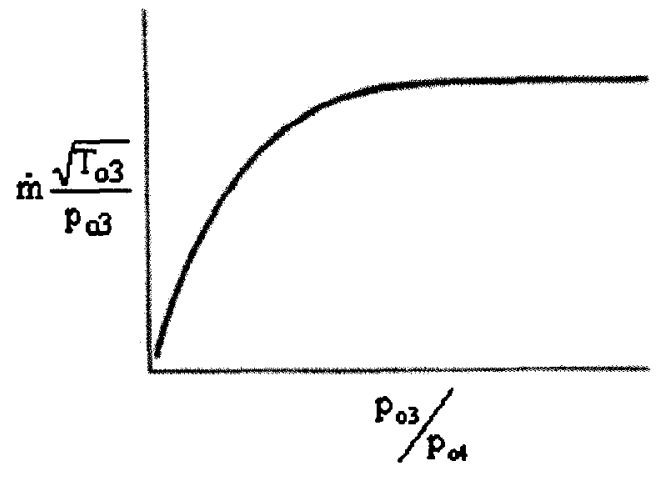

(a)

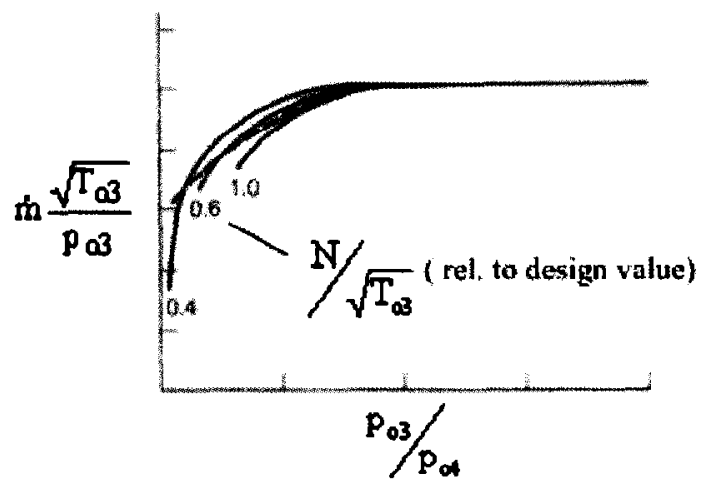

(b)

Figure 2.2: (a) Turbine characteristic independent of non-dimensional speed (b) Realistic turbine characteristic (Saravanamuttoo et al., 2001)

As a second assumption, they assumed constant specific heats $\left(c_{p}\right)$ (hence, constant specific heat ratio, $\gamma$ ). This assumption is used to reduce the computational complexity but, in turn, reduces modeling accuracy. To model the dynamic response without using this simplifying assumption, temperature $\left(\mathrm{T}_{0}\right)$ and power $(\dot{\mathrm{W}})$ should be determined iteratively using Eqns 2.3 and 2.4 respectively (Gauthier, 2005).

$$
\begin{aligned}
\int_{0}^{T_{025}}\left(c_{p}(T) \frac{d T}{T}\right) & =\int_{0}^{T_{01}}\left(c_{p}(T) \frac{d T}{T}\right)+R \ln \left(\frac{P_{02}}{P_{o 1}}\right) \\
\dot{W} & =\dot{m}_{a}\left(h_{02}-h_{o 1}\right)
\end{aligned}
$$


Note that $R$ is known as the gas constant and $P_{0}$ represents stagnation pressure at a given condition. $h_{0}$ represents specific enthalpy at stagnation conditions and $\dot{\mathrm{m}}_{\mathrm{a}}$ is known as mass flow of air.

The Air Force Aero Propulsion Laboratory were the first to apply a more efficient numerical solution, called the Newton-Raphson method for component-level, steady-state engine performance models in the mid-1960s (Jaw and Garg, 2005). This new solution technique significantly reduced the computational time and therefore reduced the need for simplifying assumption. In recent years, Kurzke (1995) used this method while demonstrating the capabilities of an advanced user-friendly gas turbine performance program for a personal computer. Real component maps were used and the component matching was done iteratively. The method consisted of reducing sets of errors generated during the iteration process from imperfect input variable estimates to near-zero values using the Newton-Raphson numerical method. A brief outline of the matching method, applied to a simple turbojet, is highlighted by the flowchart of Figure 2.3. The key to this method rapid matching ability lies in the capability of providing an equivalent number of iteration errors and input variables to the numerical method. Using the same philosophy as Saravanamuttoo et al. (2001), Kurzke (1995) used the principles of compatibility of flow and compatibility of work to assess iteration errors. Based on these principles and compatibility of pressure, he showed that it was possible to generate an equivalent number of errors and inputs for a variety of gas turbine arrangements, therefore proving the versatility of the method. Kurzke used this component matching method to develop a well known commercial code called GasTurb, which dealt with design and off-design calculations of various engine configurations. 


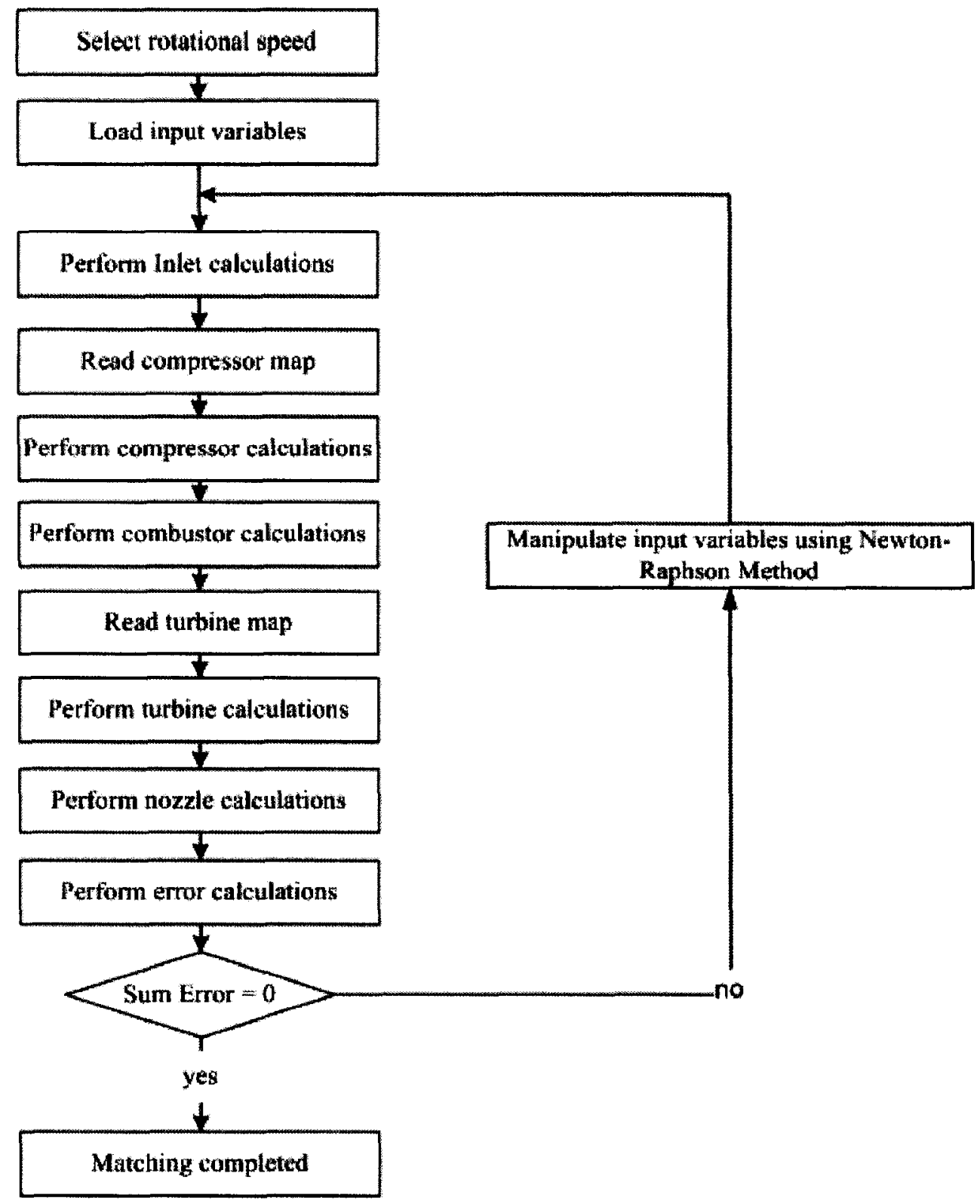

Figure 2.3: Simple turbojet component matching procedure using a Newton-Raphson Iteration (adapted from Kurzke, 1995)

A major obstacle in developing a nonlinear dynamic model is the lack of component characteristics available. These characteristics, also known as maps, are produced experimentally at an advanced stage of the component design process. Furthermore, these are in general proprietary to the manufacturer. To overcome this problem, Saravanamuttoo and MacIsaac (1983) developed a method for estimating component characteristics. They found that it was possible to generate adequate 
compressor and turbine maps through relative scaling of published component characteristics. As seen in Figure 2.4, they demonstrated by plotting the change of relative flow from surge to choke as a function of relative speed for compressors covering a significant range of engines and pressure ratios that the data collapsed well enough to use an average curve for each.

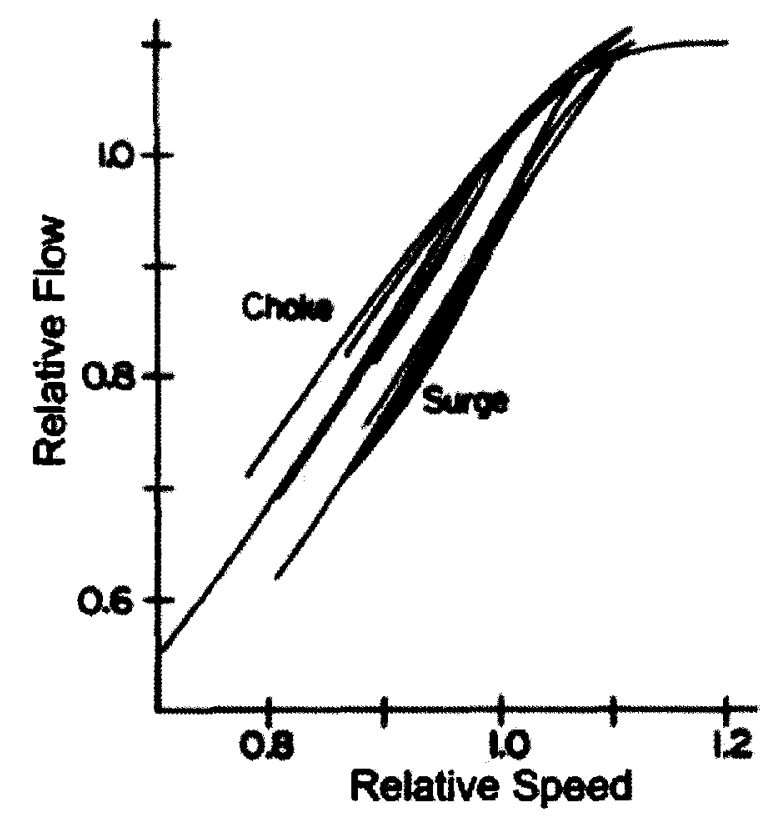

Figure 2.4: Variation in relative flow range (adapted from Saravanamuttoo and MacIsaac, 1983)

Plotting similar graphs for relative pressure ratios and relative temperature ratios, they obtained two points for each speed lines. Using these points and a typical average shape, they were able to build a generalized compressor map for the given class of compressor considered (Figure 2.5). 


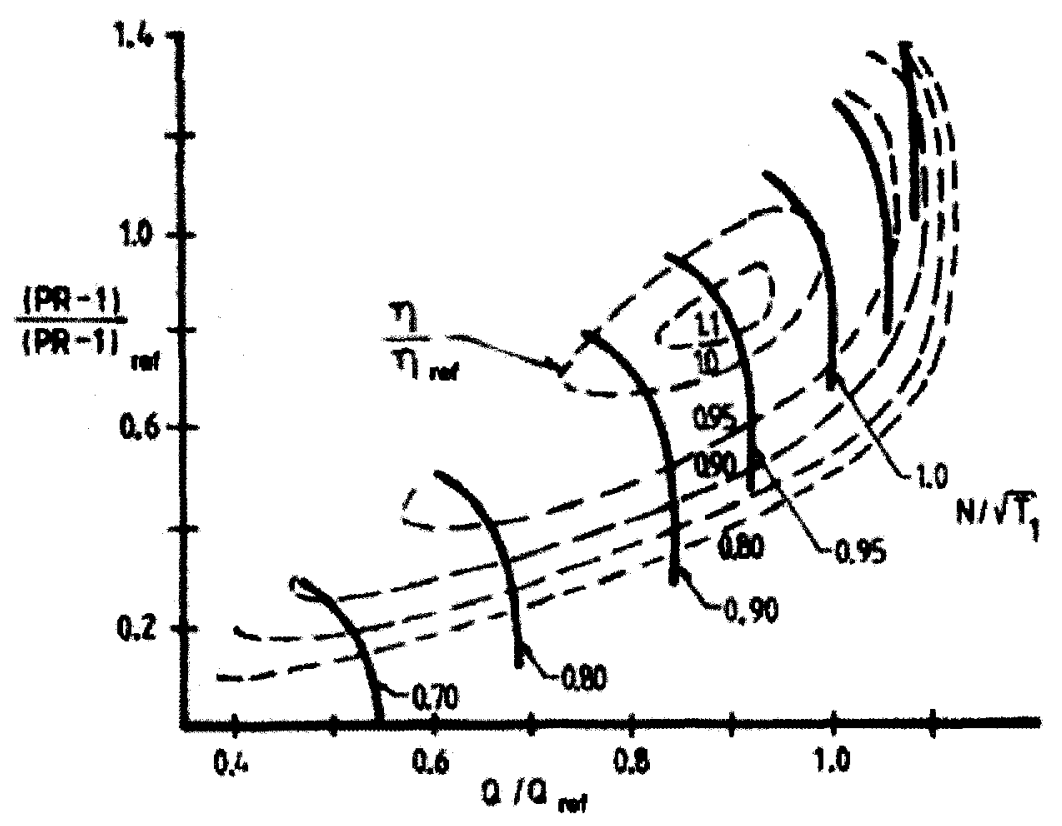

Figure 2.5: Generalized compressor characteristic (adapted from Saravanamuttoo and MacIsaac, 1983)

The resulting compressor maps have been found to be valid for low to midpressure ratio compressors, up to compression ratios of 8:1 (Zhu and Saravanamuttoo, 1992). A generalized turbine map can be constructed using this same procedure. Again according to Saravanamuttoo and MacIsaac (1983), in the absence of any turbine data, reasonable results could be obtained using the theoretical flow relationships for a convergent nozzle. Zhu and Saravanamuttoo (1992) used a slight variation to the turbine procedure during a simulation of an advanced twin-spool industrial gas turbine. They simplified the generalized turbine characteristic by making it speed-independent. The resulting curve could then be expressed by a polynomial or by a modified nozzle equation. They reported this method to be widely used and proven accurate.

An alternative method for estimating component maps was devised by Sellers and Daniele (1975) during the development of a steady-state and transient performance program called DYNGEN. The method used scaling laws to scale known component maps into new component maps. The scaling equations Eqn 2.5 to 2.7 scaled the map data based on a ratio between the engine design point and the given component map design point. 


$$
\begin{gathered}
\mathrm{PR}=\frac{\mathrm{PR}_{\text {des }}-1}{\mathrm{PR}_{\text {map, des }}-1}\left(\mathrm{PR}_{\text {map }}-1\right)+1 \\
\dot{\mathrm{m}}=\frac{\dot{\mathrm{m}}_{\text {des }}}{\dot{\mathrm{m}}_{\text {map, des }}}\left(\dot{\mathrm{m}}_{\text {map }}\right) \\
\eta_{\text {isen }}=\frac{\eta_{\text {isen_des }}}{\eta_{\text {isen_map,des }}}\left(\eta_{\text {isen_map }}\right)
\end{gathered}
$$

In the above equations, PR represents pressure ratio, $\dot{\mathrm{m}}$ corresponds to mass flow and $\eta_{\text {isen }}$ is defined as the isentropic efficiency.

The accuracy of the estimated map is gauged based on this ratio. Also known as a scaling factor, they stated that the closer it is to 1 , the better the estimate. Conversely they continued by adding that if the scaling ratio is not close to 1 , it does not necessarily mean that the simulation is poor since many maps have been shown typical over quite large ranges of scaling ratios. The idea is to find a published component map, which approximately matches the operating conditions of the simulated component. Kong and $\mathrm{Ki}$ (2001) used this method during performance simulations of a turboprop engine. The performance results showed that the scaling ratios used during the simulations, ranging from 0.795 to 1.2 , produced valid component map estimates.

As stated previously, steady-state component-matching methods relied on the fact that compatibility of flow and compatibility of work must be satisfied at all time. However, during transient operations, a work mismatch between the compressor and turbine is required to allow the engine to accelerate or decelerate. Therefore the assumption of compatibility of work is no longer valid during transients. Fawke and Saravanamuttoo (1971) stated that this work imbalance also leads to flow imbalance throughout the engine during transient operations. They suggested two methods for treating flow and work imbalance during dynamic modeling: 
- Iterative method

- Inter-component volume method

Even though flow imbalance is part of the engine dynamic behaviour, the iterative method relies on the fact that compatibility of flow must be satisfied at all time. For example, during transient operation flow imbalance is reduced by adjusting iteratively the component-matching engine parameters while keeping the engine speed constant; hence the name iterative method. Then once flow compatibility is achieved, work imbalance can be used to calculate the change in speed based on the torque imbalanced between the compressor and the turbine.

On the other hand, the inter-component volume method gives physical significance to flow imbalance. During steady-state operation, the mass flow entering a volume is equal to the mass flow leaving. According to Walsh and Fletcher (1998), this is no longer true under transient operation as pressure, temperature and hence density of the fluid changes with time. Known as volume packing, they stated that it can have notable impact upon engine transient performance. Accordingly, the inter-component volume method uses the flow mismatch as possible engine states during transient manoeuvres. The rate of change of pressure is then calculated for every volume based on gas laws. The rate of change of speed is calculated based on the work imbalanced between the compressor and the turbine. Using these rates, it is then possible to calculate the change in speed and pressure. Figure 2.6 depicts the typical compressor response to a step change in fuel for both methods. 


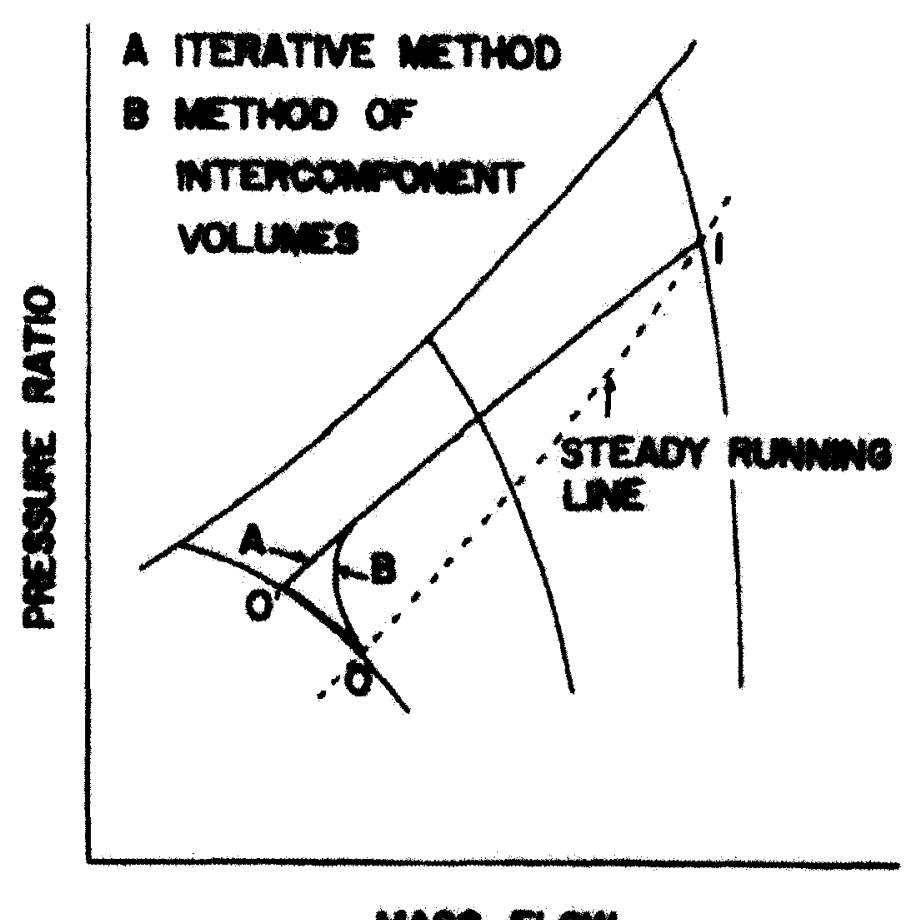

\section{uns Flow}

Figure 2.6: Operating trajectories for different computing methods (Fawke and Saravanamuttoo, 1971)

Even though, both methods only differ significantly immediately after a rapid change, Fawke and Saravanamuttoo (1971) stated that the assumption of maintaining flow compatibility at all time during transient operation is physically unrealistic, as it implies that the pressure and mass flow in the engine can change instantaneously. In an effort to give a better physical representation of a gas turbine, they suggested using the inter-component volume method. However, the iterative method should not necessarily be discarded right away based on this conclusion. As just mentioned, both methods only differ significantly immediately after a rapid change; therefore as shown in Figure 2.6, either method could be used to analyze manoeuvres consisting of long transients. 


\subsection{Dynamic Modeling of Sub-idle Gas Turbine Performance}

In many cases, the focus of the dynamic modeling procedure is placed only on part of the operating range of the engine. In fact, most linear and nonlinear dynamic modeling studies reviewed in the previous sub-sections focused only on the operating range dealing with speeds from idle to design point. The reason why this is the case is because most transient performance analyses and the bulk of the control system design work are performed above idle speed. But as explained earlier, the main goal of a dynamic model is to allow designers to assess engine performance over the whole operating range of the engine early in the design process and possibility make changes to the design cost-effectively. This includes the sub-idle operating range, which lies between zero and idle speed. Also known as the starting regime, dynamic modeling of this region is particularly important for starting system designers and engine life specialists. For example, according to Sexton (2001), turbine blade life is limited by heat stress caused by steep temperature gradients during cold starts. To alleviate this problem he found, based on a sub-idle dynamic model of the engine, that varying the surge valve bleed during startup could reduce the turbine blade temperature. Other key information such as engine starting time and minimum engine starting torque can be estimated using a sub-idle dynamic model. Walsh and Fletcher (1998) classified the sub-idle region as one of the most technically challenging aspect of gas turbine performance. Even though the fundamentals of transient performance are applicable over the whole operating range of the engine, they said that it is extremely difficult to produce sophisticated dynamic models in the sub-idle region. Numerical convergence becomes an issue as calculations are performed on uncertain, steep regions of component maps. For this reason, Walsh and Fletcher proposed using the following simpler extrapolation model. Using a steady-state component matching method, operating points were calculated in the sub-idle regime until numerical convergence fails. Then to simulate the work imbalanced during transient operation, a power offtake was applied at each point such that minimum surge margin or maximum turbine inlet temperature is achieved. Finally the compressor and turbine power were extrapolated well below idle speed using a cube law. They state that this method provides a good tool for sizing a starter motor such that start time requirements 
can be met. Alternatively, to alleviate the fact that component maps are not well defined below idle speed, Agrawal and Yunis (1982) developed a generalized mathematical model to estimate gas turbine starting characteristics. They found that the pronounced differences in component characteristics observed at higher speeds tend to become relatively small at low speeds. Based on this observation, they were able to produce single generalized component maps without introducing gross errors. These generalized maps were then used in a transient performance analysis to estimate the engine starting characteristics. Similarly to Walsh and Fletcher, and even though fairly good preliminary estimates were achieved, they stated that since this method is based on generalized characteristics and a number of simplifying assumption, it should only be used as an initial step in the starting system design process. It is important to note that most dynamic models established for an operating range from idle speed to design speed cannot accommodate either sub-idle dynamic modeling methods explained previously without incurring major modifications to the original modeling techniques. In most cases, subidle transient performance is dealt separately through a second dynamic model. To simplify this routine, Sexton (2001) proposed using a single dynamic model to analyze transient performance from start to design speed. Similarly to Agrawal and Yunis, his method relied on extrapolated component maps. But instead of generalizing the maps to a single line, he considered extrapolating the complete component map. The extrapolation technique was derived from the basic principles of the similarity laws while taking compressibility effects into considerations. As seen from Eqns 2.8 to 2.10, similarity laws relate operating characteristics as a function of speed ratio to a given exponent. The compressibility effects were quantified through tuning of the similarity law exponents (p, $q, r)$. These exponents were calculated based on the last two speed lines of the component maps and kept constant during the extrapolation process.

$$
\begin{aligned}
& \frac{\dot{\mathrm{m}}_{\text {new }}}{\dot{\mathrm{m}}_{\text {ref }}}=\left[\frac{N_{\text {new }}}{N_{\text {ref }}}\right]^{p} \\
& \frac{W_{\text {new }}}{W_{\text {ref }}}=\left[\frac{N_{\text {new }}}{N_{\text {ref }}}\right]^{q}
\end{aligned}
$$




$$
\frac{\dot{\mathrm{W}}_{\text {new }}}{\dot{\mathrm{W}}_{\text {ref }}}=\left[\frac{\mathrm{N}_{\text {new }}}{\mathrm{N}_{\text {ref }}}\right]^{\mathrm{r}}
$$

Sexton then validated simulated startup results, which were calculated using extrapolated component maps, against experimental data and showed that the simulated results agreed relatively well to the experimental starting data available. At the same time, he demonstrated that by simply extrapolating a complete component map, it was possible to analyze transient performance in the sub-idle regime without incurring any changes to the original dynamic modeling technique.

\subsection{Control System Design}

The operation of a gas turbine is complex. It is a mixture of aerodynamic, thermodynamic, chemical and mechanical processes functioning together as a single unit (Mattingly et al., 2002). To control an engine, many actors such as the sensors, the fuel pump, the metering valve, the throttle and the controller come into play by acting as the ears, the eyes, the hands and the brain of a human operator. The main features of a gas turbine control system are shown in Figure 2.7.

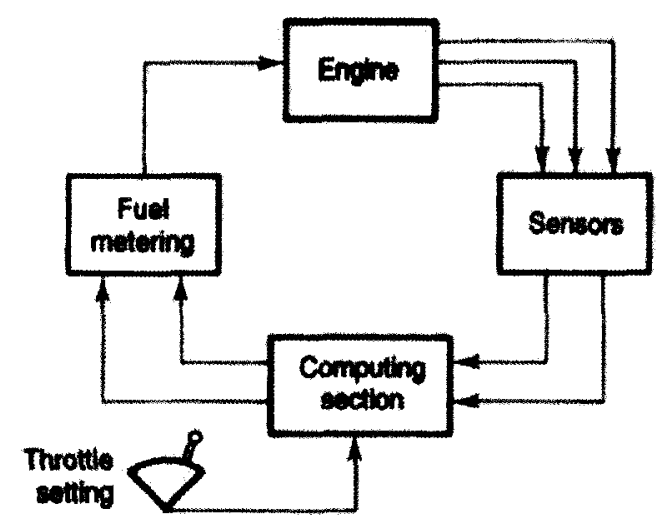

Figure 2.7: Control system components (Saravanamuttoo et al., 2001) 
The basic control process begins by determining the amount of fuel required by the engine, based on sensors and throttle settings, to produce a desired amount of power or thrust. Then the required amount of fuel is metered by the fuel delivery system and sent to the combustion chamber. The resulting power or thrust is measured and compared to the required levels set by the operator. This control process continuously loops until the required amount of power or thrust is met. A functional diagram of this process is shown in Figure 2.8.

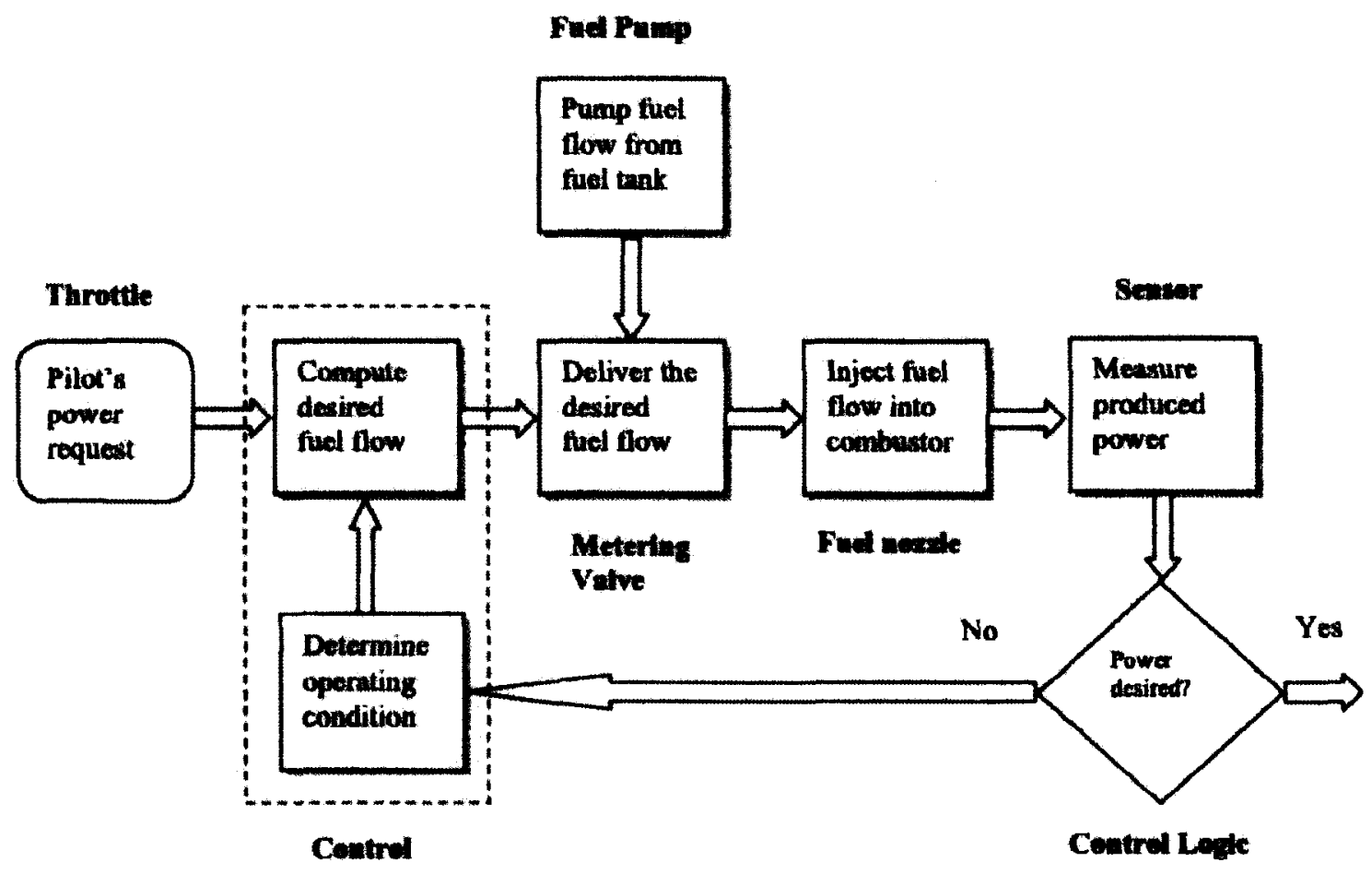

Figure 2.8: Functional process diagram of a simple engine control system (Jaw and Garg, 2005)

For many years, the computing section and the fuel metering section of the control system were incorporated into a hydromechanical system (Figure 2.9), in which fuel (or compressor delivery air for hydro-pneumatic systems) passing through the unit provided the necessary hydraulic actuation of a variety of pistons, bellows and levers which metered the required fuel to the combustion system (Saravanamuttoo et al., 2001). 

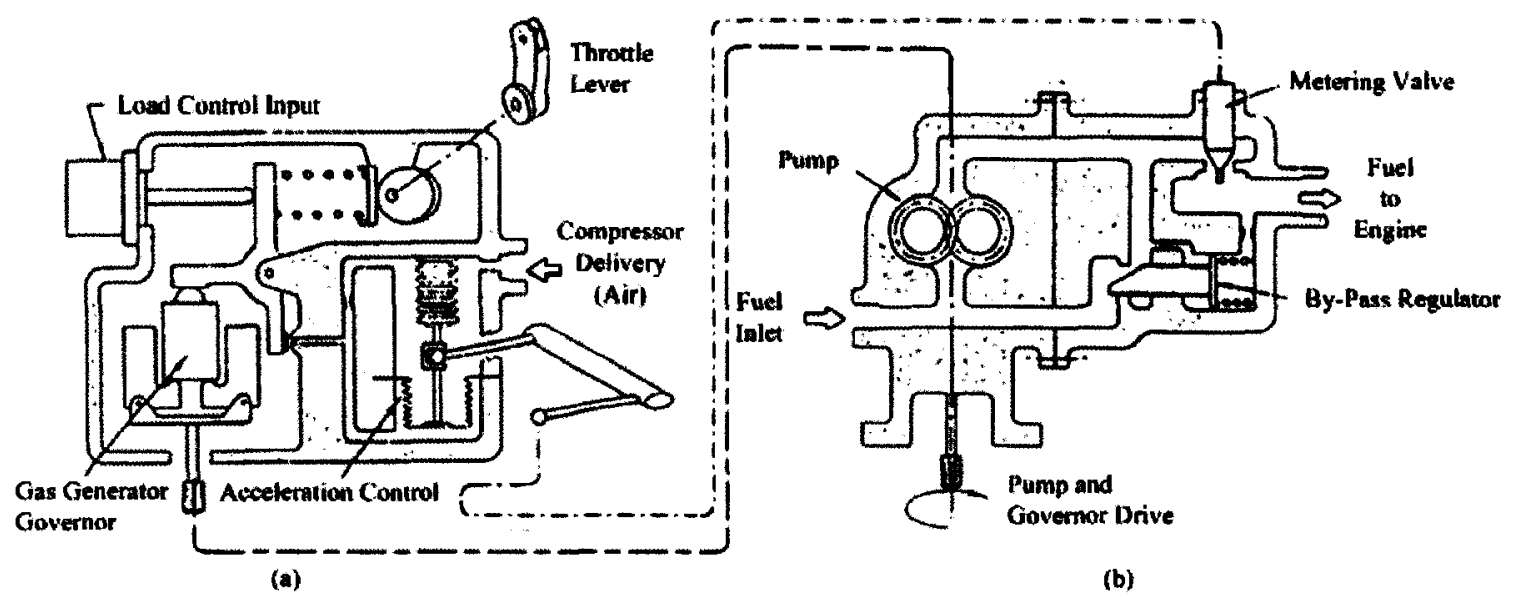

Figure 2.9: Hydromechanical system: (a) Computing section (b) Fuel metering section (adapted from Saravanamuttoo et al., 2003)

As control complexity increased, the traditional hydromechanical systems became increasingly bigger, heavier and relatively expensive. As a result, in the early 1970s, analog and digital Electronic Control Units (ECU) were designed to replace the hydromechanical systems (Jaw and Garg, 2005). Initially, the ECU was designed to provide only high-level supervisory or trim functions. But a few years after, this initiative led to the design of Full-Authority Digital Electronic Controls (FADECs), capable of controlling all modes of engine operation from start to shutdown. It is important to note that ECUs and FADECs were designed only to replace the computing section of the hydromechanical system. To complete the control system, a fuel metering section is still required (Saravanamuttoo et al., 2001). Gas turbine control system designers have been using FADECs for the past 30 years and justify using digital control based on the following benefits (Jaw and Garg, 2005):

- Significant size and weight reduction for the same control functionality

- Unrestricted power lever movement, especially in military applications, thus reducing pilot workload

- Estimation of engine trim after any control change

- Easy software updates 
- Compatibility with flight control, fire control and other on-board monitoring systems.

- Power to record engine data. Better maintainability due to increased diagnostics capabilities from electronics.

In recent year, the engine data acquisition capability found in FADECs led to the emergence of Engine Health Monitoring (EHM) systems. These systems use inputs such as thermodynamic measurements, vibration analysis and chemical analysis of the lubricating oil to assess engine health (Saravanamuttoo et al., 2001). Significant reductions in maintenance costs due to early detection of engine deterioration were attributed to such systems.

\subsubsection{Control System Design Requirements}

The fundamental requirement of a gas turbine control system is to maintain the safety of the engine, regardless of throttle changes or changing inlet conditions (Saravanamuttoo et al., 2001). To meet this sole requirement many sub-level functions and application-specific requirements must be satisfied. Figure 2.10 will be used as a roadmap to follow while identifying the control system design requirements.

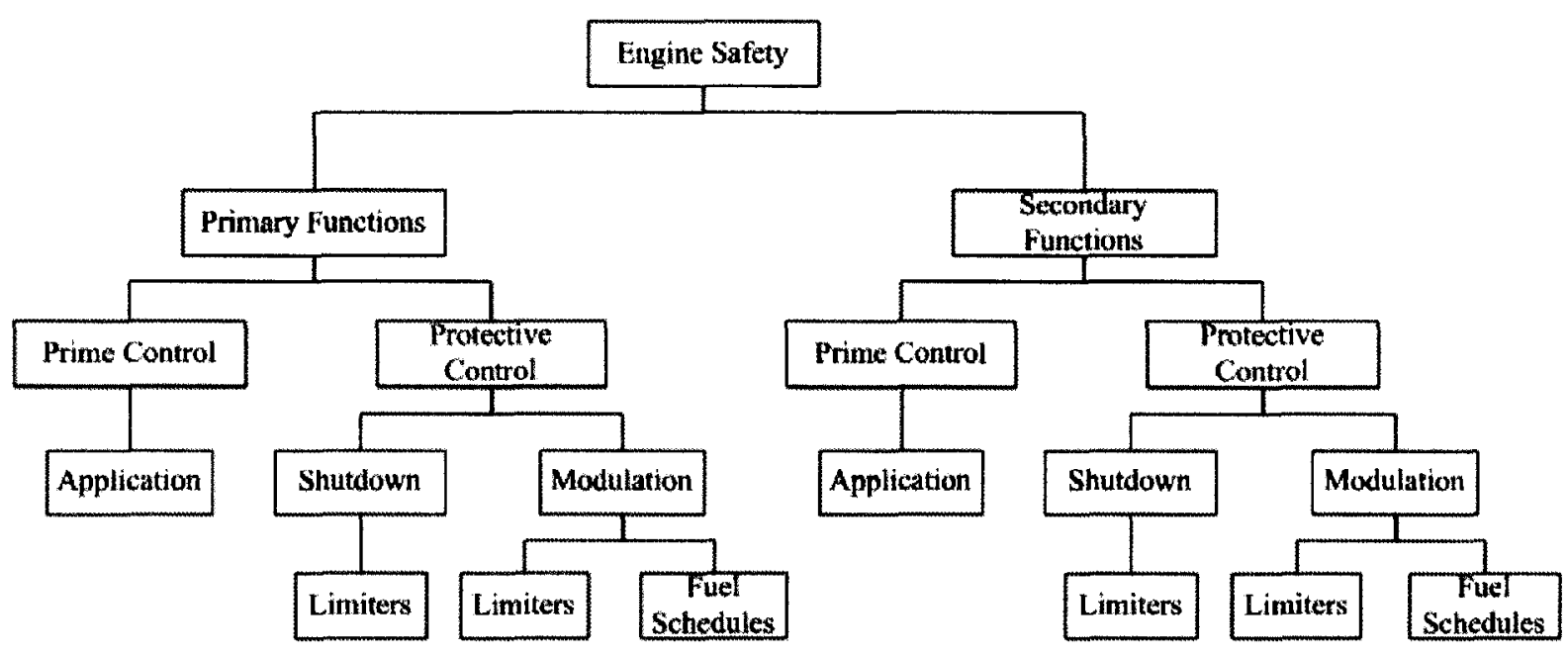

Figure 2.10: Control system requirements roadmap 
While ensuring that the fundamental requirement is met, engine control systems must also perform primary and secondary functions. The primary functions of a control system consist of (Mattingly et al., 2002):

- Maintaining consistent, stable power or thrust levels

- Maintaining smooth, repeatable performance during transient operation from one requested power or thrust level to another

- Maintaining stable airflow, internal pressures and temperatures, and rotor speeds within safe operating limits

- Avoiding stalls and surges, and significant speed, pressure or temperature variations

The main secondary functions include (Mattingly et al., 2002):

- Startup and shutdown

- Engine bleed and power extraction

- Inlet anti-icing and hot gas ingestion protection

Even though the primary and secondary control system functions are generalized for most gas turbines, specific control system requirements are usually set depending on the gas turbine application. These specific requirements are usually divided into two categories: prime control and protective control (Sawyer, 1966). The prime control category contains all requirements specific to the application of the power generated by the gas turbine. For example, in the power generation industry, gas turbines are synchronized to an overall electrical grid. It is important that the engines operate continuously at an assigned frequency because the grid is sensitive to frequency fluctuations (Boyce, 2001). Therefore the prime control requirement is to maintain constant electrical frequency by correcting any changes in frequency within seconds. On the other hand, the protective control category encloses all requirements pertinent to the safe operation of a gas turbine. Again coming back the power generation example, gas turbines used in such applications must be capable of dealing with severe changes in 
external torque produced by the electrical load. In the event of an over-speed or overtemperature, the protective control requirement would be to decelerate the engine from rated power to $5 \%$ of idle power within 3 seconds (Walsh and Fletcher, 1998). In some instances prime control requirements may compete against protective control requirements, but since the fundamental requirement of the control system is safety, protective control always wins (Sawyer, 1966). For example, the American regulations require that an aero-engine be capable of accelerating from $15 \%$ of the rated power or thrust available to $95 \%$ of rated take-off power or thrust in less than 5 seconds (MacIsaac, 1975). The prime requirement in this case is to achieve a specified power or thrust level as fast as possible. But rapid accelerations lead to high turbine inlet temperatures, which are usually restricted by a protective control requirement. Therefore, since protective controls override prime controls in such an event; the rate at which the gas turbine can accelerate will be limited by the protective control requirement. As shown in Figure 2.11, protective control requirements, also known as limiters, delimit a safe operating region for transient or steady-state operations (Sawyer, 1966).

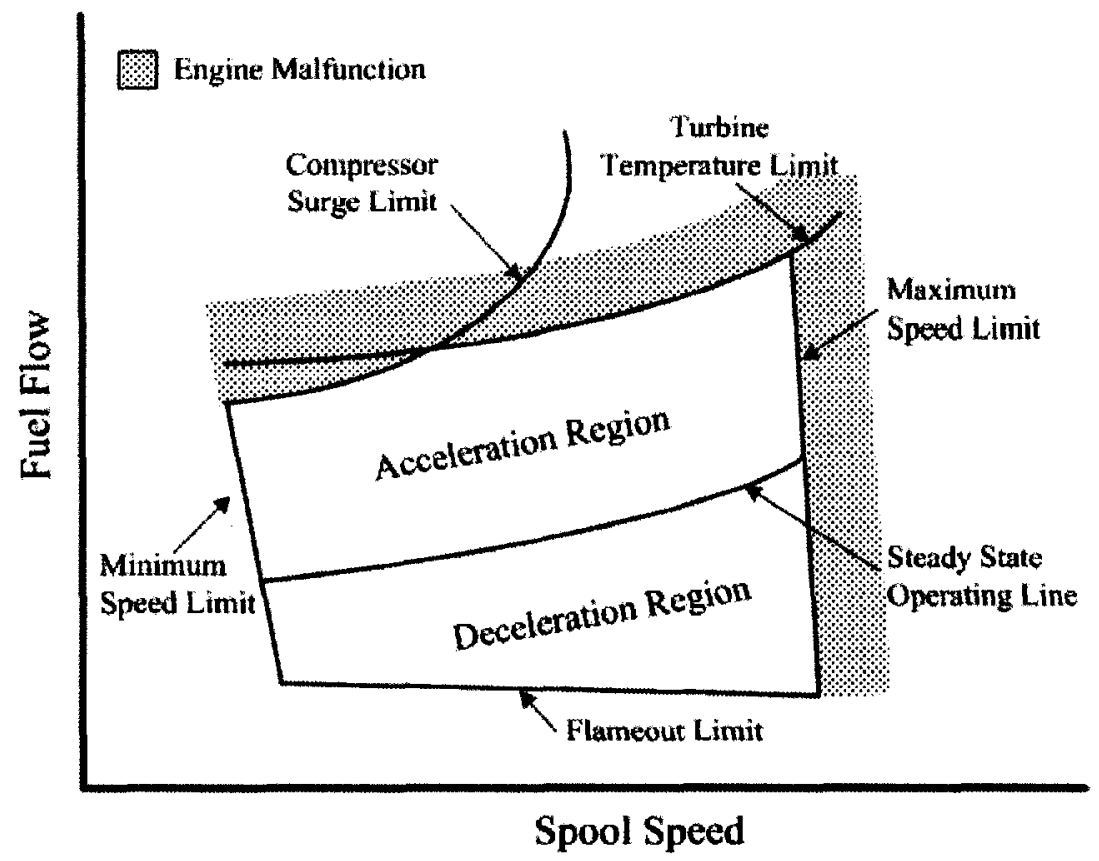

Figure 2.11: Gas turbine control limiters (adapted from Sawyer, 1966) 
These limits are usually identified to ensure adequate engine life (GasTOPS, 1990) and reduce the possibility of structural damage. To fulfill these requirements, the protective controls may proceed in two ways: 1) shutdown or 2) modulation (Sawyer, 1966). The shutdown action takes place if the protective controls detect a condition that would cause a serious malfunction. If this is the case, the fuel is cut off and the engine stops. Most gas turbine manufacturers require engine shutdown when the following malfunctions occur (Sawyer, 1966):

- Turbine over-temperature

- Turbine over-speed

- Low lube oil pressure

- High lube oil pressure

- Excessive vibration

To prevent the engine from reaching these limits and therefore shut down, a modulating action may take place by changing the operating condition (usually fuel flow) to alleviate the undesired condition. For example, a modulating curve (shown in Figure 2.12) may be used to protect the engine of reaching the maximum turbine inlet temperature.

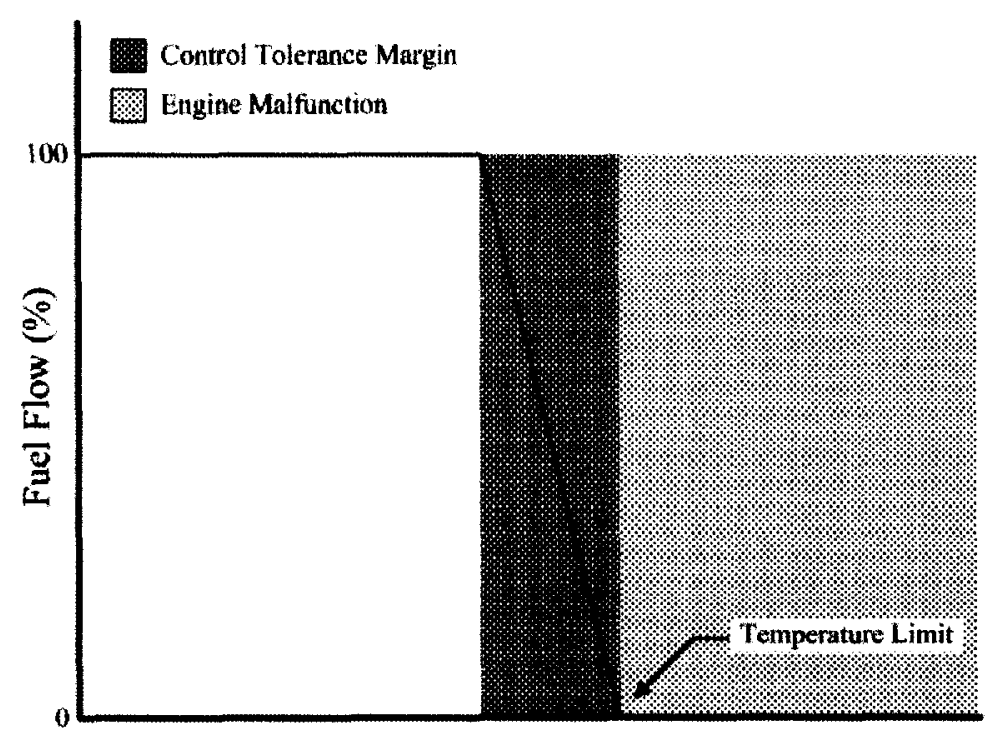

Turbine Temperature

Figure 2.12: Temperature modulating curve (adapted from Sawyer, 1966) 
The span of operating conditions over which the modulation takes place is called a control tolerance margin. Similar modulating curves and control tolerance margins may be defined for maximum and minimum spool speeds and minimum fuel-to-air ratio (flameout limit). By comparing Figure 2.11 and Figure 2.13, it is possible to see that the acceleration and deceleration regions shrink due to the presence of control tolerance margins. From this observation it is possible to deduce that maximum engine response cannot be attained with maximum engine protection (Sawyer, 1966). A compromise is usually required between prime and protective controls to ensure satisfactory engine performance, but as explained earlier priority is given to engine safety.

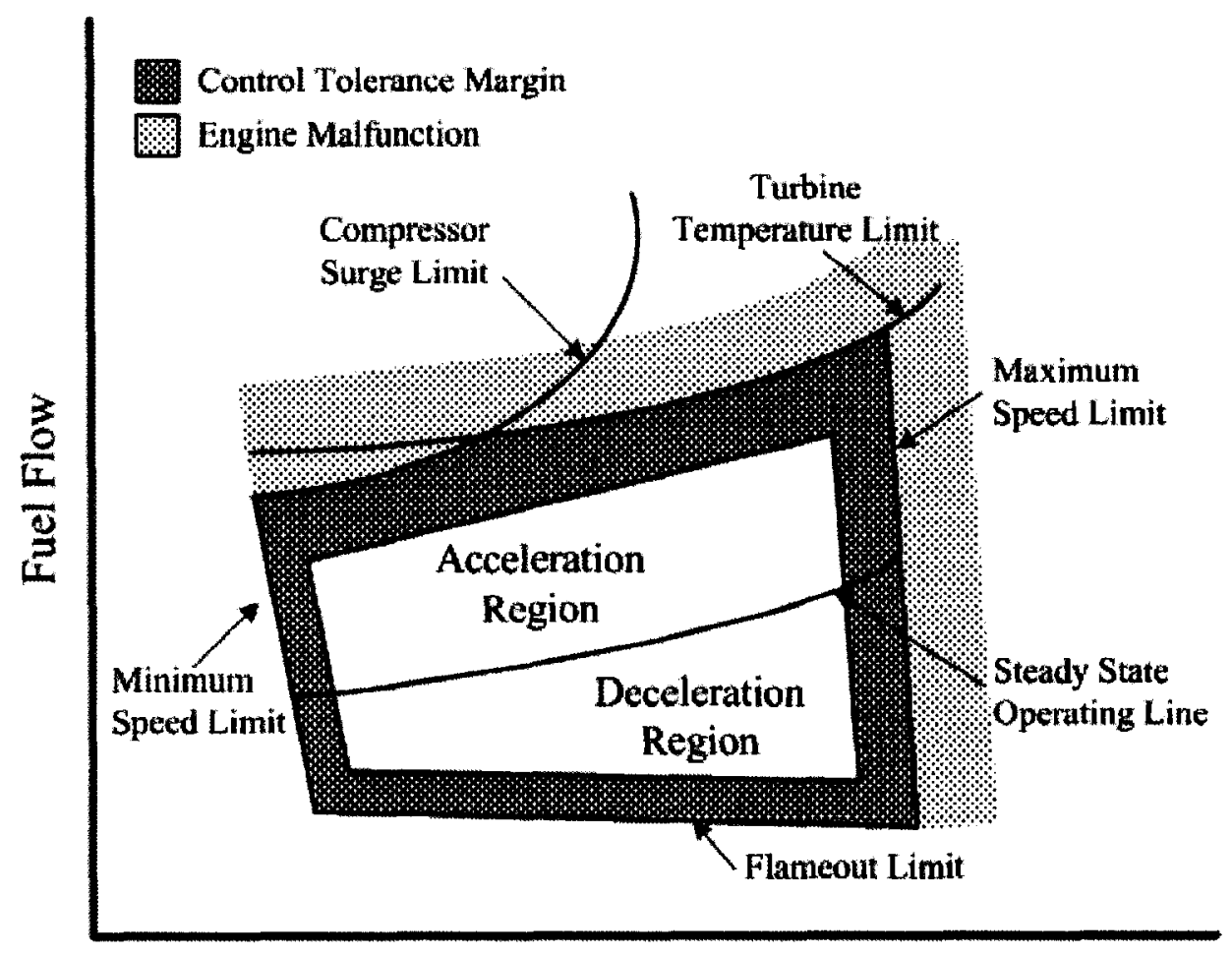

Spool Speed

Figure 2.13: Gas turbine control limiters with tolerance margins (adapted from Sawyer, 1966) 
Compressor surge is also an important malfunction to prevent. The reason why it was not part of the shutdown event list highlighted earlier is because there is no mechanism for measuring surge (GasTOPS, 1990). Surge protection cannot be accomplished in a similar fashion as turbine over-temperature or over-speed because impending compressor surge cannot be easily detected. When the compressor is in surge, it is too late to take corrective action (Sawyer, 1966). But, based on parameters such as spool speed, compressor inlet temperature, altitude and a given compressor map, it is possible to determine the operating conditions at which surge is likely to occur. As a result, modulating curves also known as acceleration schedules or acceleration fuel schedules (Figure 2.14), can be determined to ensure that the engine will operate below surge conditions. The fuel-limiting shape of the acceleration schedule depends entirely on the shape of the surge fuel boundary and on the requirements for rapid acceleration (GasTOPS, 1990). Here again, a compromise is usually required between prime and protective controls to ensure satisfactory engine performance.

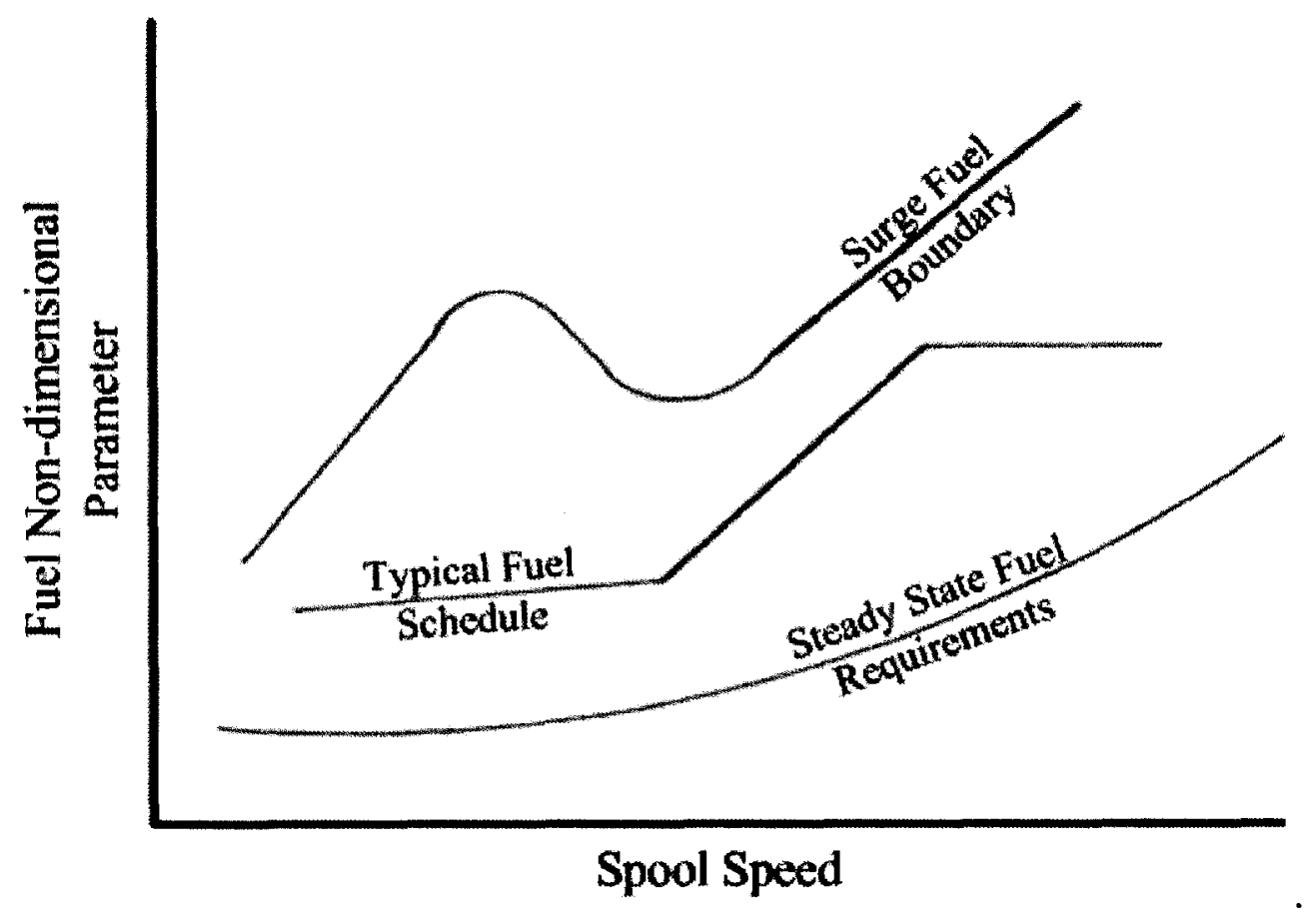

Figure 2.14: Typical fuel schedule (adapted from GasTOPS, 1990) 


\subsubsection{Basic Control Concepts and Design Methodologies}

There are two main types of controlling systems: open-loop control systems and closed-loop controls systems. An open-loop control system (Figure 2.15) is characterized by the fact that the output signal has no effect on the input signal. In such systems, the output signal is neither measured nor fed back for comparison with the input signal (Ogata, 2002). Therefore open-loop controls rely on the fact that each input corresponds to a fixed operating condition. In the context of gas turbine operation, such controls are impractical for many reasons, not the least of which is the fact that it would be difficult to calibrate (Saravanamuttoo, 2003). The accuracy of the control system depends greatly on its calibration and if in presence of disturbances the control system will not perform the desired task (Ogata, 2002).

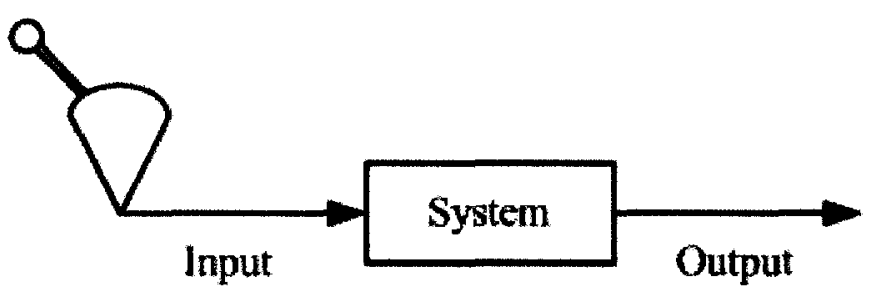

Figure 2.15: Open-loop control (adapted from Saravanamuttoo, 2003)

To alleviate some of the open-loop control system impracticalities, humans may be added to the open-loop system. Known as "human in the loop" control systems (Figure 2.16), the operator controls the engine physically based on observations and realtime data. Within physical capabilities, the human is a remarkably adaptable control system as he is capable of dealing with disturbances and changes in calibration. Early gas turbine control systems provided only essential machine protection therefore permitting the operator direct control of fuel input over the entire operating range. But, in recent years, the operating cost linked to "human in the loop" control systems, its limited capacity to process information and its physical inability to respond to higher frequencies rendered this type of control system obsolete in the presence of intricate gas turbine controlling scenarios (Saravanamuttoo, 2003). 


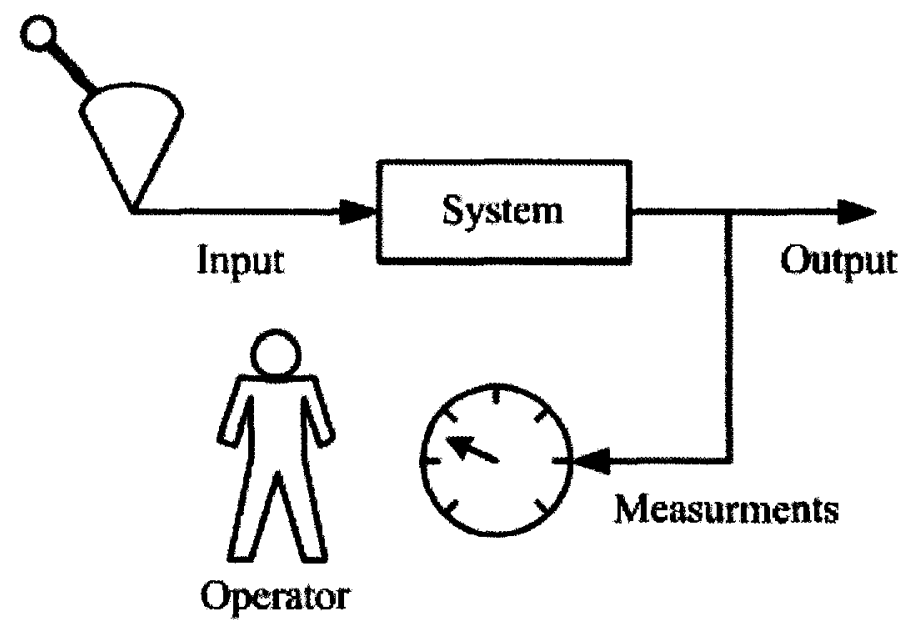

Figure 2.16: "Human in the loop control (adapted from Saravanamuttoo, 2003)

Closed-loop control systems (Figure 2.17), on the other hand, rely on feedback control action. In a closed-loop control system the actuating signal, which is the difference between the input signal and the output signal (also known as feedback signal), is fed to the controller to reduce the error and bring the output of the system to a desired value. An advantage of this system is that the use of feedback makes the system response relatively insensitive to external disturbances and internal variations in system parameters (Ogata, 2002). Therefore it is possible to use relatively inaccurate and inexpensive components to achieve accurate gas turbine engine control.

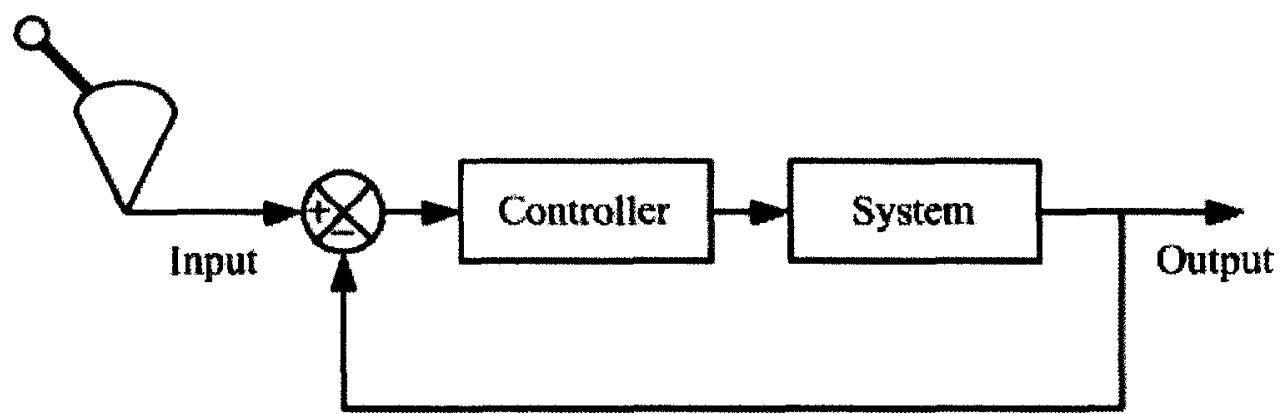

Feedback

Figure 2.17: Closed-loop control (adapted from Saravanamuttoo, 2003)

The key to adequate engine performance and engine dynamic response lies in the design of the control system controller. As explained previously, the difference between the input signal and output signal, also known as the error signal, is fed to the controller. 
The task of the controller is then to modulate the error signal to achieve the required output. In the gas turbine industry there are two types of controller used: droop governors and isochronous governors (Saravanamuttoo, 2003). A droop governor is defined as a simple proportional control. For example, as shown in Figure 2.18, the fuel flow rate to the gas turbine is made proportional to the error in speed, thus reducing the error in time.

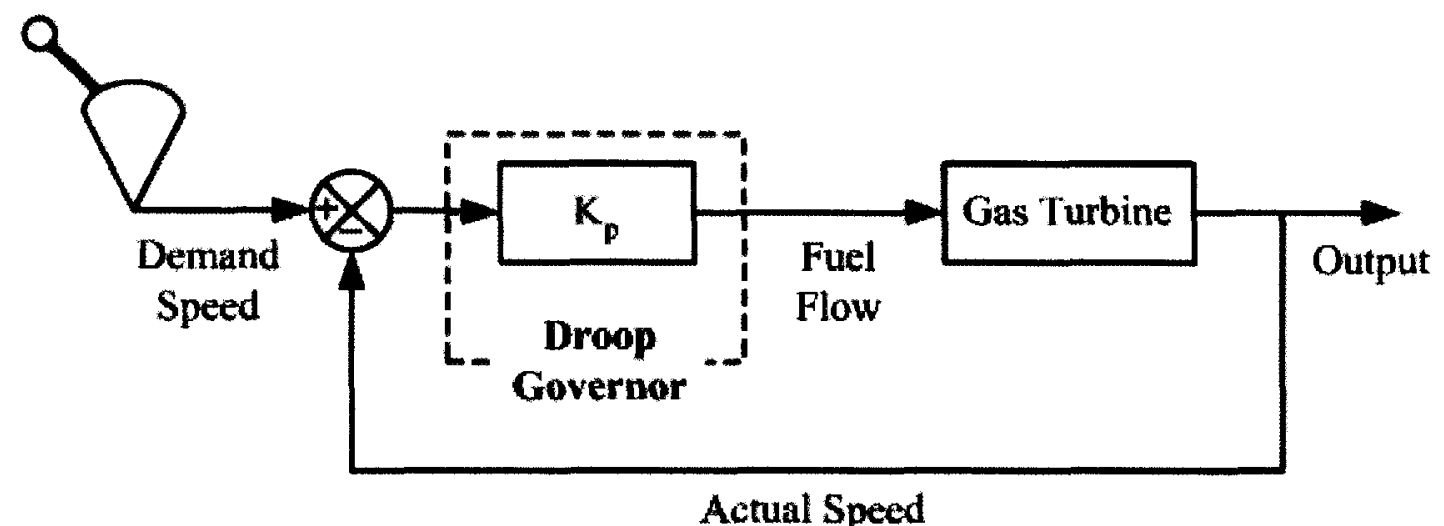

Figure 2.18: Proportional control (adapted from Ogata, 2002)

The relationship between the fuel flow $\left(\dot{\mathrm{m}}_{\mathrm{f}}\right)$ and the error in speed depicted in Figure 2.18 , can be represented mathematically by:

$$
\dot{\mathrm{m}}_{\mathrm{f}}=\mathrm{K}_{\mathrm{p}}\left(\mathrm{N}_{\mathrm{D}}-\mathrm{N}\right)
$$

where $\mathrm{K}_{\mathrm{p}}$ is known as the proportional gain.

For this type of controller to work properly, there must always be a difference between the demand speed and the actual speed (GasTOPS, 1990). Therefore as shown in Figure 2.19 , the error signal will never reduce to zero. This droop in speed must be considered when designing the proportional control as it affects the accuracy of the output response. 


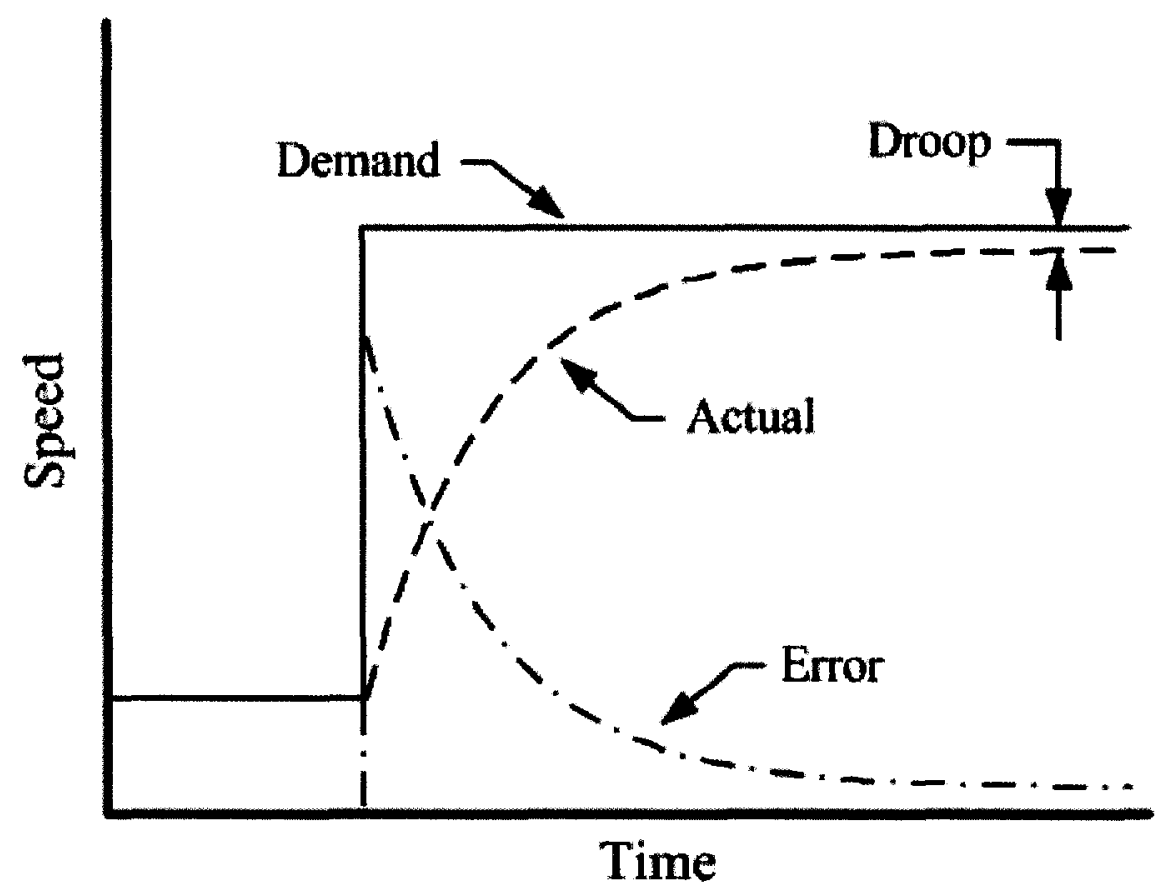

Figure 2.19: Typical proportional-controlled step response

More recent controls, particularly those which apply to free power turbine engines, are said to be "Isochronous Governors" (GasTOPS, 1990). An isochronous governor, as the name implies, synchronizes in time the demand value and the feedback value (Saravanamuttoo, 2003). As shown in Figure 2.20 , this is achieved by the addition of an integral term in the control loop.

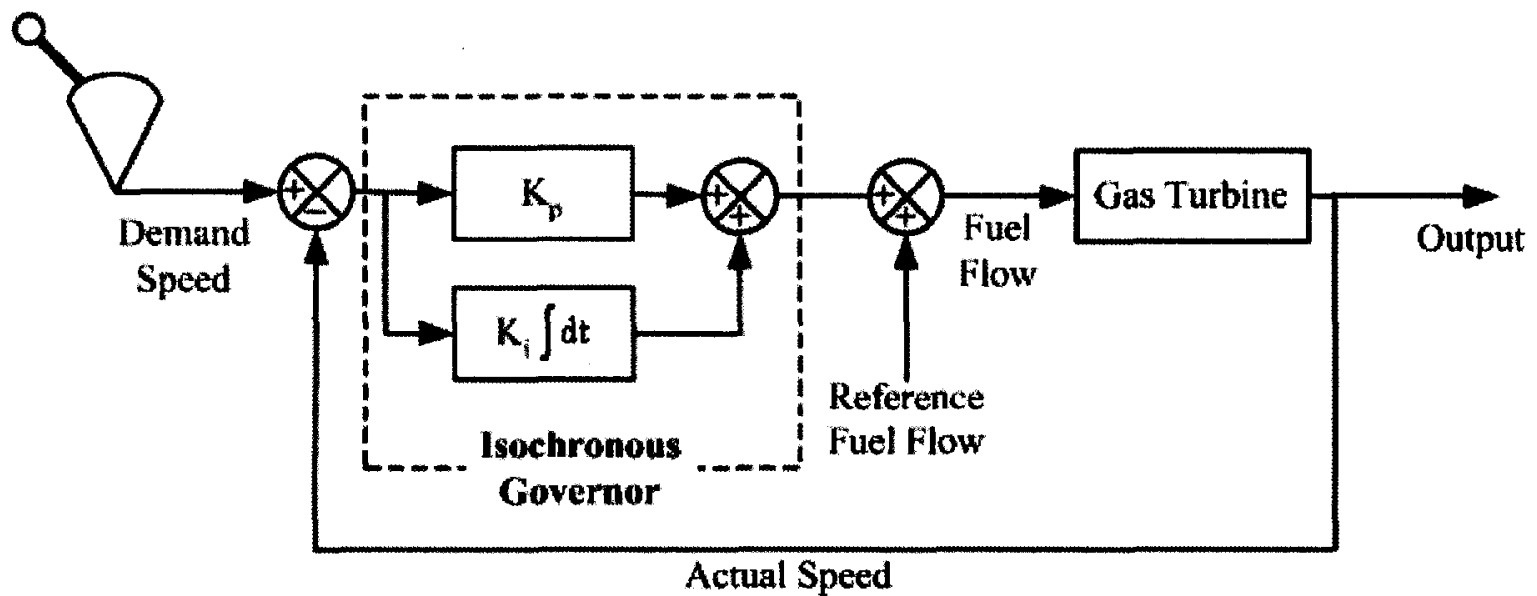

Figure 2.20: Isochronous control (adapted from Saravanamuttoo, 2003) 
In this situation, the isochronous control of fuel flow can be represented mathematically by:

$$
\dot{\mathrm{m}}_{\mathrm{f}}=\dot{\mathrm{m}}_{\mathrm{f}, \mathrm{ref}}+\left(\mathrm{K}_{\mathrm{p}}\left(\mathrm{N}_{\mathrm{D}}-\mathrm{N}\right)+\mathrm{K}_{\mathrm{i}} \int\left(\mathrm{N}_{\mathrm{D}}-\mathrm{N}\right) \mathrm{dt}\right)
$$

This type of control provides a match between the demand speed $\left(\mathrm{N}_{\mathrm{D}}\right)$ and the actual speed $(\mathrm{N})$, but as shown in Figure 2.21, it is only achievable at the expense of stability. The variable $\mathrm{K}_{\mathrm{i}}$ in Eqn 2.12 represents the integral gain.

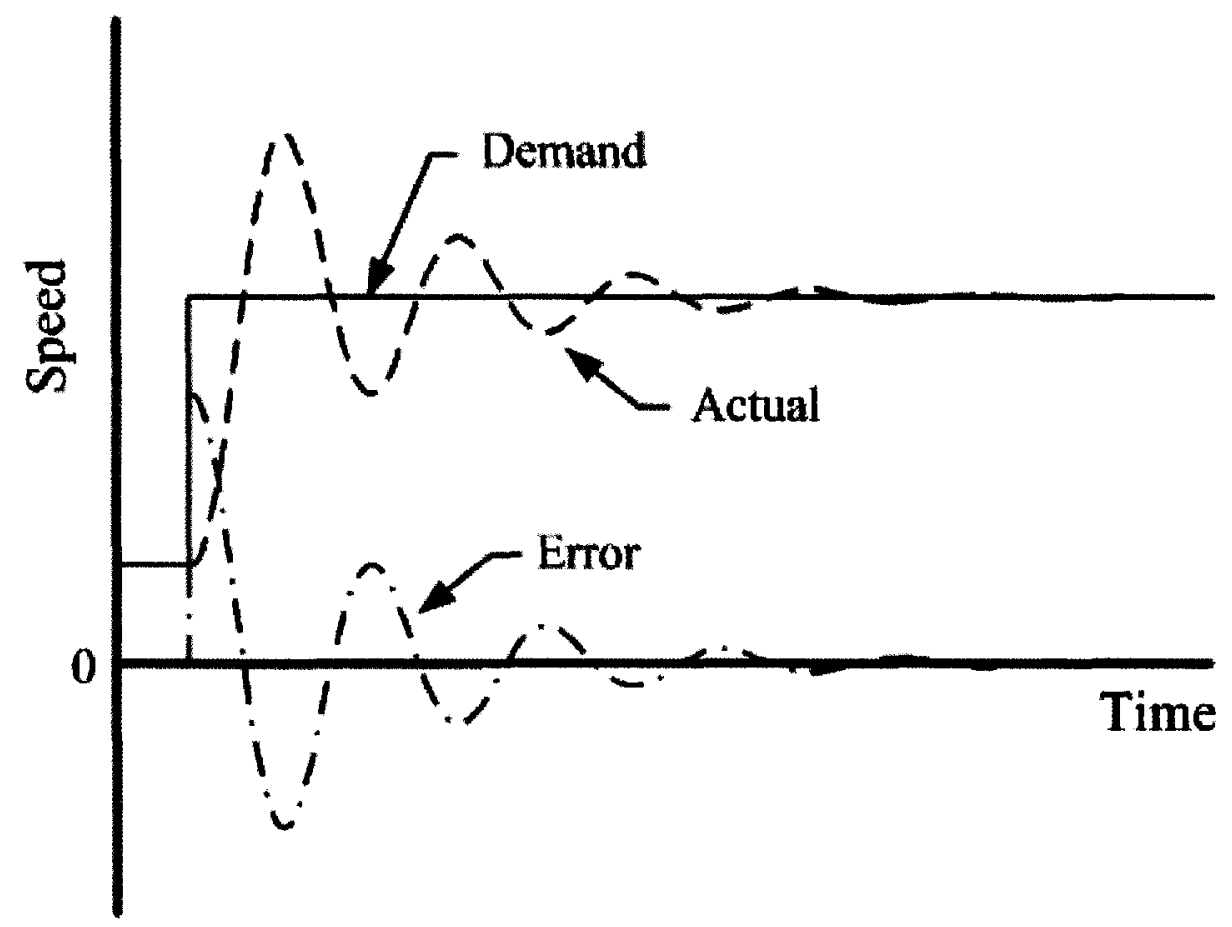

Figure 2.21: Typical isochronous-controlled step response

Another controller not yet discussed is called "Proportional-Integral-Derivative (PID) controller". This type of controller is commonly used in process control applications (Shinskey, 1994). Similarly to the droop governor and the isochronous governor, the PID controller modulates an input error signal to achieve a desired output setting. As demonstrated in Figure 2.22, a derivative term is added to the control loop. 


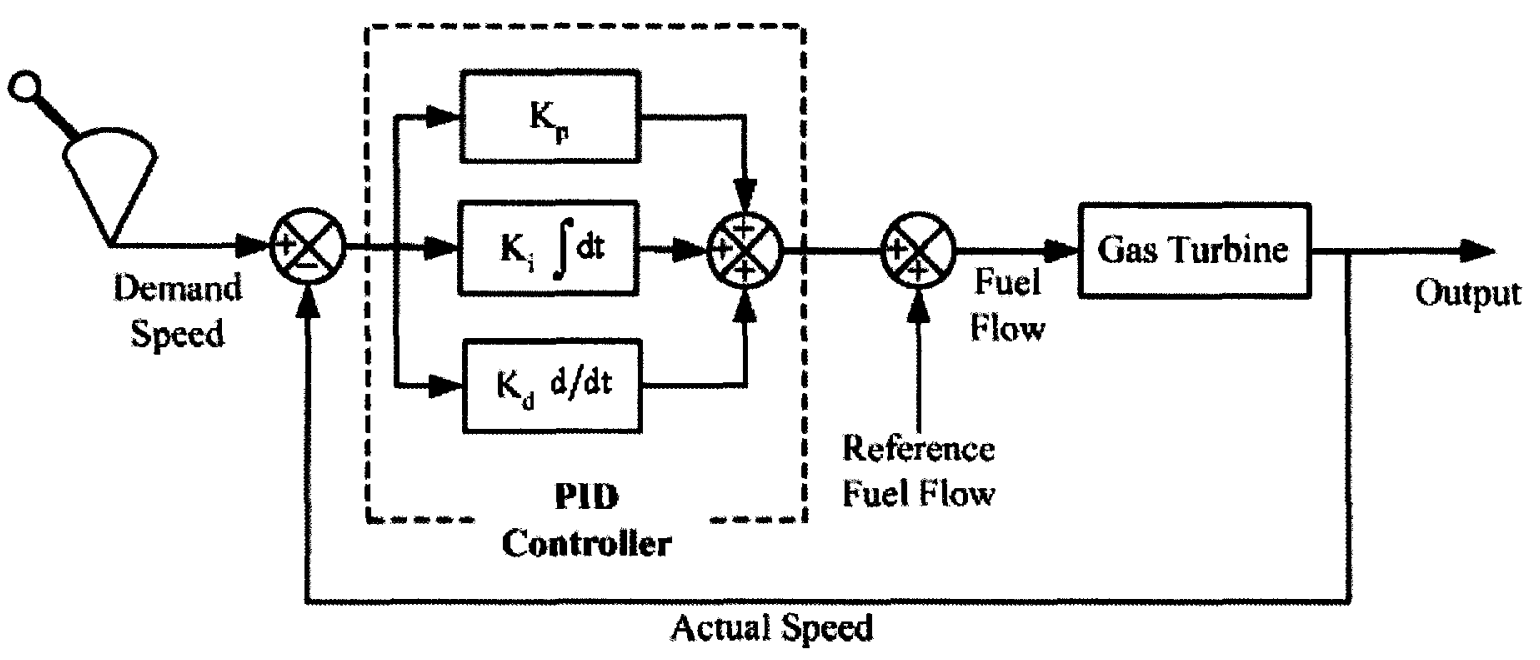

Figure 2.22: PID control (adapted from Ogata, 2002)

The PID control over the fuel flow can be expressed mathematically by:

$$
\dot{\mathrm{m}}_{\mathrm{f}}=\dot{\mathrm{m}}_{\mathrm{f}, \mathrm{ref}}+\left(\mathrm{K}_{\mathrm{p}}\left(\mathrm{N}_{\mathrm{D}}-\mathrm{N}\right)+\mathrm{K}_{\mathrm{i}} \int\left(\mathrm{N}_{\mathrm{D}}-\mathrm{N}\right) \mathrm{dt}+\mathrm{K}_{\mathrm{d}} \frac{\mathrm{d}}{\mathrm{dt}}\left(\mathrm{N}_{\mathrm{D}}-\mathrm{N}\right)\right)
$$

where $\mathrm{K}_{\mathrm{d}}$ is known as the derivative gain.

This new addition has the effect of reducing the stability issue linked to isochronous controllers, but still providing a match between the demand $\left(\mathrm{N}_{\mathrm{D}}\right)$ and the measured signals $(\mathrm{N})$ (Figure 2.23). 


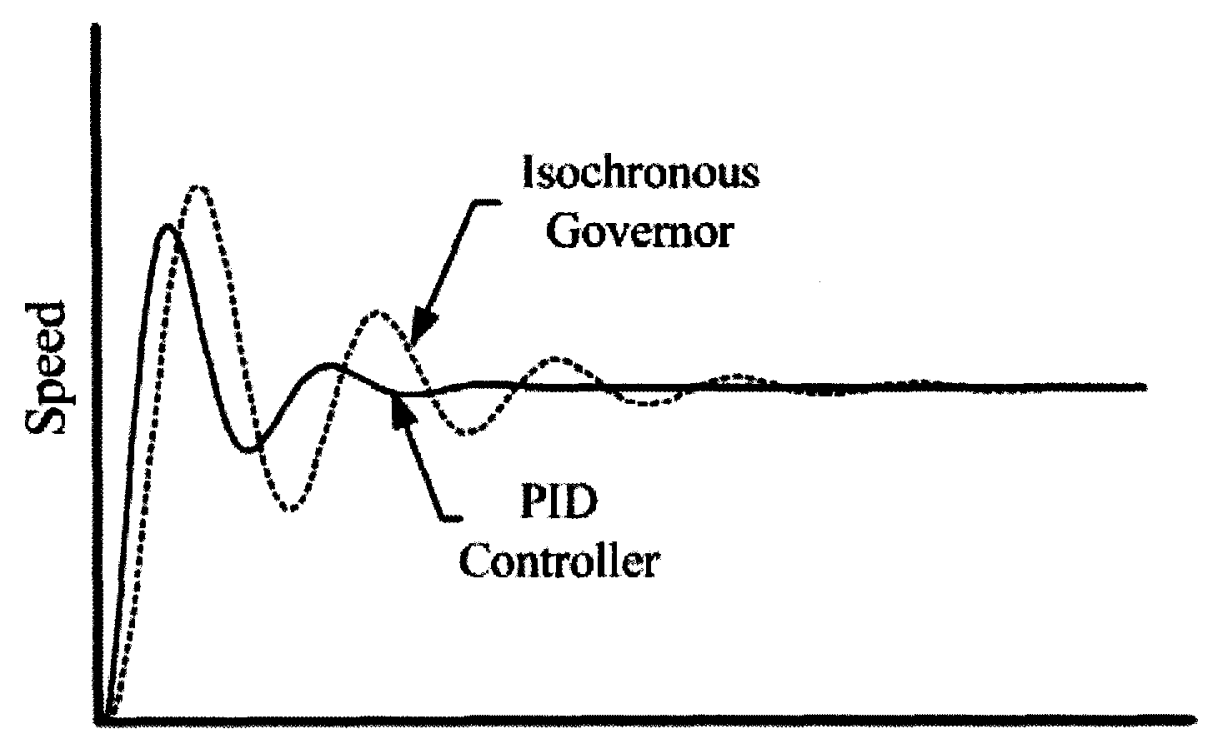

\section{Time}

Figure 2.23: Typical step response: PID controller compared to isochronous governor

A major disadvantage to this type of controller is that the derivative term is very sensitive to data acquisition noise and step changes in the reference signal (input) (Aström, 2002). These actions result in a highly undesirable impulse in the control signal since the occurrence of noise and step changes in the reference signal during operation depends greatly on the engine application. Åström (2002) suggested that the reference signal should be filtered before entering the controller. He also stated that another possibility called set-point weighing, which consists of letting the proportional action act only on part of the reference signal, could also be used to prevent the occurrence of undesirable impulses. $\mathrm{Mu}$ et al. (2002), which described the design of an optimum controller for a gas turbine engine, elaborated on another method in which sets of optimum PID controller gains $\left(\mathrm{K}_{\mathrm{d}}, \mathrm{K}_{\mathrm{p}}, \mathrm{K}_{\mathrm{i}}\right)$ where found. Based on optimum controller response requirements, they demonstrated that the optimum value for the derivative gain $\left(\mathrm{K}_{\mathrm{d}}\right)$ resulted in zero. Therefore, given optimum values for the proportional gain $\left(\mathrm{K}_{\mathrm{p}}\right)$ and the integral gain $\left(\mathrm{K}_{\mathrm{i}}\right)$, the undesirable impulses can also be avoided by replacing the PID controller by an optimum isochronous governor.

In many practical cases, the desired performance characteristics of control systems are specified in terms of time-domain quantities. Since control systems often 
exhibit damped oscillations before reaching steady state when subjected to a unit-step input, it is common practice to specify the following performance specifications when designing a control system (Ogata, 2002):

- Delay time

- Rise time

- Peak time

- Maximum overshoot

- Settling time

These performance specifications are shown graphically in Figure 2.24. Typically, control system designers try to achieve optimum response by setting theses specifications to a minimum. But, it is important to note that some of these specifications are in conflict with one another. For example, the maximum overshoot and rise time cannot be made smaller simultaneously (Ogata, 2002). Therefore compromises are usually required when selecting these specifications. 


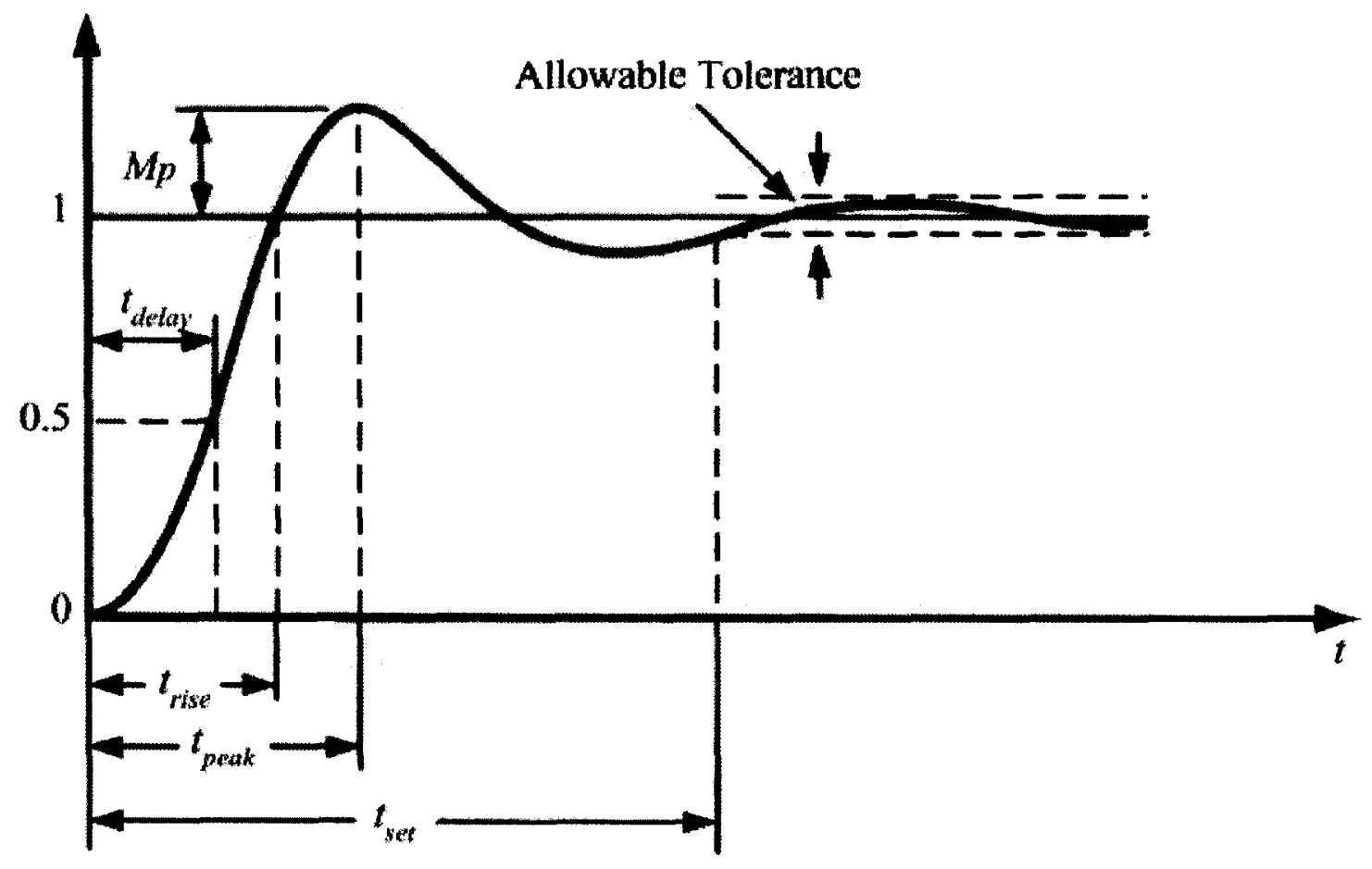

Figure 2.24: Unit-step response curve showing performance specifications (adapted from Ogata, 2002)

Once the performance characteristics of the control system are set or identified, the control system designers are responsible for meeting these specifications. This can be done in two ways: 1) they can design a controller specifically for these specifications or 2) tailor a pre-established controller such as a droop governor, an isochronous governor or a PID controller, to meet the desired performance characteristics. In most cases, the second option is chosen. Tailoring a pre-established controller, which is defined as the process of selecting the controller parameters to meet performance specification, is known in industry as controller tuning (Ogata, 2002). As discussed earlier, in the case of a droop governor, an isochronous governor or a PID controller, seen in Figure 2.18, Figure 2.20 and Figure 2.22, controller parameters are identified as gains. Modifying these gains will directly affect rise time, overshoot, settling time, steady-state error and stability. The individual effects of these gains on closed-loop performance are summarized in Table 2.1. Note that for optimum performance, $K_{p}, K_{i}$ and $K_{d}$ are mutually dependent on tuning (Ang et al., 2005). 
Table 2.1: Effects of independent $\mathrm{K}_{\mathrm{p}}, \mathrm{K}_{\mathrm{i}}$ and $\mathrm{K}_{\mathrm{d}}$ tuning (Ang et al., 2005)

\begin{tabular}{|c|c|c|c|c|c|}
\hline 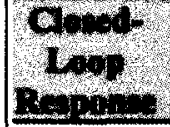 & net & Bentres & sonses & 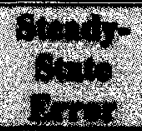 & 27,16 \\
\hline $\begin{array}{c}\text { Increasing } \\
K_{\mathrm{p}}\end{array}$ & Decrease & Increase & $\begin{array}{l}\text { Small } \\
\text { Increase }\end{array}$ & Decrease & Degrade \\
\hline $\begin{array}{l}\text { Increasing } \\
K_{1}\end{array}$ & $\begin{array}{c}\text { Small } \\
\text { Decrease }\end{array}$ & Inerease & Increase & $\begin{array}{c}\text { Large } \\
\text { Docrease }\end{array}$ & Degrade \\
\hline $\begin{array}{c}\text { Increasing } \\
K_{\mathrm{p}} \\
\end{array}$ & $\begin{array}{c}\text { Small } \\
\text { Decrease }\end{array}$ & Decrease & Decrease & $\begin{array}{c}\text { Minor } \\
\text { Change }\end{array}$ & Improve \\
\hline
\end{tabular}

During the last 50 years, the quest for optimum performance led to the development of a variety of controller tuning method or tuning formulas (Mu et al., 2002). Some well known tuning formulas developed over the years are (Ho et al., 1996):

- Ziegler-Nichols step response

- Ziegler-Nichols ultimate cycling

- Cohen-Coon

- Internal model control (IMC)

- Integral absolute error optimum (IAE)

- Integral square error optimum (ISE)

- Integral time-weighted absolute error optimum (ITAE)

In many case these formulas will not provide optimum performance on their own. The control system designer will often have to perform a series of fine tunings until acceptable results are obtained. For example, even though the Ziegler-Nichols tuning methods are considered as the most well known tuning methods, they only provide educated guesses for the parameter values (Ogata, 2002). These educated guesses are then used as a starting point for an iterative trial-and-error fine-tuning process.

A particular problem with gas turbine engine control systems and nonlinear systems in general, is that the gains of the controller have to be scheduled over the operating envelope of the plant (Chipperfield et al., 2002). The reason is that in most cases, the controller performance requirements are to remain constant for the entire 
operating range of the engine. Therefore, to meet these specifications and due to the fact that gas turbines behave nonlinearly, new sets of gains must be determined at every steady-state operating point or design point. To ensure that there is a smooth transition between these operating points, control system designers may rely on an approach called gain scheduling. As shown in Figure 2.25, gains scheduling can be achieved by simply adding a scheduling module to conventional closed-loop control systems.

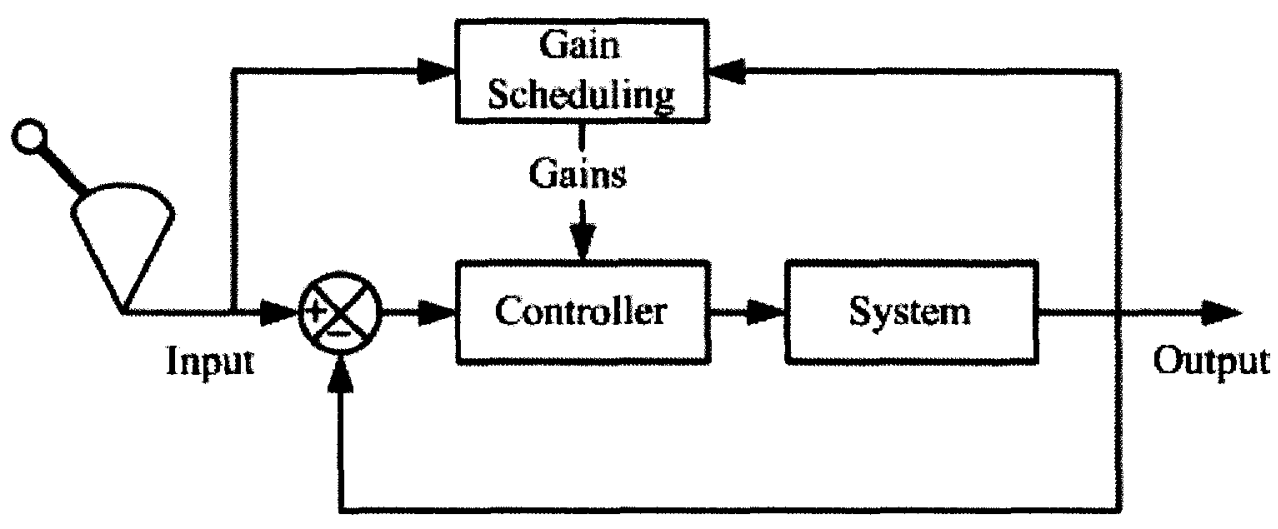

Feedback

Figure 2.25: Closed-loop control with gain scheduling (Adapted from Qi et al., 1992)

Conceptually simple, gain scheduling involves continuously interpolating parameters (gains), based on a scheduling variable, between members of a family of linearized approximations of engine performance (Leith and Leithead, 1996). The main idea in designing a gain-scheduled controller is to break the control design process into two steps (Qi et al., 1992):

- Design local linear controllers based on linear approximations of the nonlinear system at different operating points.

- Obtain a global nonlinear controller by interpolating or scheduling the gains of the local linear controllers.

As rules-of-thumb when selecting a scheduling variable, two fundamental guidelines must be followed (Shamma and Athans, 1990): 
- The scheduling variable should vary slowly

- The scheduling variable should capture the nonlinearities of the engine

Even though gain scheduling has proven to be a successful design methodology in many engineering applications (Shamma and Athans, 1990), authors such as Qi et al., (1992), Shamma and Athans, (1990) and Leith and Leithead, (1996) warn control system designers that gain scheduling remains an ad-hoc methodology. According to these researchers, techniques for analysis and design of gain-scheduled controllers remain poorly developed and in the absence of a sound analysis, the design comes with no guarantees of robustness, performance or even nominal stability of the overall gainscheduled design. As a result, computer simulations are required to ensure performance requirements are met. Above all, according to Qi et al., (1992), the success of designing a good nonlinear controller depends upon the following:

- Having a continuous and gradually changing nonlinear dynamic system

- Using a simple, fixed controller dynamic structure

- Selecting appropriate scheduling variable, which reflects the system dynamics

- Using a sufficient number of operating points to cover the operating range

This chapter highlighted the key principles and theories used for gas turbine dynamic modeling and control system design. The elaboration of a comprehensive dynamic modeling and control system design methodology developed based on these key principles and theories will be discussed in the following chapter. 


\section{Chapter 3 \\ Gas Turbine Dynamic Modeling Method}

A gas turbine dynamic model is required to facilitate transient performance analysis and control system design. The model consists of a series of tables and equations programmed into MATLAB to produce a virtual representation of a gas turbine engine. This virtual representation was used extensively as part of the design process of a control system for a 1-MW marine gas turbine with power turbine engine. This will be described further in subsequent chapters. This section will present the underlying thermodynamic equations used within the dynamic model. A general overview of the modeling method and its application will be discussed followed by a detailed look at the modeling techniques used to model each engine component individually.

\subsection{Overview}

In a general sense, a dynamic model is designed to produce a realistic virtual representation of a gas turbine engine based on a minimum number of inputs. As explained earlier, the cost-effectiveness of such a virtual representation increases drastically if it is developed and used early in the gas turbine design process. As a result, efforts were made to ensure the dynamic model was produced with only basic information available from preliminary studies. This information consisted of engine configuration, the type of turbomachinery used and data available from the thermodynamic design point studies. As seen in Figure 3.1, this type of information is available at an early stage of the gas turbine design procedure. In fact, based on approximations (which will be described further), it is possible to obtain engine transient performance data even before component aerodynamic studies and mechanical designs are performed. Since the gas turbine design procedure is iterative by nature, these assumptions and approximations can and will eventually be replaced by accurate values as they become available. 


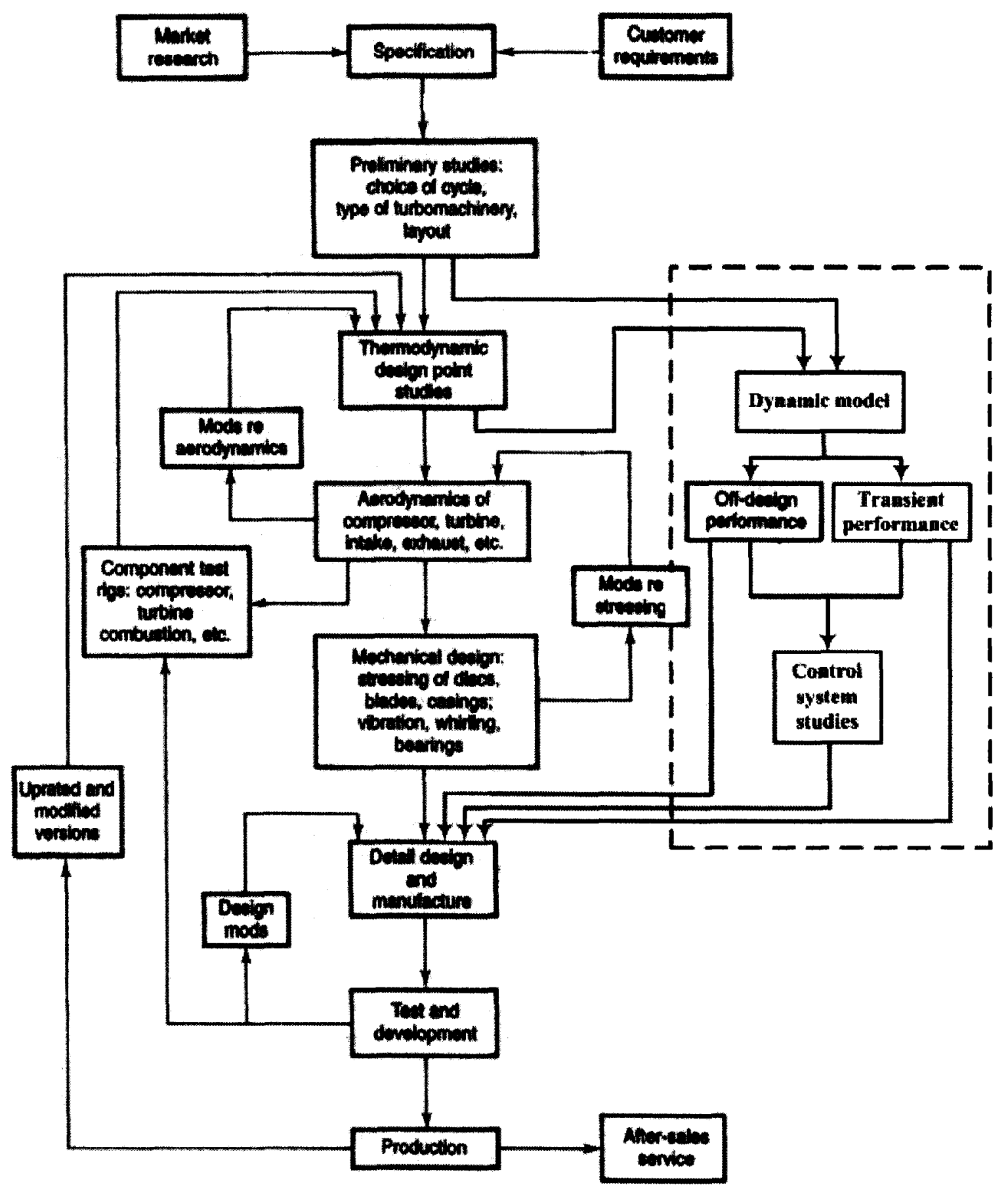

Figure 3.1: Typical gas turbine design procedure (adapted from Saravanamuttoo, 2001)

As show in Figure 3.2, the dynamic model is created following a straightforward process. 


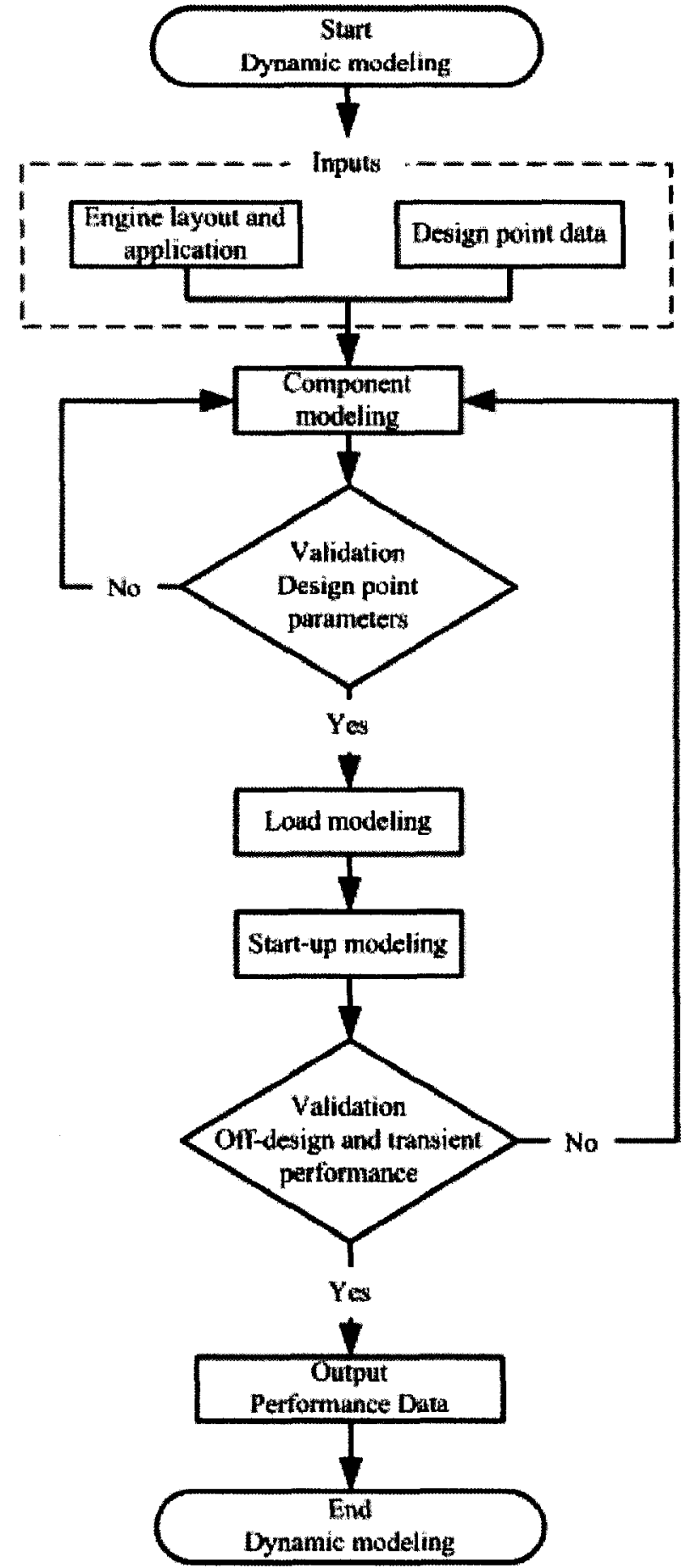

Figure 3.2: Dynamic modeling method

First, based on a given engine configuration, the gas turbine is broken down into components for ease of modeling. Then, each component and the interactions between them are captured through thermodynamic equations. As an example, a schematic 
representation of this process for a single-spool engine is shown in Figure 3.3. As discussed in Chapter 2, there are many ways of modeling the interactions between engine components. In an effort to capture most dynamic effects, the dynamic model was built using the inter-component volume method put forward by Fawke and Saravanamuttoo (1971). It was chosen for its ability to capture work and flow imbalance during transient operations and therefore provide a realistic representation of a gas turbine.

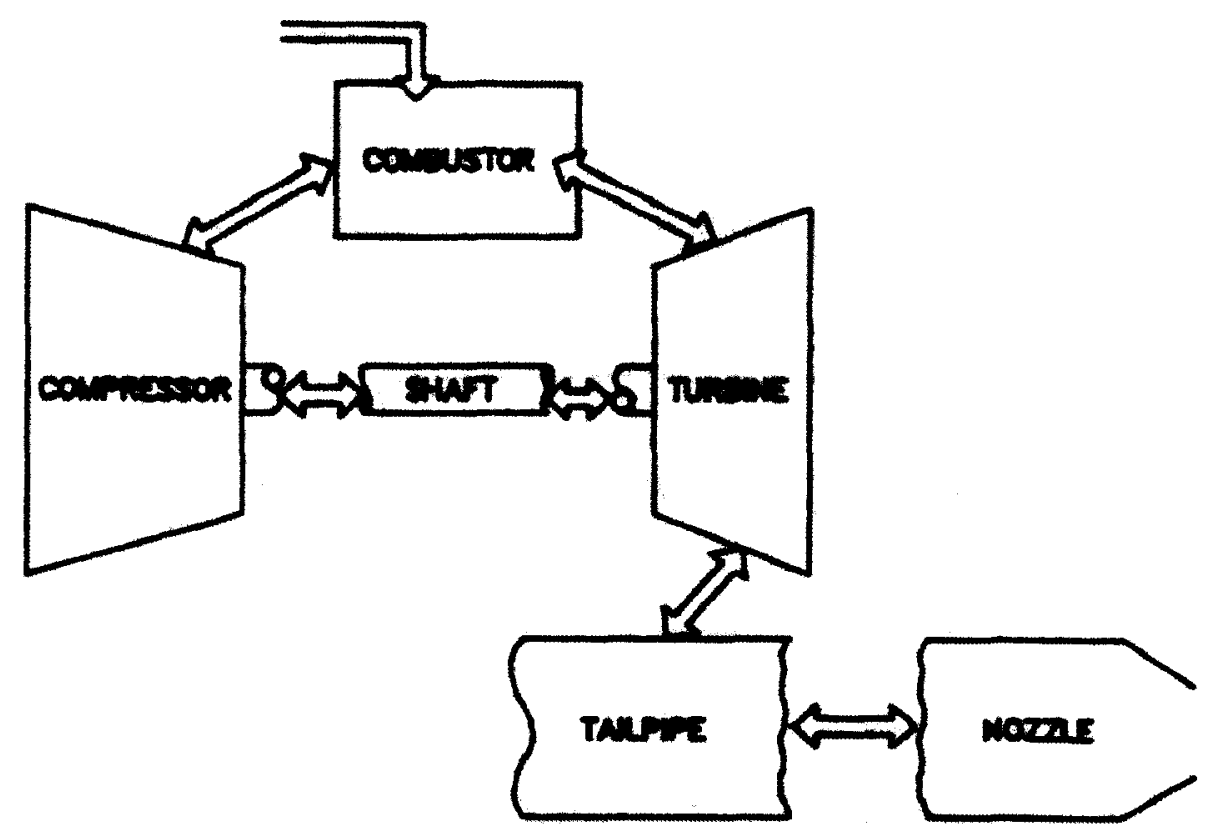

Figure 3.3: Single spool gas turbine component breakdown (GasTOPS, 1990)

The thermodynamic equations representing each component will be discussed later in subsequent chapters. Once the gas turbine components have been modeled and validated against commercial software or experimental data, the dynamic model becomes a virtual test bed. The model can be used to study steady-state off-design and transient performance under a variety of operating conditions (Figure 3.4). In addition, once the structure of the dynamic model is set up, the user may also study the effects of design point selection on off-design and transient performance. 


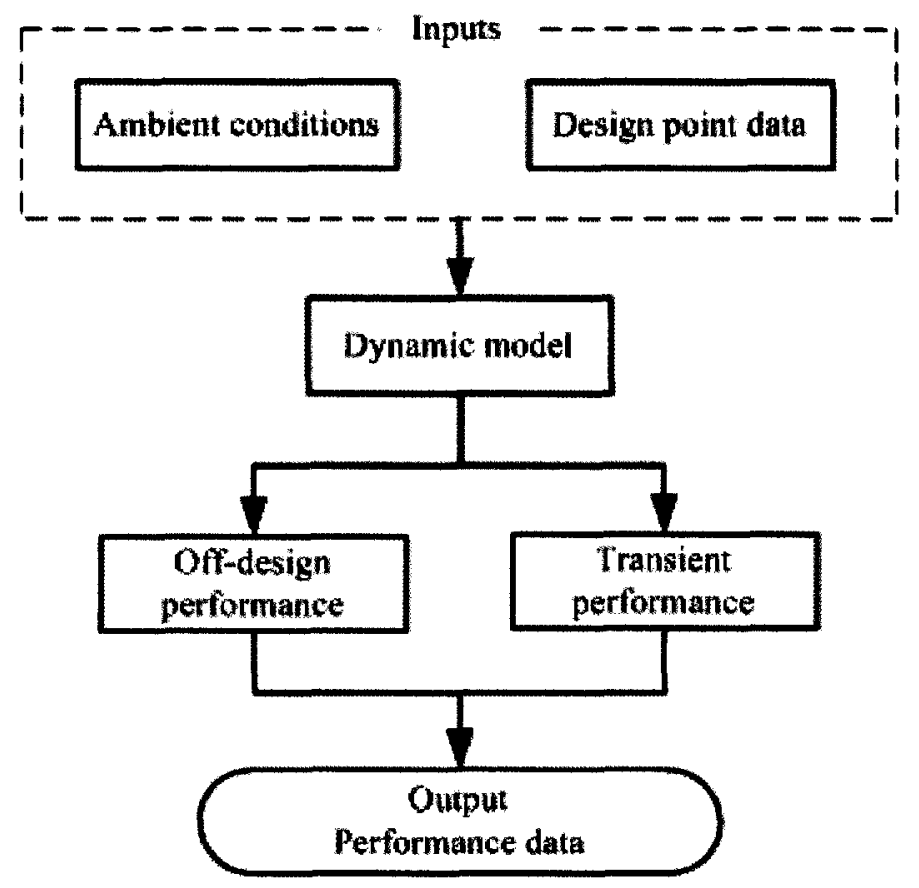

Figure 3.4: Dynamic modeling tool application

The modeling structure of the dynamic modeling method is specific to a given engine layout and application. In other words, a dynamic model developed for a turbofan may be used to analyse, for example, the effects of varying the pressure ratio or combustor dimensions on transient performance, but may not be used to analyze the performance of an aero-derivative version of this same engine. New models or modifications to the original model are required every time changes are made to the engine layout.

\subsection{Dynamic Modeling Method}

This section provides a detailed look at the thermodynamic and mathematical equations used in the dynamic model. Starting with the inputs, each engine component will be discussed individually. This section constitutes a roadmap to gas turbine engine component dynamic modeling where each modeling steps will be completed following the flow path of the working fluid. 


\subsubsection{Inputs}

The first step towards modeling dynamically a gas turbine is to gather information about the engine configuration, its application (including ambient conditions) and the design point parameters. Even though these are considered as inputs, some variables may be based on approximations. The user must be able to scan and assess the validity and accuracy of the estimated parameters and understand how each component interacts with each other. As the design evolves, approximations will be replaced with more accurate values.

Typically the number of spools or shafts, amount of bleeds, number of combustion chambers, etc., characterizes gas turbines. The easiest way to communicate and hence understand the interrelationship of each component is through a sketch. For example, to produce a dynamic model of a turboshaft engine with power turbine and handling bleeds, the following components would be considered:

- Inlet

- Compressor

- Combustor

- Gas generator Turbine

- Power Turbine

- Exhaust

- Load

Sketching the given components would result in Figure 3.5. 


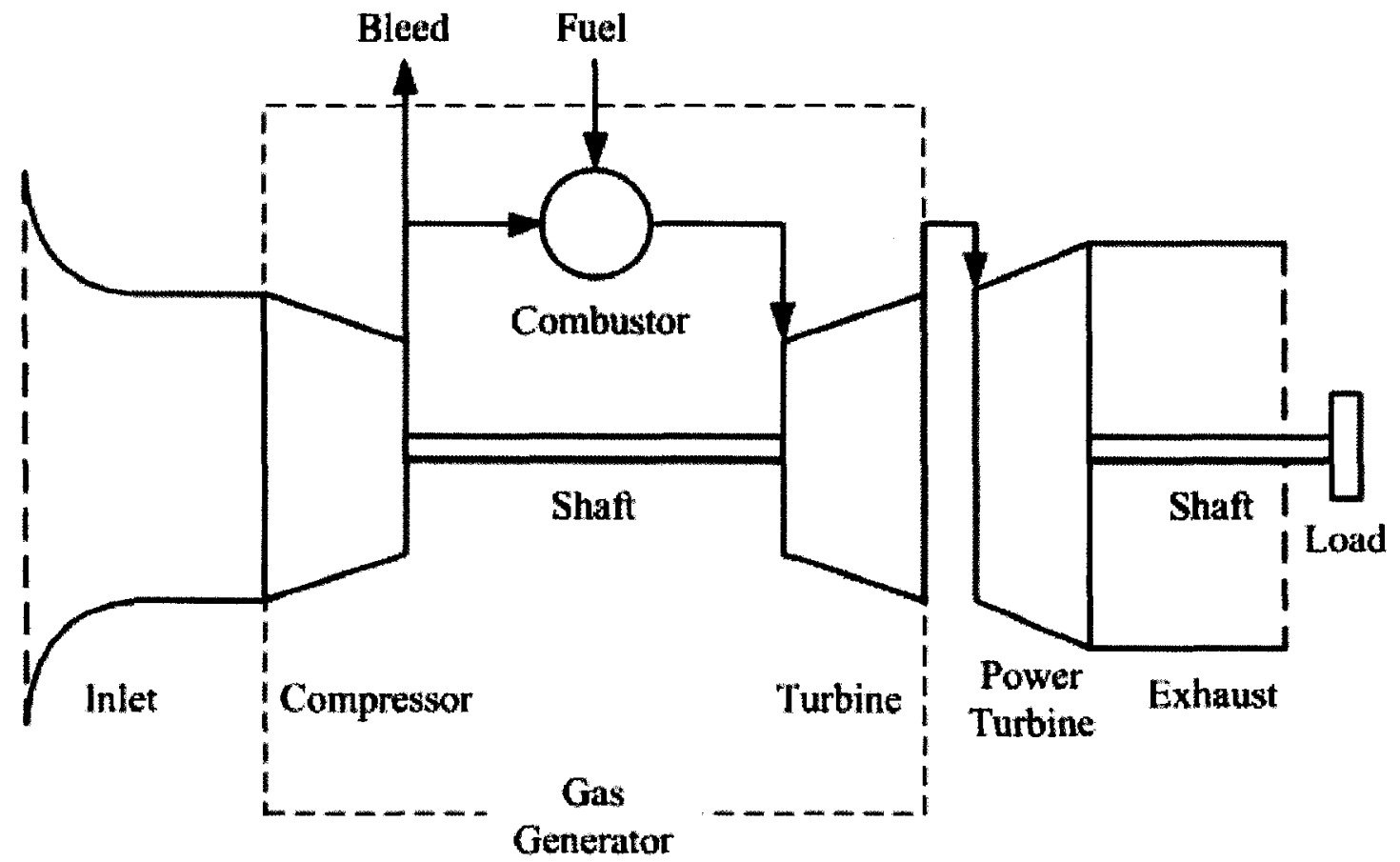

Figure 3.5: Engine layout: turboshaft engine with power turbine and handling bleed

Once the engine configuration is sketched accordingly, the next step is to gather detailed information about the design point. These parameters are necessary as they represent the foundation of the dynamic model. They play an integral part of the scaling and extrapolating methods, which are defined in more detail in subsequent sections, and are used to validate thermodynamic equations during the early steps of the dynamic modeling procedure. The number of design point parameters required as inputs vary based on engine layout. As a rule of thumb, these parameters will always include the compressor pressure ratio, turbine inlet temperature, component efficiencies and pressure losses (Saravanamuttoo et al., 2001). Additional information such as the inlet mass flow, the compressor bleed fraction, the fuel heating value and the spool speeds will also be required. Based on the schematic representation of the engine, the user will be capable of estimating the amount of inputs required. As an example, given the engine layout depicted in Figure 3.5, the dynamic model would require 16 design point parameters as inputs. These design point parameters are listed in Table 3.1. 
Table 3.1: Design point parameters

\begin{tabular}{|c|c|c|}
\hline \multirow{2}{*}{ Inlet } & $\Delta \mathrm{PR}_{\text {indel }}$ & Inlet total pressure loss [\%] \\
\hline & $\dot{m}_{\mathbf{a}}$ & Inlet air mass flow $[\mathrm{kg} / \mathrm{s}]$ \\
\hline \multirow{3}{*}{ Compressor } & $B_{c}$ & Compressor bleed fraction \\
\hline & $\mathbf{P R}_{\mathrm{e}}$ & Compressor pressure ratio \\
\hline & $\eta_{\varphi, \mathrm{j} \text { isen }}$ & Compressor isentropic efficiency \\
\hline \multirow{3}{*}{ Combustor } & $\eta_{b}$ & Combustion efficiency \\
\hline & $\Delta \mathrm{PR}_{\mathrm{h}}$ & Combustor total pressure loss [\%] \\
\hline & HV & Fuel heating value [kJ/kg] \\
\hline \multirow{3}{*}{ Turbine } & TIT & Gas generator turbine inlet temperature $[\mathrm{K}]$ \\
\hline & $\eta_{\text {i isen }}$ & Gas generator turbine isentropic efficiency \\
\hline & $\mathbf{N}_{\mathrm{p}}$ & Gas generator spool speed [RPM] \\
\hline \multirow{2}{*}{ Power Turbine } & $\eta_{\text {pt }}$ & Power turbine isentropic efficiency \\
\hline & $N_{p i}$ & Power turbine spool speed [RPM] \\
\hline Exhaust & $\Delta P R_{\text {ectangt }}$ & Exhaust total pressure loss [\%] \\
\hline Staft & $\eta_{\text {bwich }}$ & Mechanical efficiency \\
\hline Load & $\eta_{\text {gex }}$ & Gearbox efficiency \\
\hline
\end{tabular}

If any of these parameters are not available, typical published values may be used as initial approximations. The book by (Walsh and Fletcher, 1998), called Gas Turbine Performance, may act as an excellent starting reference. The dynamic accuracy of the model depends on the accuracy of the inputs. Therefore, it is important to replace initial approximations by accurate values as they become available.

Finally, geometrical characteristics of the gas turbine are also required as inputs. The polar moment of inertia and the inter-component volumes are the main characteristics requested. These characteristics are important as they dictate the transient performance of the engine. It was mentioned earlier that, based on approximations, transient performance could be analyzed even before turbomachinery and mechanical components were designed. However, this is only possible if reasonable estimates concerning the geometrical characteristics of the engine can be inputted into the dynamic 
model. Even though this is possible, designers tend to wait until turbomachinery preliminary designs are well under way before trying to assess the dynamic behaviour of the engine. This is still done relatively early in the design phase of the gas turbine. The amount of geometrical inputs for dynamic modeling will depend on the engine layout. Table 3.2 summarizes the geometrical characteristics of interest for the engine shown in Figure 3.5. Only the combustor volume is being considered as an inter-component volume. For most engines the combustor has the largest volume and hence is the primary concern (Walsh and Fletcher, 1998). This is particularly true in our case where the engine will be fitted with a lean premixed prevaporized combustor. All other ducts are assumed to have a small volume and therefore having a minimal effect on pressure, temperature and density during transient operation.

Table 3.2: Gas turbine geometrical characteristics

\begin{tabular}{|l|l|}
\hline$V_{b}$ & Combustor Volume $\left[\mathrm{m}^{3}\right]$ \\
\hline$l_{\mathrm{gg}}$ & Gas generator polar moment of inertia $\left[\mathrm{kgm}^{2}\right]$ \\
\hline $\mathrm{I}_{\mathrm{pt}}$ & Power turbine polar moment of inertia $\left[\mathrm{kgm}^{2}\right]$ \\
\hline
\end{tabular}

\subsubsection{Inlet}

The first engine component to be modeled was the inlet. The inputs to the model are ambient pressure, ambient temperature, and incoming flow velocity. This component is also characterized by a known design point pressure loss. Using these inputs and compressible flow relationships, it was possible to calculate the total pressure and total temperature at the exit plane. To simplify the modeling procedure and because the purpose of this work was aimed at a marine application, the equations proposed apply to ground-based inlets only. This simplification is based on the fact that the boat will have a relatively low velocity such that the difference between static and stagnation inlet properties can be neglected. This type of inlet is shown schematically in Figure 3.6. 


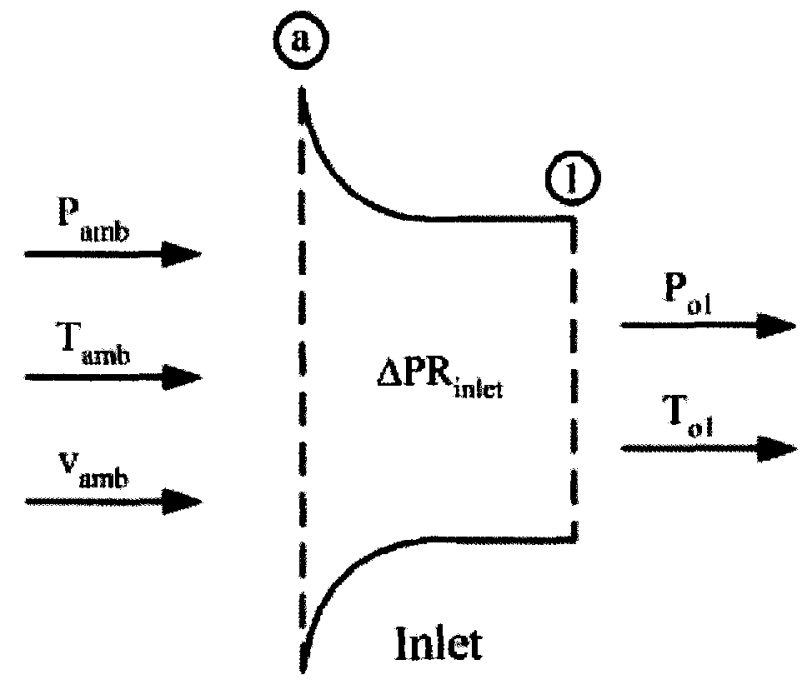

Figure 3.6: Inlet modeling

To calculate the total pressure and total temperature at the exit plane of the inlet, the ambient conditions must be first converted to total conditions. Thus,

$$
\begin{aligned}
& \mathrm{T}_{\mathrm{oa}}=\mathrm{T}_{a m b}+\left(\frac{\mathrm{v}_{\mathrm{amb}}^{2}}{2 \mathrm{c}_{\mathrm{p}}}\right) \\
& \mathrm{P}_{\mathrm{oa}}=\mathrm{P}_{a m b}\left(\frac{\mathrm{T}_{\mathrm{aa}}}{\mathrm{T}_{\mathrm{amb}}}\right)^{\frac{\gamma}{(\gamma-1)}}
\end{aligned}
$$

Assuming that the velocity is relatively low for the given application,

$$
\mathrm{v}_{\mathrm{amb}} \approx 0
$$

Therefore,

$$
\begin{aligned}
& \mathrm{T}_{\mathrm{oa}}=\mathrm{T}_{a m b} \\
& \mathrm{P}_{\mathrm{oa}}=\mathrm{P}_{a m b}
\end{aligned}
$$


By assuming that the flow crossing the inlet is not subjected to work, heat addition or heat loss, it is possible to state that the total temperature is conserved across the inlet. As a result,

$$
\mathrm{T}_{\mathrm{ol}}=\mathrm{T}_{\mathrm{oa}}
$$

The next step involves the pressure loss across the inlet. Knowing that,

$$
\left(\Delta \mathrm{PR}_{\text {inlet }}\right)=\left(1-\frac{\mathrm{P}_{\mathrm{ol}}}{\mathrm{P}_{\mathrm{oa}}}\right)
$$

then

$$
\mathrm{P}_{\mathrm{o} 1}=\mathrm{P}_{\mathrm{oa}}\left(1-\Delta \mathrm{PR}_{\text {inlet }}\right)
$$

To account for off-design operations, a part-load ducting pressure loss equation given by Kurzke (2004a) can be used. Thus,

$$
\Delta P R_{\text {inlet }}=\left(\Delta P R_{\text {inlet }}\right)_{\text {des }}\left(\frac{\left(\frac{\dot{m}_{a} \sqrt{T_{o a} R_{a}}}{P_{o a}}\right)}{\left(\frac{\dot{m}_{a} \sqrt{T_{o a} R_{a}}}{P_{o a}}\right)_{d e s}}\right)^{2}
$$

\subsubsection{Compressor}

The overall compressor performance calculation procedure may be summarized as per Figure 3.7. For a given spool speed and beta line value, it is possible to obtain information such as mass flow rate, pressure ratio and efficiency from a given compressor map. From the combination of the compressor inlet conditions $\left(\mathrm{P}_{01}\right.$ and $\left.\mathrm{T}_{01}\right)$ and the data obtained from the compressor maps, the compressor exit conditions may be calculated. To simplify the modeling process, the compressor modeling procedure was 
broken down into two steps: 1) compressor map digitization and 2) compressor calculations.

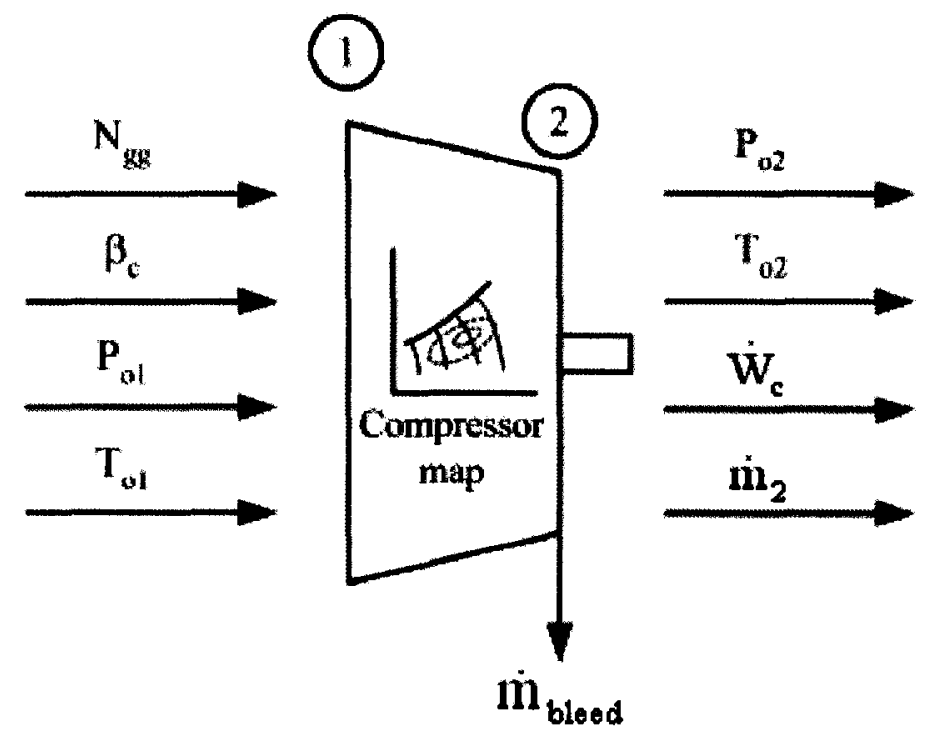

Figure 3.7: Compressor modeling

The first step was to convert a graphical compressor map into a look-up table for computational efficiency. Graphical digitization software was used to digitize the compressor map. However, depending on the shape of the compressor map speed lines, ambiguous sections containing horizontal or vertical sections of speed lines may lead to incorrect digitization. To solve this problem auxiliary coordinates called beta lines were added to the compressor map. As shown in Figure 3.8, these beta lines are equally spaced between the surge line and choke and provide unique intersection points on each speed line. For identification purposes, the auxiliary coordinates are attributed equidistant values between 0 and 1 . 


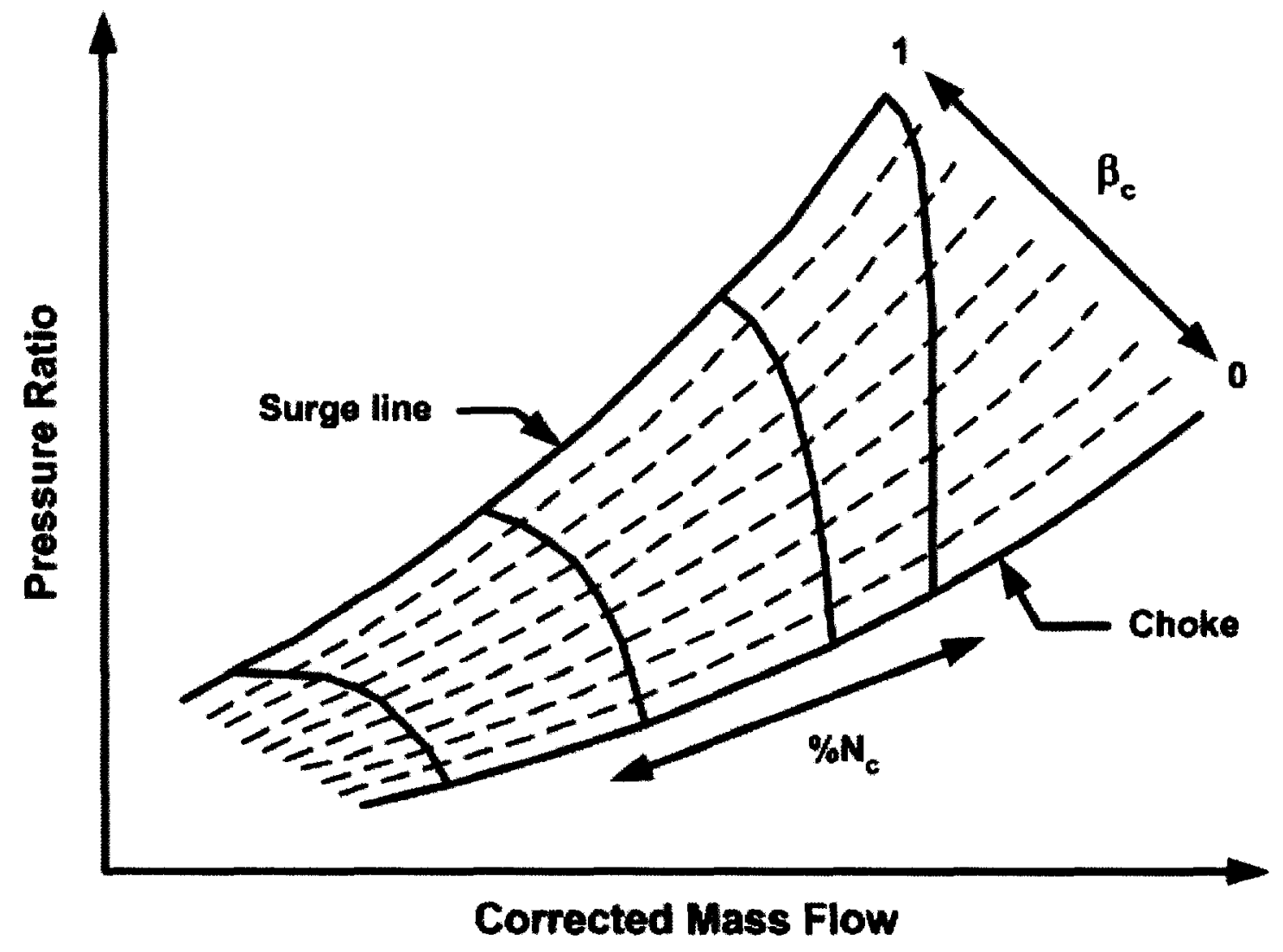

Figure 3.8: Beta line mapping (adapted from Kurzke, 2004a)

Once the beta line were added to the compressor map, the compressor characteristics were digitized such that the following functions were created:

$$
\begin{gathered}
\mathrm{PR}_{\mathrm{c}, \text { map }}=f n\left(\beta_{\mathrm{c}}, \% \mathrm{~N}_{\mathrm{c}}\right) \\
(\dot{\mathrm{m}} \sqrt{\theta} / \delta)_{\text {map }}=f n\left(\beta_{\mathrm{c}}, \% \mathrm{~N}_{\mathrm{c}}\right) \\
\eta_{\mathrm{c}, \text { isen, map }}=f n\left(\beta_{\mathrm{c}}, \% \mathrm{~N}_{\mathrm{c}}\right)
\end{gathered}
$$

where

$$
\begin{aligned}
& \theta=\mathrm{T}_{\mathrm{o}} / 288.15 \mathrm{~K} \\
& \delta=\mathrm{P}_{\mathrm{o}} / 101.325 \mathrm{kPa}
\end{aligned}
$$


and then tabulated for computational efficiency as per the format shown in Figure 3.9.

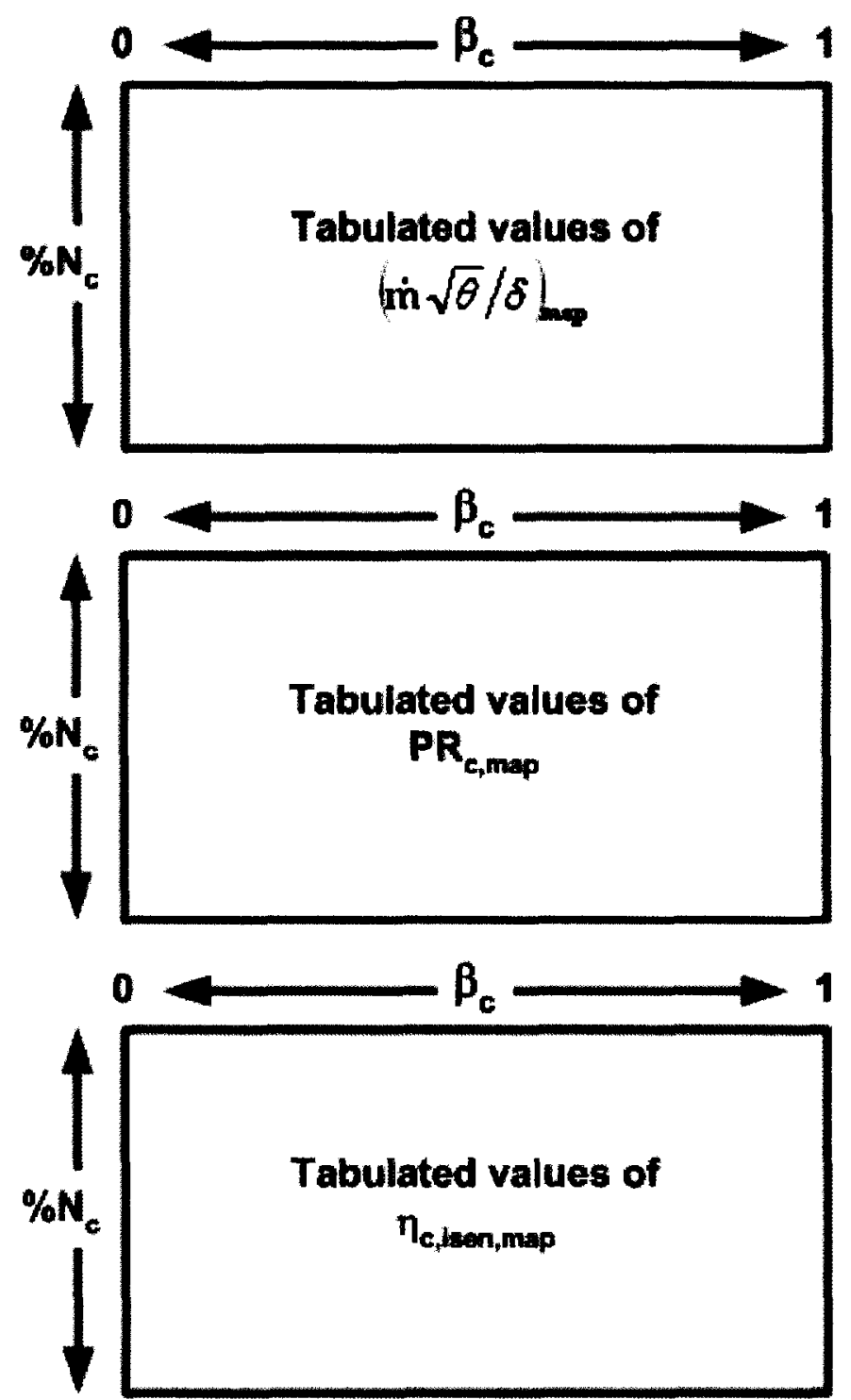

Figure 3.9: Tabulated compressor maps (adapted from Walsh and Fletcher, 1998)

However, for the compressor map digitization procedure to take place, a compressor map must first be available. Conversely, as stated in Chapter 2, compressor characteristics are rarely available at an early stage of the design process or may never be available if deemed proprietary by the engine manufacturer. As a result, since the compressor map is an essential part of the dynamic model, a method devised by Sellers and Daniele (1975) was be used for estimating compressor characteristics. This method consists of using a 
published compressor map and a given design point pressure ratio, mass flow rate and isentropic efficiency to obtain approximate compressor characteristics using Eqns 3.15 to 3.17 .

$$
\begin{gathered}
\mathrm{PR}_{\mathrm{c}}=\frac{\mathrm{PR}_{\mathrm{c}, \text { des }}-1}{\mathrm{PR}_{\mathrm{c}, \text { map , des }}-1}\left(\mathrm{PR}_{\mathrm{c}, \text { map }}-1\right)+1 \\
(\dot{\mathrm{m}} \sqrt{\theta} / \delta)_{1}=\frac{(\dot{\mathrm{m}} \sqrt{\theta} / \delta)_{1, \text { des }}}{(\dot{\mathrm{m}} \sqrt{\theta} / \delta)_{\text {map, des }}}(\dot{\mathrm{m}} \sqrt{\theta} / \delta)_{\text {map }} \\
\eta_{\mathrm{c}, \text { isen }}=\frac{\eta_{\mathrm{c} \text {, isen, des }}}{\eta_{\mathrm{c}, \text { isen, map, des }}}\left(\eta_{\mathrm{c}, \text { isen, map }}\right)
\end{gathered}
$$

This method was preferred to the method proposed by Saravanamuttoo and MacIsaac (1983) because it did not require user assistance during the characteristics estimation process. It was also chosen based on the fact that the well known commercial gas turbine performance software called GasTurb utilizes such a procedure.

Once the compressor map is implemented as look-up tables, all the required information is available to determine the compressor exit conditions. Therefore, given a gas generator spool speed $\left(\mathrm{N}_{\mathrm{gg}}\right)$ and a beta line value $\left(\beta_{\mathrm{c}}\right)$, it is possible to retrieve information from the look-up tables (compressor map) using Eqns 3.10 to 3.12,

where

$$
\% \mathrm{~N}_{\mathrm{c}}=\frac{\mathrm{N}_{\mathrm{gg}} / \sqrt{\theta}}{\left(\mathrm{N}_{\mathrm{gg}} / \sqrt{\theta}\right)_{\mathrm{des}}}
$$

To calculate the compressor exit temperature, $T_{02}$, if found from the definition of the isentropic efficiency, which is the ratio of ideal work to adiabatic work given by, 


$$
\eta_{\mathrm{c}, \text { isen }} \equiv \frac{\mathrm{h}\left(\mathrm{T}_{\mathrm{o} 2 \mathrm{~s}}\right)-\mathrm{h}\left(\mathrm{T}_{\mathrm{ol}}\right)}{\mathrm{h}\left(\mathrm{T}_{\mathrm{o} 2}\right)-\mathrm{h}\left(\mathrm{T}_{\mathrm{o} 1}\right)}
$$

The specific enthalpy of air as a function of temperature $(h(T))$ may be found in thermodynamic tables or calculated using published curve fitting correlations. A function by Chappell and Cockshutt (1974) was coded into the dynamic model to provide specific enthalpy data for air at temperatures ranging from $200 \mathrm{~K}$ to $2200 \mathrm{~K}$. However, it is apparent for Eqn 3.19 that the ideal compressor exit temperature $\left(\mathrm{T}_{02 \mathrm{~s}}\right)$ must first be calculated before solving for $\mathrm{T}_{02}$. There are a few methods for calculating the ideal compressor exit temperature, but to take into account the effects of temperature on specific heat, one may focus on the standard specific entropy relation that describes an isentropic compression of dry air. Given by,

$$
\mathrm{s}_{\text {std }}\left(\mathrm{T}_{\mathrm{o} 2 \mathrm{~s}}\right)-\mathrm{s}_{\mathrm{std}}\left(\mathrm{T}_{\mathrm{ol}}\right)=\mathrm{R}_{\mathrm{a}} \ln \left(\mathrm{PR}_{\mathrm{c}}\right)
$$

where

$$
\mathrm{s}_{\text {std }}(\mathrm{T})=\psi(\mathrm{T})\left(\frac{\mathrm{R}_{\mathrm{a}}}{\log (\mathrm{e})}\right)
$$

$\mathrm{T}_{\text {02s }}$ may be iterated until the right hand side of Eqn 3.20 equates the left hand side. Similarly as for the specific enthalpy, specific entropy of air as a function of temperature $(\psi(\mathrm{T}))$ may be found in thermodynamic tables or calculated using correlations. Here again an algorithm by Chappell and Cockshutt (1974) was implemented in the dynamic model. To accelerate the search for $T_{02 s}$, an initial guess can be generated using the following equation,

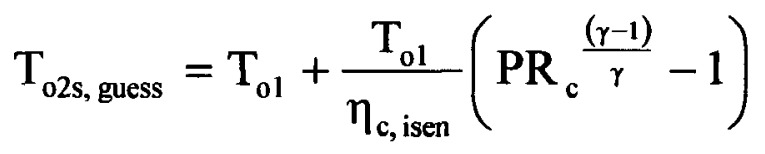


where $\gamma$ may be approximated to equal 1.4. Once $T_{02 s}$ was found, the compressor exit temperature could also be found through an iterative process solving Eqn 3.19. Again, to accelerate the search for $T_{02}$, an initial estimate was generated using Eqn 3.23.

$$
\mathrm{T}_{\mathrm{o} 2, \text { guess }}=\mathrm{T}_{\mathrm{ol}}+\frac{\mathrm{T}_{\mathrm{ol}}}{\eta_{\mathrm{c}, \text { isen }}}\left(\left(\frac{\mathrm{T}_{\mathrm{o} 2 \mathrm{~s}}}{\mathrm{~T}_{\mathrm{ol}}}\right)-1\right)
$$

Having established the compressor exit temperature and assumed that all mass flow rate bleeds is extracted at the compressor discharge (exit), the power and torque were calculated as follows,

$$
\begin{gathered}
\dot{\mathrm{W}}_{\mathrm{c}}=\dot{\mathrm{m}}_{1}\left(\mathrm{~h}\left(\mathrm{~T}_{\mathrm{o} 2}\right)-\mathrm{h}\left(\mathrm{T}_{\mathrm{o} 1}\right)\right) \\
\mathrm{G}_{\mathrm{c}}=\frac{\dot{\mathrm{W}}_{\mathrm{c}}}{\mathrm{N}_{\mathrm{gg}}} \times\left(\frac{60}{2 \pi}\right)
\end{gathered}
$$

The compressor discharge mass flow rate was then given by

$$
\dot{\mathrm{m}}_{2}=\dot{\mathrm{m}}_{1}-\dot{\mathrm{m}}_{\text {bleed }}
$$

where

$$
\dot{\mathrm{m}}_{\text {bleed }}=\mathrm{B}_{\mathrm{c}} \dot{\mathrm{m}}_{\mathrm{l}}
$$

Lastly, the compressor discharge pressure was calculated using,

$$
P_{o 2}=P_{c} \times P_{o 1}
$$




\subsubsection{Combustor}

As shown in Figure 3.10, the combustor exit parameters can be calculated based on the combustor inlet conditions, the combustion efficiency and the combustor total pressure loss.

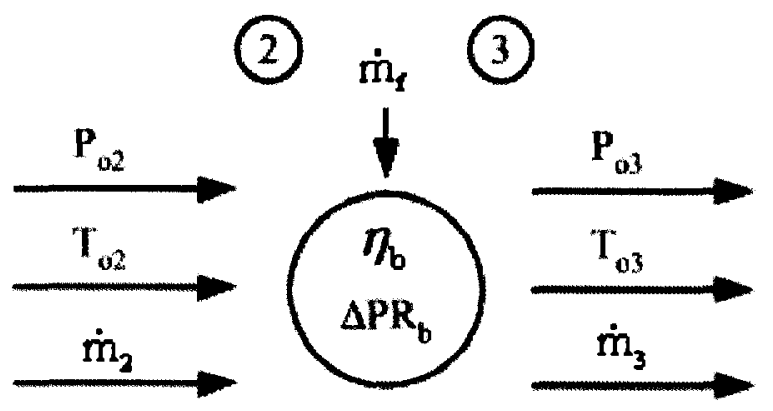

Figure 3.10: Combustor modeling

The combustion efficiency is defined as the ratio of the rate of enthalpy rise over the rate of heat addition. Mathematically this translates to,

$$
\eta_{\mathrm{b}}=\frac{\left(\dot{\mathrm{m}}_{2}+\dot{\mathrm{m}}_{\mathrm{f}}\right) \mathrm{h}\left(\mathrm{T}_{03}\right)-\left(\dot{\mathrm{m}}_{2}\right) \mathrm{h}\left(\mathrm{T}_{\mathrm{o} 2}\right)}{\dot{\mathrm{m}}_{\mathrm{f}} \cdot \mathrm{HV}}
$$

Rearranging Eqn 3.29 as,

$$
\mathrm{h}\left(\mathrm{T}_{03}\right)=\frac{\dot{\mathrm{m}}_{\mathrm{f}} \cdot \mathrm{HV} \cdot \eta_{\mathrm{b}}+\left(\dot{\mathrm{m}}_{2}\right) \mathrm{h}\left(\mathrm{T}_{\mathrm{o} 2}\right)}{\left(\dot{\mathrm{m}}_{2}+\dot{\mathrm{m}}_{\mathrm{f}}\right)}
$$

it is possible to calculate the combustor exit temperature, $T_{03}$, iteratively for a given fuel flow, heating value and combustion efficiency. Most modern combustors have very high combustion efficiency at design point (Kurzke, 2004a), but tends to decrease when operated at part load. According to Walsh and Fletcher (1998), combustion efficiency decreases with increasing combustor loading. They also added that the highest loading values in the operational envelope occur at idle. To take this factor into consideration when simulating off-design combustor performance, Walsh and Fletcher (1998) suggested approximating combustion efficiency to combustor loading through the following equation, 


$$
\eta_{b}=\frac{\left(\begin{array}{l}
-5.46974 \cdot 10^{-11} \cdot \mathrm{Load}^{5}+3.97923 \cdot 10^{-8} \cdot \mathrm{Load}^{4} \\
-8.73718 \cdot 10^{-6} \cdot \mathrm{Load}^{3}+0.000300007 \cdot \mathrm{Load}^{2}- \\
0.004568246 \cdot \mathrm{Load}+99.7
\end{array}\right)}{100}
$$

where

$$
\text { Load }=\frac{\dot{\mathrm{m}}_{2}}{\mathrm{~V}_{\mathrm{b}} \cdot\left(\frac{\mathrm{P}_{\mathrm{o} 21}}{101.325 \mathrm{kPa}}\right)^{1.8} \cdot 10^{\left(0.00145\left(\mathrm{~T}_{021}-400\right)\right)}}
$$

Off-design combustor exit temperature may then be calculated as explained earlier by inserting the approximate part load combustion efficiency calculated using Eqn 3.31 into Eqn 3.30.

The combustor exit pressure was calculated by simply subtracting the combustor pressure loss to the combustor inlet pressure as per Eqn 3.33.

$$
\mathrm{P}_{\mathrm{o} 3}=\mathrm{P}_{\mathrm{o} 2}\left(1-\Delta \mathrm{PR}_{\mathrm{b}}\right)
$$

But, similarly as for the inlet pressure loss, the combustor pressure loss will vary with off-design operations. To take this effect into account, the combustion chamber pressure loss is assumed to vary proportionally to the mass flow variation squared. Mathematically this translates to,

$$
\Delta \mathrm{PR}_{\mathrm{b}}=\left(\Delta \mathrm{PR} \mathrm{R}_{\mathrm{b}}\left(\frac{\left(\frac{\dot{\mathrm{m}}_{2} \sqrt{\mathrm{T}_{\mathrm{o} 2} \mathrm{R}_{\mathrm{a}}}}{\mathrm{P}_{\mathrm{o} 2}}\right)}{\left(\frac{\dot{\mathrm{m}}_{2} \sqrt{\mathrm{T}_{\mathrm{o} 2} \mathrm{R}_{\mathrm{a}}}}{\mathrm{P}_{\mathrm{o} 2}}\right)_{\text {des }}}\right)^{2}\right.
$$


Inserting Eqn 3.34 into Eqn 3.33, the combustor exit pressure may then be calculated at any point throughout the operational envelope.

Finally, the mass flow rate exiting the combustion chamber may be calculated using Eqn 3.35 .

$$
\dot{\mathrm{m}}_{3}=\dot{\mathrm{m}}_{2}+\dot{\mathrm{m}}_{\mathrm{f}}
$$

\subsubsection{Gas Generator Turbine}

To calculate the gas generator turbine exit conditions, it is required to know the turbine inlet conditions and the turbine characteristics (mass flow rate, pressure ratio and isentropic efficiency) for a given spool speed and beta line value (Figure 3.11).

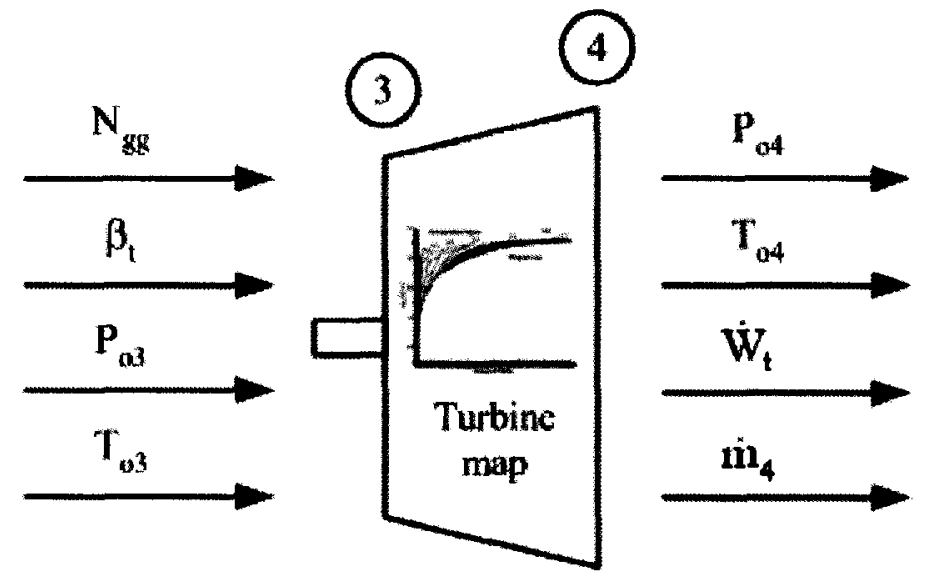

Figure 3.11: Gas generator turbine modeling

Similarly as for compressors, turbine characteristics are rarely available early in the design process and hence must be estimated. As a result, the method devised by Sellers and Daniele (1975) will also be used for estimating the turbine characteristics. Here again, the method consists of using published turbine maps and the given turbine design point pressure ratio, mass flow rate and isentropic efficiency to obtain approximate turbine characteristics. The equations required for this procedure are,

$$
P R_{t}=\frac{P R_{t, \text { des }}-1}{P R_{t, \text { map des }}-1}\left(P R_{t, \text { map }}-1\right)+1
$$




$$
\begin{gathered}
(\dot{\mathrm{m}} \sqrt{\theta} / \delta)_{3}=\frac{(\dot{\mathrm{m}} \sqrt{\theta} / \delta)_{3, \text { des }}}{(\dot{\mathrm{m}} \sqrt{\theta} / \delta)_{\mathrm{t}, \text { map , des }}}(\dot{\mathrm{m}} \sqrt{\theta} / \delta)_{\mathrm{t}, \text { map }} \\
\eta_{\mathrm{t}, \text { isen }}=\frac{\eta_{\mathrm{t}, \text { isen, des }}}{\eta_{\mathrm{t}, \text { isen, map, des }}}\left(\eta_{\mathrm{t} \text {, isen, map }}\right)
\end{gathered}
$$

The digitizing procedure explained earlier for compressor maps also apply to turbine maps. As a result, to enhance the dynamic model computational efficiency, the turbine characteristics may be tabulated into look-up tables where the data can then be extracted as per Eqns 3.39 to 3.41 .

$$
\begin{gathered}
\mathrm{PR}_{\mathrm{t}}=f n\left(\beta_{\mathrm{t}}, \% \mathrm{~N}_{\mathrm{t}}\right) \\
(\dot{\mathrm{m}} \sqrt{\theta} / \delta)_{3}=f n\left(\beta_{\mathrm{t}}, \% \mathrm{~N}_{\mathrm{t}}\right) \\
\eta_{\mathrm{t}, \text { isen }}=f n\left(\beta_{\mathrm{t}}, \% \mathrm{~N}_{\mathrm{t}}\right)
\end{gathered}
$$

where

$$
\% \mathrm{~N}_{\mathrm{t}}=\frac{\mathrm{N}_{\mathrm{gg}} / \sqrt{\theta}}{\left(\mathrm{N}_{\mathrm{gg}} / \sqrt{\theta}\right)_{\mathrm{des}}}
$$

To calculate the turbine exit temperature $\left(\mathrm{T}_{04}\right)$, the ideal turbine exit temperature $\left(\mathrm{T}_{04 \mathrm{~s}}\right)$ must first be calculated. Using the same approach discussed in the compressor subsection, it is possible to calculate the ideal turbine exit temperature by iterating $T_{04 s}$ until the right hand side and the left hand side of Eqn 3.43 are equal.

$$
s_{\text {std }}\left(T_{\text {o4s }}\right)-s_{\text {std }}\left(T_{\text {o3 }}\right)=R_{a} \ln \left(\frac{1}{P R_{t}}\right)
$$


where

$$
\mathrm{S}_{\text {std }}(\mathrm{T})=\psi(\mathrm{T})\left(\frac{\mathrm{R}_{\mathrm{a}}}{\log (\mathrm{e})}\right)
$$

To accelerate the search for $\mathrm{T}_{04 s}$, an initial guess was generated using Eqn 3.45.

$$
T_{04 s, \text { guess }}=T_{03}-T_{03} \eta_{t, \text { isen }}\left(1-\left(\frac{1}{P_{t}}\right)^{\frac{(\gamma-1)}{\gamma}}\right)
$$

The value of $\gamma$ was approximated to 1.33 .

Having calculated $T_{04 s}$, it was then possible to determine the turbine exit temperature $\left(\mathrm{T}_{\text {o4 }}\right)$ iteratively using Eqn 3.46 .

$$
\mathrm{h}\left(\mathrm{T}_{\mathrm{o4}}\right)=\mathrm{h}\left(\mathrm{T}_{03}\right)-\eta_{\mathrm{t}, \text { isen }}\left(\mathrm{h}\left(\mathrm{T}_{\mathrm{o3}}\right)-\mathrm{h}\left(\mathrm{T}_{\mathrm{o4s}}\right)\right)
$$

To accelerate the search for $\mathrm{T}_{04}$, an initial estimate was generated using Eqn 3.47.

$$
\mathrm{T}_{04, \text { guess }}=\mathrm{T}_{03}-\mathrm{T}_{03} \eta_{\mathrm{t}, \text { isen }}\left(1-\left(\frac{\mathrm{T}_{04 \mathrm{~s}}}{\mathrm{~T}_{03}}\right)\right)
$$

Based on the calculated turbine exit temperature, the power and torque produced by the expansion of the mass flow through the turbine was calculated using the following equations,

$$
\begin{gathered}
\dot{\mathrm{W}}_{\mathrm{t}}=\dot{\mathrm{m}}_{3}\left(\mathrm{~h}\left(\mathrm{~T}_{\mathrm{o} 3}\right)-\mathrm{h}\left(\mathrm{T}_{04}\right)\right) \\
\mathrm{G}_{\mathrm{t}}=\frac{\dot{\mathrm{W}}_{\mathrm{t}}}{\mathrm{N}_{\mathrm{gg}}} \times\left(\frac{60}{2 \pi}\right)
\end{gathered}
$$


Since the gas turbine being designed had no turbine blade cooling or any compressor bleed returns, the turbine discharge mass flow rate was equal to the combustor discharge value.

$$
\dot{\mathrm{m}}_{4}=\dot{\mathrm{m}}_{3}
$$

Lastly, the turbine discharge pressure was calculated as per Eqn 3.51

$$
P_{04}=\frac{P_{03}}{P R_{t}}
$$

The modeling procedure proposed in this section was also applied to power turbines. Eqn 3.36 to 3.51 were used to model power turbines by simply inputting the relevant input conditions and turbine characteristics. Since power turbines are not mechanically coupled to the gas generator, power turbine torque will be calculated as a function of power turbine speed $\left(\mathrm{N}_{\mathrm{pt}}\right)$ instead of gas generator speed $\left(\mathrm{N}_{\mathrm{gg}}\right)$.

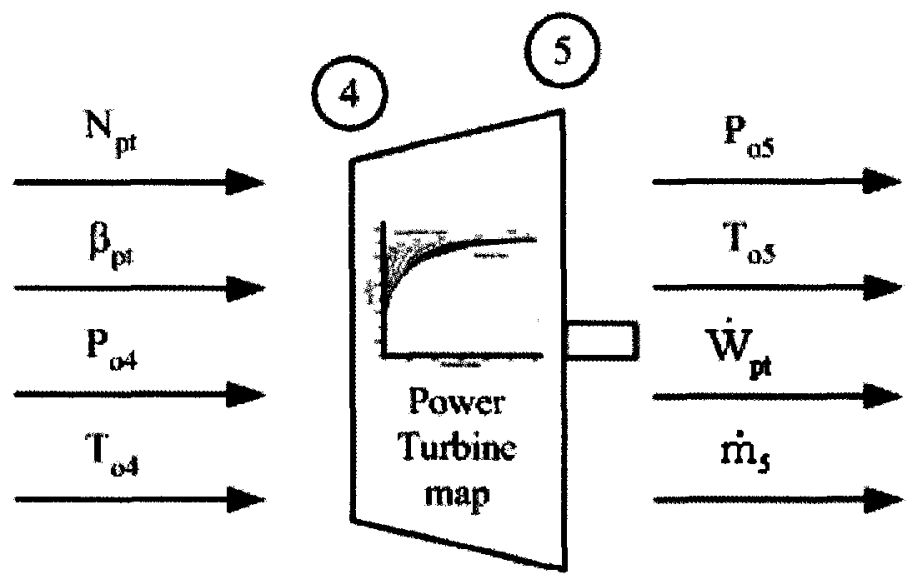

Figure 3.12: Power turbine modeling

\subsubsection{Exhaust}

Modeling the exhaust of a gas turbine was done similarly as discussed earlier for the engine inlet. As shown in Figure 3.13 or detailed by Eqn 3.52, given a known design 
point pressure loss across the exhaust ducting, it was possible to calculate the exhaust exit pressure based on the turbine discharge pressure.

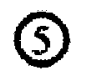

(6)

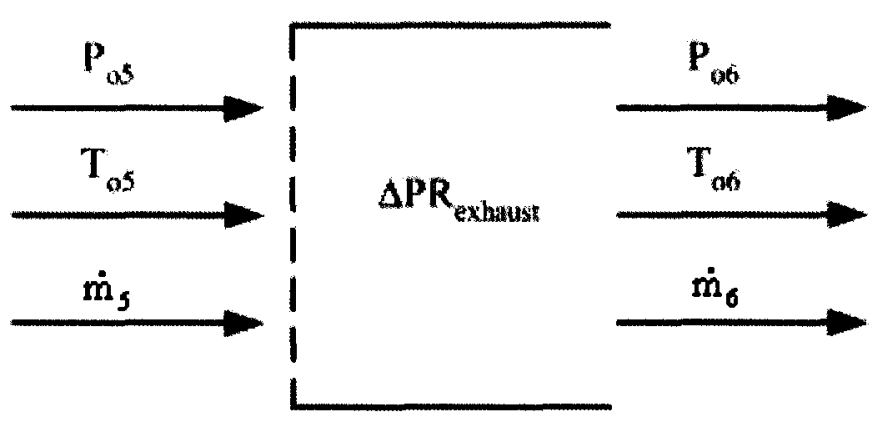

Figure 3.13: Exhaust modeling

$$
\mathrm{P}_{\mathrm{o}_{-} 6}=\mathrm{P}_{\mathrm{o5}}\left(1-\Delta \mathrm{PR}_{\text {exhaust }}\right)
$$

The pressure loss across the exhaust during off-design operations was found using a partload ducting pressure loss equation given by Kurzke (2004a). Thus,

$$
\Delta \mathrm{PR}_{\text {exhaust }}=\left(\Delta \mathrm{PR} \mathrm{exhaust}_{\mathrm{des}}\left(\frac{\left(\frac{\dot{\mathrm{m}}_{5} \sqrt{\mathrm{T}_{05} \mathrm{R}_{\mathrm{a}}}}{\mathrm{P}_{05}}\right)}{\left(\frac{\dot{\mathrm{m}}_{5} \sqrt{\mathrm{T}_{05} \mathrm{R}_{5}}}{\mathrm{P}_{05}}\right)_{\text {des }}}\right)^{2}\right.
$$

Assuming that there is no heat addition or heat loss, no work added or extracted from the exhaust and no mass flow addition or leakage, then

$$
\mathrm{T}_{\mathrm{o6}}=\mathrm{T}_{\mathrm{05}}
$$

and

$$
\dot{\mathrm{m}}_{6}=\dot{\mathrm{m}}_{5}
$$




\subsubsection{Load}

The load characteristic is an important piece of the dynamic modeling puzzle because the load applied to the power turbine affects steady-state and transient performance parameters such as surge margins, spool speeds, operating temperatures, etc. The shape of the characteristics will vary for different types of applications. Since the engine was being designed for a marine application, a fixed-pitch propeller load characteristic was considered. According to Saravanamuttoo et al. (2001), the power absorbed by a fixed-pitch propeller varies as the cube of the rotational speed of the propeller (shown in Figure 3.14).

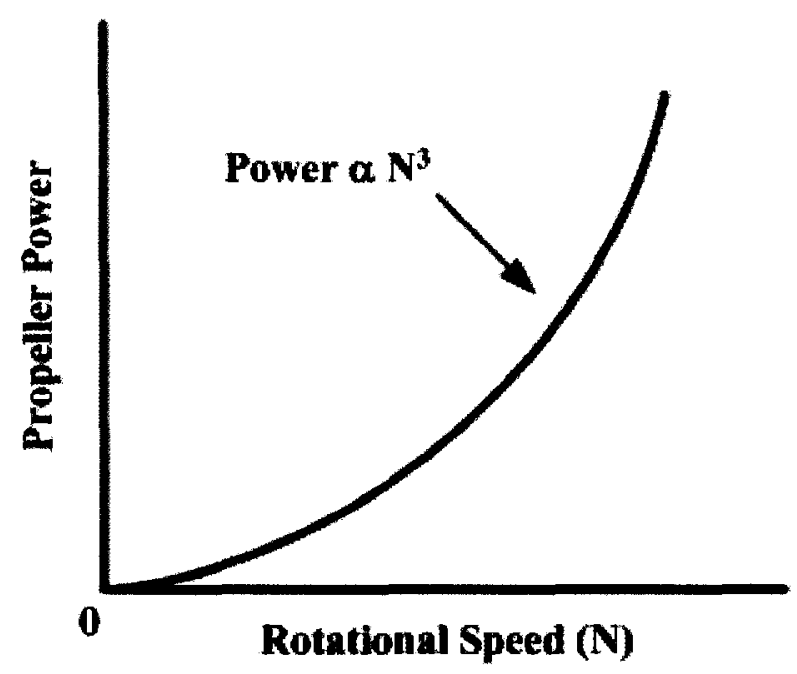

Figure 3.14: Load characteristics (Adapted from Saravanamuttoo et al., 2001)

Walsh and Fletcher (1998) confirmed that a cube law approximation is a reasonable assumption early in the design phase, but should be updated with the actual propeller load characteristic when obtained from the manufacturer. Therefore, assuming the fixed-pitch propeller is directly coupled to the power turbine (no gear reduction and no gear box losses: $N_{\text {prop }}=N_{p t}$ and $\eta_{\text {gear }}=1$ ), the power absorbed by the propeller was calculated using Eqn 3.56.

$$
\dot{\mathrm{W}}_{\text {prop }}=\left(\dot{\mathrm{W}}_{\mathrm{pt}}\right)_{\text {des }} \eta_{\text {mech }}\left(\frac{\mathrm{N}_{\mathrm{pt}}}{\left(\mathrm{N}_{\mathrm{pt}}\right)_{\text {des }}}\right)^{3}
$$


The propeller torque was then calculated as per Eqn 3.57.

$$
\mathrm{G}_{\text {prop }}=\frac{\dot{\mathrm{W}}_{\mathrm{prop}}}{\mathrm{N}_{\mathrm{pt}}} \times\left(\frac{60}{2 \pi}\right)
$$

\subsection{Off-design Performance}

As defined in the previous section, it is possible to calculate the dynamic performance of each engine component individually over all off-design operating conditions. However, to assess the overall off-design engine performance, each individual component must be linked together to form an engine. Linking components to each other has the effect of narrowing the range of possible operating points. In fact, as explained in the literature review when the operating parameters such as rotational speed, work or mass flow are matched between linked components, a unique operating point is generated at a given operating condition. The set of operating points generated for all operating conditions is known as the operating line and is used extensively to assess offdesign engine performance.

\subsubsection{Steady-State Performance Calculations}

To generate an off-design steady-state operating line, an iterative process is required to ensure that there is a match between each component. The Newton-Raphson method was chosen as the iterative solver due to its efficient numerical solving ability and its ease of application to non-linear problems. Based on Saravanamuttoo et al. (2001), two criteria must be satisfied at all time to achieve steady-state operation: 1) compatibility of flow and 2) compatibility of work. Based on these criteria, a set of iteration errors was generated for each set of matched components.

For a gas turbine engine with a power turbine coupled to a propeller, five iteration variables $\left(\beta_{\mathrm{c}}\right.$, TIT, $\beta_{\mathrm{t}}, \beta_{\mathrm{pt}}$, and $\left.\% \mathrm{~N}_{\mathrm{pt}}\right)$ are required to calculate the performance of each component at a given operating condition. Based on this observation, five iteration errors 
are required to properly constrain the non-linear problem. As shown in Figure 3.15, these five iteration errors consist of:

1. Compatibility of flow between combustor and gas generator turbine

2. Compatibility of work between compressor and gas generator turbine

3. Compatibility of flow between gas generator turbine and power turbine

4. Compatibility of work between power turbine and propeller (load)

5. Compatibility of pressure between exhaust and ambient conditions 


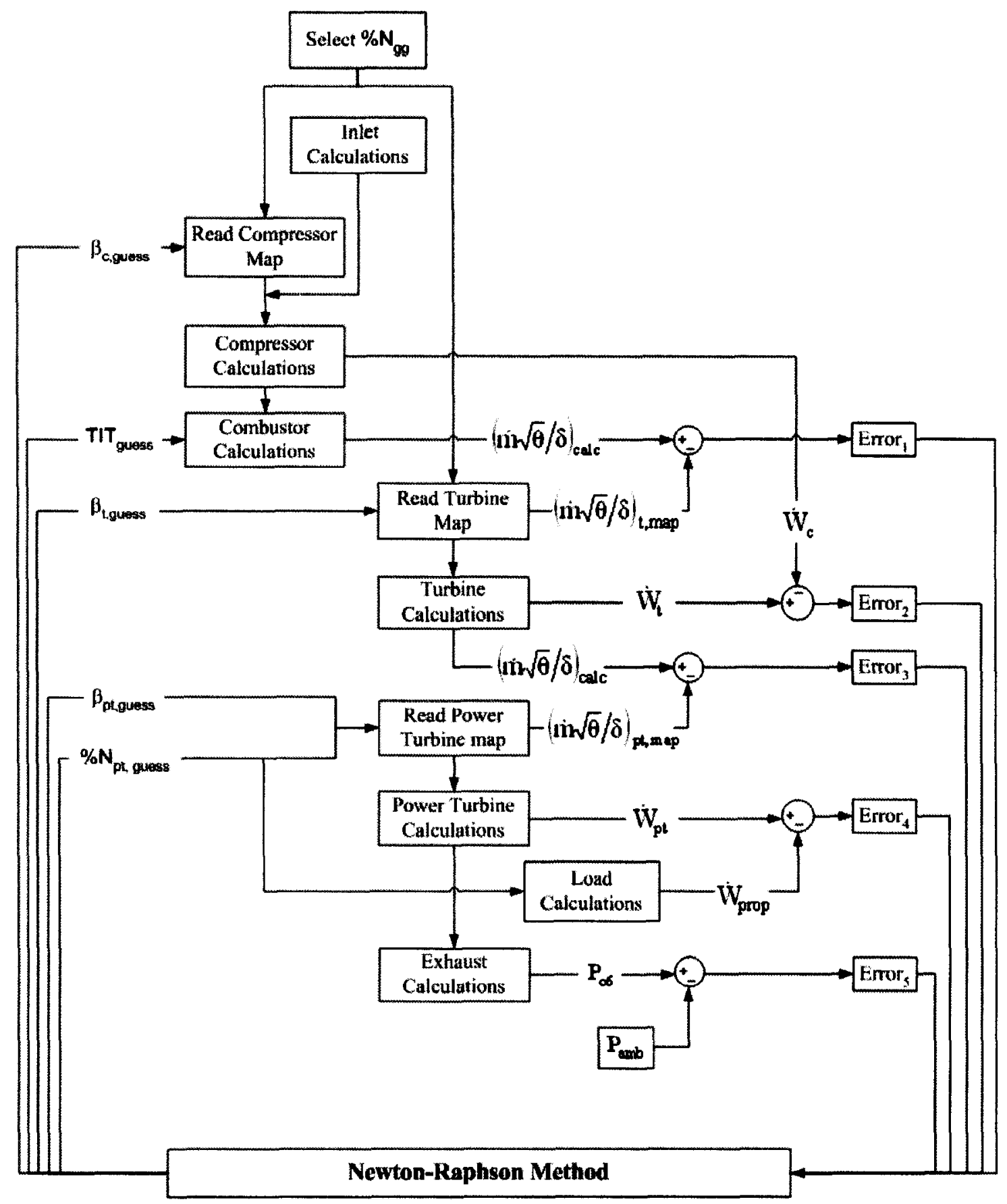

Figure 3.15: Off-design steady-state component matching

These errors are fed into the Newton-Raphson method where they are used to generate better estimates of the iteration variables. This process continues until the iteration errors are reduced to near-zero values. As explained earlier, the resulting set of iteration variables is then unique to this operating condition. Applying this process to all 
off-design operating conditions resulted in a set of steady-state operating point, which can then be used to assess engine performance.

\subsubsection{Transient Performance Calculations}

Transient performance, as the name implies, deals with the change in operating conditions required to accelerate or decelerate the engine from one steady-state operating point to another. To cause a gas turbine transient, there needs to be a work (torque) mismatch between the compressor and gas generator turbine (Eqn 3.58) or between the power turbine and the load (Eqn 3.59) to allow the engine to accelerate or decelerate.

$$
\begin{aligned}
& \frac{\mathrm{dN}_{\mathrm{gg}}}{\mathrm{dt}}=\frac{\left(\mathrm{G}_{\mathrm{t}}-\mathrm{G}_{\mathrm{c}}\right)}{\mathrm{I}_{\mathrm{gg}}} \times\left(\frac{60}{2 \pi}\right) \\
& \frac{\mathrm{dN}_{\mathrm{pt}}}{\mathrm{dt}}=\frac{\left(\mathrm{G}_{\mathrm{pt}}-\mathrm{G}_{\mathrm{prop}}\right)}{\mathrm{I}_{\mathrm{pt}}} \times\left(\frac{60}{2 \pi}\right)
\end{aligned}
$$

The work imbalance may be caused by a change in fuel flow, by opening a bleed valve, by a loss of load, etc. In all transient cases, compatibility of work can no longer be applied. As explained in the literature, work incompatibility also leads to what is known as volume packing. To capture work incompatibility and volume packing effects, the inter-component volume method proposed by Fawke and Saravanamuttoo (1971) was used to model the transient performance of the engine. As a result, in addition to Eqns 3.58 and 3.59, the rate of change of pressure caused by volume packing effects was also be considered. For a given volume, the rate of change of pressure was calculated using Eqn 3.60.

$$
\frac{\mathrm{dP}_{02}}{\mathrm{dt}}=\left(\dot{\mathrm{m}}_{\mathrm{o} 2}+\dot{\mathrm{m}}_{\mathrm{f}}-\dot{\mathrm{m}}_{\mathrm{o} 3}\right) \times \frac{\left(\mathrm{T}_{\mathrm{o} 2} \times \mathrm{R}_{\mathrm{a}}\right)}{\mathrm{V}_{\mathrm{b}}}
$$


Only the combustor volume was considered as an inter-component volume. All other ducts were assumed to have a small volume and therefore having minimal effect on pressure, temperature and density during transient operation.

Using Eqns 3.58 to 3.60 , it was possible to predict the new engine operating conditions based on the calculated change in speed and pressure for a given time interval.

$$
\begin{gathered}
\mathrm{N}_{\mathrm{gg}, \text { new }}=\mathrm{N}_{\mathrm{gg} \mathrm{,old}}+\frac{\mathrm{dN}_{\mathrm{gg}}}{\mathrm{dt}} \times \Delta \mathrm{t} \\
\mathrm{N}_{\mathrm{pt}, \text { new }}=\mathrm{N}_{\mathrm{pt} \text {,old }}+\frac{\mathrm{dN}_{\mathrm{pt}}}{\mathrm{dt}} \times \Delta \mathrm{t} \\
\mathrm{P}_{\mathrm{o} 2 \text {, new }}=\mathrm{P}_{02, \text { old }}+\frac{\mathrm{dP}_{\mathrm{o} 2}}{\mathrm{dt}} \times \Delta \mathrm{t}
\end{gathered}
$$

The transient performance calculation procedure is detailed in Figure 3.16. As shown, the process starts at a given steady-state operating condition. The data is then fed into the dynamic model where the Newton-Raphson method is used to generate a transient operating point. Based on this information new operating conditions are calculated using Eqns 3.61 to 3.63 and then used as inputs to the dynamic model. This process was applied repeatedly until steady-state operation was reached. By storing each transient operating point as a function of time, a transient operating line was generated once the procedure was completed. This line was used extensively to study transient engine performance and control system response. 


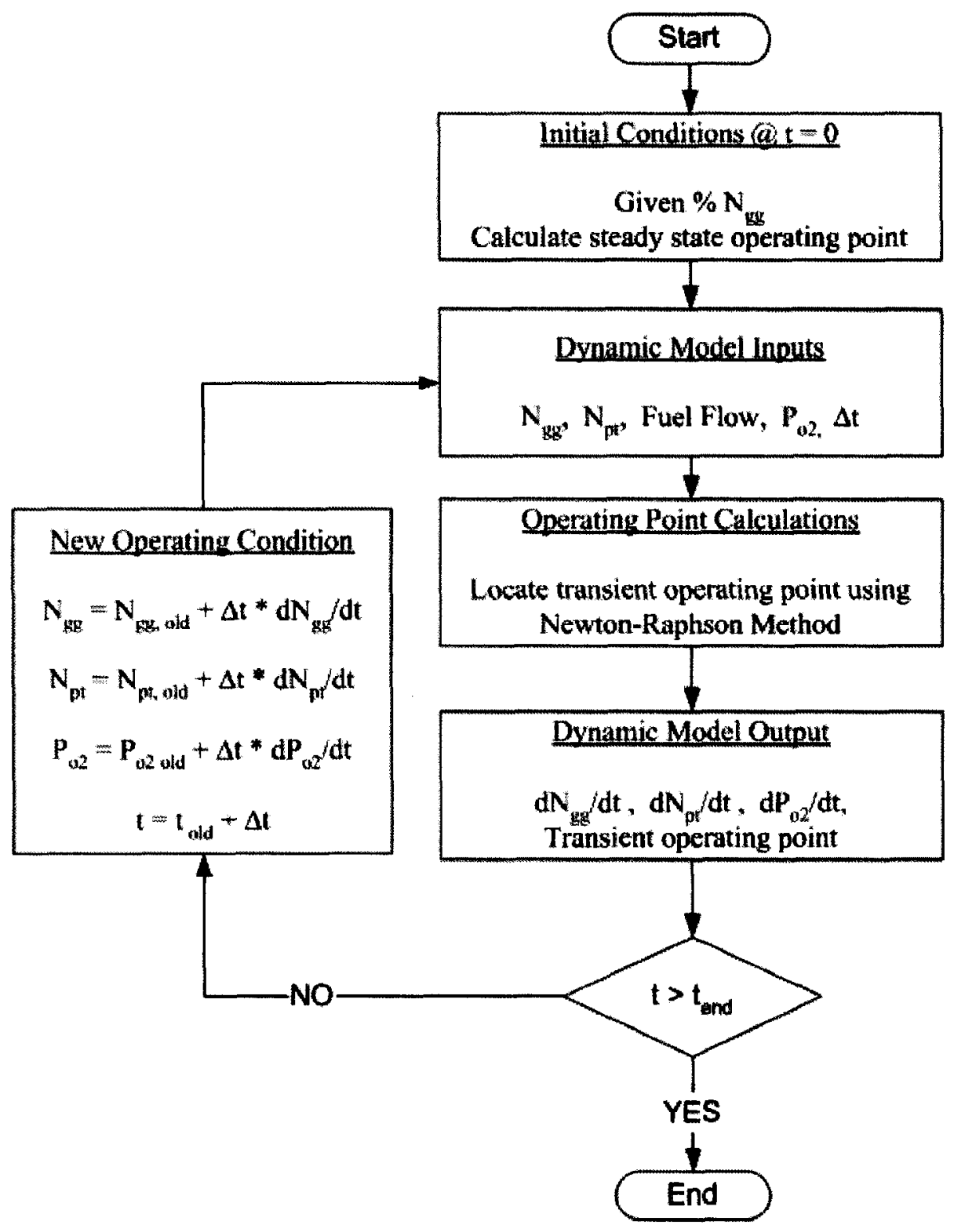

Figure 3.16: Transient performance calculation procedure

The Newton-Raphson iteration variables and iteration errors used for component matching during transient operation are not the same as for steady-state component matching. Since four input variables were fed into the dynamic model $\left(\mathrm{N}_{\mathrm{gg}}, \mathrm{N}_{\mathrm{pt}}\right.$, Fuel Flow, $\left.\mathrm{P}_{02}\right)$, only four iteration variables $\left(\beta_{\mathrm{c}}, \beta_{t}, \beta_{\mathrm{pt}}, \mathrm{P}_{04}\right)$ were required to calculate the performance of each component at the given operating condition. As a result four iteration errors were required to constraint the non-linear problem. This is shown in Figure 3.17. 


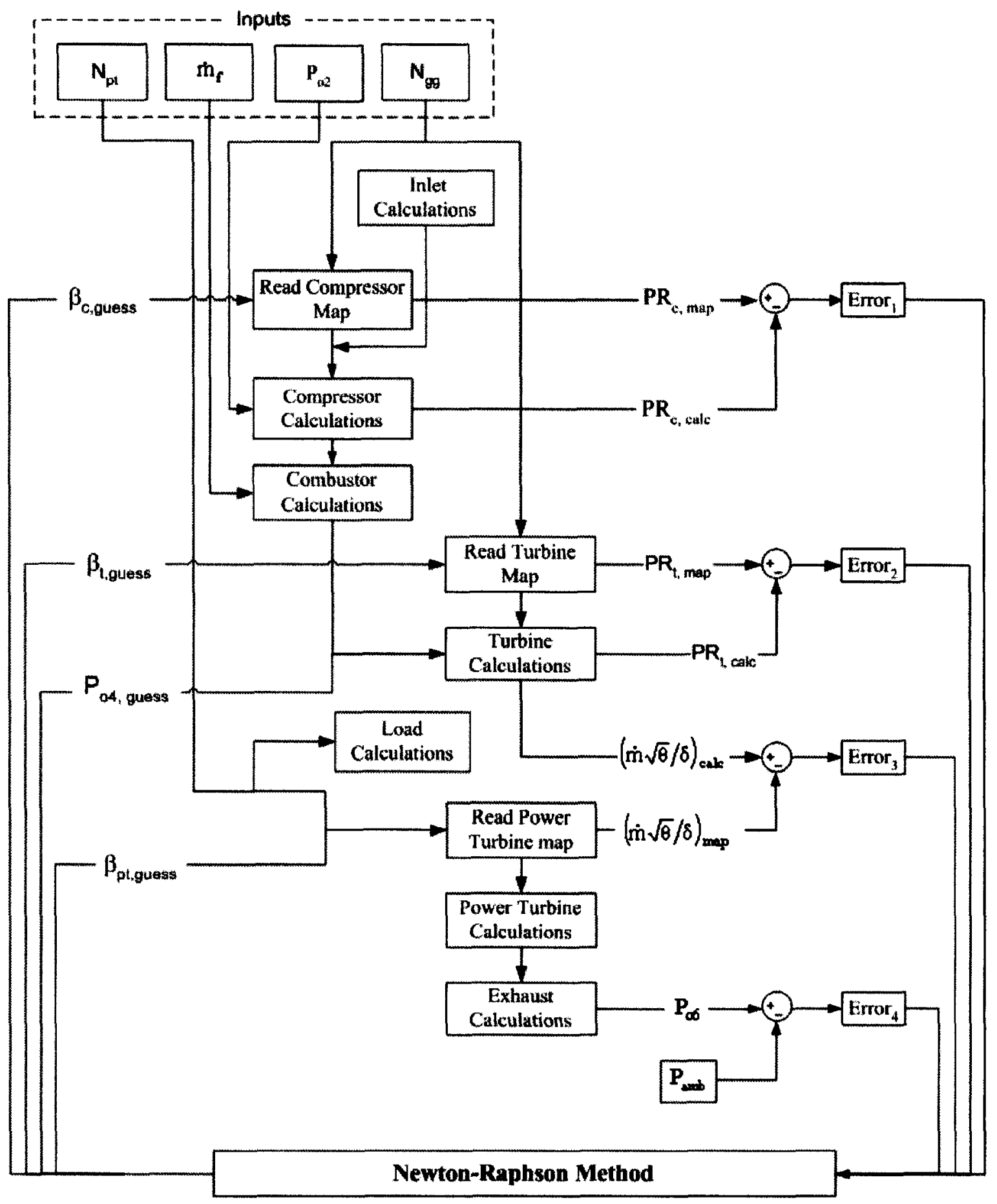

Figure 3.17: Off-design transient component matching 


\subsection{Sub-Idle Dynamic Modeling Method}

Modeling gas turbine performance in the sub-idle region is a challenge. As discussed in a previous chapter, this reality is caused by two problems: 1) an unavailability of component characteristics throughout the sub-idle region and 2) numerical convergence problems caused by calculations and extrapolations performed on uncertain, steep regions of component maps. To overcome these issues, a component map extrapolation method was devised based on the work of Sextons (2001). The method, which is described in detail below, produces detailed component characteristics in the sub-idle region and hence prevents numerical convergence problems. Based on this work, a paper called "A Simple Sub-idle Component Map Extrapolation Method" (Gaudet and Gauthier, 2007) was presented at the ASME Turbo Expo 2007 conference in Montreal, Canada in May 2007.

\subsubsection{Map extrapolation}

As briefly discussed in the literature review, the component map extrapolation method proposed by Sexton (2001) relies on the basic principles of the similarity laws. Since these laws were developed for incompressible fluids, Sexton suggested manipulating or tuning the similarity law exponents using data available from the last two speed lines of a component map to take into consideration the effects of compressibility. However, depending on the shape and distance between the last two speed lines, finding the value of the exponents required a trial-and-error approach. In other words, Sexton changed the values of the exponents slowly until the extrapolated curves appeared physically correct. In an effort to alleviate the need for trial-and-error during the extrapolation process, a new extrapolation method was developed for this work.

First using basic similarity laws for mass flow, specific work and power,

$$
\frac{\dot{\mathrm{m}}_{\mathrm{b}}}{\dot{\mathrm{m}}_{\mathrm{a}}}=\left[\frac{\mathrm{N}_{\mathrm{b}}}{\mathrm{N}_{\mathrm{a}}}\right]^{1}
$$




$$
\begin{aligned}
& \frac{\mathrm{w}_{\mathrm{b}}}{\mathrm{w}_{\mathrm{a}}}=\left[\frac{\mathrm{N}_{\mathrm{b}}}{\mathrm{N}_{\mathrm{a}}}\right]^{2} \\
& \frac{\dot{\mathrm{W}}_{\mathrm{b}}}{\dot{\mathrm{W}}_{\mathrm{a}}}=\left[\frac{\mathrm{N}_{\mathrm{b}}}{\mathrm{N}_{\mathrm{a}}}\right]^{3}
\end{aligned}
$$

Eqns 3.64 to 3.66 were modified to reflect the data available in component maps and allow for exponent manipulation. Hence,

$$
\begin{gathered}
\frac{(\dot{\mathrm{m}} \sqrt{\theta} / \delta)_{\mathrm{b}}}{(\dot{\mathrm{m}} \sqrt{\theta} / \delta)_{\mathrm{a}}}=\left[\frac{\% \mathrm{~N}_{\mathrm{b}}}{\% \mathrm{~N}_{\mathrm{a}}}\right]^{\mathrm{p}} \\
\frac{\mathrm{w}_{\mathrm{b}}}{\mathrm{w}_{\mathrm{a}}}=\left[\frac{\% \mathrm{~N}_{\mathrm{b}}}{\% \mathrm{~N}_{\mathrm{a}}}\right]^{\mathrm{q}} \\
\frac{\dot{\mathrm{W}}_{\mathrm{b}}}{\dot{\mathrm{W}}_{\mathrm{a}}}=\left[\frac{\% \mathrm{~N}_{\mathrm{b}}}{\% \mathrm{~N}_{\mathrm{a}}}\right]^{\mathrm{r}}
\end{gathered}
$$

where

$$
\% \mathrm{~N}=\frac{\mathrm{N} / \sqrt{\theta}}{\mathrm{N}_{\mathrm{des}} / \sqrt{\theta}}
$$

Typically, component characteristics are given as a function of relative speed and beta line value. Thus,

$$
(\dot{\mathrm{m}}, \mathrm{PR}, \eta)=f n(\beta, \% \mathrm{~N})
$$

By rearranging Eqns 3.67 to 3.69 based on this statement, it is possible to manipulate the similarity law exponents along a constant beta line. 


$$
\begin{aligned}
& \mathrm{p}=f n(\dot{\mathrm{m}}, \% \mathrm{~N}) \\
& \mathrm{q}=f n(\mathrm{w}, \% \mathrm{~N}) \\
& \mathrm{r}=f n(\dot{\mathrm{W}}, \% \mathrm{~N})
\end{aligned}
$$

Since the thermodynamic equations for specific work and power are specific to the type of turbomachinery being considered, the underlying equations used to calculate new similarity law exponents will be discussed separately for turbines and compressors.

\section{Turbines}

Starting with the turbines, the mass flow relationship exponent $\mathrm{p}$ can simply be found by re-arranging Eqn 3.67.

$$
\mathrm{p}=\frac{\log \left(\frac{(\dot{\mathrm{m}} \sqrt{\theta} / \delta)_{\mathrm{b}}}{(\dot{\mathrm{m}} \sqrt{\theta} / \delta)_{\mathrm{a}}}\right)}{\log \left(\frac{\% \mathrm{~N}_{\mathrm{b}}}{\% \mathrm{~N}_{\mathrm{a}}}\right)}
$$

Having calculated the exponent (p), it can then be used to find extrapolated values of mass flow as per Eqn 3.76

$$
(\dot{\mathrm{m}} \sqrt{\theta} / \delta)_{\mathrm{x}}=(\dot{\mathrm{m}} \sqrt{\theta} / \delta)_{\mathrm{a}} \times\left[\frac{\% \mathrm{~N}_{\mathrm{x}}}{\% \mathrm{~N}_{\mathrm{a}}}\right]^{\mathrm{p}}
$$

The work relationship exponent (q) for turbines can be calculated based on a relationship between pressure ratio and specific work. In fact, for simplification reasons, the relationship will depend on ideal specific work only, therefore removing turbine efficiency as an input. This allows for single characteristic calculation and extrapolation. 
Turbine efficiency will be dealt with later. Therefore, based on this statement Eqn 3.68 becomes

$$
\frac{\mathrm{w}_{\text {ideal, }, \mathrm{b}}}{\mathrm{w}_{\text {ideal, }, \mathrm{a}}}=\left[\frac{\mathrm{\%} \mathrm{N}_{\mathrm{b}}}{\mathrm{\%} \mathrm{N}_{\mathrm{a}}}\right]^{\mathrm{q}}
$$

From Saravanamuttoo et al., (2001), turbine ideal specific work is given by

$$
\mathrm{w}_{\text {ideal }}=\mathrm{c}_{\mathrm{p}} \mathrm{T}_{\mathrm{o} 1}\left[1-\left(\frac{1}{\mathrm{PR}}\right)^{\frac{(\gamma-1)}{\gamma}}\right]
$$

Inserting Eqn 3.78 into Eqn 3.77 and rearranging to solve for $q$, an equation for the work relationship exponent (q) can then be found (Eqn 3.79).

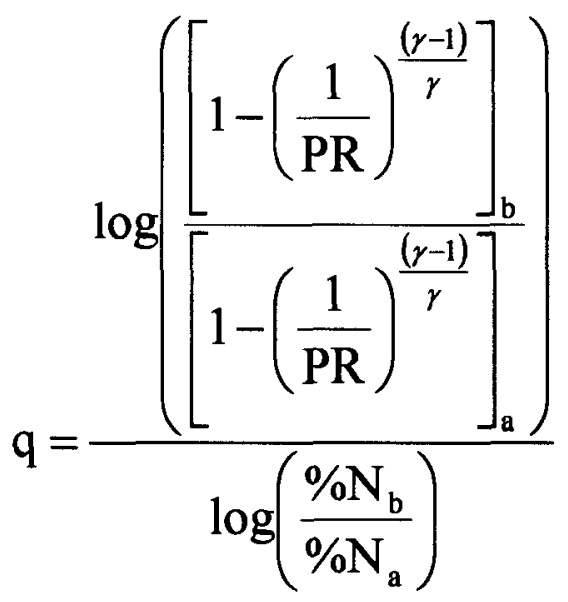

Having identified the exponent q, and by rearranging Eqn 3.78, it is possible to extrapolate pressure ratio values as a function of relative speed (Eqn 3.80).

$$
\mathrm{PR}_{\mathrm{x}}=\frac{1}{\left(1-\left(\left(1-\left(\frac{1}{\mathrm{PR}_{\mathrm{a}}}\right)^{\frac{(\gamma-1)}{\gamma}}\right) \times\left(\frac{\% \mathrm{~N}_{\mathrm{x}}}{\% \mathrm{~N}_{\mathrm{a}}}\right)^{\mathrm{q}}\right)\right)^{\frac{\gamma}{(\gamma-1)}}}
$$


Similarly to the work relationship exponent, the power relationship exponent ( $r$ ) cannot be calculated directly from similarity laws. Knowing from Saravanamuttoo et al., (2001) that turbine power is defined as

Eqn 3.69 becomes

$$
\dot{\mathrm{W}}=\dot{\mathrm{m}} \eta \mathrm{c}_{\mathrm{p}} \mathrm{T}_{\mathrm{ol}}\left[1-\left(\frac{1}{\mathrm{PR}}\right)^{\frac{(\gamma-1)}{\gamma}}\right]
$$

$$
\frac{\left(\dot{\mathrm{m}} \eta \mathrm{c}_{\mathrm{p}} \mathrm{T}_{\mathrm{ol}}\left[1-\left(\frac{1}{\mathrm{PR}}\right)^{\frac{(\gamma-1)}{\gamma}}\right]\right)_{\mathrm{b}}}{\left(\dot{\mathrm{m}} \eta \mathrm{c}_{\mathrm{p}} \mathrm{T}_{\mathrm{ol}}\left[1-\left(\frac{1}{\mathrm{PR}}\right)^{\frac{(\gamma-1)}{\gamma}}\right]\right)_{\mathrm{a}}}=\left[\frac{\mathrm{N}_{\mathrm{b}}}{\% \mathrm{~N}_{\mathrm{a}}}\right]^{\mathrm{r}}
$$

Using Eqns 3.76 to 3.78, Eqn 3.82 can be simplified to

$$
\left(\frac{\eta_{b}}{\eta_{a}}\right)\left[\frac{\% N_{b}}{\% N_{a}}\right]^{p}\left[\frac{\% N_{b}}{\% N_{a}}\right]^{q}=\left[\frac{\% N_{b}}{\% N_{a}}\right]^{r}
$$

Rearranging Eqn 3.83, it is now possible to solve for the power relationship exponent (r).

$$
r=(p+q)+\frac{\log \left(\frac{\eta_{b}}{\eta_{a}}\right)}{\log \left(\frac{\% N_{b}}{\% N_{a}}\right)}
$$

Extrapolated values of turbine efficiency can thus be calculated as per Eqn 3.85

$$
\eta_{x}=\eta_{a} \times\left[\frac{\% N_{x}}{\% N_{a}}\right]^{r-(p+q)}
$$




\section{Compressor}

The mass flow relationship can be applied to both compressors and turbines without requiring modifications. Therefore, the mass flow relationship exponent $(p)$ and the extrapolated mass flow values for compressors were also calculated using Eqns 3.75 and 3.76 .

Similarly as for turbines, the work relationship exponent (q) can be calculated based on a relationship between pressure ratio and ideal specific work. From Saravanamuttoo et al., (2001), it is given that the ideal specific work for compressors can be expressed as

$$
\mathrm{w}_{\text {ideal }}=\mathrm{c}_{\mathrm{p}} \mathrm{T}_{\mathrm{ol}}\left[(\mathrm{PR})^{\left.\frac{(\gamma-1)}{\gamma}-1\right]}\right.
$$

Therefore, by inserting Eqn 3.86 into Eqn 3.77 and rearranging the equation, as shown by Eqn 3.87 it is possible to solve for work relationship exponent (q).

$$
q=\frac{\log \left(\frac{\left[(P R)^{\frac{(\gamma-1)}{\gamma}}-1\right]_{b}}{\left[(P R)^{\frac{(\gamma-1)}{\gamma}}-1\right]_{a}}\right)}{\log \left(\frac{\% N_{b}}{\% N_{a}}\right)}
$$

Once $\mathrm{q}$ has been found, Eqn 3.87 can be rearranged to calculate extrapolated values of pressure ratio (Eqn 3.88).

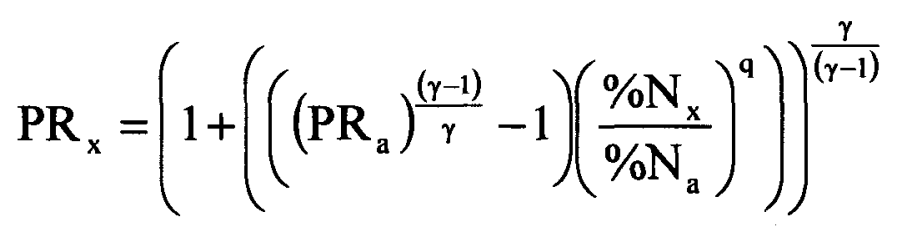


To calculate the power relationship exponent (r), an expression for component power as a function of the given component characteristics is required. Knowing from Saravanamuttoo et al., (2001) that compressor power is given by

$$
\dot{\mathrm{W}}=\dot{\mathrm{m}} \mathrm{c}_{\mathrm{p}} \frac{\mathrm{T}_{\mathrm{ol}}}{\eta}\left[(\mathrm{PR})^{\frac{(\gamma-1)}{\gamma}}-1\right]
$$

Expressions for the power relationship exponent (r) and extrapolated efficiency values can be found by following the same steps described in the turbine sub-section. As a result the power relationship exponent (r) were calculated using Eqn 3.90 and extrapolated efficiency values were found using Eqn 3.91.

$$
\begin{aligned}
& r=(p+q)-\frac{\log \left(\frac{\eta_{b}}{\eta_{a}}\right)}{\log \left(\frac{\% N_{b}}{\% N_{a}}\right)} \\
& \eta_{x}=\eta_{a} \times\left[\frac{\% N_{x}}{\% N_{a}}\right]^{(p+q)-r}
\end{aligned}
$$

\section{Extrapolation Method}

The extrapolation method to calculated sub-idle characteristics consisted of three steps:

Step 1: Selecting a reference speed line

Step 2: Calculating similarity law exponents $(p, q$ and $r$ )

Step 3: Extrapolating component characteristics

These steps apply to both constant geometry turbines and compressors (not applicable to components with variable vanes).

The first step calls for the selection of a reference speed line. Since the extrapolation method was aimed at the sub-idle region, the reference speed line should be 
located at the lower end of the component map. Although not stated explicitly, the exponent manipulation calculations require two speed lines: a reference speed line (a) and a speed line of lower value (b). As a result, the second-last non-extrapolated speed line of the given component map should be selected as the reference speed line. Caution shall be taken to ensure that the selected reference speed line is well drawn and consistent with physics. For illustration purposes, a generic compressor map adapted from the commercial performance modeling software GasTurb, will be used to demonstrate the different steps of the extrapolation method. Step 1 is shown in Figure 3.18. The beta lines are not shown in Figure 3.18 for reasons of clarity.

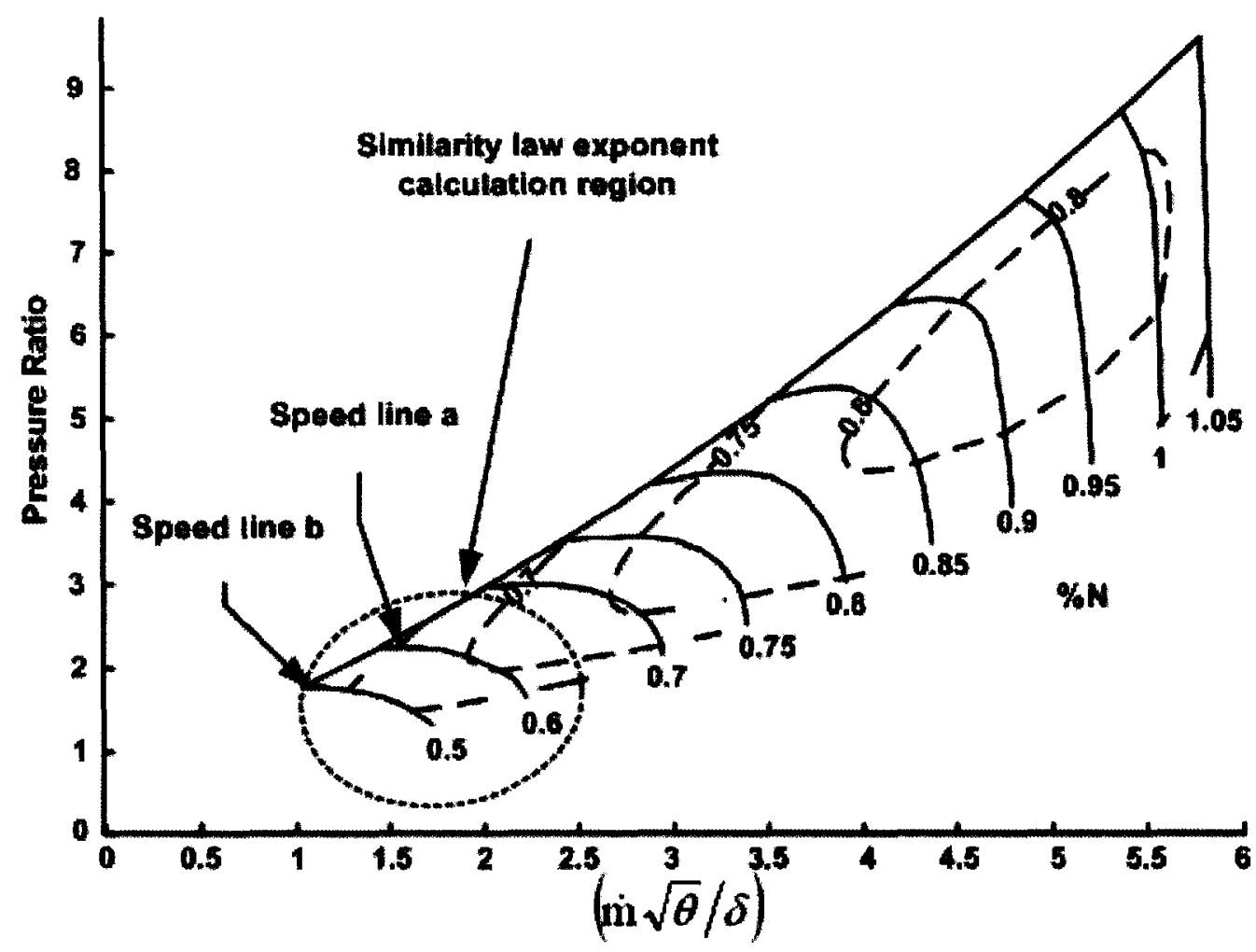

Figure 3.18: Generic compressor map (adapted from Kurzke (2004b))

The next step consists of calculating the similarity law exponents. According to Sexton (2001), these exponents depend greatly on the shape of the reference speed line and may require some user interaction to generate adequate extrapolated speed lines. Therefore, to alleviate the need for user input and to capture the exponent dependence to 
the shape of the reference speed line, the similarity law exponents were calculated as a function of beta values. Thus,

$$
(\mathrm{p}, \mathrm{q}, \mathrm{r})=f n(\beta)
$$

As a result, based on Eqns 3.75, 3.87 and 3.90, which are specific to compressors, a set of similarity law exponents was calculated for every beta value available. This was done using the information available at the points of intersection between the given speed lines (speed line $a$ and $b$ ) and each individual beta line. These points of intersection are shown in Figure 3.19. The smoothness of the extrapolated speed line depends on the amount of beta lines available. Once the similarity law exponents were calculated and tabulated as a function of beta value, they remained constant for the remaining extrapolation process.

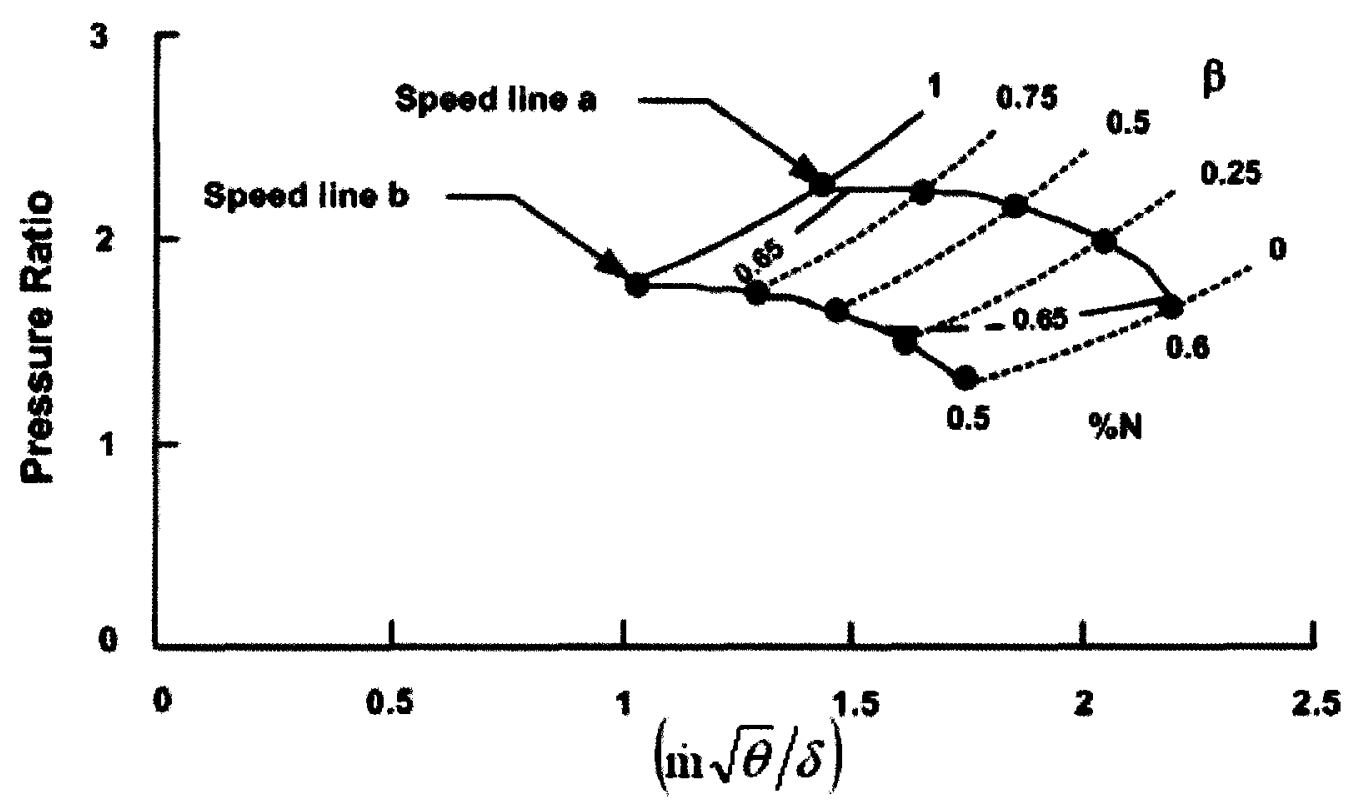

Figure 3.19: Intersection points used to calculate similarity law exponents

The final step of the component map extrapolation method deals specifically with characteristics extrapolation. Using the tabulated similarity law exponents obtained from Step 2, it was possible to extrapolate the component characteristics following a simple extrapolation algorithm. 
The extrapolation algorithm for a compressor is detailed below:

$$
\begin{aligned}
& \text { for } \% \mathrm{~N}_{\mathrm{x}}=\% \mathrm{~N}_{\mathrm{a}} \text { to } 0 \\
& \text { for } \beta=0 \text { to } 1 \\
& \quad \beta_{\text {now }}=\beta \\
& \quad\left(\mathrm{p}_{\text {now }}, \mathrm{q}_{\text {now }}, \mathrm{r}_{\text {now }}\right)=\left[\mathrm{p}\left(\beta_{\text {now }}\right), \mathrm{q}\left(\beta_{\text {now }}\right), \mathrm{r}\left(\beta_{\text {now }}\right)\right] \\
& \quad(\dot{\mathrm{m}} \sqrt{\theta} / \delta)_{\mathrm{x}}=\text { as per Eqn. 3.76 where } \mathrm{p}=\mathrm{p}_{\text {now }} \\
& \mathrm{PR}_{\mathrm{x}}=\text { as per Eqn } 3.88 \text { where } \mathrm{q}=\mathrm{q}_{\text {now }} \\
& \quad \eta_{\mathrm{x}}=\text { as per Eqn } 3.91 \text { where } \mathrm{r}=\mathrm{r}_{\text {now }} \\
& \text { end } \\
& \text { end }
\end{aligned}
$$

Once the algorithm had been carried out, the extrapolated speed lines were added to the original component map to produce a complete compressor map which extended well into the sub-idle region to allow for engine modeling from zero to design speed. This is shown in Figure 3.20. Here again, the beta lines are not shown for clarity.

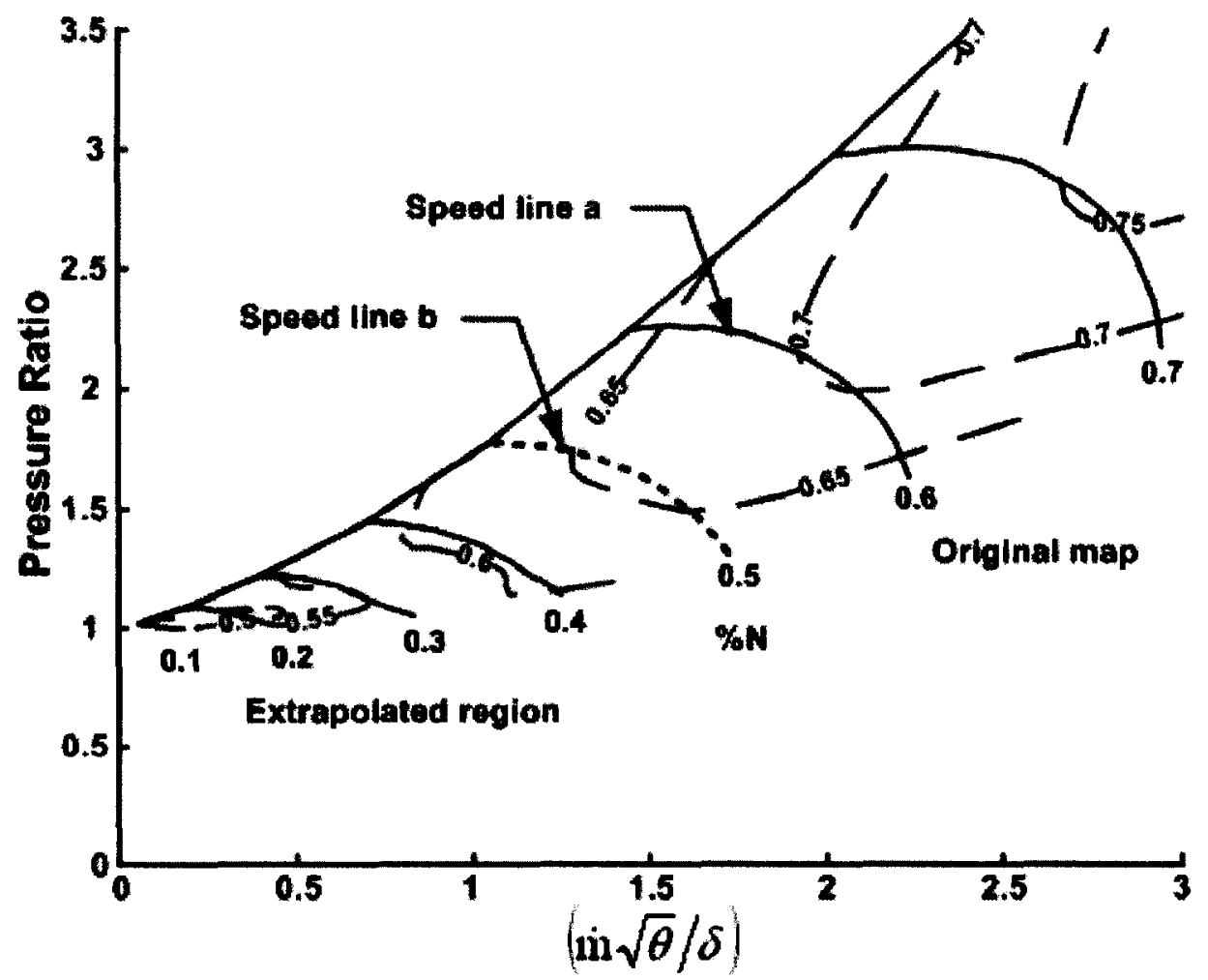

Figure 3.20: Extrapolated compressor map 
As stated previously, the component map extrapolation method can also be applied to turbines. Using the same three steps, but utilizing turbine-specific equations, the generic turbine map shown in Figure 3.21 was extrapolated to produce the turbine characteristics shown in Figure 3.22.

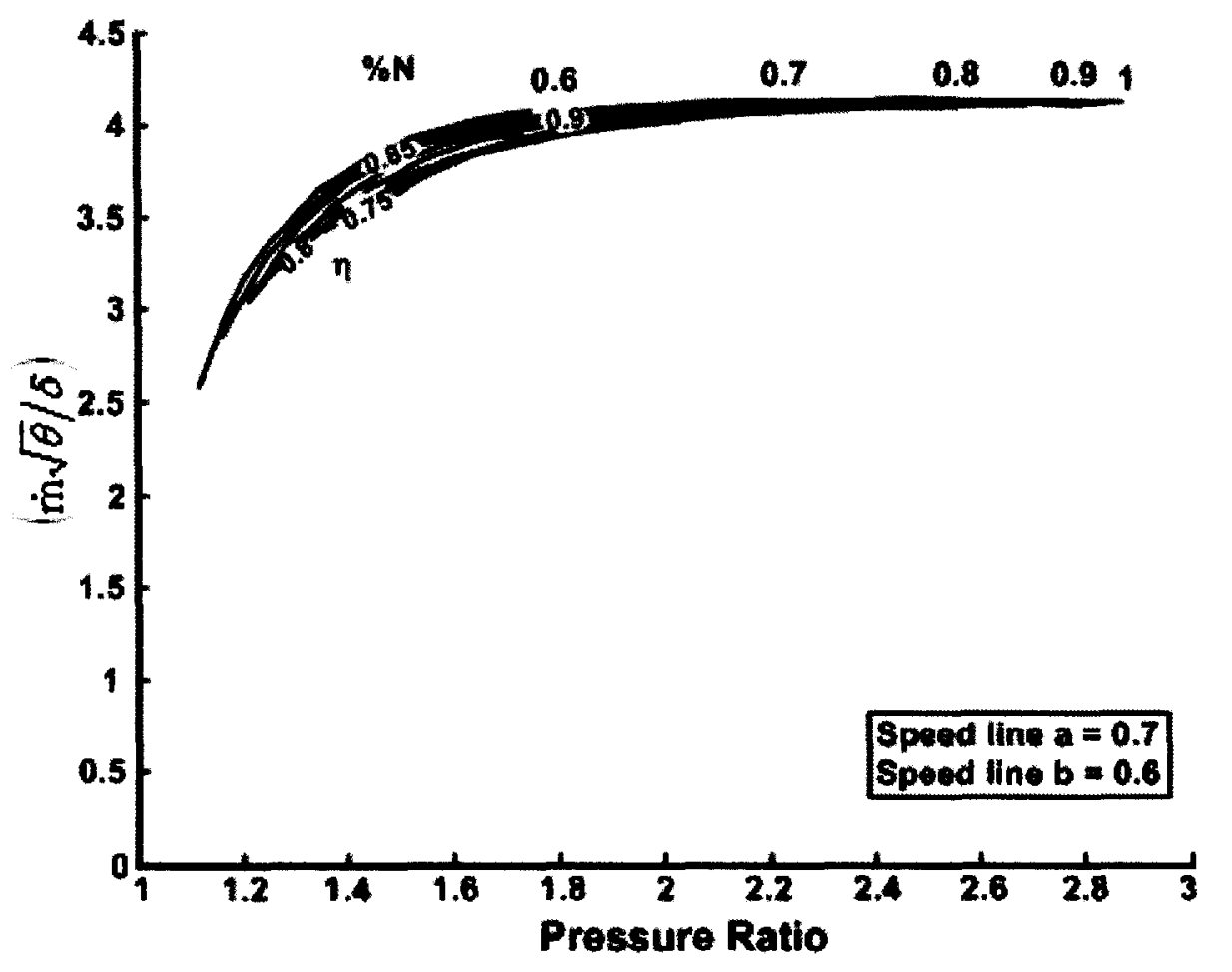

Figure 3.21: Generic turbine map (adapted from Kurzke (2004b) 


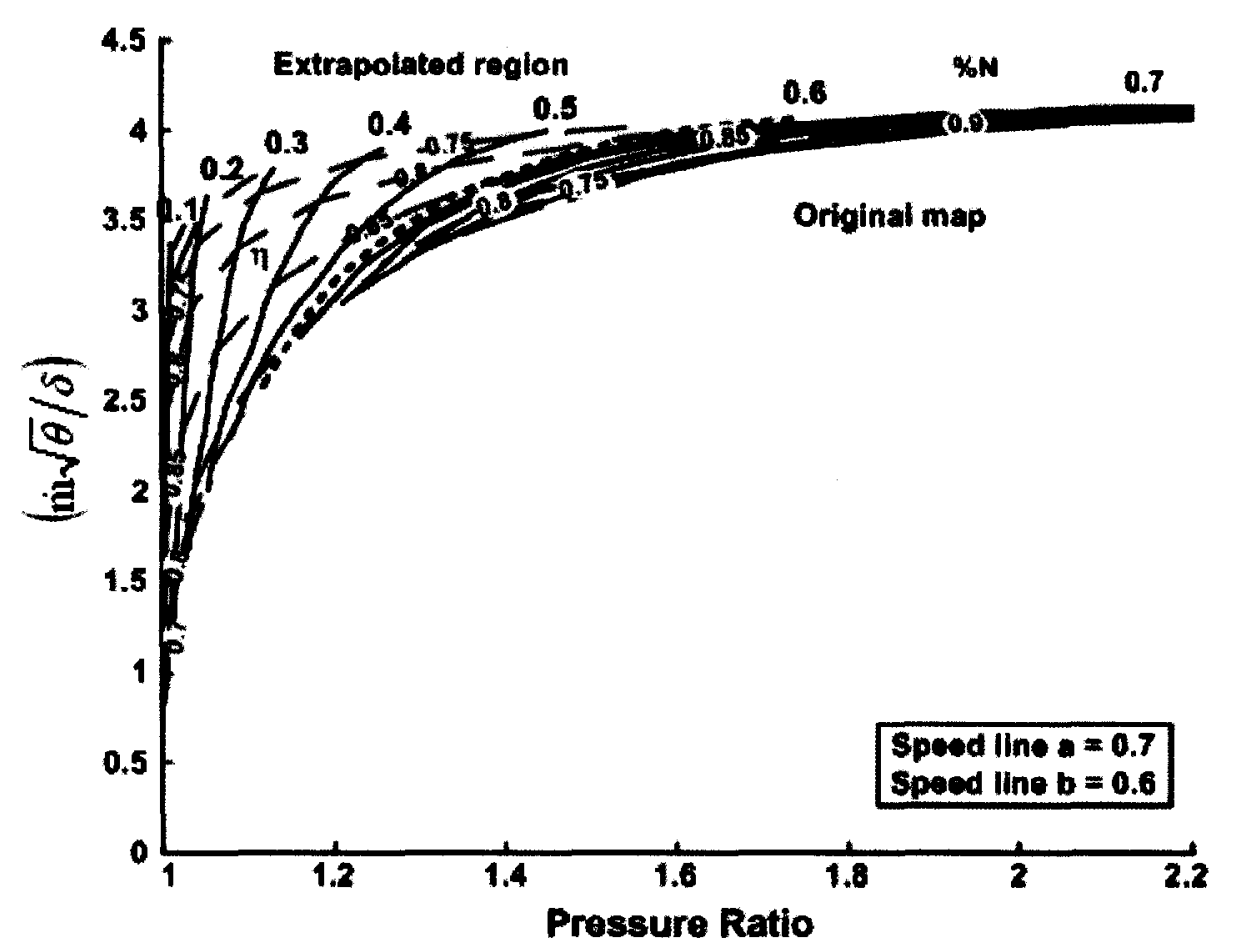

Figure 3.22: Extrapolated turbine map

\subsubsection{Gas Turbine Start modeling}

Gas turbine start models play an essential role in the starter sizing process as it provides key design requirements such as starter torque and starter power required to meet a given startup time. However, similarly to component maps, the information pertinent to the sizing procedure is only available late in the detailed design phase of an engine development program.

Two methods were reviewed and combined to produce a gas turbine start model. The first method consisted of dynamically modeling the engine start region using the extrapolated component maps discussed earlier. The second method consisted of using the start extrapolation model proposed by Walsh and Fletcher (1998) discussed in the literature review. At very low speeds, ( $\% \mathrm{~N}=20 \%$ and lower), it is expected that the dynamic model using extrapolated component map would suffer numerical convergence issues because a large number of beta lines will be stacked closely together to cover a small area of the component map. For this reason a combination of the first method and 
the second method was used to produce start characteristics, which can then be used to model engine startup performance or size engine starters.

First, using a dynamic model and the extrapolated component maps, steady-state operating points were calculated well into the sub-idle region until numerical convergence became an issue. Based on Walsh and Fletchers (1998), a power off-take was applied to every point such that the compressor surge margin was at the minimum allowable or the engine turbine inlet temperature was at its maximum. This was required to simulate the power imbalance required to accelerate the engine to idle. Using compressor and gas generator turbine data obtained from the last converged operating point; startup power and torque characteristics for both compressor and gas generator turbine were extrapolated. For a compressor, this process is a follows,

\section{Compressor Start Extrapolation}

$$
\begin{aligned}
& \text { for } \mathrm{N}_{\mathrm{gg}, \mathrm{x}}=\mathrm{N}_{\mathrm{gg} \text {, last }} \text { to } 0 \\
& \dot{\mathrm{W}}_{\mathrm{c}, \mathrm{x}}=\dot{\mathrm{W}}_{\mathrm{c}, \text { last }}\left(\frac{\mathrm{N}_{\mathrm{gg}, \mathrm{x}}}{\mathrm{N}_{\mathrm{gg}, \text { last }}}\right)^{3} \\
& \mathrm{G}_{\mathrm{c}, \mathrm{x}}=\frac{\dot{\mathrm{W}}_{\mathrm{c}, \mathrm{x}}}{\mathrm{N}_{\mathrm{gg}, \mathrm{x}}}\left(\frac{60}{2 \pi}\right)
\end{aligned}
$$

The same process cannot be applied to the gas generator turbine since combustion affects turbine power production (power is proportional to the turbine inlet temperature). This said, according to Walsh and Fletcher (1998), at top of crank (just before ignition), the power generated by the gas generator turbine is about $25 \%$ of the power generated when the combustor is lit at the same speed. For this reason, the extrapolation process was done in two folds: 1) from the last converged operating point to the ignition speed, then 2) from ignition speed to zero speed. The algorithm for this process is as follows: 
Gas Generator Turbine Start Extrapolation - Combustor Lit

$$
\text { for } \begin{aligned}
\mathrm{N}_{\mathrm{gg}, \mathrm{x}} & =\mathrm{N}_{\mathrm{gg}, \text { last }} \text { to } \mathrm{N}_{\mathrm{gg}, \text { ign }} \\
\dot{\mathrm{W}}_{\mathrm{t}, \mathrm{x}} & =\dot{\mathrm{W}}_{\mathrm{t}, \text { last }}\left(\frac{\mathrm{N}_{\mathrm{gg}, \mathrm{x}}}{\mathrm{N}_{\mathrm{gg}, \text { last }}}\right)^{3} \\
\mathrm{G}_{\mathrm{t}, \mathrm{x}} & =\frac{\dot{\mathrm{W}}_{\mathrm{t}, \mathrm{x}}}{\mathrm{N}_{\mathrm{gg}, \mathrm{x}}}\left(\frac{60}{2 \pi}\right)
\end{aligned}
$$

end

\section{Gas Generator Turbine Start Extrapolation - Dry Crank}

$$
\text { for } \begin{aligned}
\mathrm{N}_{\mathrm{gg}, \mathrm{x}} & =\mathrm{N}_{\mathrm{gg}, \mathrm{ign}} \text { to } 0 \\
\dot{\mathrm{W}}_{\mathrm{t}, \mathrm{x}} & =\dot{\mathrm{W}}_{\mathrm{t}, \mathrm{ign}}\left(\frac{\mathrm{N}_{\mathrm{gg}, \mathrm{x}}}{\mathrm{N}_{\mathrm{gg}, \mathrm{ign}}}\right)^{3} \\
\mathrm{G}_{\mathrm{t}, \mathrm{x}} & =\frac{\dot{\mathrm{W}}_{\mathrm{t}, \mathrm{x}}}{\mathrm{N}_{\mathrm{gg}, \mathrm{x}}}\left(\frac{60}{2 \pi}\right)
\end{aligned}
$$

end

$$
\text { where } \dot{\mathrm{W}}_{\mathrm{t}, \mathrm{ign}}=0.25 \dot{\mathrm{W}}_{\mathrm{t}, \mathrm{x}}\left(\text { at } \mathrm{N}_{\mathrm{gg}, \text { ign }}\right. \text { and Combustor lit) }
$$

Using the extrapolated power and torque characteristics of the compressor and turbine, it was possible to assess the effect of starter torque characteristics on engine startup time by estimating spool acceleration using Eqn 3.93. The engine spool accelerates based on the torque imbalance seen between the turbomachinery and the starter. The spool acceleration is also dependant on the inertia of the assembly.

$$
\mathrm{dN}_{\mathrm{gg}}=\frac{60\left(\mathrm{G}_{\mathrm{t}, \mathrm{x}} \eta_{\mathrm{m}}-\mathrm{G}_{\mathrm{c}, \mathrm{x}}+\mathrm{G}_{\mathrm{start}}\right)}{2 \pi \mathrm{I}_{\mathrm{gg}}}
$$




\section{Chapter 4 \\ Gas Turbine Control System Design Method}

This section will detail a comprehensive control system design method applicable early in the gas turbine design process. A general overview of the method will be discussed followed by a detailed look at control philosophies and modeling techniques used to design and model the control system.

\subsection{Overview}

The main goal of the control system design method is to alleviate the burden of control system design faced during the early stages of gas turbine design. Even though gas turbine design is an iterative process; the core functions of the control system will not change drastically from preliminary design to production. The proposed method aims at highlighting these core functions and ensuring that they are implemented into the control system early in the design process. To ease the process, a roadmap to control system design was created.

As shown in Figure 4.1, the first step involves classifying the fundamental controlling functions into either open-loop system or closed-loop system. As discussed in the literature review, these fundamental functions are comprised of: startup and shutdown sequencing, steady-state control and engine protection. In practice, startup and shutdown sequencing functions are captured in open-loop systems where steady-state control and protection functions are captured in closed-loop systems. 


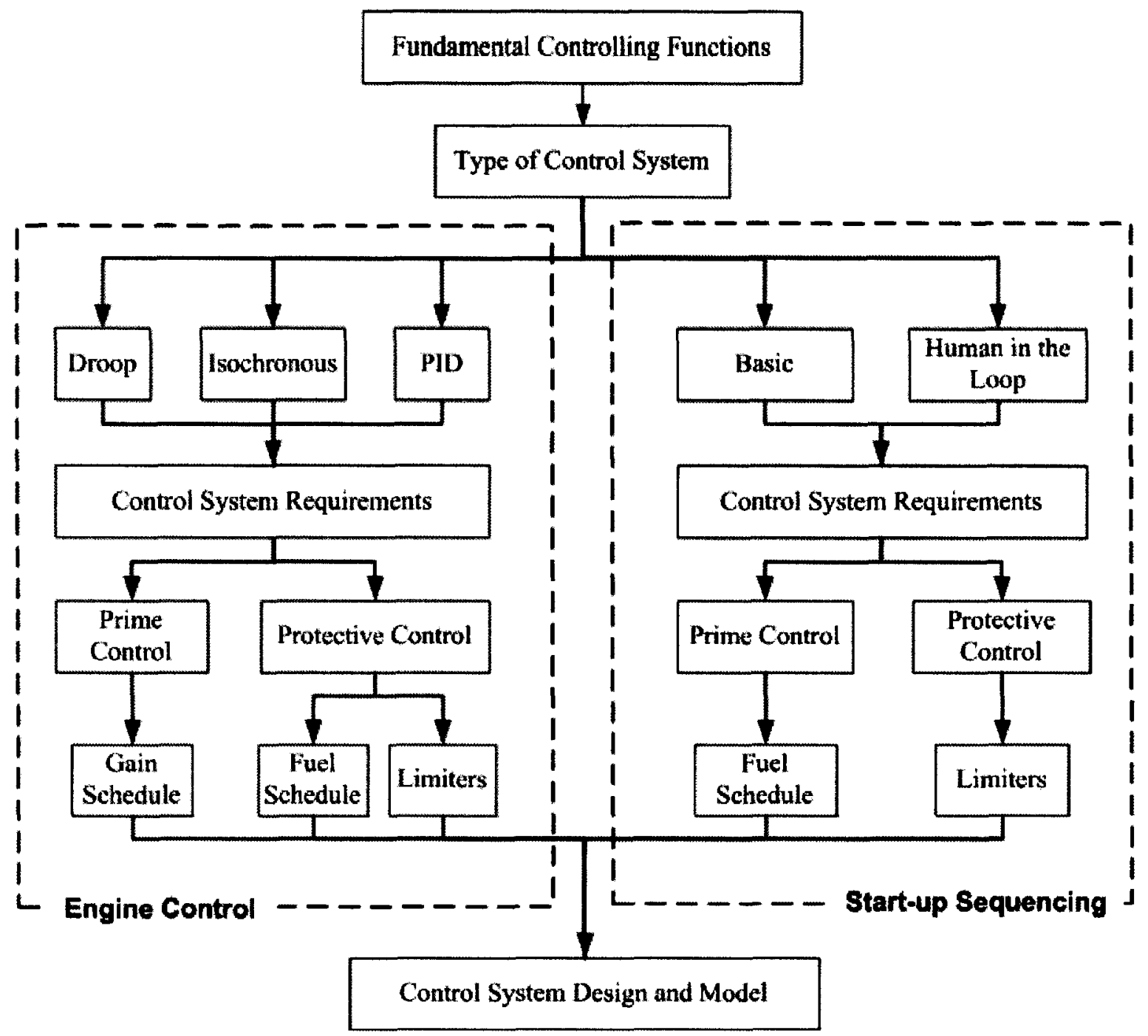

Figure 4.1: Control system design method overview

The next step deals with selecting the controlling method. The choice will vary from droop to PID for closed-loop systems, to basic or human in the loop for open-loop systems. The selection process results will differ from applications to applications and usually depend on the accuracy requirements, complexity involved and the resulting cost.

Once the controller has been selected, the foundation of the control system is defined. However, up to this point only the fundamental controlling functions have been considered. For this reason, the next step aims at building on this foundation by implementing the control system requirements. These control requirements may come 
from a variety of sources such as client contract agreements, material property limitations, performance requirements, etc. Given control system requirements, the next step involves categorizing the requirements into prime and protective functions. Once this is done, the functions will be modeled into mathematical expressions or lookup tables and finally implemented into the selected controller. This step will involve extensive use of an engine dynamic model to properly layout the prime and protective control boundaries (gain and fuel schedules).

The resulting control system design and model may then be updated with additional control requirements as the gas turbine design evolves.

\subsection{Engine Control}

The engine control section of the control system design procedure will deal with steady-state operation, transient operation and engine protection functions. As discussed in the literature review, these fundamental controlling functions are responsible for:

- Maintaining consistent, stable power

- Maintaining smooth, repeatable performance during transient operation from one requested power to another

- Maintaining stable airflow, internal pressures and temperatures, and rotor speeds within safe operating limits

- Avoiding stalls and surges, and significant speed, pressure or temperature variations

To achieve these requirements, the control system will rely on feedback control (closed-loop systems). Based on this statement, any of the three main types of controllers, droop, isochronous and PID, may be selected to fulfill the requirements. However the selection process is application driven. In this case, the application is a marine turboshaft engine with a power turbine. Therefore, as detailed in the literature review, it is recommended to use an isochronous controller. As a result, the following steps of the Engine Control section of the control system roadmap will be focused around the selected 
isochronous controller. However, the process could be applied to any of the other two closed-loop controllers with only slight modifications.

The next step will consist of understanding the control system requirements at a high level (without going into the details). This is achieved by simply answering the following fundamental questions:

- What is the control system input?

- What is the control system output?

Depending on the application the demand (input) could take various shapes such as a power lever angle (PLA), a gas generator speed, a power setting, etc. The demand will normally be specified in the control system requirements. Since close-loop controllers work on the error between the demand and the feedback signal, the feedback measurement will also be dependent of the control system input. On the other hand, fuel flow is, in all cases, the control system output for simple gas turbine applications. Other outputs such as bleed flows or variable geometry settings may also be required as outputs, but these are dependent on the application and the design of the gas turbine. Again, if other outputs are required, this will be highlighted in the control system requirements.

This preliminary understanding of the control system requirements may be sketched as shown in Figure 4.2, and modeled mathematically as per Eqn 4.1

$$
\dot{\mathrm{m}}_{\mathrm{f}}=\mathrm{K}_{\mathrm{p}}(\text { Demand }- \text { Measurement } \mathrm{t})+\mathrm{K}_{\mathrm{i}} \int(\text { Demand }- \text { Measuremen } \mathrm{t}) \mathrm{dt}
$$




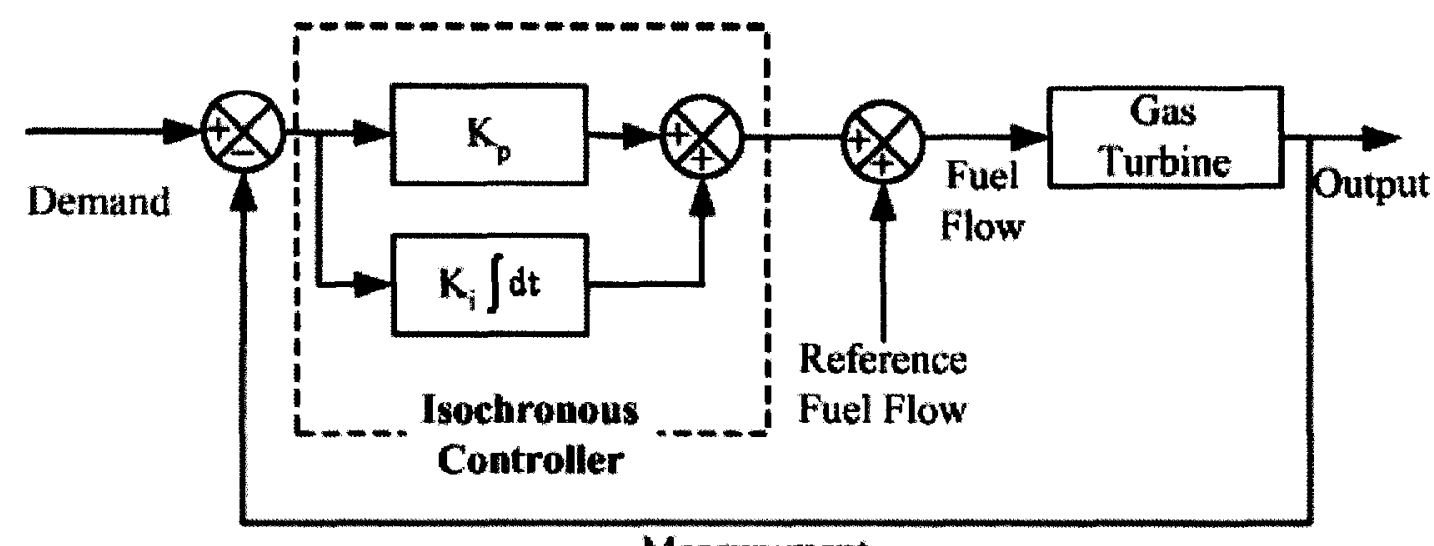

Measurement

Figure 4.2: Isochronous control

The next step will consist of understanding the control system requirements in more details such that they can be translated into prime and protective functions.

\subsubsection{Gain Scheduling (Prime Control)}

The prime control requirements of a control system are always stated in the control system requirements. In fact, the control system input is directly dependent on the prime control requirements. As stated earlier, these requirements are application dependent and are usually aimed at constraining engine dynamic response. This is done by tuning the controller gains so that the engine responds adequately for a given operating condition. In the case of a control system designed for a marine application, the control system prime control requirement is to ensure that the gas turbine engine will operate steadily at various steady-state operating speeds based on a power, RPM or boat speed demand. In the presence of disturbances or during transient manoeuvres, the controller prime control requirement is to remain constant. But as discussed in the literature review, gas turbines behave nonlinearly throughout the operating range. Therefore, to satisfy the prime control requirement, a set of control gains must be generated for each operating point. This is known as gain scheduling. The gain schedules may be generated following a procedure put forward by Qi et al. (1992). As they stated, the main idea is to break the control design process into two steps: 
- Design local linear controllers based on linear approximations of the nonlinear system at different operating points

- Obtain a global non-linear controller by interpolating or scheduling the gains of the local linear controllers

By splitting the first bullet into three sub-steps, it is possible to design local controllers early in the gas turbine design process by using the dynamic model of a gas turbine engine. The procedure is as follows:

First, a demand step change is inputted into the dynamic model to generate an engine response curve between two steady-state operating points. This is done in an effort to measure the engine time constant $(\tau)$ and to produce a first-order linear approximation of the engine response. Since the time constant is defined as the time required to reach $63.2 \%$ of the change in demand, it is possible to measure the time constant of the response by plotting the engine response in a similar fashion as shown in Figure 4.3.

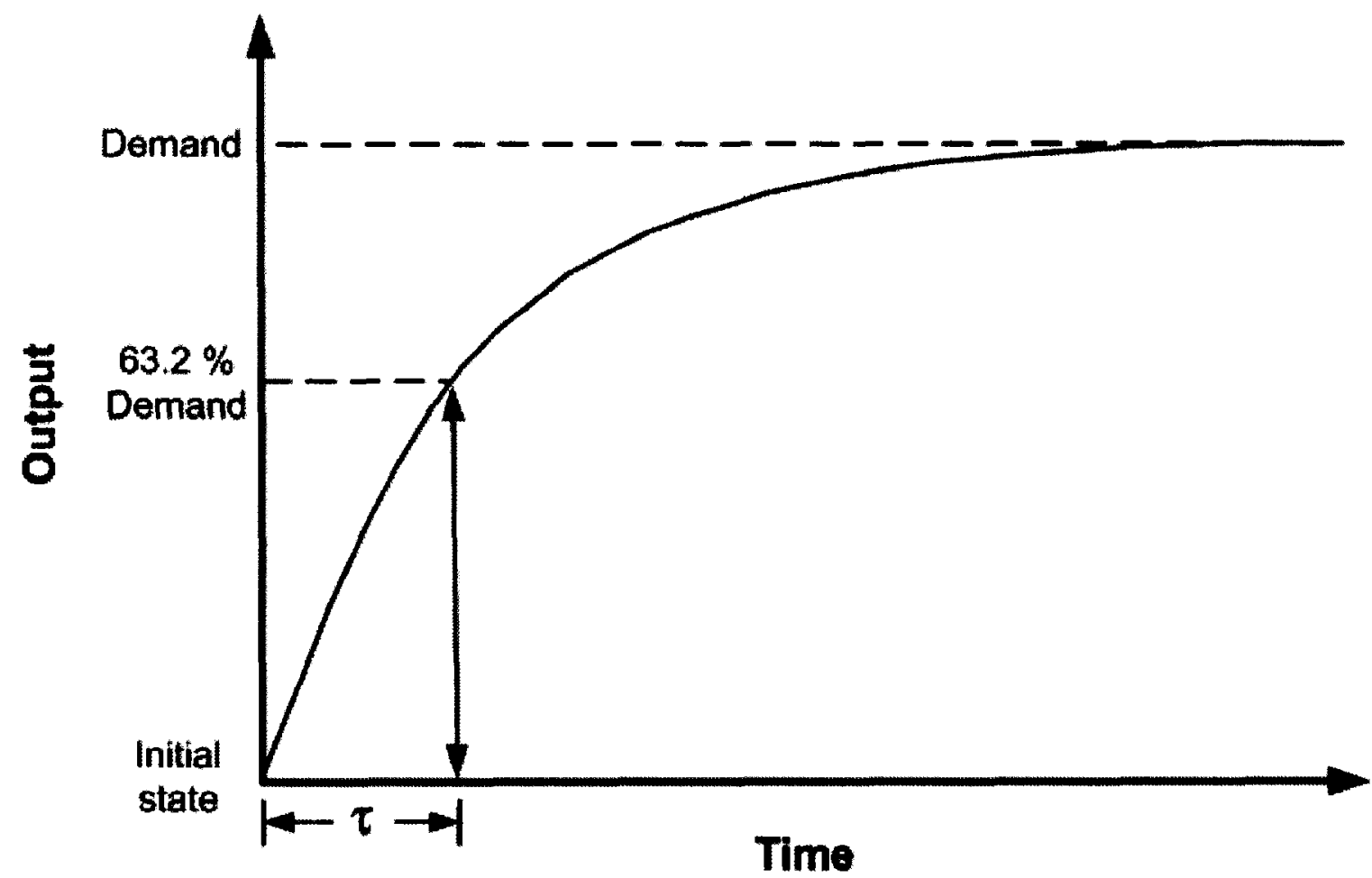

Figure 4.3: Engine response and time constant 
Once the time constant is measured, the engine response between the two steady-state operating points may be approximated in the Laplace domain as per Eqn 4.2.

$$
\mathrm{Y}(\mathrm{s})=\mathrm{X}(\mathrm{s}) \frac{1}{(\tau \mathrm{s}+1)}
$$

This linear approximation will then be used locally as a substitute to the dynamic model to represent the engine dynamically. This allows for quicker engine response analyses without losing much accuracy. It is important to note that this first step is done open-loop with no control system connected to dynamic model.

The next step deals with tuning the controller locally such that the prime control functions are satisfied. Tuning the controller, involves searching for controller gains such that the engine response will fall within the control response requirements. This is done close-loop with the controller connected to the engine response linear approximation (Eqn 4.2). In the Laplace domain, the system may be represented graphically as shown in Figure 4.4.

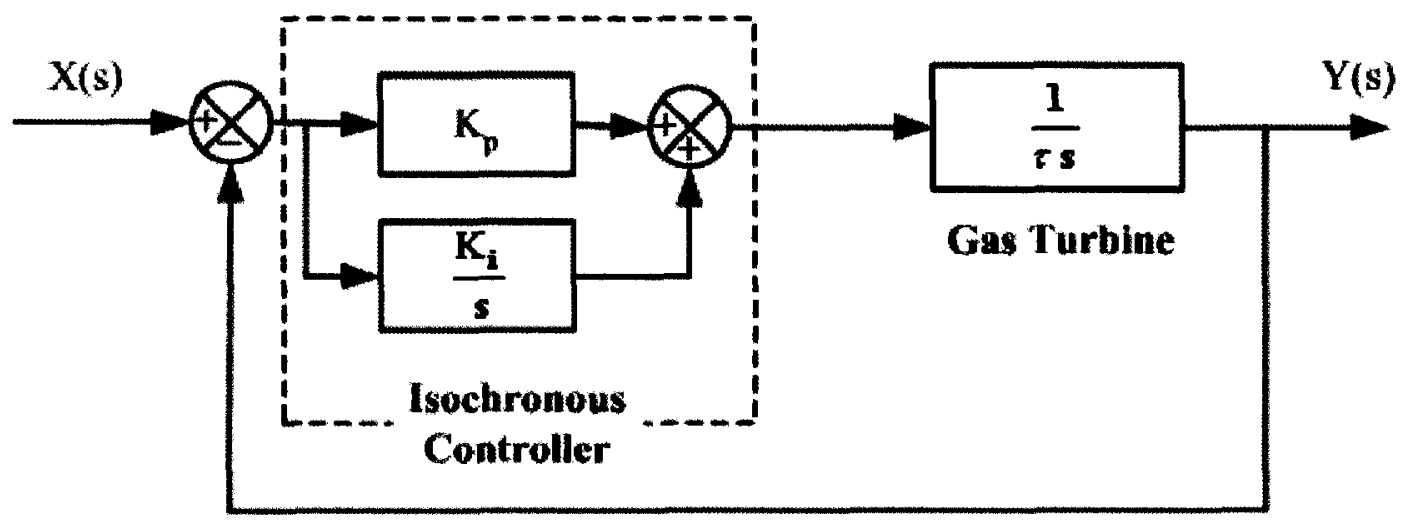

Figure 4.4: Control system block diagram 
Note that an isochronous controller is shown in Figure 4.4 due to its previous selection. However this procedure may be applied to the other closed-loop controllers. The inputoutput relationship for this system is given by the second-order equation Eqn 4.3,

$$
\frac{Y(s)}{X(s)}=\frac{\left(K_{p}\right) s+K_{i}}{s^{2}+\left(K_{p} / \tau\right) s+K_{i} / \tau}
$$

As discussed in the literature review, there are many tuning methods available. However, the methods do not provide optimum performance and often required a series of fine tunings until acceptable results are obtained. Based on this statement and on the fact that the control system is being designed at an early stage of the gas turbine design, a simplistic method which ignores fine tuning will be proposed for this procedure and therefore leave the actual tuning method selection and fine tuning to the control system designer's discretion.

The proposed simplistic method is based on the standard form of the second-order system. Given by,

$$
\frac{Y(s)}{X(s)}=\frac{\omega_{n}^{2}}{s^{2}+2 \zeta \omega_{n} s+\omega_{n}^{2}}
$$

the dynamic behaviours of a second-order system can be described in terms of damping ratio $(\zeta)$ and the undamped natural frequency $\left(\omega_{n}\right)$, (Ogata, 2002). In most case, the main control system response requirements are given in terms of maximum overshoot $(\mathrm{Mp})$ and settling time $\left(t_{\text {set }}\right)$. Therefore, knowing that the maximum overshoot of a standard second-order system is given by,

$$
\mathrm{Mp}=e^{-\left(\zeta / \sqrt{1-\zeta^{2}}\right) \pi}
$$

and the settling time is given by 


$$
\mathrm{t}_{\mathrm{set}}=\frac{4}{\zeta \omega_{\mathrm{n}}} \quad(2 \% \text { criterion })
$$

or

$$
\mathrm{t}_{\mathrm{set}}=\frac{3}{\zeta \omega_{\mathrm{n}}} \quad(5 \% \text { criterion })
$$

it is possible, by rearranging Eqns 4.5 to 4.7, to calculate the damping ratio (Eqn 4.8) and undamped natural frequency (Eqn 4.9 or 4.10 ) required to ensure that the system meets exactly the control system requirements ( $M p$ and $t_{\text {set }}$ ).

$$
\begin{gathered}
\zeta=\sqrt{\frac{(\ln (\mathrm{Mp}) /(-\pi))^{2}}{1+(\ln (\mathrm{Mp}) /(-\pi))^{2}}} \\
\omega_{\mathrm{n}}=\frac{4}{\zeta \mathrm{t}_{\mathrm{set}}} \quad(2 \% \text { criterion })
\end{gathered}
$$

or

$$
\omega_{\mathrm{n}}=\frac{3}{\zeta \mathrm{t}_{\mathrm{set}}} \quad(5 \% \text { criterion })
$$

Now, even though Eqn 4.3 represents a second-order system, it does not match exactly the standard form of a second-order system (Eqn 4.4). However, in an effort to generate initial tuning estimate for the controller gains, the effect of the numerator on the system response will be ignored. Therefore the gains, $\mathrm{K}_{\mathrm{p}}$ and $\mathrm{K}_{\mathrm{i}}$ can be estimated using Eqns 4.11 and 4.12 .

$$
\begin{gathered}
\mathrm{K}_{\mathrm{p}}=2 \zeta \omega_{\mathrm{n}} \tau \\
\mathrm{K}_{\mathrm{i}}=\omega_{\mathrm{n}}^{2} \tau
\end{gathered}
$$


The gain estimates are then entered in Eqn 4.3 and the system response is analyzed to ensure the system meets the response requirements. Depending on the outcome, the gains may require fine-tuning. Once the control system is tuned adequately for the given engine response, the process is re-iterated between two other steady-state operating points. As shown in Figure 4.5 and Figure 4.6, this is done throughout the operating range for both acceleration and deceleration step changes.

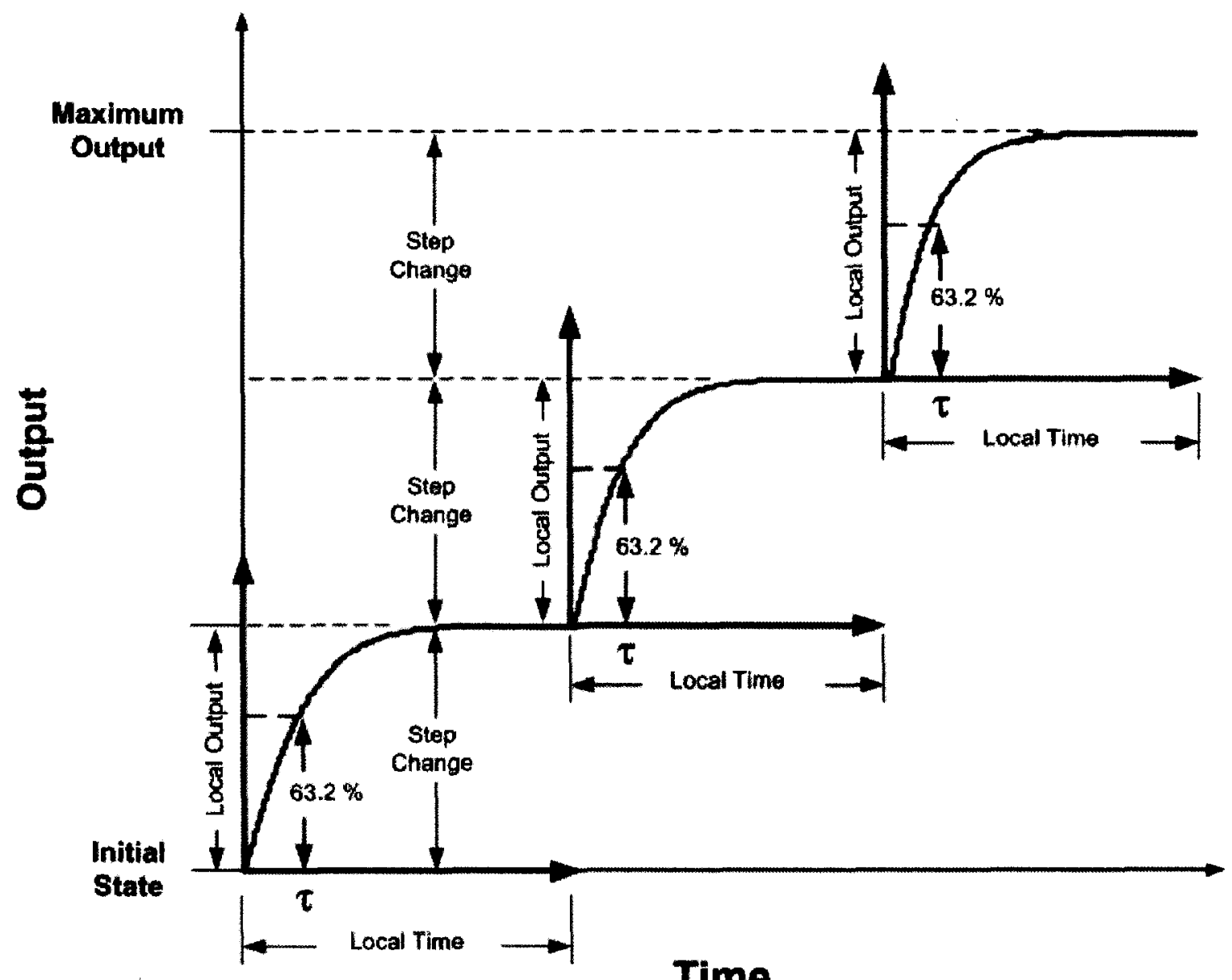

Figure 4.5: Acceleration step response analysis 


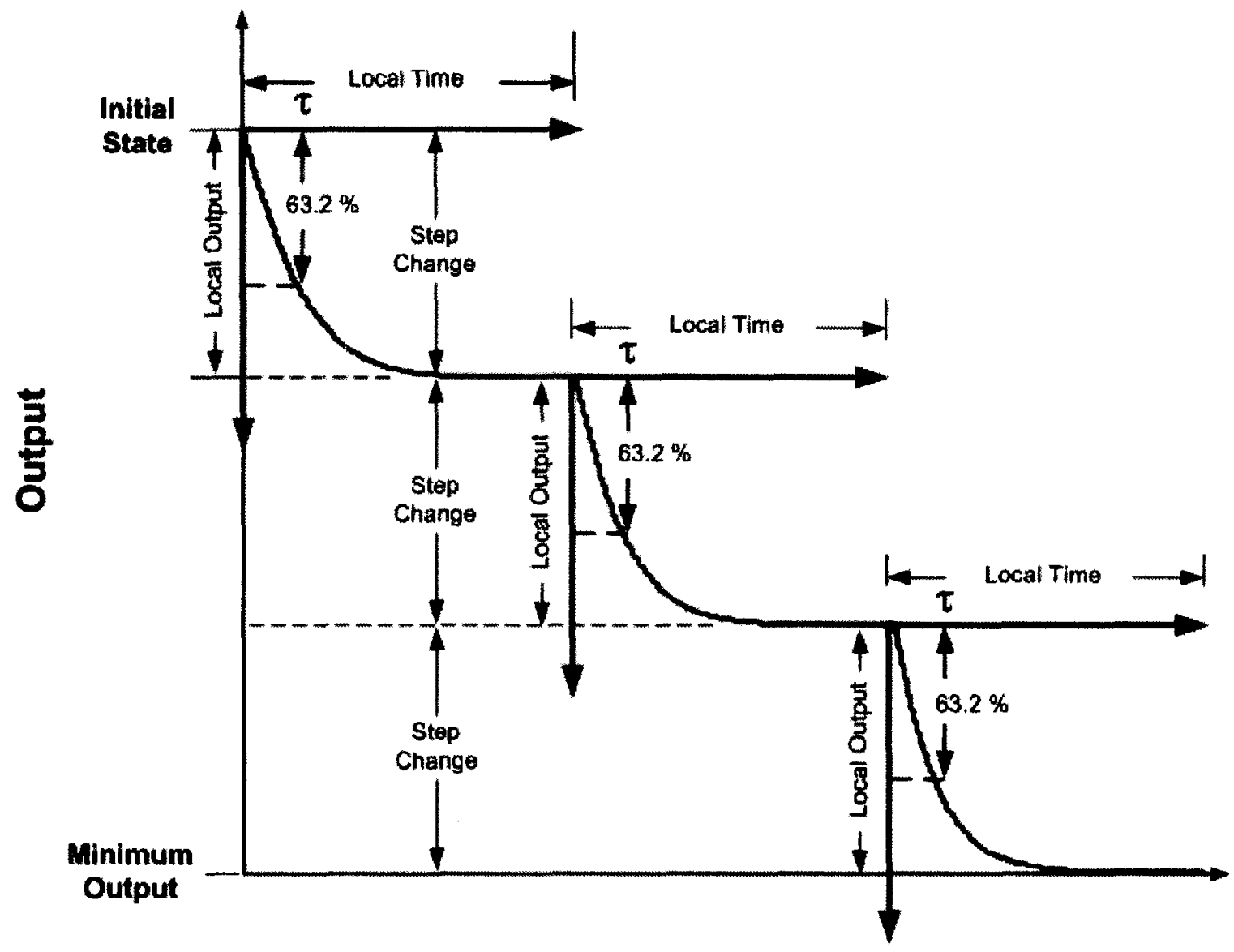

Time

Figure 4.6: Deceleration step response analysis

The gains are collected in a look-up table to form the acceleration and deceleration gain schedules. The gains are stored as a function of reference speed. The reference speed is the initial steady-state operating speed, prior to the input step change. Note that since gas turbine response is non-linear, the number and size of step changes studied throughout the operating range will play a factor on the global non-linear controller response.

Finally, the prime control requirements can be met through global non-linear control. As shown in Figure 4.7, this is done by varying the isochronous controller gains through interpolation of the local linear controller gains. The gains are interpolated as a function of engine spool speed where the demand input signal is used to select the proper gain schedule (acceleration or deceleration). 


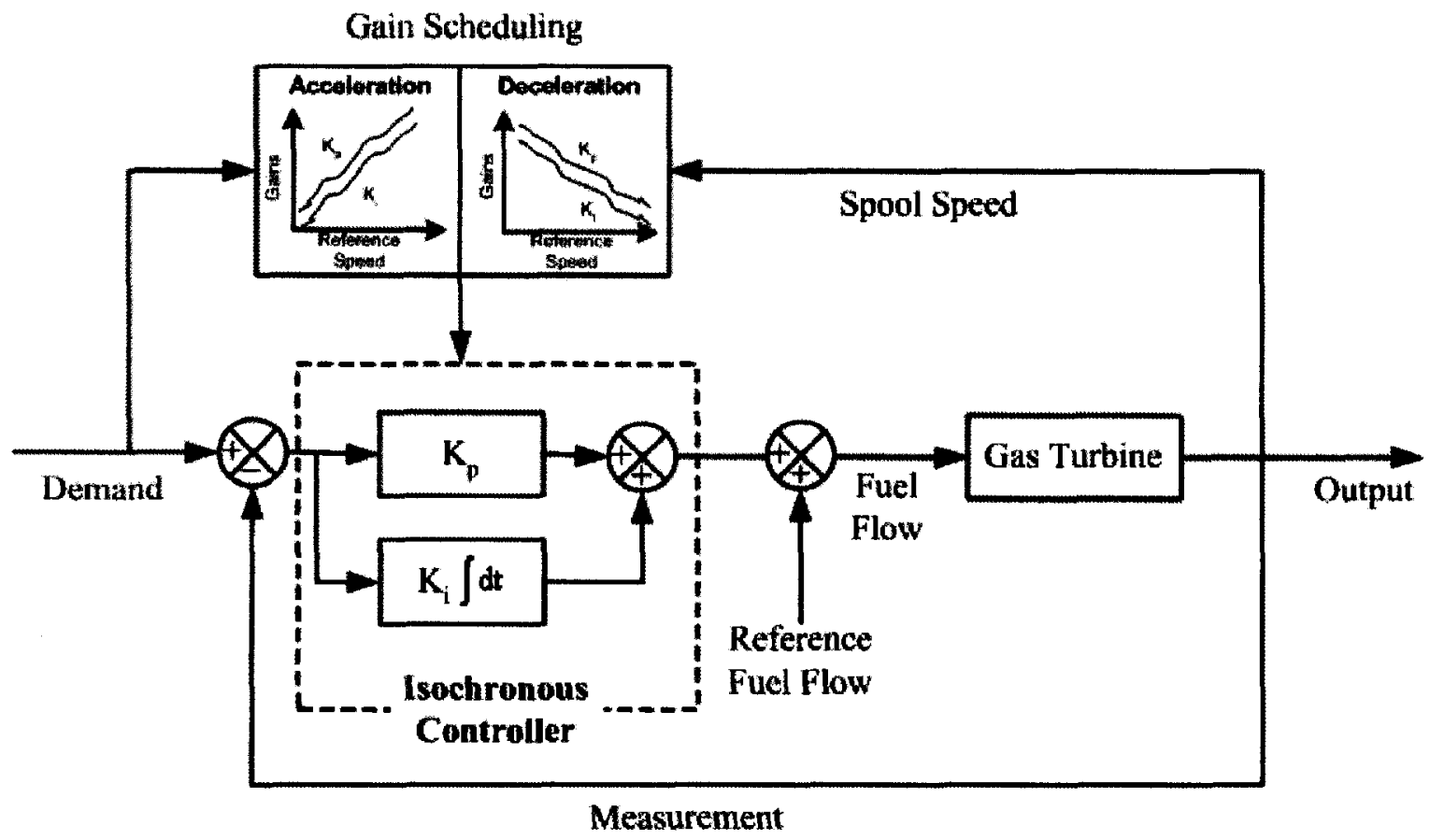

Figure 4.7: Isochronous control with gain scheduling

\subsubsection{Performance Limiters (Protective Control)}

As stated in the literature review, protective control requirements are necessary to delimit the safe transient and steady-state operating regions of a gas turbine (Sawyer, 1966). Usually a function of the material properties, these protective control requirements take the form of performance limiters to ensure adequate gas turbine operating life. The component designers specify these limiters in the control system requirements. There are two types of performance limiters: 1) engine protection limiters and 2) engine operation limiters.

Engine protection limiters are used to ensure that the engine does not suffer any physical damage. To prevent engine malfunction caused by over-temperature or overspeed, modulation control is required. As explained earlier, modulation control consists of modulating the controller output in such a way to limit the response within a safe operating region. As shown in Figure 4.8, this is done using a modulating curve that linearly modifies the controller output between $100 \%$ and $0 \%$ based on a temperature or 
spool speed feedback signal. The curves are drawn based on the given temperature and spool speed limiters.

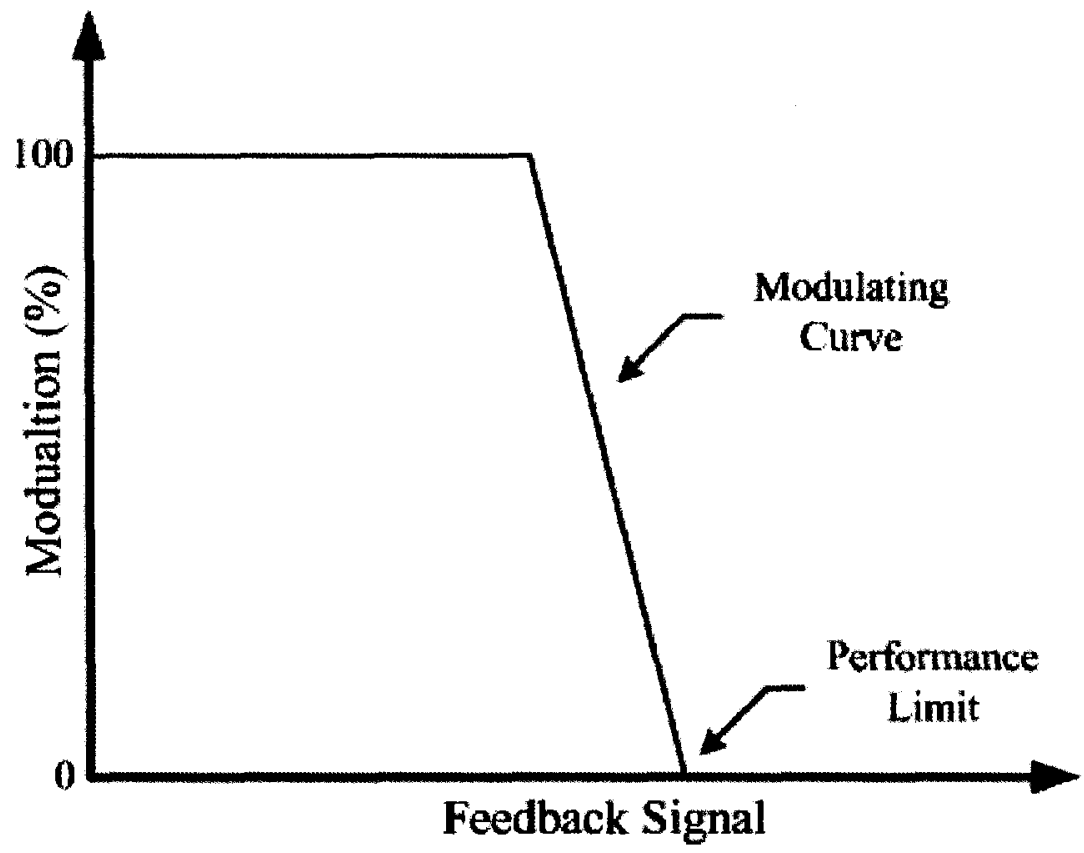

Figure 4.8: Generic modulating curve

To ensure that protective control requirements win over prime control requirements, a low-select function will also be added to the controls system. As show in Figure 4.9, the low-select function will be used to choose the lowest change in fuel flow to be sent to the engine between the controller output and the outputs of the modulation controls. This has the effect of preventing the controller of leading the engine in unsafe operating regions. 


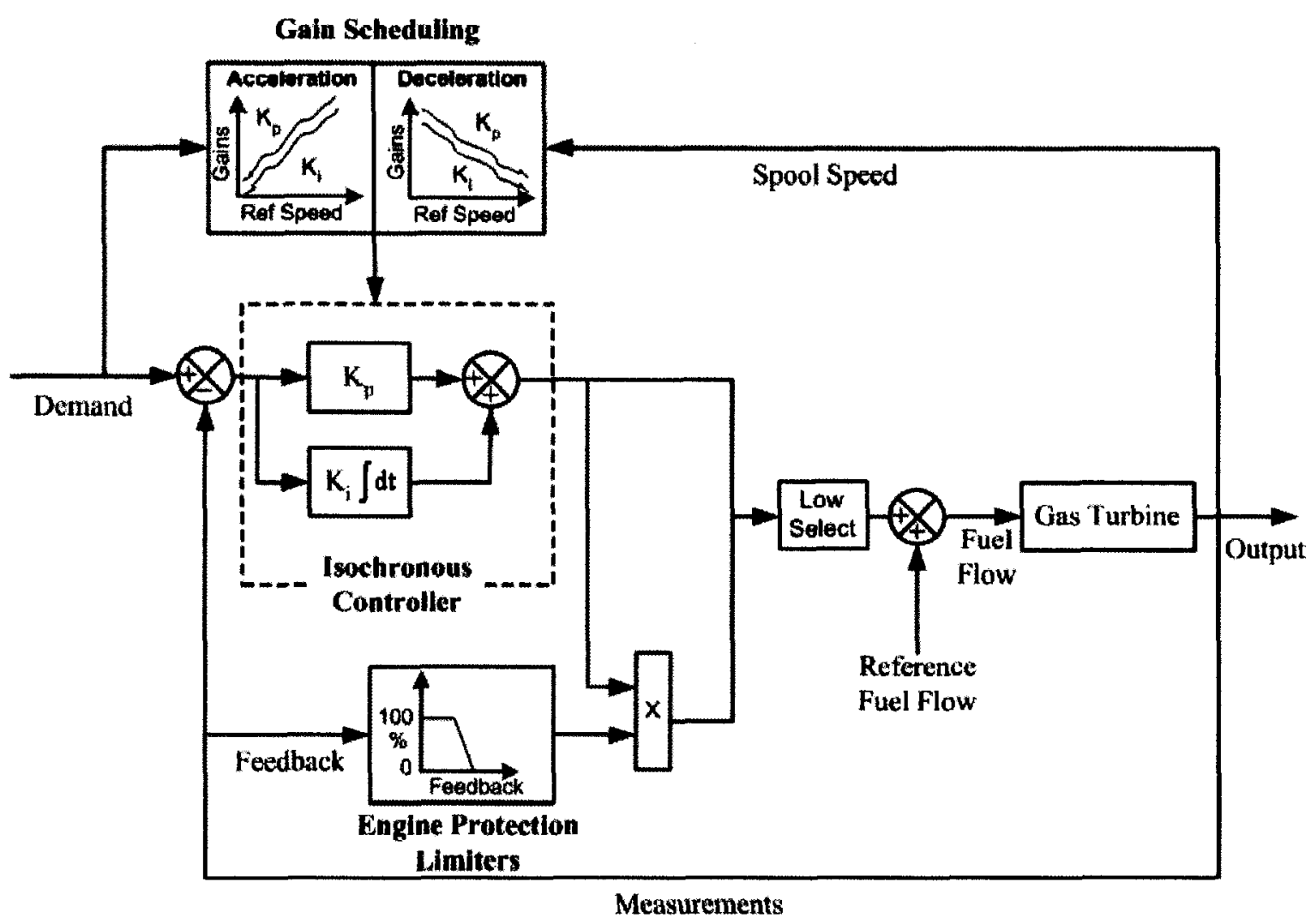

Figure 4.9: Isochronous control with gain scheduling and engine protection limiters

On the other hand, engine operation limiters are used to ensure that the engine operates within predictable operating regimes. Controlling the engine close to or beyond the minimum spool speed limit, flameout limit or the compressor surge limit is rarely attempted as engine response becomes unpredictable in these regions and this may lead to engine damage. For this reason, modulation control is also used in this case to ensure that the engine does not exceed the engine operation limits. Here again, the given limiters are used to draw the modulation curve. To ensure that protective control requirements win over prime control requirements, a high-select function is required. The reason for the high-select function is simply to prevent that the controller pushes the engine out of the safe and stable operating region. Figure 4.10 demonstrates graphically the interactions between the controller and the engine operation limiters. 
Gain Scheduling

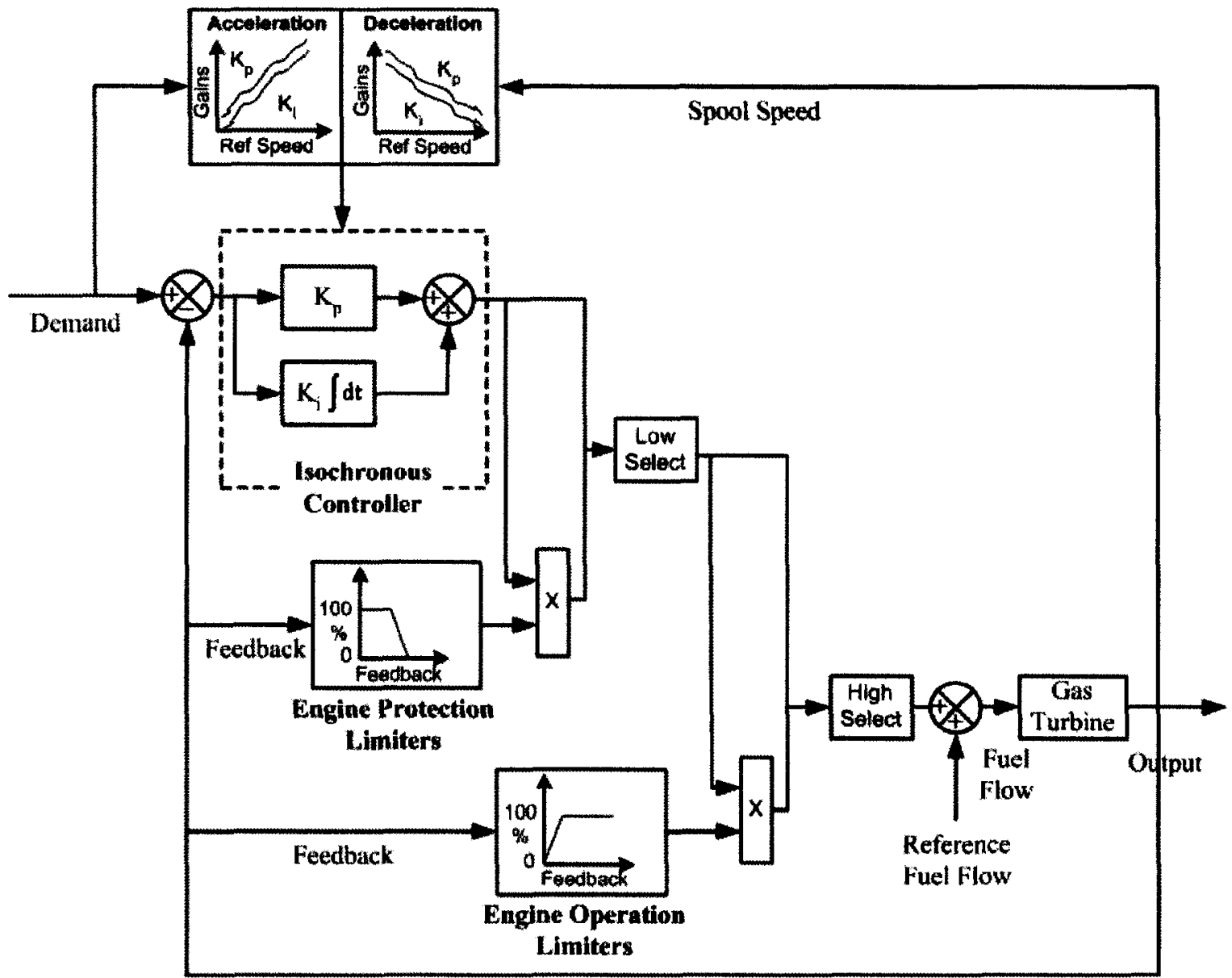

Measurements

Figure 4.10: Isochronous control with gain scheduling, engine protection limiters and engine operation limiters

However, it is important to note that since the onset of compressor surge cannot be measured accurately, the surge limit cannot be enforced using modulation control. Another protective control method will be discussed in the following sub-section.

\subsubsection{Maximum and Minimum Fuel Schedule (Protective Control)}

To re-iterate, the main goal of protective controls is to limit gas turbine operations to the safe transient and steady-state operating regions. The modulation control method proposed earlier relies on the fact that it is possible to measure and hence prevent the engine from reaching an operating condition that may lead to damage or failure. 
However, since the transition from normal operating conditions to surge is extremely fast, ( 0.05 to 0.2 seconds according to Walsh and Fletcher (1998)), it is very difficult to predict the onset of surge due to instrumentation response limitations. Similarly, it is very difficult to predict the onset of engine flameout caused by combustor instabilities during transient deceleration manoeuvres. As a result, modulation control cannot be used to prevent the engine of reaching these operating states. Instead, maximum and minimum fuel schedules will be used as the protective control method. These fuel schedules may be regarded as walls, which block the engine from reaching surge or flameout by limiting the fuel sent to the engine. As discussed in the literature review, the shape of the fuel schedules depends entirely on the shape of the surge or flameout fuel boundaries and on the requirements for fast acceleration or deceleration (GasTOPS, 1990). In fact, generating the fuel schedules shall be influence by all protective control requirements which encapsulate the safe acceleration and deceleration transient regions. Using the engine dynamic model, the following steps are proposed as a guide to sketching initial maximum and minimum fuel schedules.

The first step is to generate the steady-state fuel flow boundaries at the following operating conditions:

- Normal conditions

- Maximum turbine inlet temperature

- Maximum spool speed

- Minimum spool speed

- Minimum fuel flow (flameout limit)

- Compressor surge

The steady-state fuel flow boundaries are generated using the dynamic model of the gas turbine engine. Next, as shown in Figure 4.11, all the fuel boundaries can be plotted on the same graph allowing the designer to visualize the size of the acceleration and deceleration regions. 


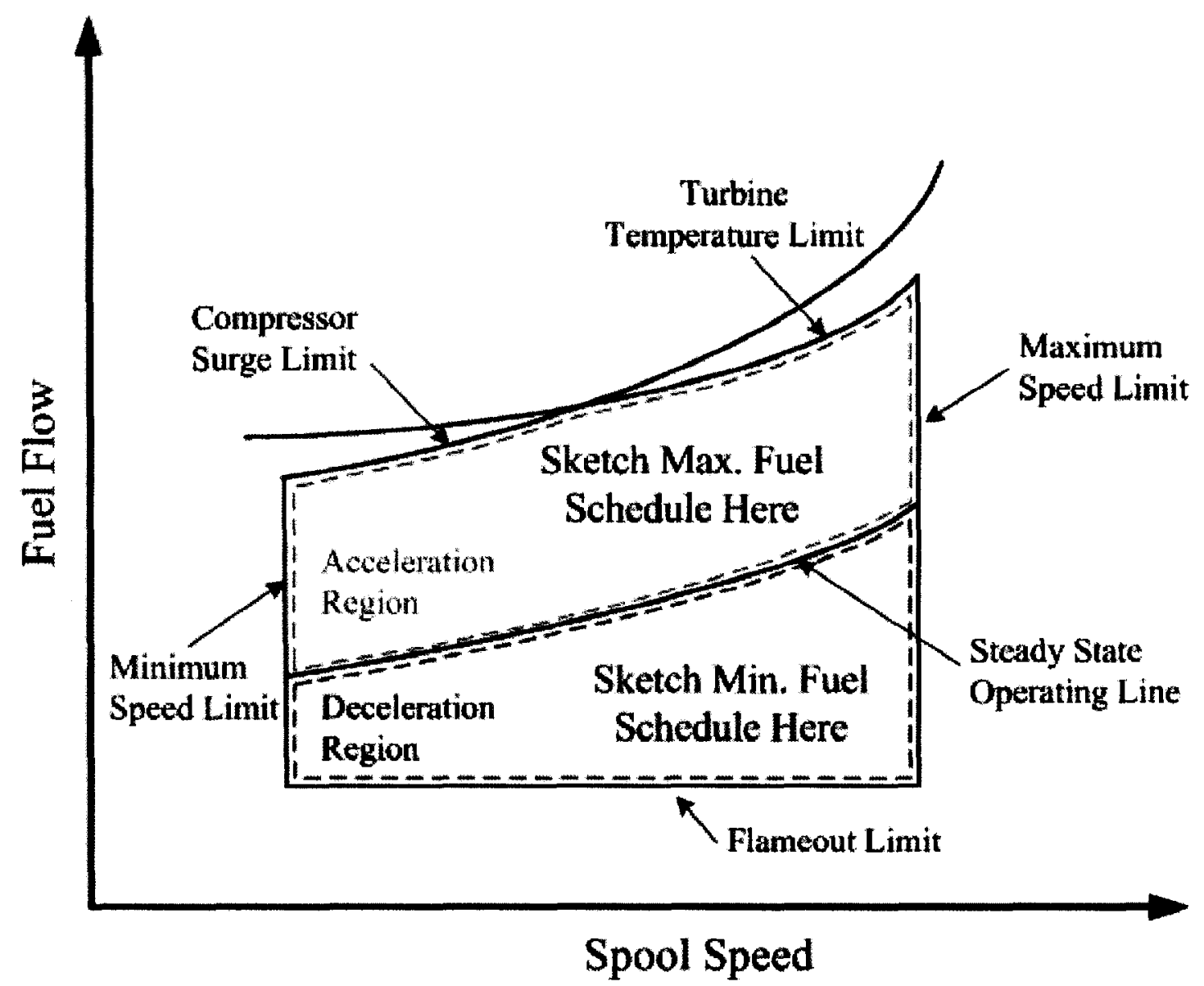

Figure 4.11: Typical fuel boundaries

Based on the prime control requirements, the designer can then sketch possible fuel schedules within the limited operating regions and assess their transient and steadystate effects on engine performance using the dynamic model. Again to emphasize, it is very important to have a good grasp on the prime and protective control requirements as the fuel schedules will be tailored specifically to meet these requirements. Finally, when the fuel schedules are properly defined, they are imported into the control system as lookup tables. According to Walsh and Fletcher (1998), fuel schedules are typically stored as referred fuel flow as a function of referred spool speed to minimize the effects of operating different ambient conditions (altitude, ambient pressure, ambient temperature and velocity). 


$$
\frac{\dot{\mathrm{m}}_{\mathrm{f}} \sqrt{\mathrm{T}_{\mathrm{o} 2}}}{\mathrm{P}_{\mathrm{o} 2}}=\mathrm{fn}\left(\frac{\mathrm{N}_{\mathrm{gg}}}{\sqrt{\mathrm{T}_{\mathrm{o}}}}\right)
$$

However, in practice the combustor inlet temperature $\left(\mathrm{T}_{02}\right)$ is often omitted as it only has a secondary effect on the performance of the control system. Therefore, the fuel schedules are to be stored in look-up tables as per Eqn 4.14.

$$
\frac{\dot{\mathrm{m}}_{\mathrm{f}}}{\mathrm{P}_{\mathrm{o} 2}}=\mathrm{fn}\left(\frac{\mathrm{N}_{\mathrm{gg}}}{\sqrt{\mathrm{T}_{\mathrm{o} 1}}}\right)
$$

As stated earlier, fuel schedules are protective control. Therefore, to ensure that protective controls win over prime control requirements, a low-select function between the maximum fuel flow schedule and the controller output is required. For the same reasons, a high-select function is required between the minimum fuel flow schedule and the controller output. The resulting control system is shown in Figure 4.12. 


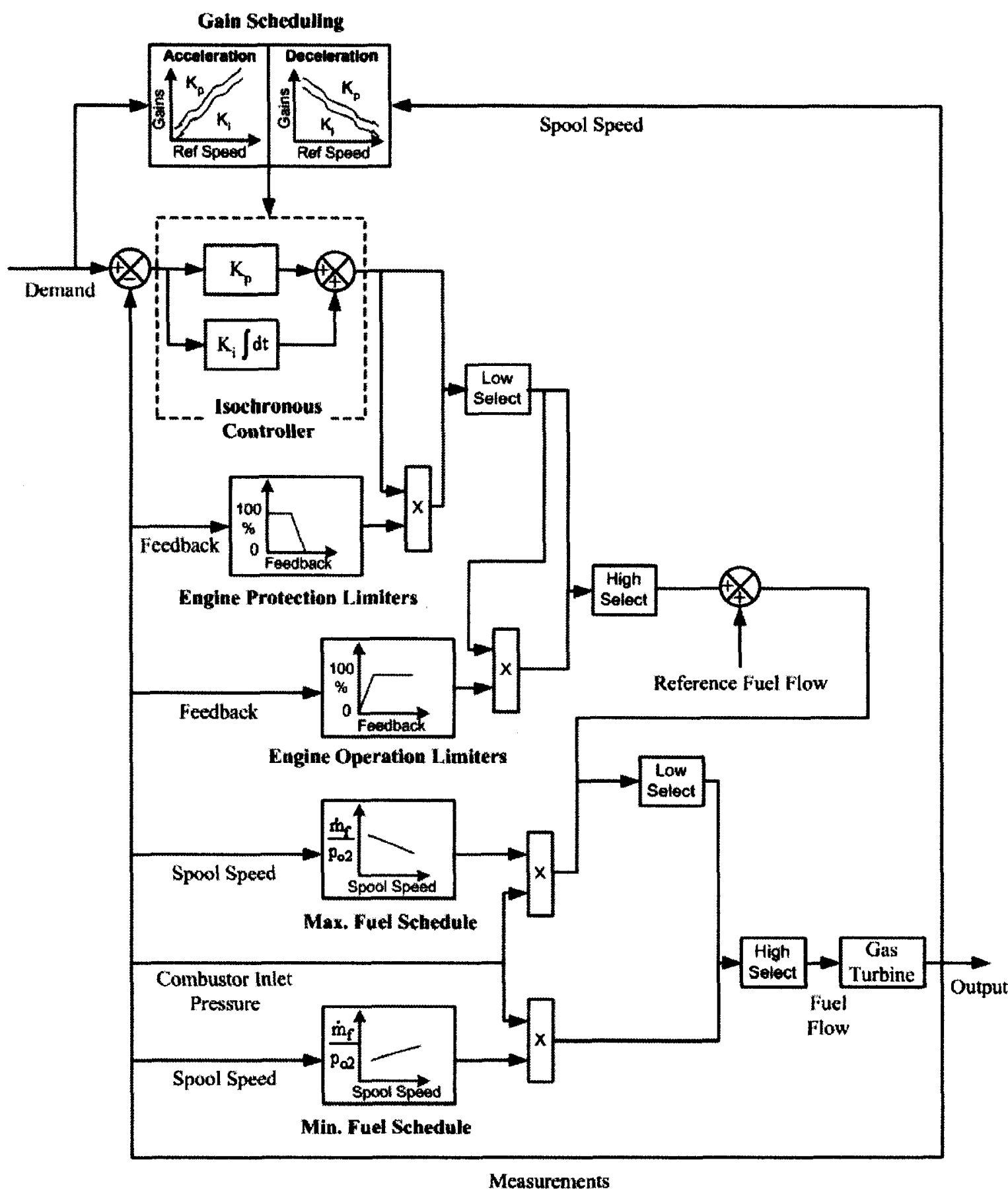

Figure 4.12: Isochronous control with gain scheduling, engine protection limiters, engine operation limiters and fuel schedules 


\subsection{Startup Sequencing}

The startup sequencing section of the control system design procedure deals with transient operation and engine protection functions from zero speed to idle speed. Similarly to engine control, startup sequencing controls have to be capable of

- Maintaining smooth, repeatable performance during transient operation from zero speed to idle speed

- Maintaining stable airflow, internal pressures and temperatures, and rotor speeds within safe operating limits

- Avoiding stalls and surges, and significant speed, pressure or temperature variations

However, engine startup is not as straightforward as expected. The challenge lies in controlling turbomachinery in a steep and relatively unstable part of the performance characteristics. For this reason, in practice, prime control requirement are met using open-loop controls and protective control requirements are met using close-loop. In most case, the control strategy required to startup the engine is determined through experimental rig testing. The following sub-sections will highlight how the prime and protective control requirements are met through startup sequencing.

\subsubsection{Startup Fuel Scheduling (Prime Control)}

Similarly to the engine control section, the prime control requirements are always stated in the control system requirements. Even though the actual requirements (variable geometry modifications or bleed valve modulations) may vary from application to application, the prime control requirement of startup sequencing will always be to accelerate the engine from zero speed to idle speed within a specified time delay. This requirement is usually met open-loop by programming a startup fuel schedule into the control system. In reality, the term open-loop does not necessarily apply as described in the literature review. Here open-loop is used to indicate that engine control will be done without the use of a controller. In fact, as shown in Figure 4.13, the fuel flow will simply be fed to the engine based on a spool speed feedback signal. 


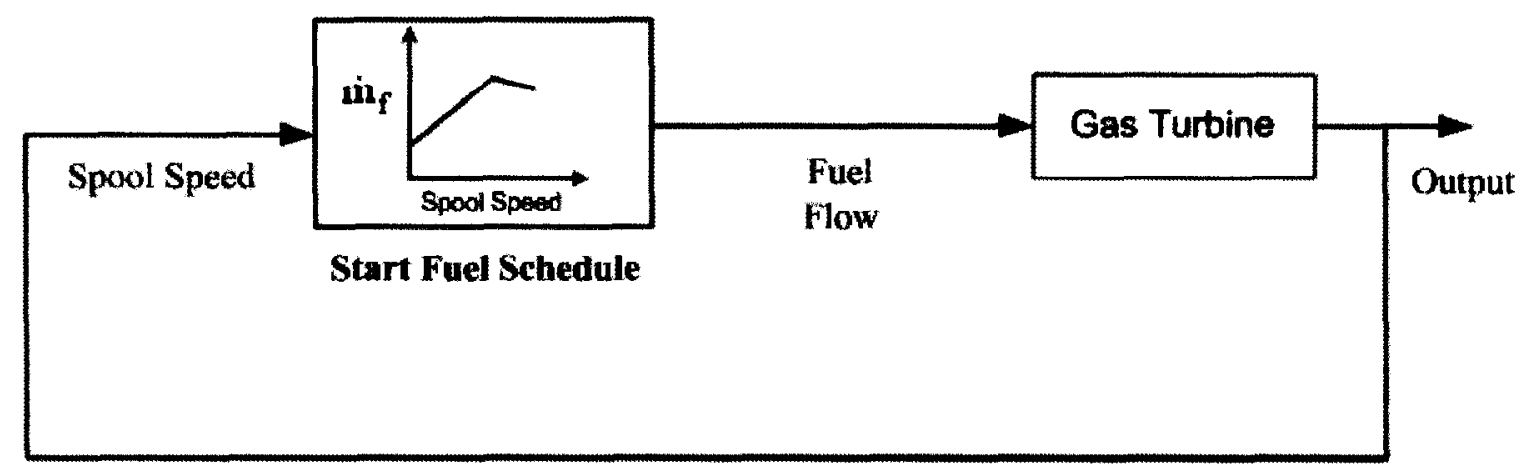

Figure 4.13: Startup sequencing prime control

According to Walsh and Fletcher (1998), fuel scheduling for startup acceleration must be low enough to avoid rotating stall and over-temperature, but high enough to avoid hang while achieving the desired start time. 'Hang' is the condition where the engine in not capable of accelerating to idle speed during startup. However, generating such a fuel schedule without relying on rig testing, early in the gas turbine design process, may prove to be a challenge. As discussed earlier, the challenge lies in producing a fuel schedule in a steep and relatively unstable part of the performance characteristics. By accepting a reduction in accuracy, it is possible to generate a fuel schedule using the dynamic model of the gas turbine and a modified version of Walsh and Fletcher's start extrapolation model. First, using the dynamic model, it is possible to generate the fuel flow boundaries well into the sub-idle region for the surge line, maximum turbine inlet temperature and steady-state operating conditions. Plotting the three fuel boundaries on a single plot allows the designer to visualize the acceleration region. As shown in Figure 4.14, it is then possible to sketch a line from the last converged operating point to idle. This will comprise the first leg of the start fuel schedule. 


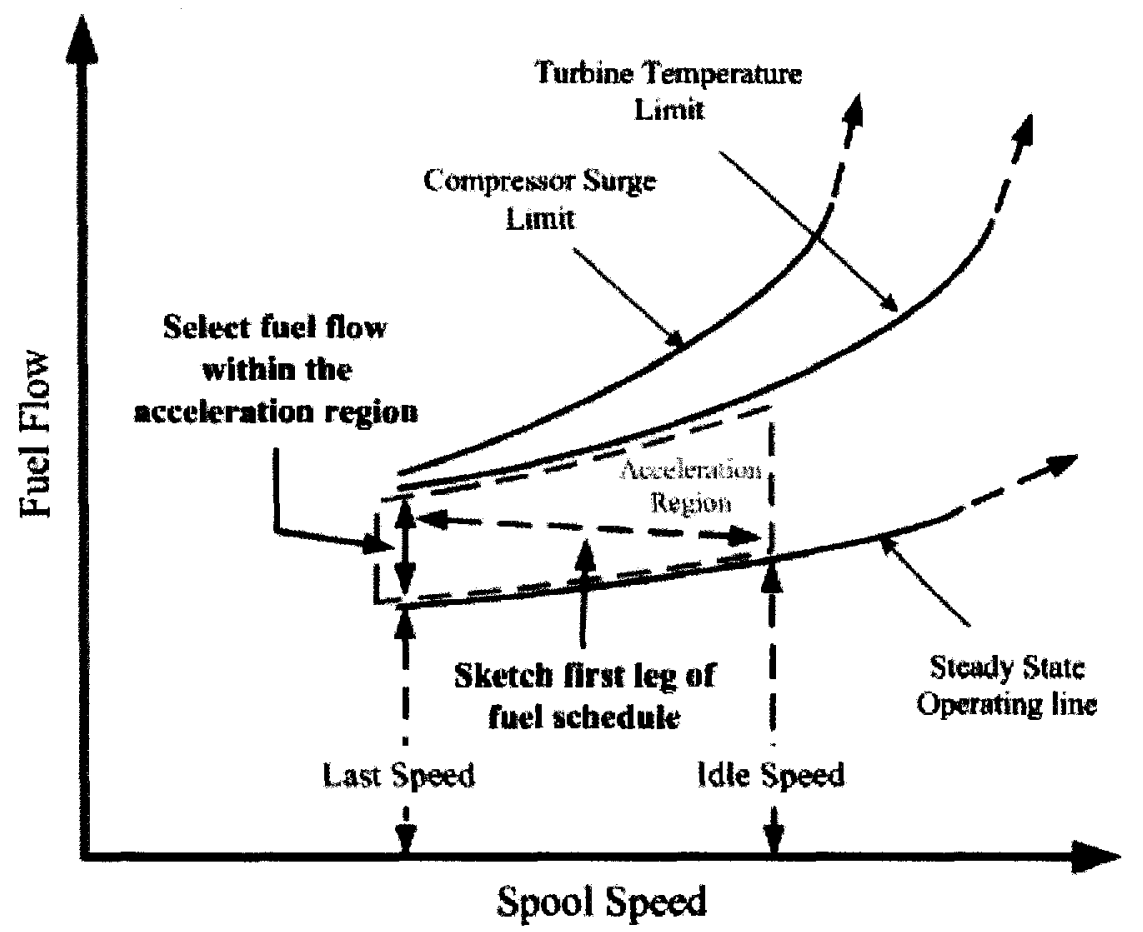

Figure 4.14: Sketching the first leg of the start fuel schedule

The second leg may be produced by modifying Walsh and Fletcher's (1998) start extrapolation model. According to the method, power may be extrapolated as per Eqn 4.15.

$$
\dot{W}_{\mathrm{x}}=\dot{\mathrm{W}}_{\text {last }}\left(\frac{\mathrm{N}_{\mathrm{gg}, \mathrm{x}}}{\mathrm{N}_{\mathrm{gg} \text { last }}}\right)^{3}
$$

Assuming power varies linearly with fuel flow then Eqn 4.15 may be modified such to extrapolate fuel flows down to ignition.

$$
\dot{\mathrm{m}}_{\mathrm{f}, \mathrm{x}}=\dot{\mathrm{m}}_{\mathrm{f}, \text { last }}\left(\frac{\mathrm{N}_{\mathrm{gg}, \mathrm{x}}}{\mathrm{N}_{\mathrm{gg}, \text { last }}}\right)^{3}
$$

Therefore, as shown in Figure 4.15, the second leg may be generated using Eqn 4.16 based on the fuel flow located at the end of the first leg. The two legs can then be assembled and stored in a look-up table as fuel flow versus spool speed. 


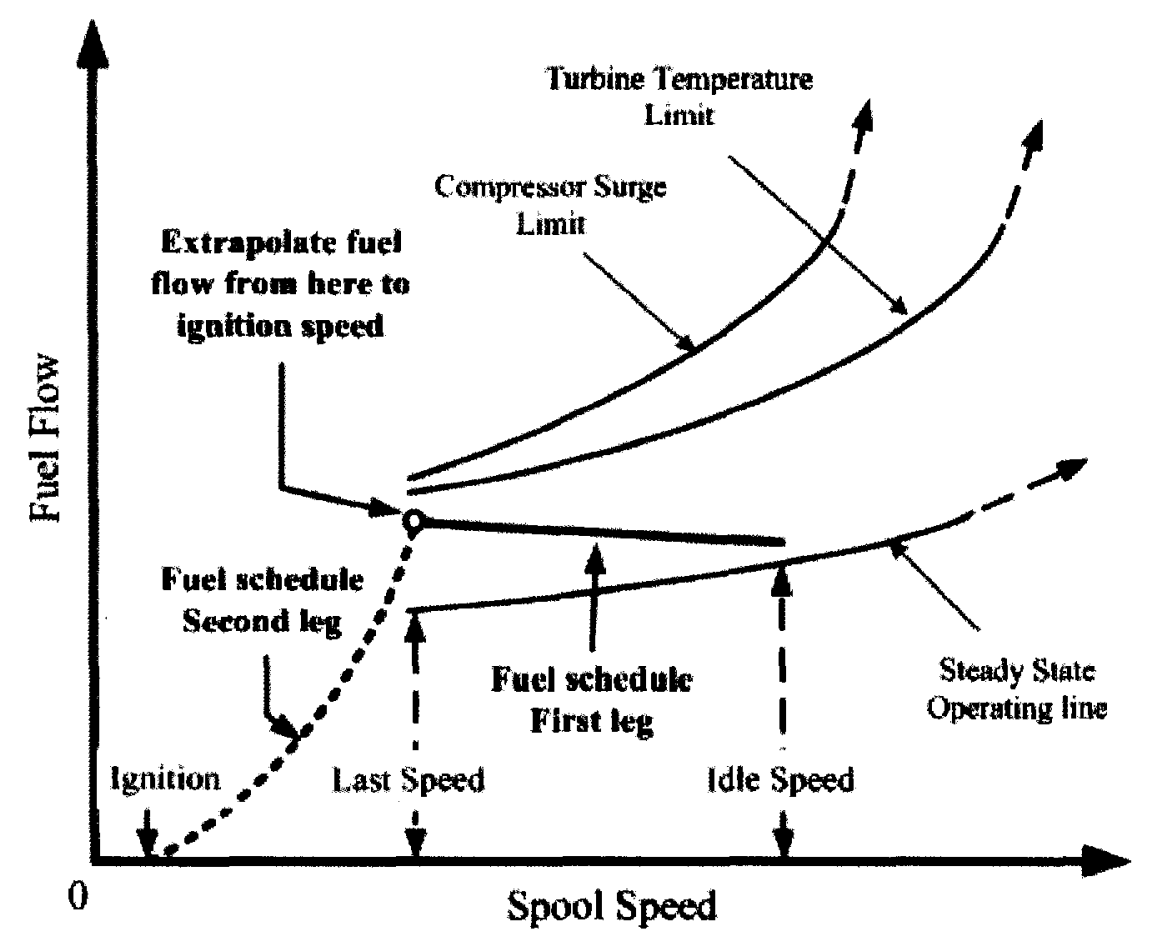

Figure 4.15: Generating the second leg of the start fuel schedule

However the resulting start fuel flow schedule shall only be regarded as a conceptual design and improved as rig testing becomes available.

\subsubsection{Performance Limiters (Protective Control)}

Here again, as stated in the literature review, protective control requirements are necessary to delimit the safe transient operating region. These requirements are stated in the control system requirements and are very similar to engine control protective control requirements with the addition of a minimum spool speed acceleration limiter. In combination with the turbine inlet temperature measurement, the minimum spool speed acceleration limiter is used to prevent engine hang. However since prime control requirements are met with controlling schedules (no controller); protective controls cannot be based on modulation. This is because modulation control may lead the engine into engine hang when modulating the scheduled fuel flow. For this reason, protective control requirements will be met using shutdown controls. The engine will be shutdown 
automatically if any of the performance limiters are exceeded. The resulting control system is shown in Figure 4.16.

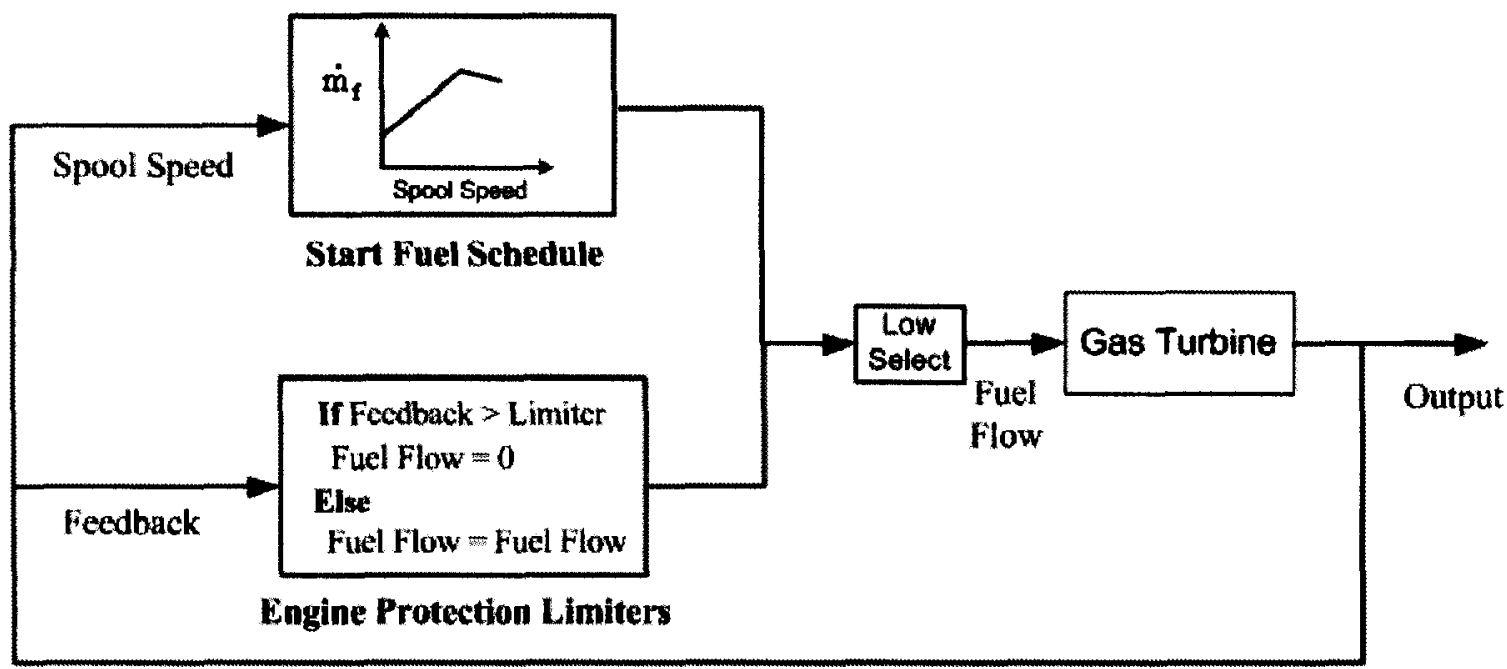

Figure 4.16: Startup sequencing prime and protective controls

This chapter detailed a roadmap to gas turbine control system design. The proposed method discussed both engine control and startup sequencing, while focusing on prime and protective control requirements. Based on these requirements, techniques were proposed to develop gain and fuel schedules. The following chapter will cover the application of the control system design method to a test case such to demonstrate the potential of the proposed method. 


\section{Chapter 5 Dynamic Modeling and Control System Design}

The purpose of this chapter is to describe the dynamic modeling and control system design process for a 1-MW gas turbine application. The main goal is to demonstrate that the comprehensive design methodologies explained earlier can be applied early in the gas turbine design process while simply relying on a minimum amount of information.

As defined by the methodologies, the dynamic model was first created based on design point information, followed by control system design. This chapter will cover component map scaling, component map extrapolation, gain scheduling and fuel scheduling, leading to an overall control system design solution.

\subsection{Gas Turbine Dynamic Modeling}

This section covers the steps followed to generate the dynamic model of a 1-MW gas turbine application. Starting by identifying the design point requirements, a list of inputs to the dynamic model was generated. Then, component maps were scaled based on published data and a load characteristic was approximated based on design point information. Finally, the inputs, characteristics and component modeling equations were assembled within an "in-house" MATLAB code and linked to a Newton-Raphson solver to produce steady-state and transient operating lines.

\subsubsection{Gas Turbine Design Point Requirements}

The overall project objective consisted of developing a low-cost turboshaft engine for a powerboat application. Based on the client requirement of producing 1-MW of power at Standard Day Conditions, the following engine design point parameters were set 
by project management in an effort to optimize engine size, specific consumption and cost.

\section{$\underline{\text { Intake }}$}

- The pressure loss across the intake shall be no more than $1 \%$ of the incoming ambient pressure

- The mass flow rate shall be $5.5 \mathrm{~kg} / \mathrm{s}$

\section{Compressor}

- The pressure ratio across the compressor shall be 7

- The compressor isentropic efficiency shall be no less than $80.5 \%$

- The maximum compressor extraction bleed flow shall be no more that $1.5 \%$ of the total compressor mass flow rate

\section{Combustor}

- Combustion efficiency shall be no less than $99 \%$

- The combustor pressure loss shall be no more than $5 \%$ of the combustor inlet pressure

- The fuel shall have a lower heating value no less than $43100 \mathrm{~kJ} / \mathrm{kg}$

\section{Gas Generator Turbine}

- The turbine inlet temperature shall be $1200 \mathrm{~K}$ (hence, uncooled)

- The turbine isentropic efficiency shall be no less than $89 \%$

\section{Power Turbine}

- The power turbine isentropic efficiency shall be no less than $89 \%$

Shaft

- The mechanical efficiency of each shaft shall be no less than $99 \%$ 


\section{Exhaust}

- The pressure loss across the intake shall be no more than $2 \%$ of the exhaust inlet pressure

Load

- The power turbine shall be directly coupled to a fixed pitch propeller. No gearbox will be required (gearbox efficiency $=100 \%$ )

\subsubsection{Geometrical Characteristics}

As stated in the literature review, engine response depends in part on geometrical characteristics such as polar moment of inertia and volumes. These geometrical characteristics are set during the component design process and are directly linked to the design point parameters stated above. The following estimates have been provided by the engine component designers:

\section{$\underline{\text { Rotational Speed }}$}

- Design point gas generator spool speed $=28000 \mathrm{RPM}$

- Gas generator idle spool speed $=17500$ RPM

- Design point power turbine spool speed $=25000 \mathrm{RPM}$

\section{Component Volume}

- Combustor volume $=0.0289 \mathrm{~m}^{3}$

\section{Polar Moment of Inertia}

- Gas generator spool $=0.08 \mathrm{kgm}^{2}$

- Power turbine spool $=0.05 \mathrm{kgm}^{2}$

\subsubsection{Dynamic Model Inputs}

Since there is limited data available early in the gas turbine design process, the design point requirements are taken directly as inputs to the dynamic model. But, as the 
design progresses; these assumptions will be replaced by actual design values. Therefore, based on the design point requirements and geometrical characteristics stated earlier, the dynamic model inputs are summarized in Table 5.1.

Table 5.1: Dynamic model inputs

\begin{tabular}{|c|c|c|c|}
\hline \multirow{2}{*}{ Inlet } & $\Delta P R_{\text {inlet }}$ & $1 \%$ & Inlet total pressure loss \\
\hline & $\hat{\mathbf{m}}_{\mathrm{a}}$ & $5.5 \mathrm{~kg} / \mathrm{s}$ & Inlet air mass flow \\
\hline \multirow{3}{*}{ Compressor } & $B_{c}$ & $1.5 \%$ & Compressor bleed fraction \\
\hline & $\mathbf{P R}_{\mathrm{c}}$ & 7 & Compressor pressure ratio \\
\hline & $\eta_{\mathrm{e}_{\text {i iwen }}}$ & $80.5 \%$ & Compressor isentropic efficiency \\
\hline \multirow{4}{*}{ Combustor } & $n_{b}$ & $99 \%$ & Combustion efficiency \\
\hline & $\Delta \mathrm{PR}_{\mathrm{b}}$ & $5 \%$ & Combustor total pressure loss \\
\hline & HV & $43100 \mathrm{~kJ} / \mathrm{kg}$ & Fuel heating value \\
\hline & $v_{b}$ & $0.0289 \mathrm{~m}^{3}$ & Combustor Volume \\
\hline \multirow{4}{*}{ Turbine } & TIT & $1200 \mathrm{~K}$ & Gas generator turbine inlet temperature \\
\hline & $\eta_{t_{\text {ineell }}}$ & $89 \%$ & Gas generator turbine isentropic efficiency \\
\hline & $\mathrm{N}_{\mathrm{kg}}$ & $28000 \mathrm{RPM}$ & Gas generator spool speed \\
\hline & $I_{\mathrm{g}}$ & $0.08 \mathrm{kgm}^{2}$ & Gas generator polar moment of inertia \\
\hline \multirow{3}{*}{ Power Turbine } & $\boldsymbol{\eta}_{p_{\text {isen }}}$ & $89 \%$ & Power turbine isentropic efficiency \\
\hline & $\mathrm{N}_{\mathrm{pr}}$ & $25000 \mathrm{RPM}$ & Power turbine spool speed \\
\hline & $I_{p t}$ & $0.05 \mathrm{kgm}^{2}$ & Power turbine polar moment of inertia \\
\hline Exhaust & $\Delta P R_{\text {exhaust }}$ & $2 \%$ & Exhaust total pressure loss \\
\hline Shaft & $\eta_{\text {medx }}$ & $99 \%$ & Mechanical efficiency \\
\hline Load & $\eta_{\text {gean }}$ & $100 \%$ & Gearbox efficiency \\
\hline
\end{tabular}

For graphical representation, these inputs were sketched on Figure 5.1. 


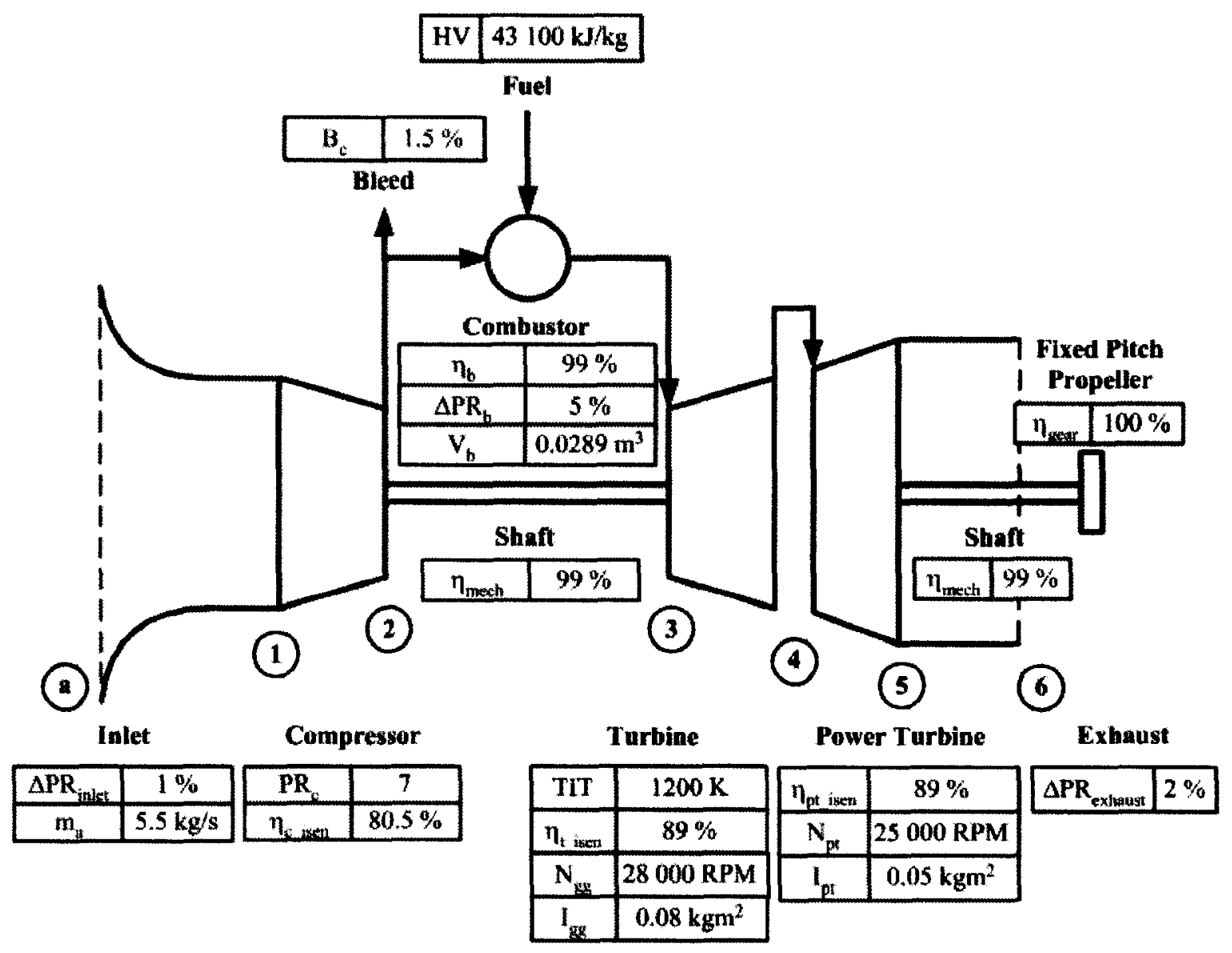

Figure 5.1: Sketch of the turboshaft engine

\subsubsection{Design Point Performance Data}

Design point performance calculations were performed by project management during the project definition process. Even though these calculations were out of the scope of this thesis, the resulting design point performance data was required for the dynamic modeling procedure. This data was also required for validation purposes. Figure 5.2 summarizes the key design point performance parameters used during these two exercises. 


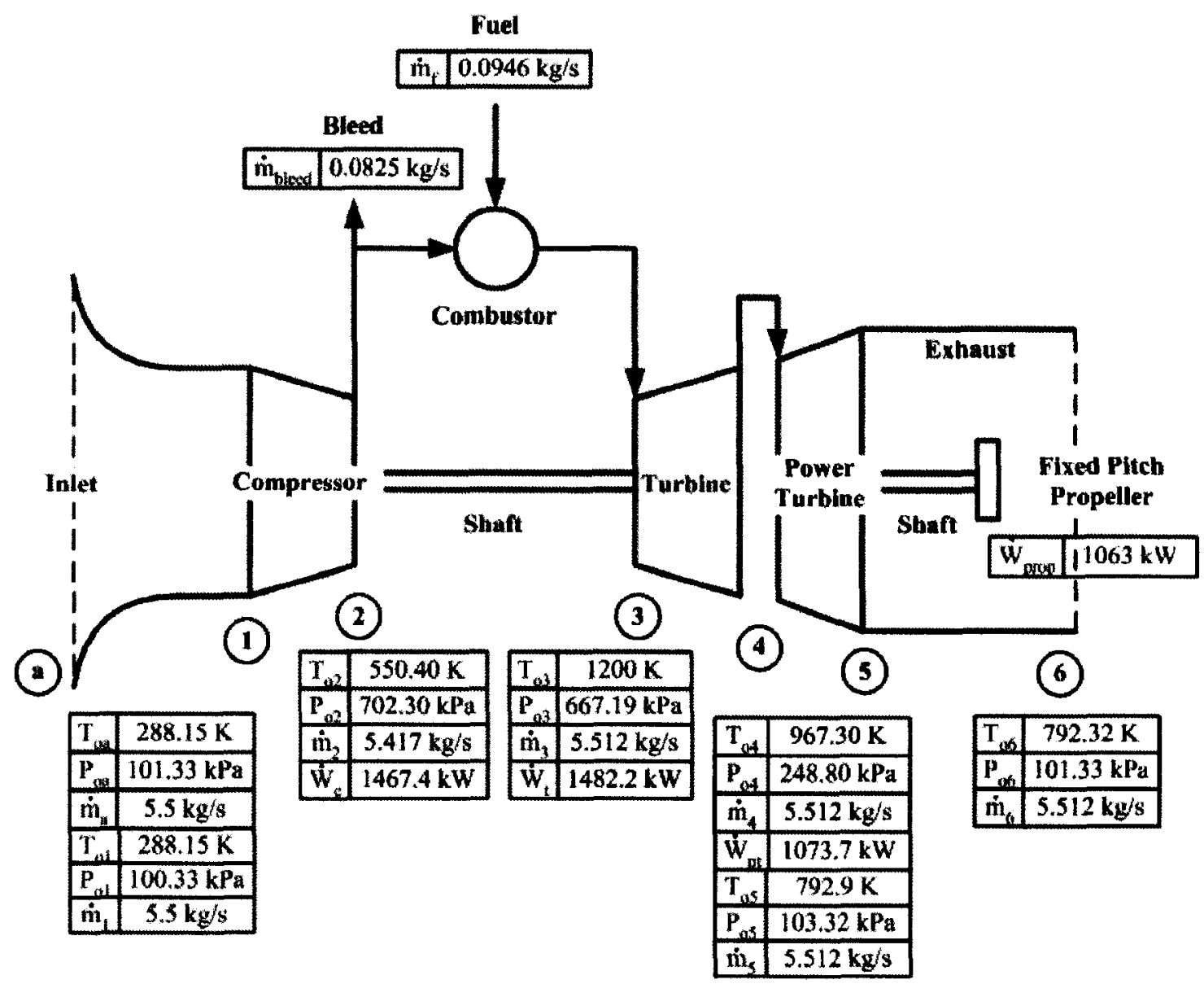

Figure 5.2: Design point performance data

\subsubsection{Component Map Scaling}

Since the project is at an early stage of the design process, there were no component maps supplied by either the compressor, gas generator turbine or power turbine designers. Therefore, as suggested earlier as part of the dynamic modeling procedure, published component maps were used to generate approximate component characteristics. These published component maps were found in the commercial software GasTurb. The digitization process which would be needed for a printed map was skipped since the published component maps in GasTurb were already stored as look-up tables. The GasTurb component characteristics look-up tables can be found in Appendix B. 
Based on the design point information available in Table 5.1 and Figure 5.2, the maps were scaled as per Eqns 3.15 to 3.17 for the compressor and Eqns 3.39 to 3.41 for the gas generator turbine and power turbine. The resulting scaled component maps are shown in Figure 5.3 to Figure 5.5. Note that a false zero was used in Figure 5.4 for clarity reasons.

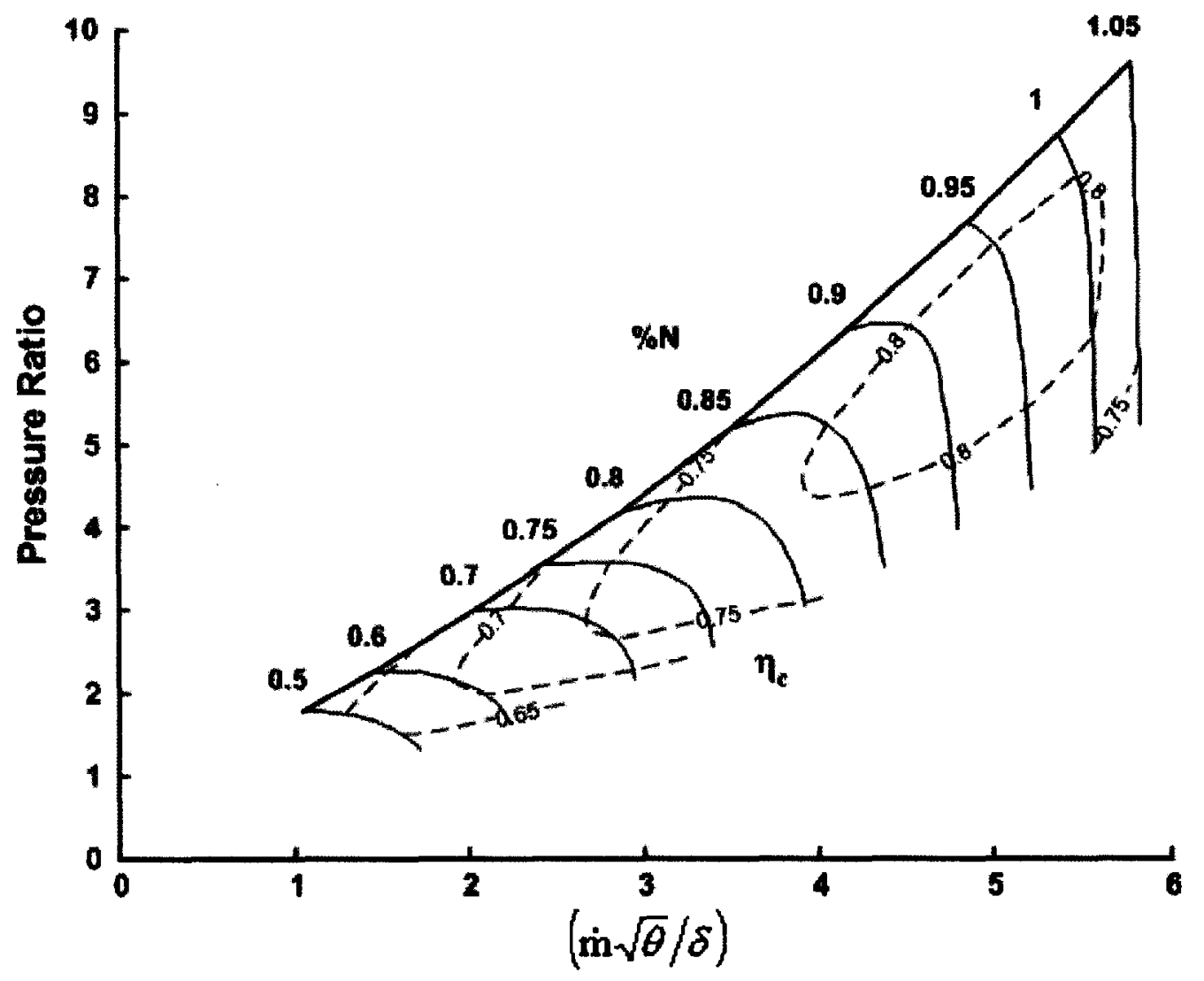

Figure 5.3: Scaled compressor map 


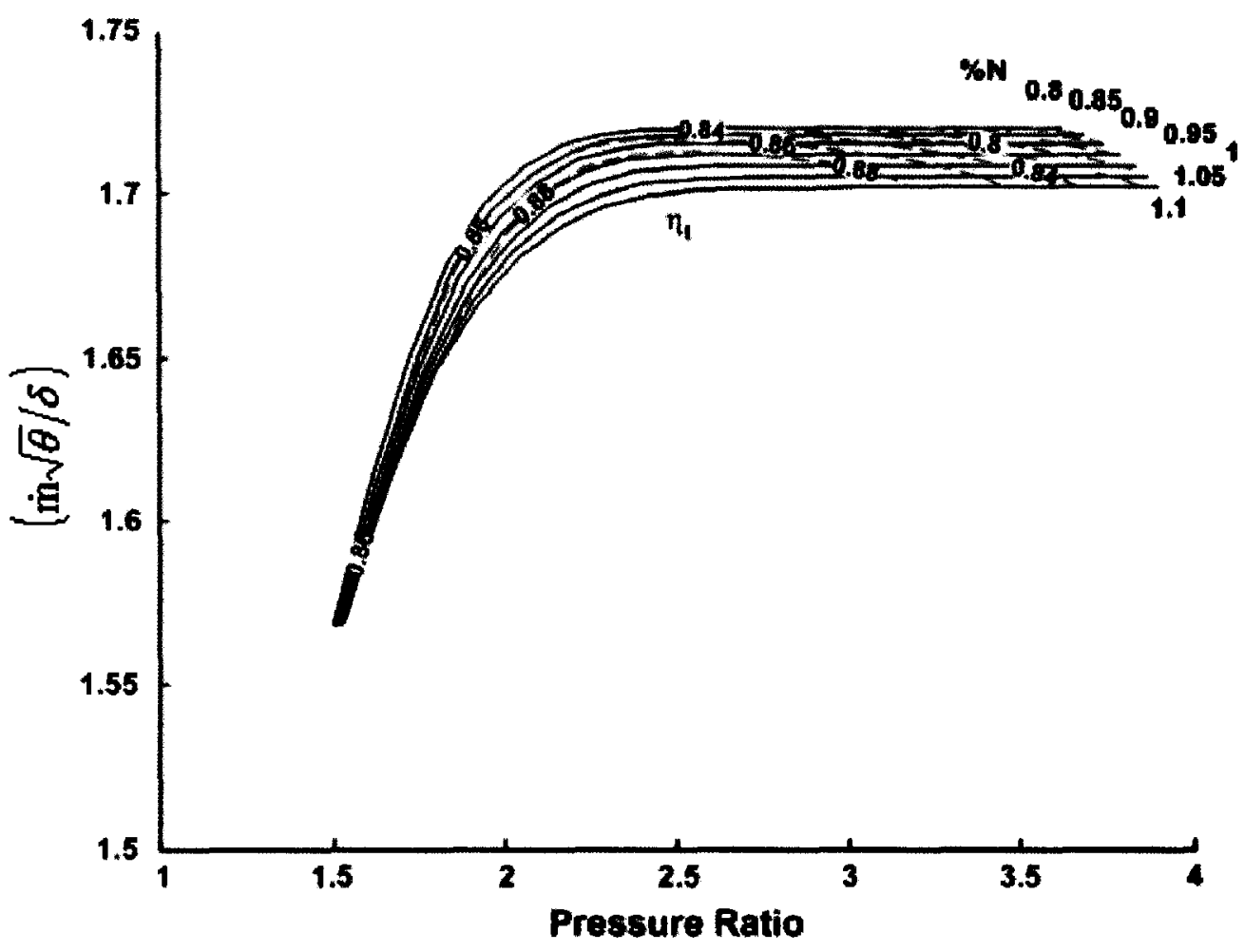

Figure 5.4: Scaled gas generator turbine map

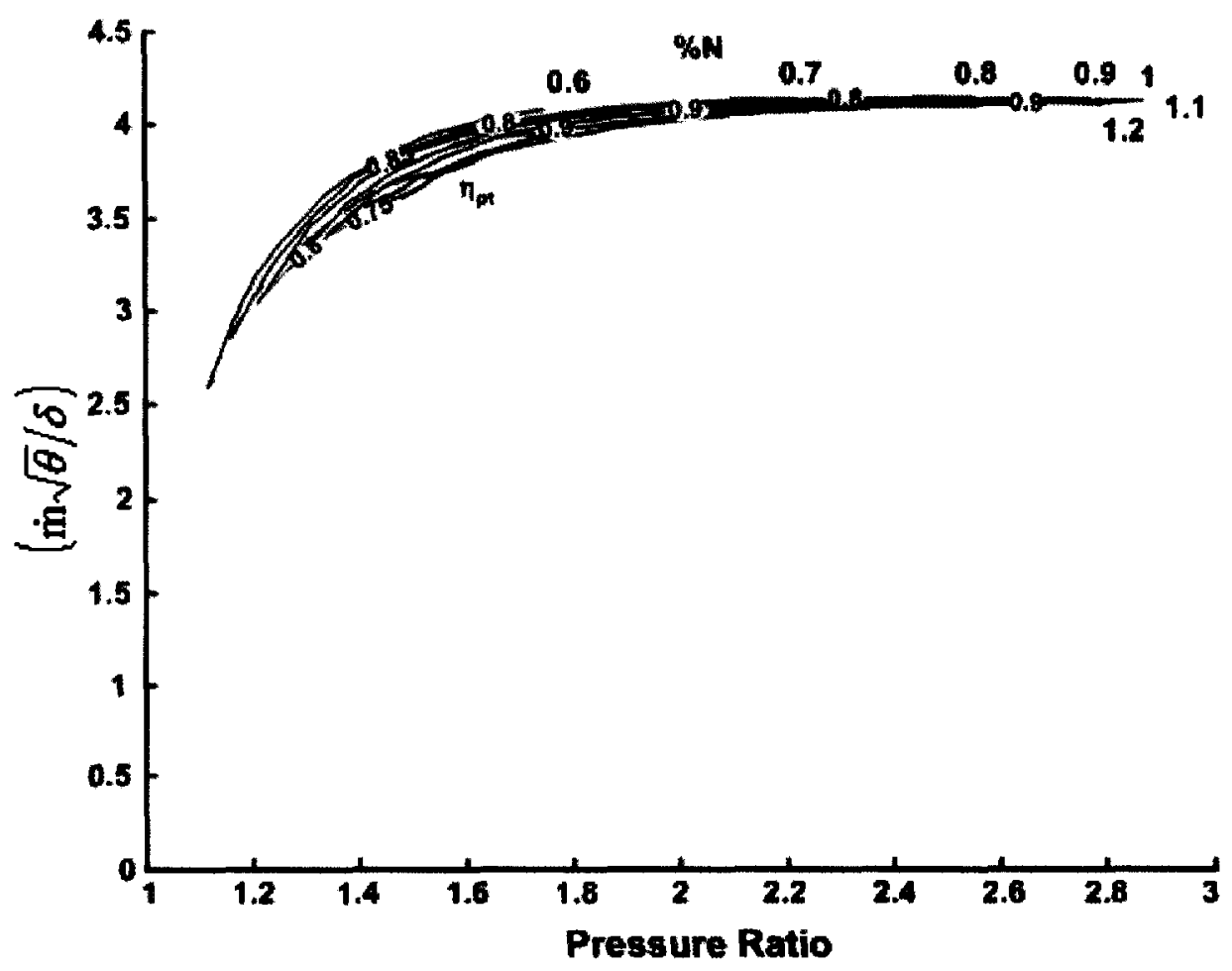

Figure 5.5: Scaled power turbine map 
To ease the process, the component maps scaling equations were coded in an in-house program, which produced look-up tables for each component characteristic. The code can be seen in Appendix D.

\subsubsection{Load Characteristic}

As stated in the literature review, load characteristics affect engine dynamic response. However, at this stage of the design, the fixed-pitch propeller load characteristic was not fully defined. As a result, the cube law approximation proposed in Section 3.2.7 had to be used to generate a load characteristic for the fixed-pitch propeller. Therefore, knowing the design point power turbine shaft power (1 MW) and the design point power turbine rotational speed (25000 RPM), the load characteristic shown in Figure 5.6 was generated using Eqn 3.56.

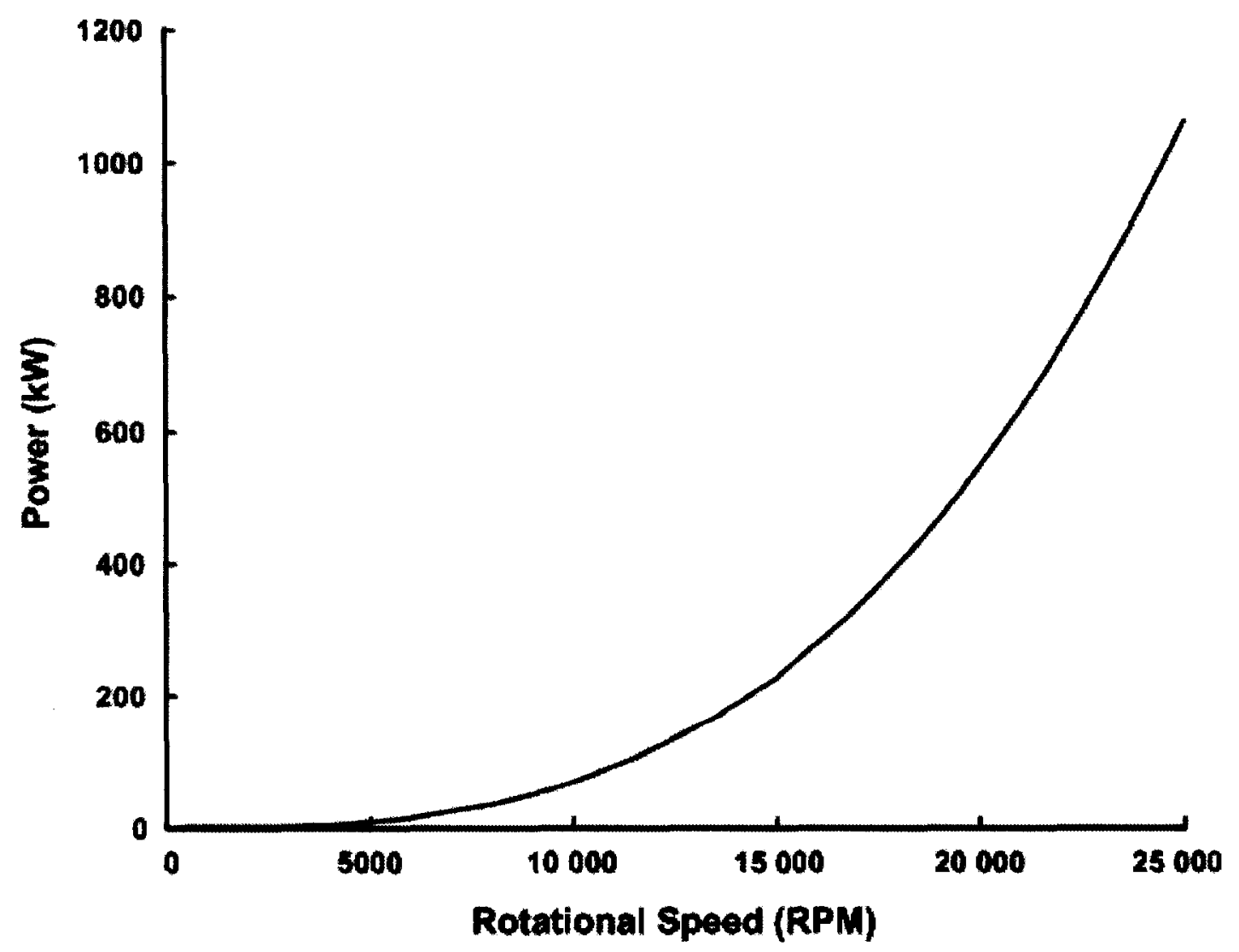

Figure 5.6: Load characteristic 
The load characteristic approximation is for a fixed-pitch propeller directly coupled to a power turbine. This implies that there are no gearbox losses.

\subsubsection{Dynamic Model Assembly}

Dynamic model assembly consisted of regrouping all the information available at this early stage of the design process and producing a functional dynamic model of the gas turbine. This was done by linking the inputs, the design point performance data, the component maps and the load characteristic to one another using the component modeling equations stated in Section 3.2. The assembly was coded in MATLAB and linked to a Newton-Raphson solver, which was also coded in the MATLAB language. The resulting in-house code can be seen in Appendix D. The in-house code, which will be referred to as the dynamic model for the remaining of this thesis, was then used extensively as part of the control system design process where steady-state and transient operating lines were generated under various operating conditions.

\subsection{Gas Turbine Sub-Idle Dynamic Modeling}

This section covers the steps followed to enhance the dynamic modeling capabilities of the code such to cover the sub-idle region of gas turbine operation. This was achieved by adding a startup modeling section to the dynamic model. Additional information in the form of sub-idle component maps and starter torque characteristics were required to complete the startup modeling section.

\subsubsection{Component Map Extrapolation}

Based on Figure 5.3, Figure 5.4 and Figure 5.5, it became apparent that startup modeling was going to be challenging do to the lack of information in the sub-idle region. For this reason, the component map extrapolation method proposed in Section 3.4.1 was used to produce sub-idle characteristics. The resulting extrapolated component maps are 
shown in Figure 5.7 to Figure 5.9. Note that a false zero scale was used in Figure 5.8 for clarity reasons.

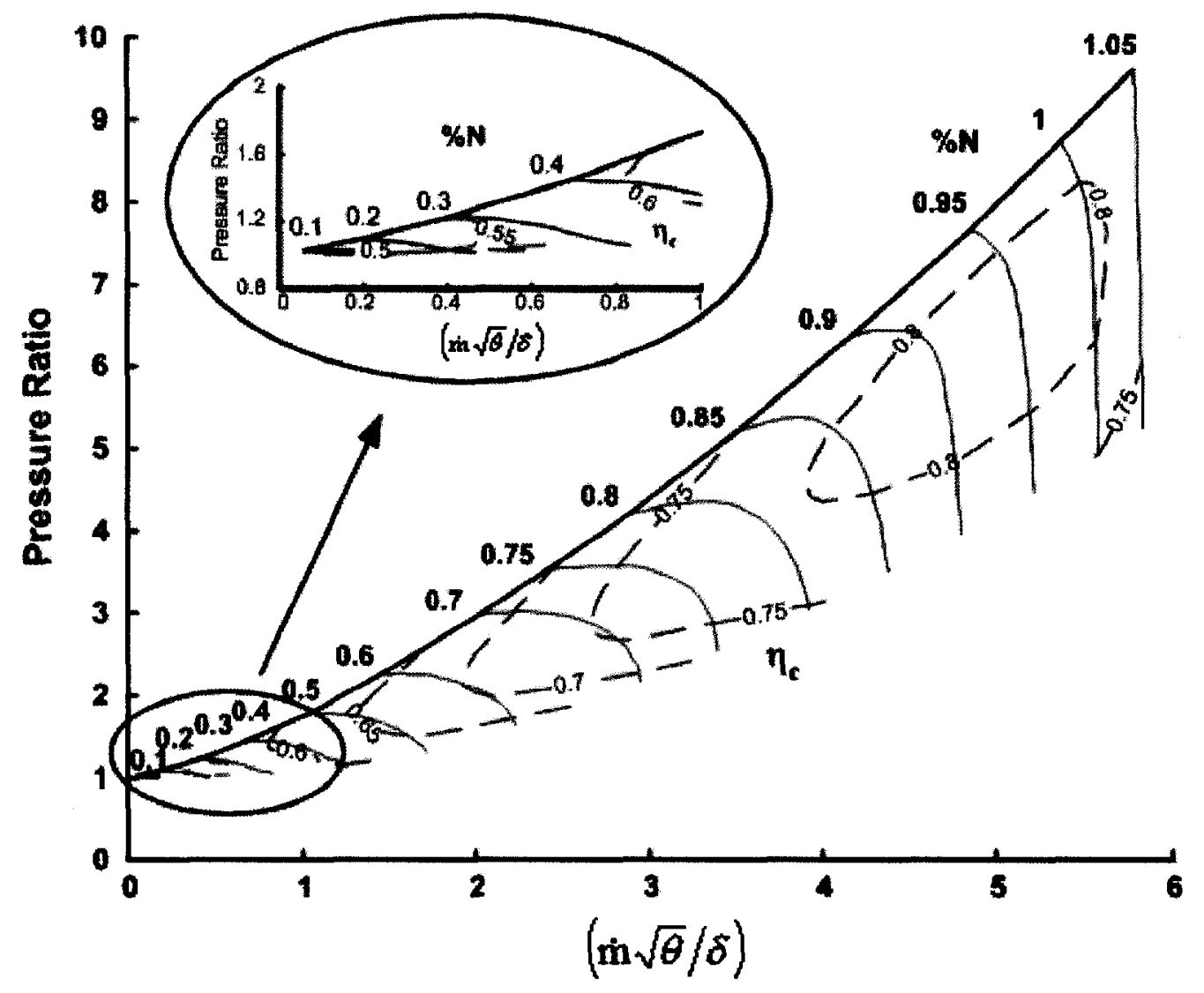

Figure 5.7: Extrapolated compressor map 


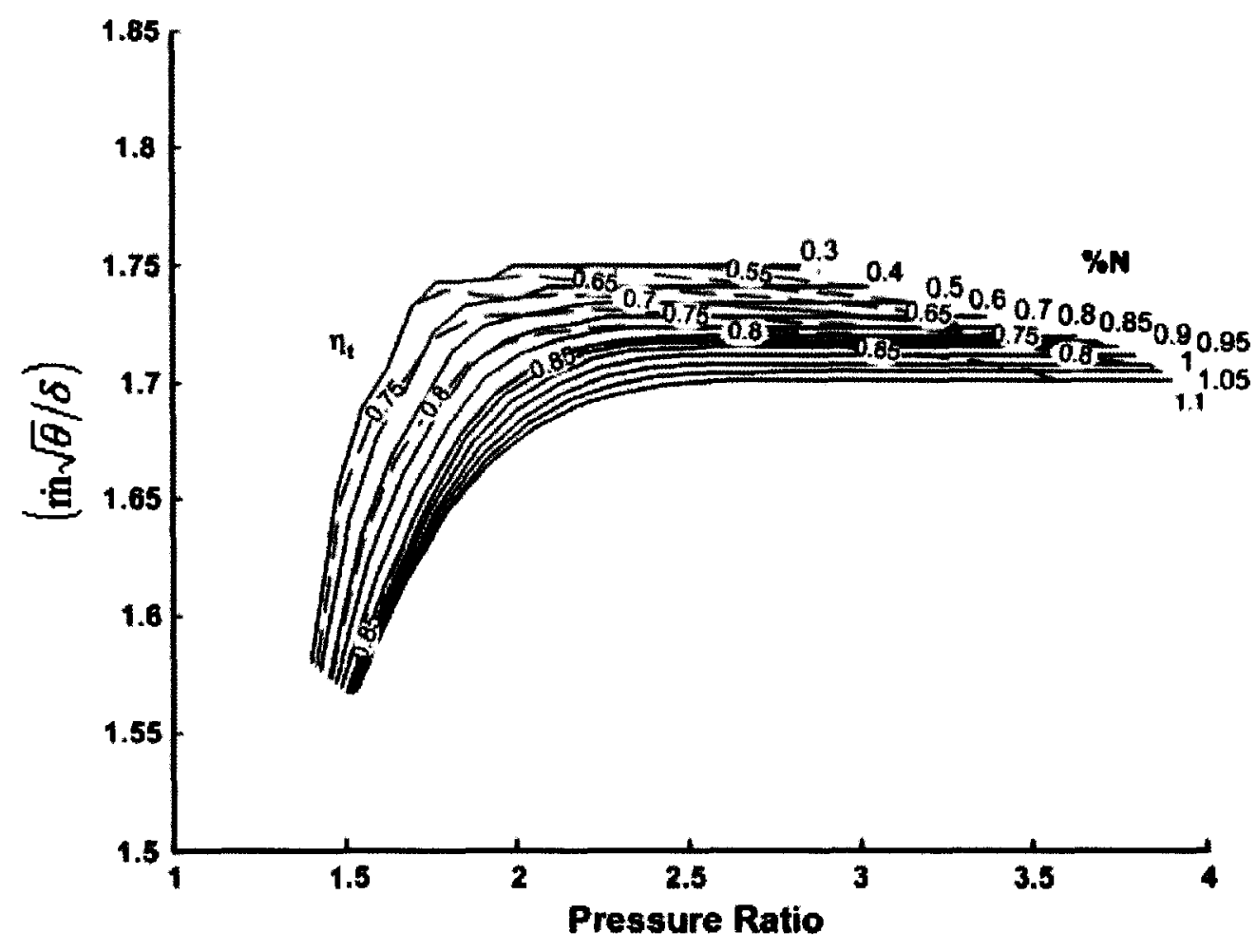

Figure 5.8: Extrapolated gas generator turbine map

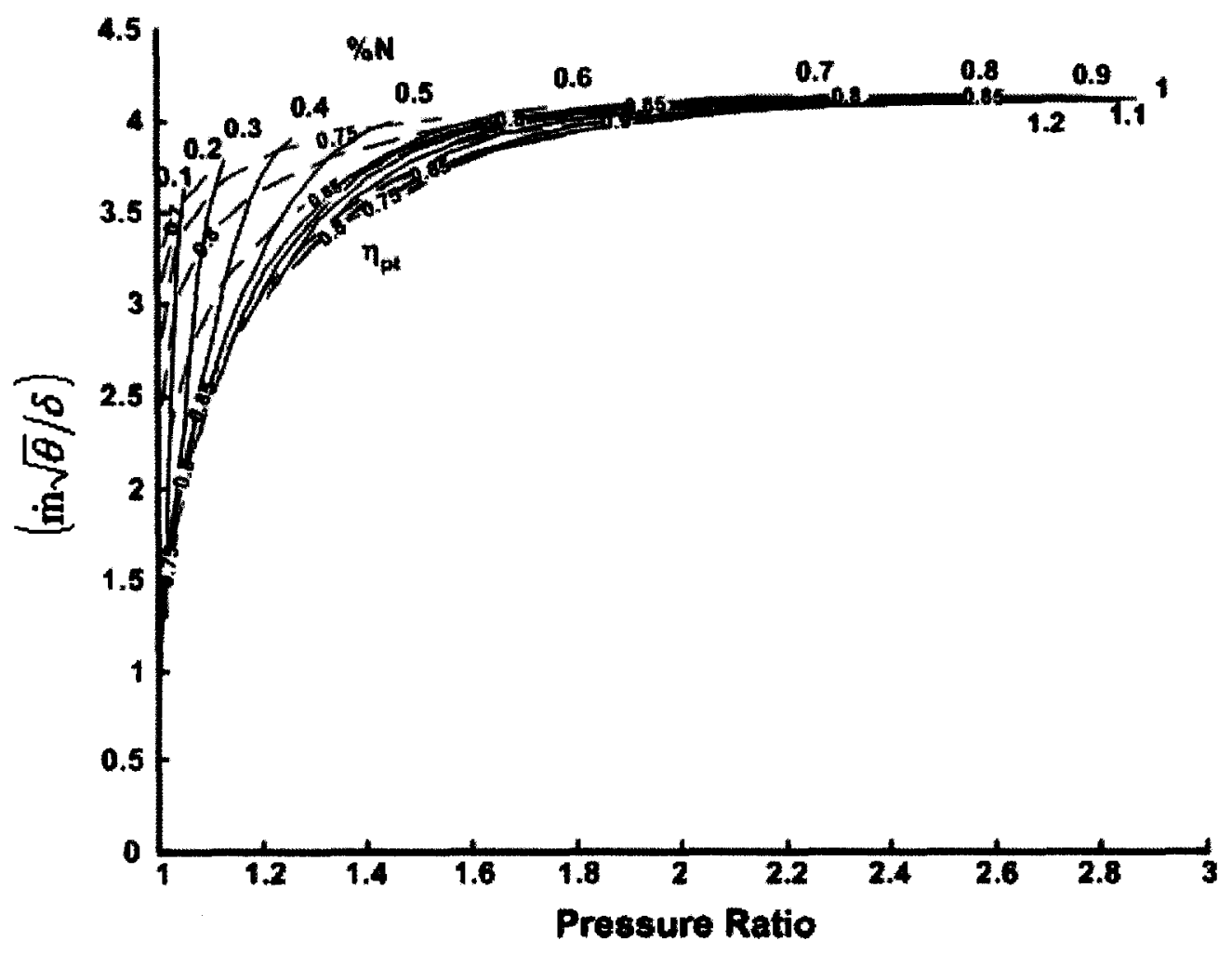

Figure 5.9: Extrapolated power turbine map 
At first glance, it seemed that the extrapolation process failed for the turbine map. However, upon closer examination, it was noticed that the extrapolation process did extrapolate speed lines from 0.8 down to $0.1 \% \mathrm{~N}$. But due to lack of information, the process did not extrapolate the speed lines below a referred mass flow of 1.5. To remedy this situation and allow for startup modeling it was found by analyzing Figure 5.9, that it was possible to generate approximate characteristics at lower pressure ratios by simply extending the given speed lines through simple extrapolation. To simplify the process, a MATLAB function called "interp2" was added to the table look-up function and hence allowed speed line extrapolation.

Similarly to the scaled component map procedure, the extrapolation equations stated in Section 3.4.1 were coded in an in-house program such to produce look-up tables for each component characteristic. The code can be seen in Appendix D.

\subsubsection{Starter Torque Characteristics}

To properly model engine performance during startup, a starter torque characteristic, the combustor light-up speed and the starter cut-off speed were required. Because the design process was at an early stage, these parameters were not available. To solve this issue, typical published values were used as initial estimates. These initial estimates will be replaced by accurate data once the starter sizing procedure is completed.

The starter torque characteristic used during startup modeling was found in a paper by Agrawal and Yunis (1982) and is shown in Figure 5.10. 


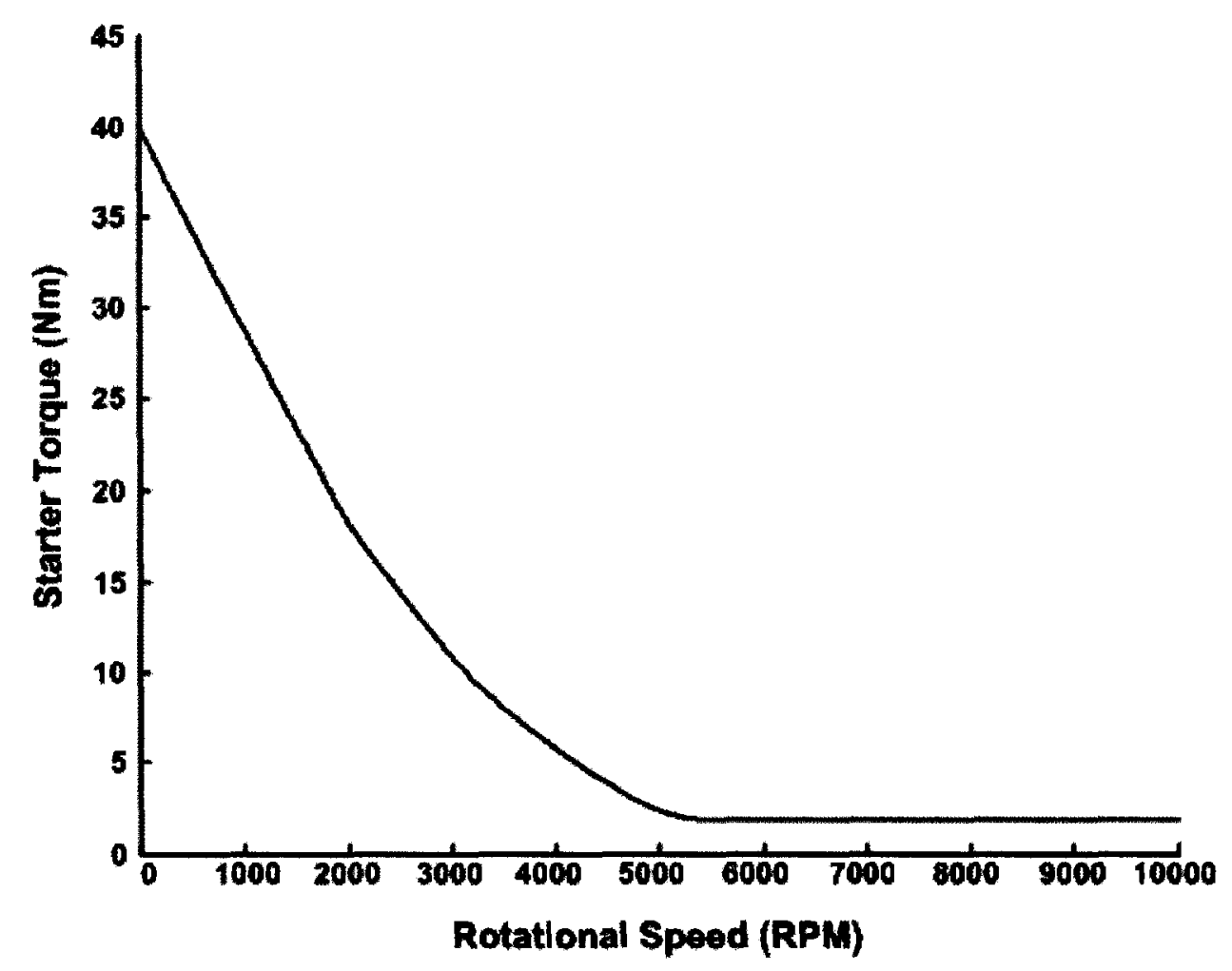

Figure 5.10: Starter torque characteristic (adapted from Agrawal and Yunis, 1982)

The light-up speed was estimated at $10 \%$ of the gas generator spool speed and the starter cut-off speed was set at $30 \%$ of the gas generator spool speed. These estimates were set based on the work of Walsh and Fletcher (1998).

It is important to mention that it is possible to use the sub-idle dynamic model as a tool to define an ideal starter torque characteristic based on starting time requirements. The starting system designers can then select a starter based on the ideal torque characteristic. However, since this type of work fell out of the scope of the thesis, this procedure was not implemented for this project and shall be regarded as a recommendation for future starting system design work.

\subsubsection{Startup Modeling}

Based on the extrapolated component maps and the starter torque characteristic, startup modeling was done following the method proposed in Section 3.4.2. The method 
was coded in an in-house program and added to the dynamic model. The resulting inhouse code can be seen in Appendix D. As explained in a subsequent section, the startup model was then used to define the startup fuel schedule as part of the control system design process.

\subsection{Control system design}

This section covers the conceptual design of an engine control system for a 1-MW marine turboshaft engine. The fundamental controlling functions of the control system were startup sequencing and engine control. As recommended in the literature and in the control system design method (Chapter 4), an isochronous controller was chosen for engine control. Startup sequencing was done using starting fuel schedules (no controller). Based on the control system requirements, gain schedules and fuel schedules were defined using the engine dynamic model. Finally, the schedules and performance limiters were all linked together to produce a control system design solution.

\subsubsection{Control System Requirements - Engine Control}

As stated previously, the objective consisted of designing a control system for a powerboat engine. The first task in the designing process was to identify all the control system requirements, which characterized the given application. These requirements were formulated by the client and/or imposed by the component designers.

First, it was identified that the control system was required to control the output power turbine spool speed through modulation of the fuel flow sent to the combustor. As a prime control requirement, stable off-design steady-state operation from idle speed to design speed with a minimum of power turbine spool speed droop (less than $1 \%$ ) was required. For transient manoeuvres, typical control system requirements for the given application were imposed:

Between Idle speed to $90 \% \mathrm{~N}_{\mathrm{gg}}$

- Maximum power turbine spool speed overshoot shall be less than 5\% 
- Power turbine spool speed rise time shall be less than 2 seconds

- Power turbine spool speed settling time shall be less than 3 seconds (using $2 \%$ criterion)

\section{Between $90 \% \mathrm{~N}_{\mathrm{gg}}$ to Design point speed, $\mathrm{N}_{\mathrm{gg}}$}

- Maximum power turbine spool speed overshoot shall be less than $15 \%$

- Rise time shall be less than 2 seconds

- Settling time shall be less than 3 seconds (using $2 \%$ criterion)

Secondly, the component designers imposed control system requirements in the form of performance limiters. As detailed earlier, these control system requirements were imposed as protective control requirements to protect the engine against malfunctions or physical damage. The following performance limiters were set by the component designers based on the material properties of each component:

\section{Temperature Limits}

- Maximum transient gas generator turbine inlet temperature shall not exceed $1250 \mathrm{~K}$. Note that these transient excursion above the steady state gas generator inlet temperature $(1200 \mathrm{~K})$ are required for short periods of time when accelerating the engine from idle to design point.

- Turbine inlet temperature limit shall not exceed the over-temperature limit of $1300 \mathrm{~K}$. Operating the engine above this temperature will permanently damage the gas generator turbine.

\section{$\underline{\text { Rotational Speed Limits }}$}

- Maximum gas generator spool speed shall not exceed $105 \%$ of the design point gas generator spool speed

- Maximum power turbine spool speed shall not exceed $110 \%$ of the design point power turbine spool speed 
- Minimum gas generator spool speed shall not be less than $95 \%$ of the gas generator idle spool speed

\section{Fuel-to air-Ratio}

- Minimum transient fuel-to-air ratio shall not be less than 0.0081 to prevent engine flameout during rapid deceleration (Walsh and Fletcher, 1998)

\subsubsection{Controller Selection}

An isochronous controller was chosen as the engine controller. The main purpose of selecting this type of controller was to reduce the error between the demand and the feedback signal to zero. It was stated in the control system requirements that the controller was needed to control the power turbine spool speed through fuel flow changes. However, the power turbine could not be controlled directly through fuel flow changes as its response depends mainly on the amount of energy available in the exhaust flow after the gas generator expansion. To translate the power turbine spool speed demand into a fuel flow requirement, system proportional gains were added to the controller. These gains were used to convert the power turbine spool speed demand into a gas generator spool speed demand that could then be converted again to a fuel flow requirement. The resulting isochronous controller can be seen in Figure 5.11.

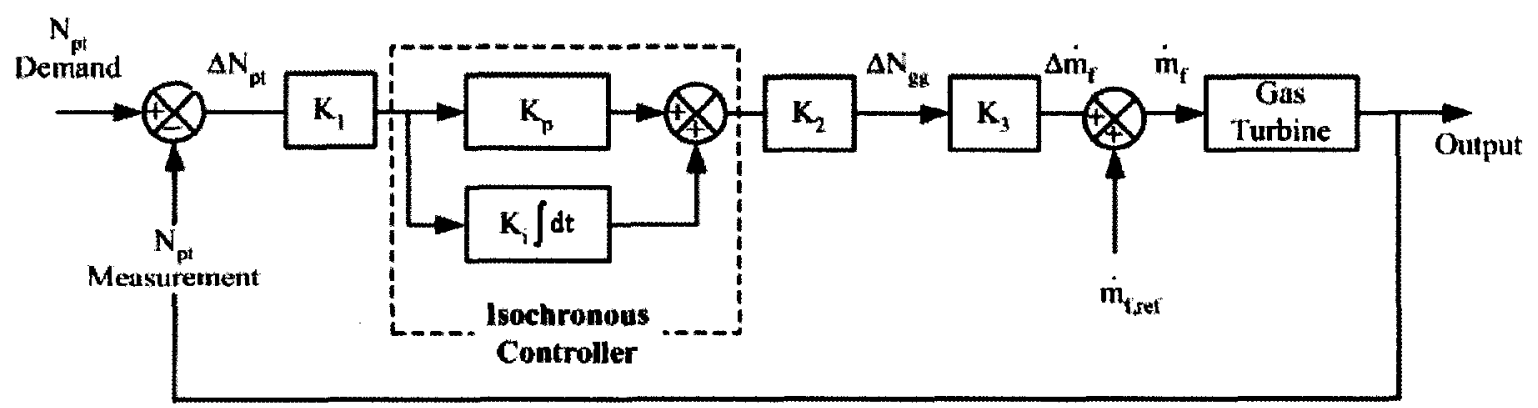

Figure 5.11:Isochronous controller with additional proportional gains 


\subsubsection{Acceleration and Deceleration Gain Schedules}

As explained in Section 4.2.1, gain scheduling is required when a controller is intended to control a wide non-linear operating range. Since stable operation throughout the operating range was identified as a prime control requirement, acceleration and deceleration gain schedules were required for this application. Following the procedure found in Section 4.2.1, the gain schedules were defined using the dynamic model extensively.

First, 15 acceleration fuel step changes (from idle to design point) and 15 deceleration fuel step changes (from design point to idle) were inputted into the dynamic model to assess the engine acceleration and deceleration response (Figure 5.12).

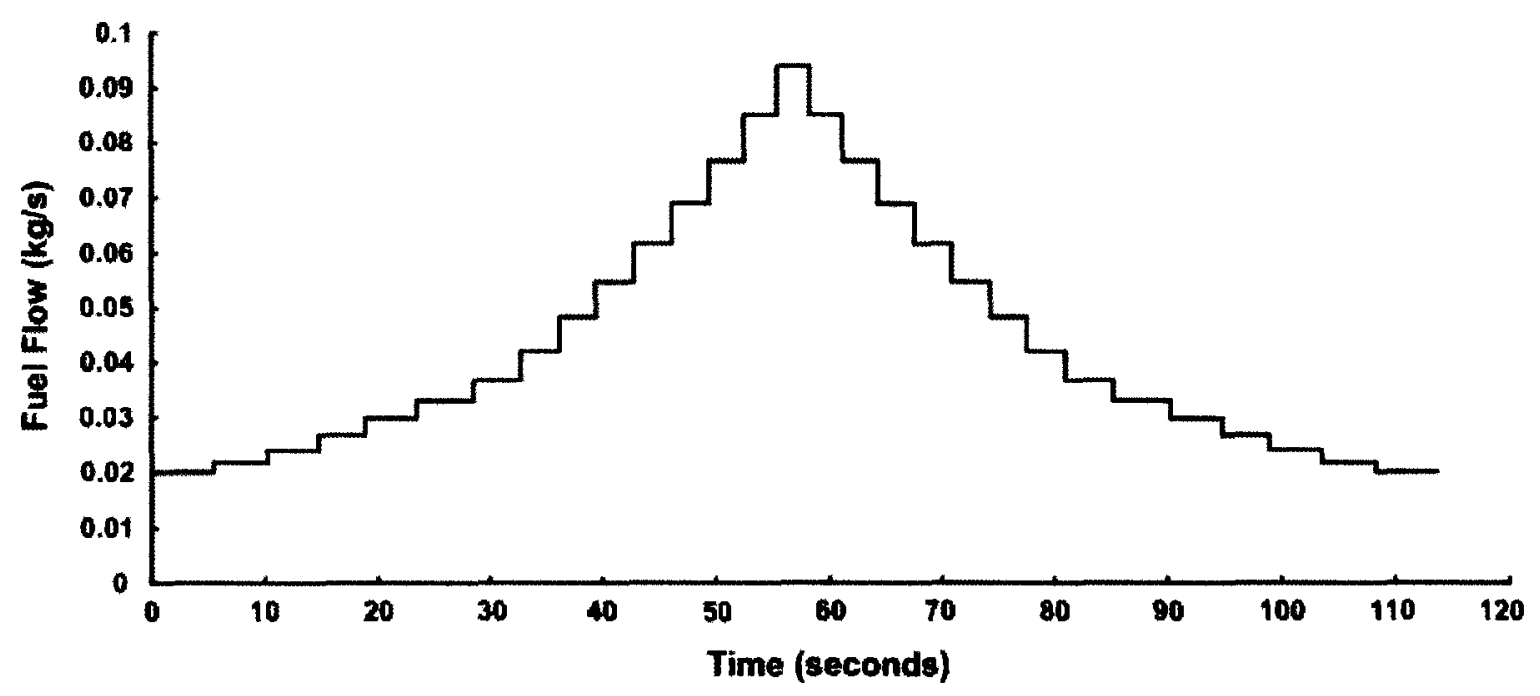

Figure 5.12: Fuel step changes inputs

Since controlling the power turbine spool speed was identified as the prime control requirement, the power turbine spool speed response was extracted from the dynamic model as a dataset and used during the gains scheduling process. The acceleration and deceleration power turbine spool speed responses are shown in Figure 5.13 . 


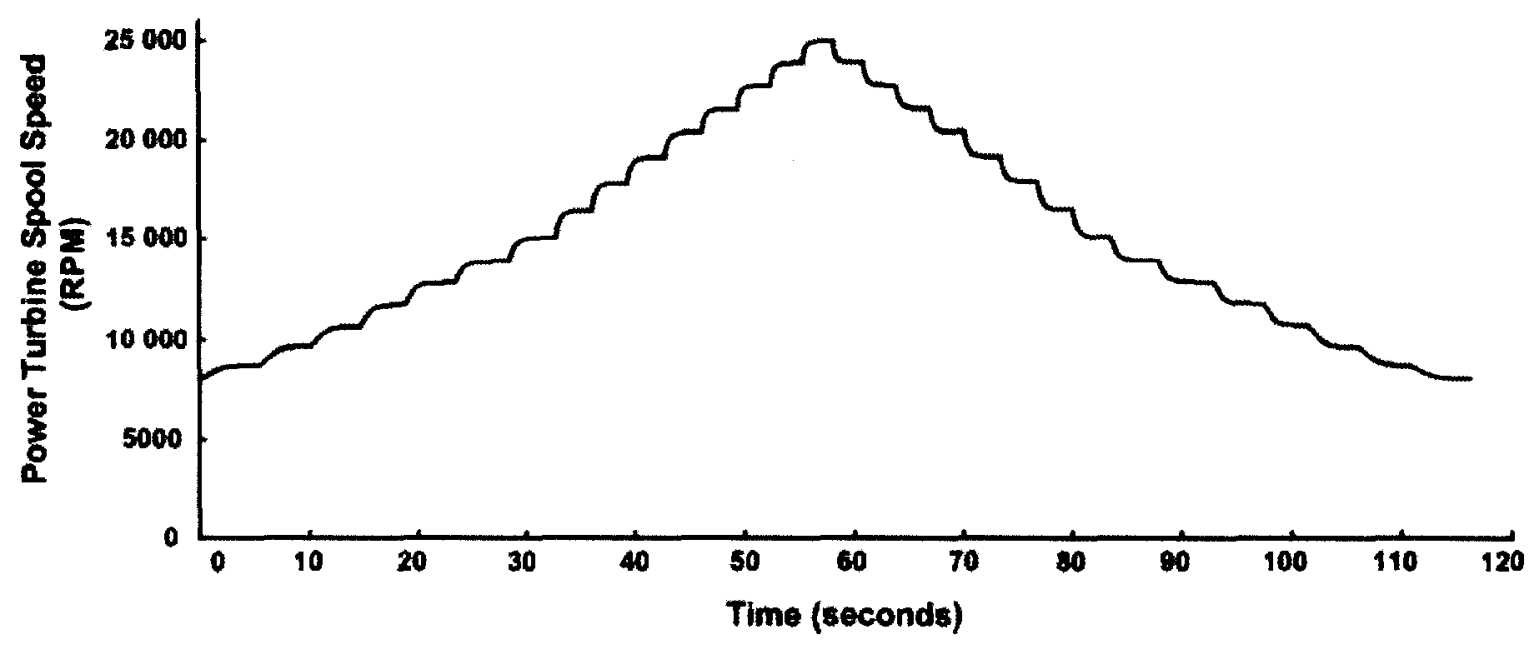

Figure 5.13: Power turbine spool speed step response

Based on this data, the time constants for each step change were calculated in a similar fashion as shown in Figure 4.5. This allowed for local controller tuning based on a linear approximation of the local engine response. The local tuning was done using the simplistic tuning method proposed in the control system design method. Based on the control system requirements, the damping ratio $(\zeta)$ and the undamped natural frequency $\left(\omega_{n}\right)$ were calculated using Eqns 4.8 and 4.9. Combining these requirements and each calculated time constants, it was then possible to calculate the controller gains $\left(\mathrm{K}_{\mathrm{p}}\right.$, and $\mathrm{K}_{\mathrm{i}}$ ) using Eqns 4.11 and 4.12 for each local controller. The resulting gains were collected into a look-up table as a function of reference speed. Note that reference speed refers to the initial steady-state gas generator spool speed prior to the step change. The resulting acceleration and deceleration proportional $\left(\mathrm{K}_{\mathrm{p}}\right)$ and integral $\left(\mathrm{K}_{\mathrm{i}}\right)$ gain schedules are shown graphically in Figure 5.14 and Figure 5.15. 


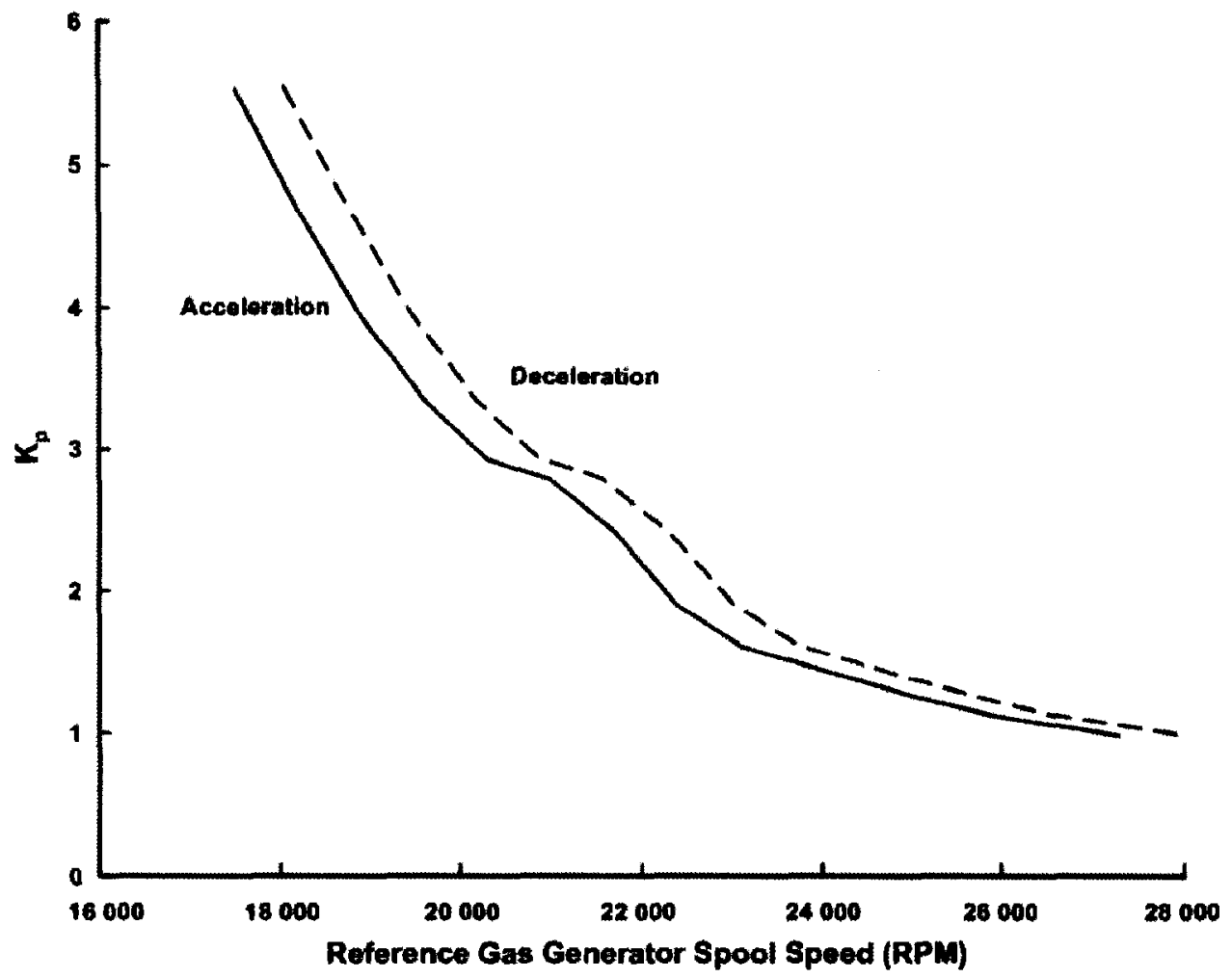

Figure 5.14: Controller proportional gain schedules

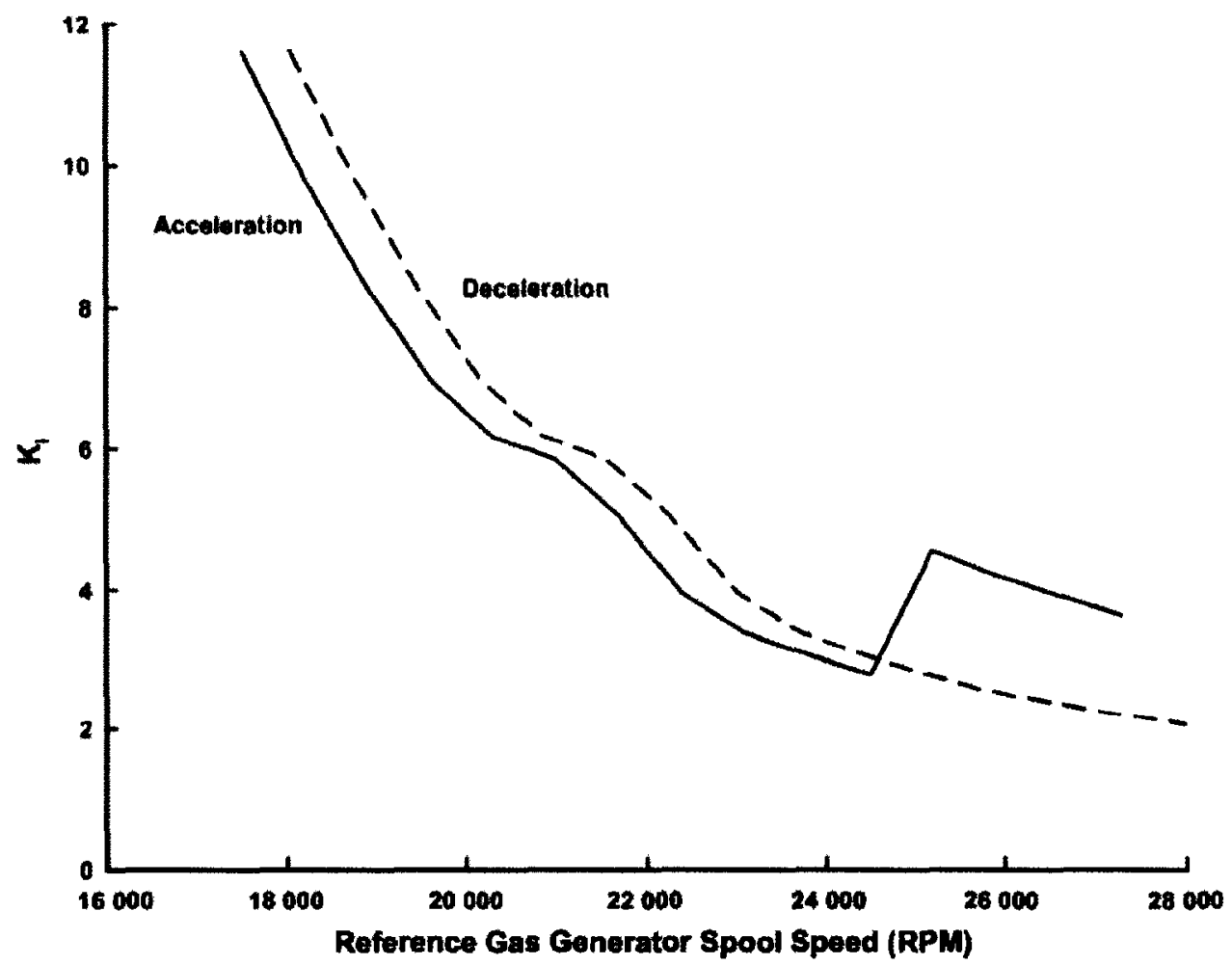

Figure 5.15: Controller integral gain schedules 
As explained earlier, additional system proportional gains were added to the controller to convert the power turbine spool speed demands into fuel flow requirements. Similarly to time constants, these proportional gains are system dependant and directly linked to the response. Hence, the gains were calculated for each step change using Eqns 5.1 to 5.3 using the power turbine spool speed step response data (Figure 5.13).

$$
\begin{aligned}
& \mathrm{K}_{1}=\left(\frac{1}{\Delta \mathrm{N}_{\mathrm{pt}}}\right) \\
& \mathrm{K}_{2}=\left(\Delta \mathrm{N}_{\mathrm{gg}}\right) \\
& \mathrm{K}_{3}=\left(\frac{\Delta \dot{\mathrm{m}}_{\mathrm{f}}}{\Delta \mathrm{N}_{\mathrm{gg}}}\right)
\end{aligned}
$$

where

$$
\begin{gathered}
\Delta \mathrm{N}_{\mathrm{pt}}=\left(\mathrm{N}_{\mathrm{pt}, \max }-\mathrm{N}_{\mathrm{pt}, \text { min }}\right) \\
\Delta \mathrm{N}_{\mathrm{gg}}=\left(\mathrm{N}_{\mathrm{gg}, \max }-\mathrm{N}_{\mathrm{gg}, \min }\right) \\
\Delta \dot{\mathrm{m}}_{\mathrm{f}}=\left(\dot{\mathrm{m}}_{\mathrm{f}, \max }-\dot{\mathrm{m}}_{\mathrm{f}, \min }\right)
\end{gathered}
$$

Similarly as for the controller gains, the proportional gains were stored in look-up tables as a function of reference speed. The resulting acceleration and deceleration proportional gains schedules are shown in Figure 5.16, Figure 5.17 and Figure 5.18. 


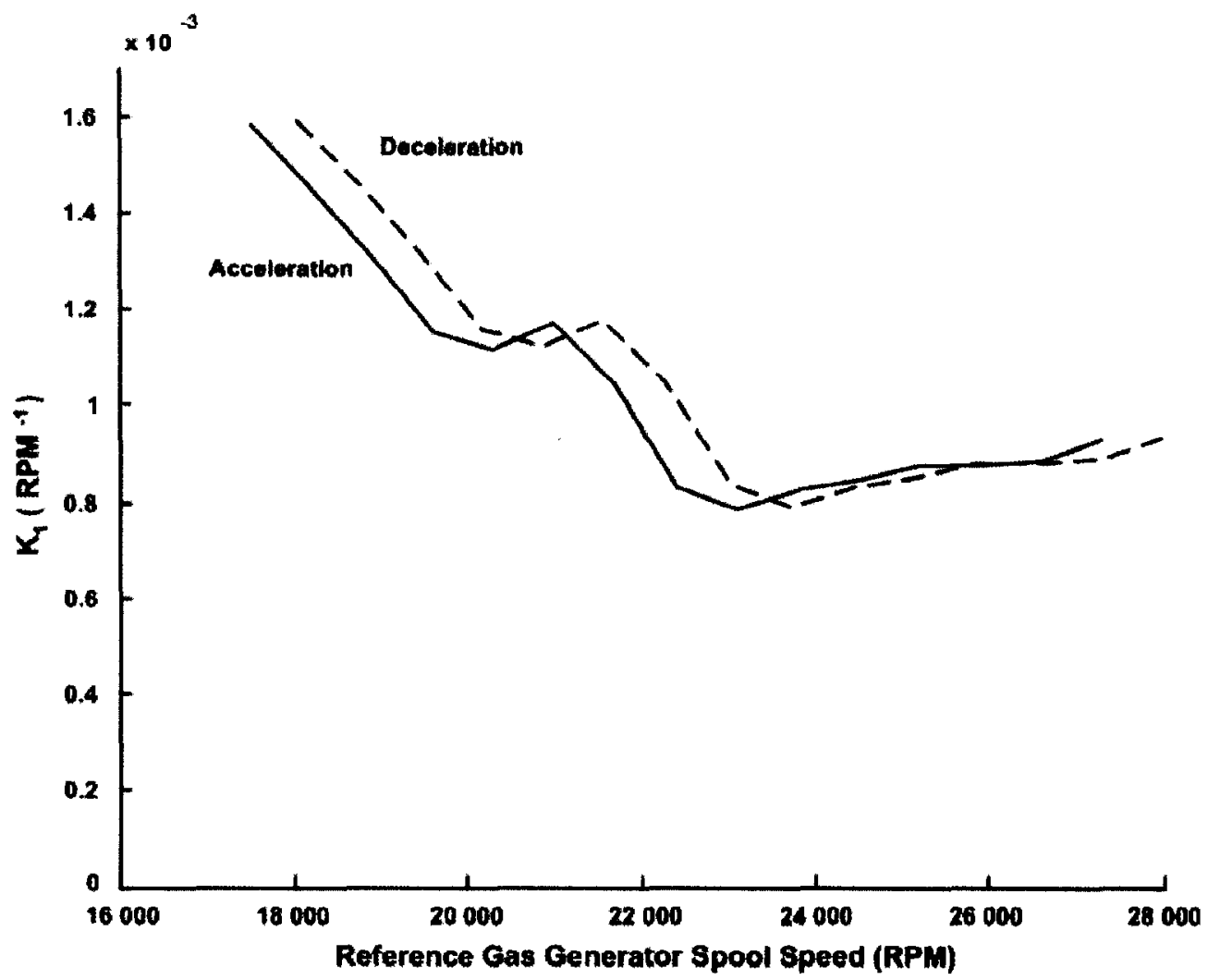

Figure 5.16: $\mathrm{K}_{1}$ gain schedules

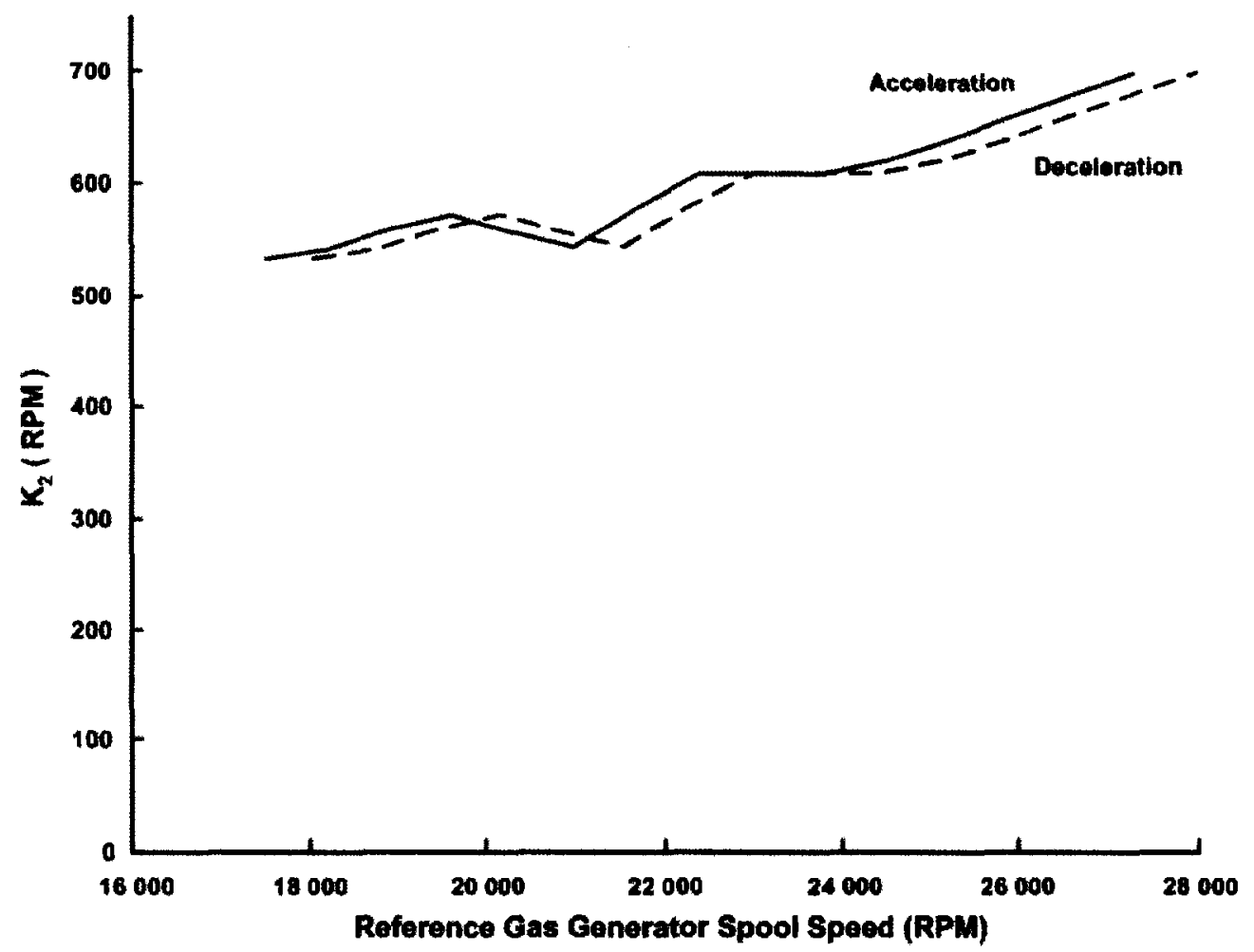

Figure 5.17: $\mathrm{K}_{2}$ gain schedules 


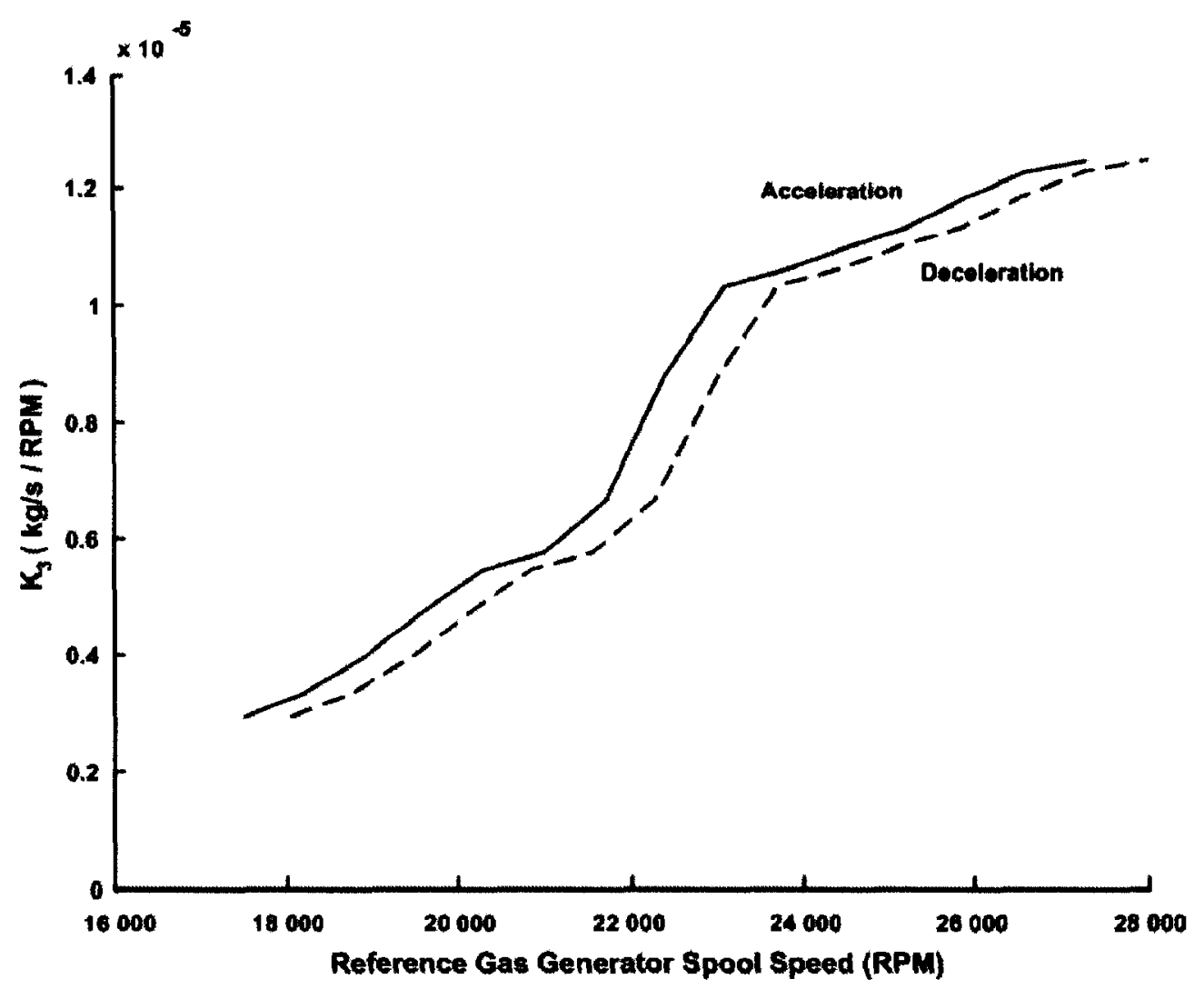

Figure 5.18: $\mathrm{K}_{3}$ gain schedule

\subsubsection{Performance Limiters}

The performance limiters stated in the control system requirements were subdivided into engine protection limiters and engine operation limiters and converted to modulation controls through modulating curves.

The engine protection limiters consisted of the maximum gas generator turbine inlet temperature, gas generator over-speed and power turbine over-speed.

- Maximum gas generator turbine inlet temperature $=1300 \mathrm{~K}$

- Gas generator over-speed = 29400 RPM

- Power turbine over-speed = 27500 RPM

Modulation was set to take place between design point and the maximum operating conditions for the spool speed protection and above the maximum transient turbine inlet 
temperature $(1250 \mathrm{~K}$ to $1300 \mathrm{~K})$ for the over-temperature protection. The engine protection modulating curves were generated based on this statement. The resulting curves can be seen in Figure 5.19, Figure 5.20 and Figure 5.21.

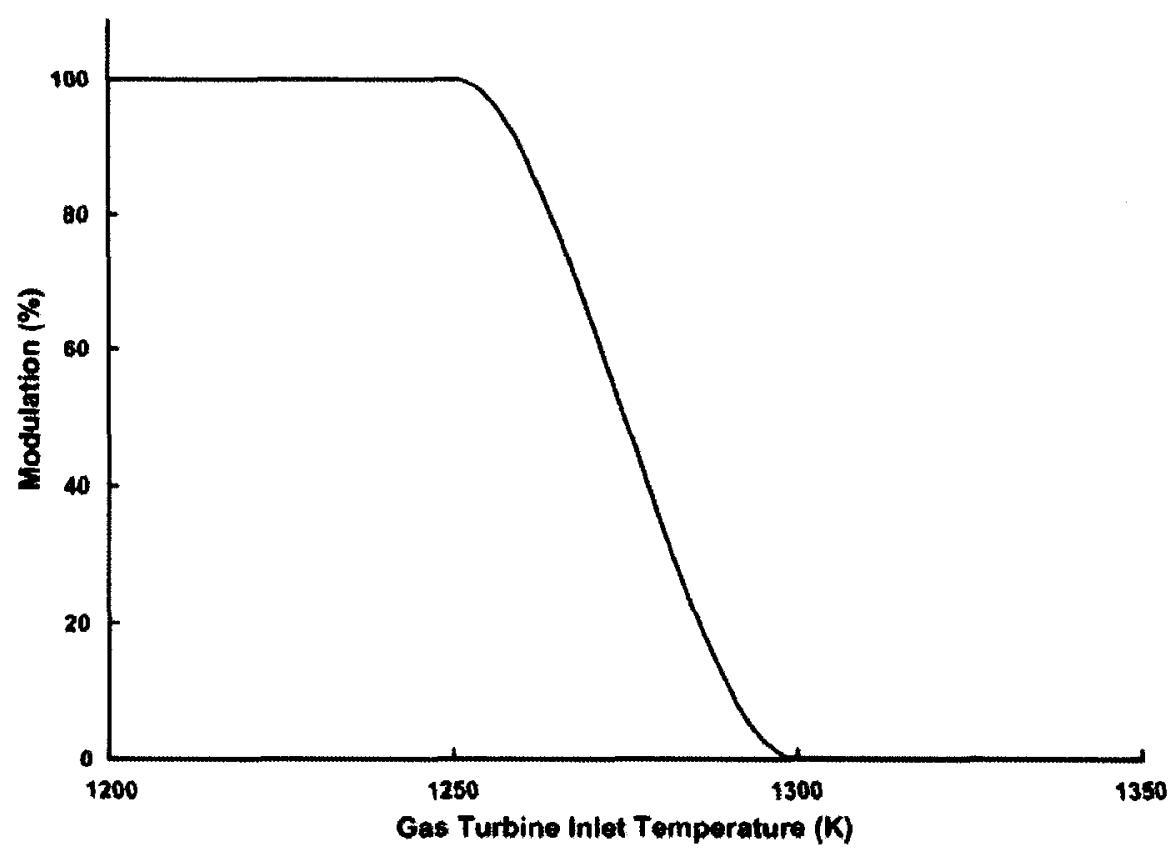

Figure 5.19: Over-temperature engine protection

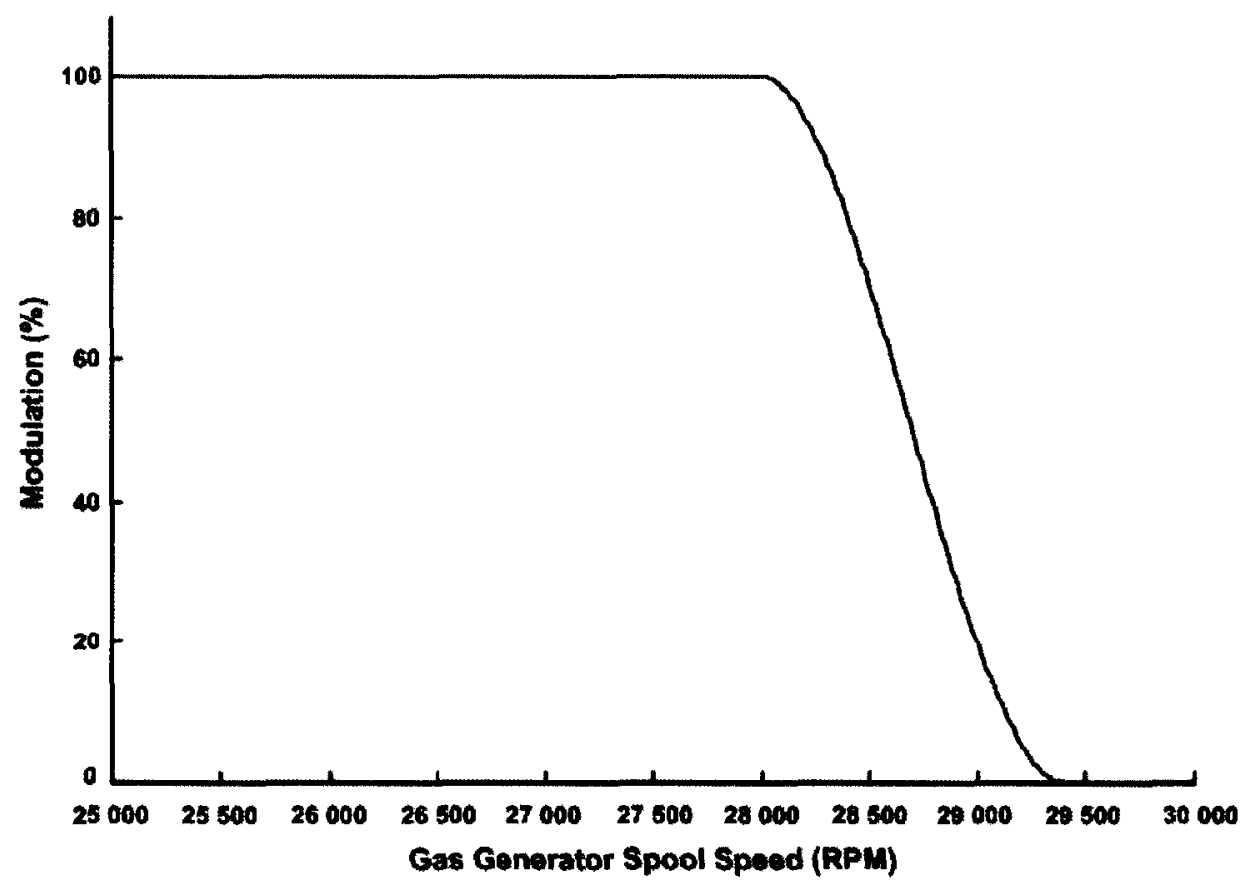

Figure 5.20: Gas generator over-speed protection 


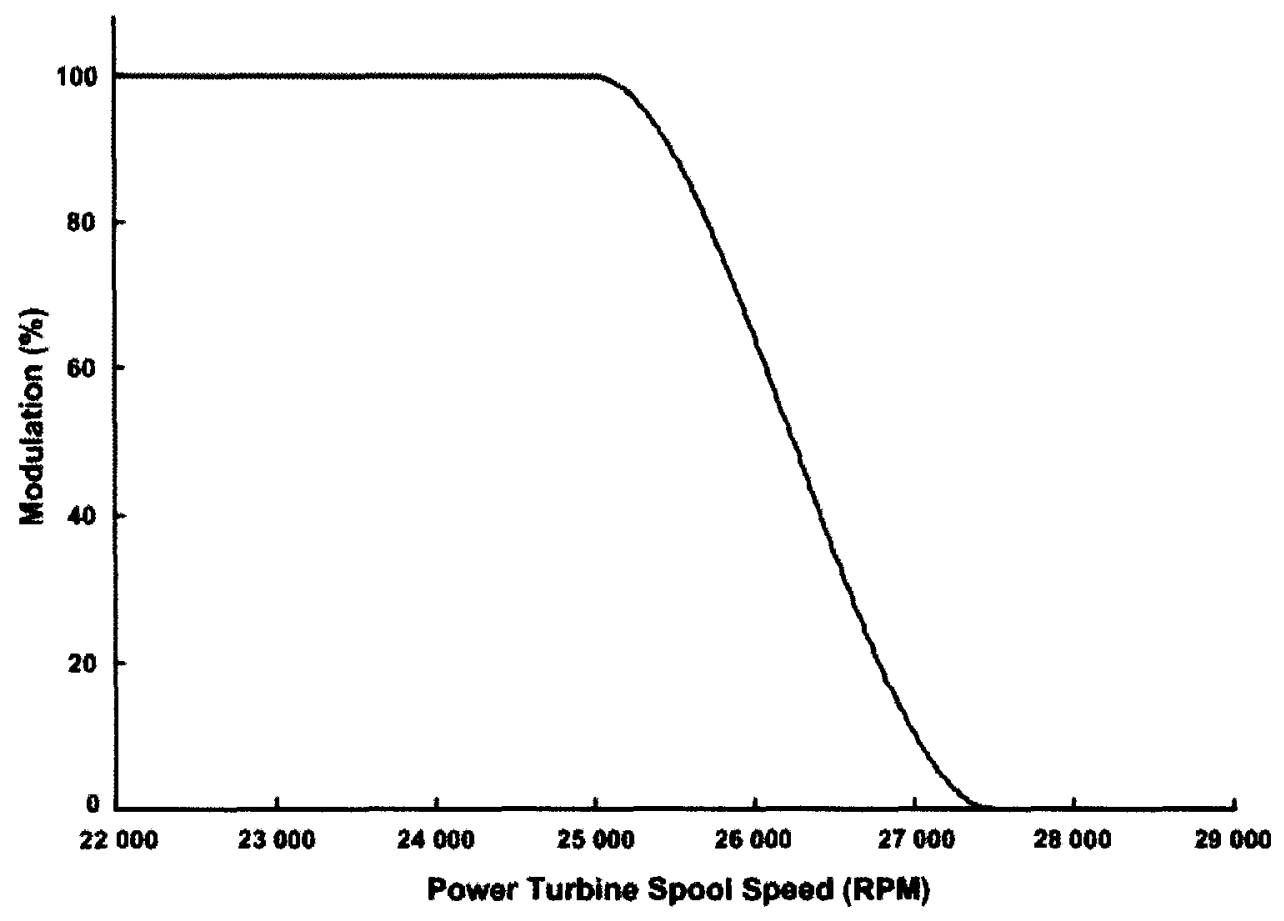

Figure 5.21: Power turbine over-speed protection

The engine operation limiters consisted of minimum gas generator spool speed and minimum fuel to air ratio.

- Minimum gas generator spool speed $=16625$ RPM

- minimum fuel to air ratio $=0.0081$

In this case, modulation was set to take place between the minimum operating conditions and idle operating condition. The resulting modulating curves can be seen in Figure 5.22 and Figure 5.23. 


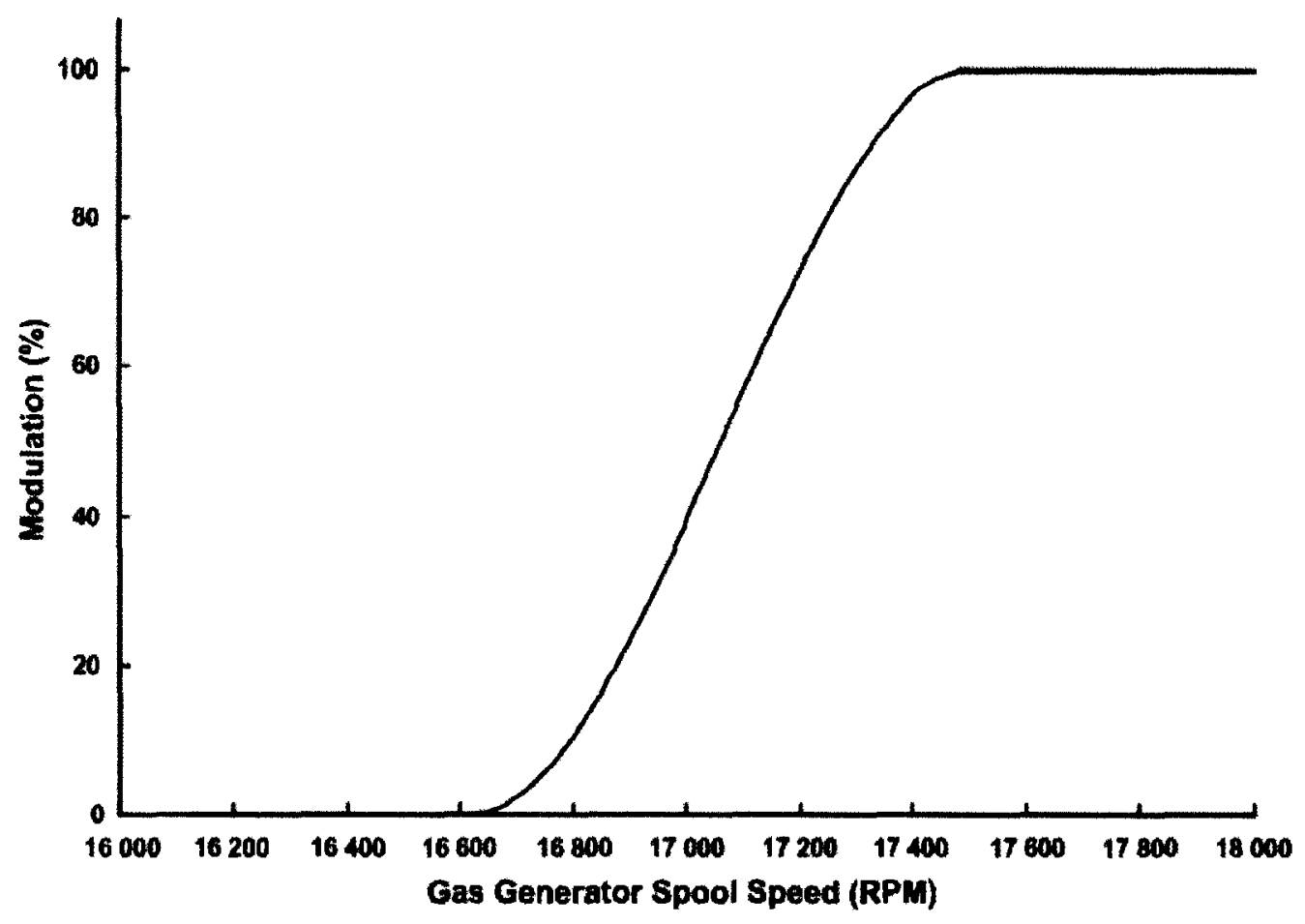

Figure 5.22: Gas generator minimum spool speed limiter

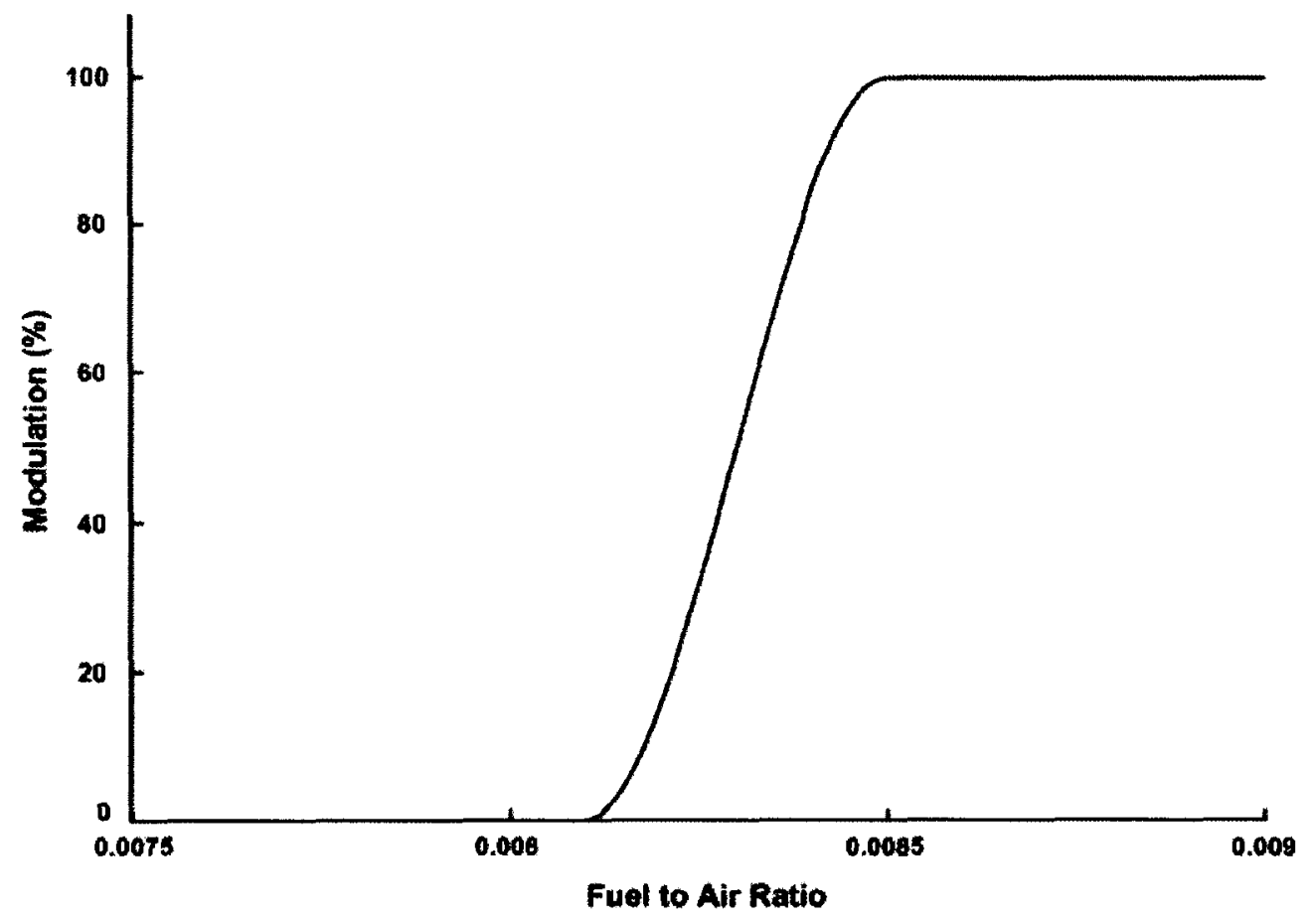

Figure 5.23: Minimum fuel to air ratio limiter 


\subsubsection{Maximum and Minimum Fuel Schedule (Protective Control)}

The fuel schedules were defined based on the protective control requirements, which encapsulated the safe acceleration and deceleration transient regions. Using the gas turbine dynamic model, the steady-state fuel flow boundaries of each of the following protective control requirements were generated and plotted on the same graph to visualize the size of the acceleration and deceleration operating regions.

- Steady-state operating conditions

- Maximum transient gas generator turbine inlet temperature

- Maximum spool speed

- Minimum spool speed

- Minimum fuel flow (flameout limit)

- Compressor surge

As shown in Figure 5.24, the fuel flow boundaries were plotted as per Eqn 4.14 to minimize the effects of ambient pressure and hence allow for a proper assessment of the acceleration and deceleration regions. 


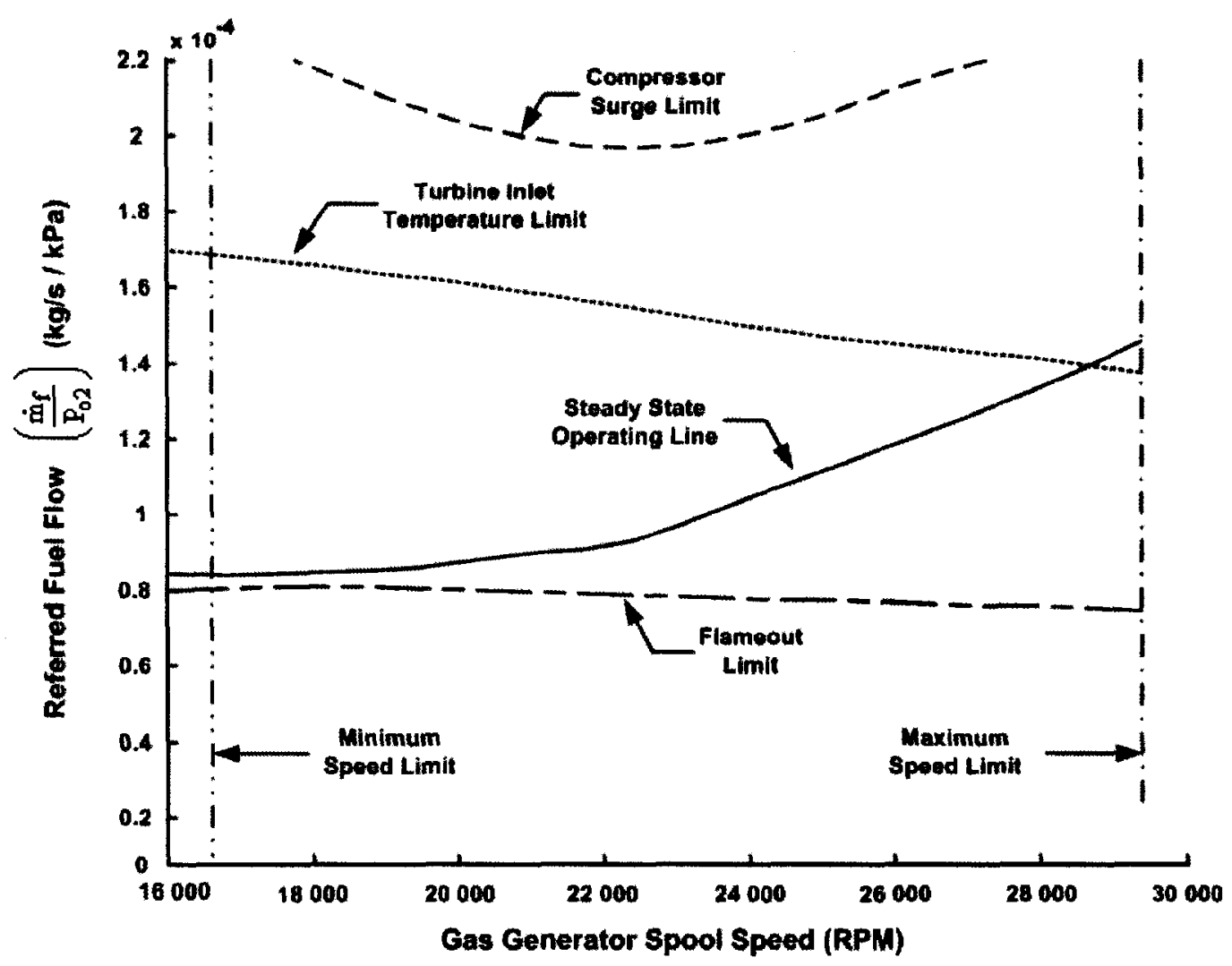

Figure 5.24: Referred fuel flow boundaries

However it was found that it was conceptually simpler to analyze the fuel flow boundaries using fuel flow directly instead of referred fuel flow as a function of gas generator spool speed (Figure 5.25). 


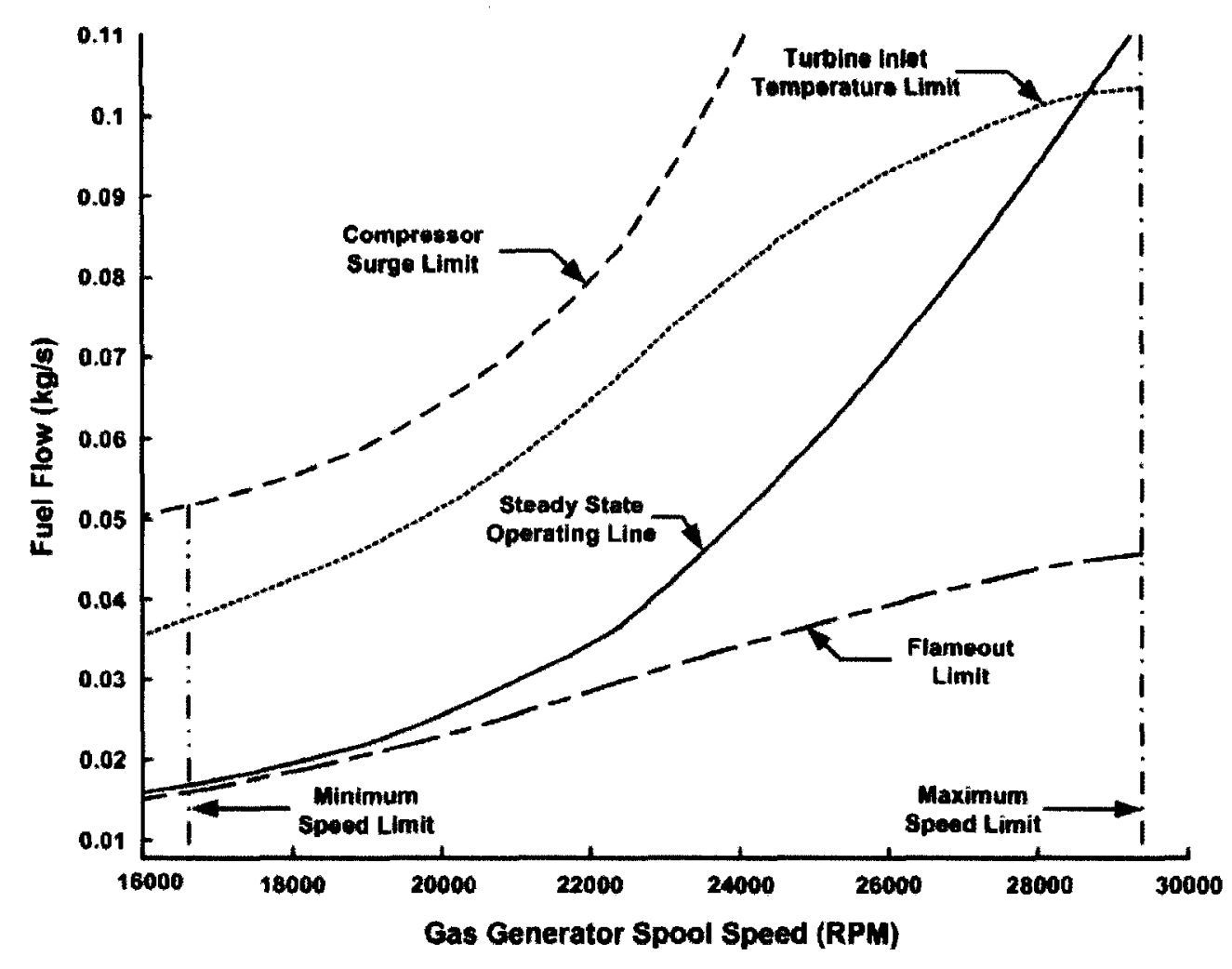

Figure 5.25: Fuel flow boundaries

This approach was used to determine the acceleration and deceleration fuel schedules. Three potential acceleration fuel schedules were sketched within the limited operating region and their transient effects on engine performance were assessed using the dynamic model. The reasons for sketching these schedules were based on the following rationals:

- Schedule A: Product of the steady state fuel flow (Constant $\mathbf{x}$ fuel flow)

- Schedule B: Typical fuel schedule shape (GasTOPS, 1990)

- Schedule C: Maximum fuel schedule within the acceleration limits

The three acceleration fuel schedules are shown in Figure 5.26. An acceleration fuel schedule was then selected based on the performance response it generated. Assessment of the resulting performance data leading to the final selection of the acceleration fuel schedule will be discussed in Chapter 6 . 


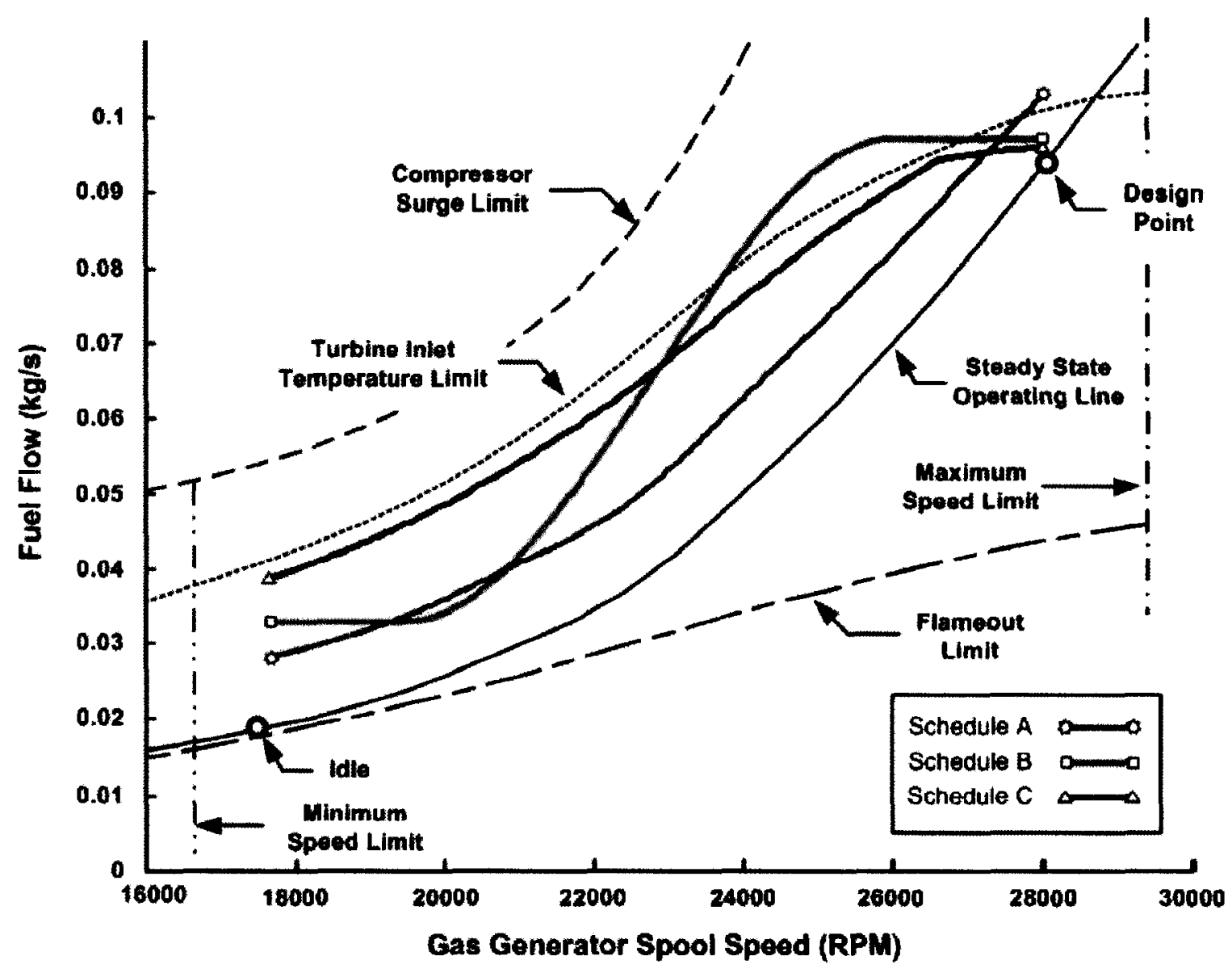

Figure 5.26: Acceleration fuel schedules

A different approach was used to determine the deceleration fuel schedule because combustion stability is a concern when the engine is decelerating (Walsh and Fletcher, 1998). To facilitate engine deceleration, Walsh and Fletcher suggested that the fuel flow should be reduced relative to that of the steady-state operating line by $20-50 \%$ to prevent the risk of engine flameout. Since combustion stability curves were not available early in the design process (to be determined experimentally) and there was no firm deceleration response time requirement stated in the control system requirements, a conservative under-fueling margin of $30 \%$ was selected for the deceleration fuel schedule. The deceleration fuel schedule is shown in Figure 5.27. The resulting dynamic response generated by this fuel schedule will be discussed in Chapter 6 . 


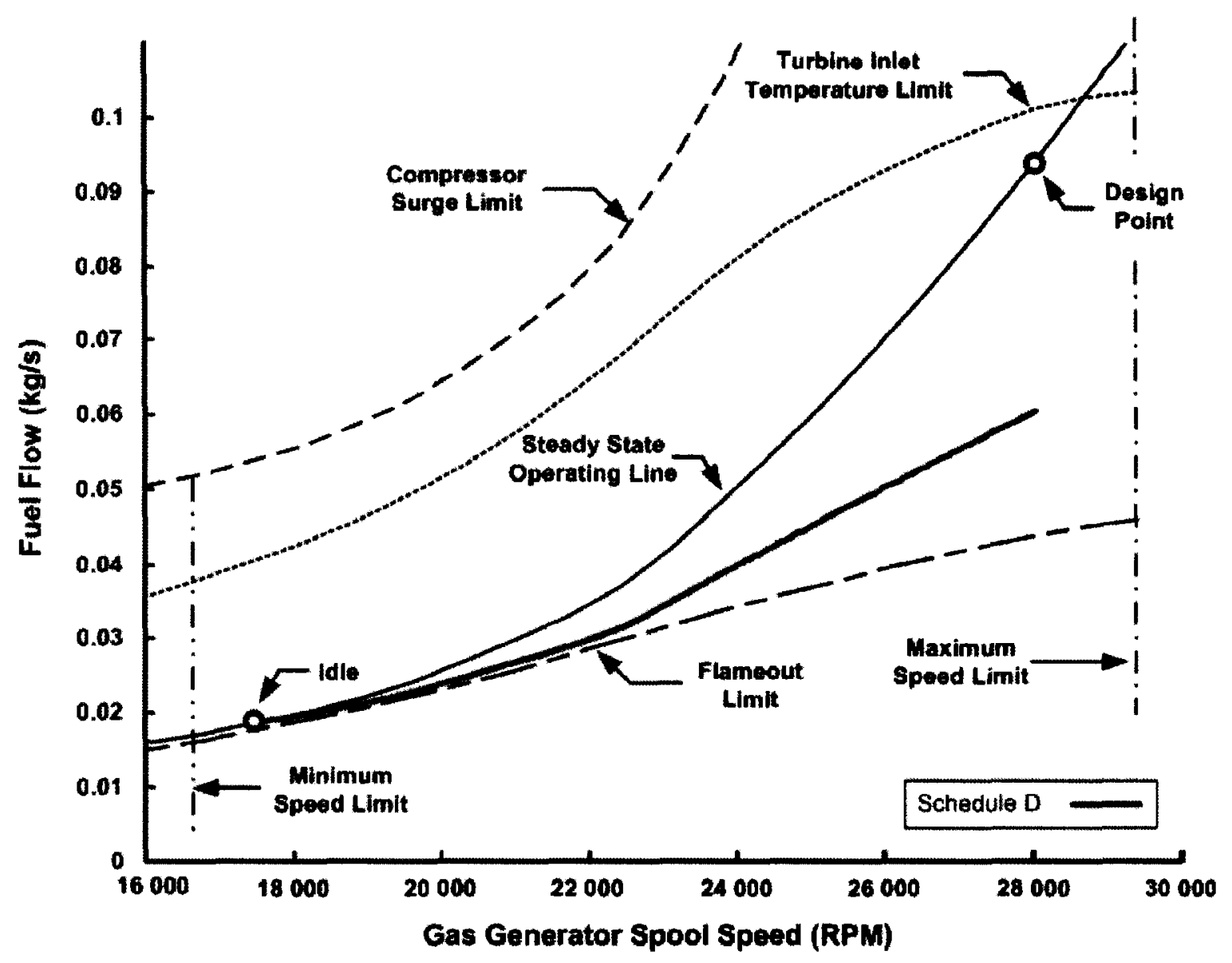

Figure 5.27: Deceleration fuel schedule

It is important to note that both acceleration and deceleration fuel schedules specify the maximum and minimum total fuel flow allowed for safe transient operations. However, as discussed earlier, the controller will output a change in fuel flow requirement to reduce the error between the demand and the feedback. Since protective controls rely on a high- or low-select approach, it is important to compare apples with apples. Based on this observation, a reference fuel flow versus reference gas generator spool speed look-up table was added to the control system to help the comparison process (Figure 5.28). 


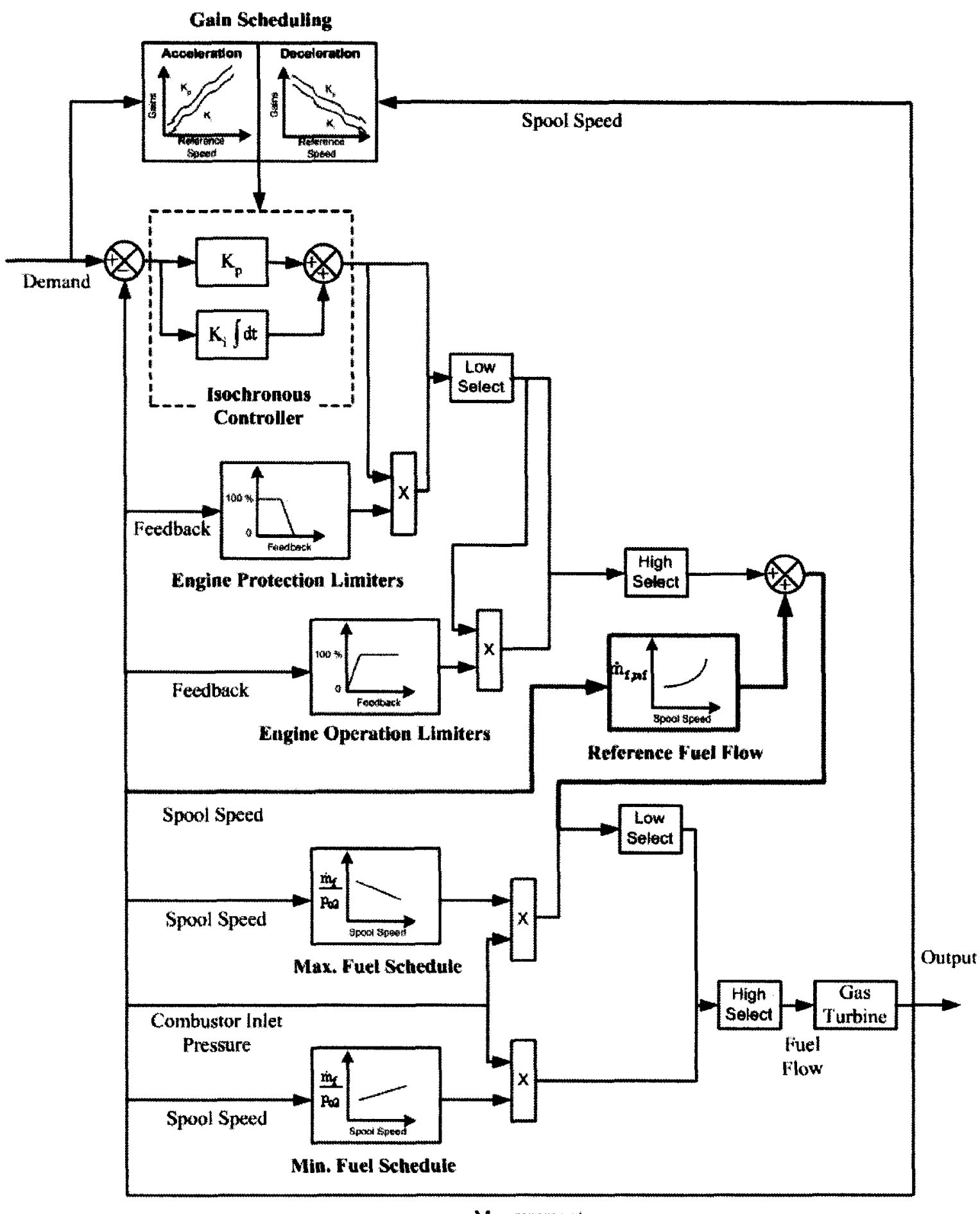

Measurements

Figure 5.28: Control system with reference fuel flow

Similarly as for the reference spool speed, the reference fuel flow is the initial steady-state fuel flow prior to the step change and was deduced from Figure 5.12. The 
reference fuel flow as a function of the reference gas generator spool speed is shown graphically in Figure 5.29.

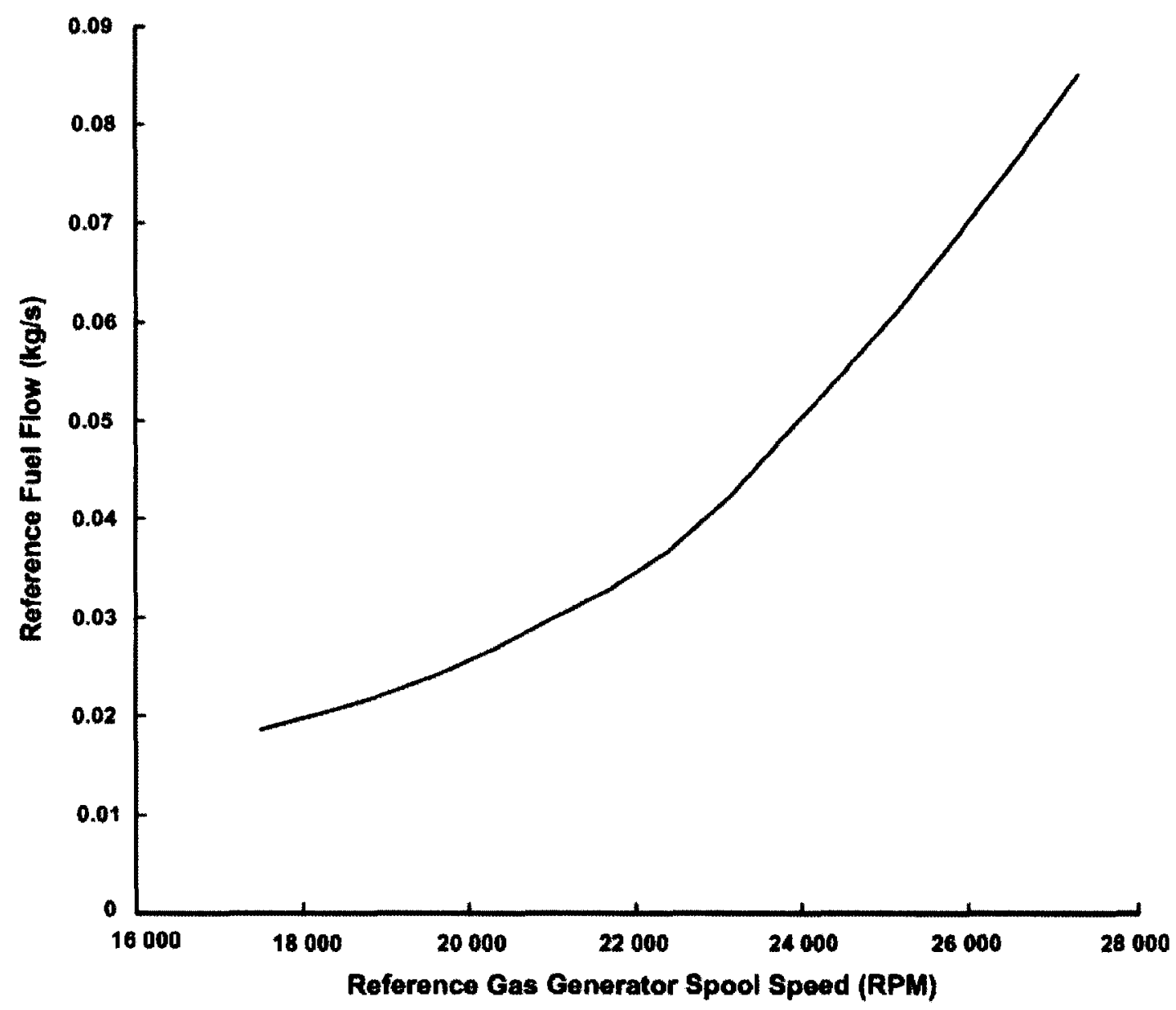

Figure 5.29: Reference fuel flow

\subsubsection{Control System Requirements - Startup Sequencing}

As for the engine control section of the control system design process, before designing the startup sequence the control system requirements needed to be identified. The following requirements were formulated by the client and imposed by the component designers:

\section{Prime Control Requirement}

- Startup time ( 0 to idle speed) shall be less than 1 minute 


\section{Temperature Limits}

- Maximum transient gas generator turbine inlet temperature shall not exceed $1250 \mathrm{~K}$. These short transient excursions above the steady state gas generator turbine inlet temperature $(1200 \mathrm{~K})$ are required to accelerate the engine to idle during startup.

- Gas generator turbine inlet temperature limit shall not exceed the overtemperature limit of $1300 \mathrm{~K}$. Note that the gas generator turbine will suffer permanent damage if the over-temperature limit is exceeded.

\section{$\underline{\text { Minimum Gas Generator Spool Speed Acceleration Limit }}$}

- Minimum spool speed acceleration shall not be less than 100 RPM / s

\subsubsection{Startup Fuel Scheduling}

Startup fuel scheduling was utilized to meet the prime control requirement. As detailed in the controls system design method, startup fuel scheduling consisted of scheduling fuel flow to the engine based on a spool speed feedback signal. The fuel schedule was produced using the method proposed in Section 4.3.1.

First, using the dynamic model, the fuel flow boundaries for the surge line, maximum transient gas generator turbine inlet temperature and steady-state operating conditions were produced well into the sub-idle region and plotted as a function of gas generator spool speed (Figure 5.30). Then, the first leg of the startup fuel schedule was sketched within the acceptable operating limits from idle to the last converged operating speed. 


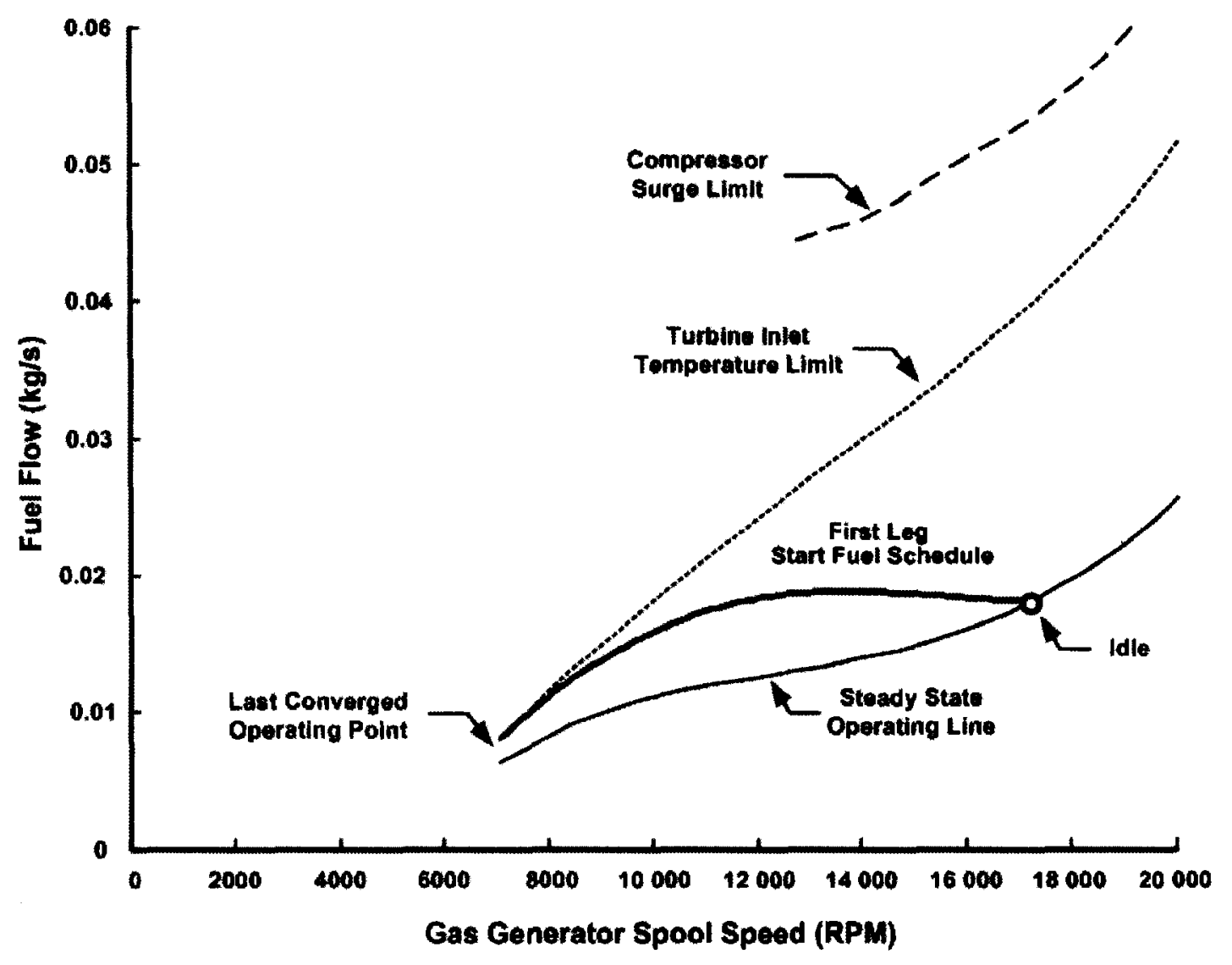

Figure 5.30: First leg of the startup fuel schedule

Then, the second leg of the fuel schedule was generated between the light-up speed $(10 \%$ of gas generator design point spool speed $=2800 \mathrm{RPM})$ and the last converged operating point using Eqn 4.16 based on the first leg fuel flow located at the last converged operating speed. The resulting startup fuel schedule is shown in Figure 5.31 . 


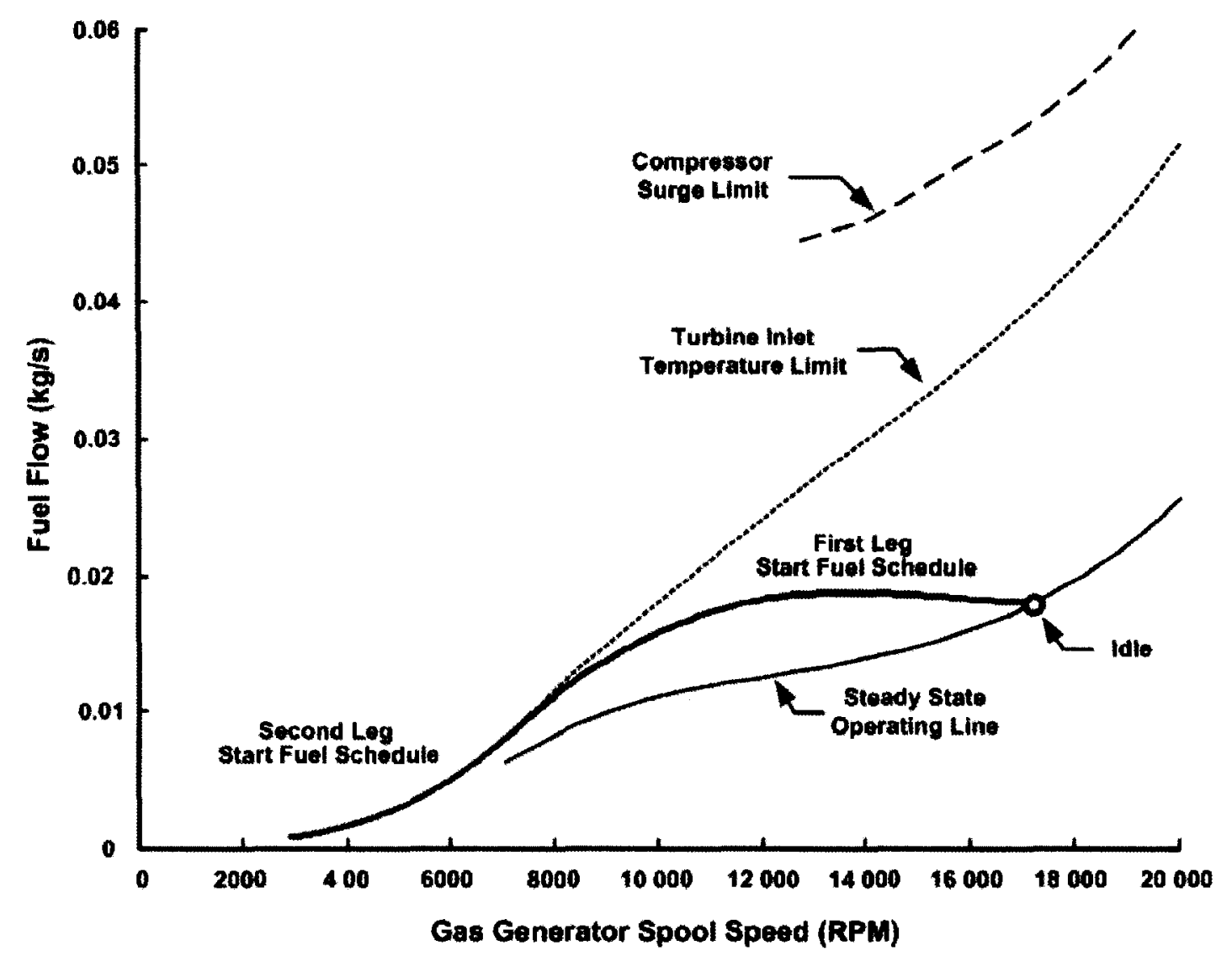

Figure 5.31: Complete startup fuel schedule

Even though shown here graphically, the startup fuel schedule was store as a look-up table as fuel flow as a function of gas generator spool speed for computational efficiency. The resulting startup engine response will be discussed in Chapter 6 .

\subsubsection{Startup Performance Limiters}

Performance limiters were necessary to delimit the safe transient operating region during startup. As detailed in the startup sequencing control requirements, the limiters consisted of the gas generator turbine inlet over-temperature $(1300 \mathrm{~K})$ and the minimum gas generator spool acceleration limit (100 RPM/s). To prevent engine hang, startup protective control was based on shutdown control instead of modulation control. As a result, the following 'if then else' commands were added to the startup control system as shutdown controls. 


\section{Temperature Limit Shutdown Control Algorithm}

If TIT feedback $>1300 \mathrm{~K}$

Fuel Flow $=0 \mathrm{~kg} / \mathrm{s}$

Else

Fuel Flow $=$ Fuel Flow

End

Min. Spool Acceleration limit Shutdown Control Algorithm

If Spool Acceleration feedback < 100 RPM / s

Fuel Flow $=0 \mathrm{~kg} / \mathrm{s}$

Else

Fuel Flow $=$ Fuel Flow

End

Based on these shutdown controls, the engine will shut down automatically if any of the performance limiters are exceeded.

\subsubsection{Control System Solution}

Once the controller, the fuel schedules and the performance limiters were determined, all components were assembled together to produce the control system design solution. It was decided that the input to the control system would be based on a power lever (PLA) setting which represented a percentage of the total power turbine spool speed. As a result, an additional look-up table was added to the control system to convert the PLA setting to a power turbine spool speed demand (graphically represented as Figure 5.32). 


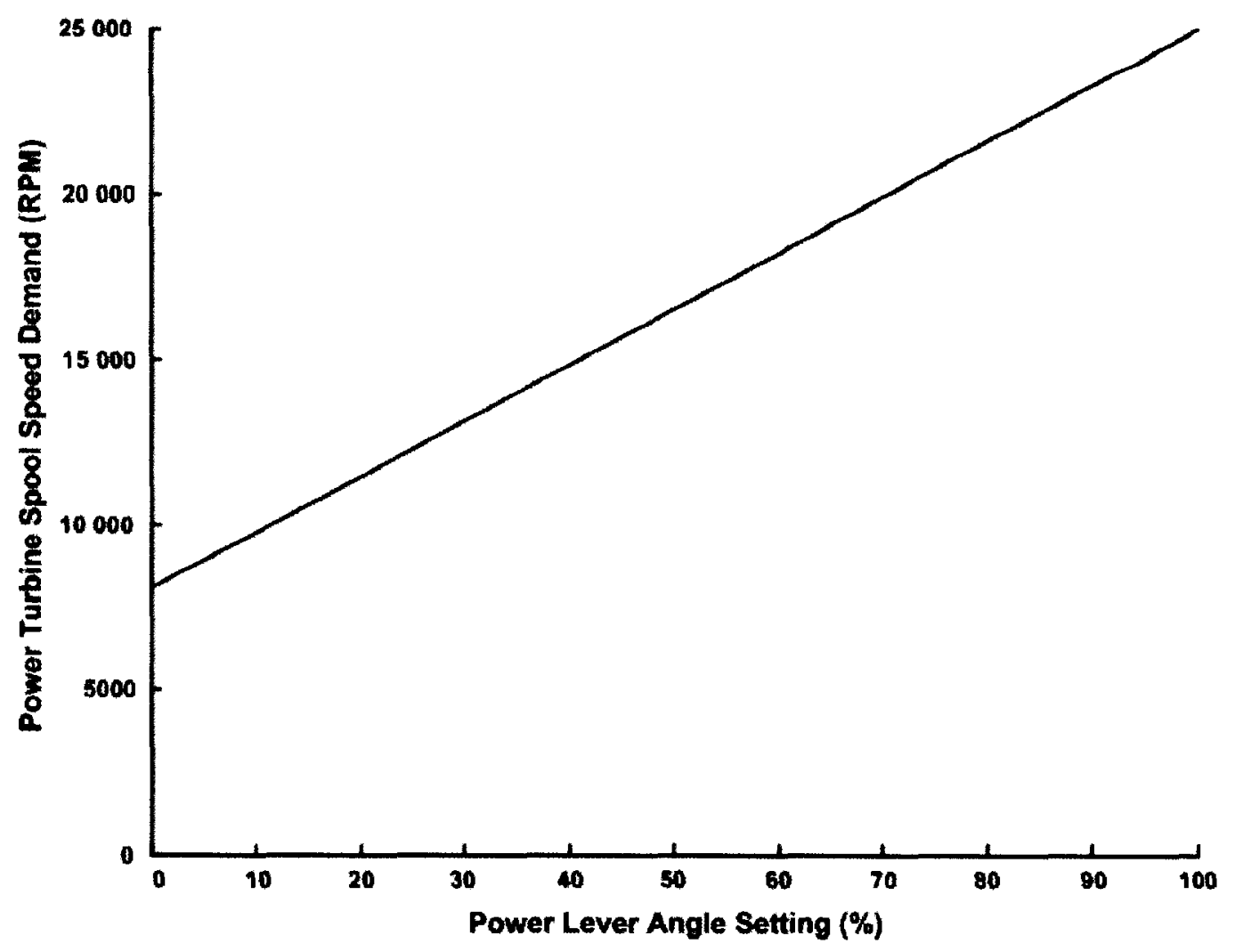

Figure 5.32: Power turbine spool speed demand as a function of PLA setting

The overall control system design solution is shown in Figure 5.33 and Figure 5.34.

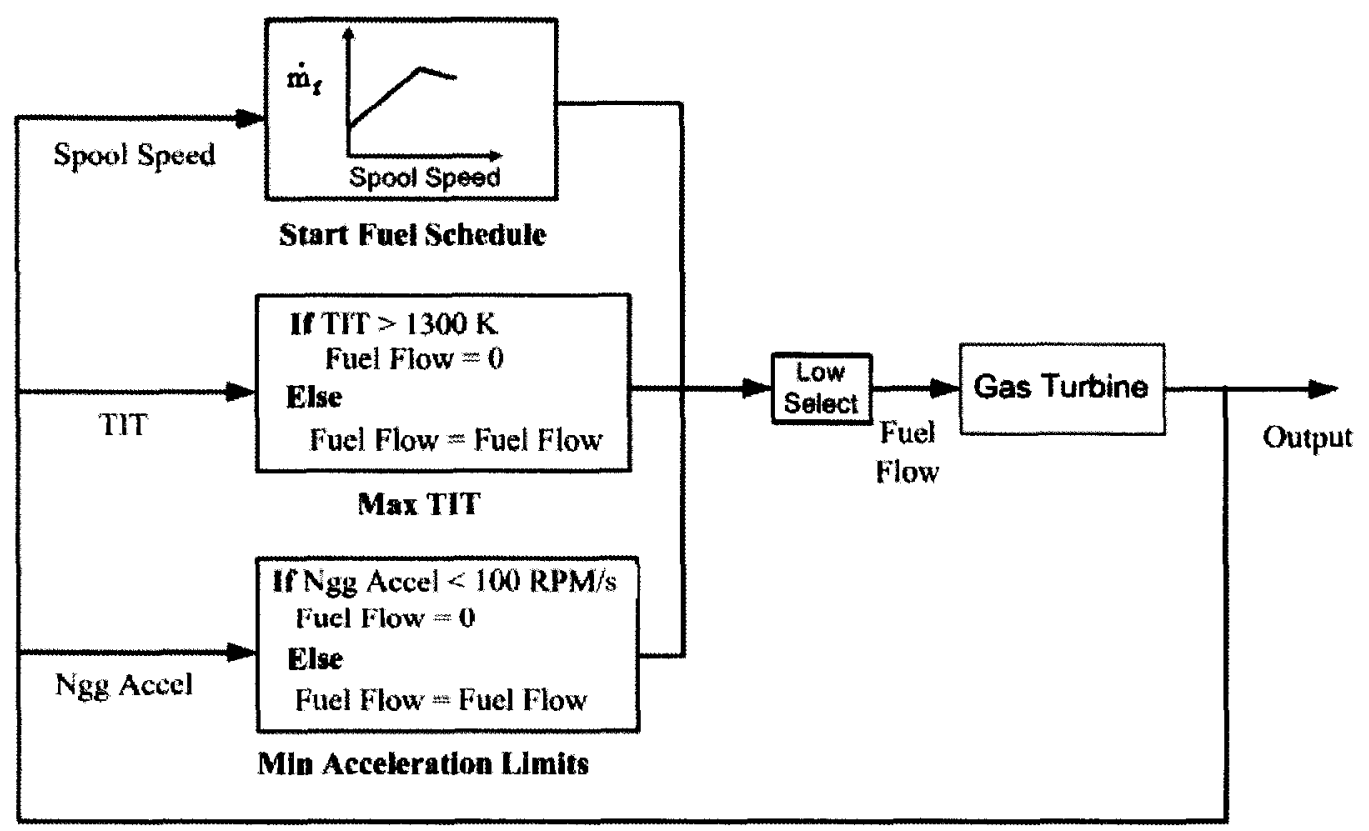

Figure 5.33: Overall start sequencing system solution 


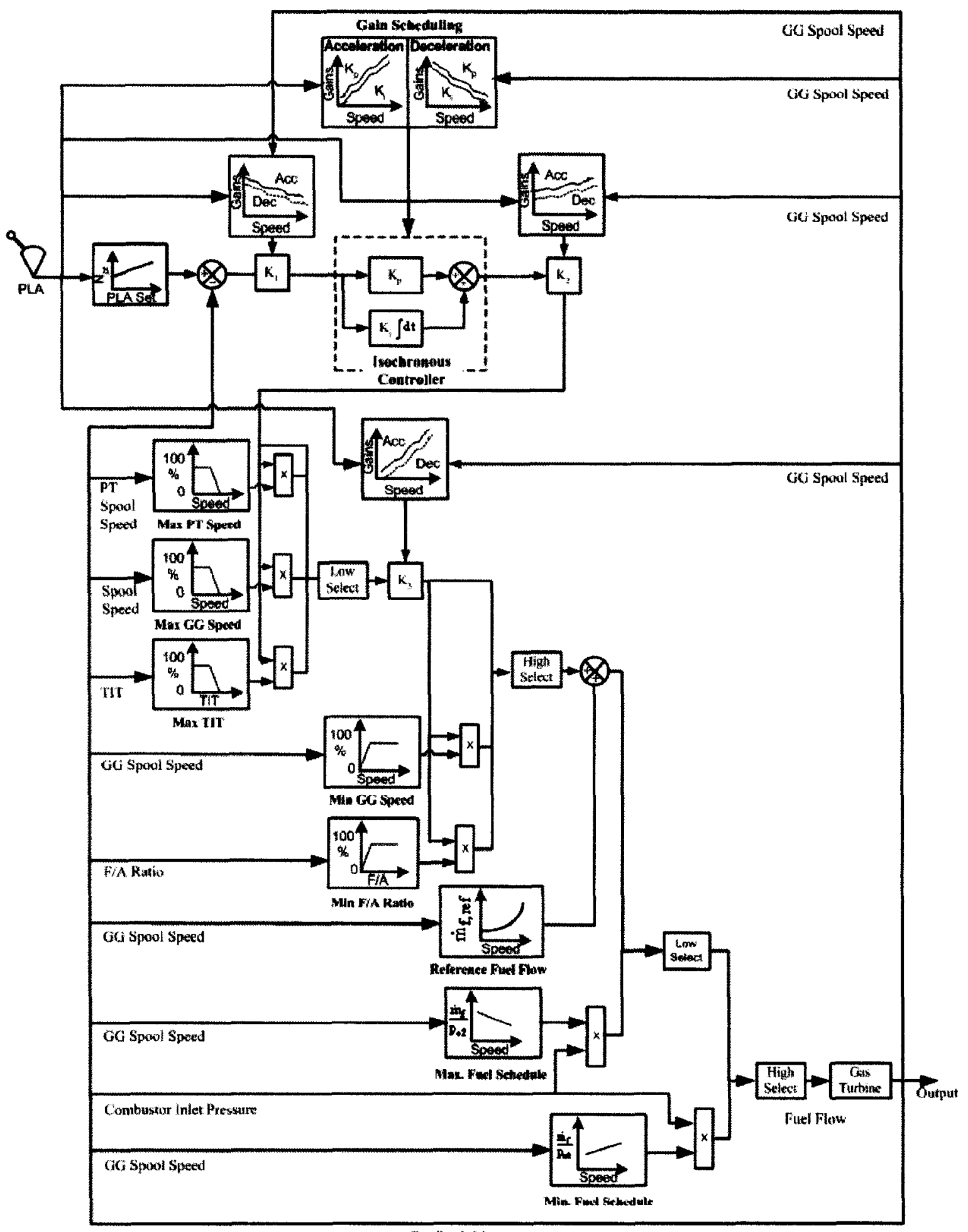

Ficedback Measurements

Figure 5.34: Overall engine control system solution

The startup sequencing section of the control system will only be active during a startup request and disabled once the gas generator spool speed reaches idle speed. At 
that point, engine control will be activated and remain active until shutdown. The control system startup procedure is shown in Figure 5.35.

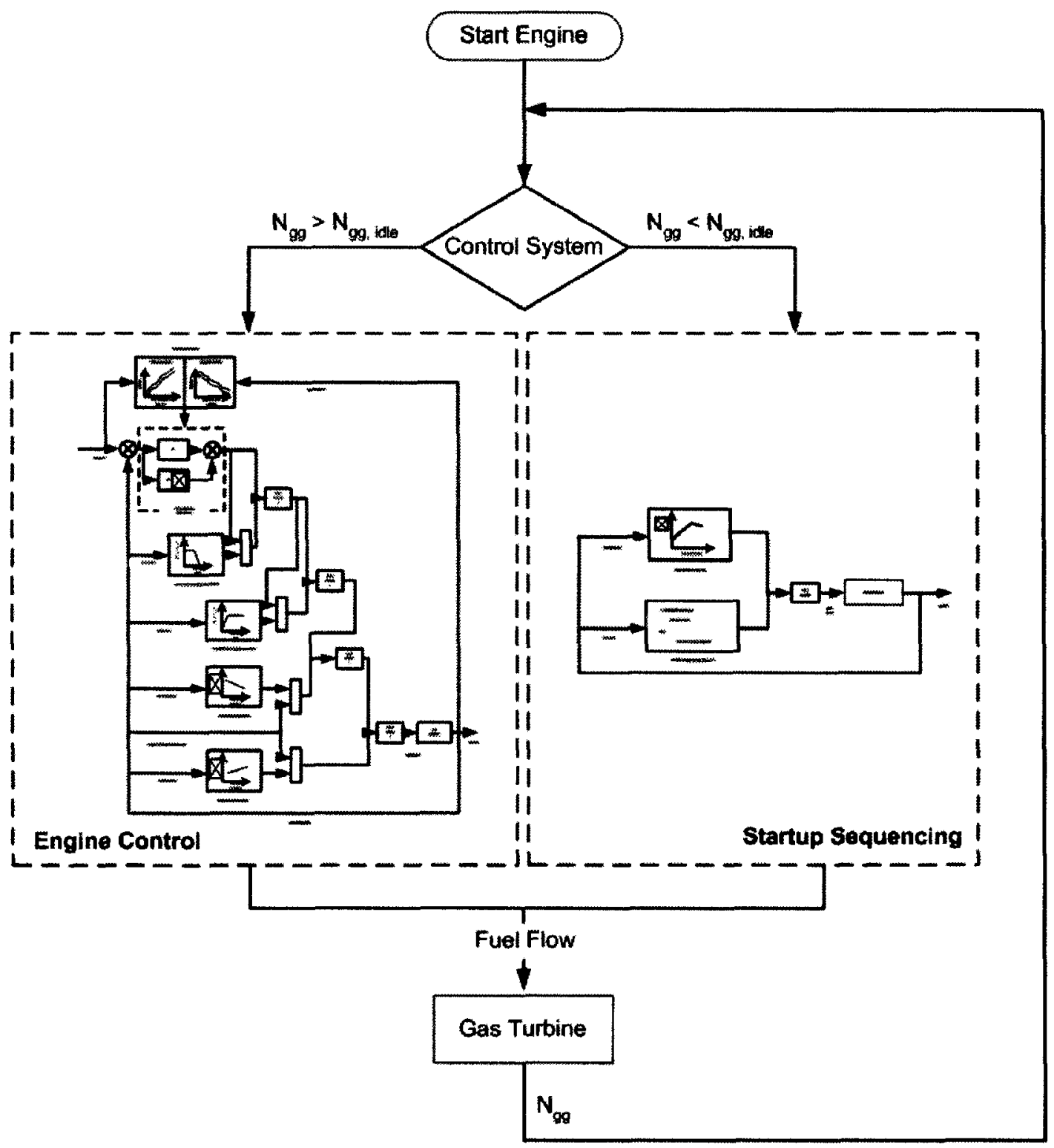

Figure 5.35: Control system startup procedure

For the shutdown sequence, it was determined that simply shutting off the fuel flow at idle speed would be adequate for this application. 
The purpose of this chapter was to describe the dynamic modeling and control system design process for a 1-MW gas turbine application. As defined by the methodologies, the dynamic model was first created based on design point information, followed by control system design. This chapter covered component map scaling, component map extrapolation, gain scheduling and fuel scheduling, leading to an overall control system design solution. The following chapter will cover the validation of the dynamic model and the control system design solution. 


\section{Chapter 6 Results and Discussion}

The elaboration of a gas turbine dynamic model and the design of a control system for a 1-MW gas turbine were presented in details in Chapter 5. The scope of this chapter is to compare the simulation results obtained from the dynamic modeling and control system design methods to simulation results produced by the performance software GasTurb 10. The purpose of this task is to validate the results of the proposed methods and to build confidence in their ability to meet the design requirements.

The first part of this chapter will cover the gas turbine dynamic model validation results. This includes the validation of the transient performance, extrapolated component maps and finally sub-idle dynamic modeling. To keep the discussion to a reasonable length, the validation of design point and off-design steady-state thermodynamic equations will be covered in Appendix C. The second part of the chapter will cover control system design analysis and validation results. In this section, various control system response analyses will be conducted in effort to assess the usefulness of the control system design method.

\subsection{Gas Turbine Dynamic Model Validation}

To build confidence in a dynamic model, performance simulations are usually validated using experimental data. However experimental data is only available late in the development stage of the gas turbine design. Since the focus of this thesis was to develop functional tools early in the design process, an alternate validation strategy was required. A common validation procedure in industry, used early in the design process, is to validate against a pre-validated dynamic model or against an in-house validated performance software. Another option is to use a well known, well established performance modeling software available commercially. In this case, the second alternative was chosen to validate the dynamic model outputs. The commercial 
performance modeling software called GasTurb 10 was selected as the validation tool for this project.

GasTurb is a gas turbine performance simulation program written and distributed by former MTU Aero Engines employee Joachim Kurzke. Based around a comprehensive set of pre-defined engine configurations, the program performs design point, off-design and transient performance modelling, parametric studies, cycle optimisation and Monte Carlo simulations. The program is widely used both in the power generation and propulsion industries and in teaching institutions (Wikipedia, 2007). The performance code GasTurb is publicly available since 1995 and has been steadily improved over the years. The software has been the main subject or part of published papers yearly since 1995 as part of the ASME Turbo Expo conferences organized by of the International Gas Turbine Institute and recognized as a useful performance software benchmarking tool for both industrial and academic settings.

To validate the dynamic model, a pre-defined turboshaft engine layout, available in the GasTurb software, was selected (Figure 6.1). This engine layout was selected as it mimicked closely the current marine gas turbine application. As shown below, the selected layout is a twin-spool engine (gas generator with free power turbine) with engine bleeds.

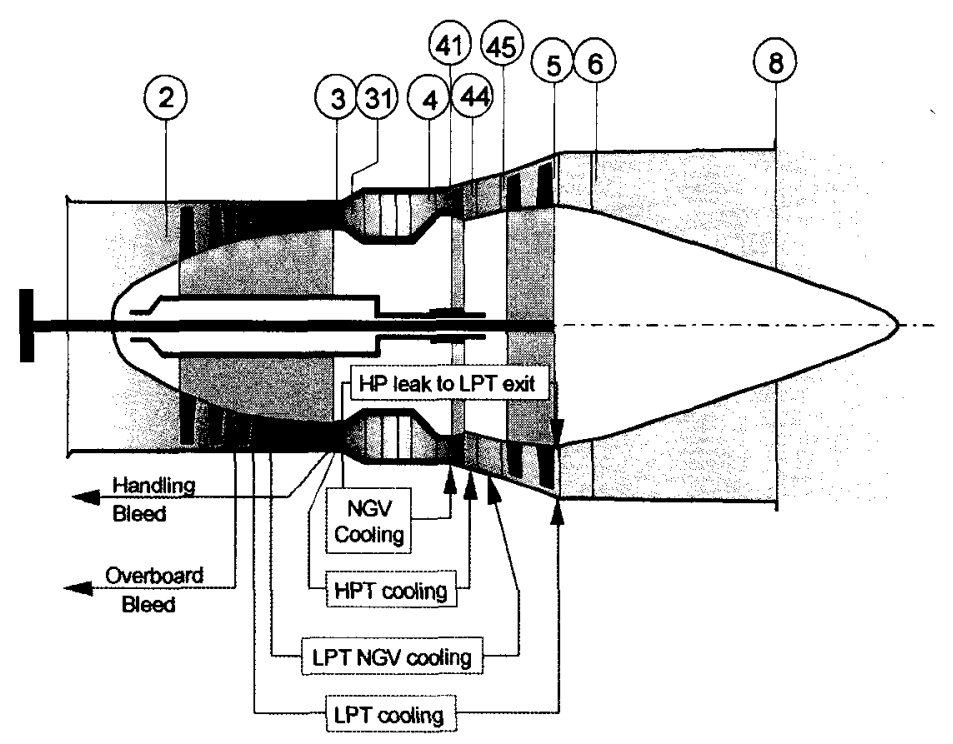

Figure 6.1: GasTurb 10 pre-defined turboshaft engine layout 
Similarly to the dynamic modeling method, only a minimum of design point parameters were required by the performance software to generate the design point and off-design performance data (Figure 6.2).

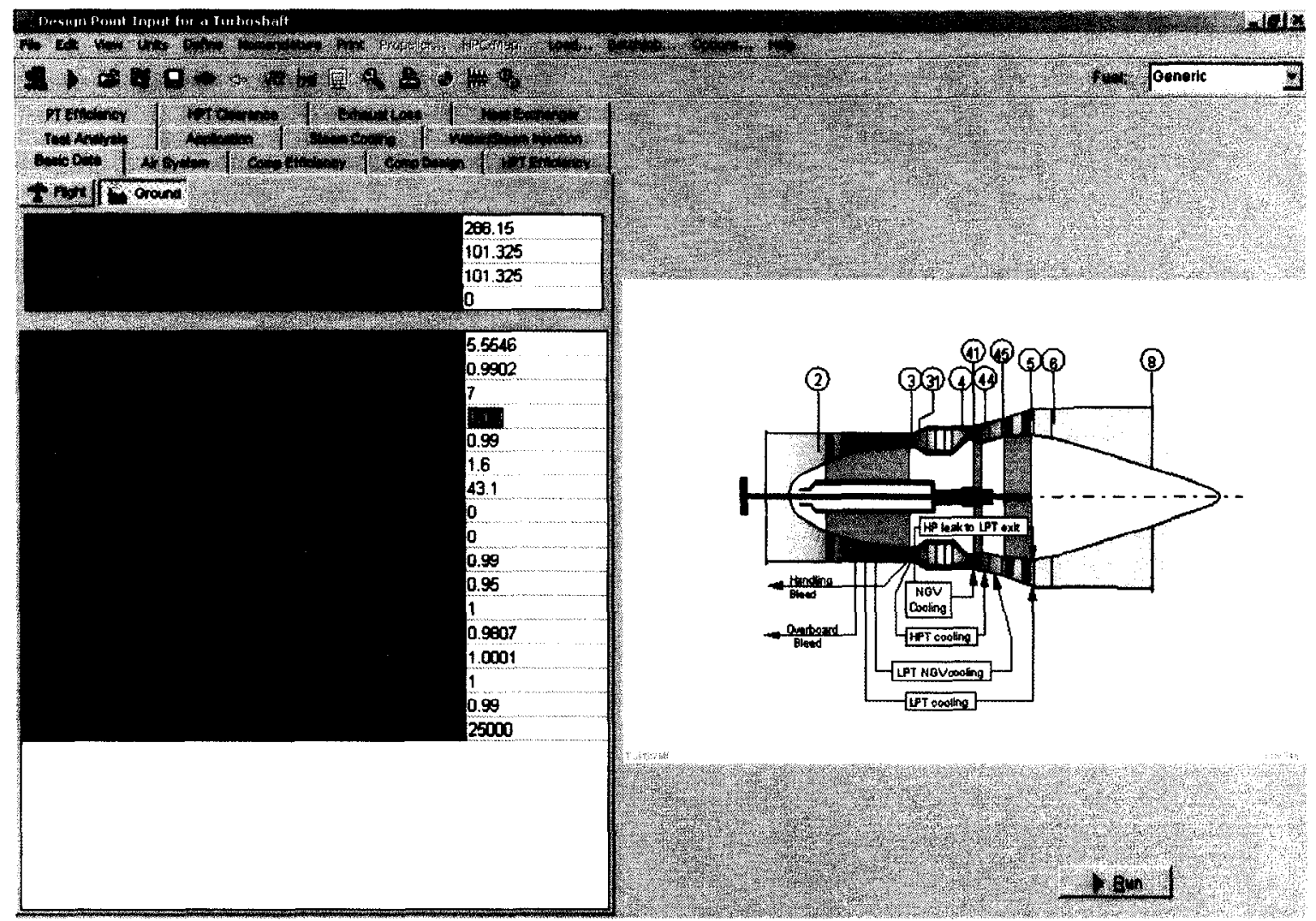

Figure 6.2: GasTurb 10 design point inputs for a turboshaft engine

Based on these given parameters, which can be found in Section 5.1.3, the resulting design point, off-design and transient performance trends were produced using the GasTurb software and used to validate the dynamic model.

Since the dynamic model covered a wide range of operating conditions, the validation process was sub-divided into three sections: design point validation, off-design steady-state validation and off-design transient validation. However since the main focus of this chapter was to report on the dynamic model algorithm implementation, only the 
off-design transient validation was covered in this section. The validation of the design point and off-design steady-state thermodynamic equations implementation was covered in Appendix C.

\subsubsection{Off-design - Transient Validation}

Off-design transient validation was done to verify the accuracy and validity of the dynamic model transient response. Following the same validation strategy established for steady-state operations, the transient responses of key engine parameters were assessed using GasTurb as the benchmark. Constant power turbine spool speed had to be assumed due to GasTurb load modeling limitations.

The first part of the validation strategy dealt with analyzing the transient response of the engine by plotting the transient operating line on the compressor map. The transient manoeuvres were induced through predefined fuel steps. However, since there was a possibility of generating an infinite number of transient operating lines throughout the operating regime (from idle to design point), the validation strategy had to be further defined to limit data analysis to a minimum while building confidence in the modeling capabilities. Since the off-design steady-state operating points were already validated (see Appendix C), it was decided to analyze the transient response from one validated steady-state operating point to another. Even though GasTurb had great capability for design point and off-design steady-state performance modeling, it had limited capability for transient performance modeling. GasTurb was coded to perform transient manoeuvres around the design point mainly. As a result, it was decided to validate the dynamic model using four transient manoeuvres: two accelerations and two decelerations around the design point (from $\mathrm{N}_{\mathrm{gg}}=22400$ to $28000 \mathrm{RPM}$ ) from one validated steady-state operating point to another. The manoeuvres were as follow

- Deceleration 1: $\mathrm{N}_{\mathrm{gg}}=28000$ to $25200 \mathrm{RPM}$

- Deceleration 2: $\mathrm{N}_{\mathrm{gg}}=25200$ to $22400 \mathrm{RPM}$

- Acceleration 1: $\mathrm{N}_{\mathrm{gg}}=22400$ to $25200 \mathrm{RPM}$

- Acceleration 2: $\mathrm{N}_{\mathrm{gg}}=25200$ to $28000 \mathrm{RPM}$ 
The four manoeuvres were plotted on the same compressor maps and analyzed for discrepancies (Figure 6.3).

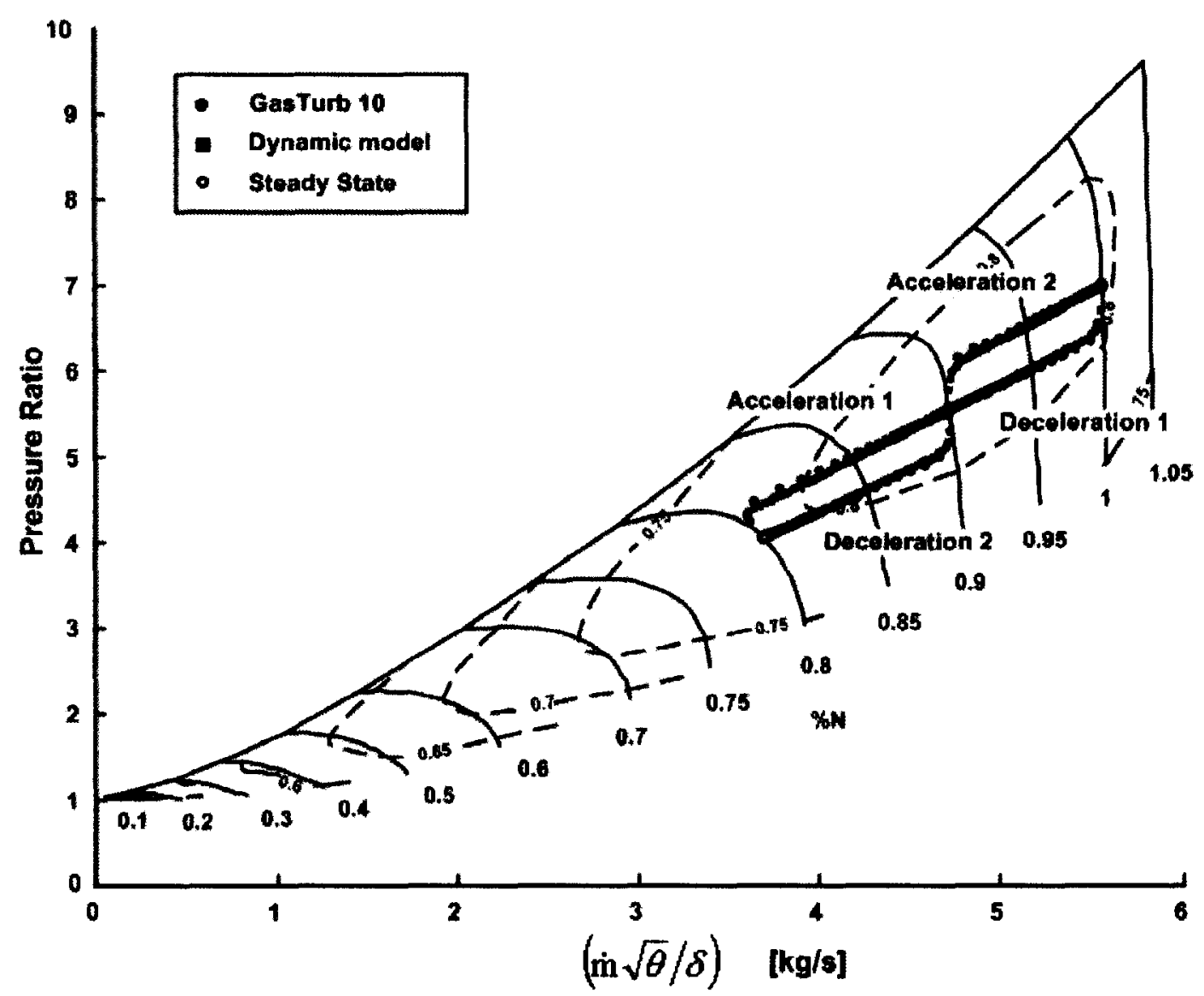

Figure 6.3: Transient manoeuvres plotted on compressor map

As seen from Figure 6.3, there was a good correlation between the dynamic model and GasTurb. However, upon closer examination of the transient operating lines, it was found that there were slight discrepancies in the trends at the beginning of the transient manoeuvres. By plotting the error between GasTurb and the dynamic model as function of time (Figure 6.4), spikes in the pressure ratio and mass flow error were discovered at the beginning of each transient manoeuvres. 


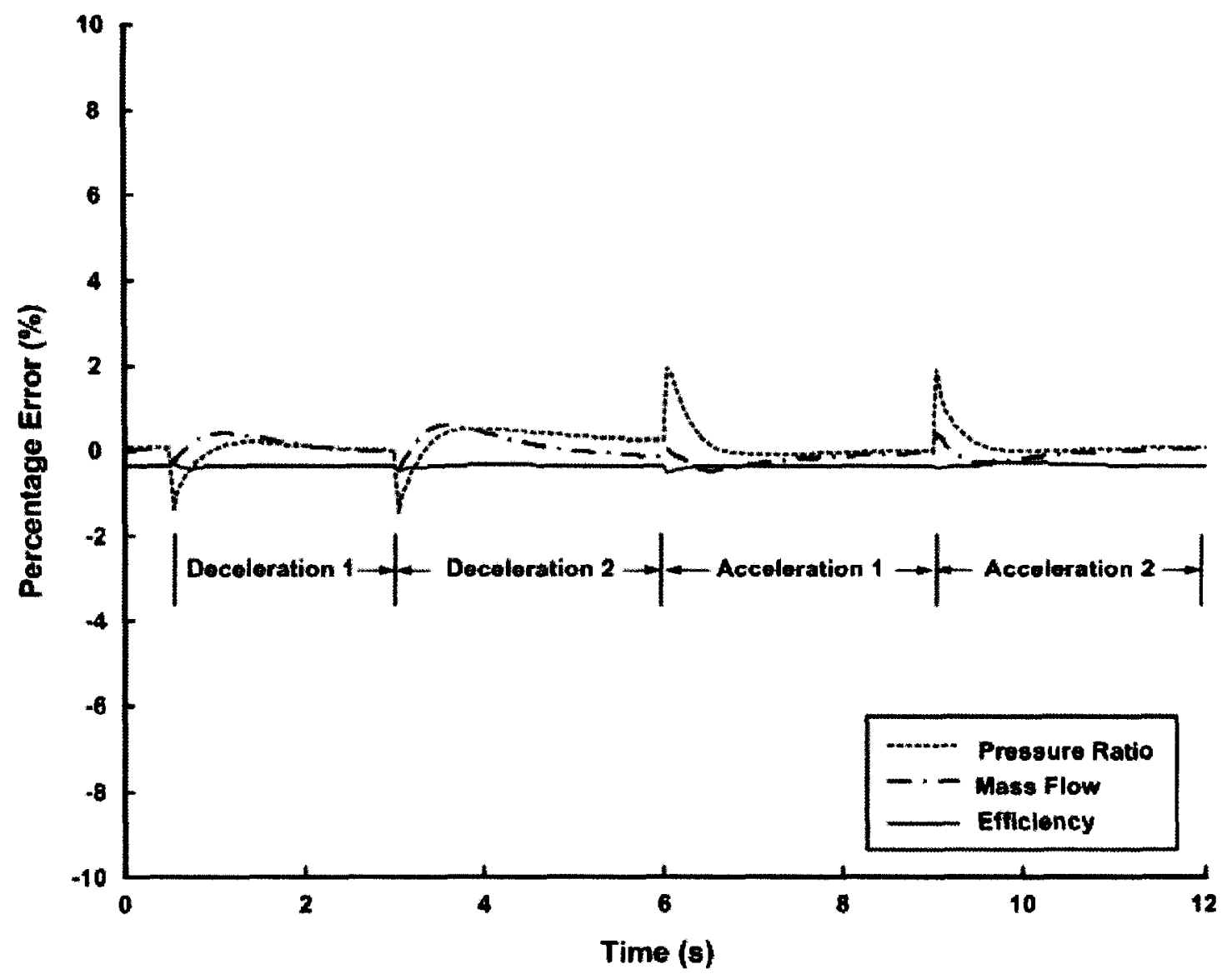

Figure 6.4: Transient operating line error

Looking through the literature review for answers, it was determined that these sudden jumps in mass flows and pressure ratios during transient manoeuvres were characteristics of the method used to model the transient performance. In fact, it was found that GasTurb used the iterative method, which ignores volume dynamics. On the other hand, the dynamic model used the inter-component volume method, which considers volume dynamics. This explained the discrepancies observed at the beginning of each transient manoeuvres (same as shown in Figure 2.6). Even though both modeling methods produced similar transient results, it is believed, based on Fawke and Saravanamuttoo, (1971), that the dynamic model produced better overall transient responses (realistic) than GasTurb. Therefore neglecting the spikes, it was concluded that the errors shown in Figure 6.4 fell well within acceptable limits. 
The second part of the transient validation strategy was done to assess the dynamic modeling accuracy of engine parameters linked to the control system. The assessment was done using the data generated from the 4 transient manoeuvres detailed previously. The engine parameters assessed were:

- gas generator spool speed $\left(\mathrm{N}_{\mathrm{gg}}\right)$

- compressor exit pressure $\left(\mathrm{P}_{02}\right)$

- gas generator turbine inlet temperature (TIT)

- fuel-to-air ratio (F/A)

- fuel flow $\left(\dot{\mathrm{m}}_{\mathrm{f}}\right)$

The resulting parameter responses were plotted as a function of time and are shown in Figure 6.5 to Figure 6.9 .

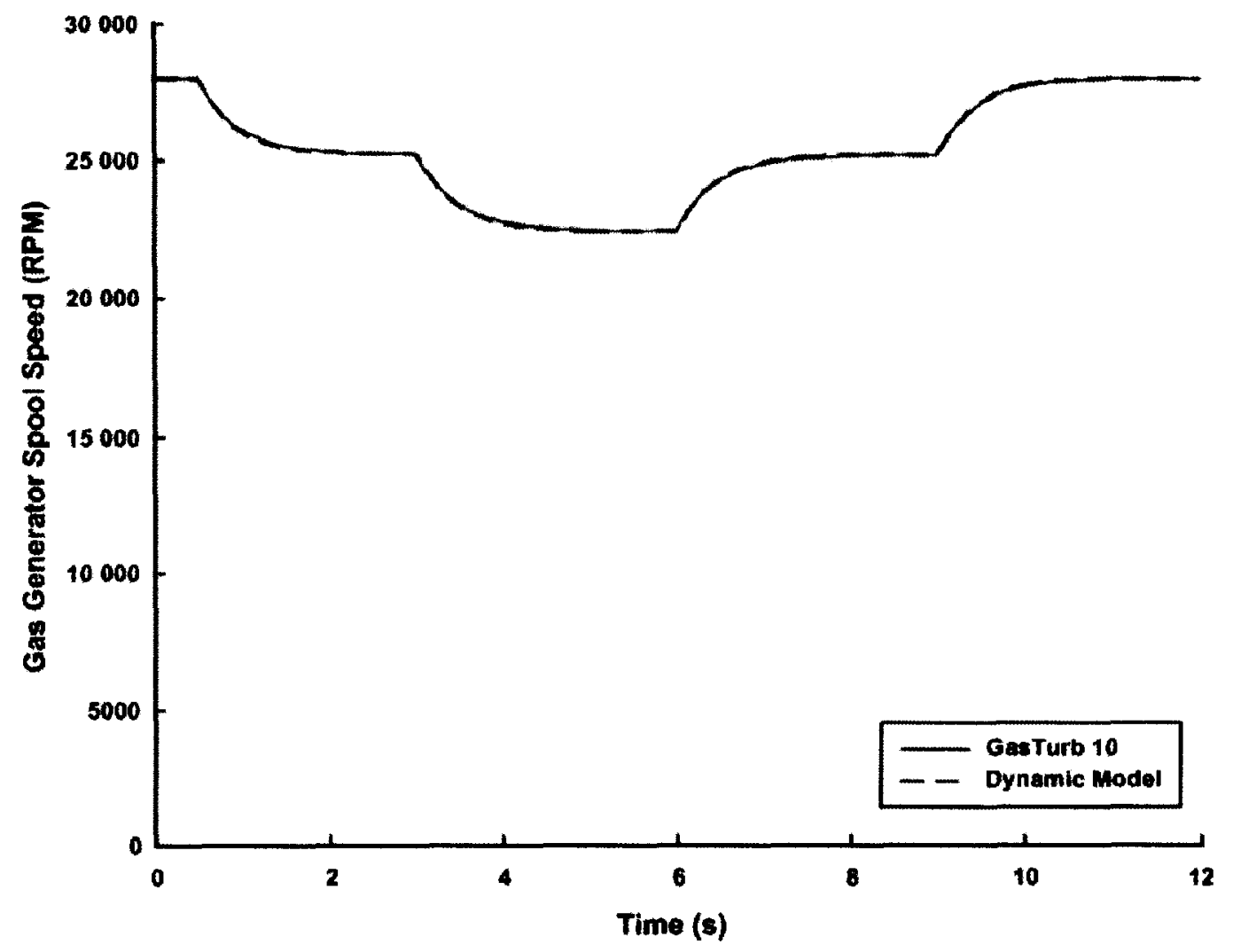

Figure 6.5: Gas generator spool speed transient response comparison 


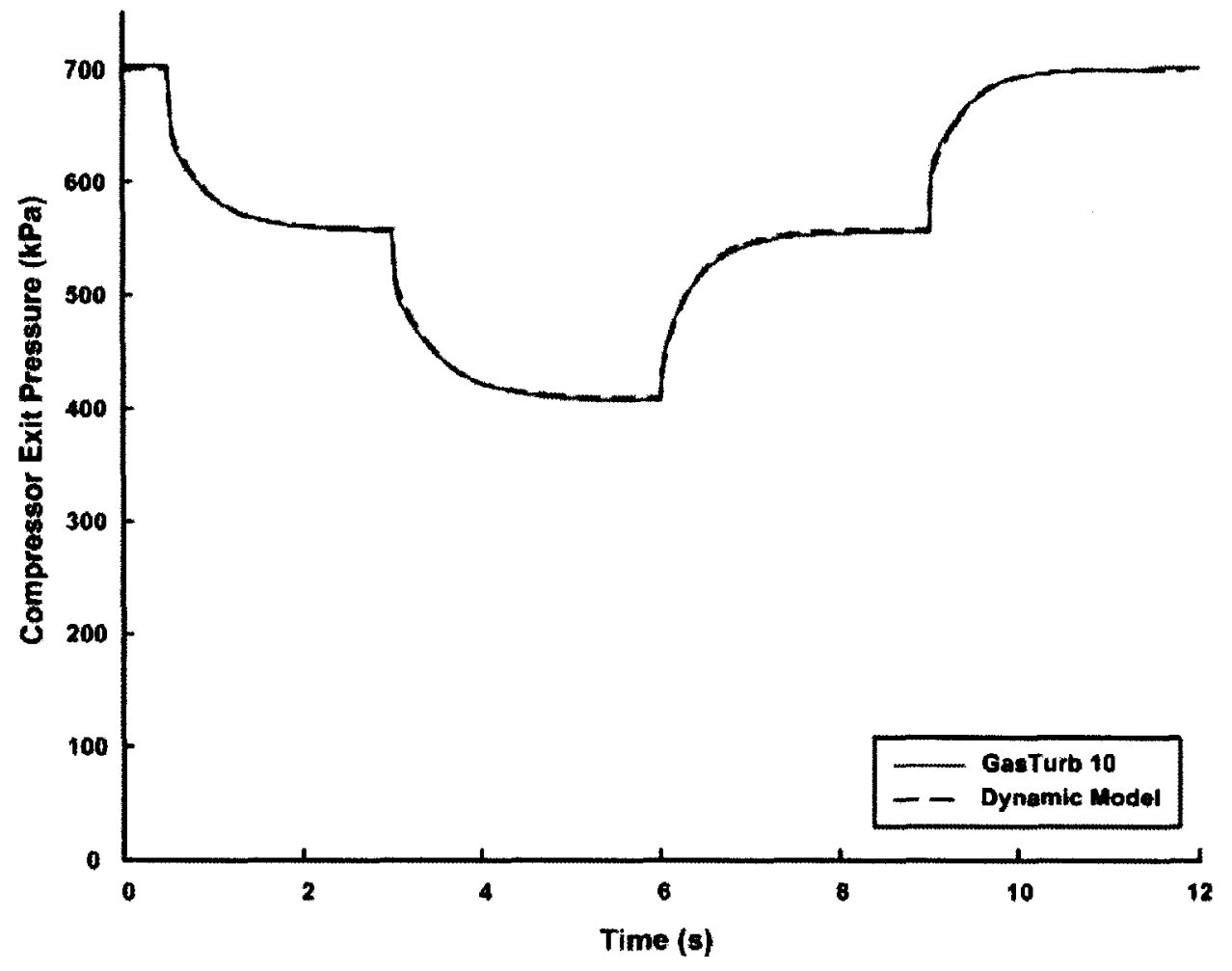

Figure 6.6: Compressor exit pressure transient response comparison

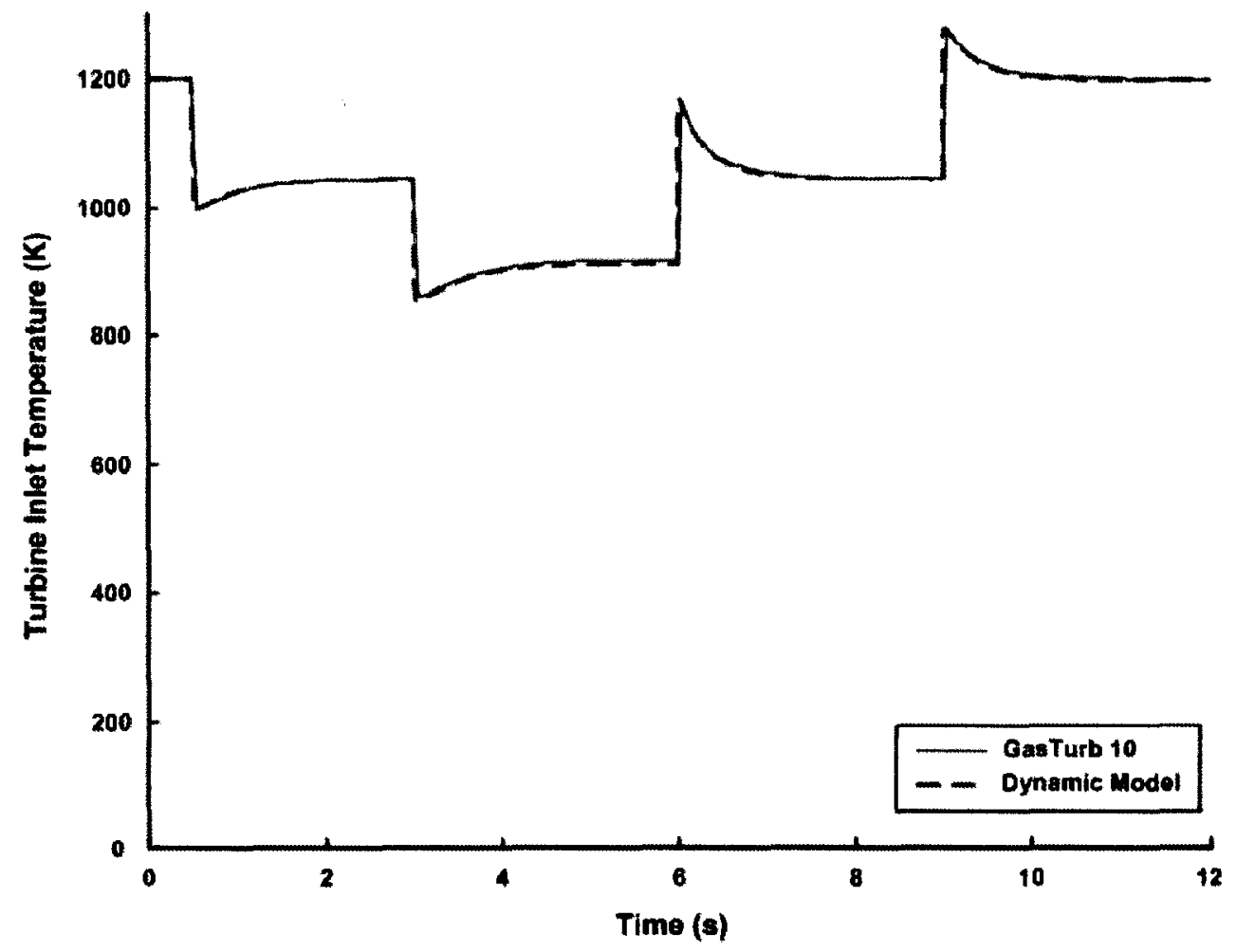

Figure 6.7: Gas generator turbine inlet temperature transient response comparison 


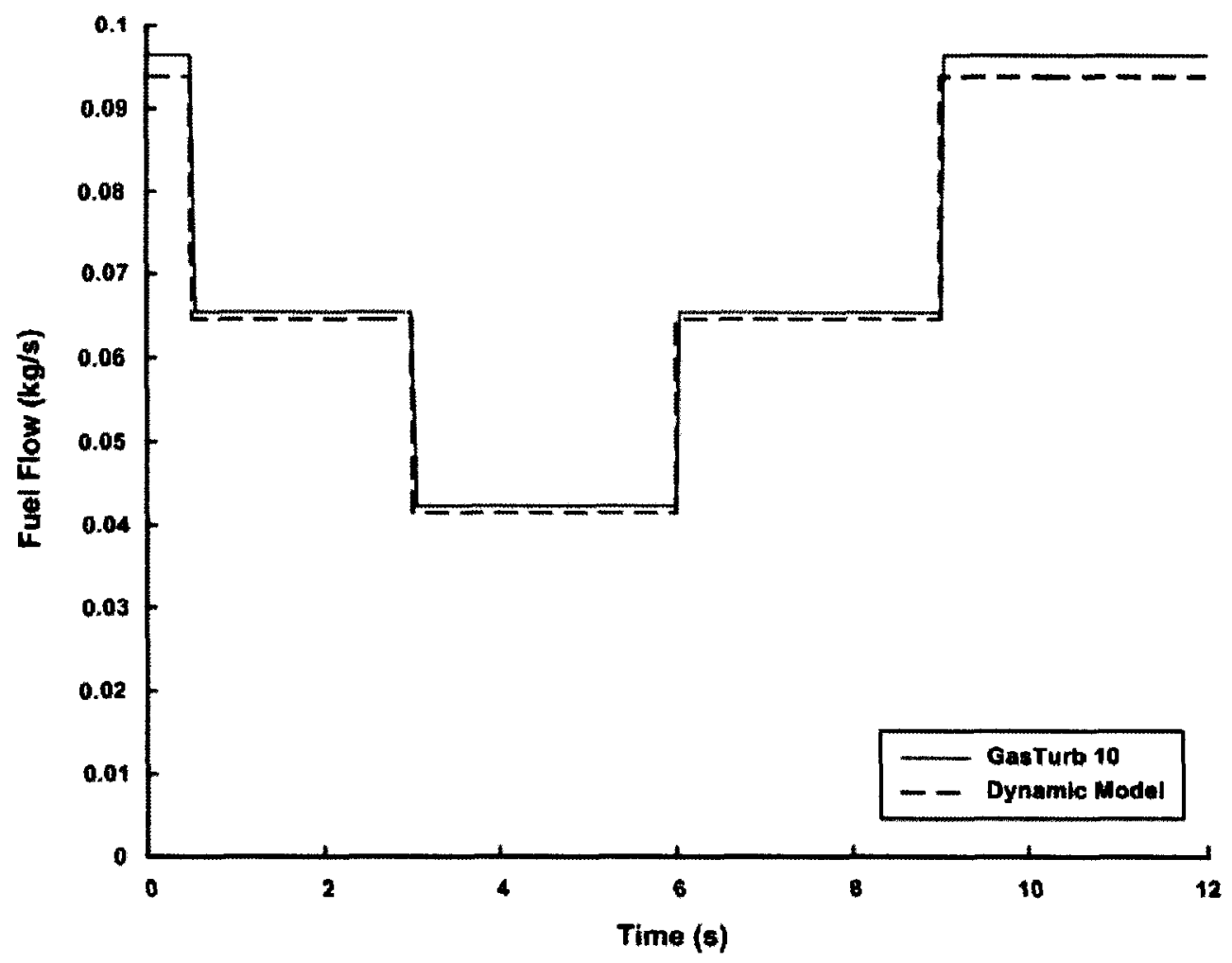

Figure 6.8: Fuel flow transient response comparison

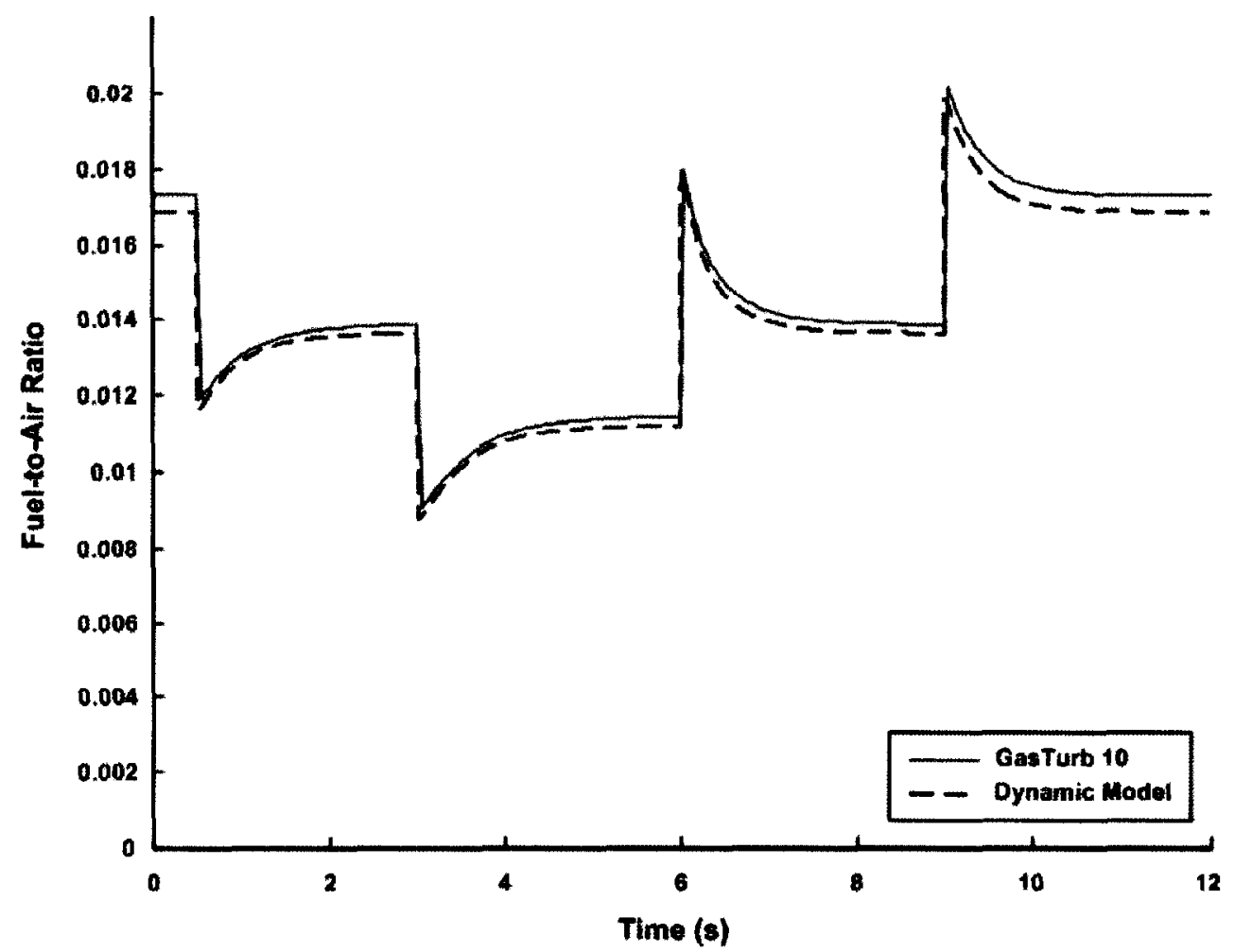

Figure 6.9: Fuel-to-air ratio transient response comparison 
Again these plots show a good correlation between the dynamic model and GasTurb. The temperature spikes observed in Figure 6.7 were expected, as they are representative of a fuel step engine response. The temperature dynamics are instantaneous while pressure and spool speed take more time to react, as they are dependant on volume and inertia. However, instantaneous temperature response is an assumption taken in both the dynamic model and GasTurb to simplify the dynamic modeling calculations. As the design progresses and the requirement to validate the dynamic model response against experimental data surfaces, heat soakage and combustion delay effects will have to be added to the dynamic model. These will have the effect of slowing down the temperature response of the engine and hence slightly altering the overall engine response.

The slight discrepancies observed on Figure 6.8 and Figure 6.9, were mainly caused by the dissociation effects discussed earlier. Combustion efficiency also played a part in the fuel flow error, however since the analysis was done close to design point, the error generated between the between the dynamic model and the GasTurb was less apparent.

Additionally, by depicting the fuel-to-air ratio transient response as per Figure 6.9 , the possibility of combustion stability issues during large fuel step changes was exposed. The graph showed that a rapid decrease in fuel flow led to a rapid decrease in fuel-to air ratio, which created situations where the minimum fuel-to-air ratio came close to exceeding the flameout limit. This is because the fuel system response was faster than the engine mass flow response (which depends on turbomachinery inertia and volumes). It is important that these dynamics be considered when designing the engine control system.

To finalize the transient validation strategy, the error of each engine parameters linked to the control system were plotted on the same graph and assessed. As shown in Figure 6.10, the errors fell within the errors accepted for design point and steady-state 
off-design validation. Again to re-iterate, the peaks observed on the graph were caused by the lack of volume dynamics considered within GasTurb.

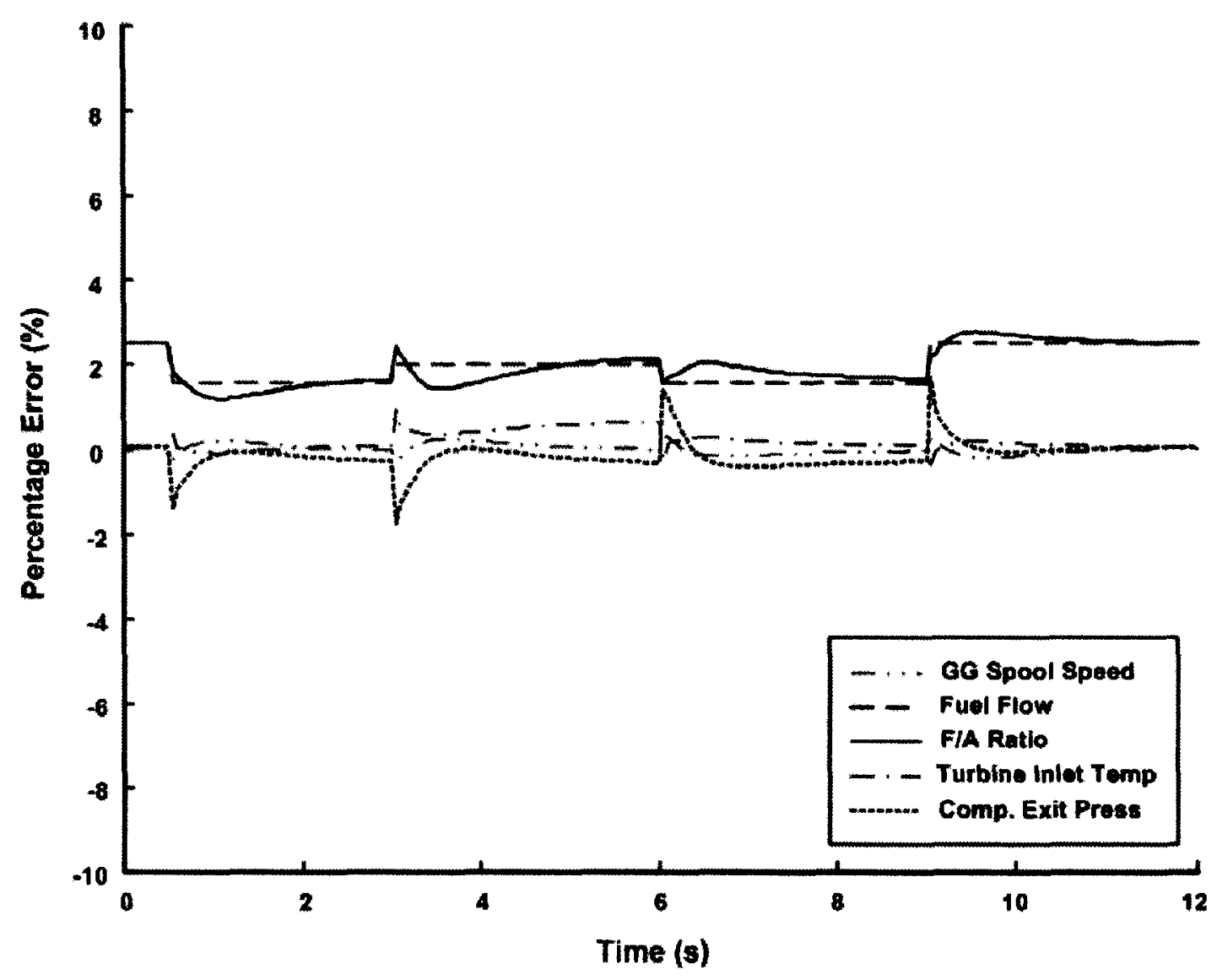

Figure 6.10: Transient percen error - engine parameters linked to the control system

Even though the transient validation strategy took place on part of the total operating region, the dynamic modeling fundamentals were validated. Using analogy, the remaining operating regimes were validated based on data available from the off-design steady-state validation. It was determined that the dynamic model accuracy would slightly decrease with decreasing operating speed due to effects of combustion efficiency. The discrepancies created due to lack of volume dynamics within GasTurb was also expected to increase for larger fuel step (larger transient manoeuvres), but overall would remain within acceptable limits for this project. 


\subsection{Sub-idle Dynamic Model Validation}

The sub-idle dynamic modeling validation strategy was fairly straightforward. The sub-idle steady-state and transient validation was done through analogy because there were no benchmarks available in the sub-idle regime. As explained previously, GasTurb can only perform steady-state calculations from idle speed to design point, and transient performance calculations around the design point. Since a reduction of accuracy was already expected while performing sub-idle performance modeling early in the design process, it was determined that the actual accuracy of the sub-idle model was not required for validation. However emphasis was placed on demonstrating the validity of the sub-idle modeling methods and building confidence in the model.

As explained in the literature review and in the sub-idle modeling method, dynamic modeling equations are valid throughout the operating regime. This said, the validated dynamic modeling equations for steady-state and transient performance modeling above idle should produce similar result below idle speed. Based on this assumption, sub-idle steady-state operating points were generated and sketched along with the validated steady-state operating points on the same compressor map to verify for discontinuities in the results. As seen from Figure 6.11, there were no discontinuities in the data. The sub-idle steady-state operating line simply extended the validated operating line well into the sub-idle regime. 


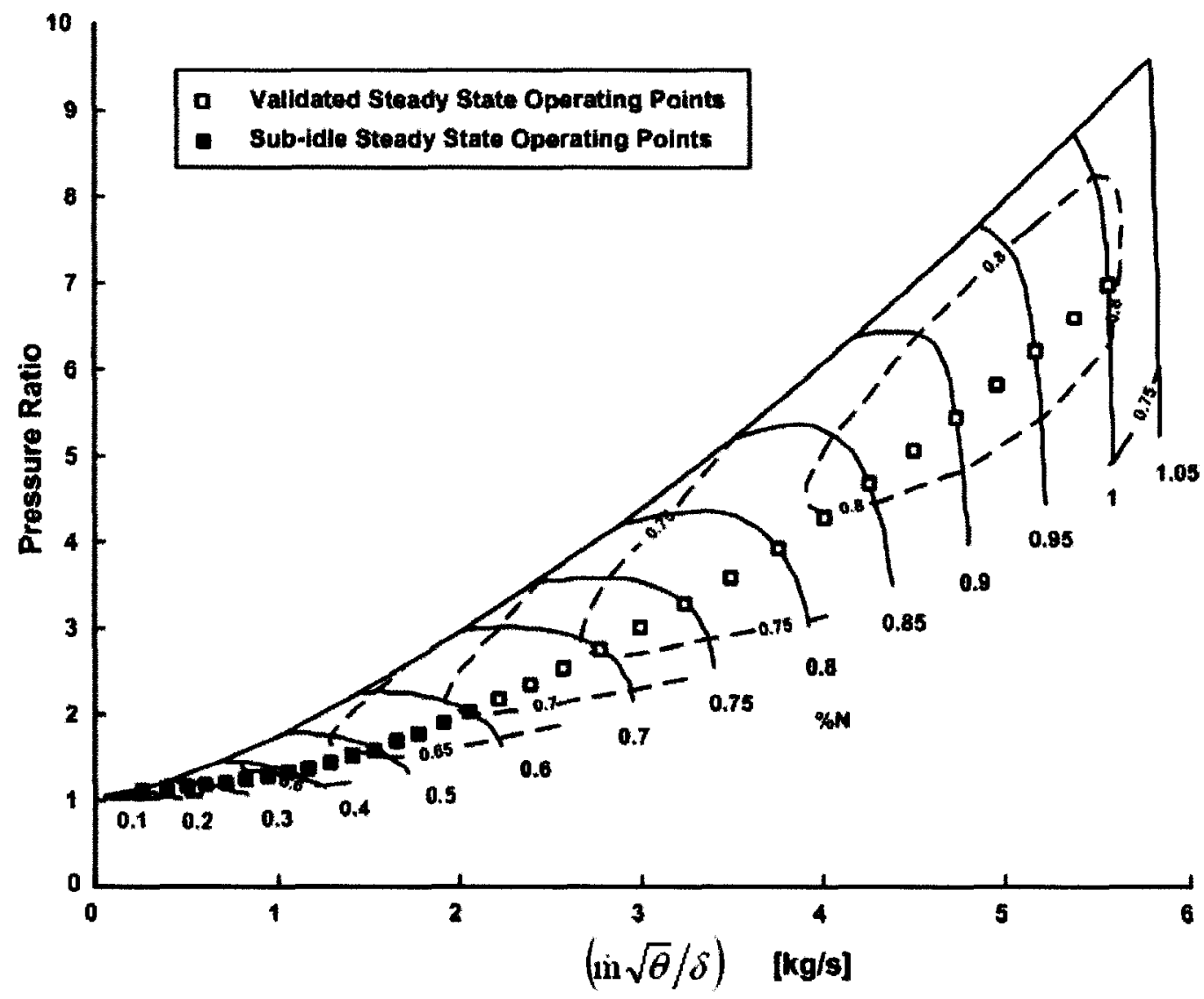

Figure 6.11: Sub-idle steady-state operating points

In the same mindset, a transient manoeuvre was performed in the sub-idle region to verify if the transient dynamic modeling calculation behaved as expected. The transient manoeuvre was initiated by a fuel step (as shown in Figure 6.12), which led to a small spool speed acceleration from one steady-state operating point to another. The resulting transient operating line was then plotted on the compressor map (shown in Figure 6.13). Based on this graph and additional key engine parameter responses (Figure 6.14 to Figure 6.16), it was determined that the sub-idle transient calculations produced transient responses similar to the transient characteristics discussed earlier as part of the transient validation discussions. 


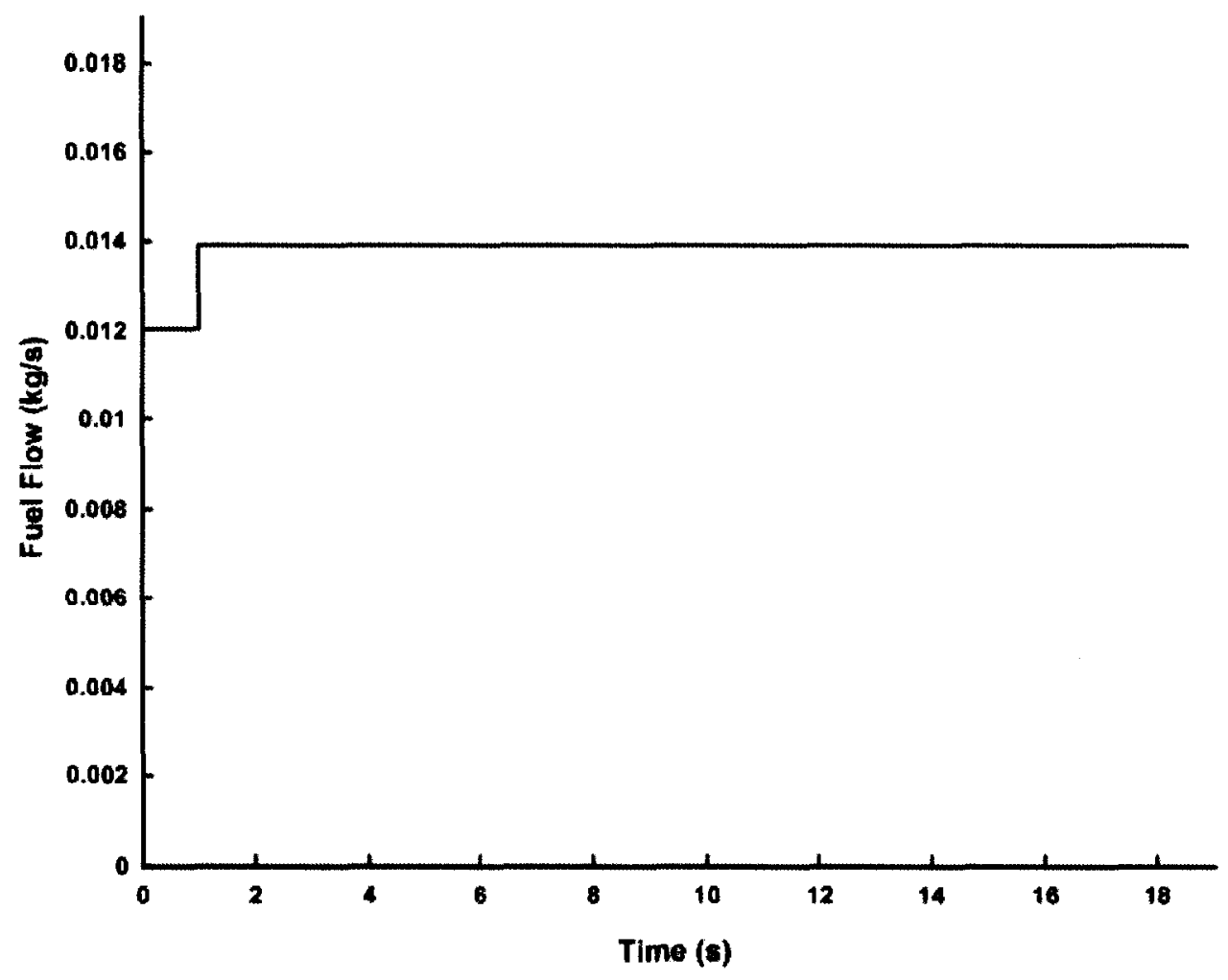

Figure 6.12: Transient fuel step

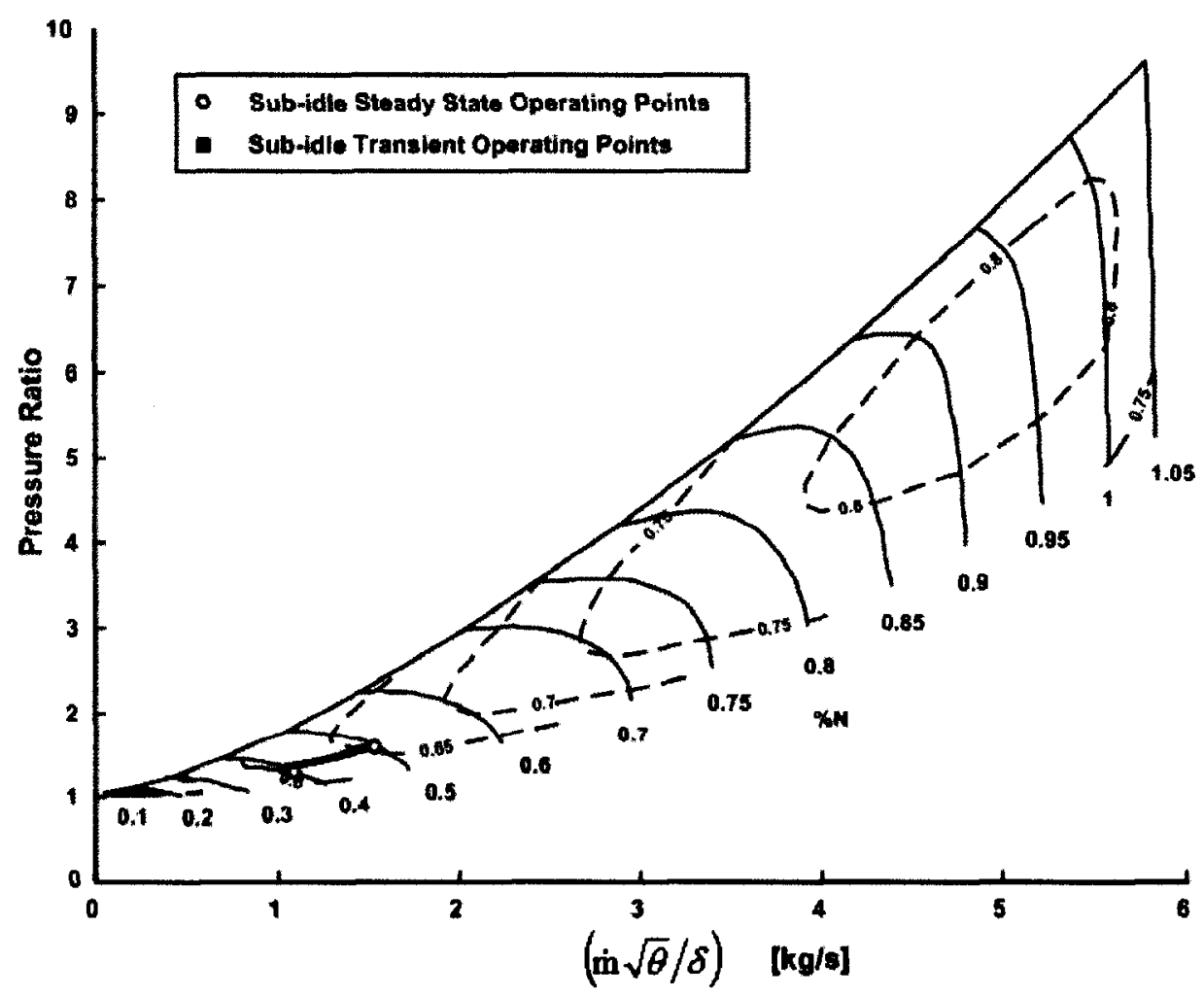

Figure 6.13: Sub-idle transient operating line 


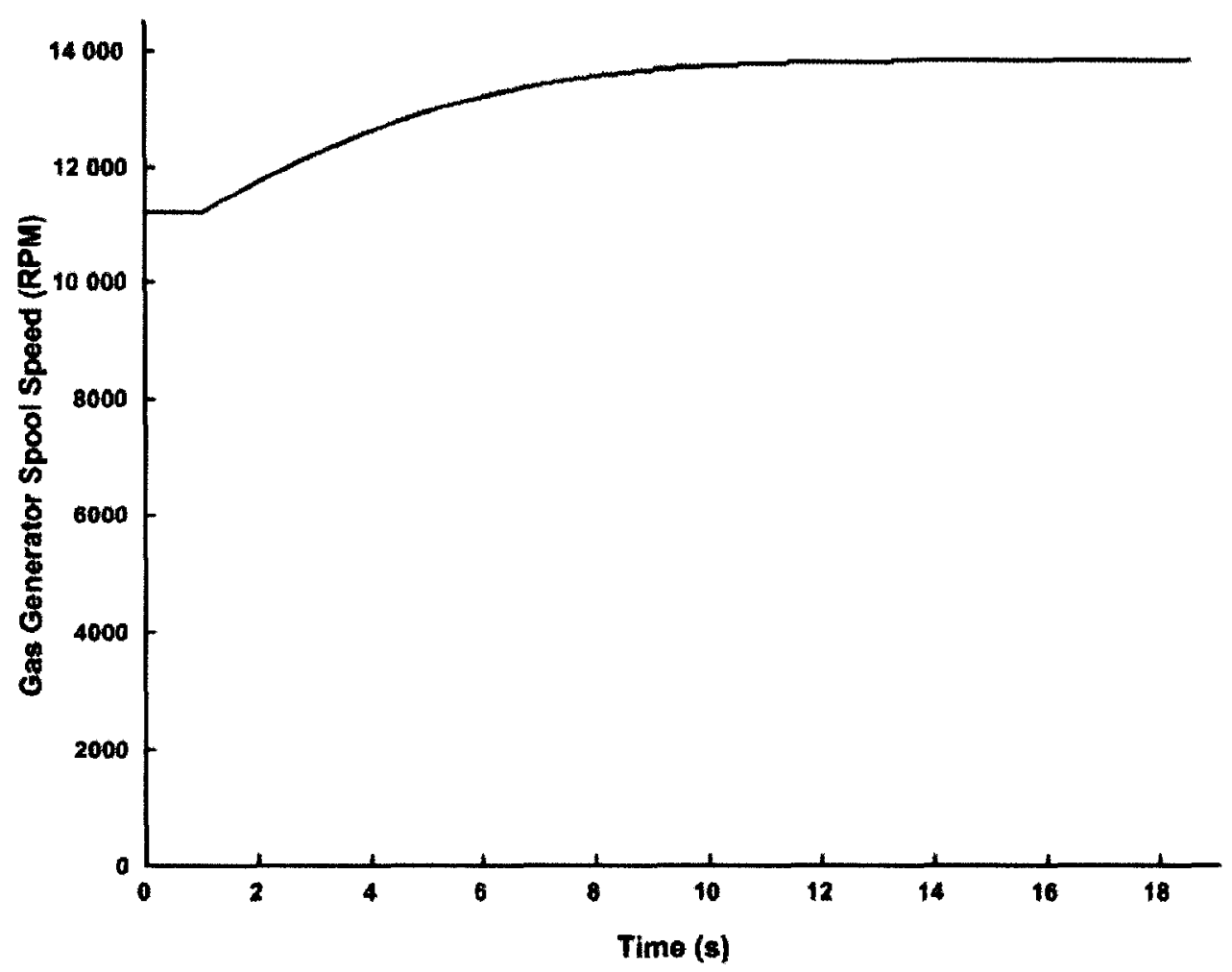

Figure 6.14: Sub-Idle gas generator spool speed transient response

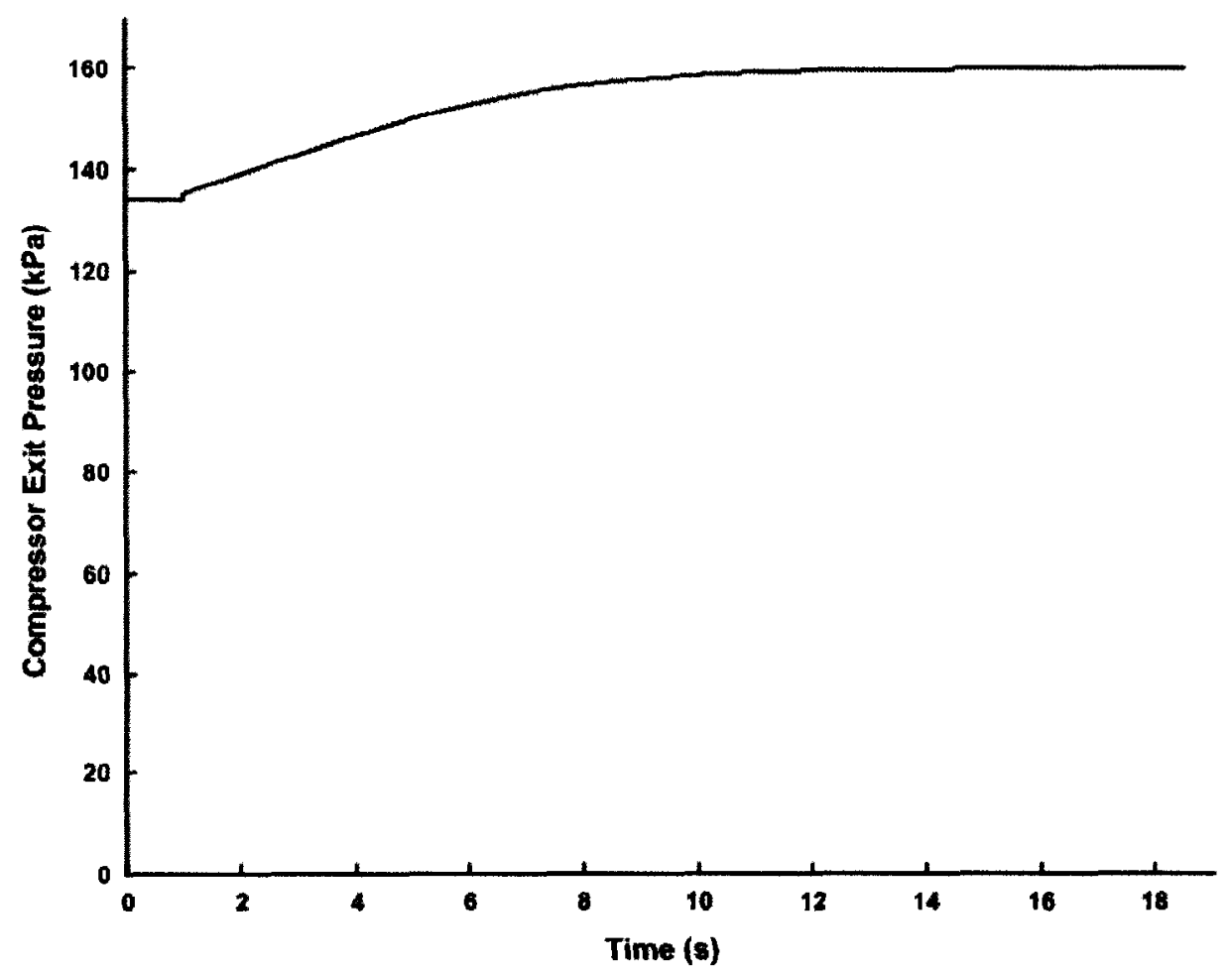

Figure 6.15: Sub-idle compressor exit pressure transient response 


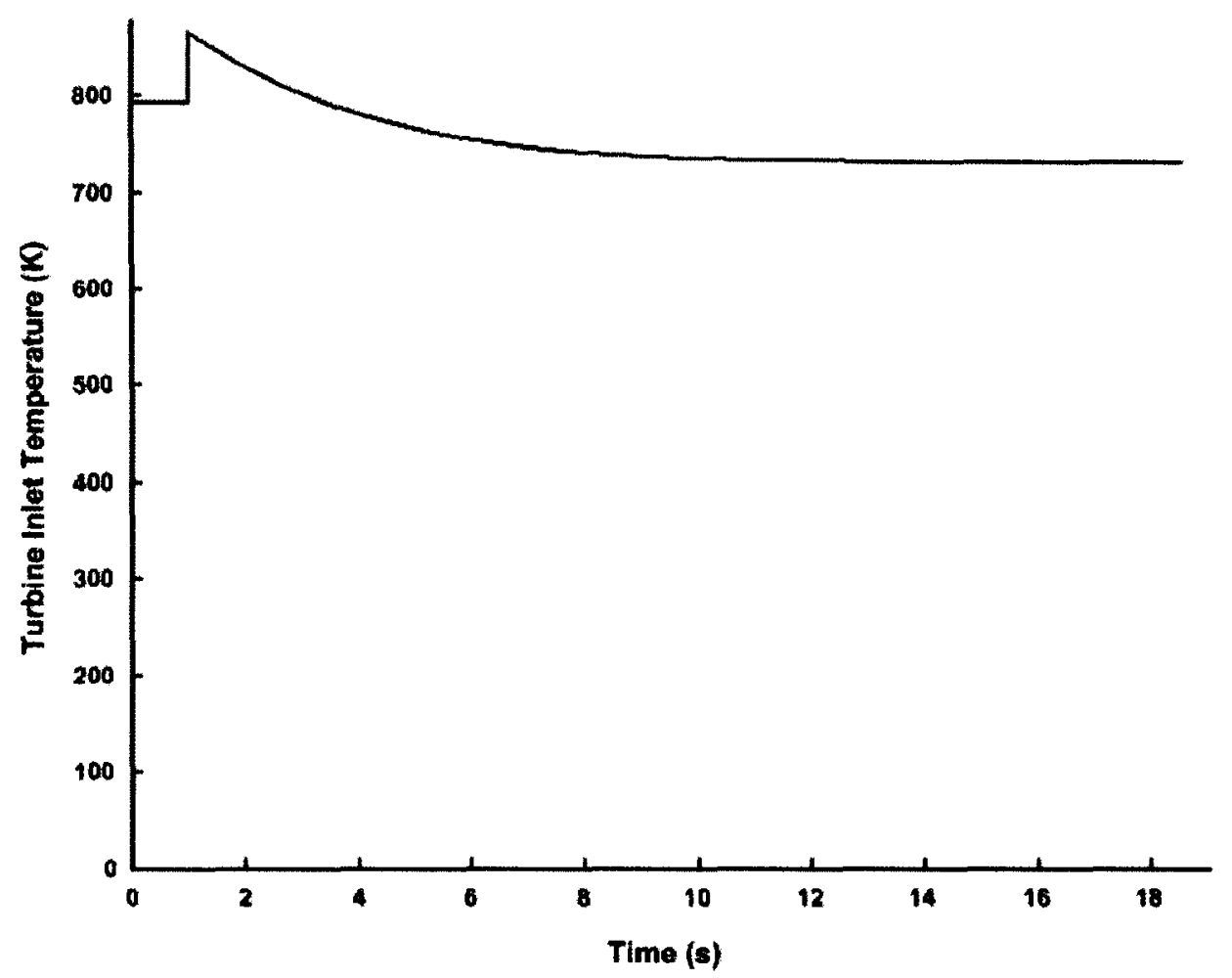

Figure 6.16: Sub-idle gas generator turbine inlet temperature transient response

Further investigating Figure 6.16, it seemed counter intuitive that the steady-state gas generator turbine inlet temperature would decrease after a fuel step increase. However, it was found that this could be explained by plotting the steady-state fuel-to-air ratio as function of gas generator spool speed. As shown in Figure 6.17, the sub-idle fuelto-air ratio increased with decreasing spool speed explaining the higher turbine inlet temperatures observed at the lower speed. 


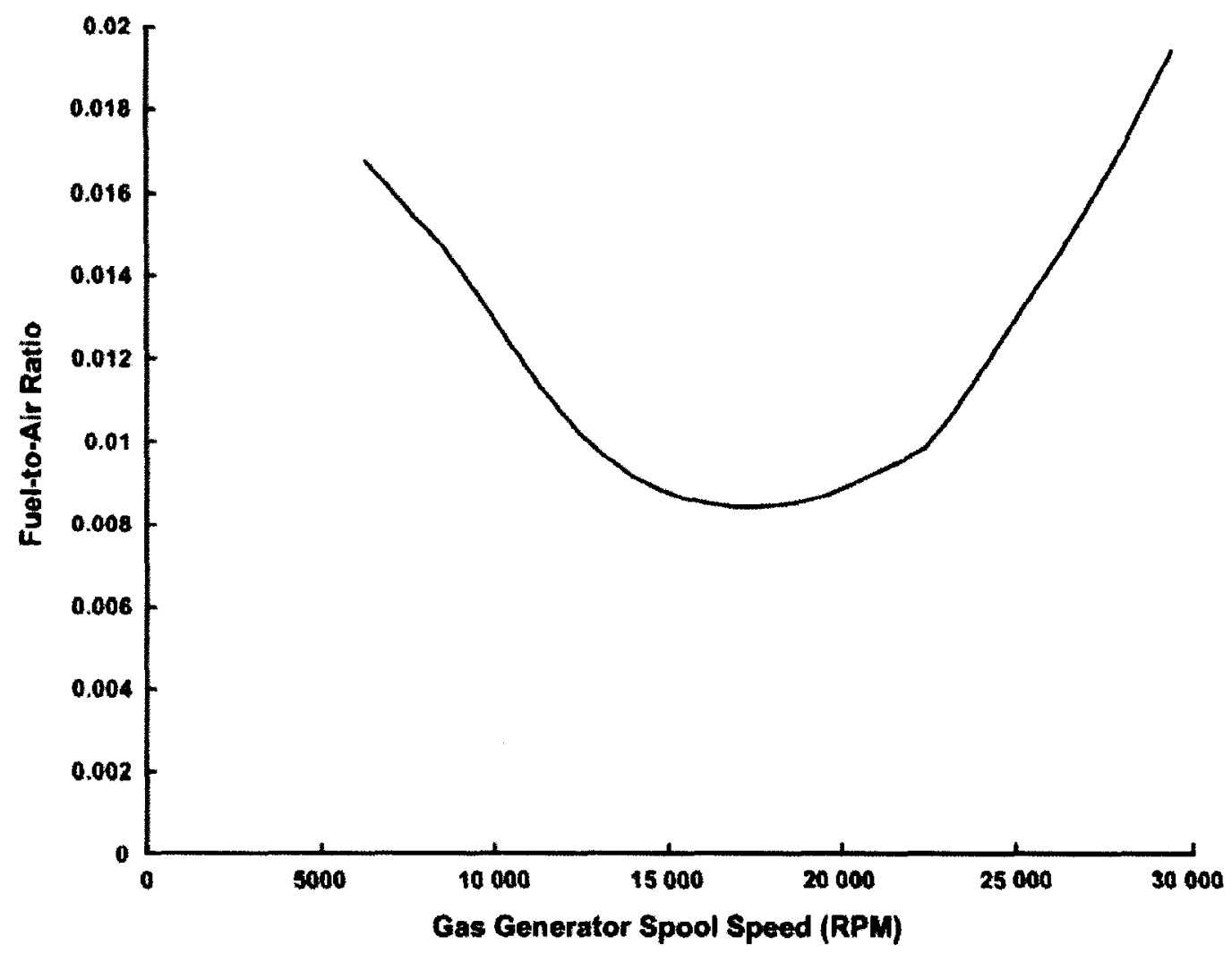

Figure 6.17: Steady-state fuel-to-air ratio

Based on the previously discussed results, it was determined that the dynamic modeling equations produce acceptable results well into the sub-idle regime, which demonstrated the validity of the sub-idle modeling methods. Even though the accuracy of these calculations was not quatified, the validation step increased the confidence level in the sub-idle dynamic model.

\subsubsection{Extrapolated Component Map}

The purpose of the sub-idle dynamic modeling validation exercise was mainly aimed at proving that the dynamic modeling equations could be applied throughout the operating range. However, these equations rely on information available within the turbomachinery characteristics. Since the accuracy of these characteristics directly impacts the accuracy of the dynamic model, an assessment of the extrapolated component maps was required. However, since detailed component maps are rarely produced from zero to design speed, the comparison between the extrapolated maps and experimental 
data could not be used as a validation step. To fix this situation, the integrity of the extrapolated component maps was estimated using the given component maps only. To build confidence in the extrapolated speed lines, the validation steps consisted of applying the extrapolation method to the mid-section of the given component maps to produce an overlapping between extrapolated and original speed lines. The discrepancies between the extrapolated and the original speed lines were then used to judge the validity of the extrapolation process.

As seen from Figure 6.18, the speed lines $\mathrm{a}$ and $\mathrm{b}$ on the given compressor map were used to generate an extrapolate speed line as per the method describe in Section 3.4.1. It became apparent from this exercise that there were discrepancies between the extrapolated and the original characteristics.

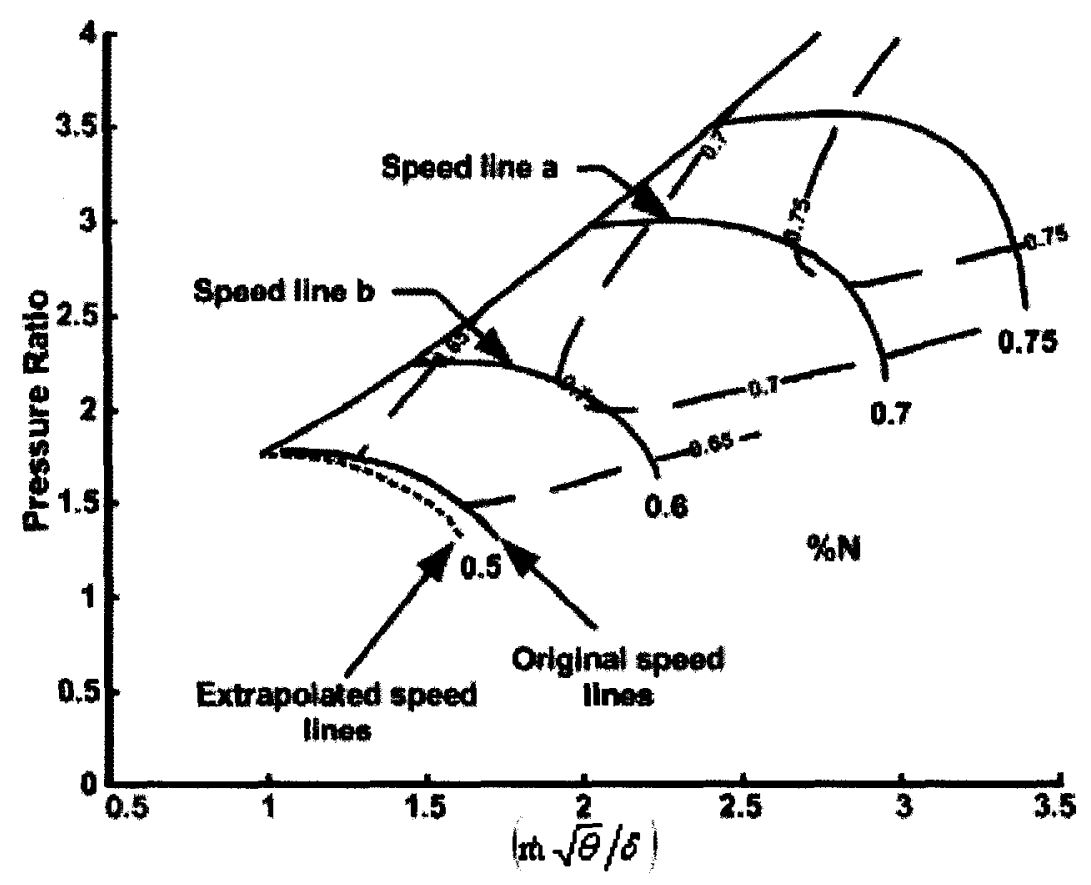

Figure 6.18: Compressor map speed line comparison

To further visualize the differences between the speed lines, the mass flow, pressure ratio and efficiency error were generated as a function of beta line and plotted in Figure 6.19. 


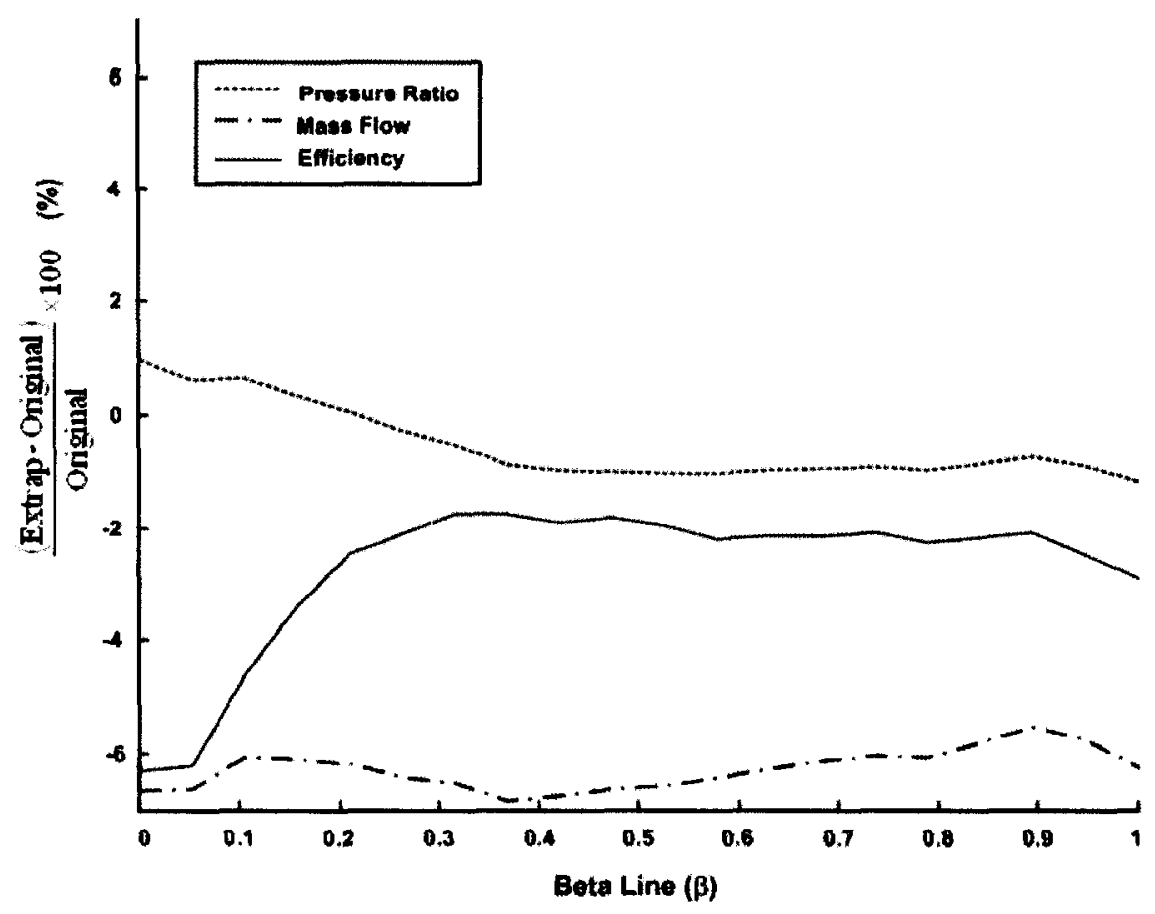

Figure 6.19: Compressor map extrapolation error

With a maximum error of $6.9 \%$, it was determined that the extrapolation method did produce an acceptable extrapolated speed line for a region were a slight decrease in accuracy was already expected. However, it is important to note that this validation step was done to a region where compressibility effects are assumed to be more pronounced then those found in the sub-idle regime. As a result, it is expected that the extrapolation error will decrease in the sub-idle regime.

The same validation strategy was applied to the gas generator turbine and power turbine characteristics. Figure 6.20 was used to summarize the gas generator turbine map errors and demonstrated a good correlation between extrapolated speed line and the original speed line. However, as shown in Figure 6.21, this was not the case for the power turbine extrapolated characteristics. 


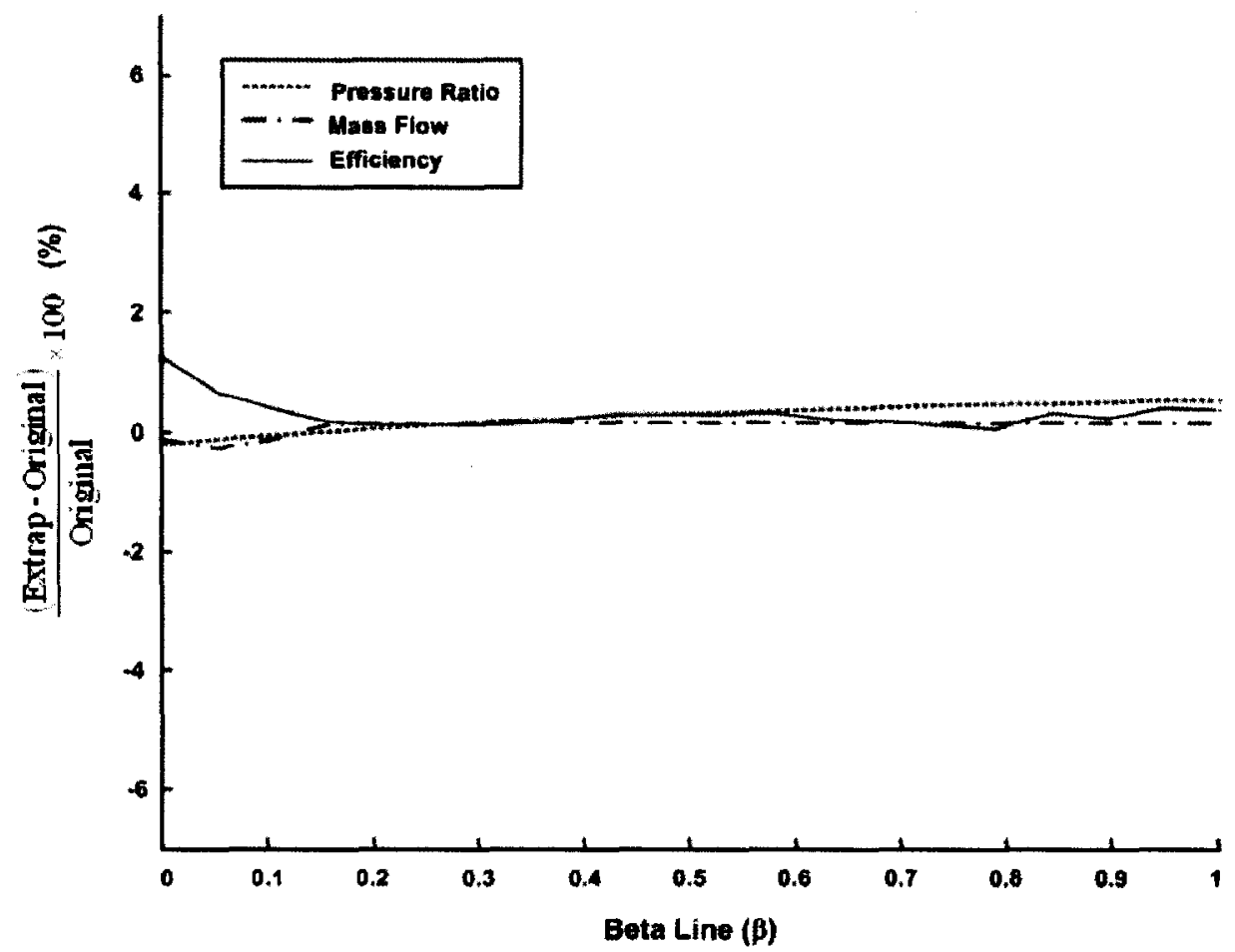

Figure 6.20: Gas generator turbine map extrapolation error

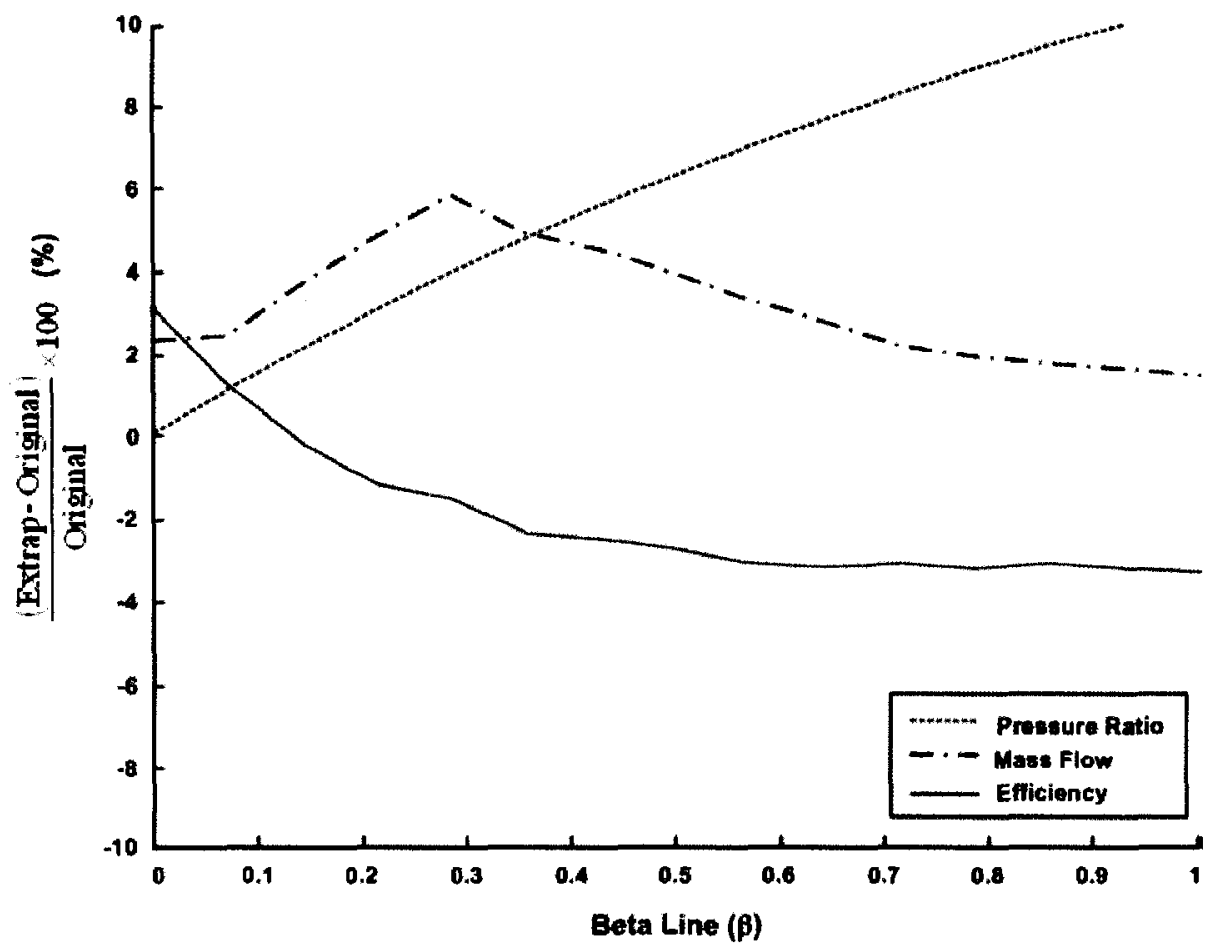

Figure 6.21: Power turbine map extrapolation error 
It was found that there was poor correlation between the extrapolated pressure ratios and the given characteristics at high beta line values. Even though this highlights a lack of robustness in the extrapolation method, it is important to consider that the error is expected to decrease when applying the method to the sub-idle region based on the same assumptions taken for the compressor map. With further investigation, it was found, as shown in Figure 6.22, that the sub-idle steady-state power turbine operating points were located on beta lines ranging from 0.1 to 0.4 . Due to the fact that the operating acceleration window drastically decreases in the sub-idle regime (limited by the surge line), it is expected that large excursions away from the power turbine steady-state beta line values will not occur during transient manoeuvres. Therefore, based on these facts, it was determined the power turbine extrapolated characteristic could still be used within the dynamic model by accepting a risk of accuracy reduction when performing calculations at high beta line values.

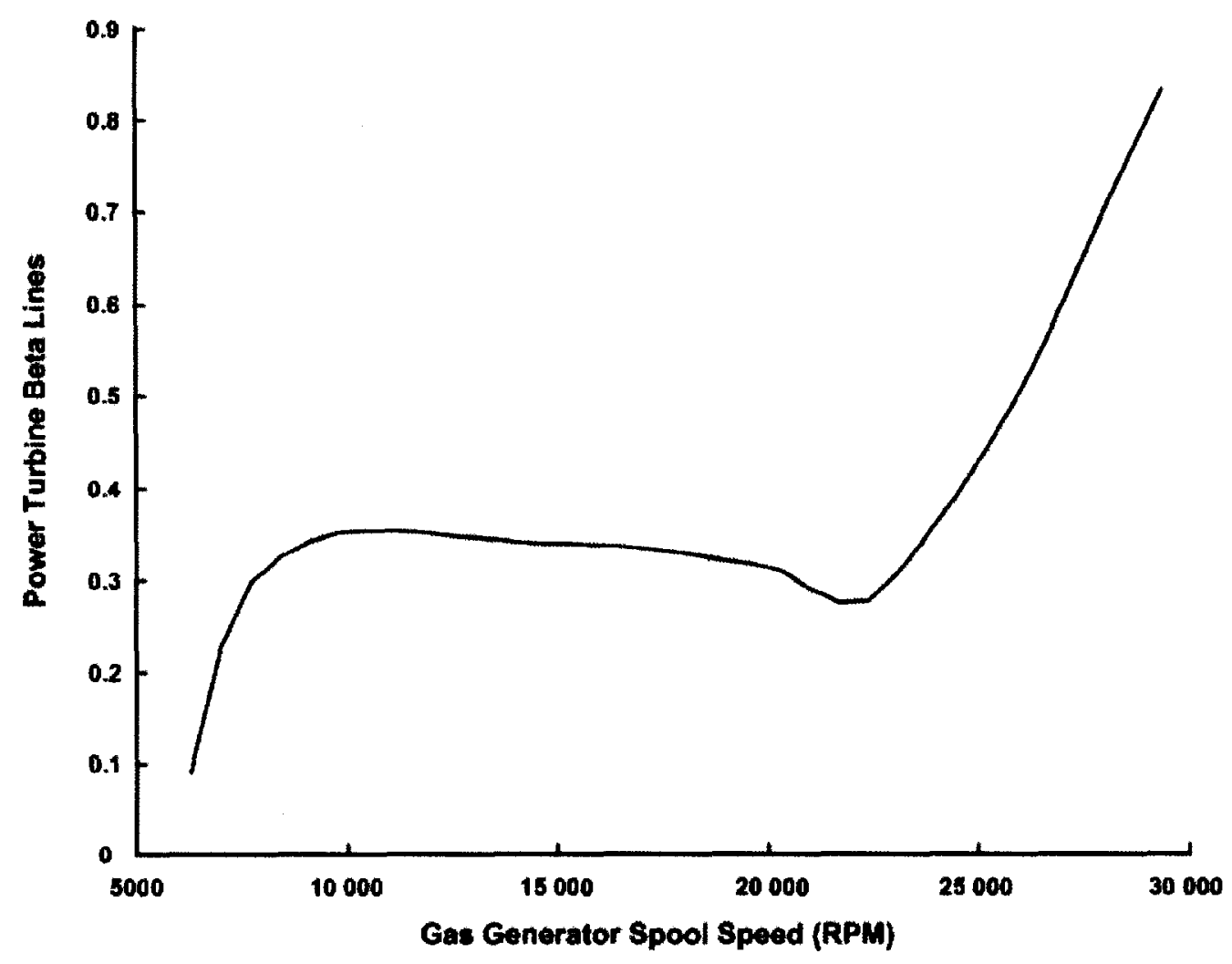

Figure 6.22: Off-design steady-state power turbine beta line variation 


\subsection{Control System Design Analysis and Validation}

The control system design validation consisted of assessing the potential of the control system design method by evaluating the proposed design solution against the control system design requirements. Since engine or rig testing was not available, the validation of the control system design was done through simulations using the gas turbine dynamic model as a virtual test bed. This validation strategy is commonly used in industry as it provides an initial assessment of the control system performance. However it is important to note that dynamic modeling accuracy plays an important role in the control system validation. An accurate dynamic representation of the gas turbine leads to an accurate representation of the control system response. As a result, the accuracy of the dynamic model was factored in when validating the control system design. To facilitate the process, the validation activities were sub-divided into two categories: engine control and startup sequencing. However before validating the control system, its design was first completed through the assessment of the proposed acceleration fuel schedules. The results of the control system analyses and validation activities are detailed in the following sub-sections.

\subsubsection{Acceleration Fuel Schedule Selection}

As part of the control system design work discussed earlier, three acceleration fuel schedules were proposed (Figure 5.26) as possible solution. The idea was that by providing multiple schedules, it was possible to assess the effects of each fuel schedules on engine performance and use the resulting engine responses to select an adequate fuel schedule. The selection process was based on three criteria:

- Surge protection

- Maximum gas generator turbine inlet temperature no greater than $1250 \mathrm{~K}$

- Rapid power turbine spool speed acceleration from idle to design point

First, the dynamic model was used as a virtual test bed to simulated the transient operating lines resulting from the three proposed fuel schedules. To assess if surge 
protection was satisfied, the resulting transient operating lines were plotted the same compressor map. From Figure 6.23, it was possible to conclude that all the three fuel schedules provided the expected surge protection.

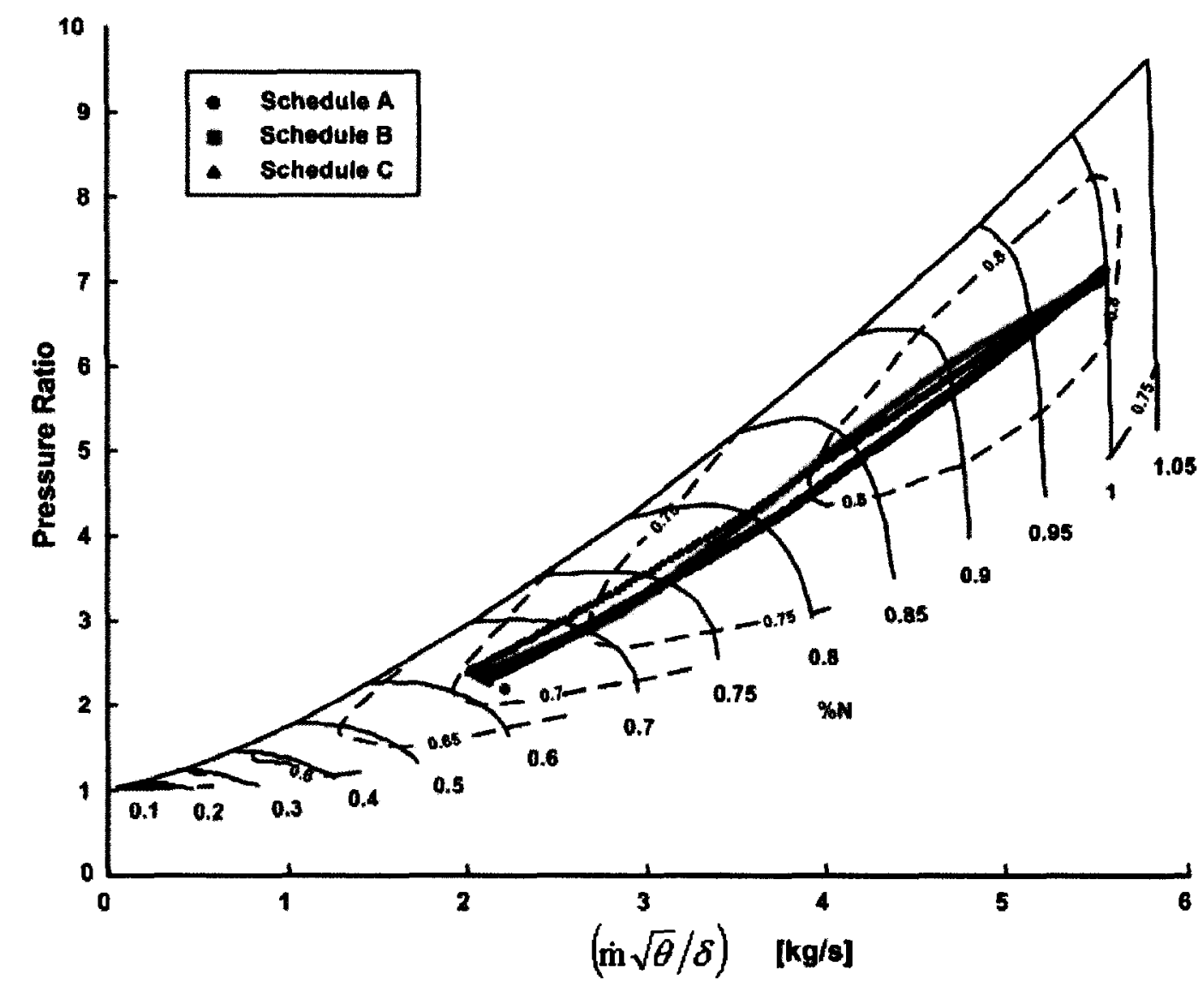

Figure 6.23: Transient operating line for each fuel schedule

To ease the selection process, the fuel schedules were then rated based on their transient operating line surge margins. According to Wash and Fletcher (1998), a minimum of 20 to $25 \%$ surge margin should be observed for marine application HP compressors. The surge margin was calculated using Eqn 6.1 (pressure ratios are at constant referred flow).

$$
\mathrm{SM}=\frac{\left(\mathrm{PR}_{\text {surge line }}-\mathrm{PR}_{\text {operating line }}\right)}{\mathrm{PR}_{\text {operating line }}} \times 100
$$


By plotting the transient operating line surge margins (Figure 6.24), it became apparent that Schedule A provided the best surge margin throughout the operating regime. Also it was noted that all three fuel schedules conserved a minimum surge margin above $20 \%$. Schedule $\mathrm{C}$ was rated second based on the fact that it provided a better surge margin than Schedule $\mathrm{B}$ at higher mass flows. The reason a better surge margin at higher mass flow was preferred was because the engine will operate within this region most of the time.

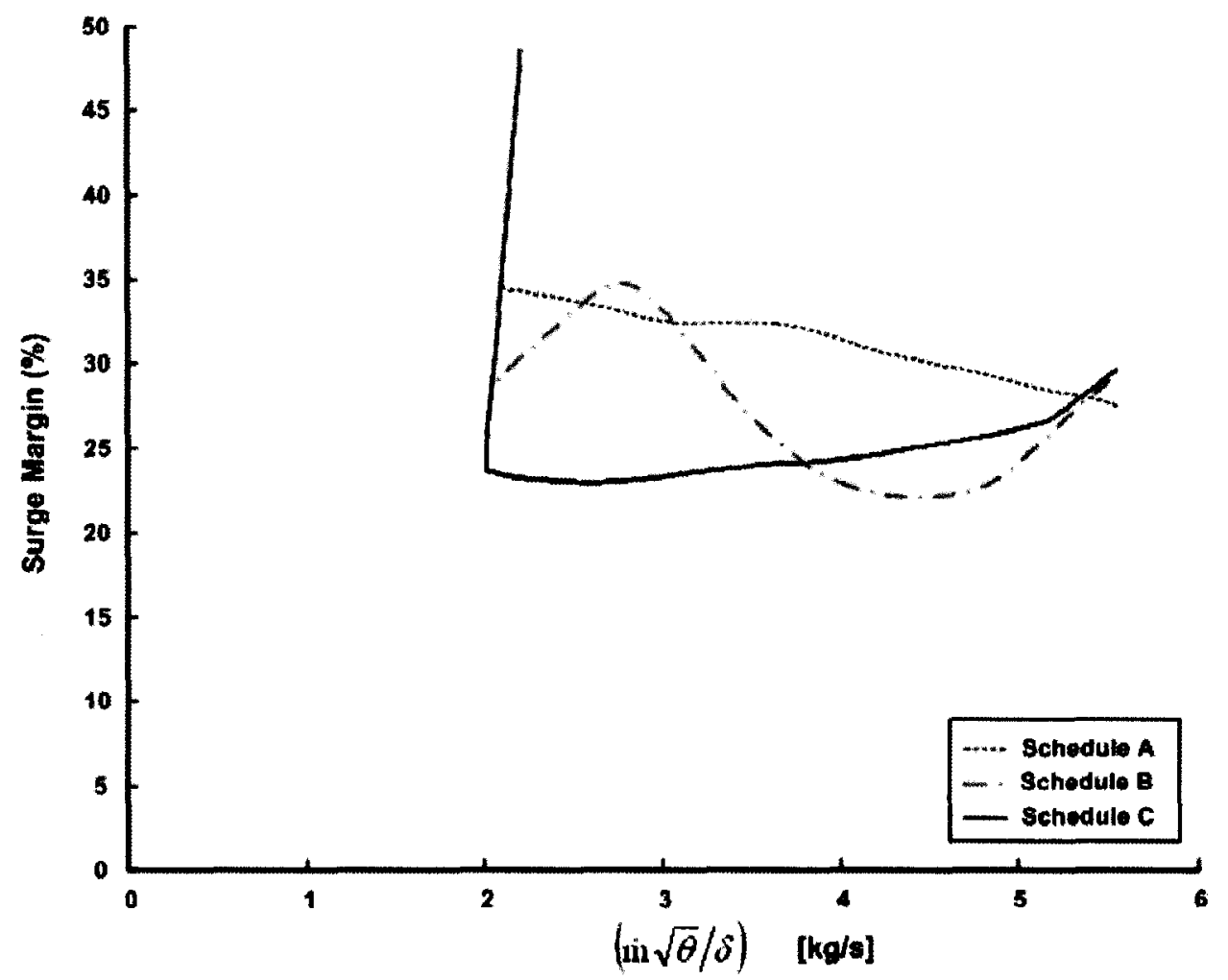

Figure 6.24: Transient operating lines surge margin

The second and third part of the selection process dealt with assessing the gas generator turbine inlet temperature response of each fuel schedule and the resulting power turbine spool speed response. Before completing any analyses, it was already expected, based on Figure 5.26 that Schedules A and B would not meet the $1250 \mathrm{~K}$ maximum temperature. However, both these schedules were proposed to see if there were advantages in increasing the gas generator turbine inlet temperature limit. Since this analysis was done early in the design process, this information could have been fed to the combustor designer to further optimize the overall design. However as seen from Figure 
6.25 and Figure 6.26, it was possible to achieve a faster acceleration time to design point without having to exceed the maximum turbine inlet temperature limit.

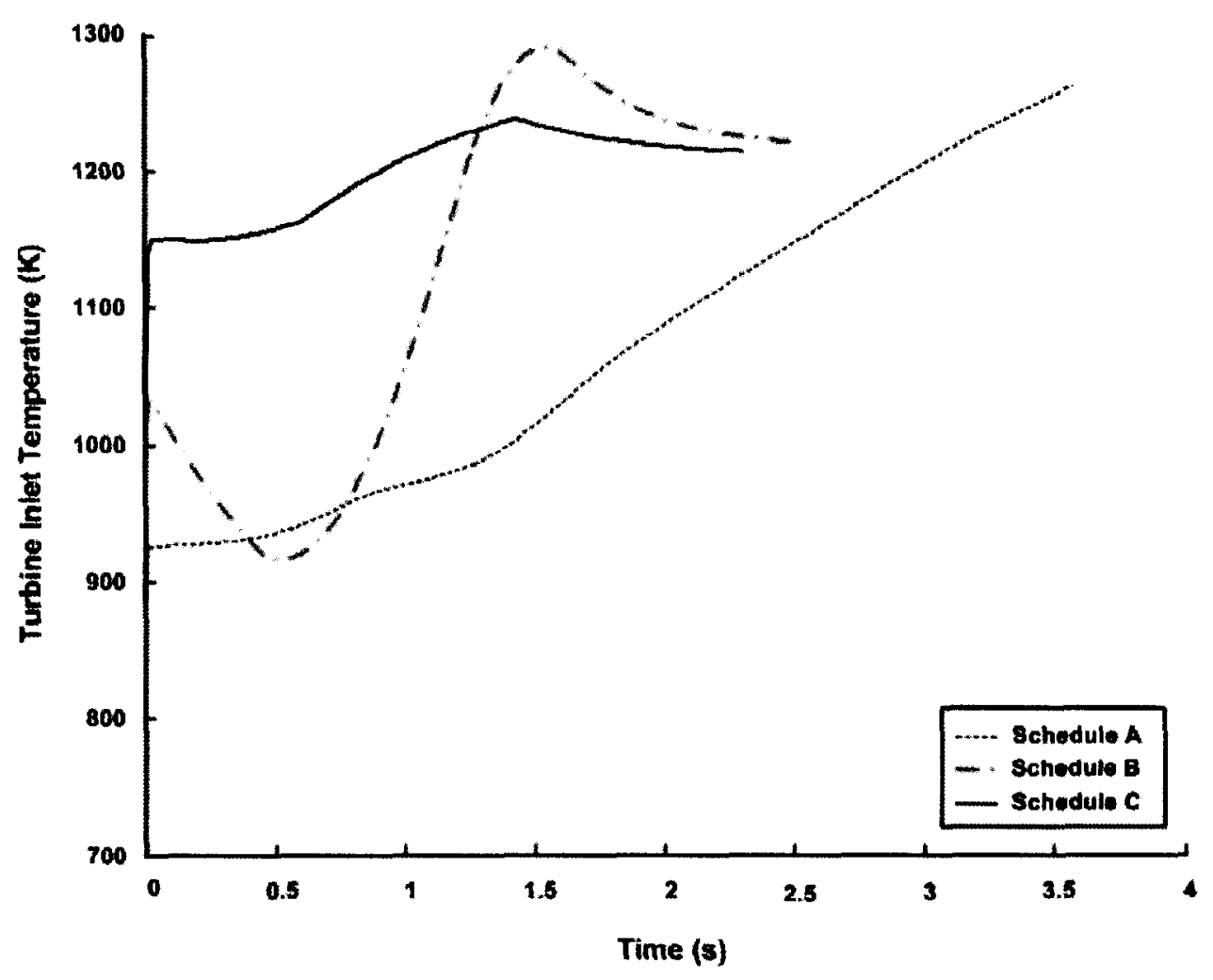

Figure 6.25: Gas generator turbine inlet temperature transient response 


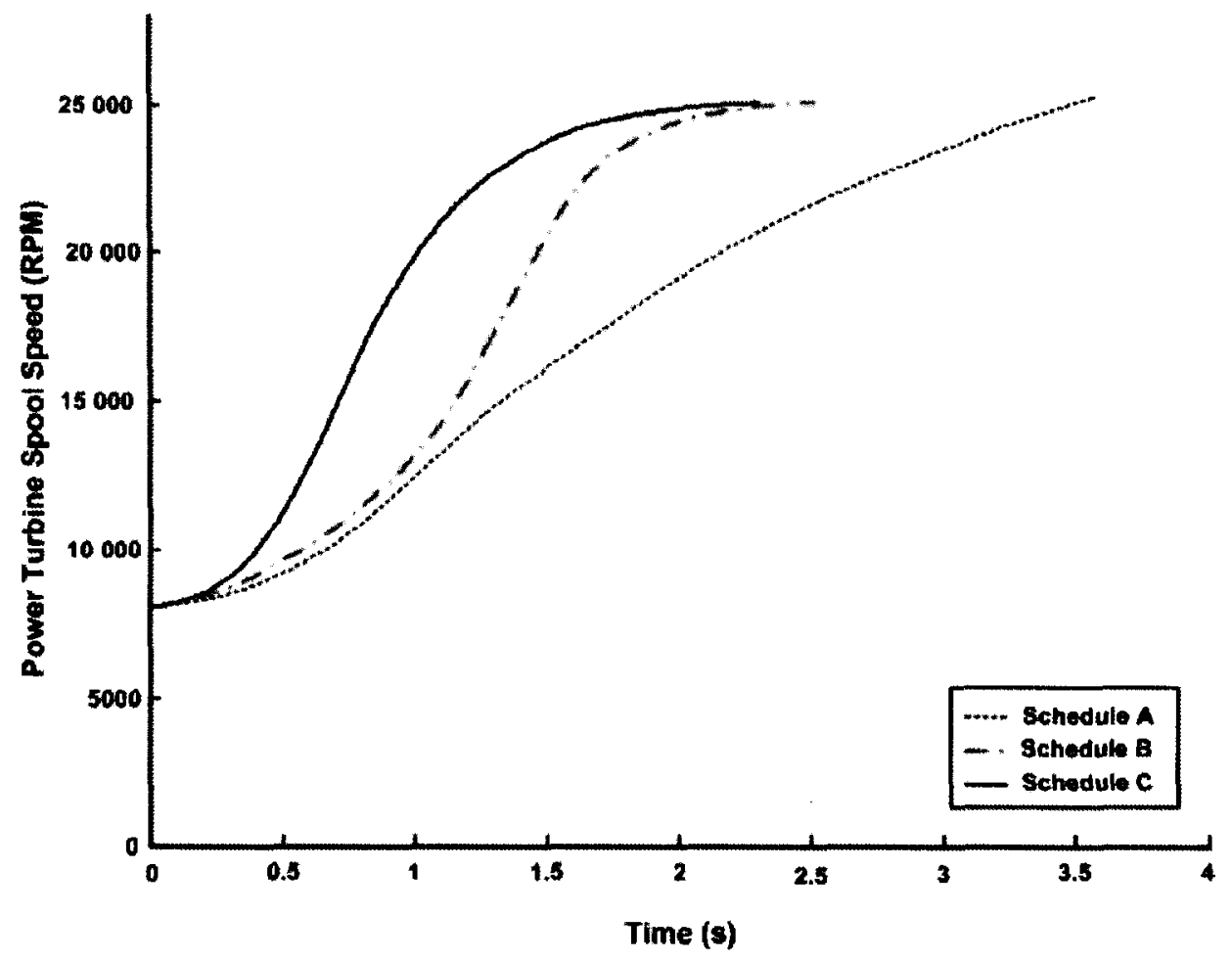

Figure 6.26: Power turbine spool speed response

The reason Schedule $\mathrm{C}$ generated a better response time than the other schedules was because it accelerated the engine quickly out of the sluggish response zone occurring at low speed. Based on the information available in Figure 6.23 to Figure 6.26, it was determined for this application that it was better to over-fuel the engine to a maximum at low speed while taking a hit on surge margin instead of over-fueling the engine at high speed and exceed the gas generator turbine inlet temperature limit. Therefore, based on the decision matrix shown in Table 6.1, the acceleration Schedule $\mathrm{C}$ was selected for this application.

Table 6.1: Acceleration fuel schedule decision matrix

\begin{tabular}{|l|c|c|c|}
\hline \multirow{2}{*}{\multicolumn{1}{|c|}{ Criteria }} & \multicolumn{3}{c|}{ Fuel Schedule } \\
\cline { 2 - 4 } & A & B & C \\
\hline Surge Margin & & 3 & 2 \\
\hline Maximum TIT Limit & 2 & 3 & \\
\hline Fast Not Response & 3 & 2 & \\
\hline \multicolumn{1}{|c|}{ Total } & 6 & 8 & 4 \\
\hline
\end{tabular}




\subsubsection{Engine Control Validation}

The purpose of engine control validation was to demonstrate that the proposed control system design met the control system requirements. To achieve this goal, the work was subdivided into two categories: 1) control system response validation and 2) control system limiter verification, were the dynamic model was used a virtual test bed to simulate engine response as a function controls system output. The resulting performance data was then used to assess the control system performance.

The first part of the engine control validation work dealt with control system response. Since the control system response requirements detailed in Section 5.3.1 were aimed, for design purposes, at the local linear controllers, it was difficult to validate the overall non-linear control system analytically. For this reason a validation strategy aimed a validating the overall operability of the control system was established. The plan consisted of inputting a series of large and small Power Lever Angle (PLA) setting step changes from idle to design point, and from design point to idle into the control system, and then evaluate the overall control system performance against the requirements. The step changes inputted to the controls system can be seen in Figure 6.27. 


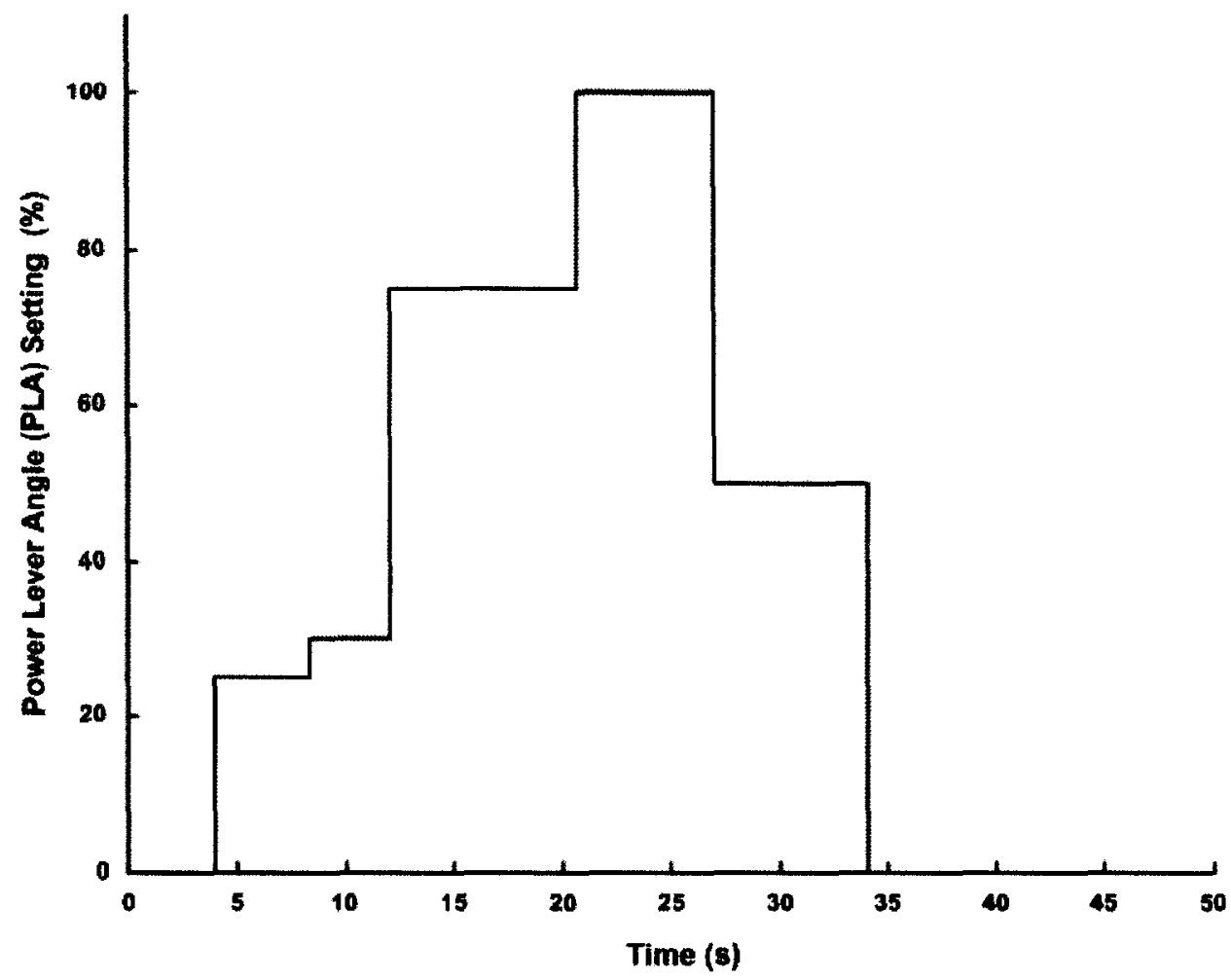

Figure 6.27: Power lever angle setting step changes

From the performance data generated by the dynamic model, it was then possible to plot the power turbine spool speed response against the power turbine spool speed demand. Even though a simplistic method was used to tune the controller gains, it can be seen from Figure 6.28, that the controller was capable of tracking the demands. However, analyzing each step individually, it was found that only Steps 1 and 2 met all the control system requirements (see Table 6.2). These results were not surprising as it was expected that the control system would not meet the rise time requirement during large step changes. This was determined based on the fact that the gain schedules were defined on an individual local controller basis and did not consider the whole control system, including fuel schedules and limiters, during the gain tuning process. Even though these results were acceptable for a first-cut design, it is recommended that gain tuning and gain scheduling optimization exercises be conducted at the next control system design iteration. 


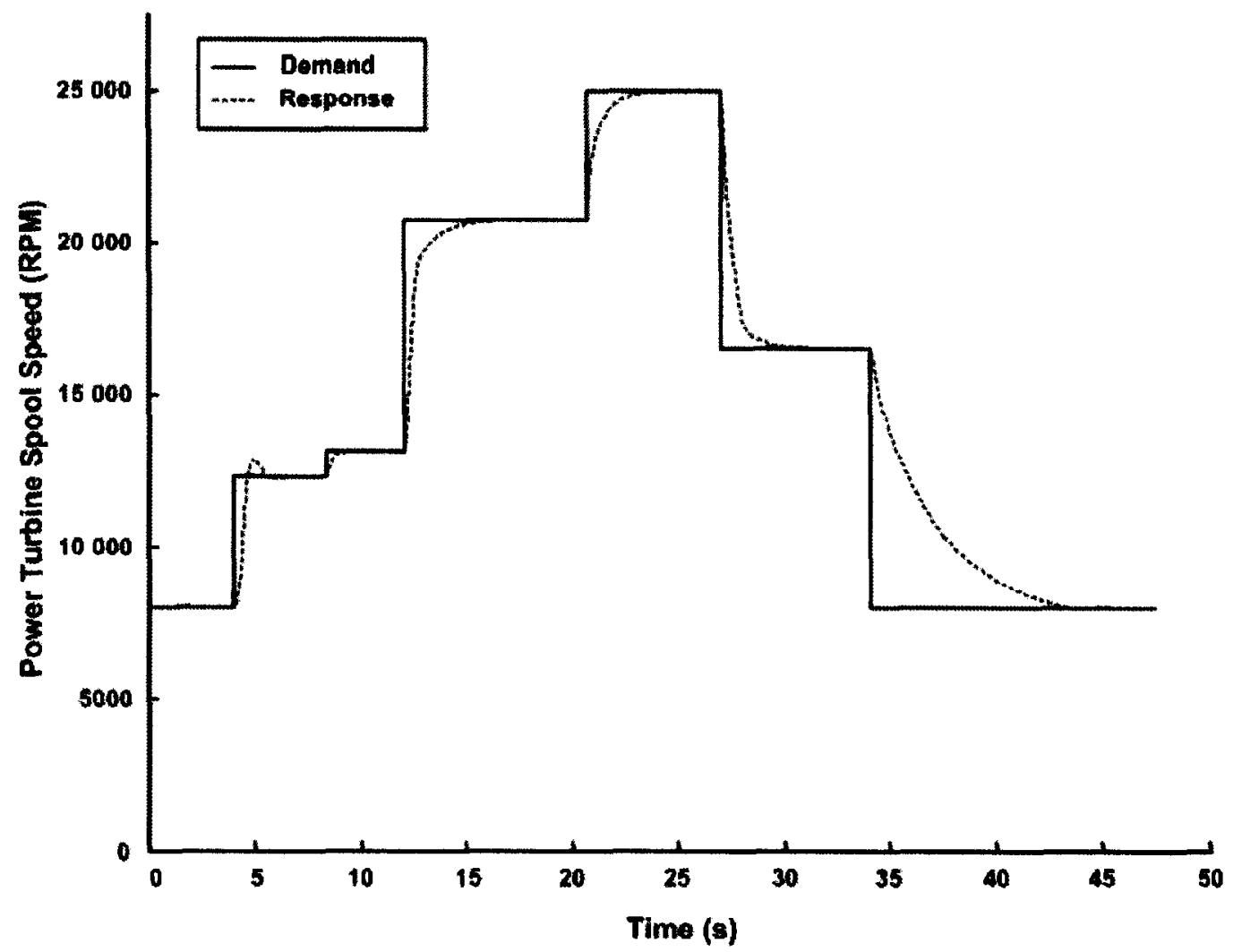

Figure 6.28: Control system power turbine spool speed response

Table 6.2: Control system response summary

\begin{tabular}{|l|c|c|c|c|c|c|}
\hline & \multicolumn{7}{|c|}{ Step } \\
\cline { 2 - 7 } & $\mathbf{1}$ & $\mathbf{2}$ & $\mathbf{3}$ & $\mathbf{4}$ & $\mathbf{5}$ & $\mathbf{6}$ \\
\hline Response & Accel. & Accel. & Accel. & Accel. & Decel & Decel \\
\hline Maximum Overshoot (\%) & 4.3 & 0 & 0 & 0 & 0 & 0 \\
\hline Rise Time (s) & 0.65 & 3.7 & 7 & 5.8 & 5.5 & 9.42 \\
\hline Settling Time (s) & 1.47 & N/A & N/A & N/A & N/A & N/A \\
\hline Droop & 0 & 0 & 0 & 0 & 0 & 0 \\
\hline
\end{tabular}

Additionally, since the control system was design for a marine application, a partial load shed caused by a propeller exiting the water or cavitation was also considered as part of the operability validation strategy. A propeller partly out of the water for two seconds was simulated by instantly reducing the propeller loading on the power turbine. Afterward the load was re-established to simulate the propeller re-entering the water (load acceptance). This simulation was performed at design point where the power turbine over-speed margin was at its minimum. The resulting power turbine spool speed response was plotted in Figure 6.29. 


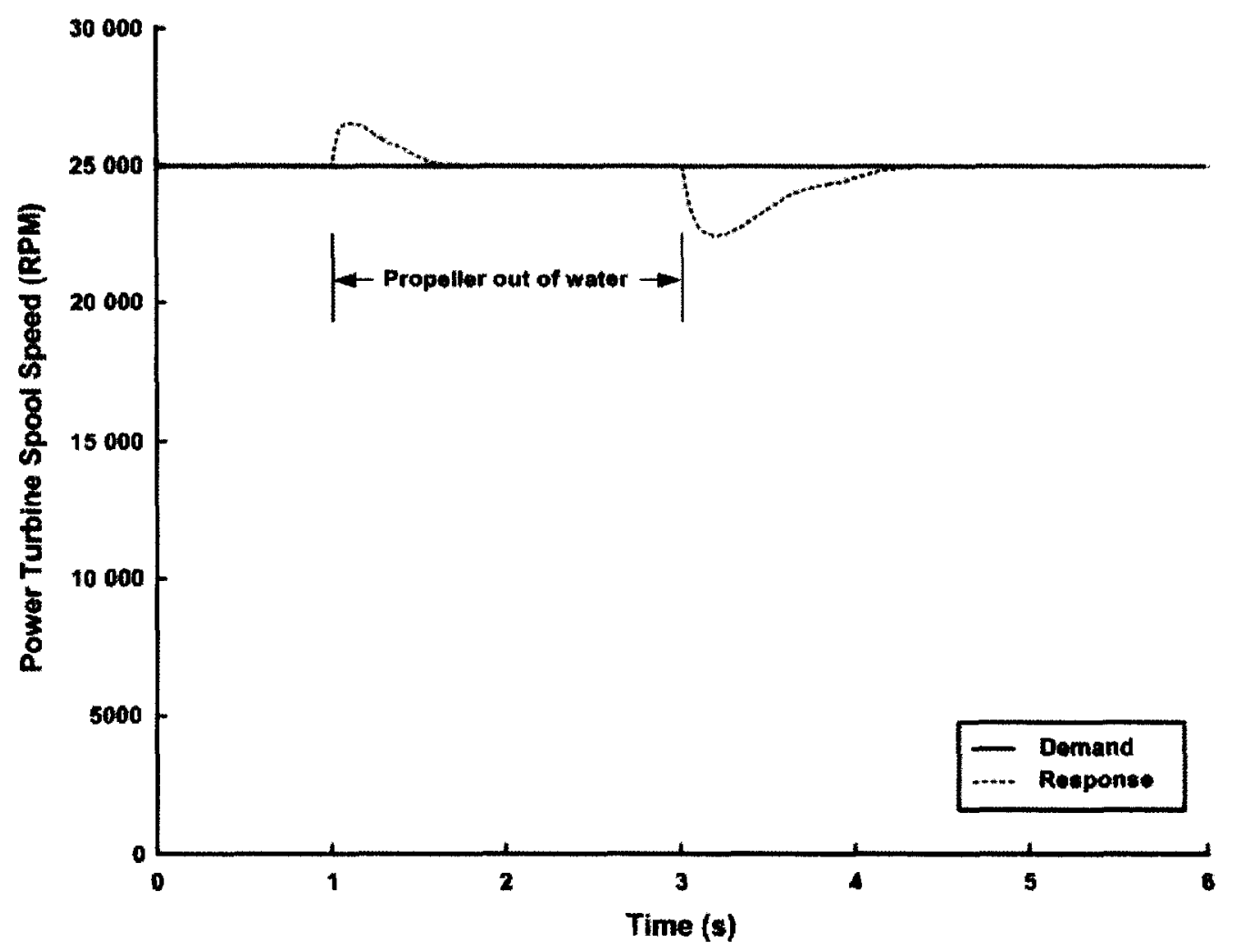

Figure 6.29: Power turbine spool speed response - propeller partially out of the water

From this data, it was determined that after a $50 \%$ propeller load loss (approximately $500 \mathrm{~kW}$ ), the control system was capable of re-establishing the power turbine spool speed to match the demand within $800 \mathrm{~ms}$ while allowing a $106 \%$ spool speed overshoot (well within the $110 \%$ maximum limit). Also, since rapid drops in load may lead to flameouts, this simulation was used to assess the transient fuel-to-air ratio. As seen from Figure 6.30, a minimum transient fuel-to-air of 0.01 was observed during the drop in load. With a value well above the flameout limit of 0.0081 , it was determine that combustion stability would not be an issue during a 50\% drop in load. Note that the $50 \%$ load loss was assumed to be a worst-case scenario in which the engine would be required to operate normally. Any larger load loss was assumed to lead to an emergency shutdown. However, since these simulations were done early in the design process, the emergency shutdown procedure was not established yet and hence not simulated. 


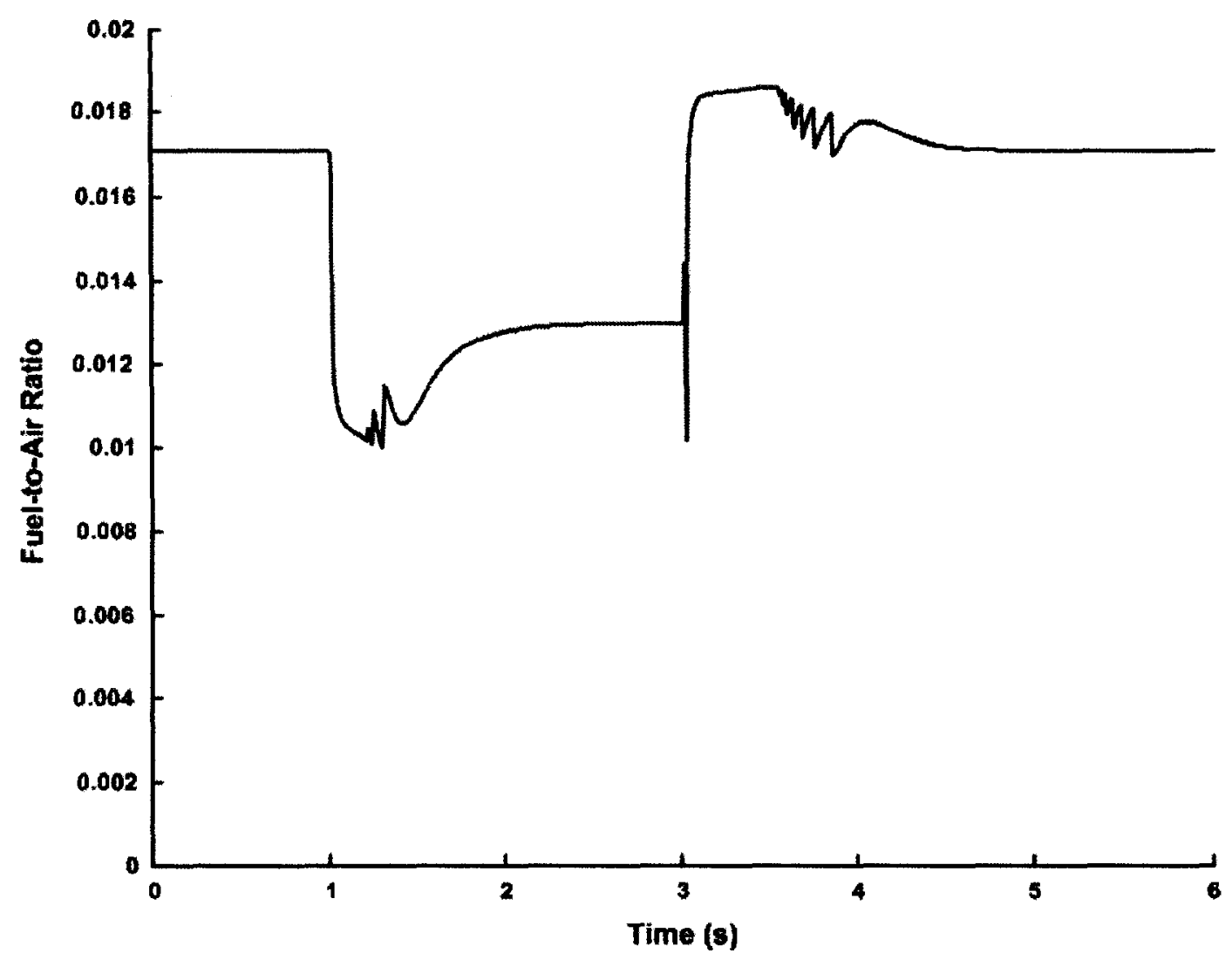

Figure 6.30: Transient fuel-to-air ratio - propeller partially out of water

The second part of the engine control validation process consisted of performance limiter verification. This work was done concurrently with the control system response analysis and was regarded as a sanity check to ensure performance limiter were coded properly within the control system. Using the data generated from the manoeuvres sketched in Figure 6.27, the maximum simulated gas generator turbine inlet temperature, gas generator spool speed, power turbine spool speed, and the minimum fuel-to-air ratio and gas generator spool speed were surveyed. As seen from Table 6.3, none of the performance limiters were exceeded during the manoeuvres. Even when considering the simulation errors, which were discussed earlier as part of the dynamic model validation, it was found that the engine operated within the performance limits. 
Table 6.3: Performance limiter survey

\begin{tabular}{|l|c|c|c|c|}
\hline & $\begin{array}{c}\text { Maximum } \\
\text { Simulated } \\
\text { Value }\end{array}$ & Limiter & $\begin{array}{c}\text { Estimated } \\
\text { Simulation Error } \\
(\%)\end{array}$ & $\begin{array}{c}\text { Safety Margin } \\
(\%)\end{array}$ \\
\hline GG Turbine Inlet Temperature (K) & 1229 & 1300 & 2 & 3.6 \\
\hline GG Spool Speed (RPM) & 28000 & 29400 & 1 & 3.8 \\
\hline PT Spool Speed (RPM) & 25000 & 27500 & 1 & 8.2 \\
\hline & $\begin{array}{c}\text { Minimum } \\
\text { Simulated } \\
\text { Value }\end{array}$ & Limiter & $\begin{array}{c}\text { Estimated } \\
\text { Simulation Error } \\
(\%)\end{array}$ & $\begin{array}{c}\text { Safety Margin } \\
(\%)\end{array}$ \\
\hline Fuel-to-Air Ratio & 0.0082 & 0.0081 & 6 & 7.3 \\
\hline GG Spool Speed (RPM) & 17454 & 16625 & 1 & 6.0 \\
\hline
\end{tabular}

Based on these results and the operability validation results discussed earlier, it was concluded that the proposed engine control system was acceptable as a first cut design.

\subsubsection{Startup Sequencing Validation}

This sub-section covered the validation of the startup sequencing section of the control system. Here again, the validation work was done to verify that the control system met the design requirements. Using the proposed startup fuel schedule (shown in Figure 5.31), the startup performance data was generated using the startup model. To assess the engine startup time, the gas generator spool speed response was plotted as a function of time. As seen from Figure 6.31, the engine reached idle speed within 25 seconds. This was well within the 1-minute startup requirement stated in the controls system requirements. Additionally, it was possible to see from this graph the interaction between the two models used during the startup modeling. The low speed calculations were performed using the extrapolation model and the remaining calculations were performed using the dynamic model. 


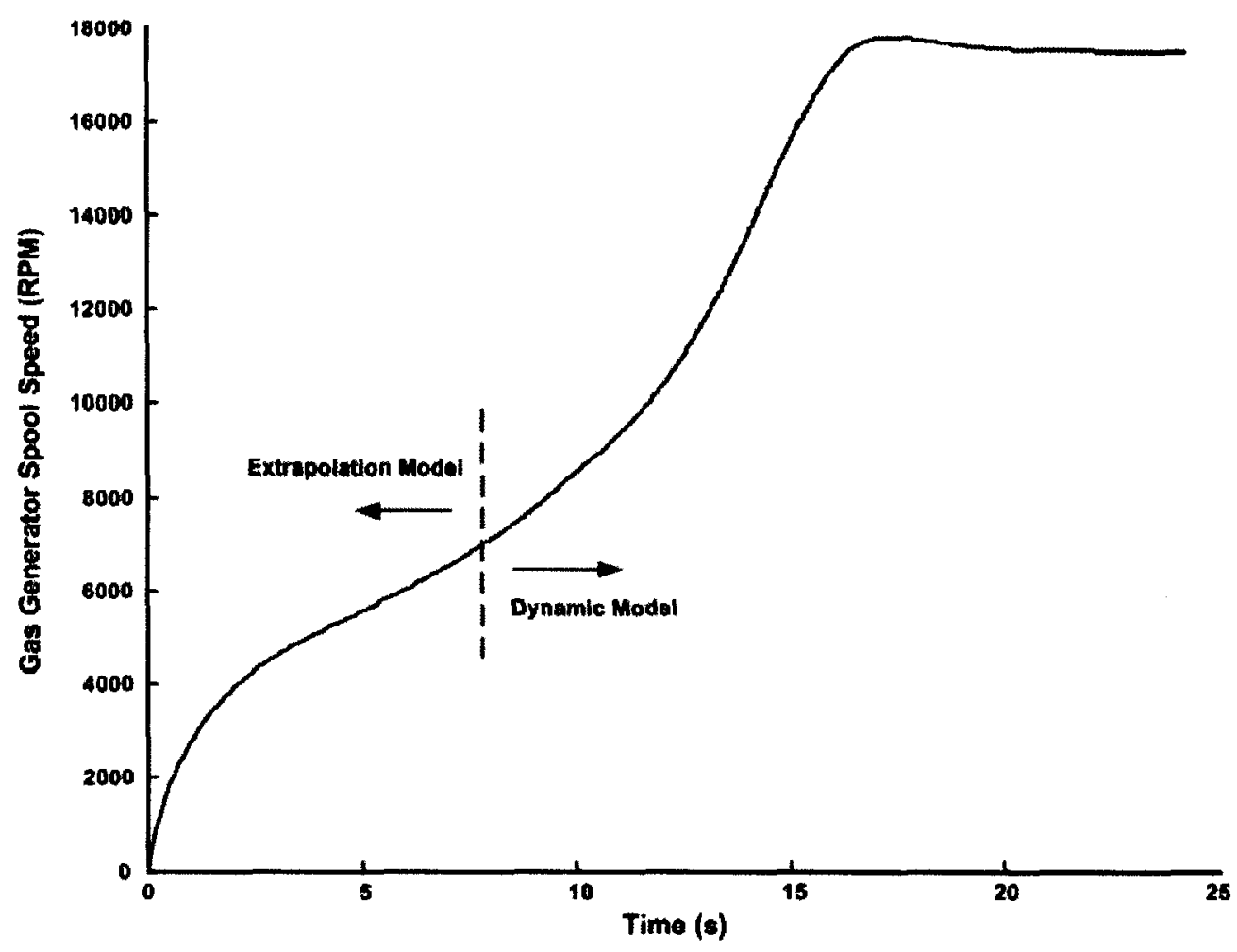

Figure 6.31: Gas generator spool speed response during startup

Having generated the startup performance data, it was then possible to assess the starter implication in the engine startup sequence. As seen from Figure 6.32, the starter played a major role in accelerating the gas generator towards idle speed. Before ignition and up to 4000 RPM, the torque imbalance required to accelerate the engine came mainly from the starter. Based on these observations, it was determined that the engine startup time was mainly dependent of the starter torque characteristic. Therefore during the next design iteration, it is suggested that the startup model be used to optimize the size of the starter. Since the engine startup time is 4 times faster than required, this starter optimization exercise may lead to a more economical starter solution. However, it is important to remember that these performance calculations were performed at ISO day conditions (Sea Level, $\mathrm{P}_{\mathrm{amb}}=101.325 \mathrm{kPa}$ and $\mathrm{T}_{\mathrm{amb}}=15^{\circ} \mathrm{C}$ ) while neglecting ambient temperature effects. Therefore as the gas turbine design evolves; the effect of ambient temperature on engine startup response should also be considered. Higher starting torques will be required on colder days. 


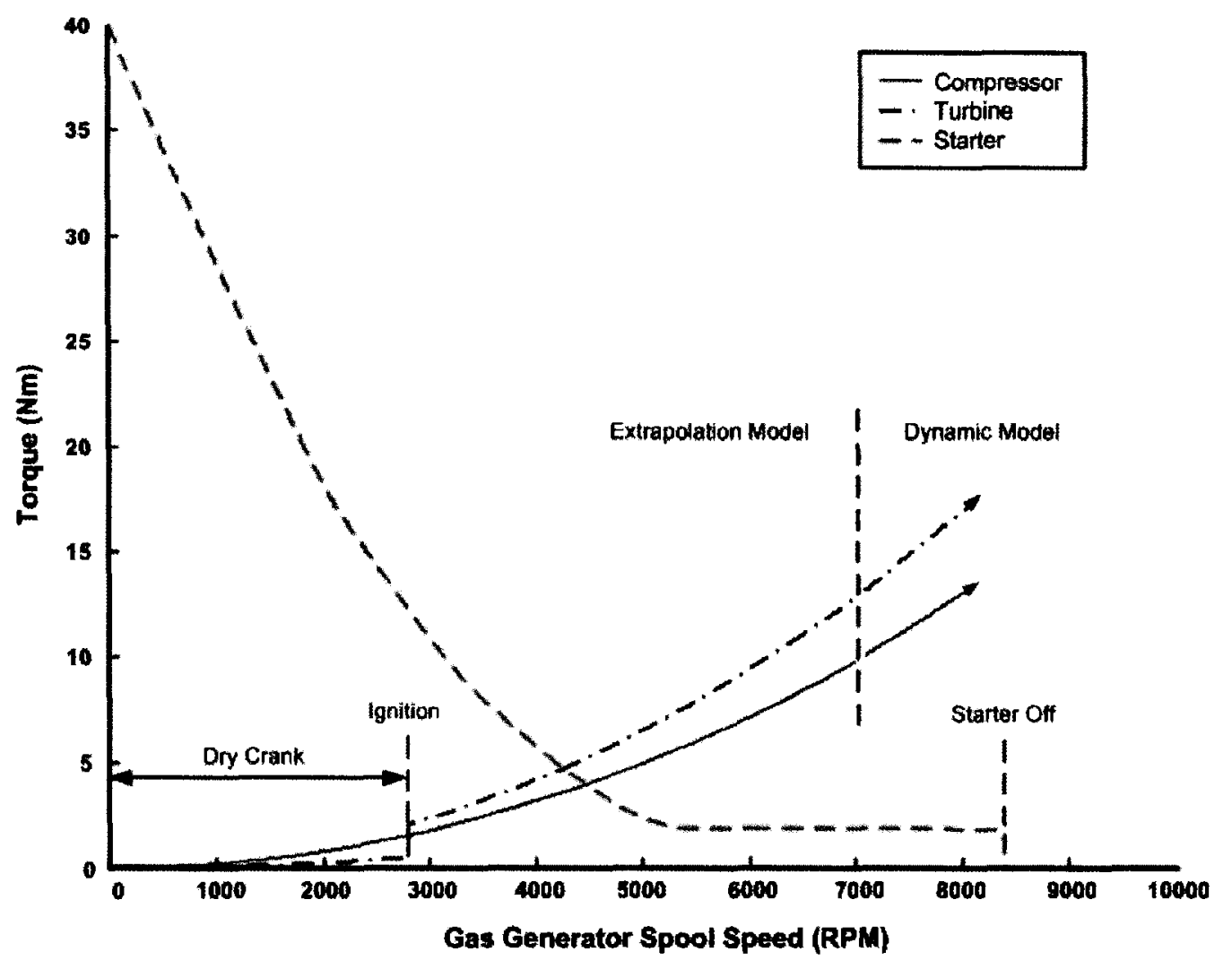

Figure 6.32: Startup torques

As a final validation check, the gas generator turbine inlet temperature response was plotted as a function of time. However, due to modeling limitation within the extrapolation model, the gas generator turbine inlet temperature could only be assessed eight seconds after startup. As seen from Figure 6.33, the turbine inlet temperature was $1250 \mathrm{~K}$ eight seconds into startup and decreased gradually as the engine reached idle speed. Even though the data was not available below eight seconds, it was estimated that the temperature would be in the range of $1300 \mathrm{~K}$ after ignition and slowly decreasing to $1250 \mathrm{~K}$ as the gas generator increases in speed. This was estimated based on the fact the start would be aborted if the temperature exceeded $1300 \mathrm{~K}$. Therefore, based on this estimation, the engine hot section would be exposed to temperatures above the maximum transient gas generator turbine inlet temperature limit for eight seconds every start. During the next design iteration this factor will need to be considered, as it will play a role on the overall engine life. 


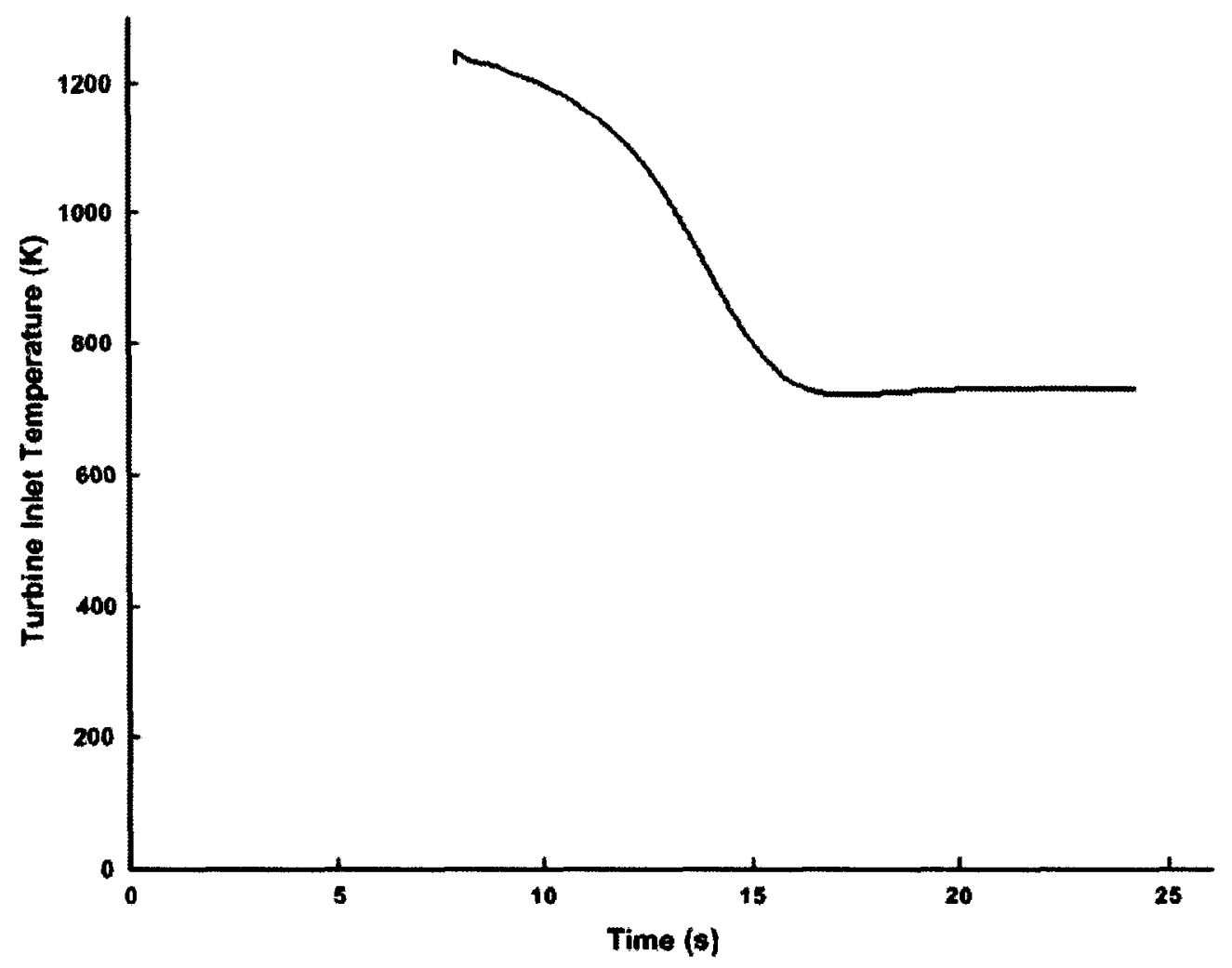

Figure 6.33: Gas generator turbine inlet temperature response during startup

Based on the startup sequencing performance modeling results, it was determined that the propose startup fuel schedule met the control system design requirements. However, since a reduction of accuracy was assumed during the performance modeling, further analysis will be required as the design evolves. Therefore, these results will be regarded as preliminary figures used to initiate the start system design process. The final validation will be done through experimental testing. 


\section{Chapter 7 \\ Conclusions and Recommendations}

This chapter presents an overview of the accomplishments linked to the development and application of the dynamic modeling and control system design methodologies.

A number of recommendations will also be presented. These are based on further actions required in the advancement of the dynamic modeling and control system design methodologies.

\subsection{Conclusion}

The complete dynamic modeling and control system design process for a 1-MW marine gas turbine application was presented. Comprehensive dynamic modeling and control system design methodologies, applicable at an early stage of the gas turbine design, were developed to assist the design process. From given gas turbine design point data, a dynamic model capable of simulating steady-state and transient performance, from engine start to design point, was produced. The dynamic model was then validated using the commercial performance software GasTurb. A control system comprised of startup sequencing and engine control was developed. Using the dynamic model as a virtual test bed, the control system was tested from engine start to design point to ensure the control system design requirements were met.

It was found that the dynamic model produced comparable results to GasTurb from idle to design point. In the sub-idle region, a slight reduction of accuracy was estimated. Even though dynamic modeling within the sub-idle regime was not fully validated, it was determined that the results could still be used to get a general sense on how the engine will operate during startup and provide preliminary estimates for starting system design. Finally, it was determined that the control system design methodology 
produced an adequate preliminary design of the control system early in the gas turbine design process. Having demonstrated the validity of the dynamic modeling and control system design methodology, the models may now be used to optimize the current control system design as the gas turbine design evolves.

\subsection{Recommendations}

With the dynamic model and the control system design initiated, it is possible to concentrate on the optimization of the current design and initiate the control software and hardware preliminary design work. In addition to continuously updating the dynamic model with accurate data, advancements to the dynamic modeling and control system design methodologies should be made. Recommended actions include:

- The addition of combustion products properties calculations. Currently, the combustion products properties are simulated as hot air. The accuracy of the dynamic model will increase by incorporating the effects of the combustion gas properties. The calculations should consider fuel composition.

- The addition of $\mathrm{CO}$ and NOx emissions calculations. Environmental constraints play an important role in the gas turbine design process. By incorporating emissions calculations, these environmental constraints may then be considered during the elaboration of the fuel schedules.

- A method to incorporate the dissociation effects on the gas generator turbine inlet temperature should be implemented. This action is required to further add emissions modeling capability to the dynamic model .

- The addition of heat soakage and combustion delay calculations. Adding these characteristics will allow the control system designer to assess the variations between cold and hot day engine operation and understand the effects of combustion delay on the engine dynamic response.

- Multiple combustion efficiency models should be added to the dynamic model. The current combustion efficiency algorithm assumes a high efficiency throughout the operating regime. Since this is not always the case, especially for 
dry low emissions combustors, the choice of various typical combustion efficiency models would increase the fuel flow modeling accuracy.

- The startup extrapolation model should be improved such to simulate a wide range of engine parameters. Currently it is not possible to assess the temperature response during startup at low speed. This upgrade would allow for a better assessment of the effects of engine startup on engine life.

- The addition of multiple gain tuning methods. Currently a simplistic approach is used in the design method. The addition of multiple tuning techniques would ease the gain tuning optimization process.

- Automating the dynamic modeling and control system design methods.

- Streamlining the computational code to reduce the computational time.

- Validating the dynamic model and control system design with experimental data.

Additional recommendations for the overall control system design are also provided. The recommended actions include:

- Starter sizing optimization. To prevent the additional cost of an oversized starter, the dynamic model should be used to properly size the starter under various ambient operating conditions.

- Considering the control hardware response time during the preliminary design work. Currently, the controls system design method does not consider any control hardware or feedback signal response time. These will affect the overall control system response and should be considered early in the preliminary design process.

- Developing a real-time control system simulator to create a bridge between dynamic modeling and experimental testing. 


\section{References}

Agrawal, R.K. and Yunis, M., A Generalized Mathematical Model to Estimate Gas Turbine Starting Characteristics, Journal of Engineering for Power, Vol. 104, Issue 1, pp. 194-201, 1982

Ang, K.H., Chong, G., and Li, Y., PID Control System Analysis, Design and Technology, IEEE Transaction on Control System Technology, Vol. 13, No. 4, 2005

Anonymous, Gas Turbine Transient Performance Course Notes, GasTOPS Ltd., 1990

Åström, K. J., Control System Design Lecture Notes, University of California, 2002

Boyce, M.P., Gas Turbine Engineering Handbook $2^{\text {nd }}$ edition, Gulf Publishing Company, 2001

Chappell M.S. and Cockshutt, E.P., Gas Turbine Cycle Calculations: Thermodynamic Data Tables for Air and Combustion Products for Three Systems of Units, National Research Council of Canada, NRC No. 14300. Aeronautical Report LR-579, 1974

Chipperfield, A. J., Bica, B., and Fleming, J., Fuzzy Scheduling Control of a Gas Turbine Aero-Engine: A Multiobjective Approach, IEEE Transaction on Industrial Electronics, Vol. 49, No. 3, 2002

Fawke, A.J., and Saravanamuttoo, H.I.H., Digital Computer Methods for Prediction of the Gas Turbine Dynamic Response, SAE Paper 710550, SAE Mid-Year Meeting, Montreal Qc. Canada, 1971

Gaudet, S.R. and Gauthier, J.E.D, A Simple Sub-Idle Component Map Extrapolation Method, GT2007-27193, Proceedings of the ASME Turbo Expo 2007, Montreal, Quebec, Canada, May 14-17, 2007

Gauthier, J.E.D., Gas Turbine Course Notes, Carleton University, 2005

Ho, W. K., Gan, O. P., Tay, E. B., and Ang, E. L., Performance and Gain and Phase Margins of Well-Known PID Tuning Formulas, IEEE Transaction on Control System Technology, Vol.4, NO. 4, 1996

Jaw, L.C. and Garg S., Propulsion Control Technology Development in the United States - A Historical Perspective, NASA/TM - 2005-213978, 2005 
Kim, J.H., Song, T.W., Kim, T.S. and Ro, S.T., Dynamic Simulation of Full Start-up Procedure of Heavy Duty Gas Turbines, 2001-GT-0017, Proceedings of the ASME Turbo Expo 2001, New Orleans, Louisiana, USA, June 4-7, 2001

Kong, C. and Ki, J., Performance Simulation of Turboprop Engine for Basic Trainer, 2001-GT-0391, Proceedings of the ASME Turbo Expo 2001, New Orleans, Louisiana, USA, June 4-7, 2001

Kurzke, J., Advanced User-friendly Gas Turbine Performance Calculations on a Personal Computer, 95-GT-147, International Gas Turbine and Aeroengine Congress and Exposition, Houston, Texas, USA, June 5-8, 1995

Kurzke, J., GasTurb 10: User's Manual, Germany, 2004a

Kurzke, J., GasTurb 10 software, 2004b

Leith, D.J. and Leithead, W.E., Can an Appropriate Gain-Scheduling Realization Enhance Performance?, UKACC International Conference on Control '96, Conference Publication No. 427, Exeter, UK, 2-5 September, 1996

MacIsaac, B.D., Techniques for Improving the Dynamic Response of the Gas Turbine: A Comparative Study Using a Hybrid Computer Model, Carleton University PhD Thesis, 1975

Mattingly, J.D., Heiser W.H. and Pratt, D.T., Aircraft Engine Design, $2^{\text {nd }}$ Edition, AIAA Education Series, American Institute of Aeronautics and Astronautics Inc., 2002

Mu, J., Rees, D., Evans, C. and Chiras, N., Design of Optimum Controllers for Gas Turbine Engines, ASCC Paper WM9-24, $4^{\text {th }}$ Asian Control Conference, Singapore, September 25-27 2002

Ogata, K., Modern Control Engineering $4^{\text {th }}$ edition, Prentice Hall, 2002

Qi, O.F., Gawthrop, P.J. and Maccallum N.R.L., Meeting the Performance Requirements of a Single-Spool Gas Turbine Engine Using a Gain Scheduled Controller, Proceedings of the IEEE International Symposium on Intelligent Control, pp. 385-390, Glasgow, UK, August 11-13, 1992

Saravanamuttoo, H.I.H. and Fawke, A.J., Simulation of Gas Turbine Dynamic Performance, 70-GT-23, ASME Gas Turbine Conference \& Product Show, Brussels, Belgium, May 24-28, 1970 
Saravanamuttoo, H.I.H. and MacIsaac, B.D., Thermodynamic Models for Pipeline Gas Turbine Diagnostics, Journal of Engineering for Power, Vol. 105, pp.875-884, October, 1983

Saravanamuttoo, H.I.H., Rogers, G.F.C., and Cohen, H., Gas Turbine Theory $5^{\text {th }}$ Edition, Pearson Education Limited, 2001

Saravanamuttoo, H.I.H., Sjolander, S.A., Gauthier, J.E.D., Straznicky, P.V., MacIsaac, B.D., Gas Turbine Performance and Design - Short Course, Carleton University, 2003

Sawyer, J.W., Gas Turbine Engineering Handbook, Gas Turbine Publications, Inc., 1966

Sellers, J.F. and Daniele, C.J., DYNGEN - A Program for Calculating Steady-State and Transient Performance of Turbojets and Turbofan Engines, NASA TN D-7901, 1975

Sexton, W.R., A Method to Control Turbofan Engine Starting by Varying Compressor Surge Valve Bleed, Virginia Polytechnic Institute and State University Master of Science Thesis, 2001

Shamma, J.S. and Athans M., Analysis of Gain Scheduled Control of Nonlinear Plants, IEEE Transaction on Automatic Control, Vol. 35, No. 8, 1990

Shinskey, F.G., Feedback Controllers for the Process Industries, McGraw-Hill, Inc., 1994

Turns S.R., An Introduction to Combustion, Concepts and Applications, $2^{\text {nd }}$ Edition, McGraw-Hill Companies, 2000

Walsh, P.P. and Fletcher P., Gas Turbine Performance, Blackwell Science Ltd, 1998

Wikipedia, The Free Encyclopedia, http://en.wikipedia.org/wiki/Gasturb, Accessed, Sep. 2007

Zhu, P. and Saravanamuttoo, H.I.H., Simulation of an Advanced Twin-spool Industrial Gas Turbine, Journal of Engineering for Gas Turbines and Power, Vol. 114, pp. 181-185, 1992 


\section{Appendix A - Newton-Raphson Method}

The following in-house code contains the generalized Newton-Raphson method for the solution of non-linear equations. This code was generated based on the equations available in Turns (2000).

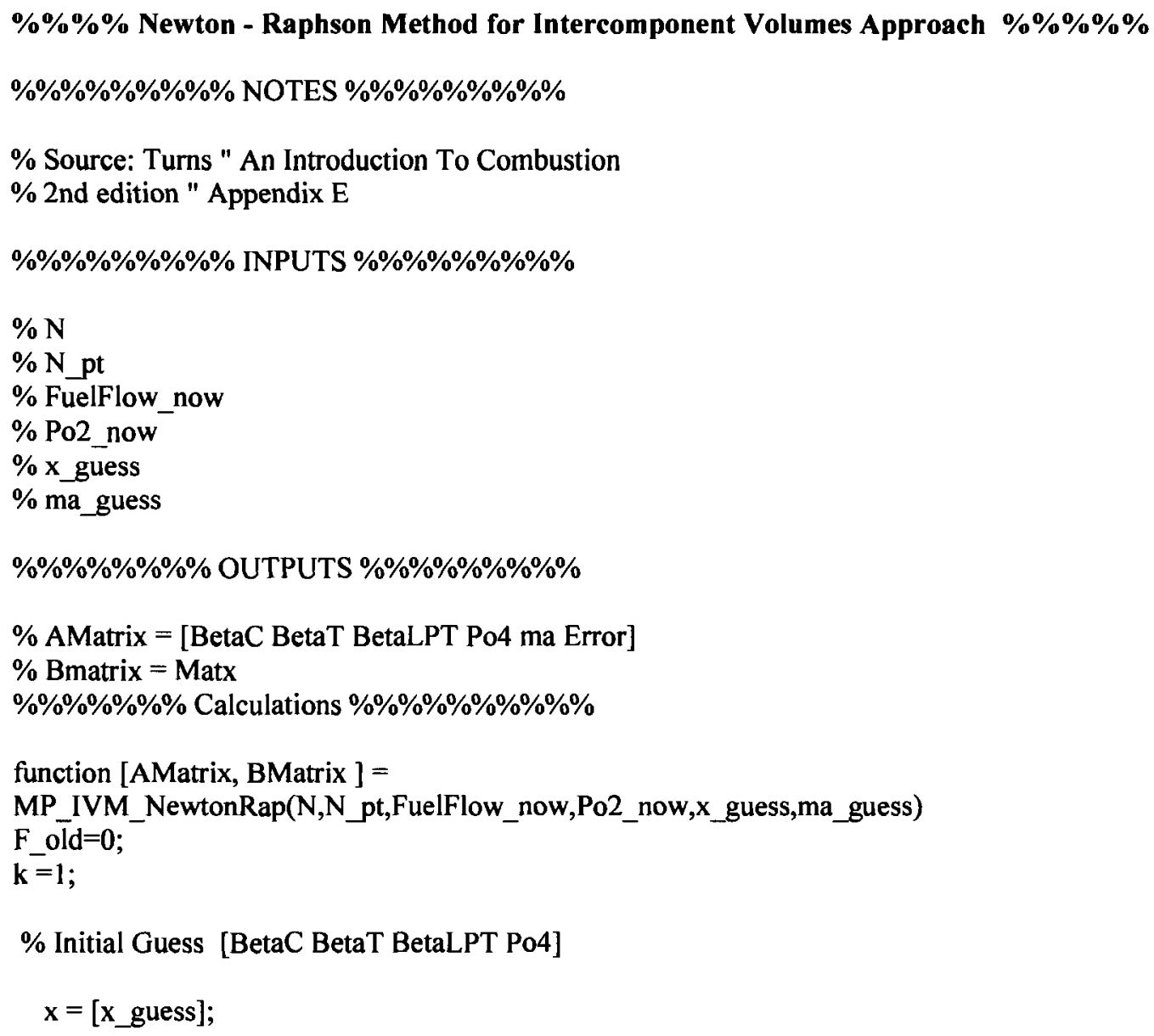


ma_guess $=\mathrm{m} 1$;

\% Solve using Gauss Elimination (in MATLAB this is down using "〉")

$\mathrm{dx}=(\mathrm{J} \backslash \mathrm{F})$;

$\% \% \% \% \% \% \% \% \%$ Damping $\% \% \% \% \% \% \% \% \%$

$\%$ this process is used to enable better convergence

if $(\operatorname{norm}(\operatorname{abs}(\mathrm{F})))>\left(\operatorname{norm}\left(\operatorname{abs}\left(\mathrm{F} \_\right.\right.\right.$old $\left.\left.)\right)\right)$ $\mathrm{dx}=\mathrm{dx} . / 5$

end

F_old $=$ F;

$\% \% \% \% \% \% \% \%$ Calculations $\% \% \% \% \% \% \% \% \%$

$\mathbf{x}=\mathbf{x}-\mathbf{d x}$

$\% x=\operatorname{abs}(x)$

Error_square $=(\operatorname{sum}(F \cdot \wedge 2))$

$\% \% \% \% \%$ Convergence Tolerances $\% \% \% \% \%$

bound_Check $=[x(1: 3)]>1.5$;

if $\max ($ bound Check ) $==1$

fprintf( 1 ,'Search did not converge for $N=\% 6.2 f(n ', N)$

AMatrix $=[x$ ma_guess Error_square $]$;

BMatrix = Matx;

return

end

if $(\operatorname{sum}(F . \wedge 2))<10^{\wedge}(-8)$

AMatrix $=[\mathrm{x}$ ma guess Error_square $]$

BMatrix = Matx;

return

end

end

fprintf(1,'Maximum iterations reached ! Search did not converge for $\left.N=\% 6.2 f n^{\prime}, N\right)$

AMatrix $=$ [x ma_guess Error_square $]$;

BMatrix = Matx;

$\% \% \% \% \% \% \% \%$ End $\% \% \% \% \% \% \%$ 


\section{Appendix B - GasTurb 10 Component Maps}

The following details the original component characteristics look-up table used during the dynamic modeling of the 1-MW gas turbine marine application. These look-up tables are available in GasTurb 10.

\section{Compressor Characteristics Look-up Tables}

99 NASA TM 101433 Example Compressor Map

Reynolds: $\mathrm{RNI}=0.1 \mathrm{f}=0.95 \mathrm{RNI}=1 \mathrm{f}=1$

$\begin{array}{ccccc}\text { Mass Flow } & & & & \\ 11.02100 & 0.00000 & 0.05263 & 0.10526 & 0.15789 \\ 0.21053 & 0.26316 & 0.31579 & 0.36842 & 0.42105 \\ 0.47368 & 0.52632 & 0.57895 & 0.63158 & 0.68421 \\ 0.73684 & 0.78947 & 0.84211 & 0.89474 & 0.94737 \\ 1.00000 & & & & \\ 0.50000 & 10.38683 & 10.23236 & 10.05630 & 9.87849 \\ 9.69593 & 9.50797 & 9.30393 & 9.10332 & 8.89518 \\ 8.67522 & 8.44689 & 8.21855 & 7.98237 & 7.75325 \\ 7.50371 & 7.25881 & 7.01299 & 6.76902 & 6.53247 \\ 6.29870 & & & & \\ 0.60000 & 13.46753 & 13.36364 & 13.24861 & 13.08534 \\ 12.90724 & 12.70130 & 12.48052 & 12.23791 & 12.00186 \\ 11.74954 & 11.48237 & 11.21521 & 10.93321 & 10.64564 \\ 10.33952 & 10.02783 & 9.71614 & 9.40445 & 9.07792 \\ 8.75139 & & & & \\ 0.70000 & 17.77922 & 17.74583 & 17.63451 & 17.50093 \\ 17.35250 & 17.15955 & 16.93692 & 16.68460 & 16.40260 \\ 16.09091 & 15.76438 & 15.42975 & 15.06679 & 14.68089 \\ 14.28942 & 13.89357 & 13.46237 & 13.03117 & 12.60297 \\ 12.20223 & & & & \\ 0.75000 & 20.46382 & 20.41373 & 20.35442 & 20.24675 \\ 20.11317 & 19.95663 & 19.76252 & 19.52876 & 19.26160 \\ 18.96104 & 18.62709 & 18.27644 & 17.89239 & 17.46928 \\ 17.00742 & 16.52657 & 16.02937 & 15.53803 & 15.03711 \\ 14.55288 & & & & \\ 0.80000 & 23.59740 & 23.54731 & 23.44243 & 23.33024 \\ 23.19666 & 23.02968 & 22.84601 & 22.63741 & 22.41187 \\ 22.16141 & 21.89425 & 21.57699 & 21.24304 & 20.84230 \\ 20.37477 & 19.85714 & 19.30670 & 18.67161 & 18.00371 \\ 17.38590 & & & & \\ 0.85000 & 26.38548 & 26.31610 & 26.24671 & 26.17733 \\ 26.10019 & 25.99224 & 25.89239 & 25.77365 & 25.62523\end{array}$




$\begin{array}{ccccc}25.46197 & 25.26902 & 25.06122 & 24.79406 & 24.51206 \\ 24.15584 & 23.76994 & 23.30983 & 22.68646 & 21.94434 \\ 21.12801 & & & & \\ 0.90000 & 28.92022 & 28.88683 & 28.84230 & 28.79777 \\ 28.75325 & 28.69605 & 28.65373 & 28.58970 & 28.51632 \\ 28.44293 & 28.37477 & 28.27458 & 28.16327 & 28.01855 \\ 27.78479 & 27.48423 & 27.05799 & 26.50464 & 25.89239 \\ 25.14286 & & & & \\ 0.95000 & 31.44805 & 31.42208 & 31.39610 & 31.36364 \\ 31.33117 & 31.29221 & 31.25284 & 31.19943 & 31.14935 \\ 31.09091 & 31.02597 & 30.95455 & 30.86364 & 30.75974 \\ 30.62987 & 30.47403 & 30.23377 & 29.94156 & 29.62385 \\ 29.24026 & & & & \\ 1.00000 & 33.64750 & 33.64007 & 33.62894 & 33.61410 \\ 33.59926 & 33.58071 & 33.56215 & 33.54360 & 33.52134 \\ 33.49907 & 33.46939 & 33.43599 & 33.39147 & 33.33581 \\ 33.25788 & 33.15770 & 33.00318 & 32.80519 & 32.60482 \\ 32.38367 & & & & \\ 1.050000 & 35.19239 & 35.18033 & 35.16456 & 35.14972 \\ 35.13488 & 35.12096 & 35.10612 & 35.09221 & 35.07847 \\ 35.06289 & 35.04675 & 35.03117 & 35.01336 & 34.99610 \\ 34.97857 & 34.95962 & 34.93933 & 34.91929 & 34.89740 \\ 34.87421 & & & & \end{array}$

$\begin{array}{ccccc}\text { Efficiency } & & & & \\ 11.02100 & 0.00000 & 0.05263 & 0.10526 & 0.15789 \\ 0.21053 & 0.26316 & 0.31579 & 0.36842 & 0.42105 \\ 0.47368 & 0.52632 & 0.57895 & 0.63158 & 0.68421 \\ 0.73684 & 0.78947 & 0.84211 & 0.89474 & 0.94737 \\ 1.00000 & & & & \\ 0.50000 & 0.65395 & 0.67150 & 0.68233 & 0.68970 \\ 0.69511 & 0.69917 & 0.70158 & 0.70308 & 0.70398 \\ 0.70418 & 0.70349 & 0.70173 & 0.69833 & 0.69391 \\ 0.68749 & 0.68097 & 0.67390 & 0.66699 & 0.66038 \\ 0.65406 & & & & \\ 0.60000 & 0.67053 & 0.69108 & 0.71063 & 0.72541 \\ 0.73719 & 0.74421 & 0.74822 & 0.74997 & 0.74972 \\ 0.74872 & 0.74596 & 0.74170 & 0.73694 & 0.73068 \\ 0.72341 & 0.71514 & 0.70637 & 0.69734 & 0.68695 \\ 0.67757 & & & & \\ 0.70000 & 0.72354 & 0.74750 & 0.76561 & 0.77965 \\ 0.79110 & 0.79865 & 0.80195 & 0.80385 & 0.80346 \\ 0.80075 & 0.79714 & 0.79185 & 0.78541 & 0.77741 \\ 0.76876 & 0.75979 & 0.74881 & 0.73706 & 0.72536 \\ 0.71564 & & & & \\ 0.75000 & 0.75886 & 0.77734 & 0.79288 & 0.80416\end{array}$




$\begin{array}{lllll}0.81368 & 0.82020 & 0.82396 & 0.82596 & 0.82647 \\ 0.82546 & 0.82346 & 0.82045 & 0.81594 & 0.80942 \\ 0.80115 & 0.79138 & 0.78010 & 0.76882 & 0.75629 \\ 0.74376 & & & & \\ 0.80000 & 0.79561 & 0.80970 & 0.82107 & 0.82935 \\ 0.83541 & 0.84043 & 0.84419 & 0.84662 & 0.84823 \\ 0.84857 & 0.84799 & 0.84639 & 0.84316 & 0.83737 \\ 0.82875 & 0.81865 & 0.80687 & 0.79358 & 0.78005 \\ 0.76727 & & & & \\ 0.85000 & 0.81807 & 0.82579 & 0.83211 & 0.83807 \\ 0.84386 & 0.84834 & 0.85276 & 0.85649 & 0.85895 \\ 0.86000 & 0.86013 & 0.85947 & 0.85737 & 0.85456 \\ 0.85035 & 0.84534 & 0.83825 & 0.82804 & 0.81474 \\ 0.80012 & & & & \\ 0.90000 & 0.81977 & 0.82985 & 0.83872 & 0.84517 \\ 0.85030 & 0.85494 & 0.85902 & 0.86218 & 0.86444 \\ 0.86613 & 0.86669 & 0.86609 & 0.86489 & 0.86308 \\ 0.85997 & 0.85657 & 0.85145 & 0.84454 & 0.83702 \\ 0.82738 & & & & \\ 0.95000 & 0.81677 & 0.82714 & 0.83556 & 0.84308 \\ 0.84912 & 0.85466 & 0.85902 & 0.86233 & 0.86504 \\ 0.86639 & 0.86684 & 0.86654 & 0.86534 & 0.86338 \\ 0.86098 & 0.85797 & 0.85436 & 0.85075 & 0.84564 \\ 0.84173 & & & & \\ 1.00000 & 0.79965 & 0.81298 & 0.82417 & 0.83368 \\ 0.84124 & 0.84812 & 0.85299 & 0.85611 & 0.85865 \\ 0.85975 & 0.86045 & 0.86045 & 0.86015 & 0.85912 \\ 0.85772 & 0.85544 & 0.85333 & 0.85035 & 0.84667 \\ 0.84164 & & & & \\ 1.05000 & 0.77587 & 0.78316 & 0.79123 & 0.79789 \\ 0.80526 & 0.81158 & 0.81712 & 0.82255 & 0.82707 \\ 0.83095 & 0.83470 & 0.83797 & 0.84087 & 0.84314 \\ 0.84506 & 0.84662 & 0.84692 & 0.84586 & 0.84271 \\ 0.83517 & & & & \\ & & & & \end{array}$

\section{Pressure Ratio}

$\begin{array}{ccccc}11.02100 & 0.00000 & 0.05263 & 0.10526 & 0.15789 \\ 0.21053 & 0.26316 & 0.31579 & 0.36842 & 0.42105 \\ 0.47368 & 0.52632 & 0.57895 & 0.63158 & 0.68421 \\ 0.73684 & 0.78947 & 0.84211 & 0.89474 & 0.94737 \\ 1.00000 & & & & \\ 0.50000 & 1.38577 & 1.44768 & 1.50467 & 1.55906 \\ 1.61040 & 1.65851 & 1.70165 & 1.74268 & 1.77985 \\ 1.81229 & 1.84044 & 1.86570 & 1.88659 & 1.90590 \\ 1.91828 & 1.92855 & 1.93561 & 1.94007 & 1.94321 \\ 1.94409 & & & & \end{array}$




$\begin{array}{ccccc}0.60000 & 1.77778 & 1.86684 & 1.95273 & 2.02940 \\ 2.10136 & 2.16614 & 2.22552 & 2.27796 & 2.32841 \\ 2.37260 & 2.41055 & 2.44505 & 2.47301 & 2.49621 \\ 2.51172 & 2.52220 & 2.52887 & 2.53175 & 2.52732 \\ 2.51901 & & & & \\ 0.70000 & 2.42348 & 2.55507 & 2.67226 & 2.78366 \\ 2.89022 & 2.98576 & 3.07243 & 3.14967 & 3.21697 \\ 3.27381 & 3.32309 & 3.36617 & 3.39812 & 3.41986 \\ 3.43538 & 3.44494 & 3.44056 & 3.43105 & 3.41726 \\ 3.40587 & & & & \\ 0.75000 & 2.88271 & 3.03211 & 3.17892 & 3.31501 \\ 3.44399 & 3.56595 & 3.67716 & 3.77636 & 3.86428 \\ 3.94031 & 4.00387 & 4.05866 & 4.10011 & 4.12624 \\ 4.13660 & 4.13611 & 4.12530 & 4.11025 & 4.08671 \\ 4.06220 & & & & \\ 0.80000 & 3.47425 & 3.64853 & 3.81024 & 3.96865 \\ 4.12035 & 4.26204 & 4.39706 & 4.52301 & 4.64142 \\ 4.74986 & 4.85008 & 4.93254 & 5.00578 & 5.05514 \\ 5.07958 & 5.08315 & 5.07047 & 5.02546 & 4.96328 \\ 4.90942 & & & & \\ 0.85000 & 4.05085 & 4.24362 & 4.43523 & 4.62568 \\ 4.81304 & 4.99123 & 5.16979 & 5.34157 & 5.50313 \\ 5.65805 & 5.80164 & 5.93775 & 6.05237 & 6.15831 \\ 6.23631 & 6.29957 & 6.33293 & 6.30556 & 6.23073 \\ 6.12270 & & & & \\ 0.90000 & 4.61613 & 4.83851 & 5.05754 & 5.27580 \\ 5.49329 & 5.70655 & 5.92301 & 6.13244 & 6.33797 \\ 6.54226 & 6.74694 & 6.94010 & 7.12789 & 7.30250 \\ 7.44390 & 7.55806 & 7.62260 & 7.63497 & 7.61851 \\ 7.54363 & & & & \\ 0.95000 & 5.21884 & 5.46513 & 5.71096 & 5.95455 \\ 6.19756 & 6.43811 & 6.67785 & 6.91256 & 7.14739 \\ 7.37861 & 7.60665 & 7.83132 & 8.04792 & 8.25829 \\ 8.45736 & 8.64449 & 8.79678 & 8.92504 & 9.03867 \\ 9.12101 & & & & \\ 1.00000 & 5.77492 & 6.04588 & 6.31568 & 6.58421 \\ 6.85247 & 7.11932 & 7.38584 & 7.65202 & 7.91662 \\ 8.18082 & 8.44201 & 8.70133 & 8.95594 & 9.20556 \\ 9.44559 & 9.67546 & 9.88171 & 10.06750 & 10.24897 \\ 10.41827 & & & & \\ 1.05000 & 6.18312 & 6.46704 & 6.74967 & 7.03229 \\ 7.31463 & 7.59698 & 7.87878 & 8.16061 & 8.44224 \\ 8.72297 & 9.00321 & 9.28336 & 9.56237 & 9.84127 \\ 10.11973 & 10.39730 & 10.67396 & 10.95035 & 11.22557 \\ 11.49980 & & & & \\ & & & & \end{array}$




\author{
SurgeLine \\ $\begin{array}{llllll}2.011 & 8.61500 & 10.9140 & 13.1840 & 14.8950\end{array}$ \\ $\begin{array}{lllll}17.6820 & 21.3110 & 25.3060 & 29.7180 & 33.0590\end{array}$ \\ 34.9193 \\ $\begin{array}{lllll}1.000 & 1.82000 & 2.48100 & 3.43500 & 4.06600\end{array}$ \\ 4.934006 .142007 .573009 .000009 .81400 \\ 10.9504
}

\title{
Turbine Characteristics Look-up Tables
}

99 High Work Low Aspect Ratio Turbine NASA TM83655. 1984

Reynolds: $\mathrm{RNI}=0.100 \mathrm{f}=0.950 \mathrm{RNI}=1.000 \mathrm{f}=1.000$

\section{Min Pressure Ratio}

$2.006000000 \quad 0.8000000120 .899999976 \quad 1.000000000 \quad 1.049999952$

1.100000024

$\begin{array}{llllll}0.800000012 & 1.530609012 & 1.546450496 & 1.565390110 & 1.576021791\end{array}$

1.587428093

\section{Max Pressure Ratio}

$2.006000000 \quad 0.8000000120 .899999976 \quad 1.000000000 \quad 1.049999952$ 1.100000024

0.8000000123 .7671058183 .8946537973 .9910802844 .027623177

4.056385517

\section{Mass Flow}

$\begin{array}{llllll}6.021000000 & 0.000000000 & 0.052631579 & 0.105263159 & 0.157894731\end{array}$

$\begin{array}{lllllll}0.210526317 & 0.263157904 & 0.315789461 & 0.368421048 & 0.421052635\end{array}$

$\begin{array}{llllllll}0.473684222 & 0.526315808 & 0.578947365 & 0.631578922 & 0.684210539\end{array}$

$\begin{array}{lllllll}0.736842096 & 0.789473712 & 0.842105269 & 0.894736826 & 0.947368443\end{array}$

1.000000000

$\begin{array}{llllll}0.800000012 & 2.865310907 & 2.947129250 & 3.014593363 & 3.066267967\end{array}$

$\begin{array}{lllllll}3.100717783 & 3.120095730 & 3.132091045 & 3.138038158 & 3.140909195\end{array}$

$\begin{array}{llllll}3.141626835 & 3.141626835 & 3.141626835 & 3.141626835 & 3.141626835\end{array}$

$\begin{array}{lllll}3.141626835 & 3.141626835 & 3.141626835 & 3.141626835 & 3.141626835\end{array}$

3.141626835

$\begin{array}{llllll}0.899999976 & 2.863688231 & 2.940669775 & 3.007350445 & 3.059090853\end{array}$

$\begin{array}{lllllll}3.091745615 & 3.111483335 & 3.124375820 & 3.130861282 & 3.133014441\end{array}$

$\begin{array}{llllll}3.133732080 & 3.133732080 & 3.133732080 & 3.133732080 & 3.133732080\end{array}$

$\begin{array}{llllll}3.133732080 & 3.133732080 & 3.133732080 & 3.133732080 & 3.133732080\end{array}$

3.133732080

$\begin{array}{llllll}1.000000000 & 2.868181705 & 2.942792654 & 3.004784584 & 3.048325300\end{array}$

$\begin{array}{lllllll}3.077751160 & 3.099282265 & 3.110765457 & 3.117537975 & 3.120095730\end{array}$

$\begin{array}{lllllll}3.120813370 & 3.120813370 & 3.120813370 & 3.120813370 & 3.120813370\end{array}$

$\begin{array}{lllll}3.120813370 & 3.120813370 & 3.120813370 & 3.120889187 & 3.120813370\end{array}$ 


\subsection{0}

$\begin{array}{llllll}1.049999952 & 2.878920078 & 2.948118925 & 3.005323648 & 3.045695305\end{array}$

$\begin{array}{llllll}3.073644638 & 3.093222618 & 3.104187012 & 3.110687494 & 3.113353729\end{array}$

$\begin{array}{llllll}3.114356756 & 3.114522934 & 3.114534378 & 3.114682198 & 3.114712954\end{array}$

$\begin{array}{lllll}3.114712954 & 3.114712954 & 3.114722729 & 3.114740849 & 3.114712954\end{array}$

3.114712954

$\begin{array}{lllll}1.100000024 & 2.889118433 & 2.953747988 & 3.006698608 & 3.043700218\end{array}$

$\begin{array}{lllllll}3.069856405 & 3.087799072 & 3.097926617 & 3.104306221 & 3.106858015\end{array}$

$\begin{array}{llllll}3.108085394 & 3.108259916 & 3.108254194 & 3.108612537 & 3.108612537\end{array}$

$\begin{array}{lllll}3.108612537 & 3.108612537 & 3.108612537 & 3.108612537 & 3.108612537\end{array}$

3.108612537

\section{Efficiency}

$\begin{array}{llllll}6.021000000 & 0.000000000 & 0.052631579 & 0.105263159 & 0.157894731\end{array}$

$\begin{array}{lllllll}0.210526317 & 0.263157904 & 0.315789461 & 0.368421048 & 0.421052635\end{array}$

$\begin{array}{lllllll}0.473684222 & 0.526315808 & 0.578947365 & 0.631578922 & 0.684210539\end{array}$

$\begin{array}{lllllll}0.736842096 & 0.789473712 & 0.842105269 & 0.894736826 & 0.947368443\end{array}$

1.000000000

$\begin{array}{lllllll}0.800000012 & 0.862686574 & 0.864444435 & 0.866148710 & 0.866418302\end{array}$

$\begin{array}{llllllll}0.865771115 & 0.864789903 & 0.862686574 & 0.860199034 & 0.856484234\end{array}$

$\begin{array}{lllllll}0.851741314 & 0.846666694 & 0.840298533 & 0.832835793 & 0.823582113\end{array}$

$\begin{array}{lllllll}0.813764513 & 0.801824212 & 0.787495852 & 0.772518158 & 0.756914675\end{array}$

0.741971910

$\begin{array}{llllll}0.899999976 & 0.874129355 & 0.877280295 & 0.880596995 & 0.883084595\end{array}$

$\begin{array}{llllllll}0.885406315 & 0.887064695 & 0.887562215 & 0.887562215 & 0.886397421\end{array}$

$\begin{array}{lllllll}0.883723259 & 0.880066335 & 0.875059068 & 0.867661715 & 0.859203994\end{array}$

$\begin{array}{lllllll}0.848955214 & 0.837114453 & 0.824192345 & 0.809166431 & 0.794162512\end{array}$

0.778720021

$\begin{array}{lllllll}1.000000000 & 0.875415266 & 0.883388698 & 0.890298486 & 0.896616936\end{array}$

$\begin{array}{lllllll}0.902126253 & 0.906343281 & 0.909302354 & 0.910897017 & 0.911096334\end{array}$

$\begin{array}{lllllll}0.910447776 & 0.908106327 & 0.903980076 & 0.898139536 & 0.890671670\end{array}$

$\begin{array}{lllllll}0.880596995 & 0.869288862 & 0.855504930 & 0.841044784 & 0.825183511\end{array}$

0.809701502

$\begin{array}{llllll}1.049999952 & 0.880042434 & 0.887722194 & 0.894605160 & 0.900887907\end{array}$

$\begin{array}{lllllll}0.906177402 & 0.910082340 & 0.912785828 & 0.914506793 & 0.914833784\end{array}$

$\begin{array}{lllllll}0.914079785 & 0.911949337 & 0.908656716 & 0.903283596 & 0.896417916\end{array}$

$\begin{array}{lllllll}0.887761176 & 0.877313435 & 0.866268635 & 0.853432834 & 0.839104474\end{array}$

0.824776113

$\begin{array}{llllll}1.100000024 & 0.880863786 & 0.889169455 & 0.895721376 & 0.901857376\end{array}$

$\begin{array}{lllllll}0.906832516 & 0.910315096 & 0.912757456 & 0.914750814 & 0.915124357\end{array}$

$\begin{array}{lllllll}0.914418578 & 0.912757456 & 0.909435213 & 0.904842436 & 0.898043096\end{array}$

$\begin{array}{lllllll}0.890498340 & 0.880630195 & 0.869353235 & 0.858076274 & 0.844435215\end{array}$

0.829994678 


\section{Power Turbine Characteristics Look-up Tables}

99 AGARD two-stage turbine

Reynolds: $\mathrm{RNI}=0.1 \mathrm{f}=0.95 \mathrm{RNI}=1 \mathrm{f}=1$

Min Pressure Ratio $=\mathrm{f}(\mathrm{N} / \operatorname{sqrt}(\mathrm{T}))$

$\begin{array}{lll}2.00800 & 0.60000 & 0.70000\end{array}$

$\begin{array}{lll}1.00000 & 1.10000 & 1.20000\end{array}$

$\begin{array}{lllll}0.00000 & 1.17461 & 1.23847 & 1.31249 & 1.39667\end{array}$

$\begin{array}{lll}1.49100 & 1.59549 & 1.71013\end{array}$

Max Pressure Ratio $=\mathrm{f}(\mathrm{N} / \mathrm{sqrt}(\mathrm{T}))$

$\begin{array}{lllll}2.00800 & 0.60000 & 0.70000 & 0.80000 & 0.90000 \\ 1.00000 & 1.10000 & 1.20000 & & \\ 0.00000 & 2.11055 & 2.80304 & 3.31182 & 3.63689 \\ 3.77825 & 3.73589 & 3.50983 & & \end{array}$

Mass Flow $=\mathrm{f}(\mathrm{N} / \mathrm{sqrt}(\mathrm{T})$,relative Pressure Ratio)

$\begin{array}{lllll}8.01600 & 0.00000 & 0.07143 & 0.14286 & 0.21429 \\ 0.28571 & 0.35714 & 0.42857 & 0.50000 & 0.57143 \\ 0.64286 & 0.71429 & 0.78571 & 0.85714 & 0.92857\end{array}$

$\begin{array}{lllll}0.64286 & 0.71429 & 0.78571 & 0.85714 & 0.92857\end{array}$

1.00000

$\begin{array}{llllll}0.60000 & 70.37594 & 79.89975 & 86.61654 & 91.63452\end{array}$

$\begin{array}{lllll}95.31143 & 98.83739 & 101.37780 & 103.44978 & 105.18874\end{array}$

$\begin{array}{lllll}106.65414 & 107.88471 & 108.75940 & 109.48872 & 110.06516\end{array}$

110.51629

$\begin{array}{llllll}0.70000 & 77.51880 & 88.17043 & 95.30702 & 100.57644\end{array}$

$\begin{array}{lllll}104.08521 & 106.32995 & 107.96992 & 109.09774 & 109.95614\end{array}$

$\begin{array}{llllll}110.65789 & 111.14035 & 111.53509 & 111.88596 & 112.13693\end{array}$

112.30457

$\begin{array}{lllll}0.80000 & 82.61905 & 94.04762 & 100.30023 & 104.67419\end{array}$

$\begin{array}{lllll}106.93042 & 108.67254 & 109.73183 & 110.48872 & 111.09023\end{array}$

$\begin{array}{lllll}111.57644 & 111.93734 & 112.13784 & 112.29825 & 112.38451\end{array}$

112.45591

$\begin{array}{llllll}0.90000 & 87.44039 & 97.18222 & 102.54386 & 106.05263\end{array}$

$\begin{array}{lllll}108.28575 & 109.73684 & 110.54333 & 111.10526 & 111.47368\end{array}$

$\begin{array}{lllll}111.75439 & 111.96491 & 112.08772 & 112.15789 & 112.20175\end{array}$

112.21053

$\begin{array}{lllll}1.00000 & 91.96417 & 99.43609 & 103.72180 & 106.66165\end{array}$

$\begin{array}{lllll}108.60902 & 109.66165 & 110.33835 & 110.92105 & 111.28947\end{array}$

$\begin{array}{lllll}111.54511 & 111.74812 & 111.85338 & 111.89098 & 111.91729\end{array}$

111.91729

$\begin{array}{llllll}1.10000 & 95.18498 & 100.56391 & 103.87218 & 106.35338\end{array}$

$\begin{array}{lllll}108.04045 & 109.06015 & 109.79864 & 110.46423 & 110.92322\end{array}$

$\begin{array}{lllll}111.22866 & 111.39098 & 111.52632 & 111.60150 & 111.63158\end{array}$

111.63158 
$\begin{array}{llllll}1.20000 & 97.85714 & 101.76692 & 104.29543 & 106.05358\end{array}$

$\begin{array}{llllll}107.38247 & 108.34660 & 109.14787 & 109.83992 & 110.35412\end{array}$

$\begin{array}{lllll}110.72932 & 110.98496 & 111.18045 & 111.28571 & 111.34586\end{array}$

111.36090

Efficiency $=\mathrm{f}(\mathrm{N} / \mathrm{sqrt}(\mathrm{T})$,relative Pressure Ratio)

$\begin{array}{lllll}8.01600 & 0.00000 & 0.07143 & 0.14286 & 0.21429 \\ 0.28571 & 0.35714 & 0.42857 & 0.50000 & 0.57143 \\ 0.64286 & 0.71429 & 0.78571 & 0.85714 & 0.92857 \\ 1.00000 & & & & \\ 0.60000 & 0.82112 & 0.89330 & 0.91140 & 0.91096 \\ 0.89902 & 0.88622 & 0.87285 & 0.86033 & 0.84830 \\ 0.83627 & 0.82423 & 0.81440 & 0.80370 & 0.79301 \\ 0.78231 & & & & \\ 0.70000 & 0.83766 & 0.90583 & 0.91585 & 0.91184 \\ 0.90094 & 0.88534 & 0.87301 & 0.86082 & 0.84909 \\ 0.83824 & 0.82874 & 0.81992 & 0.81153 & 0.80315 \\ 0.79477 & & & & \\ 0.80000 & 0.82964 & 0.90683 & 0.92123 & 0.92187 \\ 0.91474 & 0.90301 & 0.89230 & 0.88227 & 0.87325 \\ 0.86372 & 0.85567 & 0.84841 & 0.84095 & 0.83524 \\ 0.82953 & & & & \\ 0.90000 & 0.80558 & 0.89530 & 0.92086 & 0.92788 \\ 0.92888 & 0.92487 & 0.91886 & 0.91134 & 0.90432 \\ 0.89731 & 0.89013 & 0.88216 & 0.87416 & 0.86616 \\ 0.85816 & & & & \\ 1.00000 & 0.78140 & 0.87285 & 0.90952 & 0.92637 \\ 0.93338 & 0.93439 & 0.93278 & 0.92997 & 0.92637 \\ 0.92192 & 0.91726 & 0.91236 & 0.90633 & 0.90030 \\ 0.89388 & & & & \\ 1.10000 & 0.75263 & 0.84211 & 0.89023 & 0.91429 \\ 0.92623 & 0.93383 & 0.93825 & 0.93982 & 0.94000 \\ 0.93860 & 0.93614 & 0.93298 & 0.92940 & 0.92526 \\ 0.92105 & & & & \\ 1.20000 & 0.73083 & 0.81203 & 0.85414 & 0.88195 \\ 0.90301 & 0.91579 & 0.92448 & 0.93135 & 0.93643 \\ 0.93951 & 0.94102 & 0.94124 & 0.94094 & 0.94027 \\ 0.93917 & & & & \end{array}$




\section{Appendix C -Design Point and Off-Design Steady-State Validation}

\section{C.1 Design Point Validation}

The design point validation step was done to ensure that the dynamic model was properly coded. Using the resulting design point performance data generated by project management during the project definition process (see Section 5.1.4), the dynamic model was first debugged accordingly. The dynamic model was then run at design point condition to produce its own performance data. Similarly, GasTurb was also used to produce a set of design point parameters. The two sets of design point parameters were then compared to assess the accuracy of the dynamic model at design point.

Table C.1: Design point validation results

\begin{tabular}{|l|c|c|c|c|}
\hline \multicolumn{1}{|c|}{ Parameter } & Units & $\begin{array}{c}\text { Dynamic } \\
\text { Model }\end{array}$ & GasTurb & $\begin{array}{c}\text { Error } \\
\%\end{array}$ \\
\hline Ambient Pressure & $\mathrm{kPa}$ & 101.3 & 101.3 & 0.00 \\
\hline Ambient Temperature & $\mathrm{K}$ & 288.2 & 288.2 & 0.00 \\
\hline Inlet Mass Flow & $\mathrm{kg} / \mathrm{s}$ & 5.50 & 5.50 & 0.00 \\
\hline Inlet Temperature & $\mathrm{K}$ & 288.2 & 288.2 & 0.00 \\
\hline Inlet Pressure & $\mathrm{kPa}$ & 100.3 & 100.3 & 0.00 \\
\hline Compressor Exit Temp & $\mathrm{K}$ & 550.4 & 550.9 & 0.09 \\
\hline Compressor Exit Press & $\mathrm{kPa}$ & 702.3 & 702.3 & 0.00 \\
\hline Compr Exit Flow & $\mathrm{kg} / \mathrm{s}$ & 5.50 & 5.50 & 0.00 \\
\hline Compressor Power & $\mathrm{kW}$ & 1467.7 & 1472.7 & 0.34 \\
\hline Burner Exit Pressure & $\mathrm{kPa}$ & 667.2 & 667.2 & 0.00 \\
\hline Burner Exit Temperature & $\mathrm{K}$ & 1200 & 1200 & 0.00 \\
\hline Burner Exit Flow & $\mathrm{kg} / \mathrm{s}$ & 5.51 & 5.52 & 0.05 \\
\hline GG Turbine Exit Temp & $\mathrm{K}$ & 967.3 & 973.1 & 0.60 \\
\hline GG Turbine Exit Press & $\mathrm{kPa}$ & 248.8 & 249.3 & 0.22 \\
\hline GG T Rotor Inlet Flow & $\mathrm{kg} / \mathrm{s}$ & 5.51 & 5.52 & 0.05 \\
\hline GG Turbine Power & $\mathrm{kW}$ & 1482.2 & 1487.6 & 0.36 \\
\hline PT Turbine Exit Temp & $\mathrm{K}$ & 792.5 & 801.6 & 1.14 \\
\hline PT Turbine Exit Press & $\mathrm{kPa}$ & 103.3 & 103.3 & 0.01 \\
\hline PT Inlet Flow & $\mathrm{kg} / \mathrm{s}$ & 5.51 & 5.52 & 0.05 \\
\hline PT Power & $\mathrm{kW}$ & 1073.7 & 1086.7 & 1.19 \\
\hline Exit Duct Press & $\mathrm{kPa}$ & 101.3 & 101.3 & 0.00 \\
\hline Fuel Flow & $\mathrm{kg} / \mathrm{s}$ & 0.094 & 0.097 & 3.19 \\
\hline Handling Bleed & $\mathrm{kg} / \mathrm{s}$ & 0.0825 & 0.0825 & 0.00 \\
\hline Shaft Power Delivered & $\mathrm{kW}$ & 1063.0 & 1075.7 & 1.18 \\
\hline
\end{tabular}


As shown in Table C.1, the discrepancies were mainly found in the hot section of the gas turbine. Upon investigation, it was determined that assumptions linked to combustion gas properties and dissociation effects were the main cause of the discrepancies. It was found that GasTurb considers the effects of the combustion products $\mathrm{H}_{2} \mathrm{O}$ and $\mathrm{CO}_{2}$ on the specific heat, enthalpy, entropy and gas constant and takes into account $\mathrm{CO}$, NOx and unburnt hydrocarbon dissociation effects on the combustion temperature rise. Since dissociation reduces flame temperature, and hence reduces the temperature rise across the combustor, a higher fuel flow is required to achieve the same turbine inlet temperature achieved without dissociation effects. Since these effects were not included in the dynamic modeling equations, a fuel flow error of $3.19 \%$ between the dynamic model and GasTurb was observed. The gas properties of the combustion product were also not considered in the dynamic model (air properties only) resulting in a 0.2 to $1.8 \%$ mismatch in the hot section parameters between the model and GasTurb. The reason dissociation and combustion products were neglected during the dynamic modeling process was to reduce the computational complexity of the code. Remembering that the focus of this project was to develop a dynamic model early in the design process, it was decided that a slight reduction of accuracy would be accepted for the added computational benefits. Therefore, in light of this fact and based on the results shown in Table C.1, it was determined that the accuracy of the dynamic model at design point fell well within the acceptable limits for this project.

\section{C.2 Off-design - Steady-State Validation}

The reason for off-design steady-state validation was to verify the accuracy and validity of the steady-state operating line generated by the dynamic model between idle and the design point. This was achieved by comparing the dynamic model engine parameters against the benchmark performance data generated by GasTurb at various offdesign spool speeds. However, since there was a wide range of engine parameters to assess, a two-part validation strategy was put in place to streamline the process. First, it was determined that the best method to compare and validate off-design performance data was to plot both operating line on the same compressor characteristic. The reason for 
this approach lies in the fact that there is only a single steady-state operating point for a given set of engine parameters. Therefore, by comparing both operating line on the same compressor characteristic, it was possible to assess the accuracy of the model without having to assess large amounts of data. Secondly, since the dynamic model accuracy is going to play an important role in the control system design validation, specific engine parameters linked to the control system such as compressor exit pressure $\left(\mathrm{P}_{02}\right)$, turbine inlet temperature (TIT), fuel flow and fuel-to-air ratio were also analyzed in more details.

When plotting both off-design steady-state operating lines (GasTurb and Dynamic model) on the same compressor characteristic (Figure C.1), it became apparent that lines did not overlap as expected. As shown below, the operating lines did converge at the design point but slightly diverged as the modeling progressed down to idle speed.

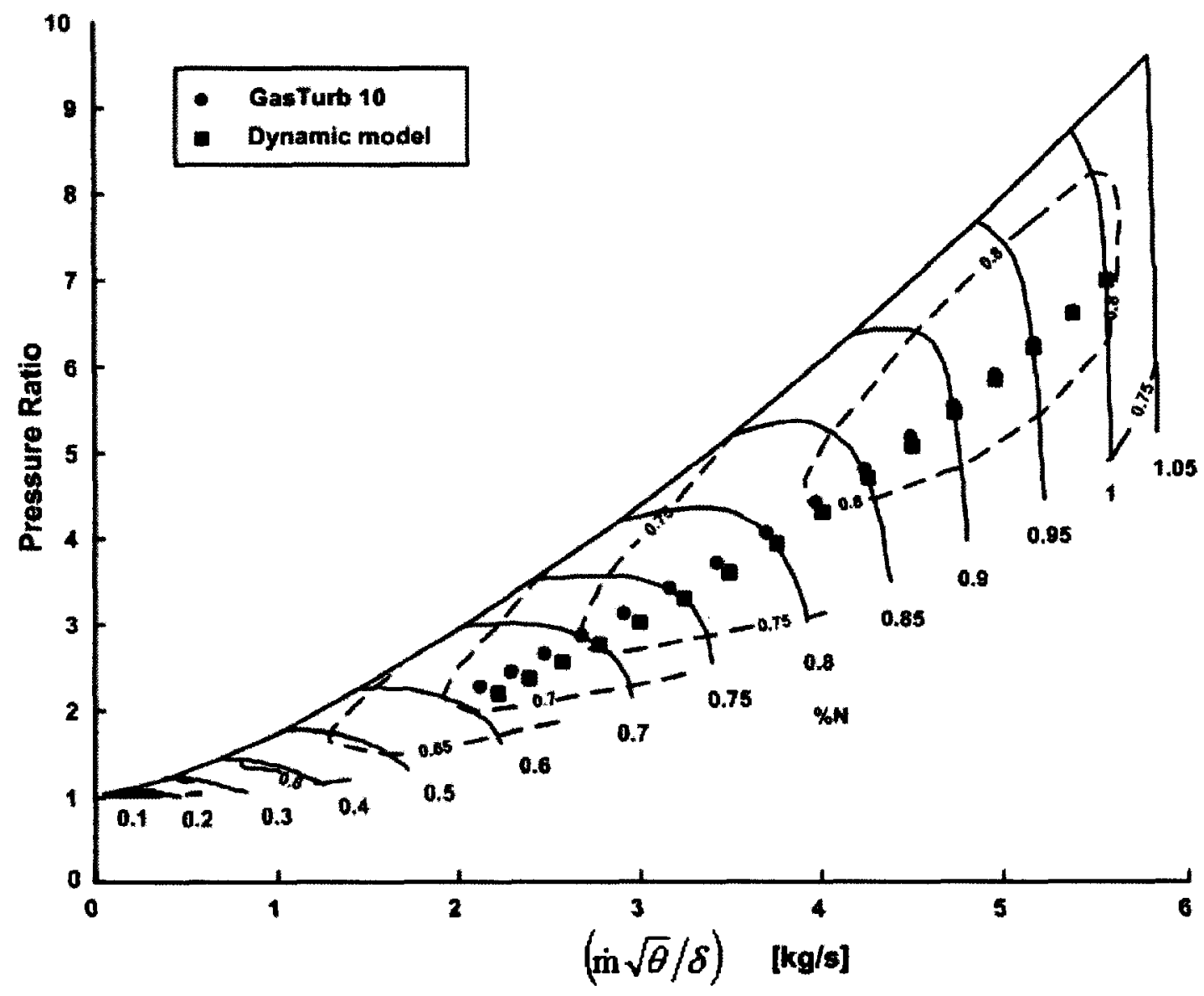

Figure C.1: Off-design steady-state operating line comparison 
Since both models were subjected to the same operating conditions, the discrepancies in pressure ratio and mass flow seemed to insinuate modeling issues. The lower pressure ratio and higher mass flow observed at each operating point suggested that the dynamic model compressor was slightly less loaded than the GasTurb compressor at lower spool speeds. This deduction led to the investigation of the engine load characteristic modeling procedure. It was found that GasTurb was not capable of modeling specified load characteristics such as the one shown in Figure 5.6. The predetermine turboshaft engine model found in GasTurb imposes a constant power turbine spool speed operating condition to its model. Therefore, to allow for proper validation, the dynamic model was slightly modified to impose the constant spool speed requirement and ran to generate another steady-state off-design operating line. Again both operating lines were plotted onto the same compressor characteristic. In this case, as shown in Figure C.2, both operating line overlapped as expected.

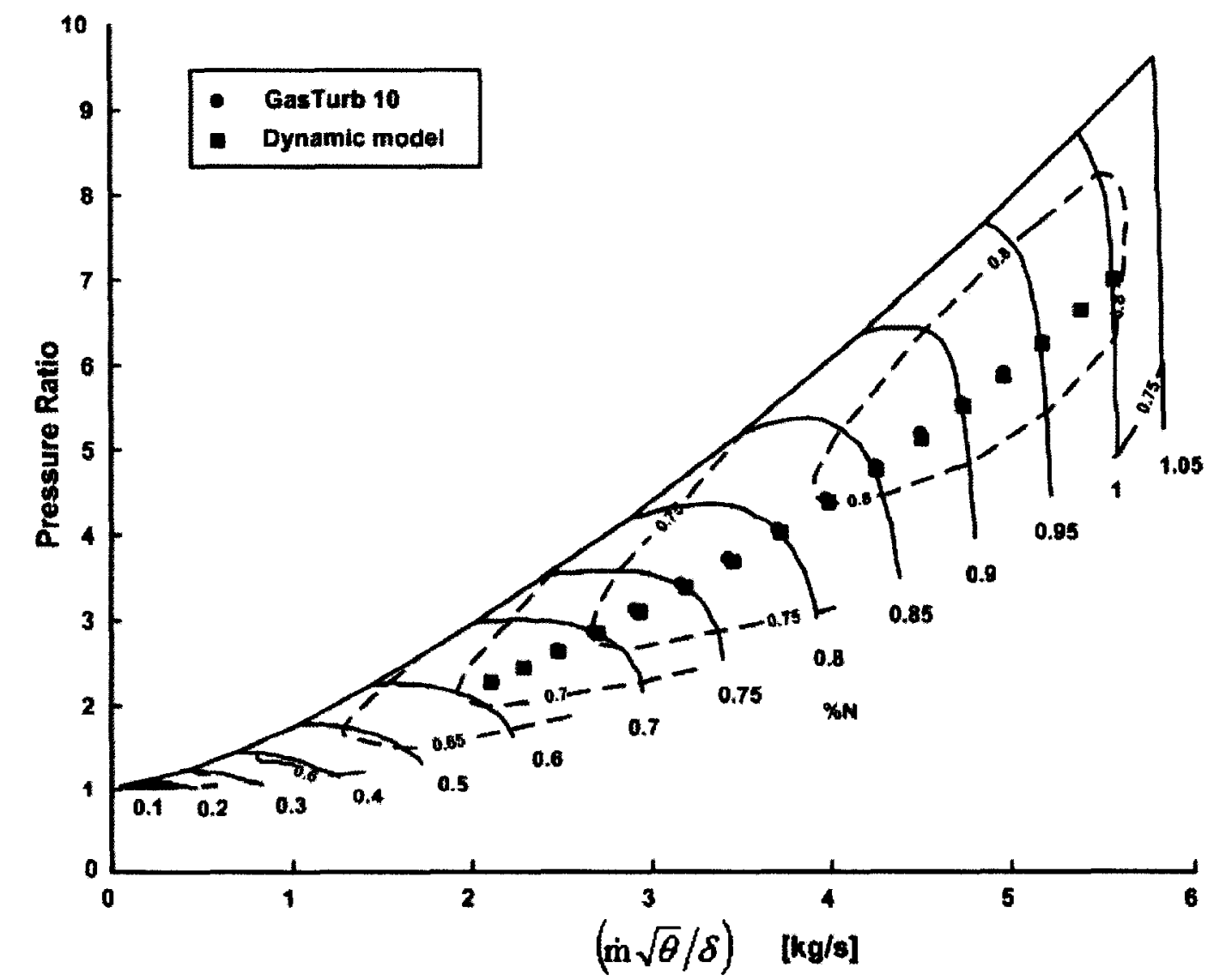

Figure C.2: Off-design steady-state operating line comparison (at constant $\mathrm{N}_{\mathrm{pt}}$ ) 
To further enhance the confidence level in the steady-state modeling, the compressor mass flow, pressure ratio and efficiency error in reference to the benchmark was plotted below (Figure C.3).

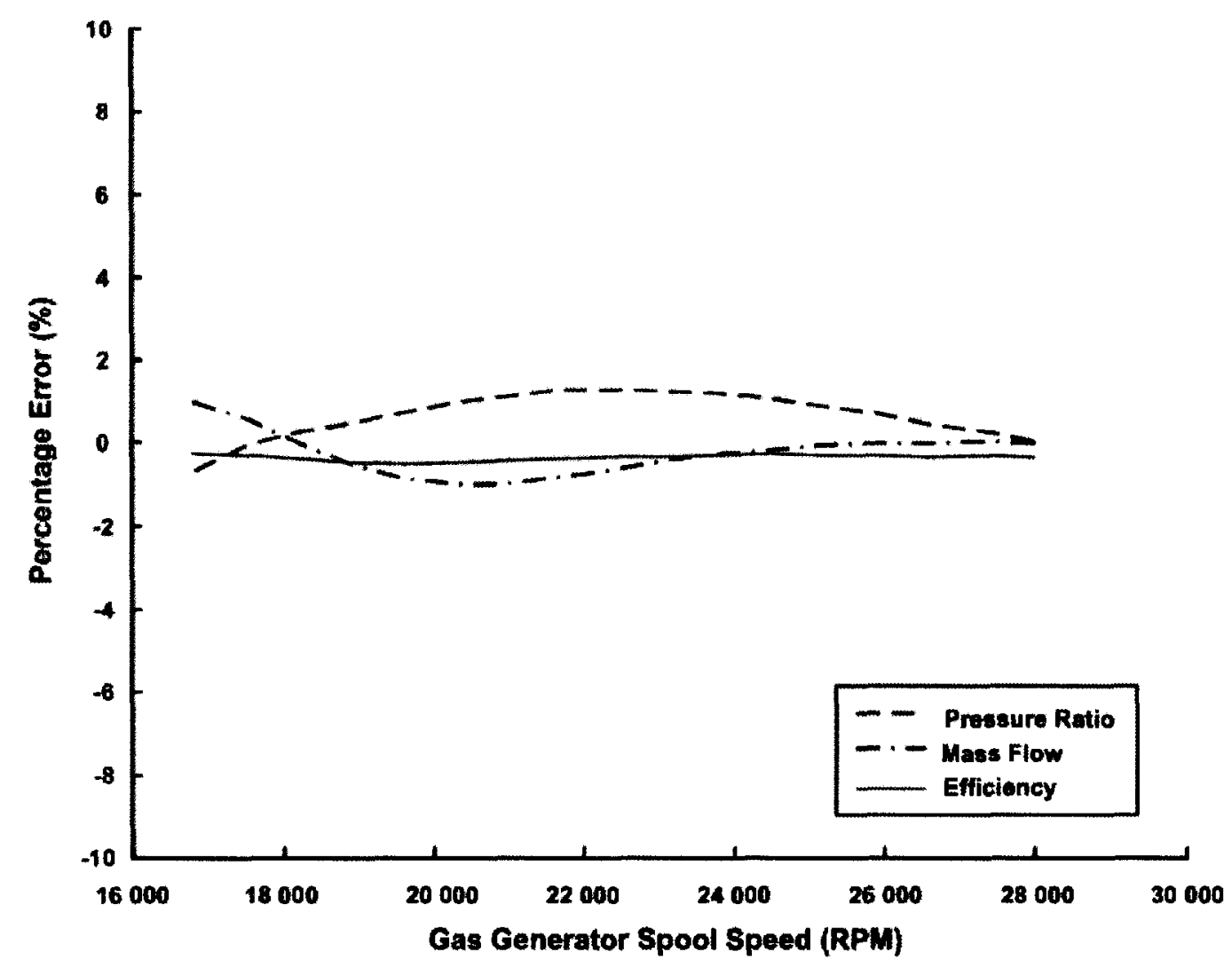

Figure C.3: Steady-state operating line error

Overall, a maximum error of $2 \%$ was recorded and deemed acceptable for this project. It is important to note that by validating the constant power turbine spool speed version of the dynamic model using GasTurb, the actual model containing the proper load characteristic was also validated through analogy.

To assess the dynamic modeling accuracy of engine parameters linked to the control system, important parameters were validated against GasTurb throughout the steady-state operating region. The assessed parameters were compressor exit pressure $\left(\mathrm{P}_{\mathrm{o} 2}\right)$, the gas generator turbine inlet temperature (TIT), the fuel flow and finally the fuelto-air ratio. The error of each parameter is depicted in Figure C. 4 


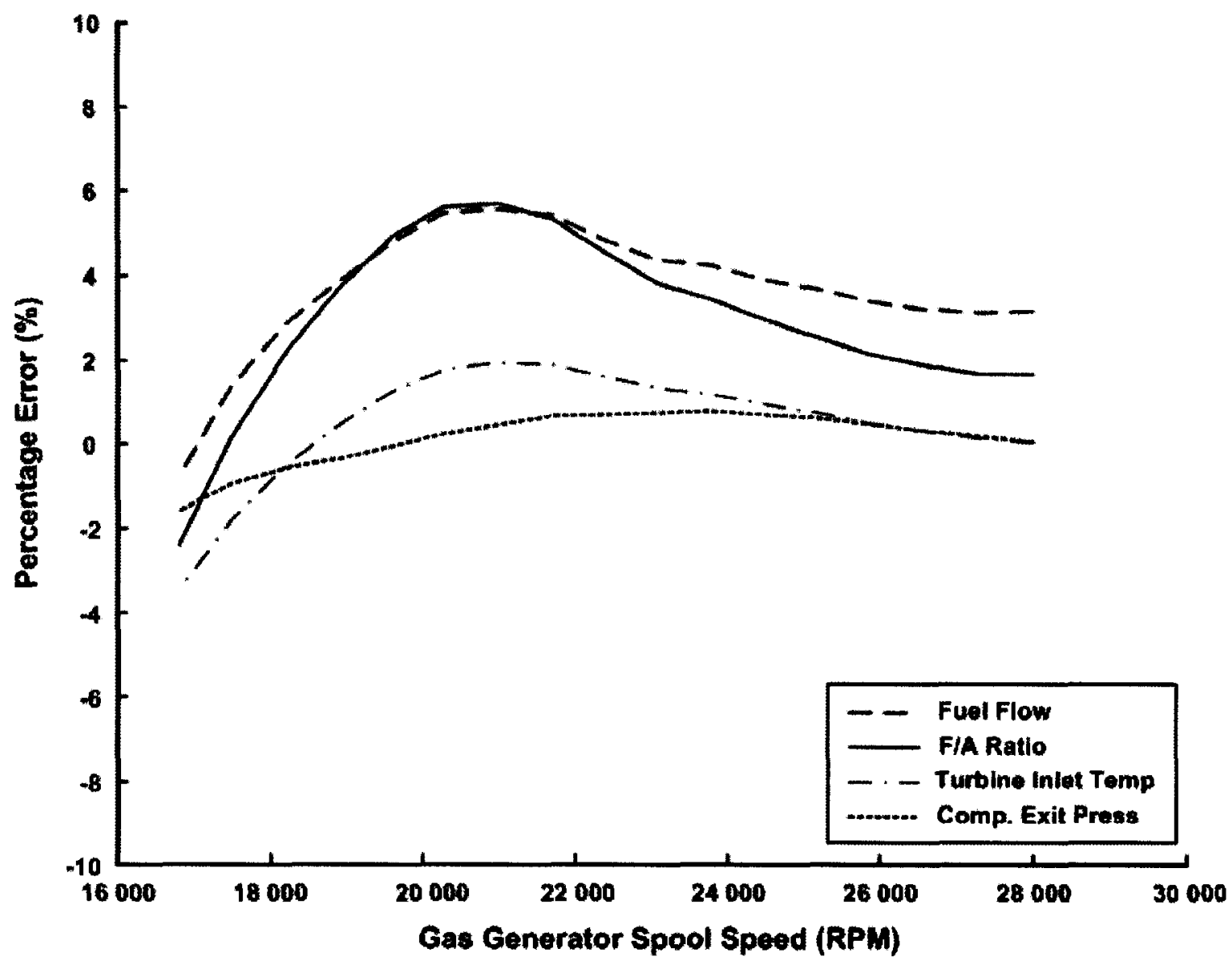

Figure C.4: Error - engine parameters linked to the control system

Overall, the errors recorded were within the expected range. The fuel-to-air ratio and gas generator turbine inlet temperature trends mimicked the fuel flow trend, as expected since they are directly related. However it was expected that the fuel flow error would remain relatively flat throughout the operating range based on the dissociation effects discussed earlier in the design point validation section. With a bit of research, it was determined that there were two reasons for the changes in the fuel flow trend. First, the increase in error was found to be linked to the part-load burner efficiency equation. The burner efficiency within the dynamic model is calculated using Eqn 3.31 based on combustion loading calculated using Eqn 3.32. On the other hand GasTurb calculates burner efficiency through relative scaling of the design point burner efficiency using empirical constants. When plotting both combustion efficiency trends on the same plot it was found that GasTurb generates a pessimistic view of the burner efficiency at lower speed (Figure C.5). 


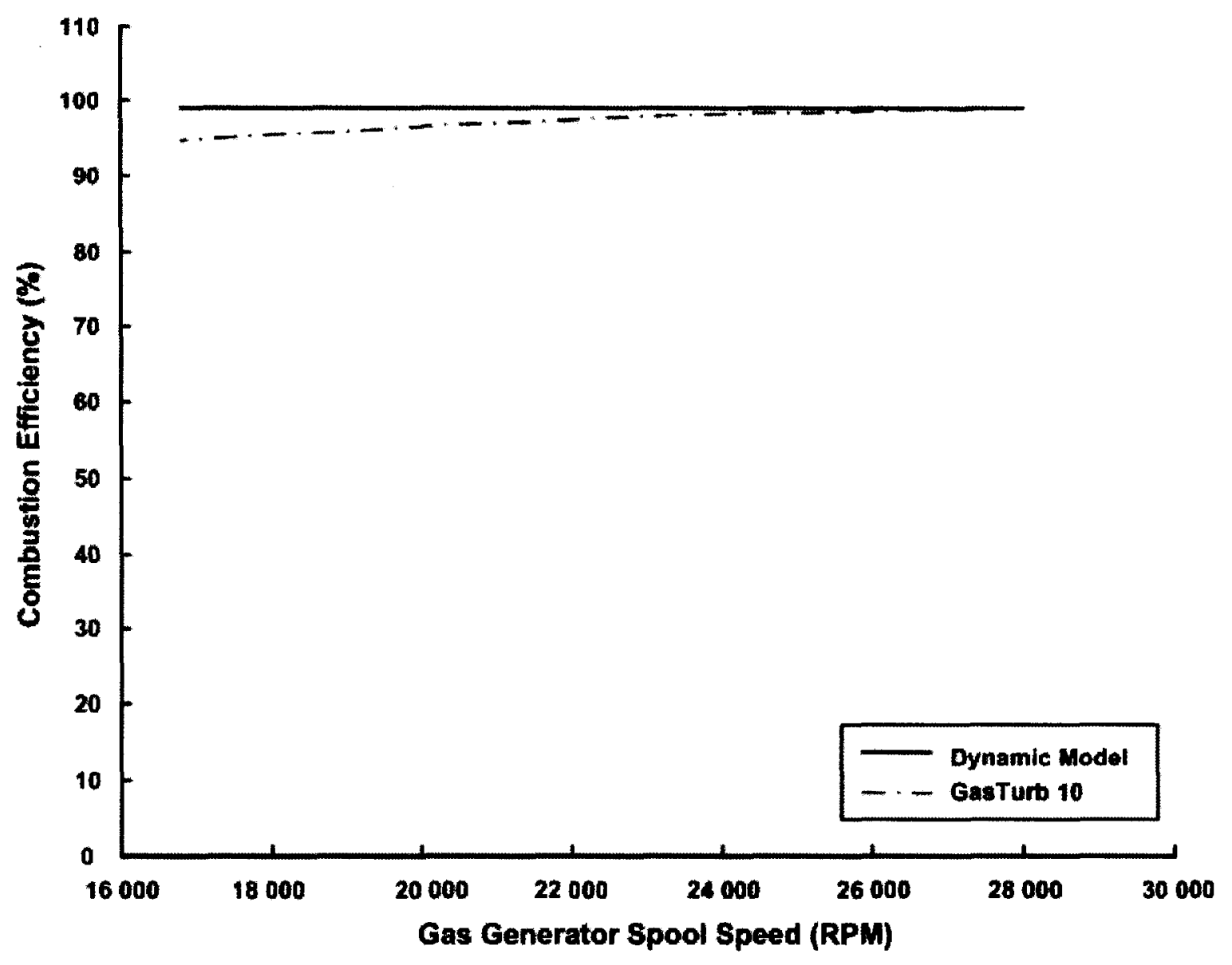

Figure C.5: Combustion efficiency comparison

The lower combustion efficiency has the effect of increasing the fuel flow requirement and hence is reflected as an increase in fuel flow error in Figure C.4. However it is extremely difficult to predict combustion efficiency early in the design process (rig test is required). Since both efficiency methods were derived empirically for well-defined combustors and injectors, the actual accuracy of combustion efficiency may vary with the design and therefore cannot fully be assessed at the preliminary design phase. This will only be possible late in the design process. Additionaly, it was found that the power turbine efficiency extrapolation calculations were generating erroneous data at speeds at lower spool speeds (Figure C.6). However these calculations were purely the byproduct of having to validate the dynamic model at constant power turbine speed. 


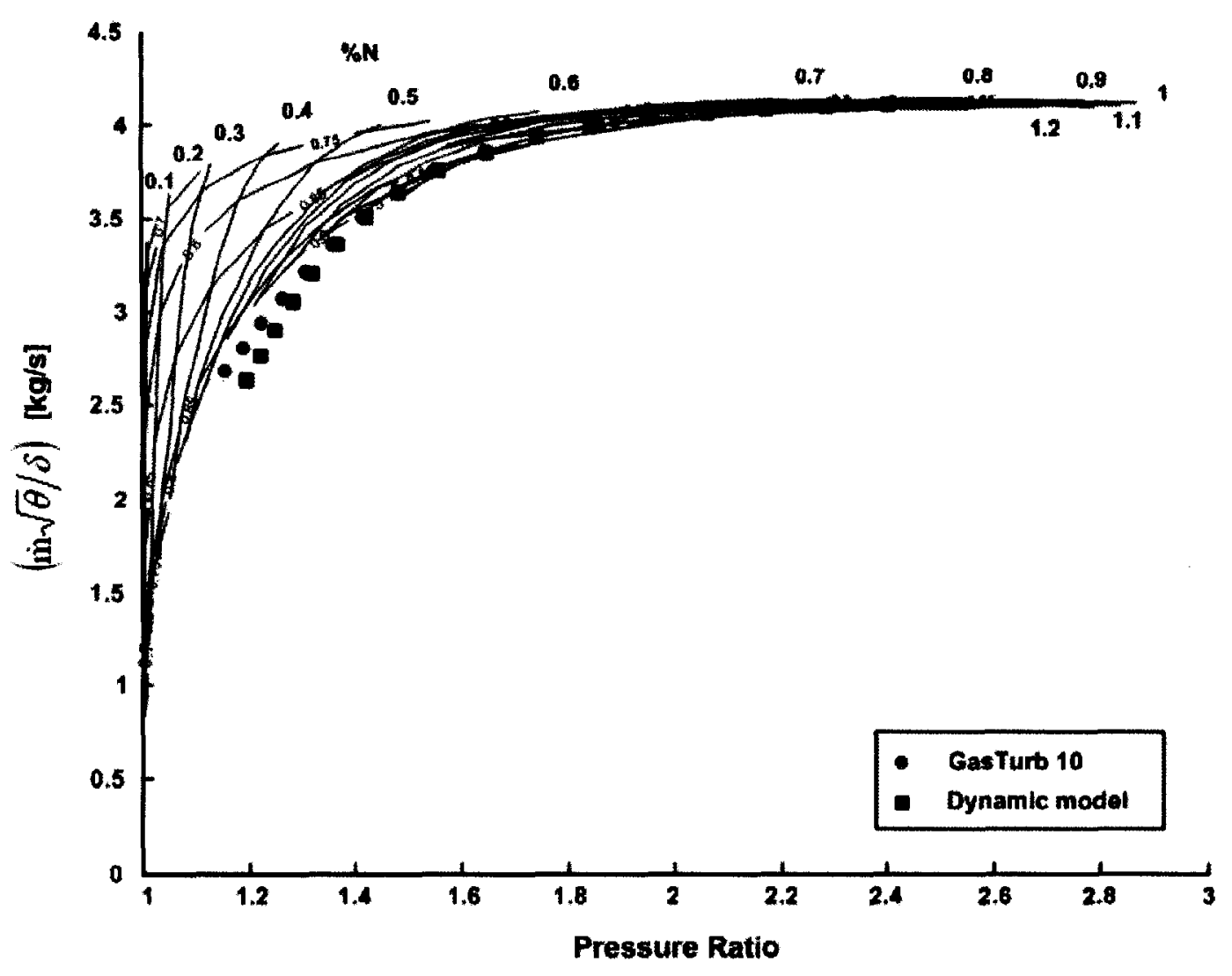

Figure C.6: Power turbine steady-state operating line (constant $\mathrm{N}_{\mathrm{pt}}$ )

As shown in Figure C.7, when the required load characteristic was inputted into the dynamic model, the operating points fell within the boundaries of the power turbine map. Therefore it is expected that the rapid decrease in fuel flow error found at lower spool speeds (below 20000 RPM) would not exist if GasTurb had the capability of simulating load characteristics. 


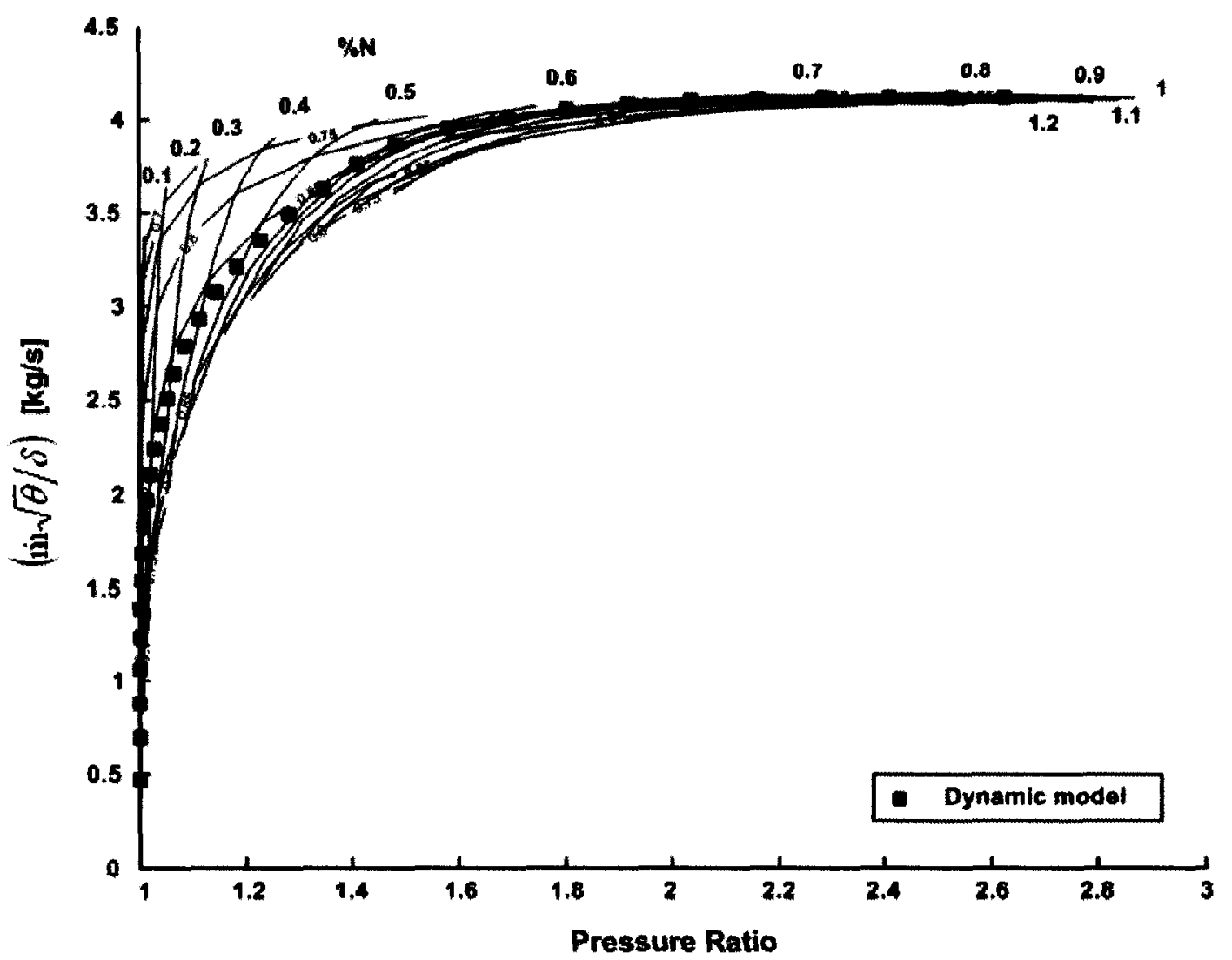

Figure C.7: Power turbine steady-state operating line (with load characteristic) 


\section{Appendix D - Dynamic Model and Control System In-house Code}

The following appendix contains the dynamic model and control system in-house MATLAB code.

$\% \% \% \% \% \% \% \% \% \% \% \% \% \% \% \% \% \%$ Master Program.m \%\%\%\%\%\%\%\%\%\%\%\%\%\%\%\%

$\% \%$ This script file is used to link all sub-script files and functions

$\% \% \%$ Inputs $\% \% \% \%$

fprintf( $1, \ln ==============$ Start Master Program $================$ (n')

fprintf( 1, 'In Loading Inputs.................................')

MP_Inputs;

fprintf( 1 ,' Done $\left.\backslash n^{\prime}\right)$

$\% \% \%$ Design Point \%\%\%

MP_DesignPoint;

$\% \% \% \%$ Scaling Factors $\% \% \% \%$

MP_ScalingFactor;

$\% \% \% \%$ Compressor Map $\% \% \% \%$

fprintf(1,'In Loading Component Characteristics.

MP HPC01;

$\% \% \% \%$ HP Tubine Map $\% \% \% \% \%$

MP_HPT01;

$\% \% \% \%$ LP Tubine Map $\% \% \% \% \%$

MP LPT01;

fprintf( 1 ,' Done $\backslash n ')$

$\% \% \% \%$ Steady State Off Design (Load following CubeLaw on PT) $\% \% \% \%$

MP_OffDesign_load;

fprintf $(1, \mathrm{ln}============$ Gas Generator Idle Speed

fprintf(1,'nn Selecting Idle Speed (based on combustor stability)ไn')

[min_FA,loc_idle] $=\min ($ OffDesign_Data_load(:,20)./OffDesign_Data_load(:,12));

Ngg_idle = OffDesign_Data_Ioad(loc_idle, 8$)$;

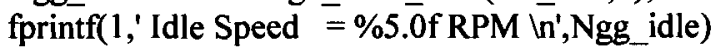

fprintf( $1,{ }^{\prime}$ Min FA Ratio $=\% 5.5 f \backslash n '$, min_FA)

min_Ngg = Ngg_idle; $\%$ Schedule minimum speed max_Ngg = N_GG; \% Schedule maximum speed Ngg_range $=[$ min_Ngg : $100:$ max_Ngg]; 
fprintf( 1 ,'In Gas Generator Operating Range (n')

fprintf( $1, \%$ 5.0f RPM to \%5.0f RPM $\backslash n$ ',min_Ngg,max_Ngg)

$\min \_N p t=$ Interpl(OffDesign_Data_load(:,8),OffDesign_Data_load(:,36), Ngg_idle,'spline'); max_Npt $=$ N_PT;

Npt_range $=\left[\right.$ min_Npt :100: $\left.\max \_N p t\right] ;$

fprintf(1, 'In Power Turbine Operating Range $\backslash n$ ')

fprintf(1,\% 5.0f RPM to \%5.0f RPM \n',min_Npt,max_Npt)

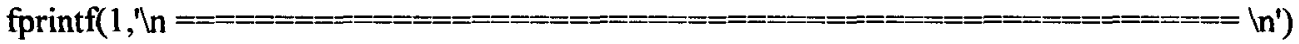

$\% \% \% \%$ Limiters and Fuel Schedules $\% \% \% \%$

MP_FuelLimits;

$\% \% \% \%$ Step Response Analysis \%\%\%\%

MP_StepResponse;

$\% \% \% \%$ Controller Response Analysis \%\%\%\%

MP_ControllerResponse;

\%\%\%\%\%\%\%\%\%\%\%\%\%\%\%\%\%\%\%\%\%\%\% End \%\%\%\%\%\%\%\%\%\%\%\%\%\%\%\%\%\%\%\%\%\%\%\%\%\%

$\% \% \% \% \% \% \% \% \% \% \% \% \% \% \% \% \%$ MP_Inputs.m $\% \% \% \% \% \% \% \% \% \% \% \% \% \% \% \% \% \% \%$

\%\%\%\%\%\%\%\%\%\%\%\%\%\%\%\%\%\%\% Ambient Conditions \%\%\%\%\%\%\%\%\%\%\%\%\%\%\%\%\%\%\%\%\%\%

$\begin{array}{llcl}\mathrm{V} & =0 ; & \%[\mathrm{~km} / \mathrm{hr}] & \text { Velocity } \\ \text { Tamb } & =288.15 ; & \%[\mathrm{~K}] & \text { Ambient Temperature } \\ \text { Pamb } & =101325 ; & \%[\mathrm{~Pa}] & \text { Ambient Pressure }\end{array}$

$\% \% \%$ Inlet Conditions $\% \% \%$

\begin{tabular}{llll} 
Inlet_Delta_P $=4 ;$ & \multicolumn{2}{c}{$\%[$ inH2O $]$} & Pressure Loss across Inlet \\
ma & $=5.5 ;$ & $\% \mathrm{~kg} / \mathrm{s}$ & Inlet Air Mass Flow \\
$\mathrm{Bc}$ & $=0.015 ;$ & $\%$ & Compr. Bleed Frac.(Downstream of last Stage)
\end{tabular}

$\% \% \%$ Compressor Input Data $\% \% \%$

$\begin{array}{llll}\text { PRc } & =7 ; & \% & \text { Compressor Pressure Ratio } \\ \text { Cnpoly } & =0.85 ; & \% & \text { Compr. Polytropic Efficiency }\end{array}$

$\% \% \%$ Burner Input Data \%\%\%

\begin{tabular}{llll} 
Bn & $=0.99 ;$ & $\%$ & \multicolumn{2}{c}{ Combustion Efficiency } \\
Burner_Delta_P $=0.05 ;$ & $\%$ & Press. Loss across the Burner \\
HV $=43100 ;$ & $\%[\mathrm{~kJ} / \mathrm{kg}]$ & Fuel Heating Value (No. I Diesel)
\end{tabular}

$\% \% \%$ Ducting Pressure Losses $\% \% \%$

CompToBurn_Delta_P $=0$;

Plenum_Delta_ $\mathrm{P}=0$;

InterTurb_Delta_P $=0$; $\begin{array}{cc}\% & \text { Ducting Press. Loss from Comp to Burner } \\ \% & \text { Ducting Press. Loss from Burner to HPT } \\ \% & \text { Ducting Press. Loss from HPT to LPT }\end{array}$

$\% \% \%$ Turbine Input Data \%\%\% 
$\begin{array}{lccc}\text { TIT } & =1200 ; & \%[\mathrm{~K}] & \text { Turbine Inlet Temperature (TIT) } \\ \text { HPTnpoly } & =0.88 ; & \% & \text { HP Turbine Polytropic Efficiency } \\ \text { LPTnpoly } & =0.88 ; & \% & \text { LP Turbine Polytropic Efficiency }\end{array}$

$\% \% \%$ Exhaust Losses \%\%\%

Exhaust_Delta_P = 8; $\quad \%$ [inH2O $] \quad$ Pressure Loss across Exhaust System

$\% \% \%$ Mechanical Efficiencies $\% \% \%$

$\begin{array}{llll}\text { Mn } & =0.99 ; & \% & \text { Mechanical Efficiency (each Shaft) } \\ \text { GBn } & =1 ; & \% & \text { Gearbox Efficiency (set to } 1 \text { to compare with GasTurb) }\end{array}$

$\% \% \% \%$ Rotational Speed \%\%\%

$\begin{array}{lcc}\text { N_GG }=28000 ; & \%[R P M] & \text { Gas Generator Speed } \\ \text { N_PT }=25000 ; & \%[R P M] & \text { LP Turbine Speed }\end{array}$

$\% \% \%$ Auxiliaries \%\%\%

Control_Power $=0 ; \quad \%[\mathrm{~kW}] \quad$ Controls Power Requirements.

FuelPump_Power $=0 ; \quad \%[\mathrm{~kW}] \quad$ Fuel Pump Power Requirements

OilPump_Power $=0 ; \quad \%[\mathrm{~kW}] \quad$ Oil Pump Power Requirements

$\% \% \%$ Customer Power Requirement \%\%\%

WorkNet $\quad=1 ; \quad \%[M W] \quad$ Work Net Required by Client

$\% \% \%$ Constants $\% \% \%$

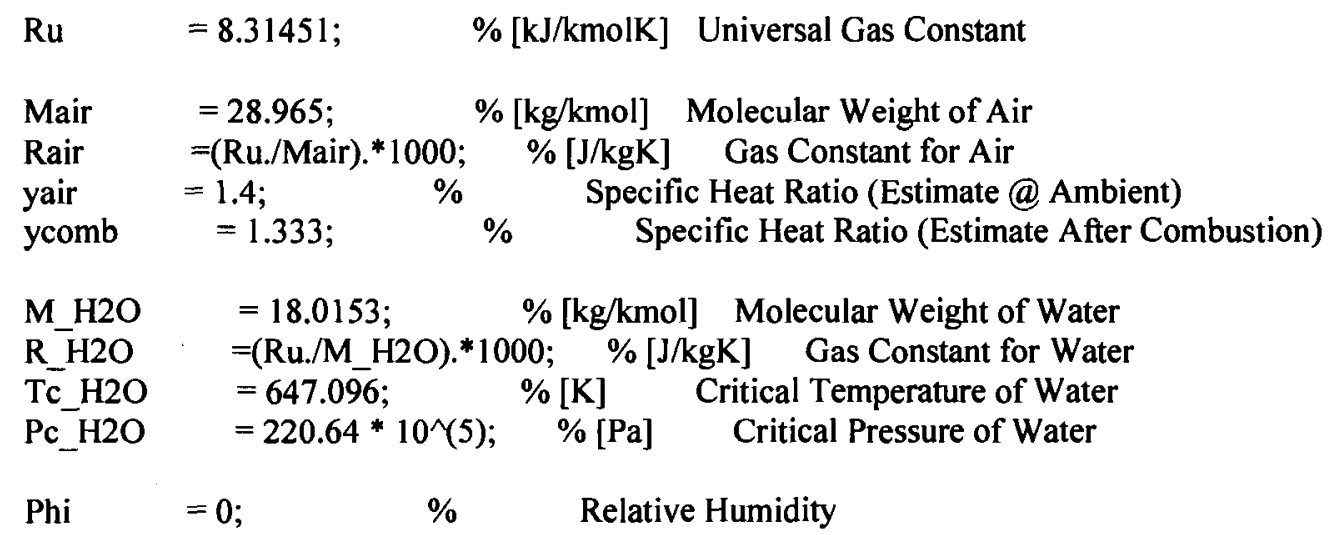

$\% \% \%$ Standard Day Conditions $\% \% \%$

\begin{tabular}{|c|c|c|c|}
\hline $\begin{array}{l}\text { Tstd } \\
\text { Pstd } \\
\text { Rstd }\end{array}$ & $\begin{array}{l}=288.15 \\
=101.325 \\
=\text { Rair; }\end{array}$ & $\begin{array}{c}\%[\mathrm{~K}] \\
\%[\mathrm{kPa}] \\
\%[\mathrm{~J} / \mathrm{kgK}]\end{array}$ & $\begin{array}{l}\text { Ambient Temperature } \\
\text { Ambient Pressure } \\
\text { Gas Constant for Air }\end{array}$ \\
\hline
\end{tabular}

$\% \% \%$ Unit Conversion Factors \%\%\%

bar $=10^{\wedge} 5 ; \quad \%[\mathrm{~Pa}]$

$\mathrm{kPa}=10^{\wedge} 3 ; \quad \%[\mathrm{~Pa}]$ 


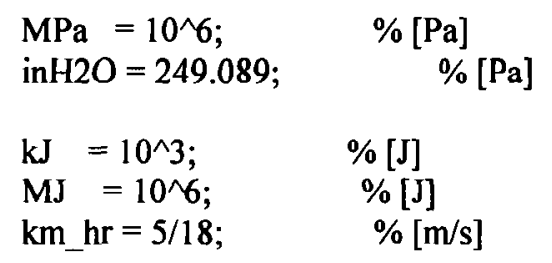

$\% \% \%$ Component Map Scaling Parameters $\% \% \% \%$

$\%$ Compressor Map

CBetaValue $=0.5$;

CSpeed $=1$;

\% Turbine Map

TBetaValue $=0.5$;

TSpeed $=1$;

$\%$ Power Turbine Map

PTBetaValue $=0.7$;

PTSpeed $=1$;

$\% \% \%$ Component Volumes \& Inertia \%\%\%

$\begin{array}{ll}\text { Vcomb }=0.0117 ; & \% \text { Compbustor Volume }\left[\mathrm{m}^{\wedge} 3\right] \\ \text { Vplenum }=0.017176 ; & \% \text { Plenum Volume }\left[\mathrm{m}^{\wedge} 3\right]\end{array}$

Vinter $=0.005 ; \quad \%$ Inter Turbine Volume $\left[\mathrm{m}^{\wedge} 3\right]$

$\mathrm{Ig}=0.08 ; \quad \%$ Polar Moment of Inertia of Rotating Components [kgm^2]

Ig_pt $=0.05 ; \quad \%$ Polar Moment of Inertia of Power turbine and Propeller [kgm^2]

$\% \% \% \%$ Performance Limiters $\% \% \%$

TIT_Limit $=1250 ; \quad \%$ Maximum Transient Turbine Inlet Temperature [K]

OverTemp $=$ TIT_Limit $+50 ; \%$ Over Temperature [K] (Damage will occur at this temperature)

OverSpeed $=0.0 \overline{5} ; \quad \%$ Maximum OverSpeed $[\%]$

LowerSpeed $=0.05 ; \quad \%$ Maximum UnderSpeed [\%]

Max_PT_RPM $=1.1 . *$ N_PT; \% Maximum Power Turbine Spool Speed [RPM]

FA_Limit $=0.0081 ; \quad \%$ Minimum Fuel to Air Ratio

$\% \%$ Note $\% \%$

$\%$ Fuel to air ratio should be greater than 0.008 during transient

$\%$ operations (Walsh \& Fletcher Gas Turbine Performance Page 456)

$\% \% \%$ Start Up Inputs $\% \% \%$

$\%$ According to Walsh and Fletcher Light off speed is usally depends

$\%$ therefore we estimate $10 \%$ Spool Speed

reIN_LightOff $=0.1$;

relN_StartCutOff $=\mathbf{0 . 3}$; 
$\% \% \% \% \% \% \% \% \% \% \% \% \% \% \%$ MP_DesignPoint.m \%\%\%\%\%\%\%\%\%\%\%\%\%\%\%\%\%\%

$\%$ note that there is no disc cooling, customer bleeds, blade cooling, NGV cooling and leakage

$\%$ considered in this code.

$\%$ Also note that Dry Air is assumed for calculation

fprintf( $1, \mathrm{\prime n}============$ Design Point Calculation $==============(\mathrm{n}$ ')

$\% \% \% \%$ Upstream Conditions $\% \% \%$

$\mathrm{Ra}=$ Rair;

$\mathrm{Cpamb}=\mathrm{Cp} \_$air(Tamb); \% Ambient Specific Heat $\quad[\mathrm{kJ} / \mathrm{kgK}]$

yamb $=($ Cpamb. $/($ Cpamb- $(\mathrm{Ra} / \mathrm{kJ}))) ; \quad \%$ Ratio of Specific Heats

$\mathrm{Ta}=\mathrm{Tamb} ; \quad \%$ Static Temperature at a $[\mathrm{K}]$

$\mathrm{Toa}=\mathrm{Ta}+\left(\left(\mathrm{V} .{ }^{*} \mathrm{~km} \_\mathrm{hr}\right) .^{\wedge} 2 /\left(2 .{ }^{*} \mathrm{Cpamb} * 1000\right)\right) ; \%$ Stagnation Temperature at a $[\mathrm{K}]$

$\mathrm{Pa}=\mathrm{Pamb} / \mathrm{kPa} ; \quad$ \% Static Presure at a $\quad[\mathrm{kPa}]$

Poa $=\mathrm{Pa}^{*}(\mathrm{Toa} . / \mathrm{Ta})^{\wedge}($ yamb./(yamb-1)); \% Stagnation Pressure at a $[\mathrm{kPa}]$

$\% \% \% \%$ Engine Intake Conditions $\% \% \%$

Tol = Toa; $\quad$ \% Stagnation Temperature at $1[\mathrm{~K}]$

Po1 $=$ Poa-((Inlet_Delta_P.*inH2O $) / \mathrm{kPa}) ; \%$ Stagnation Pressure at $1 \quad[\mathrm{kPa}]$

$\mathrm{ml}=\mathrm{ma} ; \quad$ \% Inlet Air Mass Flow Rate $[\mathrm{kg} / \mathrm{s}]$

m1_corr $=\mathrm{m} 1{ }^{*}$ sqrt((Ra.*Tol)./(Rstd .*Tstd))./(Pol./Pstd); \% Corrected Inlet Air Mass Flow Rate $[\mathrm{kg} / \mathrm{s}]$

$\% \% \% \%$ Compressor Calculations \%\%\%\%

To2s = idealTo2 (PRc, To1, Cnpoly, yamb, Ra);\% Ideal Stagn. Temp. Function at 2 [K]

To2 = realTo2 (PRc, To1, To2s, Cnpoly, Ra); \% Real Stagn. Temp Function at 2 [K]

$\mathrm{Cpc}=$ Cp_air $\left(0.5 .{ }^{*}(\mathrm{To} 1+\mathrm{To2})\right) ; \quad \%$ Compressor Specific Heat $[\mathrm{kJ} / \mathrm{kgK}]$

yc $=\mathrm{Cpc} . /(\mathrm{Cpc}-(\mathrm{Ra} / \mathrm{kJ})) ; \quad$ \% Ratio Specific Heat (Compressor)

Cnisen $=($ h_air(To2s)-h_air(To1))./(h_air(To2)-h_air(To1)); \% Compressor Isentropic Efficiency

Po2 $=$ Pol. ${ }^{* P R c} ; \quad$ \% Stagnation Pressure at $2 \quad[\mathrm{kPa}]$

$\mathrm{m} 2=\mathrm{m} 1 .^{*}(1-\mathrm{Bc}) ; \quad$ \% Compressor Discharge Mass Flow Rate

m2_corr $=\mathrm{m} 2{ }^{*}$ sqrt((Ra. ${ }^{*}$ To2)./(Rstd . ${ }^{*}$ Tstd))./(Po2./Pstd); \% Corrected Compressor Discharge Mass Flow Rate [kg/s]

CPower $=m 1 . *\left(h \_a i r(T 02)-h \_a i r(T o 1)\right) ; \quad \%$ Compressor Power $\quad[\mathrm{kW}]$ 
$\% \% \% \%$ Compressor to Burner Ducting \%\%\%\%

Po21 $=$ Po2.* $(1-$ CompToBurn_Delta_P $) ; \quad \%$ Stagnation Pressure at $21 \quad[\mathrm{kPa}]$

$\%$ Note that To21 is assumed to be equal to the To2 because we are assuming

$\%$ no heat loss between the Compressor and the Burner. This is an

$\%$ approximation and should be corrected with an accurate value for To21.

To21 $=$ To2; $\quad$ \% Stagnation Temperature at $21[\mathrm{~K}]$

$\mathrm{m} 21=\mathrm{m} 2 ; \quad$ \% Mass Flow Rate at $21 \quad[\mathrm{~kg} / \mathrm{s}]$

$\mathrm{m} 21$ corr $=\mathrm{m} 21 * \operatorname{sqrt}\left(\left(\mathrm{Ra} .{ }^{*}\right.\right.$ To21)./(Rstd .*Tstd))./(Po21./Pstd); \% Corrected Mass Flow Rate [kg/s]

$\% \%$ Combustion Chamber (Burner) Calculations \%\%\%

$\%$ Note that To3 is assumed to be equal to the TIT because we are assuming

$\%$ no heat loss between the burner and the HP turbine. This is an

$\%$ approximation and should be corrected with an accurate value for To3.

To3 $=\mathrm{TIT} ; \quad \%$ Stagnation Temperature at $3[\mathrm{~K}]$

FuelFlow $=($ m21.*(h_air(To3)-h_air(To21)))./(HV.*Bn - (h_air(To3))); \% [kg/s]

FA =FuelFlow./m21; $\quad$ \% Fuel-to-Air Ratio

Po3 $=$ Po21.* $(1-$ Burner_Delta_P $) ; \quad \%$ Stagnation Pressure at $3 \quad[\mathrm{kPa}]$

$\mathrm{m} 3=\mathrm{m} 21+$ FuelFlow; $\quad \%$ Mass Flow Rate at $3 \quad[\mathrm{~kg} / \mathrm{s}]$

m3_corr $=\mathrm{m} 3 .^{*} \operatorname{sqrt}\left(\left(\mathrm{Ra} .{ }^{*}\right.\right.$ To3)./(Rstd .*Tstd))./(Po3./Pstd); \% Corrected Mass Flow Rate [kg/s]

$\% \% \%$ Burner to HP Turbine Ducting (Plenum) \%\%\%

Po31 $=$ Po3.* $(1-$ Plenum_Delta_P $) ; \quad \%$ Stagnation Pressure at $31 \quad[\mathrm{kPa}]$

To31 = TIT; $\quad \%$ Stagnation Temperature at $31[\mathrm{~K}]$

$\mathrm{m} 31=\mathrm{m} 3 ; \quad$ \% Mass Flow Rate at $31 \quad[\mathrm{~kg} / \mathrm{s}]$

$\mathrm{m} 31 \_$corr $=\mathrm{m} 31{ }^{*} \operatorname{sqrt}\left(\left(\mathrm{Ra} .{ }^{*}\right.\right.$ To31)./(Rstd.${ }^{*}$ Tstd $\left.)\right) . /($ Po31./Pstd $) ; \%$ Corrected Mass Flow Rate [kg/s]

$\% \% \% \%$ Auxiliaries Calculations \%\%\%\%

Aux $=$ Control_Power + FuelPump_Power + OilPump_Power; \% Auxiliaries Power $[\mathrm{kW}]$

$\% \% \%$ HPTurbine Calculations \%\%\%

$\mathrm{m} 4=\mathrm{m} 3 \mathrm{I} ; \quad$ \% Mass Flow Rate at 4

$\%$ note that $\mathrm{m} 4$ is assumed to be equal to $\mathrm{m} 31$ since no cooling is required

$\%$ for this design

HPTPower $=($ CPower./Mn $)+$ Aux; $\quad$ \% HP Turbine Power $\quad[k W]$ 
To4 $=$ HPTurbExt $($ To31, HPTPower, m31, m4); $\quad$ \% Stagnation Temp. at $4 \quad$ [K]

PR_HPT = HPT_PR (To31, Po31, To4, HPTnpoly, Ra); \% HP Turbine Pressure Ratio

Po4 = P031./PR_HPT; $\quad$ \% Stagnation Pressure at $4 \quad[\mathrm{kPa}]$

To4s = To4ideal ( To31, Po31, Po4, HPTnpoly, Ra); \% Ideal Stagn. Temp. Function at 4 [K]

Cp_HPT $=$ Cp_air(0.5 . ${ }^{*}($ To3 $1+$ To4 $\left.)\right) ; \quad$ \% HPT Specific Heat $\quad[\mathrm{kJ} / \mathrm{kgK}]$

yHPT $=$ Cp_HPT./(Cp_HPT - $($ Rair/kJ)); $\quad$ \% Ratio Specific Heat (HP Turbine)

HPTnisen = (h_air(To31)-h_air(To4))./(h_air(To31)-h_air(To4s)); \% Turbine Isentropic Efficiency m4_corr $=\mathrm{m} 4{ }^{*}$ sqrt((Ra. ${ }^{*}$ To4)./(Rstd . ${ }^{*}$ Tstd))./(Po4./Pstd); \% Corrected Mass Flow Rate [kg/s] $\% \% \%$ Inter-Turbine Ducting Calculations \%\%\%

Po41 $=$ Po4.* ${ }^{*} 1$ - InterTurb_Delta_P $) ; \quad \%$ Stagnation Pressure at $41 \quad[\mathrm{kPa}]$

$\%$ Note that To4 1 is assumed to be equal to the To4 because we are assuming

$\%$ no heat loss between Turbines. This is an

$\%$ approximation and should be corrected with an accurate value for To41.

To41 = To4; $\quad \%$ Stagnation Temperature at $41[\mathrm{~K}]$

$\mathrm{m} 41=\mathrm{m} 4 ; \quad$ \% Mass Flow Rate at $41 \quad[\mathrm{~kg} / \mathrm{s}]$

m41_corr $=\mathrm{m} 41{ }^{*} \operatorname{sqrt}\left(\left(\mathrm{Ra} .{ }^{*}\right.\right.$ To41)./(Rstd .*Tstd))./(Po41./Pstd); \% Corrected Mass Flow Rate [kg/s] $\% \% \% \%$ LPTurbine Calculations \%\%\%

Po5 $=$ Poa $+\left(\right.$ Exhaust_Delta_P. $\left.{ }^{* i n H 2 O}\right) \cdot / \mathrm{kPa} ; \quad \%$ Stagnation Pressure at $5 \quad[\mathrm{kPa}]$

PR_LPT $=$ Po41./Po5 ; $\quad$ \% LP Turbine Pressure Ratio

To5s $=$ Toideal $($ To41, Po41, Po5, LPTnpoly, Ra); \% Ideal Stagn. Temp. Function at $6[\mathrm{~K}]$

To5 $=$ Toreal $($ To41, To5s, Po41, Po5, LPTnpoly, Ra); \% Real Stagn. Temp Function at 6 [K]

Cp_LPT $=$ Cp_air $(0.5 . *($ To4 $1+$ To5)); $\quad$ \% LPT Specific Heat $\quad[\mathrm{kJ} / \mathrm{kgK}]$

yLPT $=$ Cp_LPT./(Cp_LPT - $(\mathrm{Ra} / \mathrm{kJ})) ; \quad$ \% Ratio Specific Heat (LP Turbine)

LPTnisen = (h_air(To41)-h_air(To5))./(h_air(To41)-h_air(To5s)); \% LP Turbine Isentropic Efficiency

$\mathrm{m} 5=\mathrm{m} 41 ; \quad \%$ Mass Flow Rate at $5 \quad[\mathrm{~kg} / \mathrm{s}]$

m5_corr $=\mathrm{m} 5{ }^{*}$ sqrt((Ra. ${ }^{*}$ To5)./(Rstd .*Tstd))./(Po5./Pstd); \% Corrected Mass Flow Rate [kg/s]

LPTPower $=m 5 . *\left(h \_a i r(T 041)-h \_a i r(T o 5)\right) ; \quad$ \% LP Turbine Power $\quad[k W]$

$\% \% \%$ Exhaust Pressure \%\%\%

$\mathrm{To6}=\mathrm{To5}$ 


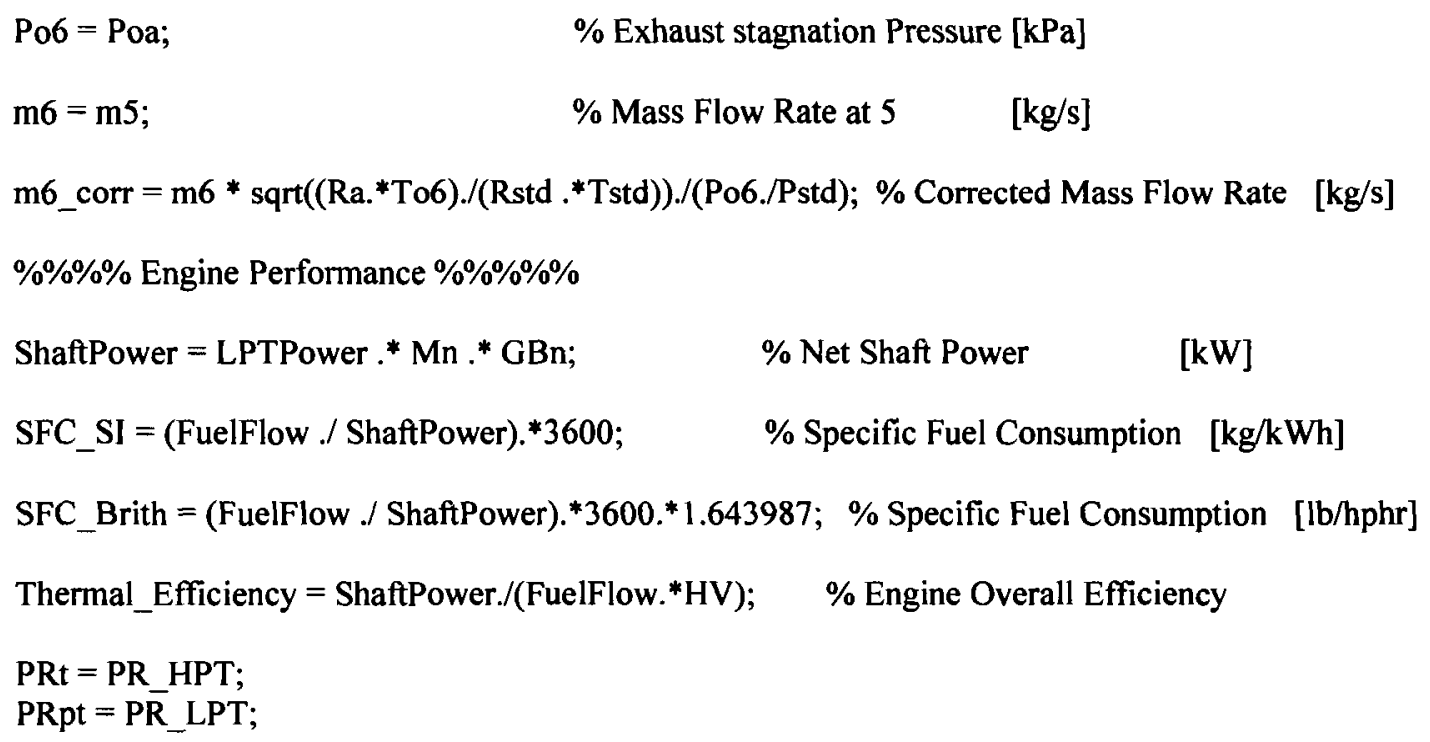


non_m5_des $=$ m5.* sqrt(To5.*Ra)./(Po5.*1000);

Po5_des = Po5;

LPTPower_des = LPTPower;

FuelFlow_des = FuelFlow;

relFuel_des $=$ (FuelFlow_des./Po2_des);

\%\%\% PartLoad Burner Efficiency (From Walsh \& Fletcher (Gas Turbine Performance) \%\%\%\%

Load_des $=\left(\mathrm{m} 21 . /\left(\left((\operatorname{Po} 21 . / 101.325)^{\wedge} 1.8 .{ }^{*}\right.\right.\right.$ Vcomb $) .{ }^{*} 10 . \wedge\left(0.00145 .{ }^{*}(\right.$ To2 1-400) $\left.\left.)\right)\right) ; \%$ Burner Loading At Desgn.Point

\%\% PartLoad Burner Pressure Loss (From Walsh \& Fletcher (Gas Turbine Performance) \%

$\% \%$ Modified Formula 5.7.10 (W\&F GAS Turbine Performance)

$\%$ We are assuming all Burner losses come from Kcold

$\%$ Khot $=($ Burner_Delta_P.* Po21)./(Po21.*((To3./To21)-1).*...

$\%(\mathrm{~m} 21 . * \operatorname{sqrt}(\mathrm{To} 21) . / \mathrm{Po} 2) . \wedge 2)$

Kcold $=($ Burner_Delta_P.* Po21)./(Po21.*(m21.*sqrt(To21)./Po2).^2);

$\% \% \%$ Duct Pressure Loss \%\%\%

IntakeLoss_des $=(1-$ Po1./Poa $)$

non_ma_des $=$ ma. ${ }^{*}$ sqrt(Toa. ${ }^{*}$ Ra)./(Poa. $\left.{ }^{*} 1000\right)$;

Plenum_des $=(1-$ Po31./Po3 $)$;

Inter_des $=(1-$ Po41./Po4 $)$

ExhaustLoss_des $=(1-$ Po6./Po5);

\%\%\%\%\%\%\%\%\%\%\%\%\%\%\%\%\%\%\%\%\%\%\%\% End \%\%\%\%\%\%\%\%\%\%\%\%\%\%\%\%\%\%\%\%\%\%\%\%\%

$\% \% \% \% \% \% \% \% \% \% \% \% \% \% \% \% \% \%$ MP_HPC01.m $\% \% \% \% \% \% \% \% \% \% \% \% \% \% \% \% \% \%$

\% Original Compressor Map (Axial Compressor)

Original_HPC01

\% Scale Map using Design point Data

MP_CMapScaling;

\% Sub-Idle Extrapolation

MP_CMapExtrapolation;

$\% \% \% \% \% \% \% \% \% \% \% \% \% \% \% \% \% \% \% \% \% \% \% \% \%$ End $\% \% \% \% \% \% \% \% \% \% \% \% \% \% \% \% \% \% \% \% \% \% \% \%$

$\% \% \% \% \% \% \% \% \% \% \% \% \% \% \% \% \%$ Original_HPC01.m $\% \% \% \% \% \% \% \% \% \% \% \% \% \% \% \% \% \%$ $\% \% \%$ NOTES $\% \% \%$

$\%$ Tables where found in GasTurb 10 
\% NASA TM 101433 Example Compressor Map

\% Reynolds: $\mathrm{RNI}=0.1 \mathrm{f}=0.95 \mathrm{RNI}=1 \mathrm{f}=1$

$\% \% \%$ Mass Flow \%\%\%

\% Mass Flow data at speed lines 0.5 to 1.05

$\% 20$ Beta lines (from 0 to 1 )

\begin{tabular}{ccccc}
\multicolumn{1}{c}{ MF $=[11.02100$} & 0.00000 & 0.05263 & 0.10526 & $0.15789 \ldots$ \\
0.21053 & 0.26316 & 0.31579 & 0.36842 & $0.42105 \ldots$ \\
0.47368 & 0.52632 & 0.57895 & 0.63158 & $0.68421 \ldots$ \\
0.73684 & 0.78947 & 0.84211 & 0.89474 & $0.94737 \ldots$ \\
$1.00000 ; \ldots$ & & & & \\
0.50000 & 10.38683 & 10.23236 & 10.05630 & $9.87849 \ldots$ \\
9.69593 & 9.50797 & 9.30393 & 9.10332 & $8.89518 \ldots$ \\
8.67522 & 8.44689 & 8.21855 & 7.98237 & $7.75325 \ldots$ \\
7.50371 & 7.25881 & 7.01299 & 6.76902 & $6.53247 \ldots$ \\
$6.29870 ; \ldots$ & & & & \\
0.60000 & 13.46753 & 13.36364 & 13.24861 & $13.08534 \ldots$ \\
12.90724 & 12.70130 & 12.48052 & 12.23791 & $12.00186 \ldots$ \\
11.74954 & 11.48237 & 11.21521 & 10.93321 & $10.64564 \ldots$ \\
10.33952 & 10.02783 & 9.71614 & 9.40445 & $9.07792 \ldots$ \\
$8.75139 ; \ldots$ & & & & \\
0.70000 & 17.77922 & 17.74583 & 17.63451 & $17.50093 \ldots$ \\
17.35250 & 17.15955 & 16.93692 & 16.68460 & $16.40260 \ldots$ \\
16.09091 & 15.76438 & 15.42975 & 15.06679 & $14.68089 \ldots$ \\
14.28942 & 13.89357 & 13.46237 & 13.03117 & $12.60297 \ldots$ \\
$12.20223 ; \ldots$ & & & & \\
0.75000 & 20.46382 & 20.41373 & 20.35442 & $20.24675 \ldots$ \\
20.13117 & 19.95663 & 19.76252 & 19.52876 & $19.26160 \ldots$ \\
18.96104 & 18.62709 & 18.27644 & 17.89239 & $17.46928 \ldots$ \\
17.00742 & 16.52657 & 16.02937 & 15.53803 & $15.03711 \ldots$ \\
$14.55288 ; \ldots$ & & & & \\
0.80000 & 23.59740 & 23.54731 & 23.44243 & $23.33024 \ldots$ \\
23.19666 & 23.02968 & 22.84601 & 22.63741 & $22.41187 \ldots$ \\
22.16141 & 21.89425 & 21.57699 & 21.24304 & $20.84230 \ldots$ \\
20.37477 & 19.85714 & 19.30670 & 18.67161 & $18.00371 \ldots$ \\
$17.38590 ; \ldots$ & & & & \\
0.85000 & 26.38548 & 26.31610 & 26.24671 & $26.17733 \ldots$ \\
26.10019 & 25.99224 & 25.89239 & 25.77365 & $25.62523 \ldots$ \\
25.46197 & 25.26902 & 25.06122 & 24.79406 & $24.51206 \ldots$ \\
24.15584 & 23.76994 & 23.30983 & 22.68646 & $21.94434 \ldots$ \\
$21.12801 ; \ldots$ & & & & \\
0.90000 & 28.92022 & 28.88683 & 28.84230 & $28.79777 \ldots$ \\
28.75325 & 28.69605 & 28.65373 & 28.58970 & $28.51632 \ldots$ \\
28.44293 & 28.37477 & 28.27458 & 28.16327 & $28.01855 \ldots$ \\
27.78479 & 27.48423 & 27.05799 & 26.50464 & $25.89239 \ldots$ \\
$25.14286 ; \ldots$ & & & & \\
0.95000 & 31.44805 & 31.42208 & 31.39610 & $31.36364 \ldots$ \\
31.33117 & 31.29221 & 31.25284 & 31.19943 & $31.14935 \ldots$ \\
31.09091 & 31.02597 & 30.95455 & 30.86364 & $30.75974 \ldots$ \\
30.62987 & 30.47403 & 30.23377 & 29.94156 & $29.62385 \ldots$ \\
$29.24026 ; \ldots$ & & & & \\
1.00000 & 33.64750 & 33.64007 & 33.62894 & $33.61410 \ldots$ \\
33.59926 & 33.58071 & 33.56215 & 33.54360 & $33.52134 \ldots$ \\
33.49907 & 33.46939 & 33.43599 & 33.39147 & $33.33581 \ldots$ \\
\hline & & & &
\end{tabular}




$\begin{array}{lllll}33.25788 & 33.15770 & 33.00318 & 32.80519 & 32.60482 \ldots \\ 32.38367 ; \ldots & & & & \\ 1.050000 & 35.19239 & 35.18033 & 35.16456 & 35.14972 \ldots \\ 35.13488 & 35.12096 & 35.10612 & 35.09221 & 35.07847 \ldots \\ 35.06289 & 35.04675 & 35.03117 & 35.01336 & 34.99610 \ldots \\ 34.97857 & 34.95962 & 34.93933 & 34.91929 & 34.89740 \ldots \\ 34.87421] ; & & & & \end{array}$

$\% \% \%$ Efficiency $\% \%$

$\%$ Isentropyic Efficiency data at speed lines 0.5 to 1.05 $\% 20$ Beta lines (from 0 to 1)

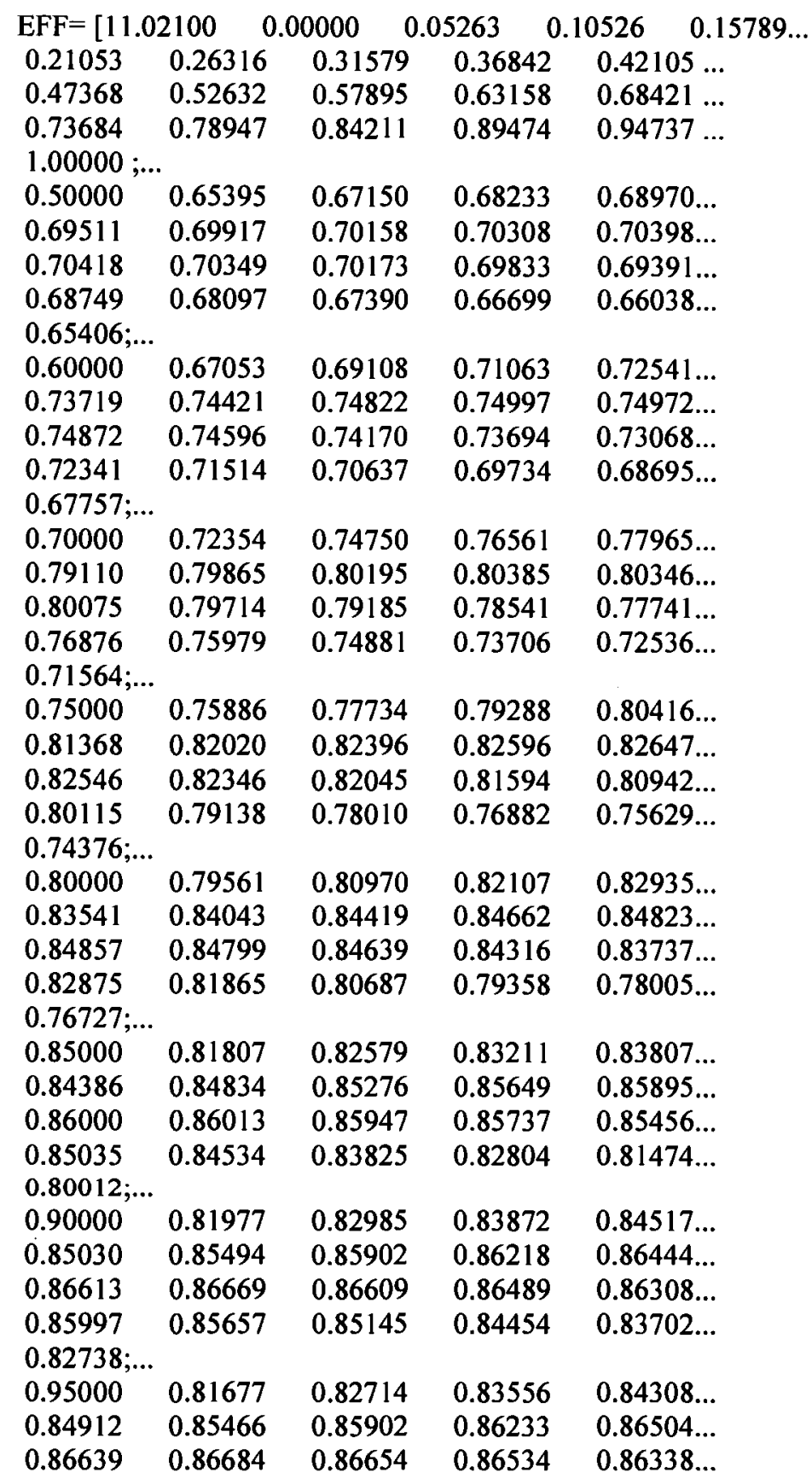




$\begin{array}{lllll}0.86098 & 0.85797 & 0.85436 & 0.85075 & 0.84564 \ldots \\ 0.84173 ; \ldots & & & & \\ 1.00000 & 0.79965 & 0.81298 & 0.82417 & 0.83368 \ldots \\ 0.84124 & 0.84812 & 0.85299 & 0.85611 & 0.85865 \ldots \\ 0.85975 & 0.86045 & 0.86045 & 0.86015 & 0.85912 \ldots \\ 0.85772 & 0.85544 & 0.85333 & 0.85035 & 0.84667 \ldots \\ 0.84164 ; \ldots & & & & \\ 1.05000 & 0.77587 & 0.78316 & 0.79123 & 0.79789 \ldots \\ 0.80526 & 0.81158 & 0.81712 & 0.82255 & 0.82707 \ldots \\ 0.83095 & 0.83470 & 0.83797 & 0.84087 & 0.84314 \ldots \\ 0.84506 & 0.84662 & 0.84692 & 0.84586 & 0.84271 \ldots \\ 0.83517] ; & & & & \end{array}$

\%\%\% Pressure Ratio \%\%\%

$\%$ Pressure Ratio data at speed lines 0.5 to 1.05 $\% 20$ Beta lines (from 0 to 1 )

$\begin{array}{llllll}\mathrm{PR}=[11.02100 & 0.00000 & 0.05263 & 0.10526 & 0.15789 \ldots \\ 0.21053 & 0.26316 & 0.31579 & 0.36842 & 0.42105 \ldots \\ 0.47368 & 0.52632 & 0.57895 & 0.63158 & 0.68421 \ldots \\ 0.73684 & 0.78947 & 0.84211 & 0.89474 & 0.94737 \ldots \\ 1.00000 ; \ldots & & & & \\ 0.50000 & 1.38577 & 1.44768 & 1.50467 & 1.55906 \ldots \\ 1.61040 & 1.65851 & 1.70165 & 1.74268 & 1.77985 \ldots \\ 1.81229 & 1.84044 & 1.86570 & 1.88659 & 1.90590 \ldots \\ 1.91828 & 1.92855 & 1.93561 & 1.94007 & 1.94321 \ldots \\ 1.94409 ; \ldots & & & & \\ 0.60000 & 1.77778 & 1.86684 & 1.95273 & 2.02940 \ldots \\ 2.10136 & 2.16614 & 2.22552 & 2.27796 & 2.32841 \ldots \\ 2.37260 & 2.41055 & 2.44505 & 2.47301 & 2.49621 \ldots \\ 2.51172 & 2.52220 & 2.52887 & 2.53175 & 2.52732 \ldots \\ 2.51901 ; \ldots & & & & \\ 0.70000 & 2.42348 & 2.55507 & 2.67226 & 2.78366 \ldots \\ 2.89022 & 2.98576 & 3.07243 & 3.14967 & 3.21697 \ldots \\ 3.27381 & 3.32309 & 3.36617 & 3.39812 & 3.41986 \ldots \\ 3.43538 & 3.44494 & 3.44056 & 3.43105 & 3.41726 \ldots \\ 3.40587 ; \ldots & & & & \\ 0.75000 & 2.88271 & 3.03211 & 3.17892 & 3.31501 \ldots \\ 3.44399 & 3.56595 & 3.67716 & 3.77636 & 3.86428 \ldots \\ 3.94031 & 4.00387 & 4.05866 & 4.10011 & 4.12624 \ldots \\ 4.13660 & 4.13611 & 4.12530 & 4.11025 & 4.08671 \ldots \\ 4.06220 ; \ldots & & & & \\ 0.80000 & 3.47425 & 3.64853 & 3.81024 & 3.96865 \ldots \\ 4.12035 & 4.26204 & 4.39706 & 4.52301 & 4.64142 \ldots \\ 4.74986 & 4.85008 & 4.93254 & 5.00578 & 5.05514 \ldots \\ 5.07958 & 5.08315 & 5.07047 & 5.02546 & 4.96328 \ldots \\ 4.90942 ; \ldots & & & & \\ 0.85000 & 4.05085 & 4.24362 & 4.43523 & 4.62568 \ldots \\ 4.81304 & 4.99123 & 5.16979 & 5.34157 & 5.50313 \ldots \\ 5.65805 & 5.80164 & 5.93775 & 6.05237 & 6.15831 \ldots \\ 6.23631 & 6.29957 & 6.33293 & 6.30556 & 6.23073 \ldots \\ 6.12270 ; \ldots & & & & \\ 0.90000 & 4.61613 & 4.83851 & 5.05754 & 5.27580 \ldots \\ 5.49329 & 5.70655 & 5.92301 & 6.13244 & 6.33797 \ldots \\ 6.54226 & 6.74694 & 6.94010 & 7.12789 & 7.30250 \ldots \\ & & & & \end{array}$




$\begin{array}{lllll}7.44390 & 7.55806 & 7.62260 & 7.63497 & 7.61851 \ldots \\ 7.54363 ; \ldots & & & & \\ 0.95000 & 5.21884 & 5.46513 & 5.71096 & 5.95455 \ldots \\ 6.19756 & 6.43811 & 6.67785 & 6.91256 & 7.14739 \ldots \\ 7.37861 & 7.60665 & 7.83132 & 8.04792 & 8.25829 \ldots \\ 8.45736 & 8.64449 & \mathbf{8 . 7 9 6 7 8} & 8.92504 & 9.03867 \ldots \\ 9.12101 ; \ldots & & & & \\ 1.00000 & 5.77492 & 6.04588 & 6.31568 & 6.58421 \ldots \\ 6.85247 & 7.11932 & 7.38584 & 7.65202 & 7.91662 \ldots \\ 8.18082 & 8.44201 & 8.70133 & 8.95594 & 9.20556 \ldots \\ 9.44559 & 9.67546 & 9.88171 & 10.06750 & 10.24897 \ldots \\ 10.41827 ; \ldots & & & & \\ 1.05000 & 6.18312 & 6.46704 & 6.74967 & 7.03229 \ldots \\ 7.31463 & 7.59698 & 7.87878 & 8.16061 & 8.44224 \ldots \\ 8.72297 & 9.00321 & 9.28336 & 9.56237 & 9.84127 \ldots \\ 10.11973 & 10.39730 & 10.67396 & 10.95035 & 11.22557 \ldots \\ 11.49980] ; & & & & \end{array}$

$\% \% \%$ Surge Line $\% \%$

$\%$ Surge Line Data

$\%$ data given as PR vs Corrected Mass Flow

$\operatorname{SLm}=M F(2: \operatorname{size}(M F, 1), \operatorname{size}(M F, 2))$;

$\operatorname{SLPR}=\mathrm{PR}(2: \operatorname{size}(\mathrm{MF}, 1)$,size $(M F, 2))$;

\%\%\%\%\%\%\%\%\%\%\%\%\%\%\%\%\%\%\%\%\%\%\%\%\% End \%\%\%\%\%\%\%\%\%\%\%\%\%\%\%\%\%\%\%\%\%\%\%\%

$\% \% \% \% \% \% \% \% \% \% \% \% \% \% \% \% \%$ MP_CmapScaling.m $\% \% \% \% \% \% \% \% \% \% \% \% \% \% \% \%$

$\%$ This scaling method was found in GasTurb 10

$\%$ A similar approach is described in ASME Journal of Engineering for Power

$\%$ Called " Thermodynamic Models for Pipeline Gas Turbine Diagnostics"

$\%$ By Saravanamuttoo and MacIsaac, 1983

$\mathrm{X}=\mathrm{MF}(1,2: \operatorname{size}(\mathrm{MF}, 2)) ; \quad \%$ Beta values

$\mathrm{Y}=\mathrm{MF}(2$ :size $(\mathrm{MF}, 1), 1)$; $\quad$ \% Speed line Values

MF_Z $=$ MF(2:size(MF,1),2:size(MF,2)); \% Mass Flow Table

EFF_Z $=$ EFF(2:size(EFF, 1),2:size(EFF,2)); \% Efficiency Table

PR_Z $=$ PR(2:size(PR, 1),2:size(PR,2)); \% Pressure Ratio Table

$\mathrm{mf}=$ interp2(X,Y,MF_Z,CBetaValue,CSpeed); \% Mass Flow Scaling Factor

eff $=$ interp2(X,Y,EFF_Z,CBetaValue,CSpeed); \% Efficiency Scaling Factor

pr = interp2(X,Y,PR_Z,CBetaValue,CSpeed); \% Pressure Ratio Scaling Factor

$\%$ Rearranging Matrices to the original order

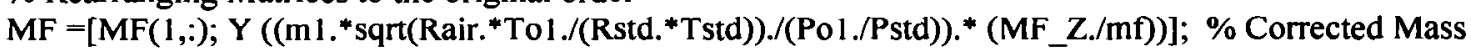

Flow

$\mathrm{EFF}=[\operatorname{EFF}(1,:) ; \mathrm{Y}$ Cnisen.*(EFF_Z./eff)];

$\mathrm{PR}=\left[\mathrm{PR}(1, \mathrm{)}) ; \mathrm{Y}\left((\mathrm{PRc}-1){ }^{*}(\mathrm{PR} Z \mathrm{Z}-1) \cdot /(\mathrm{pr}-1)\right)+1\right]$;

$\mathrm{SLm}=\left(\mathrm{ml} .{ }^{*}\right.$ sqrt(Rair.*Tol./(Rstd. ${ }^{*}$ Tstd $\left.)\right) . /($ Pol.$/$ Pstd $\left.)\right) . *(\mathrm{SLm} . / \mathrm{mf}) ;$

SLPR $=\left((\right.$ PRc-1 $) \cdot{ }^{*}($ SLPR-1 $\left.) \cdot /(\mathrm{pr}-1)\right)+1$;

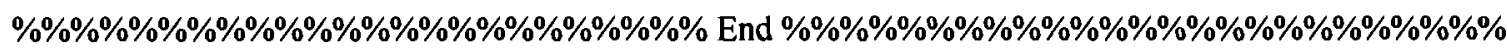


$\%$ This approach was adapted from Master Thesis " A method to control tubofan $\%$ engine starting by varying combressor surge valve bleed " by Wayne $\%$ Randolphe Sexton, '2001'

$\% \%$ Pressure Ratio $\% \%$ Based on exponent laws $\% \%$ Assume that ratio of ideal specific work $=[\%$ Nnew $/ \% \mathrm{Nref}] \wedge \mathrm{p}$ $\% \%$ we know that (ideal spec work $) / \mathrm{CpTo}=\left(\left(\mathrm{PR}^{\wedge}((\right.\right.$ yair-1)/yair $\left.))-1\right)=[\% \text { Nnew } / \% \mathrm{Nref}]^{\wedge} \mathrm{p}$ $\% \%$ use second last speed line as reference

$\mathrm{a}=3$;

$\mathrm{b}=2$;

int $=0.1 ; \%$ speed line interval

PR_ref $=$ PR(a,2:size(PR,2));

$P R$ last $=P R(b, 2: \operatorname{size}(P R, 2))$;

relN $\_$ref $=P R(a, 1)$

relN_last $=$ PR(b, 1$)$;

relN_new $=[0.1$ :int:relN_last-int $]$;

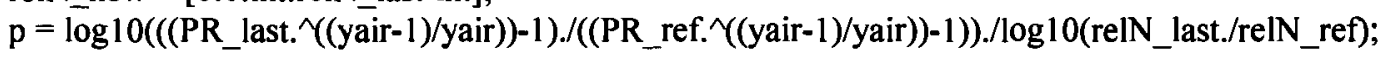

for $\mathrm{j}=1$ :size((relN_new),2)

PressRatio_new $=\left(1+\left(\left(\left(P R \_\right.\right.\right.\right.$ref. $`(($ yair-1)./yair) $)-1){ }^{*}($ relN_new $(j) . /$ relN_ref $\left.\left.) . \wedge p\right)\right) \cdot{ }^{\wedge}($ yair./(yair-1) $)$; PRc_new(j,:) $=[$ relN_new(j) PressRatio_new $]$; end

$\% \%$ Mass flow Parameter $\% \%$ Based on exponent laws $\% \%$ Assume that ratio of mass flow $=[\% \text { Nnew } / \% \text { Nref }]^{\wedge} q$ $\% \%$ use second last speed line as reference

MF_ref $=M F(a, 2: \operatorname{size}(P R, 2))$;

MF_last $=M F(b, 2: \operatorname{size}(P R, 2))$;

relN_ref $=$ PR(a, 1);

relN_last $=P R(b, 1)$;

relN_new $=[0.1$ :int:relN_last-int $]$;

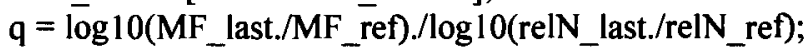

for $\mathrm{j}=1$ :size((relN_new),2)

$M F \_n e w(j,:)=[$ relN_new(j) MF_ref .* (relN_new(j)./relN_ref).^q]; end

$\% \%$ Efficiency

$\% \%$ Based on exponent laws

$\% \%$ Assume that Power Ratio $=[\% \text { Nnew } / \% \text { Nref }]^{\wedge} \mathrm{r}$

$\% \%$ and Power. $/ \mathrm{Cp}^{*} \mathrm{To}=\mathrm{m}^{*}((\mathrm{PR} \wedge(($ yair-1 $) /$ yair $))-1) / \mathrm{Cn}=[\%$ Nnew $/ \% \mathrm{Nref}]{ }^{\wedge}$

$\% \%$ Therfore Power. $/ \mathrm{Cp}^{*} \mathrm{To}=\left(\mathrm{C}{ }_{-} \text {ref./Cn_new }\right)^{*}[\% \text { Nnew } / \% \mathrm{Nref}]^{\wedge} \mathrm{p}^{*}[\% \text { Nnew } / \% \mathrm{Nref}]^{\wedge} \mathrm{q}$

$\% \%$ use second last speed line as reference

$E_{F F}$ ref $=\operatorname{EFF}(a, 2: \operatorname{size}(P R, 2))$;

$\mathrm{EFF}_{\text {last }}=\mathrm{EFF}(\mathrm{b}, 2: \operatorname{size}(\mathrm{PR}, 2))$;

relN_ref $=$ PR $(a, 1)$; 
relN_last $=\mathrm{PR}(\mathrm{b}, \mathbf{1})$;

relN new $=[0.1$ :int:relN last-int $]$;

$\mathbf{r}=(\overline{\mathbf{p}}+\mathrm{q})-\log 10(\mathrm{EFF}$ last./EFF_ref $) . / \log 10($ relN_last./relN_ref $)$;

for $\mathrm{j}=1$ :size((relN_new),2)

EFF_new $(j,:)=\overline{[r e l N} \_$new(j) EFF_ref .* $($relN_new(j)./relN_ref $\left.) \cdot((p+q)-r)\right] ;$

end

\%\%\%\%\% Scaled and Extrapolated Compressor Map

$\mathrm{MF}=[\mathrm{MF}(1,:) ; \mathrm{MF}$ new; $\operatorname{MF}(2: \operatorname{size}(\mathrm{PR}, 1), 1: \operatorname{size}(\mathrm{PR}, 2))]$;

$\mathrm{EFF}=\left[\operatorname{EFF}(1,:) ; \operatorname{EFF} \bar{n}_{\text {new }} \operatorname{EFF}(2: \operatorname{size}(\mathrm{PR}, 1), 1: \operatorname{size}(\mathrm{PR}, 2))\right]$;

$\mathrm{PR}=[\mathrm{PR}(1,:) ; \mathrm{PRc}$ new; PR(2:size(PR,1),1:size(PR,2))];

$\mathrm{SLm}=\mathrm{MF}(2: \operatorname{size}(\mathrm{MF}, 1), \operatorname{size}(\mathrm{MF}, 2))$;

SLPR= PR(2:size $(M F, 1)$,size $(M F, 2))$;

\%\%\%\%\%\%\%\%\%\%\%\%\%\%\%\%\%\%\%\%\%\%\%\% End \%\%\%\%\%\%\%\%\%\%\%\%\%\%\%\%\%\%\%\%\%\%\%\%\%

$\% \% \% \% \% \% \% \% \% \% \% \% \% \% \% \% \% \% \%$ MP_HPT01.m $\% \% \% \% \% \% \% \% \% \% \% \% \% \% \% \% \%$

$\%$ Original Turbine Map

Original_HPT01;

\% Scale Map using Design point Data

MP TMapScaling;

\% Sub-Idle Extrapolation

MP_TMapExtrapolation;

\%\%\%\%\%\%\%\%\%\%\%\%\%\%\%\%\%\%\%\%\%\%\%\%\%\% End \%\%\%\%\%\%\%\%\%\%\%\%\%\%\%\%\%\%\%\%\%\%\%\%\%

\%\%\%\%\%\%\%\%\%\%\%\%\%\%\%\%\%\%\% Original_HPT01.m \%\%\%\%\%\%\%\%\%\%\%\%\%\%

$\% \% \%$ NOTES $\% \% \%$

$\%$ Tables where found in GasTurb 10

$\%$ High Work Low Aspect Ratio Turbine NASA TM83655. 1984

\% Reynolds: $\mathrm{RNI}=0.100 \mathrm{f}=0.950 \mathrm{RNI}=1.000 \mathrm{f}=1.000$

$\% \% \%$ Mass Flow $\% \% \% \% \%$

$\%$ Mass Flow

$\mathrm{TMF}=\left[\begin{array}{llllll}6.021000000 & 0.000000000 & 0.052631579 & 0.105263159 & 0.157894731 \ldots\end{array}\right.$

$\begin{array}{llllllll}0.210526317 & 0.263157904 & 0.315789461 & 0.368421048 & 0.421052635 \ldots\end{array}$

$\begin{array}{llllllll}0.473684222 & 0.526315808 & 0.578947365 & 0.631578922 & 0.684210539 \ldots\end{array}$

$\begin{array}{lllllll}0.736842096 & 0.789473712 & 0.842105269 & 0.894736826 & 0.947368443 \ldots\end{array}$

$1.000000000 ; \ldots$

$\begin{array}{lllll}0.800000012 & 2.865310907 & 2.947129250 & 3.014593363 & 3.066267967 \ldots\end{array}$

$\begin{array}{llllll}3.100717783 & 3.120095730 & 3.132091045 & 3.138038158 & 3.140909195 \ldots\end{array}$

$\begin{array}{llllll}3.141626835 & 3.141626835 & 3.141626835 & 3.141626835 & 3.141626835 \ldots\end{array}$

$3.1416268353 .1416268353 .1416268353 .1416268353 .141626835 \ldots$ 
$3.141626835 ; \ldots$

$\begin{array}{llllll}0.899999976 & 2.863688231 & 2.940669775 & 3.007350445 & 3.059090853 \ldots\end{array}$ $\begin{array}{lllllll}3.091745615 & 3.111483335 & 3.124375820 & 3.130861282 & 3.133014441 \ldots\end{array}$ $\begin{array}{lllllll}3.133732080 & 3.133732080 & 3.133732080 & 3.133732080 & 3.133732080 \ldots\end{array}$ $\begin{array}{lllll}3.133732080 & 3.133732080 & 3.133732080 & 3.133732080 & 3.133732080 \ldots\end{array}$ $3.133732080 ; \ldots$

$\begin{array}{llllll}1.000000000 & 2.868181705 & 2.942792654 & 3.004784584 & 3.048325300 \ldots\end{array}$ $3.0777511603 .0992822653 .1107654573 .1175379753 .120095730 \ldots$ $\begin{array}{llllll}3.120813370 & 3.120813370 & 3.120813370 & 3.120813370 & 3.120813370 \ldots\end{array}$ $\begin{array}{lllll}3.120813370 & 3.120813370 & 3.120813370 & 3.120889187 & 3.120813370 \ldots\end{array}$ $3.120813370 ; \ldots$

$1.0499999522 .8789200782 .9481189253 .005323648 \quad 3.045695305 \ldots$ $\begin{array}{llllll}3.073644638 & 3.093222618 & 3.104187012 & 3.110687494 & 3.113353729 \ldots\end{array}$ $\begin{array}{llllll}3.114356756 & 3.114522934 & 3.114534378 & 3.114682198 & 3.114712954 \ldots\end{array}$ $3.1147129543 .1147129543 .1147227293 .1147408493 .114712954 \ldots$ $3.114712954 ; \ldots$

$\begin{array}{llllll}1.100000024 & 2.889118433 & 2.953747988 & 3.006698608 & 3.043700218 \ldots\end{array}$ $3.0698564053 .0877990723 .0979266173 .1043062213 .106858015 \ldots$ $3.1080853943 .1082599163 .1082541943 .1086125373 .108612537 \ldots$ $3.1086125373 .1086125373 .1086125373 .1086125373 .108612537 \ldots$ 3.108612537];

$\%$ Efficiency

TEFF $=\left[\begin{array}{lllllll}6.021000000 & 0.000000000 & 0.052631579 & 0.105263159 & 0.157894731 \ldots\end{array}\right.$ $\begin{array}{lllllll}0.210526317 & 0.263157904 & 0.315789461 & 0.368421048 & 0.421052635 \ldots\end{array}$ $\begin{array}{lllllll}0.473684222 & 0.526315808 & 0.578947365 & 0.631578922 & 0.684210539 \ldots\end{array}$ $\begin{array}{lllllll}0.736842096 & 0.789473712 & 0.842105269 & 0.894736826 & 0.947368443 \ldots\end{array}$ $1.000000000 ; \ldots$

$\begin{array}{lllllll}0.800000012 & 0.862686574 & 0.864444435 & 0.866148710 & 0.866418302 \ldots\end{array}$ $\begin{array}{lllllllll}0.865771115 & 0.864789903 & 0.862686574 & 0.860199034 & 0.856484234 \ldots\end{array}$ $\begin{array}{llllllll}0.851741314 & 0.846666694 & 0.840298533 & 0.832835793 & 0.823582113 \ldots\end{array}$ $\begin{array}{llllllll}0.813764513 & 0.801824212 & 0.787495852 & 0.772518158 & 0.756914675 \ldots\end{array}$ $0.741971910 ; \ldots$

$\begin{array}{llllll}0.899999976 & 0.874129355 & 0.877280295 & 0.880596995 & 0.883084595 \ldots\end{array}$ $\begin{array}{lllllll}0.885406315 & 0.887064695 & 0.887562215 & 0.887562215 & 0.886397421 \ldots\end{array}$ $\begin{array}{llllllll}0.883723259 & 0.880066335 & 0.875059068 & 0.867661715 & 0.859203994 \ldots\end{array}$ $\begin{array}{llllllll}0.848955214 & 0.837114453 & 0.824192345 & 0.809166431 & 0.794162512 \ldots\end{array}$ $0.778720021 ; \ldots$

$\begin{array}{llllll}1.000000000 & 0.875415266 & 0.883388698 & 0.890298486 & 0.896616936 \ldots\end{array}$ $\begin{array}{llllllll}0.902126253 & 0.906343281 & 0.909302354 & 0.910897017 & 0.911096334 \ldots\end{array}$ $\begin{array}{lllllll}0.910447776 & 0.908106327 & 0.903980076 & 0.898139536 & 0.890671670 \ldots\end{array}$ $\begin{array}{lllllll}0.880596995 & 0.869288862 & 0.855504930 & 0.841044784 & 0.825183511 \ldots\end{array}$ $0.809701502 ; \ldots$

$\begin{array}{lllllll}1.049999952 & 0.880042434 & 0.887722194 & 0.894605160 & 0.900887907 \ldots\end{array}$ $\begin{array}{llllllll}0.906177402 & 0.910082340 & 0.912785828 & 0.914506793 & 0.914833784 \ldots\end{array}$ $\begin{array}{llllllll}0.914079785 & 0.911949337 & 0.908656716 & 0.903283596 & 0.896417916 \ldots\end{array}$ $\begin{array}{llllllll}0.887761176 & 0.877313435 & 0.866268635 & 0.853432834 & 0.839104474 \ldots\end{array}$ $0.824776113 ; \ldots$

$\begin{array}{lllllll}1.100000024 & 0.880863786 & 0.889169455 & 0.895721376 & 0.901857376 \ldots\end{array}$ $\begin{array}{llllllll}0.906832516 & 0.910315096 & 0.912757456 & 0.914750814 & 0.915124357 \ldots\end{array}$ $\begin{array}{lllllll}0.914418578 & 0.912757456 & 0.909435213 & 0.904842436 & 0.898043096 \ldots\end{array}$ $\begin{array}{lllllll}0.890498340 & 0.880630195 & 0.869353235 & 0.858076274 & 0.844435215 \ldots\end{array}$ 0.829994678]; 
$\% \% \% \%$ Pressure Ratio $\% \% \% \%$

$\%$ Min Pressure Ratio (beta $=0$ )

TPR_min $=\left[\begin{array}{llllll}2.006000000 & 0.800000012 & 0.899999976 & 1.000000000 & 1.049999952 \ldots\end{array}\right.$ $1.100000024 ; \ldots$

$0.800000012 \quad 1.5306090121 .5464504961 .5653901101 .576021791 \ldots$

$1.587428093]$

$\%$ Max Pressure Ratio $(b e t a=1)$

TPR $\max =\left[\begin{array}{lllll}2.006000000 & 0.800000012 & 0.899999976 & 1.000000000 & 1.049999952 \ldots\end{array}\right.$ $1.100000024 ; \ldots$

$0.8000000123 .7671058183 .8946537973 .9910802844 .027623177 \ldots$

4.056385517];

$\%$ interpolation to get 20 beta line between 0 and 1

$X=\left[[0 . *(1: 5)]^{\prime}[(1: 5) . /(1: 5)]^{\prime}\right]$;

$Y=\left[T P R \_\min (2,2: 6)^{\prime} T P R \_\max (2,2: 6)^{\prime}\right]$;

$\mathrm{C}=\operatorname{nume} \overline{\mathbf{l}}(\mathrm{X}(:, 1))$;

$\mathrm{D}=20$;

TPRs $=[$ zeros $(C, D)]$;

$j=1$;

while $\mathrm{j}<=\mathrm{C}$

TPR = interpl(X(j,:),Y(j,:),TMF(1,2:21));

$\operatorname{TPRs}(\mathrm{j},:)=\mathrm{TPR}$;

$j=j+1$;

end

$T P R=\left[\left(T P R \_\min (1,2: 6)\right)^{\prime} T P R s\right] ;$

$\%$ interpolation to get speed line $(0.85$ to 0.95$)$

$\mathrm{TMFx}=\operatorname{TMF}(2: 6,1) ;$

TMFy = TMF $(2: 6,2: 21)$;

$\operatorname{TEFFx}=\operatorname{TEFF}(2: 6,1)$;

TEFFy $=$ TEFF $(2: 6,2: 21)$;

TPRx = TPR(:,1);

TPRy $=$ TPR(:,2:21);

$\mathrm{S}=\left[\begin{array}{lll}0.85 & 0.95\end{array}\right]$

$\mathrm{D}=\operatorname{numel}(\operatorname{TMFy}(1,:))$;

$\mathrm{E}=\operatorname{numel}(\mathrm{S})$;

ExtTMF = zeros(E,D);

ExtTEFF = zeros(E,D);

ExtTPR = zeros(E,D);

$\mathrm{i}=1$; 


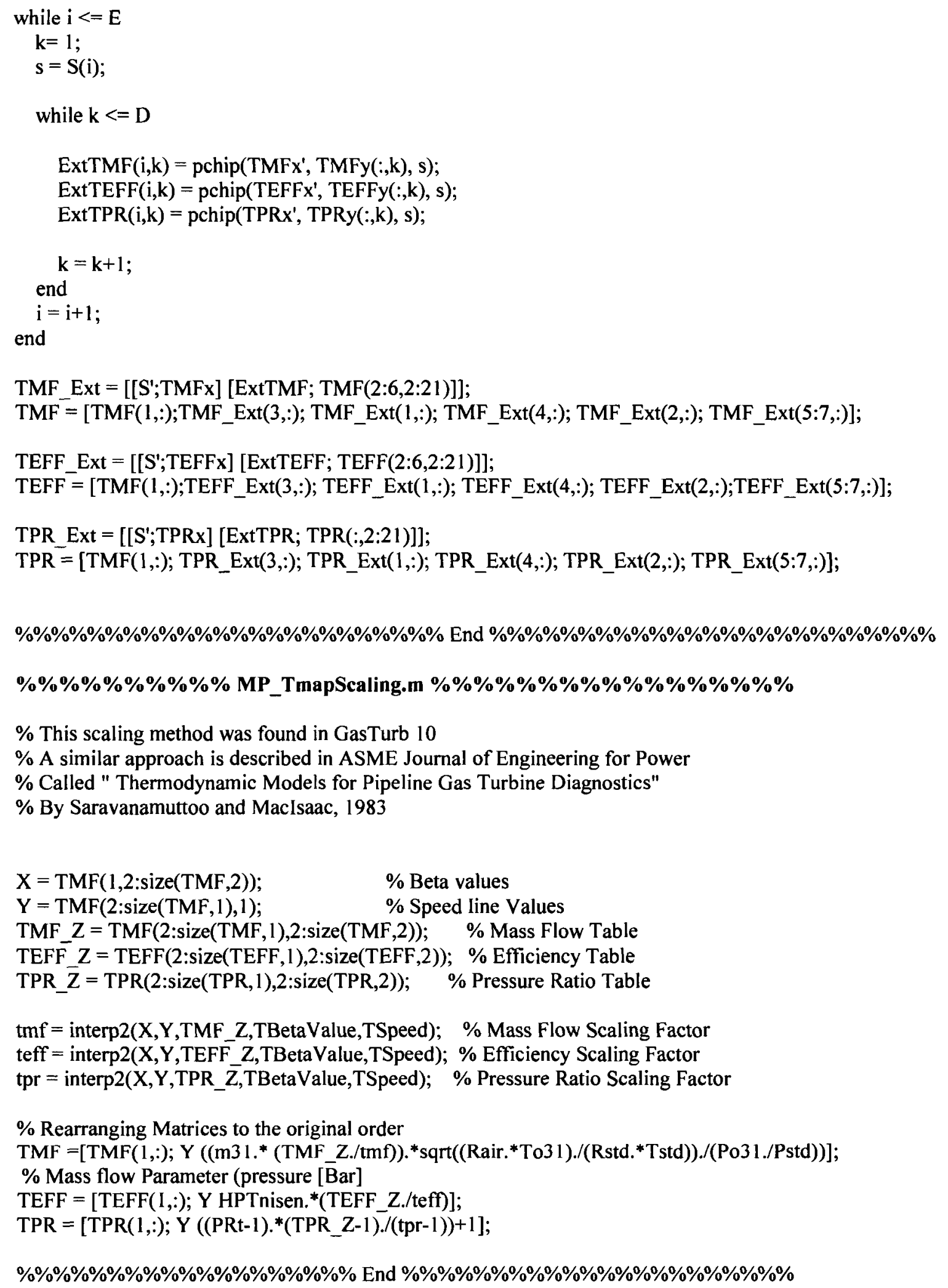


$\% \% \%$ Sub-Idle Extrapolation \%\%\%

$\%$ This approach was adapted from Master Thesis " A method to control tubofan

$\%$ engine starting by varying combressor surge valve bleed " by Wayne

$\%$ Randolphe Sexton, '2001'

$\% \%$ Pressure Ratio

$\% \%$ Based on exponent laws

$\% \%$ Assume that ratio of ideal specific work $=[\% \text { Nnew } / \% \text { Nref }]^{\wedge} p$

$\% \%$ we know that (ideal spec work $) / \mathrm{CpTo}=\left(1-(1 / \mathrm{PR})^{\wedge}((\right.$ ycomb-1)/ycomb $))=[\% \text { Nnew } / \% \mathrm{Nref}]^{\wedge} \mathrm{p}$

$\% \%$ use second last speed line as reference

at $=3$;

$\mathrm{bt}=2$;

int $=0.1 ; \%$ speed line interval

TPR_ref $=$ TPR (at,2:size(TPR,2));

TPR_last $=$ TPR(bt,2:size $(T P R, 2))$;

relN_ref $=\mathrm{TPR}(\mathrm{at}, 1)$;

relN_last $=$ TPR $(b t, 1)$;

relN_new $=[0.1$ :int:relN_last-int $]$;

$p=\overline{\log } 10\left(\left(1-(1 . / T P R\right.\right.$ last $) \wedge^{\wedge}(($ ycomb-1)/ycomb $)) . /\left(1-\left(1 . / T P R \_\right.\right.$ref $) . \wedge($ ycomb-

1)/ycomb)))./log $10($ relN_last./relN_ref);

for $\mathrm{j}=1$ :size((relN_new),2)

PR_new $=1 . /\left(1-\left(\left(1-\left(1 . / T P R \_r e f\right)\right)^{\wedge}((\right.\right.$ ycomb-

1)./ycomb))).*(relN_new(j)./relN_ref). $\wedge$ p). ${ }^{\wedge}($ ycomb./(ycomb-1));

TPR_new $(j, ;)=$ [relN_new(j) PR_new];

end

$\% \%$ Mass flow Parameter

$\% \%$ Based on exponent laws

$\% \%$ Assume that ratio of mass flow $=[\%$ Nnew $/ \%$ Nref $] \wedge q$

$\% \%$ use second last speed line as reference

TMF_ref $=$ TMF(at,2:size $(T P R, 2))$;

TMF_last $=$ TMF(bt,2:size $(T P R, 2))$;

relN_ref $=$ TPR(at, 1$)$;

relN_last $=\operatorname{TPR}(\mathrm{bt}, 1)$;

relN_new $=[0.1$ :int:relN_last-int $]$;

$\mathrm{q}=\overline{\log 10}\left(\mathrm{TMF} \_\right.$last. $/ \mathrm{TMF}$ _ref $) . / \log 10($ relN_last./relN_ref $)$;

for $j=1$ :size((relN_new),2)

TMF_new $(j,:)=\left[\right.$ relN_new(j) TMF_ref.* $($ relN_new(j)./relN_ref $\left.) \wedge^{\wedge} q\right]$;

end

$\% \%$ Efficiency

$\% \%$ Based on exponent laws

$\% \%$ Assume that Power Ratio $=[\% \text { Nnew } / \% \text { Nref }]^{\wedge} r$

$\% \%$ and Power. $/ \mathrm{Cp} *$ To $=m^{*}\left(1-(1 / \mathrm{PR}) \uparrow((\text { ycomb-1) } / \text { ycomb }))^{*} \mathrm{HPTn}=[\% \text { Nnew } / \% \text { Nref }]^{\wedge} \mathrm{r}\right.$

$\% \%$ Therfore Power./Cp*To $=($ HPTn_new./HPTn_ref $){ }^{*}[\% \text { Nnew } / \% \text { Nref }]^{\wedge} p^{*}[\% \text { Nnew } / \% \text { Nref }]^{\wedge} q$

$\% \%$ use second last speed line as reference

TEFF_ref $=$ TEFF(at,2:size $($ TPR,2));

TEFF_last $=$ TEFF(bt,2:size $(T P R, 2))$;

relN_ref $=$ TPR(at, 1$)$;

relN_last $=$ TPR $(b t, 1)$; 
relN_new $=[0.1$ :int:relN_last-int $]$;

$\mathrm{r}=(\overline{\mathrm{p}}+\mathrm{q})+\log 10\left(\mathrm{TEFF}{ }_{-}\right.$last./TEFF_ref)./log $10($ relN_last./relN_ref $) ;$

for $\mathrm{j}=1$ :size((relN_new),2)

end

TEFF_new $(j,:)=\left[\right.$ relN_new(j) TEFF_ref.* $($ relN_new(j)./relN_ref $\left.) .^{\wedge}(r-(p+q))\right]$;

$\% \% \% \%$ Load Info into Proper Matrices

TMF = [TMF(1,:); TMF_new; TMF(2:size(TPR,1), 1:size(TPR,2))];

$\operatorname{TEFF}=[\operatorname{TEFF}(1,:) ; \operatorname{TEFF}$ new; $\operatorname{TEFF}(2: \operatorname{size}(\mathrm{TPR}, 1), 1: \operatorname{size}(\mathrm{TPR}, 2))]$;

TPR = [TPR(1,:); TPR_new; TPR(2:size(TPR, 1),1:size(TPR,2))];

\%\%\%\%\%\%\%\%\%\%\%\%\%\%\%\%\%\%\%\%\% End \%\%\%\%\%\%\%\%\%\%\%\%\%\%\%\%\%\%\%\%\%\%\%\%\%\%\%\%\%\%\%

$\% \% \% \% \% \% \% \% \% \% \% \% \% \% \% \% \% \% \%$ MP_LP01.m \%\%\%\%\%\%\%\%\%\%\%\%\%\%\%\%\%\%

$\%$ Original Turbine Map

Original LPT01;

\% Scale Map using Design point Data

MP_PTMapScaling;

$\%$ Sub-Idle Extrapolation

MP_PTMapExtrapolation;

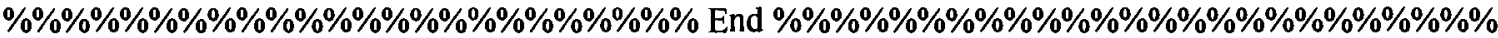

$\% \% \% \% \% \% \% \% \% \% \% \% \% \% \%$ Original LPT $01 . \mathrm{m} \% \% \% \% \% \% \% \% \% \% \% \% \% \% \% \% \% \% \%$

$\% \% \%$ NOTES $\% \% \%$

$\%$ Tables where found in GasTurb 10

$\% 99$ AGARD two-stage turbine

\% Reynolds: $\mathrm{RNI}=0.1 \mathrm{f}=0.95 \mathrm{RNl}=1 \mathrm{f}=1$

$\% \% \%$ Mass Flow $\% \% \%$

$\%$ Mass Flow $=f(N / s q r t(T)$, relative Pressure Ratio $)$

\begin{tabular}{|c|c|c|c|c|}
\hline $\mathrm{LTMF}=[\mathbf{8 . 0}$ & 1600 & 0.071 & 0.142 & $0.21429 .$. \\
\hline 0.28571 & 0.35714 & 0.42857 & $0.50000 \quad 0$. & $.57143 \ldots$ \\
\hline 0.64286 & 0.71429 & 0.78571 & 0.85714 & $.92857 \ldots$ \\
\hline $1.00000 ; \ldots$ & & & & \\
\hline 0.60000 & 70.37594 & 79.89975 & 86.61654 & $91.63452 \ldots$ \\
\hline 95.31143 & 98.83739 & 101.37780 & 103.44978 & $105.18874 \ldots$ \\
\hline $\begin{array}{l}106.65414 \\
110.51629\end{array}$ & 107.88471 & 108.75940 & 109.48872 & $110.06516 \ldots$ \\
\hline
\end{tabular}




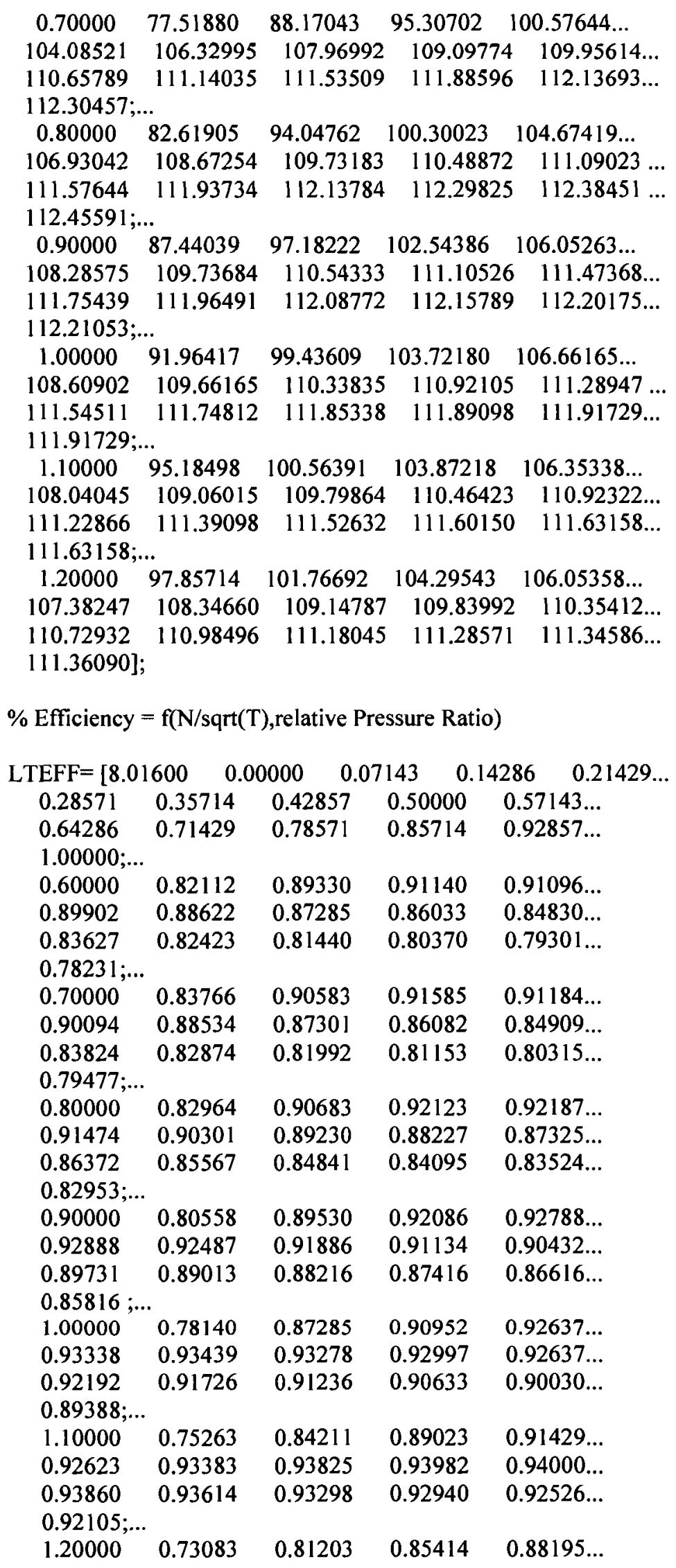




$\begin{array}{lllll}0.90301 & 0.91579 & 0.92448 & 0.93135 & 0.93643 \ldots \\ 0.93951 & 0.94102 & 0.94124 & 0.94094 & 0.94027 \ldots \\ 0.93917] ; & & & & \end{array}$

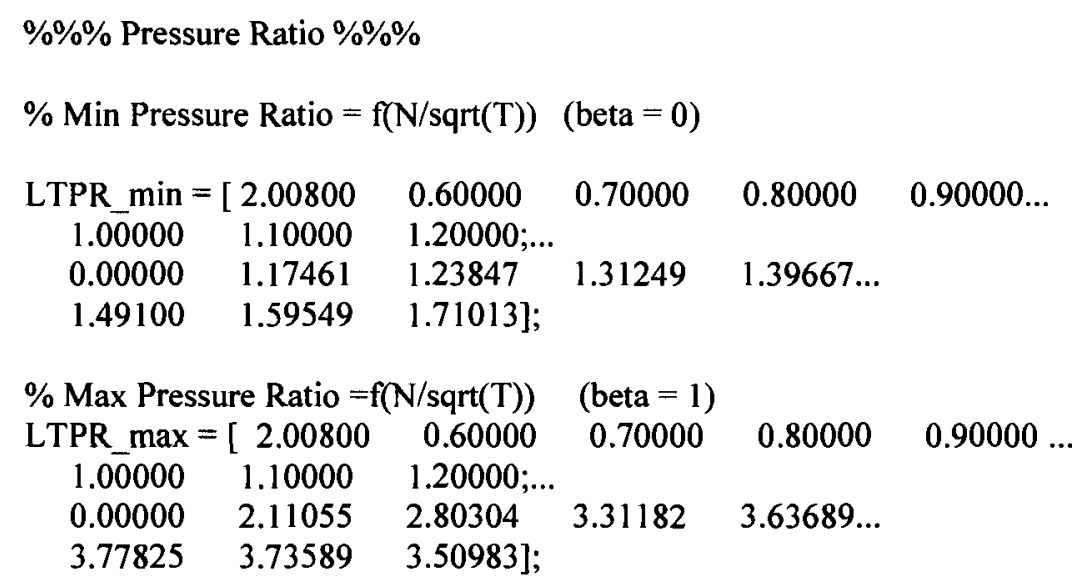

$\%$ interpolation to get 15 beta line between 0 and 1

$\mathrm{X}=\left[\left[0 .{ }^{*}(2: 8)\right]^{\prime}[(2: 8) . /(2: 8)]^{\prime}\right]$

$Y=\left[L T P R \_\min (2,2: 8)^{\prime}\right.$ LTPR_max $\left.(2,2: 8)^{\prime}\right]$;

$\mathrm{C}=\operatorname{numel}(\overline{\mathrm{X}}(:, 1))$;

$\mathrm{D}=15$;

LTPRs $=[\operatorname{zeros}(\mathrm{C}, \mathrm{D})]$;

$\mathrm{j}=1$;

while $\mathrm{j}<=\mathrm{C}$

LTPR = interpl(X(j,:),Y(j,:),LTMF(1,2:16));

LTPRs(j,:) = LTPR;

$\mathbf{j}=\mathbf{j}+\mathbf{1}$;

end

$\operatorname{LTPR}=\left[\operatorname{LTMF}(1,:) ;\left(L T P R \_\min (1,2: 8)\right)^{\prime}\right.$ LTPRs $]$;

\%\%\%\%\%\%\%\%\%\%\%\%\%\%\%\%\%\%\%\%\%\%\%\% End \%\%\%\%\%\%\%\%\%\%\%\%\%\%\%\%\%\%\%\%\%\%\%\%\%

$\% \% \% \% \% \% \% \% \% \% \% \% \% \% \% \% \%$ MP_PTMapScaling.m \%\%\%\%\%\%\%\%\%\%\%\%\%\%\%\%

$\%$ This scaling method was found in GasTurb 10

$\%$ A similar approach is described in ASME Journal of Engineering for Power

\% Called " Thermodynamic Models for Pipeline Gas Turbine Diagnostics"

$\%$ By Saravanamuttoo and Maclsaac, 1983

$\mathrm{X}=\operatorname{LTMF}(1,2: \operatorname{size}(\mathrm{LTMF}, 2))$

$\mathrm{Y}=\mathrm{LTMF}(2: \operatorname{size}(\mathrm{LTMF}, 1), 1)$; $\quad$ \% Speed line Values

LTMF_Z = LTMF(2:size(LTMF,1),2:size(LTMF,2)); \% Mass Flow Table

LTEFF_Z = LTEFF(2:size(LTEFF,1),2:size(LTEFF,2)); \% Efficiency Table

LTPR_ $\bar{z}=$ LTPR(2:size $(L T P R, 1), 2: \operatorname{size}(L T P R, 2)) ; \quad \%$ Pressure Ratio Table 
Itmf = interp2(X,Y,LTMF_Z,PTBetaValue,PTSpeed); \% Mass Flow Scaling Factor

lteff $=$ interp2(X,Y,LTEFF Z,PTBetaValue,PTSpeed); \% Efficiency Scaling Factor

ltpr $=$ interp2(X,Y,LTPR_Z,PTBetaValue,PTSpeed); \% Pressure Ratio Scaling Factor

$\%$ Rearranging Matrices to the original order

LTMF $=\left[\operatorname{LTMF}(1,:) ; \mathrm{Y}\left(\left(\mathrm{m} 41 .{ }^{*}(\mathrm{LTMF} Z \mathrm{Z} . / \mathrm{Itmf})\right) .{ }^{*}\right.\right.$ sqrt((Rair.*To41)./(Rstd.*Tstd))./(Po41./Pstd))];

$\%$ Mass flow Parameter (pressure [Bar]

LTEFF $=\left[\operatorname{LTEFF}(1, ;) ;\right.$ Y LPTnisen. ${ }^{*}($ LTEFF_Z./lteff $\left.)\right] ;$

$\operatorname{LTPR}=[\operatorname{LTPR}(1,:) ; \mathrm{Y}(($ PRpt-1).*(LTPR_Z-1)./(Itpr-1))+1];

\%\%\%\%\%\%\%\%\%\%\%\%\%\%\%\%\%\%\%\%\%\%\%\% End \%\%\%\%\%\%\%\%\%\%\%\%\%\%\%\%\%\%\%\%\%\%\%\%\%\%

$\% \% \% \% \% \% \% \% \% \% \% \% \% \% \%$ MP_OffDesign_load.m $\% \% \% \% \% \% \% \% \% \% \% \% \% \% \% \% \%$

$\%$ This script calculates off design performance parameters and stores them

$\%$ in the file SteadyState.mat

\% Load on PT

fprintf( 1 ,'In $========$ Off-Design Calculation (Load on PT) $=========1 n$ ')

relN $=[1.05:-0.025: 0]$;

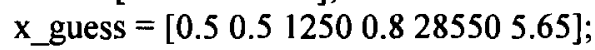

$\%$ Starter Power

StartPower $=0$;

for $\mathrm{jj}=1: \operatorname{size}($ relN, 2$)$

relN_now = relN(jj);

fprintf( 1 ,'In Calculating relN $=\% 4.3 f^{\prime}$ ',relN_now)

Newton =MP_NewtonRap_load(relN_now, $\mathbf{x} \_$guess,StartPower); \% [BetaC BetaT TIT BetaLPT N_pt ma_guess Error]

$\mathrm{x}$ guess $=[$ Newton $(1: 6)]$

$\%$ rearrange matirx to add TIT and relN

$A=[N e w t o n(1: 3)$ relN_now Newton(4:7)]; \% [BetaC BetaT TIT relN BetaLPT ma_guess Error]

if $\mathrm{A}(8)>0.0001$

fprintf( 1, 'In $\backslash n$ Off Design Calculation stopped at relN $=\% 4.3 f^{\prime}$, relN(jj-1))

break

end

OffDesign_Data_load(ji,:) = MP_Calc_OffDesign_load(A,StartPower);

$\% \quad$ OffDesign_Data_load $=$ [Toa Poa corr_m1 m1 To1 Pol Cnisen N relN BetaC PRc m2 To2 Po2 CPower $m 3$ To3 Po3...

$\% \quad$ Bn FuelFlow corr_m31_calc m31 Po31 HPTnisen relN_turb BetaT HPTPR HPTPower m4 To4 Po4...

$\% \quad$ m41 To41 Po41 corr m41_calc N_pt relN_PTurb BetaLPT LPTPR LPTnisen m5 To5 Po5

LPTPower PropPower ShaftPower SFC $\overrightarrow{\text { SI... }}$

$\%$ Thermal_Efficiency StartPower Error_square]; 
end

fprintf(1,'ının Saving: MP_OffDesign_Data_load.mat

savefile = 'MP_OffDesign_Data_load.mat';

save(savefile,'OffDesign_Data_load');

fprintf(1,' Done $\left.\ln ^{\prime}\right)$

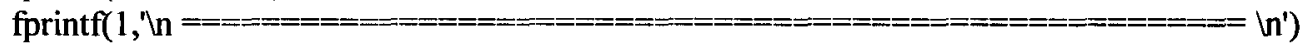

\%\%\%\%\%\%\%\%\%\%\%\%\%\%\%\%\%\%\%\%\%\%\%\%\% End \%\%\%\%\%\%\%\%\%\%\%\%\%\%\%\%\%\%\%\%\%\%\%

$\% \% \% \% \% \% \% \% \% \% \% \% \% \% \% \% \%$ MP_NewtonRap_load.m $\% \% \% \% \% \% \% \% \% \% \% \% \% \% \%$

$\%$ Off Design Operating line calculation

$\% \% \%$ NOTES $\% \% \%$

\% Source: Turns " An Intoduction To Combustion

$\%$ 2nd edition " Appendix E

$\%$ Also " Numerical Methods with Matlab" sec 8.5

$\%$ PT with load

$\% \%$ INPUTS $\% \% \%$

$\%$ relN $=$ Compressor Relative Speed

$\% \mathrm{x} \_$guess $=[$BetaC BetaT TIT BetaLPT N_pt ma_guess $]$

\%\%\%\%\%\%\%\%\%\%\%\%\%\%\%\%\%\%\%\%\%\%\%\%\%\%\%\%\%\%\% OUTPUTS

\%\%\%\%\%\%\%\%\%\%\%\%\%\%\%\%\%\%\%\%\%\%\%\%\%\%\%\%\%\%\%\%

$\%$ AMatrix $=[$ BetaC BetaT ma $]$

$\% \%$ Calculations $\% \% \%$

function AMatrix $=$ MP_NewtonRap_load(relN, $\mathbf{x}$ _guess,StartPower)

F_old $=0$;

$\mathrm{k}=1$

\% Initial Guess [BetaC BetaT TIT BetaLPT N_pt ma_guess]

$\mathbf{x}=[\mathrm{x}$ guess $(1: 5)]$

ma_guess $=\mathrm{x}$ _guess $(6)$;

$\%$ Outer Loop used in case the simulation diverges

while $\mathrm{k}<75$

$\mathrm{k}=\mathrm{k}+1$

$\% \% \% \%$ Jacobian matrix \%\%\%

$\%$ Setup of the Jacobian Matrix 
$[\mathrm{F}, \mathrm{J}, \mathrm{ml}]=$ MP_Jacob_load(relN,x,ma_guess,StartPower);

\% Solve using Gauss Elimination (in MatLab this is donw using "l")

$\mathrm{dx}=(J \mathrm{~J})$;

$\% \% \%$ Damping $\% \% \%$

ma_guess $=\mathrm{ml}$;

$\%$ this process is used to enable better conevergence

if $(\operatorname{norm}(\operatorname{abs}(\mathrm{F})))>($ norm(abs(F_old $)))$

$\mathrm{dx}=\mathrm{dx} . / 5$

end

F_old = F;

$\% \%$ Calculations $\% \% \%$

$\mathbf{x}=\mathbf{x}-\mathrm{dx}$

$\% \mathrm{x}=\operatorname{abs}(\mathrm{x})$

Error_square $=(\operatorname{sum}(F . \wedge 2))$;

$\% \% \%$ Convergence Tolerances $\% \% \% \%$

bound Check $=[x(2) x(4)]>1.2$;

if $\max$ (bound_Check) $=1$

fprintf(1,' Did not converge')

AMatrix $=$ [x ma_guess Error_square $]$;

end

return

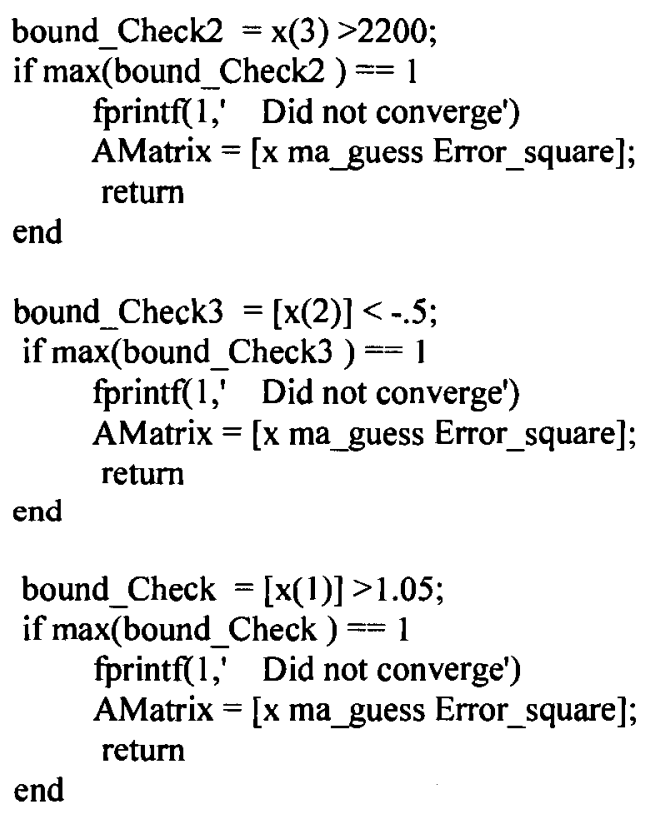


if $(\operatorname{sum}(F, \wedge))<10^{\wedge}(-8)$

AMatrix $=[\mathrm{x}$ ma_guess Error_square $]$; return

end

end

fprintf(1,' Maximum iterations reached, Did not converge')

AMatrix $=[x$ ma_guess Error_square $]$;

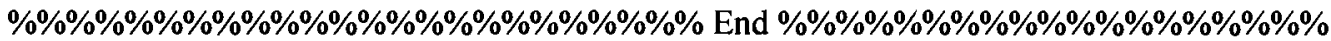

$\% \% \% \% \% \% \% \% \% \% \% \% \% \% \% \% \% \%$ MP_Jacob_load $\% \% \% \% \% \% \% \% \% \% \% \% \% \%$

$\%$ Off Design Operating line calculation

$\% \% \%$ NOTES $\% \% \%$

\% Setup the Jacobian matrix for use in the Generalized Newton's Method

$\%$ Source: Turns

$\%$ PT with load

$\% \% \%$ OUTPUTS $\% \% \%$

$\% \mathrm{f}=$ system of nonlinear equations

$\% \mathrm{~J}=$ Jacobian of the system of equations

$\% \% \%$ Calculations $\% \% \%$

function $[\mathrm{f}, \mathrm{J}, \mathrm{ml}]=\mathrm{MP}$ Jacob_load(relN,x,ma_guess,StartPower)

warning off MATLAB:fzero:UndeterminedSyntax

MP_Inputs;

load MP_DesignPointData.mat

MP ScalingFactor;

MP HPC01;

MP HPT01;

MP_LPT01;

ep $=\left[\left(10^{\wedge}(-5) \cdot{ }^{* a b s}(x(1))\right)\left(10^{\wedge}(-5) \cdot{ }^{*} \operatorname{abs}(x(2))\right)\left(10^{\wedge}(-5) . * a b s(x(3))\right)\left(10^{\wedge}(-5) *^{*} a b s(x(4))\right)\left(10^{\wedge}(-\right.\right.$

5).*abs(x(5)))];

$\mathrm{xguess}=[\mathrm{x}(1) \times(2) \times(3) \times(4) \times(5) ; \ldots$

$(\mathrm{x}(1)+\mathrm{ep}(1)) \times(2) \times(3) \times(4) \times(5) ; \ldots$

$\mathrm{x}(1)(\mathrm{x}(2)+\mathrm{ep}(2)) \mathrm{x}(3) \mathrm{x}(4) \times(5) ; \ldots$

$\mathrm{x}(1) \mathrm{x}(2)(\mathrm{x}(3)+\mathrm{ep}(3)) \mathrm{x}(4) \times(5) ; \ldots$

$\mathrm{x}(1) \mathrm{x}(2) \mathrm{x}(3)(\mathrm{x}(4)+\mathrm{ep}(4)) \mathrm{x}(5) ; \ldots$

$\mathrm{x}(1) \mathrm{x}(2) \times(3) \times(4)(\mathrm{x}(5)+\mathrm{ep}(5))]$;

for count $=I: \operatorname{size}(x g u e s s, 1)$

BetaC $=$ xguess(count, 1 );

BetaT $=x$ guess $($ count, 2$)$; 
TIT_now $=$ xguess $($ count, 3$)$;

BetaLPT $=$ xguess $($ count, 4$)$;

$\mathrm{N} \_\mathrm{pt}=\mathrm{xguess}($ count, 5$)$;

$\% \% \%$ Thermo. Calculations for Simple Cycle Twin-Shaft $1 \mathrm{MW}$ Gas Turbine \%\%\%

$\%$ note that there is no disc cooling, customer bleeds, blade cooling, NGV cooling and leakage $\%$ considered in this code.

$\%$ Also note that Dry Air is assumed for calculation

$\% \% \%$ Upstream Conditions \%\%

$\mathrm{Cpamb}=\mathrm{Cp} \_$air(Tamb); \% Ambient Specific Heat $\quad[\mathrm{kJ} / \mathrm{kgK}]$

yamb $=($ Cpamb./(Cpamb-(Ra/kJ))); \% Ratio of Specific Heats

$\mathrm{Ta}=\mathrm{Tamb} ; \quad \%$ Static Temperature at a $\quad[\mathrm{K}]$

$\mathrm{Toa}=\mathrm{Ta}+\left(\left(\mathrm{V} .{ }^{*} \mathrm{~km} \_\mathrm{hr}\right) . \wedge 2 /\left(2 .{ }^{*} \mathrm{Cpamb}{ }^{*} 1000\right)\right) ; \%$ Stagnation Temperature at a $[\mathrm{K}]$

$\mathrm{Pa}=\mathrm{Pamb} / \mathrm{kPa} ; \quad$ \% Static Presure at a $\quad[\mathrm{kPa}]$

$\mathrm{Poa}=\mathrm{Pa} .{ }^{*}(\mathrm{Toa} . / \mathrm{Ta})^{\wedge}(\mathrm{yamb} /(\mathrm{yamb}-1)) ; \quad \%$ Stagnation Pressure at a $\quad[\mathrm{kPa}]$

$\% \% \% \%$ Retrive Compressor Map Info \%\%\%

[MF_row MF_col] = size $(\mathrm{MF})$;

[PR_row PR_col] = size $(\mathrm{PR})$;

$\left[E F \bar{F}\right.$ _row $E \overline{F F} \_$col] $=$size $(E F F)$;

$\mathrm{PRc}=$ interp2(PR(1,2:PR_col),PR(2:PR_row, 1),PR(2:PR_row,2:PR_col),BetaC,relN, ${ }^{\prime *}$ spline');

corr_ml $=$ interp2(MF(1,2:MF_col),MF(2:MF_row,1),MF(2:MF_row,2:MF_col),BetaC,relN,'*spline');

Cnisen = interp2(EFF(1,2:EFF_col),EFF(2:EFF_row,1),EFF(2:EFF_row,2:EFF_col),BetaC,relN,'**spline');

$\% \% \% \%$ Engine Intake Conditions \%\%\%

Tol $=$ Toa; $\quad \%$ Stagnation Temperature at $1[\mathrm{~K}]$

$\mathrm{N}=($ relN .* (N_GG./sqrt(Tol_des))).*sqrt(To1);\% Gas Turbine speed [RPM]

\% Part Load Intake Pressure loss Calculation (From GasTurb 10 manual)

LossIntake $=1$ - (IntakeLoss_des .*((ma_guess. ${ }^{*}$ sqrt(Toa.*Ra)./(Poa.*1000))./non_ma_des).^2);

Pol $=$ LossIntake.$^{*}$ Poa;

$\mathrm{ml}=$ corr_ml .* ((Po1./Pstd)./ sqrt((To1.*Ra)./(Tstd.*Rstd)));

$\% \% \%$ Compressor Calculations $\% \% \% \%$

To2s_guess $=$ Tol $+($ Tol..$($ Cnisen $)) . *\left(P R c .^{\wedge}((\right.$ yamb-1)./yamb $)-1) ;$

To2s=fzero(@Trans_Error_To2s,To2s_guess,[],PRc, Tol, Cnisen, Ra);\% Ideal Stagn. Temp. Function at $2[\mathrm{~K}]$ 
To2_guess $=$ To1 $+($ To1./Cnisen $) .{ }^{*}(($ To2s. $/$ To1 $)-1) ;$

To2=fzero(@Trans_Error_To2 ,To2_guess,[], To1, To2s, Cnisen); \% Real Stagn. Temp Function at 2 [K]

Po2 $=$ Po1. ${ }^{* P R c} ; \quad \%$ Stagnation Pressure at $2 \quad[\mathrm{kPa}]$

$\mathrm{m} 2=\mathrm{ml} .^{*}(1-\mathrm{Bc}) ; \quad \quad \%$ Compressor Discharge Mass Flow Rate

CPower $=m 1 . *\left(h \_a i r(T o 2)-h \_a i r(T o 1)\right) ; \quad \%$ Compressor Power $\quad[\mathrm{kW}]$

$\% \% \%$ Compressor to Burner Ducting \%\%\%

Po21 $=$ Po2.* $(1$ - CompToBurn_Delta_P $) ; \quad \%$ Stagnation Pressure at $21 \quad[\mathrm{kPa}]$

$\%$ Note that $\mathrm{To} 21$ is assumed to be equal to the To2 because we are assuming

$\%$ no heat loss between the Compressor and the Burner. This is an

$\%$ approximation and should be corrected with an accurate value for To21.

$\mathrm{To21}=\mathrm{To} ; \quad \%$ Stagnation Temperature at $21[\mathrm{~K}]$

$\mathrm{m} 21=\mathrm{m} 2 ; \quad$ \% Mass Flow Rate at $21 \quad[\mathrm{~kg} / \mathrm{s}]$

$\% \% \%$ Combustion Chamber (Burner) Calculations \%\%\%

$\%$ Note that To3 is assumed to be equal to the TIT because we are assuming

$\%$ no heat loss between the burner and the HP turbine. This is an

$\%$ approximation and should be corrected with an accurate value for To3.

To3 = TIT_now;

\% Part Load Combustion Efficency Calculation (From Walsh \& Fletcher)

Load $=\left(\mathrm{m} 21 . /\left(\left((\mathrm{Po} 21 . / 101.325)^{\wedge} 1.8 .^{*}\right.\right.\right.$ Vcomb $\left.\left.){ }^{*} 10 . \wedge\left(0.00145 .{ }^{*}(\mathrm{To} 21-400)\right)\right)\right) ; \%\left[\mathrm{~kg} / \mathrm{s} \mathrm{atm}{ }^{\wedge} 1.8 \mathrm{~m}^{\wedge} 3\right]$

Bn $=$ PartLoad_Bn(Load);

FuelFlow = (m21.*(h_air(To3)-h_air(To21)))./(HV.*Bn - (h_air(To3))); \% [kg/s]

\% Part Load Burner Pressure loss Calculation (From Walsh \& Fletcher)

DPhot $=$ Khot. ${ }^{*}$ Po21.*((m21.*sqrt(To21)./Po21).^2).*((To3./To21)-1);

Po3 = Po21- DPhot; \% Stagnation Pressure at $3 \quad[\mathrm{kPa}]$

$\mathrm{m} 3=\mathrm{m} 21+$ FuelFlow; $\quad \%$ Mass Flow Rate at $3 \quad[\mathrm{~kg} / \mathrm{s}]$

$\% \% \%$ Burner to HP Turbine Ducting (Plenum) \%\%\%

To31 = To3; $\quad \%$ Stagnation Temperature at $31[\mathrm{~K}]$

\% Part Load Plenum Pressure loss Calculation (From GasTurb 10 manual)

LossPlenum $=1$ - (Plenum_des. ${ }^{*}\left(\left(\mathrm{~m} 3 .{ }^{*} \operatorname{sqrt}(\right.\right.$ To3.*Ra)./(Po3.*1000))./non_m3_des).^2);

Po31 = Po3. ${ }^{*}$ LossPlenum; $\quad \%$ Stagnation Pressure at $31 \quad[\mathrm{kPa}]$

corr_m31_calc $=$ m3. ${ }^{*}$ sqrt( $\left(\right.$ To31. ${ }^{*}$ Ra) $) /\left(\right.$ Tstd. $\left.\left.{ }^{* R s t d}\right)\right) . /($ Po31./Pstd $)$;

$\% \% \%$ Auxiliaries Calculations $\% \% \%$ 


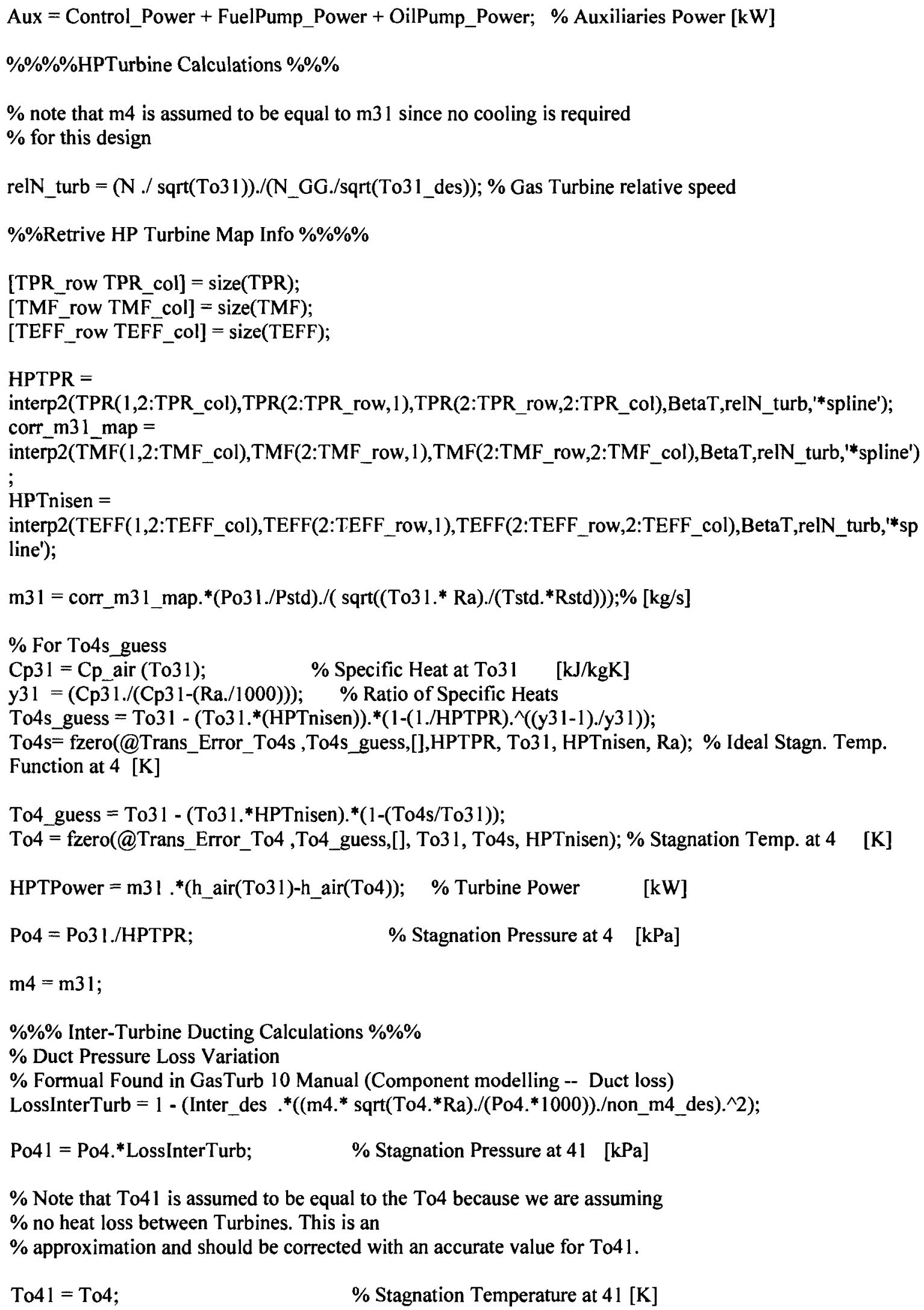


$\% \mathrm{~m} 41=\mathrm{m} 4 ; \quad \%$ Mass Flow Rate at $41 \quad[\mathrm{~kg} / \mathrm{s}]$

corr_m41_calc $=$ m4. ${ }^{*} \operatorname{sqrt}\left((\right.$ To41.* Ra) $) /\left(\right.$ Tstd. ${ }^{*}$ Rstd $\left.)\right) . /($ Po41./Pstd $)$;

$\% \% \%$ Power Turbine - Gas-Generator Matching \%\%

relN_PTurb $=($ N_pt./sqrt(To41))./(N_PT./sqrt(To41_des)); \% Power Turbine relative speed

[LTPR_row LTPR_col] = size(LTPR);

[LTMF_row LTMF_col] = size $(\mathrm{LTMF})$;

[LTEFF_row LTEFF_col] = size(LTEFF);

$\mathrm{LPTPR}=$

interp2(LTPR(1,2:LTPR_col),LTPR(2:LTPR_row,1),LTPR(2:LTPR_row,2:LTPR_col),BetaLPT,relN_PT urb,'*spline');

corr_m41_map =

interp2(LTMF(1,2:LTMF_col),LTMF(2:LTMF_row,1),LTMF(2:LTMF_row,2:LTMF_col),BetaLPT,relN_ PTurb,'*spline');

LPTnisen =

interp2(LTEFF(1,2:LTEFF_col),LTEFF(2:LTEFF_row, 1),LTEFF(2:LTEFF_row,2:LTEFF_col),BetaLPT,r elN_PTurb,'*spline');

m41 = corr_m41_map. ${ }^{*}($ Po41./Pstd)./( sqrt((To41.* Ra)./(Tstd.*Rstd)));\% [kg/s]

$\%$ For To5s_guess

Cp41 = Cp_air (To41); \% Specific Heat at To41 [kJ/kgK]

y41 $=(\mathrm{Cp} 41 . /(\mathrm{Cp} 41-(\mathrm{Ra} . / 1000))) ; \quad \%$ Ratio of Specific Heats

To5s guess $=$ To41 $-\left(\right.$ To4l. ${ }^{*}($ LPTnisen $\left.)\right) . *(1-(1 . / L P T P R) . \wedge((y 41-1) . / y 41))$;

To5s=fzero(@Trans_Error_To5s,To5s_guess,[],LPTPR, To41, LPTnisen, Ra); \% Ideal Stagn. Temp.

Function at $5[\mathrm{~K}]$

$\%$ for To5 guess

To5_guess $=$ To4 1 - (To41.*LPTnisen).*(1-(To5s/To41));

To5=fzero(@Trans_Error_To5,To5_guess,[], To41, To5s, LPTnisen); \% Stagnation Temp. at 5 [K]

LPTPower $=m 41 . *\left(h \_a i r(T 041)-h \_a i r(T o 5)\right) ; \quad$ \% LP Turbine Power $\quad[k W]$

$\% \% \% \%$ Propeller Power \%\%\%

PropPower $=\left(\right.$ LPTPower_des. $\left.{ }^{*} \mathrm{GBn} .{ }^{*} \mathrm{Mn}\right){ }^{*}\left(\mathrm{~N} \_\mathrm{pt} . / \mathrm{N} \_\mathrm{PT}\right) . \wedge 3 ; \%$ Propeller load $\quad[\mathrm{kW}]$

$\% \% \% \%$ Exhaust Pressure \%\%

$\%$ Duct Pressure Loss Variation

\% Formual Found in GasTurb 10 Manual (Component modelling -- Duct loss)

$\mathrm{m} 5=\mathrm{m} 41$

Po5= Po4 1./LPTPR; $\quad$ \% Stagnation Pressure at 5 [kPa

ExhaustLoss_RHS $=(1$ - Poa./Po5 $) ; \%$ Right hand side Exhaust Loss Eqn

ExhaustLoss_LHS $=\left(\right.$ ExhaustLoss_des.* $\left(\left(\mathrm{m} 5 .{ }^{*} \operatorname{sqrt}(\right.\right.$ To5.*Ra)./(Po5.*1000))./non_m5_des $\left.) . \wedge 2\right) ; \%$ Left hand side Exhaust Loss Eqn

$\% \% \%$ Engine Performance $\% \% \% \%$ 


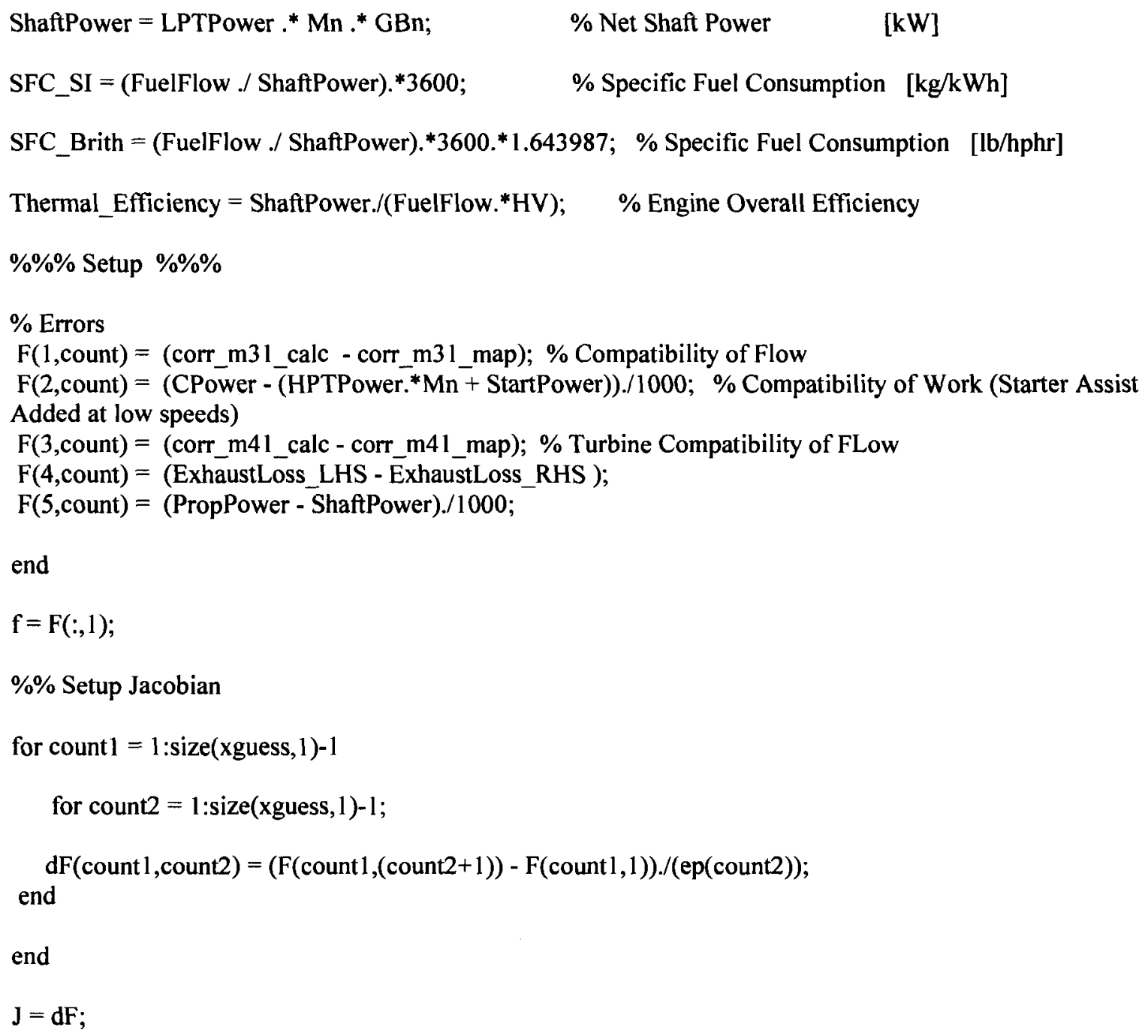

$\% \% \% \% \% \% \% \% \% \% \% \% \% \% \% \% \% \%$ MP_FuelLimits.m $\% \% \% \% \% \% \% \% \% \% \% \% \% \% \% \%$

$\%$ This script calculates off design performance parameters and stores them $\%$ in the file FuelLimits.mat... this data will be used to detemine the $\%$ surge and TIT fuel limits

fprintf( $1, \mathrm{\prime n}===========$ Limiters and Fuel Schedules $============\lfloor\mathrm{n}$ ')

$\% \% \% \%$ Surge Line Limit \%\%\%\%

MP_SurgeLimit;

$\% \% \% \%$ Constant TIT Limit \%\%\%\%

MP_TITLimit;

$\% \% \% \%$ FlameOut Limit $\% \% \%$

$\%$ Fuel to air ratio should be greater than 0.008 during transient

\%operations (Walsh \& Fletcher Gas Turbine Performance Page 456 
MP_FlameOutLimit;

$\% \% \% \%$ Acceleration Fuel Schedule $\% \% \% \%$

MP_AccSched;

$\% \% \% \%$ Deceleration Fuel Schedule \%\%\%\%

MP_DecSched;

$\% \% \% \%$ Maximum and Minimum RPM Limits \%\%\%\%

MP_RPMLimit;

fprintf(1,'lnln Saving: MP_LimiterData.mat

$\%$ Saving Files

savefile = 'MP_LimiterData.mat';

save(savefile,'SurgeLimit_Data','TITLimit_Data','TITDesign_Data','FlameOutLimit_Data','Max_RPMLimi t_Data', 'Min_RPMLimit_Data',...

'TIT_range','Demand_Control','Max_GG_RPM_range','Max_GG_Demand_Control','Min_GG_RPM_range ','Min_GG_Demand_Control',,...

'Max_PT_RPM_range','Max_PT_Demand_Control');

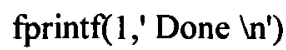

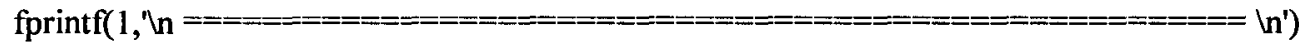

\%\%\%\%\%\%\%\%\%\%\%\%\%\%\%\%\%\%\%\%\%\%\%\% End \%\%\%\%\%\%\%\%\%\%\%\%\%\%\%\%\%\%\%\%\%\%\%\%\%

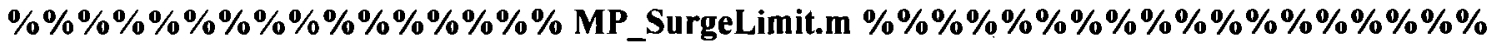

$\%$ This script calculates off design performance parameters along the

$\%$ Surge Line. This data will be used to detemine the surge fuel limits.

$\%$ note that to get this data, we are using a modified version of

$\%$ MP_OffDesign_load. A PowerOfftake term has been added to the calculations.

$\% \% \% \%$ Surge Line Limit \%\%\%\%

$\%$ Surge Line Info ( From Scaled Compressor map)

relN_surge $=\operatorname{MF}(2: \operatorname{size}(\operatorname{MF}(:, 1), 1), 1)$;

SLM_eqn = spline(relN_surge,SLm);

PRC_eqn = spline $($ relN_surge,SLPR $)$;

fprintf(1,'In

fprintf( 1, 'nn

Surge Limiter

BetaC_guess = OffDesign_Data_load $(1,10)$;

BetaT_guess = OffDesign_Data_load $(1,26)$;

BetaPT_guess = OffDesign_Data_load $(1,37)$;

TIT_guess = OffDesign_Data_load $(1,17)$;

Npt_guess = OffDesign_Data_load $(1,36)$;

$\mathrm{m} \_$guess $=$OffDesign_Data_load $(1,4)$;

$\mathrm{x} \_$guess $=\left[1\right.$ BetaT_guess TIT_guess BetaPT_guess Npt_guess $1 \mathrm{~m} \_$guess $]$; 


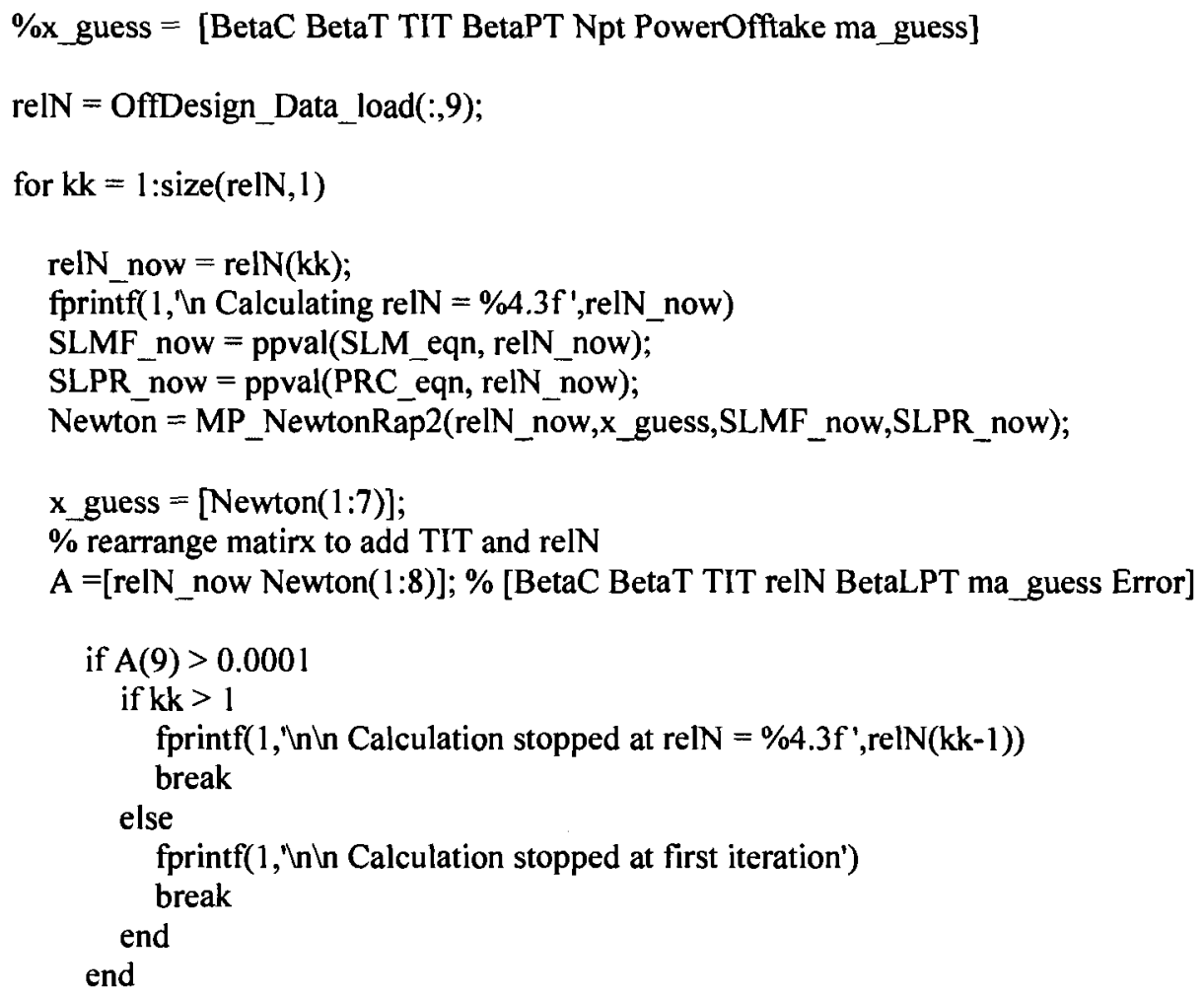


$\%$ TIT_now $=$ Turbine inlet Temperature $[\mathrm{K}]$

\%\%\%\%\%\%\%\%\%\% OUTPUTS \%\%\%\%\%\%\%\%\%\%

$\%$ AMatrix $=[$ BetaC BetaT ma $]$

$\% \% \% \% \% \%$ Calculations $\% \% \% \% \% \% \% \% \% \%$

function AMatrix $=$ MP_NewtonRap2(relN,x_guess,SLMF_now,SLPR_now)

$\mathrm{F}$ old $=0$;

$\mathrm{k}=1$;

\% Initial Guess [BetaC BetaT TIT BetaLPT N_pt P_off ma_guess]

$x=\left[x \_\right.$guess $\left.(1: 6)\right]$

ma _guess $=x$ _guess $(7)$;

$\%$ Outer Loop used in case the simulation diverges

while $k<75$

$\mathbf{k}=\mathbf{k}+1$

$\% \% \% \% \% \% \% \%$ Jacobian matrix \%\%\%\%\%

$\%$ Setup of the Jacobian Matrix

$[F, J, m 1]=$ MP_Jacob2(relN,x,ma_guess,SLMF_now,SLPR_now);

\% Solve using Gauss Elimination (in MatLab this is donw using "l")

$\mathrm{dx}=(J F)$

\%\%\%\%\%\%\%\%\%\%\%\%\% Damping \%\%\%\%\%\%\%\%\%

ma_guess $=\mathrm{m} 1$;

$\%$ this process is used to enable better conevergence

if $(\operatorname{norm}(\operatorname{abs}(\mathrm{F})))>\left(\operatorname{norm}\left(\mathrm{abs}\left(\mathrm{F}_{-}\right.\right.\right.$old $\left.\left.)\right)\right)$ $\mathrm{dx}=\mathrm{dx} . / 5$

end

F_old $=F$;

$\% \% \% \% \% \% \% \% \% \% \%$ Calculations $\% \% \% \% \% \% \% \% \% \% \% \% \%$

$\mathrm{x}=\mathrm{x}-\mathrm{dx}$

$\% x=\operatorname{abs}(x)$

Error_square $=(\operatorname{sum}(F, \wedge 2))$;

$\% \% \%$ Convergence Tolerances $\% \% \% \% \% \% \%$

bound_Check $=[x(1: 2) x(4)]>1.3$;

if $\max$ (bound_Check ) $==1$ fprintf(1,' Did not converge')

AMatrix $=$ [x ma_guess Error_square $]$;

return 
end

bound_Check2 $=x(3)>2200$;

if $\max$ (bound_Check2) $==1$

fprintf( $1, ;$ Did not converge')

AMatrix $=[\mathrm{x}$ ma_guess Error_square $]$;

return

end

if $(\operatorname{sum}(F . \wedge 2))<10^{\wedge}(-8)$

AMatrix $=\left[x\right.$ ma $\_$guess Error_square $]$;

return

end

end

fprintf(1,' Maximum iterations reached, Did not converge')

AMatrix $=[x$ ma_guess Error_square $]$;

\%\%\%\%\%\%\%\%\%\%\%\%\%\%\%\%\%\%\%\%\%\%\%\%\%\% End \%\%\%\%\%\%\%\%\%\%\%\%\%\%\%\%\%\%\%\%\%\%

$\% \% \% \% \% \% \% \% \% \% \% \% \% \% \% \% \% \% \%$ MP Jacob2.m \%\%\%\%\%\%\%\%\%\%\%\%\%\%\%\%\%\%

$\%$ Off Design Operating line calculation

$\% \% \% \%$ NOTES $\% \% \%$

$\%$ Setup the Jacobian matrix for use in the Generalized Newton's Method

$\%$ Source: Turns

$\%$ PT with load

$\% \% \% \% \% \% \% \% \%$ OUTPUTS $\% \% \% \% \% \% \% \% \% \% \% \%$

$\% \mathrm{f}=$ system of nonlinear equations

$\% \mathrm{~J}=$ Jacobian of the system of equations

$\% \% \%$ Calculations $\% \%$

function $[f, J, m l]=$ MP_Jacob2(relN,x,ma_guess,SLMF_now,SLPR_now)

warning off MATLAB:fzero:UndeterminedSyntax

MP Inputs;

load MP DesignPointData.mat

MP_ScalingFactor;

MP_HPC01;

MP_HPT01;

MP_LPT01;

ep $=\left[\left(10^{\wedge}(-5) .{ }^{*} \operatorname{abs}(x(1))\right)\left(10^{\wedge}(-5) .{ }^{*} \operatorname{abs}(x(2))\right)\left(10^{\wedge}(-5) .{ }^{*} \operatorname{abs}(x(3))\right) \ldots\right.$ 


\section{$\left.\left(10^{\wedge}(-5) \cdot{ }^{*} \operatorname{abs}(x(4))\right)\left(10^{\wedge}(-5) . * \operatorname{abs}(x(5))\right)\left(10^{\wedge}(-5) . * a b s(x(6))\right)\right]$;}

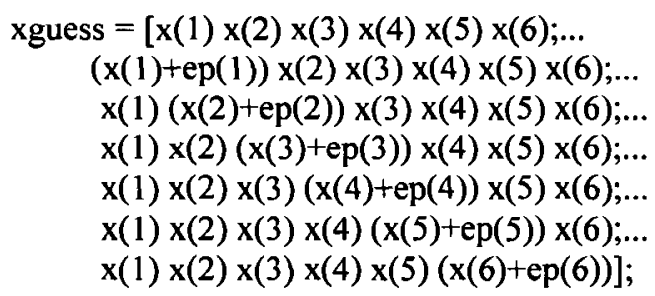

for count $=1$ :size(xguess, 1 )

BetaC $=$ xguess $($ count, 1$)$;

Beta $\mathrm{T}=$ xguess(count,2);

TIT_now $=$ xguess $($ count, 3$)$;

BetaLPT $=$ xguess $($ count, 4$)$;

$\mathrm{N} \_\mathrm{pt}=\operatorname{xguess}($ count, 5$)$;

P_off $=$ xguess $($ count, 6$)$;

$\% \% \%$ Thermo. Calculations for Simple Cycle Twin-Shaft 1 MW Gas Turbine \%\%\%

$\%$ note that there is no disc cooling, customer bleeds, blade cooling, NGV cooling and leakage $\%$ considered in this code.

$\%$ Also note that Dry Air is assumed for calculation

$\% \% \% \% \% \%$ Upstream Conditions \%\%\%\%\%

Cpamb $=$ Cp_air(Tamb); \% Ambient Specific Heat $\quad[\mathrm{kJ} / \mathrm{kgK}]$

yamb $=($ Cpamb. $/($ Cpamb-(Ra/kJ))); \% Ratio of Specific Heats

$\mathrm{Ta}=\mathrm{Tamb} ; \quad \%$ Static Temperature at a $\quad[\mathrm{K}]$

$\mathrm{Toa}=\mathrm{Ta}+\left(\left(\mathrm{V} .{ }^{*} \mathrm{~km} \_\mathrm{hr}\right) . \wedge 2 /\left(2 .{ }^{*} \mathrm{Cpamb}^{*} 1000\right)\right) ; \%$ Stagnation Temperature at a $[\mathrm{K}]$

$\mathrm{Pa}=\mathrm{Pamb} / \mathrm{kPa} ; \quad \%$ Static Presure at a $\quad[\mathrm{kPa}]$

$\mathrm{Poa}=\mathrm{Pa} .{ }^{*}(\mathrm{Toa} . / \mathrm{Ta})\left({ }^{\wedge}\right.$ yamb./(yamb-1)); \% Stagnation Pressure at a $\quad[\mathrm{kPa}]$

\%\%\%\%\%\%\%\%\%\%\%\% Retrive Compressor Map 1nfo \%\%\%\%\%

[PR_row PR_col] $=$ size $(P R)$;

$\left[E F \bar{F}\right.$ _row $E \overline{F F} \_$col $]=\operatorname{size}(E F F)$;

$P R c=$ SLPR_now;

$\%$ use PRc Test for finding BetaC based on Error between PRc and PRc_test

PRc_test = interp2(PR(1,2:PR_col),PR(2:PR_row,1),PR(2:PR_row,2:PR_col),BetaC,relN,'*spline');

corr_ml = SLMF_now;

Cnisen $=$ interp2(EFF(1,2:EFF_col),EFF(2:EFF_row,1),EFF(2:EFF_row,2:EFF_col),BetaC,relN,'*spline');

$\% \% \% \%$ Engine Intake Conditions \%\%\%\%\%

Tol $=$ Toa; $\quad \%$ Stagnation Temperature at $1[\mathrm{~K}]$ 
$\mathrm{N}=($ relN .* (N_GG./sqrt(Tol_des))).*sqrt(Tol); \% Gas Turbine speed [RPM]

\% Part Load Intake Pressure loss Calculation (From GasTurb 10 manual)

Lossintake $=1$ - (IntakeLoss_des.*((ma_guess.* sqrt(Toa.*Ra)./(Poa.*1000))./non_ma_des).^2);

Po1 = LossIntake.$^{*}$ Poa;

$\mathrm{m} 1=$ corr_m1 .* ((Pol./Pstd)./sqrt((To1.* Ra)./(Tstd.*Rstd)));

$\% \% \% \% \% \% \% \% \% \% \%$ Compressor Calculations \%\%\%\%\%\%\%\%

To2s_guess $=$ Tol $+($ Tol./(Cnisen $)){ }^{*}\left(\right.$ PRc. ${ }^{\wedge}(($ yamb-1)./yamb)-1);

To2s=fzero(@Trans_Error_To2s,To2s_guess,[],PRc, To1, Cnisen, Ra);\% Ideal Stagn. Temp. Function at $2[\mathrm{~K}]$

To2_guess $=$ To $1+($ Tol. $/$ Cnisen $) .{ }^{*}(($ To2s. $/$ Tol $)-1) ;$

To2=fzero(@Trans_Error_To2,To2_guess,[], To1, To2s, Cnisen); \% Real Stagn. Temp Function at 2 [K]

Po2 = Po1.*PRc; \% Stagnation Pressure at $2 \quad[\mathrm{kPa}]$

$\mathrm{m} 2=\mathrm{m} 1 .{ }^{*}(1-\mathrm{Bc}) ; \quad \quad \%$ Compressor Discharge Mass Flow Rate

CPower $=\mathrm{ml} 1 . *\left(\mathrm{~h} \_\right.$air(To2)-h_air(To1)); \% Compressor Power $\quad[\mathrm{kW}]$

\%\%\%\%\%\%\%\%\%\%\%\%\% Compressor to Burner Ducting \%\%\%\%\%\%\%\%

Po21 $=$ Po2. ${ }^{*}(1-$ CompToBurn_Delta_P $) ; \quad \%$ Stagnation Pressure at $21 \quad[\mathrm{kPa}]$

$\%$ Note that To21 is assumed to be equal to the To2 because we are assuming $\%$ no heat loss between the Compressor and the Burner. This is an

$\%$ approximation and should be corrected with an accurate value for To21.

To21 $=$ To2; $\quad$ \% Stagnation Temperature at $21[\mathrm{~K}]$

$\mathrm{m} 21=\mathrm{m} 2 ; \quad$ \% Mass Flow Rate at $21 \quad[\mathrm{~kg} / \mathrm{s}]$

\%\%\%\%\%Combustion Chamber (Burner) Calculations \%\%\%\%\%

$\%$ Note that To3 is assumed to be equal to the TIT because we are assuming

$\%$ no heat loss between the burner and the HP turbine. This is an

$\%$ approximation and should be corrected with an accurate value for To3.

To3 = TIT_now;

\% Part Load Burner Efficency Calculation (From Walsh \& Fletcher)

Load $=\left(\mathrm{m} 21 . /\left(\left((\mathrm{Po} 21 . / 101.325)^{\wedge} 1.8 .{ }^{*} \mathrm{~V}\right.\right.\right.$ comb $\left.\left.) .{ }^{*} 10 . \wedge\left(0.00145 .{ }^{*}(\mathrm{To} 21-400)\right)\right)\right) ; \%\left[\mathrm{~kg} / \mathrm{s} \mathrm{atm}{ }^{\wedge} 1.8 \mathrm{~m}^{\wedge} 3\right]$

Bn $=$ PartLoad_Bn(Load);

FuelFlow $=($ m21.*(h_air(To3)-h_air(To21)))./(HV.*Bn - (h_air(To3))); \% [kg/s]

FA_now $=$ FuelFlow. $/ \mathrm{m} 21 ; \%$ Fuel Flow based on required Transient Fuel to air ratio

\% Part Load Burner Pressure loss Calculation (From Walsh \& Fletcher) 


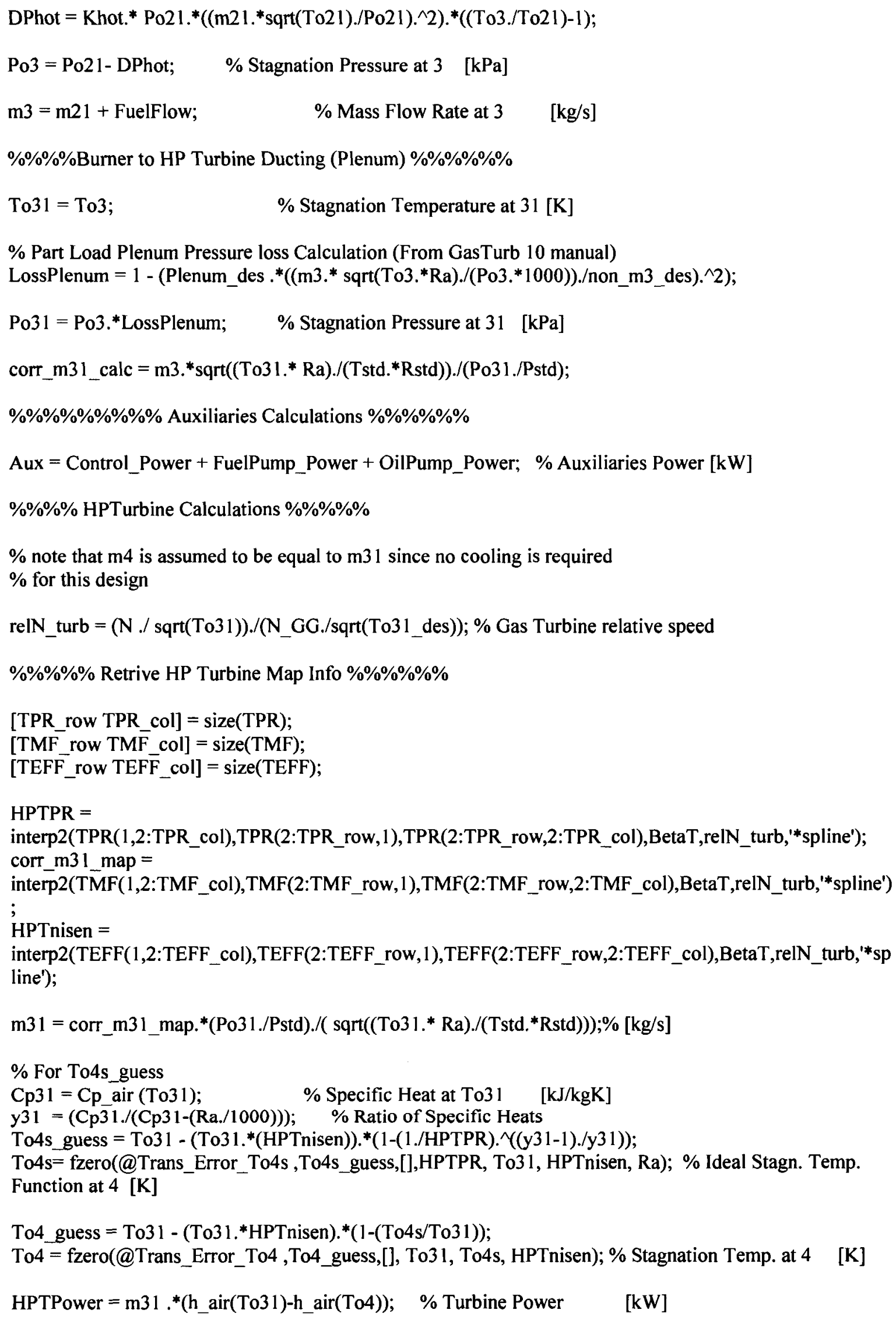


Po4 = Po31./HPTPR; $\quad$ \% Stagnation Pressure at $4 \quad[\mathrm{kPa}]$

$\mathrm{m} 4=\mathrm{m} 31$

$\% \% \% \% \%$ Inter-Turbine Ducting Calculations $\% \%$

$\%$ Duct Pressure Loss Variation

\% Formual Found in GasTurb 10 Manual (Component modelling -- Duct loss)

LossInterTurb $=1$ - (Inter_des .*((m4.* sqrt(To4.*Ra)./(Po4.*1000))./non_m4_des).^2);

Po4l = Po4. ${ }^{*}$ LossInterTurb; $\quad$ \% Stagnation Pressure at $41 \quad[\mathrm{kPa}]$

$\%$ Note that To4l is assumed to be equal to the To4 because we are assuming

$\%$ no heat loss between Turbines. This is an

$\%$ approximation and should be corrected with an accurate value for To41.

To41 = To4; $\quad \%$ Stagnation Temperature at $41[\mathrm{~K}]$

$\% \mathrm{~m} 41=\mathrm{m} 4 ; \quad$ \% Mass Flow Rate at $41 \quad[\mathrm{~kg} / \mathrm{s}]$

corr_m41_calc $=\mathrm{m} 4 .{ }^{*} \operatorname{sqrt}\left(\left(\mathrm{To} 41 .^{*} \mathrm{Ra}\right) . /\left(\mathrm{Tstd} .{ }^{*} \mathrm{Rstd}\right)\right) . /(\mathrm{Po4} 1 . / \mathrm{Pstd})$;

$\% \% \% \% \% \% \% \% \%$ Power Turbine - Gas-Generator Matching \%\%\%\%\%\%\%

relN_PTurb $=\left(\mathrm{N} \_\right.$pt./ sqrt(To4l))./(N_PT./sqrt(To41_des)); \% Power Turbine relative speed

[LTPR_row LTPR_col] = size $(L T P R)$;

[LTMF_row LTMF_col] = size $(\mathrm{LTMF})$;

[LTEFF_row LTEFF_col] = size(LTEFF);

LPTPR = interp2(LTPR(1,2:LTPR_col),LTPR(2:LTPR_row,1),LTPR(2:LTPR_row,2:LTPR_col),BetaLPT,relN_PT urb,'*spline');

corr_m41_map =

interp2(LTMF(1,2:LTMF_col),LTMF(2:LTMF_row,1),LTMF(2:LTMF_row,2:LTMF_col),BetaLPT,relN_ PTurb, ${ }^{\prime *}$ spline');

LPTnisen $=$

interp2(LTEFF(1,2:LTEFF_col),LTEFF(2:LTEFF_row, 1),LTEFF(2:LTEFF_row,2:LTEFF_col),BetaLPT,r elN_PTurb,'*spline');

m41 = corr_m41_map.*(Po41./Pstd)./( sqrt((To41.*Ra)./(Tstd.*Rstd)));\% [kg/s]

$\%$ For To5s guess

Cp41 = Cp_air (To41); $\quad$ \% Specific Heat at To41 [kJ/kgK $]$

$\mathrm{y} 41=(\mathrm{Cp} 41 . /(\mathrm{Cp} 41-(\mathrm{Ra} . / 1000))) ; \quad \%$ Ratio of Specific Heats

To5s_guess=To41 - (To41.*(LPTnisen)).*(1-(1./LPTPR).^((y41-1)./y41));

To5s=fzero(@Trans_Error_To5s,To5s_guess,[],LPTPR, To41, LPTnisen, Ra); \% 1deal Stagn. Temp.

Function at $5[\mathrm{~K}]$

\%for To5 guess

To5_guess = To41 - (To41. ${ }^{*}$ LPTnisen $) . *(1-($ To5s/To41)

To5=fzero(@Trans_Error_To5,To5_guess,[], To41, To5s, LPTnisen); \% Stagnation Temp. at 5 [K]

LPTPower $=m 41 . *\left(h \_a i r(T o 41)-h \_a i r(T o 5)\right) ; \quad$ \% LP Turbine Power $\quad[k W]$

$\% \% \% \% \% \% \% \% \%$ Propeller Power \%\%\%\%\%\%\%\%\%\%\%\%\% 
PropPower $=\left(\right.$ LPTPower_des.*GBn.*Mn) $. *\left(N_{-}\right.$pt ./ N_PT $) . \wedge 3 ; \%$ Propeller load

$\% \% \% \% \% \% \% \% \% \% \% \% \% \% \% \% \% \%$ Exhaust Pressure $\% \% \% \% \% \% \% \%$

$\%$ Duct Pressure Loss Variation

$\%$ Formual Found in GasTurb 10 Manual (Component modelling -- Duct loss)

$\mathrm{m} 5=\mathrm{m} 41$

Po5= P041./LPTPR; $\quad$ \% Stagnation Pressure at $5 \quad$ [kPa]

ExhaustLoss_RHS = (1 - Poa./Po5); \% Right hand side Exhaust Loss Eqn

ExhaustLoss_LHS $=\left(\right.$ ExhaustLoss_des. ${ }^{*}\left(\left(\mathrm{~m} 5 . * \operatorname{sqrt}\left(T o 5 .{ }^{*} \mathrm{Ra}\right) . /\left(\right.\right.\right.$ Po5. $\left.\left.{ }^{*} 1000\right)\right) . /$ non_m5_des $\left.) .{ }^{\wedge} 2\right) ; \%$ Left hand side Exhaust Loss Eqn

$\% \% \% \% \% \% \% \% \% \%$ Engine Performance $\% \% \% \% \% \% \% \%$

ShaftPower $=$ LPTPower .* Mn .*GBn; $\quad$ \% Net Shaft Power

SFC_SI $=($ FuelFlow ./ ShaftPower $){ }^{*} 3600 ; \quad \%$ Specific Fuel Consumption $\quad[\mathrm{kg} / \mathrm{kWh}]$

SFC_Brith $=($ FuelFlow ./ ShaftPower $) .{ }^{*} 3600 . * 1.643987 ; \%$ Specific Fuel Consumption [lb/hphr]

Thermal_Efficiency $=$ ShaftPower./(FuelFlow.*HV); \% Engine Overall Efficiency

$\% \% \% \% \% \% \% \% \% \% \% \% \% \% \% \% \%$ Setup $\% \% \% \% \% \% \% \% \% \% \% \% \% \%$

$\%$ Errors

$\mathrm{F}(1, \mathrm{count})=($ corr_m31_calc - corr_m31_map $) ; \%$ Compatibility of Flow

$\mathrm{F}(2$, count $)=\left(\right.$ CPower - (HPTPower. ${ }^{*}$ Mn-P_off) $) . / 1000 ; \%$ Compatibility of Work

$\mathrm{F}(3$, count $)=$ (corr m41 calc - corr m41 map); \% Turbine Compatibility of FLow

$F(4$, count $)=($ ExhäustLoss_LHS - ExhaustLoss_RHS $)$;

$\mathrm{F}(5$, count $)=$ (PropPower - ShaftPower)./1000;

$F(6$, count $)=(P R c-P R c$ test $)$;

end

$f=F(:, I)$

$\% \%$ Setup Jacobian

for count $1=1: \operatorname{size}($ xguess, 1$)-1$

for count $2=1$ :size(xguess, 1$)-1$;

$\mathrm{dF}($ count 1, count 2$)=(\mathrm{F}($ count $1,($ count $2+1))-\mathrm{F}($ count 1,1$)) . /(\operatorname{ep}($ count 2$))$;

end

end

$\mathrm{J}=\mathrm{dF}$

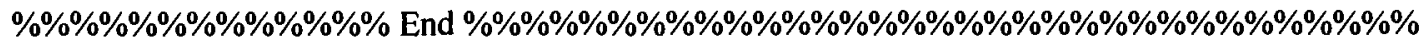


$\%$ This script calculates off design performance parameters along a

$\%$ Constant TIT limit. This data will be used to detemine the TIT fuel limits

$\%$ note that to get this data, we are using a modified version of

$\%$ MP_OffDesign_load. A PowerOfftake term has been added to the calculations.

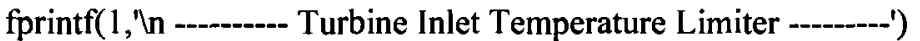

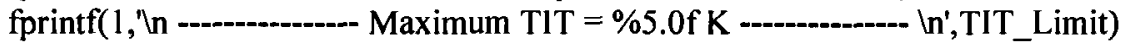

BetaC_guess = OffDesign_Data_load $(1,10)$;

BetaT_guess = OffDesign_Data_load $(1,26)$;

BetaPT_guess $=$ OffDesign_Data_load $(1,37)$;

TIT_guess = OffDesign_Data_load $(1,17)$;

Npt guess = OffDesign Data load $(1,36)$;

m_guess = OffDesign_Data_load $(1,4)$;

$\mathrm{x} \_$guess $=\left[\right.$BetaC_guess BetaT_guess TIT_guess BetaPT_guess Npt_guess $\left.1 \mathrm{~m} \_g u e s s\right]$;

$\% \mathrm{x}$ guess $=[$ BetaC BetaT TIT BetaPT Npt PowerOfftake ma_guess $]$

relN = OffDesign_Data_load(:,9);;

for $\mathrm{jj}=1$ :size $(\mathrm{relN}, 1)$

relN_now = relN(jj);

fprintf( 1, 'n Calculating relN $=\% 4.3 \mathrm{f}^{\prime}$,relN now)

Newton = MP_NewtonRap l(relN_now, $x$ _guess,TIT_Limit);

$\mathbf{x}$ guess $=[$ Newton(1:7)];

$\%$ rearrange matirx to add $\mathrm{TIT}$ and relN

$\mathrm{A}=[$ relN_now Newton(1:8)]; \% [BetaC BetaT TIT relN BetaLPT ma_guess Error]

$\%$ Boundary conditions

bound Check $=\mathrm{A}(1: 2)>1.05$;

if $\max$ (bound Check) $==1$

fprintf $\left(1\right.$, 'n $^{* * * * * *}$ Calculation out of range $\left.{ }^{* * * * * * \prime}\right)$

if $\mathrm{jj}>1$

fprintf( $\left(1, ' \ln \backslash n\right.$ Calculation stopped at relN $=\% 4.3 f^{\prime}$, relN(jj-1))

else

fprintf(1,'Inın Calculation stopped at first iteration')

end

continue

end

$\%$ Boundary conditions

bound_Check2 $=\mathrm{A}(3)>2200$;

if $\max$ (bound_Check2) $=1$

fprintf $\left(1, \ln * * * * * * *\right.$ Calculation out of range $\left.{ }^{* * * * * * * \prime}\right)$

if $\mathrm{jj}>1$

fprintf( $1, '$ In $\backslash n$ Calculation stopped at relN $=\% 4.3 f^{\prime}$, relN(jj-1))

else

fprintf( 1, , $\ln \ln$ Calculation stopped at first iteration')

end

continue

end 


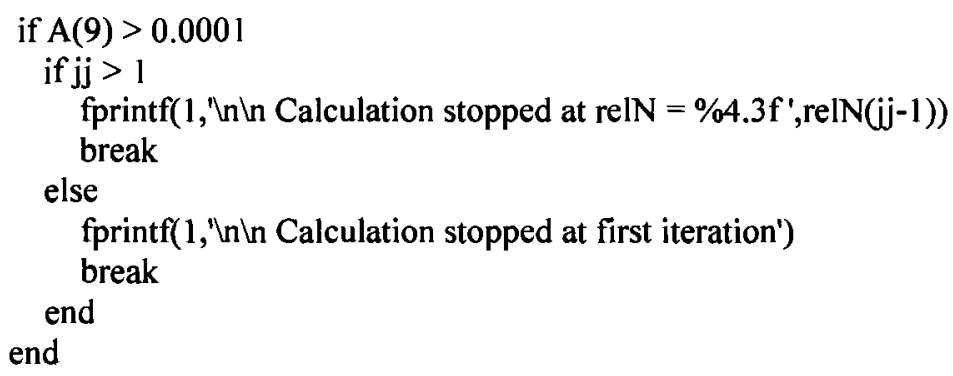

TITLimit_Data(jj,:) = MP_Calc_TITLimit(A);

$\%$ TITLimit_Data $==[$ Toa Poa corr_ml m1 Tol Po1 Cnisen N relN BetaC PRe m2 To2 Po2 CPower m3 To3 Po3...

$\% \quad$ Bn FuelFlow corr_m31_calc m31 Po31 HPTnisen relN_turb BetaT HPTPR HPTPower m4 To4 Po4...

$\% \quad \mathrm{~m} 41$ To41 Po41 corr_m4l_calc N_pt relN_PTurb BetaLPT LPTPR LPTnisen m5 To5 Po5

LPTPower PropPower ShaftPower SFC_SI...

$\% \quad$ Thermal_Efficiency Error_square P_off];

end

$\% \% \% \%$ TIT Protective Control \%\%\%\%

$\%$ Usually when hig temperature are reached a control system would shutdown

$\%$ the engine this is called a Shutdown control

$\%$ On the other hand a modulating control senses an upcoming malfunction and

$\%$ eliviates the problem by reducing the input (Fuel FLow or RPM demand)

$\%$ we will be using a Modualting control

$\%$ since the engine is protected by a fuel schedule from 0 to TIT Limit we

$\%$ only need to protect from TIT Limit to Overtemp

TIT_protect $=[0$ TIT_Limit OverTemp OverTemp+50]; \% [K]

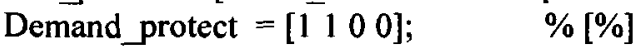

TIT range $=[0:$ OverTemp +50$]$;

Demand_Control $=$ Interpl $($ TIT_protect,Demand_protect,TIT_range,'pchip');

fprintf(1, 'Inln --:--- $\ln$ ')

\%\%\%\%\%\%\%\%\%\%\%\%\%\%\%\%\%\%\%\%\%\% End \%\%\%\%\%\%\%\%\%\%\%\%\%\%\%\%\%\%\%\%\%\%\%\%\%\%

$\% \% \% \% \% \% \% \% \% \% \% \% \% \% \%$ MP_NewtonRap1.m $\% \% \% \% \% \% \% \% \% \% \% \% \% \% \% \% \% \%$

$\%$ Off Design Operating line calculation

\%\%\%\%\%\%\%\%\%\%\%\%\%\%\%\%\%\%\%\%\%\%\%\%\%\%\%\%\%\%\% NOTES

\%\%\%\%\%\%\%\%\%\%\%\%\%\%\%\%\%\%\%\%\%\%\%\%\%\%\%\%\%\%\%\%\%\%

\% Source: Turns " An Intoduction To Combustion

$\%$ 2nd edition " Appendix E

\% Also " Numerical Methods with Matlab" sec 8.5 
\% PT with load

\%\%\%\%\%\%\%\%\%\%\%\%\%\%\%\%\%\%\%\%\%\%\%\%\%\%\%\%\%\%\% INPUTS

\%\%\%\%\%\%\%\%\%\%\%\%\%\%\%\%\%\%\%\%\%\%\%\%\%\%\%\%\%\%\%\%\%

$\%$ relN = Compressor Relative Speed

$\%$ TIT_now $=$ Turbine inlet Temperature $[\mathrm{K}]$

\%\%\%\%\%\%\%\%\%\%\%\%\%\%\%\%\%\%\%\%\%\%\%\%\%\%\%\%\%\%\% OUTPUTS

\%\%\%\%\%\%\%\%\%\%\%\%\%\%\%\%\%\%\%\%\%\%\%\%\%\%\%\%\%\%\%\%

$\%$ AMatrix $=[$ BetaC BetaT ma $]$

\%\%\%\%\%\%\%\%\%\%\%\%\%\%\%\%\%\%\%\%\%\%\%\%\%\%\%\%\% Calculations \%\%\%\%\%\%\%\%\%\%\%\%\%\%\%\%\%\%\%\%\%\%\%\%\%\%\%\%\%\%

function AMatrix= MP_NewtonRap1(relN,x_guess,TIT_Lmt)

F old $=0$;

$\mathrm{k}=1$;

\% Initial Guess [BetaC BetaT TIT BetaLPT N_pt P_off ma_guess]

$\mathrm{x}=\left[\mathrm{x} \_\right.$guess $\left.(1: 6)\right]$

ma_guess $=x$ _guess $(7)$;

$\%$ Outer Loop used in case the simulation diverges

while $\mathrm{k}<75$

$\mathrm{k}=\mathrm{k}+1$

\%\%\%\%\%\%\%\%\%\%\%\%\%\%\%\%\%\%\%\%\%\%\%\%\%\%\% Jacobian matrix \%\%\%\%\%\%\%\%\%\%\%\%\%\%\%\%\%\%\%\%\%\%\%\%\%\%\%\%\%

$\%$ Setup of the Jacobian Matrix

$[F, J, m l]=$ MP_Jacob1(relN,x,ma_guess,TIT_Lmt);

\% Solve using Gauss Elimination (in MatLab this is donw using "I")

$\mathrm{dx}=(\mathrm{J} F)$;

\%\%\%\%\%\%\%\%\%\%\%\%\%\%\%\%\%\%\%\%\%\%\%\%\%\%\%\%\%\%\% Damping \%\%\%\%\%\%\%\%\%\%\%\%\%\%\%\%\%\%\%\%\%\%\%\%\%\%\%\%\%\%\%\%\%

ma guess $=\mathrm{m} 1$

$\%$ this process is used to enable better conevergence

if $(\operatorname{norm}(\operatorname{abs}(F)))>\left(\right.$ norm $\left.\left(\operatorname{abs}\left(F \_o l d\right)\right)\right)$

end

$$
\mathrm{dx}=\mathrm{dx} . / 5 \text {; }
$$

F_old $=F$; 


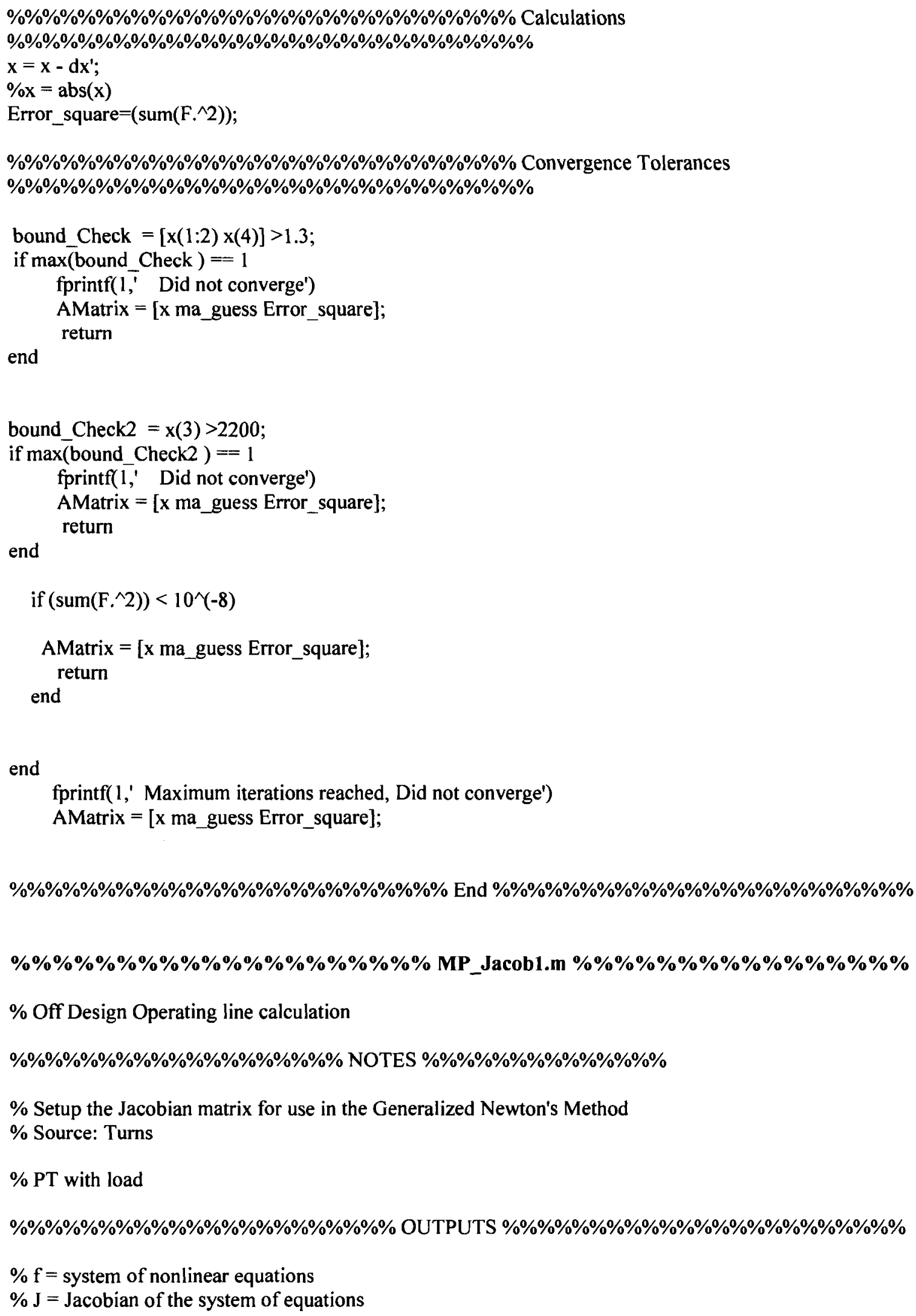




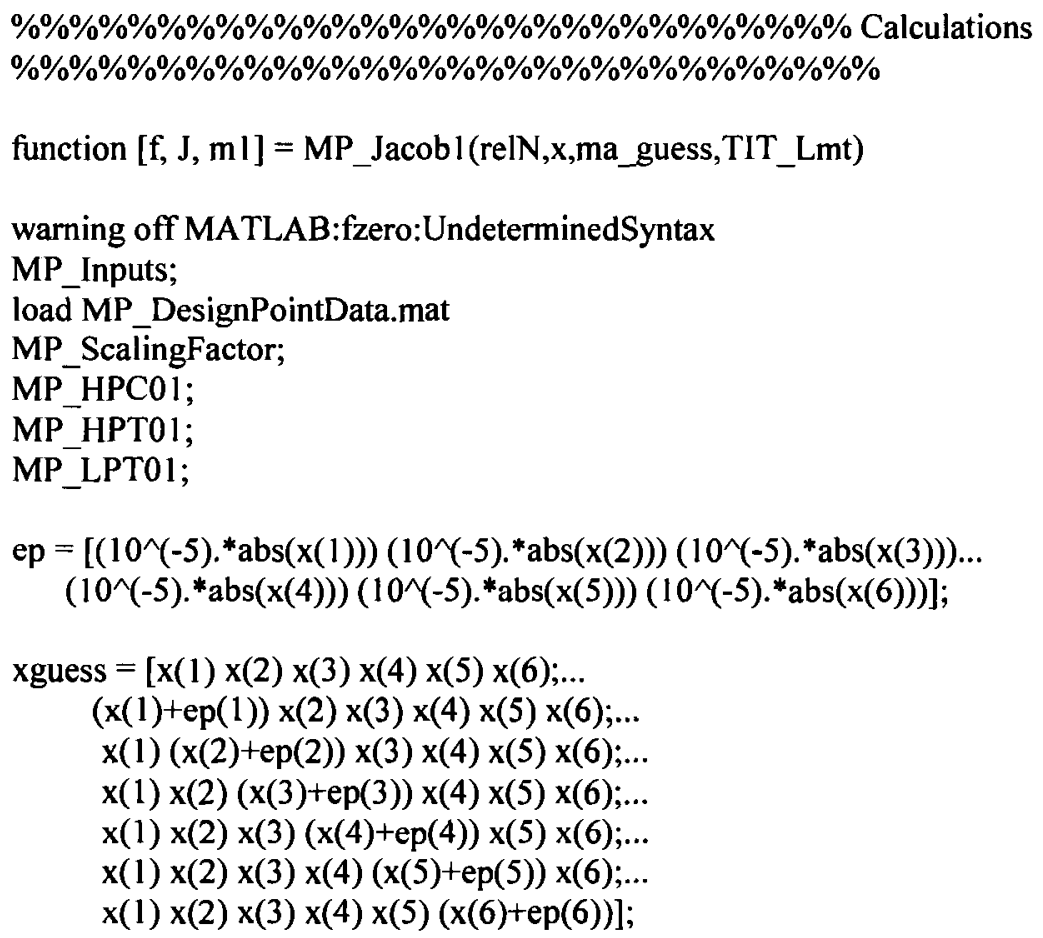

for count= 1 :size(xguess, 1 )

BetaC $=$ xguess $($ count, 1$)$;

BetaT $=x$ guess $($ count, 2$)$;

TIT_now = xguess $($ count, 3$)$;

BetaLPT $=$ xguess(count,4);

$\mathrm{N} \_$pt $=$xguess $($count, 5$)$;

P_off $=$ xguess $($ count, 6$)$;

$\% \% \%$ Thermo. Calculations for Simple Cycle Twin-Shaft $1 \mathrm{MW}$ Gas Turbine \%\%\%

$\%$ note that there is no disc cooling, customer bleeds, blade cooling, NGV cooling and leakage $\%$ considered in this code.

$\%$ Also note that Dry Air is assumed for calculation

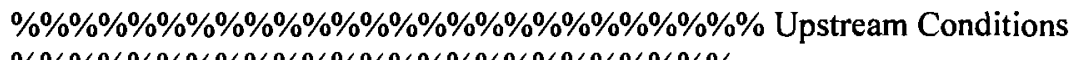
\%\%\%\%\%\%\%\%\%\%\%\%\%\%\%\%\%\%\%\%\%\%\%\%\%

$\mathrm{Cpamb}=\mathrm{Cp}$ _air(Tamb); \% Ambient Specific Heat $\quad[\mathrm{kJ} / \mathrm{kgK}]$

yamb $=($ Cpamb./(Cpamb-(Ra/kJ))); \% Ratio of Specific Heats

$\mathrm{Ta}=\mathrm{Tamb} ; \quad$ \% Static Temperature at a $\quad[\mathrm{K}]$

$\mathrm{Toa}=\mathrm{Ta}+\left(\left(\mathrm{V} .{ }^{*} \mathrm{~km} \_\mathrm{hr}\right) . \wedge 2 /\left(2 .{ }^{*} \mathrm{Cpamb}^{*} 1000\right)\right) ; \%$ Stagnation Temperature at a $[\mathrm{K}]$

$\mathrm{Pa}=\mathrm{Pamb} / \mathrm{kPa} ; \quad \%$ Static Presure at a $\quad[\mathrm{kPa}]$

$\mathrm{Poa}=\mathrm{Pa} .{ }^{*}(\mathrm{Toa} . / \mathrm{Ta}) \wedge($ yamb. $/($ yamb-1) $) ; \quad \%$ Stagnation Pressure at a $[\mathrm{kPa}]$

\%\%\%\%\%\%\%\%\%\%\%\%\%\%\%\%\%\%\%\%\%\%\% Retrive Compressor Map Info \%\%\%\%\%\%\%\%\%\%\%\%\%\%\%\%\%\%\%\%\%\%\%\% 
[PR_row $P R \_$col $]=\operatorname{size}(\mathrm{PR})$;

$[\mathrm{MF}$ row $\mathrm{MF}$ col] = size $(\mathrm{MF})$;

$\left[E F F \_\right.$row $E F \bar{F} \_$col $]=\operatorname{size}(E F F)$;

PRc = interp2(PR(1,2:PR_col),PR(2:PR_row, 1),PR(2:PR_row,2:PR_col),BetaC,relN,'*spline');

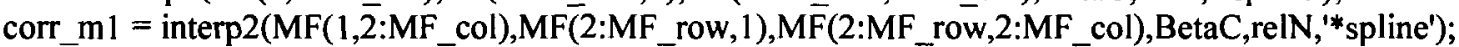

Cnisen $=$ interp2(EFF(1,2:EFF_col),EFF(2:EFF_row,1),EFF(2:EFF_row,2:EFF_col),BetaC,relN,'*spline');

\%\%\%\%\%\%\%\%\%\%\%\%\%\%\%\%\%\%\%\%\%\%\% Engine Intake Conditions

\%\%\%\%\%\%\%\%\%\%\%\%\%\%\%\%\%\%\%\%\%\%\%\%

Tol $=$ Toa; $\quad \%$ Stagnation Temperature at $1[\mathrm{~K}]$

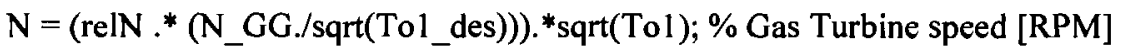

$\%$ Part Load Intake Pressure loss Calculation (From GasTurb 10 manual)

LossIntake = 1 - (IntakeLoss_des .*((ma_guess.* sqrt(Toa.*Ra)./(Poa.*1000))./non_ma_des).^2);

Pol $=$ LossIntake ${ }^{*}$ Poa;

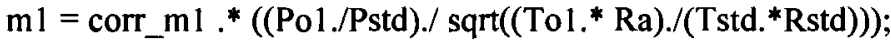

\%\%\%\%\%\%\%\%\%\%\%\%\%\%\%\%\%\%\%\%\%\%\% Compressor Calculations

$\% \% \% \% \% \% \% \% \% \% \% \% \% \% \% \% \% \% \% \% \% \% \% \%$

To2s_guess $=$ To1 $+($ Tol./(Cnisen $)){ }^{*}\left(\right.$ PRc. ${ }^{\Upsilon}(($ yamb-1)./yamb $)-1)$

To2s=fzero(@Trans_Error_To2s,To2s_guess,[],PRc, To1, Cnisen, Ra);\% Ideal Stagn. Temp. Function at $2[\mathrm{~K}]$

To2_guess $=$ To1 $+($ To1./Cnisen $){ }^{*}(($ To2s. $/$ To1 $)-1) ;$

To2=fzero(@Trans_Error_To2,To2_guess,[], To1, To2s, Cnisen); \% Real Stagn. Temp Function at 2 [K]

Po2 $=$ Po1.*PRc; $\quad \%$ Stagnation Pressure at $2 \quad[\mathrm{kPa}]$

$\mathrm{m} 2=\mathrm{m} 1 .^{*}(1-\mathrm{Bc}) ; \quad$ \% Compressor Discharge Mass Flow Rate

CPower $=\mathrm{m} 1 . *\left(\mathrm{~h} \_\right.$air(To2)-h_air(To1)); \% Compressor Power $\quad[\mathrm{kW}]$

$\% \% \% \% \% \% \% \% \% \% \% \% \% \% \% \% \% \% \% \% \% \% \% \% \% \% \% \%$ Compressor to Burner Ducting \%\%\%\%\%\%\%\%\%\%\%\%\%\%\%\%\%\%\%\%\%\%\%\%\%\%\%

Po21 $=$ Po2.*(1 - CompToBurn_Delta_P $) ; \quad \%$ Stagnation Pressure at $21 \quad[\mathrm{kPa}]$

$\%$ Note that To21 is assumed to be equal to the To2 because we are assuming

$\%$ no heat loss between the Compressor and the Burner. This is an

$\%$ approximation and should be corrected with an accurate value for To21.

To21 = To2; $\quad \%$ Stagnation Temperature at $21[\mathrm{~K}]$

$\mathrm{m} 21=\mathrm{m} 2 ; \quad$ \% Mass Flow Rate at $21 \quad[\mathrm{~kg} / \mathrm{s}]$

\%\%\%\%\%\%\%\%\%\%\%\%\%\%\%\%\%\%\%\% Combustion Chamber (Burner) Calculations

\%०\%\%\%\%\%\%\%\%\%\%\%\%\%\%\%\%\%\%\%\% 
$\%$ Note that To 3 is assumed to be equal to the TIT because we are assuming

$\%$ no heat loss between the burner and the HP turbine. This is an

$\%$ approximation and should be corrected with an accurate value for To3.

To3 = TIT_now;

\% Part Load Burner Efficency Calculation (From Walsh \& Fletcher)

Load $=\left(\mathrm{m} 21 . /\left(\left((\mathrm{Po} 21 . / 101.325)^{\wedge} 1.8 .{ }^{*} \mathrm{Vcomb}\right) .{ }^{*} 10 . \wedge\left(0.00145 .{ }^{*}(\mathrm{To} 21-400)\right)\right)\right) ; \%\left[\mathrm{~kg} / \mathrm{s} \mathrm{atm}{ }^{\wedge} 1.8 \mathrm{~m}^{\wedge} 3\right]$

$\mathrm{Bn}=$ PartLoad_Bn(Load);

FuelFlow $=\left(m 21 . *\left(h \_a i r(T o 3)-h \_a i r(T o 21)\right)\right) . /\left(H V . * B n-\left(h \_a i r(T o 3)\right)\right) ; \%[k g / s]$

FA_now $=$ FuelFlow. $/ \mathrm{m} 21 ; \%$ Fuel Flow based on required Transient Fuel to air ratio

\% Part Load Burner Pressure loss Calculation (From Walsh \& Fletcher)

DPhot $=$ Khot. ${ }^{*}$ Po21.*((m21.**sqt(To21)./Po21).^2).*((To3./To21 )-1);

Po3 = Po21-DPhot; \% Stagnation Pressure at $3 \quad[\mathrm{kPa}]$

$\mathrm{m} 3=\mathrm{m} 21+$ FuelFlow; $\quad \%$ Mass Flow Rate at $3 \quad[\mathrm{~kg} / \mathrm{s}]$

\%\%\%\%\%\%\%\%\%\%\%\%\%\%\%\%\%\%\%\% Burner to HP Turbine Ducting (Plenum)

$\% \% \% \% \% \% \% \% \% \% \% \% \% \% \% \% \% \% \%$

To31 $=$ To3; $\quad$ \% Stagnation Temperature at $31[\mathrm{~K}]$

\% Part Load Plenum Pressure loss Calculation (From GasTurb 10 manual)

LossPlenum = 1 - (Plenum_des .*((m3.* sqrt(To3.*Ra)./(Po3.*1000))./non_m3_des).^2);

Po31 = Po3. ${ }^{*}$ LossPlenum; $\quad \%$ Stagnation Pressure at $31 \quad[\mathrm{kPa}]$

corr_m31_calc $=$ m3.*sqrt((To31.* Ra)./(Tstd.*Rstd))./(Po31./Pstd);

\%\%\%\%\%\%\%\%\%\%\%\%\%\%\%\%\%\%\%\%\%\%\% Auxiliaries Calculations

$\% \% \% \% \% \% \% \% \% \% \% \% \% \% \% \% \% \% \% \% \% \% \% \% \% \% \% \% \%$

Aux $=$ Control_Power + FuelPump_Power + OilPump_Power; \% Auxiliaries Power $[\mathrm{kW}]$

\%\%\%\%\%\%\%\%\%\%\%\%\%\%\%\%\%\%\%\%\%\%\%\%\%\%\%\% HPTurbine Calculations

\%\%\%\%\%\%\%\%\%\%\%\%\%\%\%\%\%\%\%\%\%\%\%\%\%\%\%

$\%$ note that $\mathrm{m} 4$ is assumed to be equal to $\mathrm{m} 31$ since no cooling is required

$\%$ for this design

relN_turb $=(\mathrm{N} . /$ sqrt(To31))./(N_GG./sqrt(To31_des)); \% Gas Turbine relative speed

$\% \% \% \% \% \% \% \% \% \% \% \% \% \% \% \% \% \% \% \% \% \% \%$ Retrive HP Turbine Map Info

$\% \% \% \% \% \% \% \% \% \% \% \% \% \% \% \% \% \% \% \% \% \% \% \%$

[TPR_row TPR_col] $=$ size $(\mathrm{TPR})$;

[TMF_row $T M \bar{F} \_$col] = size $(T M F)$;

$[\mathrm{TEFF}$ _row TEFF_col] $=$ size $(\mathrm{TEFF})$;

$\mathrm{HPTPR}=$

interp2(TPR(1,2:TPR_col),TPR(2:TPR_row,1),TPR(2:TPR_row,2:TPR_col),BetaT,relN_turb,'*spline'); 


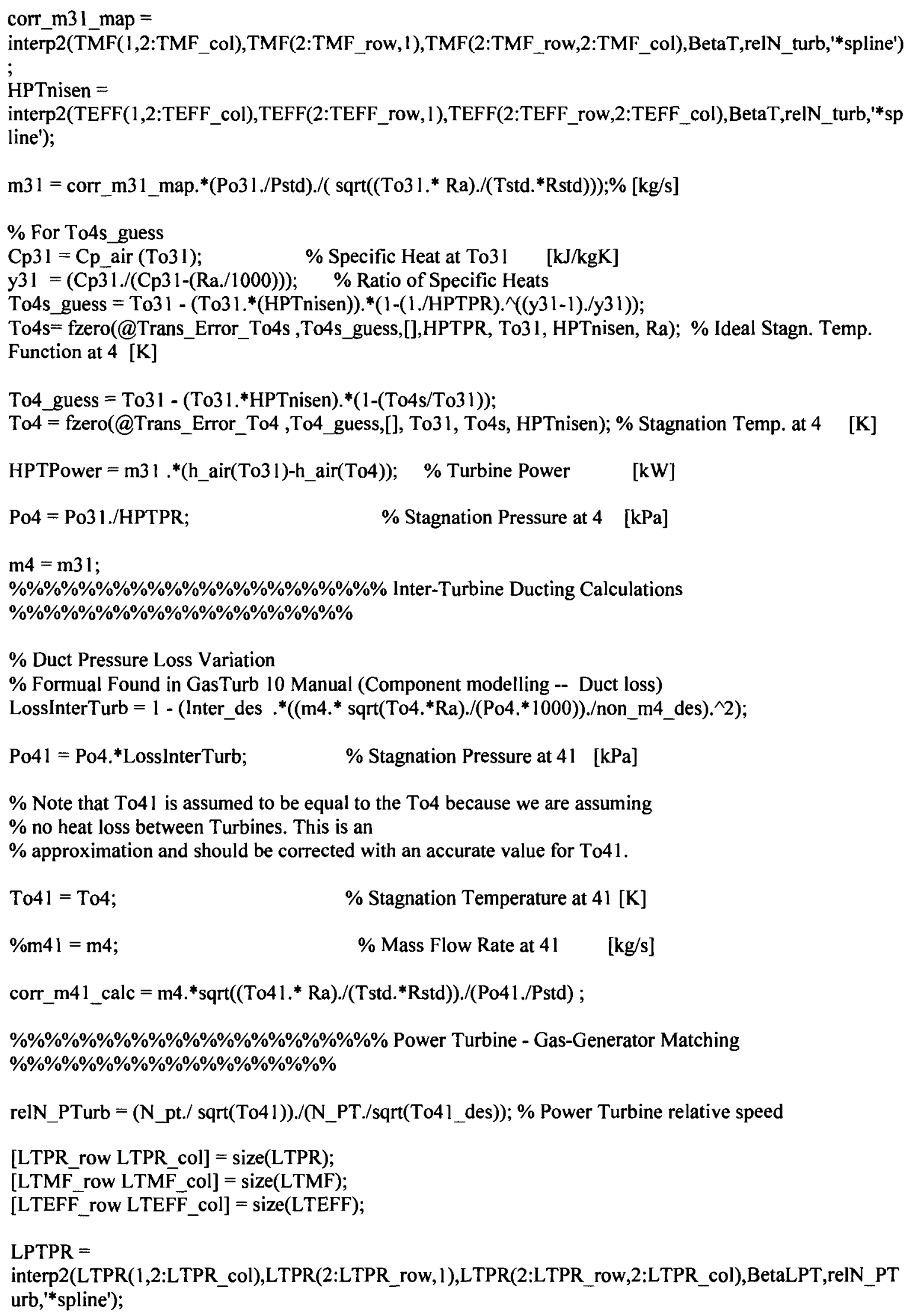


corr_m41_map $=$

interp2(LTMF(1,2:LTMF_col),LTMF(2:LTMF_row,1),LTMF(2:LTMF_row,2:LTMF_col),BetaLPT,relN_ PTurb,'*spline');

LPTnisen $=$

interp2(LTEFF(1,2:LTEFF_col),LTEFF(2:LTEFF_row,1),LTEFF(2:LTEFF_row,2:LTEFF_col),BetaLPT,r elN_PTurb,'*spline');

m41 = corr_m41_map.*(Po41./Pstd)./( sqrt((To41.* Ra)./(Tstd.*Rstd)));\% [kg/s]

$\%$ For To5s_guess

Cp4l = Cp_air (To4l); $\quad$ \% Specific Heat at To41 [kJ/kgK $]$

y41 $=(\mathrm{Cp} 41 . /(\mathrm{Cp} 41-(\mathrm{Ra} . / 1000))) ; \quad \%$ Ratio of Specific Heats

To5s_guess $=$ To41 - $($ To4 1.*(LPTnisen $)) . *(1-(1 . / L P T P R) . \wedge((y 41-1) . / y 41))$;

To5s= fzero(@Trans_Error_To5s,To5s_guess,[],LPTPR, To41, LPTnisen, Ra); \% Ideal Stagn. Temp.

Function at $5[\mathrm{~K}]$

$\%$ for To5 guess

To5 guess $=$ To41 - (To41.*LPTnisen).*(1-(To5s/To41));

To5=fzero(@Trans_Error_To5,To5_guess,[], To4 1, To5s, LPTnisen); \% Stagnation Temp. at 5 [K]

LPTPower $=m 41 . *\left(h \_\right.$air(To41)-h_air(To5)); $\quad$ \% LP Turbine Power $\quad[k W]$

\%\%\%\%\%\%\%\%\%\%\%\%\%\%\%\%\%\%\%\%\%\%\%\%\%\%\% Propeller Power

$\% \% \% \% \% \% \% \% \% \% \% \% \% \% \% \% \% \% \% \% \% \% \% \% \% \%$

PropPower $=\left(\right.$ LPTPower_des. $\left.{ }^{*} \mathrm{GBn} .{ }^{*} \mathrm{Mn}\right) .{ }^{*}\left(\mathrm{~N} \_\mathrm{pt} . / \mathrm{N} \_\mathrm{PT}\right) . \wedge 3 ; \%$ Propeller load $\quad[\mathrm{kW}]$

$\% \% \% \% \% \% \% \% \% \% \% \% \% \% \% \% \% \% \% \% \% \% \% \% \% \% \%$ Exhaust Pressure

$\% \% \% \% \% \% \% \% \% \% \% \% \% \% \% \% \% \% \% \% \% \% \% \% \% \%$

$\%$ Duct Pressure Loss Variation

\% Formual Found in GasTurb 10 Manual (Component modelling -- Duct loss)

$\mathrm{m} 5=\mathrm{m} 41$

Po5= Po4 1./LPTPR; $\quad$ \% Stagnation Pressure at 5 [kPa

ExhaustLoss_RHS $=(1$ - Poa./Po5); \% Right hand side Exhaust Loss Eqn

ExhaustLoss_LHS $=\left(\right.$ ExhaustLoss_des.* $\left(\left(\mathrm{m} 5 .{ }^{*}\right.\right.$ sqrt(To5.*Ra)./(Po5.*1000))./non_m5_des).^2); \% Left hand side Exhaust Loss Eqn

$\% \% \% \% \% \% \% \% \% \% \% \% \% \% \% \% \% \% \% \% \% \% \% \% \%$ Engine Performance

$\% \% \% \% \% \% \% \% \% \% \% \% \% \% \% \% \% \% \% \% \% \% \% \% \% \% \%$

ShaftPower $=$ LPTPower .* Mn .* GBn; $\quad$ \% Net Shaft Power $\quad[k W]$

SFC_SI $=($ FuelFlow.$/$ ShaftPower $) . * 3600 ; \quad \%$ Specific Fuel Consumption $[\mathrm{kg} / \mathrm{kWh}]$

SFC_Brith $=\left(\right.$ FuelFlow ./ ShaftPower). ${ }^{*} 3600 .{ }^{*} 1.643987 ; \%$ Specific Fuel Consumption $\quad[\mathrm{lb} / \mathrm{hphr}]$

Thermal_Efficiency $=$ ShaftPower./(FuelFlow. ${ }^{*}$ HV); $\quad \%$ Engine Overall Efficiency

\%\%\%\%\%\%\%\%\%\%\%\%\%\%\%\%\%\%\%\%\%\%\%\%\%\%\%\%\%\%\%\%\%\%\%\%\%\%\% Setup

\%\%\%\%\%\%\%\%\%\%\%\%\%\%\%\%\%\%\%\%\%\%\%\%\%\%\%\%\%\%\%\%\%\%\%\%

$\%$ Errors 
$F(1$, count $)=($ corr_m31_calc - corr_m31_map $) ; \%$ Compatibility of Flow

$\mathrm{F}(2$, count $)=\left(\right.$ CPower $-\left(\right.$ HPTPower. ${ }^{*}$ Mn-P_off $\left.)\right) . / 1000 ; \%$ Compatibility of Work

$\mathrm{F}(3$, count $)=($ corr $\mathrm{m} 4 \mathrm{l}$ calc - corr $\mathrm{m} 41$ map $) ; \%$ Turbine Compatibility of FLow

$\mathrm{F}(4$, count $)=($ ExhaustLoss_LHS - ExhaustLoss_RHS $)$;

$\mathrm{F}(5$, count $)=$ (PropPower - ShaftPower $). / 1000$;

$\mathrm{F}(6$, count $)=\left(\right.$ TIT_now $-\mathrm{TIT} \_$Lmt $)$;

end

$f=F(:, 1)$

$\% \%$ Setup Jacobian

for count $1=1$ :size(xguess, 1$)-1$

for count2 = 1 :size(xguess, 1$)-1$;

$\mathrm{dF}(\operatorname{count} 1, \operatorname{count} 2)=(\mathrm{F}(\operatorname{count} 1,(\operatorname{count} 2+1))-\mathrm{F}(\operatorname{count} 1,1)) . /(\operatorname{ep}(\operatorname{count} 2)) ;$ end

end

$\mathrm{J}=\mathrm{dF}$

\%\%\%\%\%\%\%\%\%\%\%\%\%\%\%\%\%\%\%\%\% End \%\%\%\%\%\%\%\%\%\%\%\%\%\%\%\%\%\%\%\%\%\%\%\%\%\%\%

$\% \% \% \% \% \% \% \% \% \% \% \% \% \%$ MP_FlameoutLimit.m $\% \% \% \% \% \% \% \% \% \% \% \% \% \% \% \% \% \% \%$

$\%$ This script calculates off design performance parameters along a

$\%$ Constant FA limit. This data will be used to detemine the FlameOut fuel limits

$\% \% \%$ Note $\% \% \%$

$\%$ note that to get this data, we are using a modified version of

$\%$ MP_OffDesign_load. A PowerOfftake term has been added to the calculations.

\%Fuel to air ratio should be greater than 0.008 during transient

\%operations (Walsh \& Fletcher Gas Turbine Performance Page 456)

fprintf(1, $1 \mathrm{n}$ Fuel to Air Ratio Limiter

fprintf(1, $1 \mathrm{n}$ Minimum Transient FA $=\% 6.4 \mathrm{f}$ (n',FA_Limit)

if FA_Limit $<0.008$

fprintf $(1,1 \mathrm{n} * * * * * * * * * * * * * * * * * * * * * * * * *$ Note

fprintf(1,'n FA ratio should be $>0.008$ during transient operation ')

fprintf $\left(1, \ln * * * * * * * * * * * * * * * * * * * * * * * * * * * * * * * * * * * * * * * * * * * * * * * * * * * * \ln { }^{\prime}\right)$

end

BetaC_guess = OffDesign_Data_load $(1,10)$

BetaT_guess = OffDesign_Data_load $(1,26)$; 


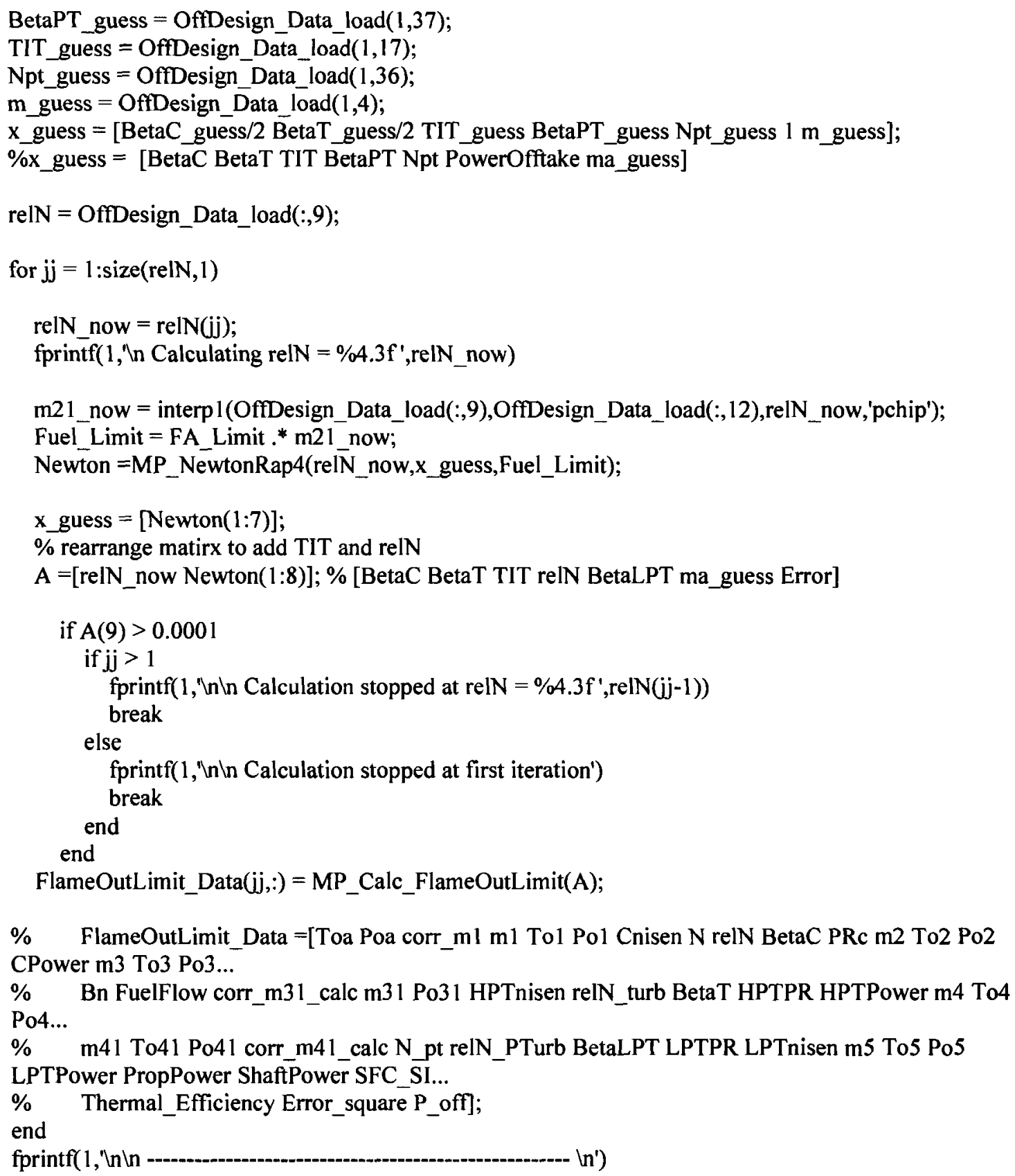




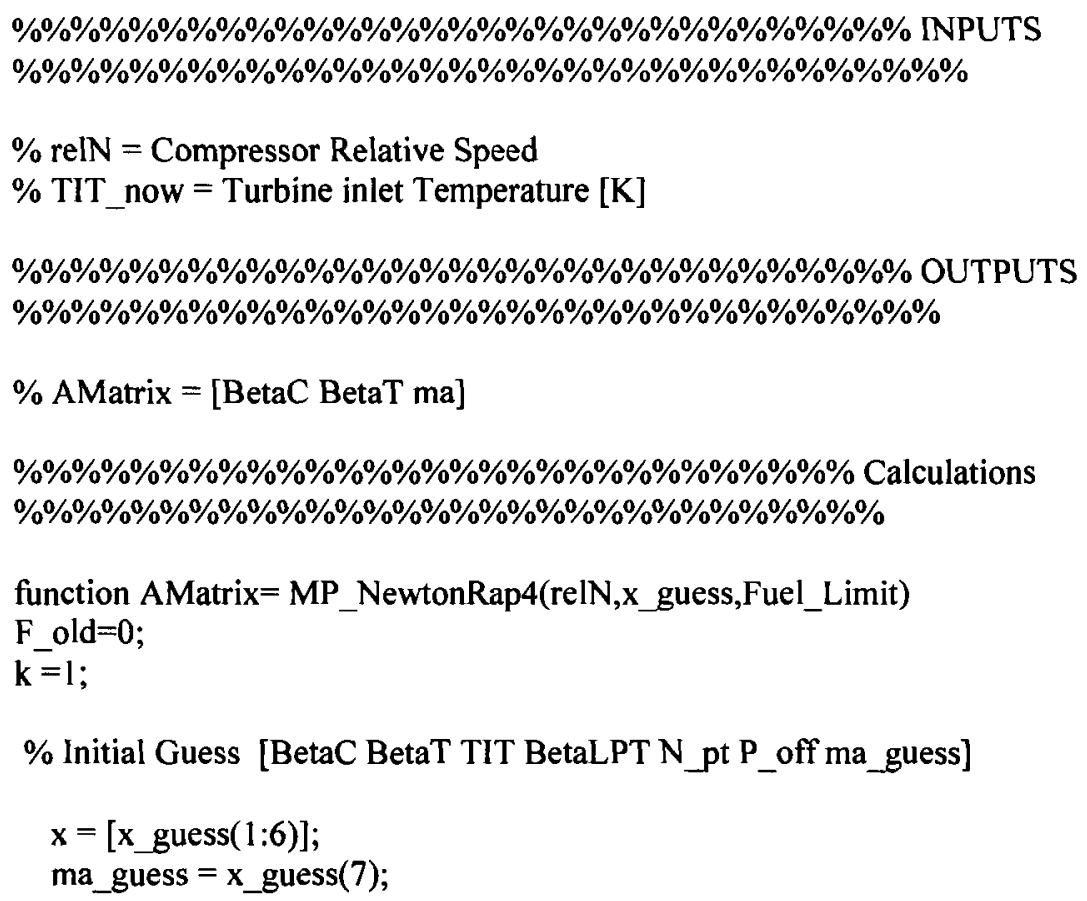




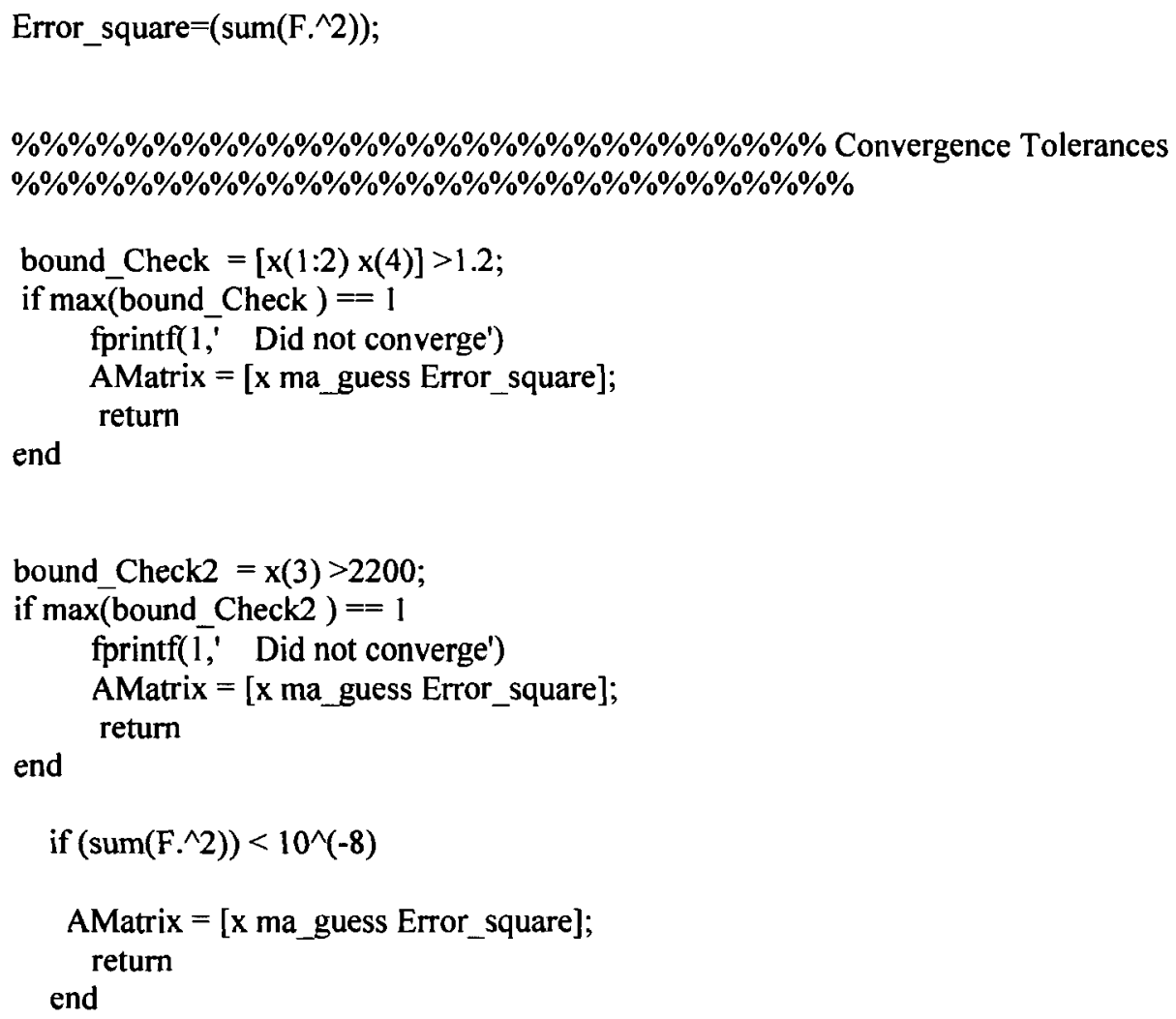

end

fprintf( 1, ' Maximum iterations reached, Did not converge')

AMatrix $=[x$ ma_guess Error_square $]$;

\%\%\%\%\%\%\%\%\%\%\%\%\%\%\%\%\%\%\%\%\%\%\% End \%\%\%\%\%\%\%\%\%\%\%\%\%\%\%\%\%\%\%\%\%\%\%\%\%

$\% \% \% \% \% \% \% \% \% \% \% \% \% \% \% \% \%$ MP_Jacob4.m $\% \% \% \% \% \% \% \% \% \% \% \% \% \% \% \% \% \% \% \%$

$\%$ Off Design Operating line calculation

$\% \% \% \% \% \% \% \% \% \% \% \% \% \% \% \% \% \% \% \% \% \% \% \% \% \% \% \% \% \% \% \% \% \%$ NOTES

\%\%\%\%\%\%\%\%\%\%\%\%\%\%\%\%\%\%\%\%\%\%\%\%\%\%\%\%\%\%\%\%\%\%\%\%\%

$\%$ Setup the Jacobian matrix for use in the Generalized Newton's Method

$\%$ Source: Turns

\% PT with load

\%\%\%\%\%\%\%\%\%\%\%\%\%\%\%\%\%\%\%\%\%\%\%\%\%\%\%\%\%\%\%\%\%\% OUTPUTS

\%०\%\%\%\%\%\%\%\%\%\%\%\%\%\%\%\%\%\%\%\%\%\%\%\%\%\%\%\%\%\%\%\%\%

$\% \mathrm{f}=$ system of nonlinear equations

$\% \mathrm{~J}=\mathrm{Jacobian}$ of the system of equations

\%\%\%\%\%\%\%\%\%\%\%\%\%\%\%\%\%\%\%\%\%\%\%\%\%\%\%\%\%\%\%\%\% Calculations

$\% \% \% \% \% \% \% \% \% \% \% \% \% \% \% \% \% \% \% \% \% \% \% \% \% \% \% \% \% \%$ 
function $[f, J, m 1]=M P \_J a c o b 4\left(r e I N, x, m a \_g u e s s, F u e l \_L i m i t\right)$

warning off MATLAB:fzero:UndeterminedSyntax

MP_Inputs;

load MP_DesignPointData.mat

MP_ScalingFactor;

MP_HPC01;

MP HPT01;

MP_LPT01;

ep $=\left[\left(10^{\wedge}(-5) . * \operatorname{abs}(x(1))\right)\left(10^{\wedge}(-5) . * \operatorname{abs}(x(2))\right)\left(10^{\wedge}(-5) . * \operatorname{abs}(x(3))\right) \ldots\right.$

$\left.\left(10^{\wedge}(-5) \cdot{ }^{*} \operatorname{abs}(x(4))\right)\left(10^{\wedge}(-5) \cdot{ }^{*} \operatorname{abs}(x(5))\right)\left(10^{\wedge}(-5) \cdot * \operatorname{abs}(x(6))\right)\right]$

xguess $=[x(1) \times(2) \times(3) \times(4) \times(5) \times(6) ; \ldots$

$(\mathrm{x}(1)+\mathrm{ep}(1)) \mathrm{x}(2) \times(3) \times(4) \times(5) \times(6) ; \ldots$

$\mathrm{x}(1)(\mathrm{x}(2)+\mathrm{ep}(2)) \mathrm{x}(3) \mathrm{x}(4) \mathrm{x}(5) \mathrm{x}(6) ; \ldots$

$\mathrm{x}(1) \mathrm{x}(2)(\mathrm{x}(3)+\mathrm{ep}(3)) \mathrm{x}(4) \mathrm{x}(5) \mathrm{x}(6) ; \ldots$

$\mathrm{x}(1) \mathrm{x}(2) \mathrm{x}(3)(\mathrm{x}(4)+\mathrm{ep}(4)) \mathrm{x}(5) \mathrm{x}(6) ; \ldots$

$\mathrm{x}(1) \mathrm{x}(2) \mathrm{x}(3) \mathrm{x}(4)(\mathrm{x}(5)+\mathrm{ep}(5)) \mathrm{x}(6) ; \ldots$

$\mathrm{x}(1) \mathrm{x}(2) \times(3) \times(4) \times(5)(\mathrm{x}(6)+\mathrm{ep}(6))]$;

for count $=1: \operatorname{size}(x g u e s s, 1)$

BetaC $=$ xguess $($ count, 1$)$;

BetaT $=$ xguess $($ count, 2$)$;

TIT_now $=$ xguess $($ count, 3$)$;

Betal $P T=x$ guess $($ count, 4$)$;

N_pt $=$ xguess $($ count, 5$)$;

P_off = xguess $($ count, 6$)$;

$\% \% \%$ Thermo. Calculations for Simple Cycle Twin-Shaft $1 \mathrm{MW}$ Gas Turbine \%\%\%

$\%$ note that there is no disc cooling, customer bleeds, blade cooling, NGV cooling and leakage $\%$ considered in this code.

$\%$ Also note that Dry Air is assumed for calculation

\%\%\%\%\%\%\%\%\%\%\%\%\%\%\%\%\%\%\%\%\%\%\%\%\%\% Upstream Conditions

\%\%\%\%\%\%\%\%\%\%\%\%\%\%\%\%\%\%\%\%\%\%\%\%\%

$\mathrm{Cpamb}=\mathrm{Cp} \_$air(Tamb); \% Ambient Specific Heat $\quad[\mathrm{kJ} / \mathrm{kgK}]$

yamb $=($ Cpamb./(Cpamb-(Ra/kJ))); \% Ratio of Specific Heats

$\mathrm{Ta}=\mathrm{Tamb} ; \quad \%$ Static Temperature at a $\quad[\mathrm{K}]$

$\mathrm{Toa}=\mathrm{Ta}+\left(\left(\mathrm{V} .{ }^{*} \mathrm{~km} \_\mathrm{hr}\right) . \wedge 2 /\left(2 .{ }^{*} \mathrm{Cpamb}{ }^{*} 1000\right)\right) ; \%$ Stagnation Temperature at a $[\mathrm{K}]$

$\mathrm{Pa}=\mathrm{Pamb} / \mathrm{kPa} ; \quad \%$ Static Presure at a $\quad[\mathrm{kPa}]$

$\mathrm{Poa}=\mathrm{Pa} .{ }^{*}(\mathrm{Toa} . / \mathrm{Ta})^{\mathcal{Y}}($ yamb. $/($ yamb-1)); \% Stagnation Pressure at a $\quad[\mathrm{kPa}]$

$\% \% \% \% \% \% \% \% \% \% \% \% \% \% \% \% \% \% \% \% \% \% \%$ Retrive Compressor Map Info $\% \% \% \% \% \% \% \% \% \% \% \% \% \% \% \% \% \% \% \% \% \% \% \%$

$[\mathrm{MF}$ row MF_col] $=\operatorname{size}(\mathrm{MF})$; 
$\left[P R \_\right.$row $P R \_$col $]=$size $(\mathrm{PR})$;

$[E F \bar{F}$ row $E \overline{F F}$ _col $]=\operatorname{size}(E F F)$;

$\mathrm{PRc}=$ interp2(PR(1,2:PR_col),PR(2:PR_row,1),PR(2:PR_row,2:PR_col),BetaC,relN,'*spline'); corr_ml = interp2(MF(1,2:MF_col),MF(2:MF_row, 1),MF(2:MF_row,2:MF_col),BetaC,relN,'*spline'); Cnisen $=$ interp2(EFF(1,2:EFF_col),EFF(2:EFF_row, 1$), \operatorname{EFF}\left(2: \overline{E F F}_{-}\right.$row, 2: $\mathrm{EFF}_{-}$col),BetaC,relN,'*spline');

$\% \% \% \% \% \% \% \% \% \% \% \% \% \% \% \% \% \% \% \% \% \% \%$ Engine Intake Conditions

$\% \% \% \% \% \% \% \% \% \% \% \% \% \% \% \% \% \% \% \% \% \% \% \% \%$

Tol = Toa; $\quad \%$ Stagnation Temperature at $1[\mathrm{~K}]$

$\mathrm{N}=\left(\right.$ relN.${ }^{*}\left(\mathrm{~N} \_\right.$GG./sqrt(Tol_des) $\left.)\right) .{ }^{*}$ sqrt(Tol); \% Gas Turbine speed [RPM]

$\%$ Part Load Intake Pressure loss Calculation (From GasTurb 10 manual)

LossIntake $=1-\left(\right.$ IntakeLoss_des.$^{*}\left(\left(\right.\right.$ ma_guess. ${ }^{*}$ sqrtt(Toa.*Ra)./(Poa.*1000))./non_ma_des).^2);

Pol = LossIntake $*^{*}$ Poa;

$\mathrm{m} 1=$ corr_m1 .* ((Pol./Pstd)./sqrt((To1.*Ra)./(Tstd.*Rstd)));

$\% \% \% \% \% \% \% \% \% \% \% \% \% \% \% \% \% \% \% \% \% \% \%$ Compressor Calculations

$\% \% \% \% \% \% \% \% \% \% \% \% \% \% \% \% \% \% \% \% \% \% \% \% \% \% \%$

To2s guess $=$ To $1+($ To1./(Cnisen $)) .{ }^{*}($ PRc. $\Upsilon(($ yamb-1)./yamb $)-1)$

To2s=fzero(@Trans_Error_To2s,To2s_guess,[],PRc, Tol, Cnisen, Ra);\% Ideal Stagn. Temp. Function at $2[\mathrm{~K}]$

To2_guess $=$ To $1+($ To1./Cnisen $) .{ }^{*}(($ To2s./To1 $)-1)$

To2=fzero(@Trans_Error_To2,To2_guess,[], To1, To2s, Cnisen); \% Real Stagn. Temp Function at 2 [K]

Po2 $=$ Po1.*PRc; $\quad$ \% Stagnation Pressure at $2 \quad[\mathrm{kPa}]$

$\mathrm{m} 2=\mathrm{m} 1 .^{*}(1-\mathrm{Bc}) ; \quad$ \% Compressor Discharge Mass Flow Rate

CPower $=m 1 . *(h$ air(To2)-h air(Tol)); \% Compressor Power $\quad[k W]$

\%\%\%\%\%\%\%\%\%\%\%\%\%\%\%\%\%\%\%\%\%\%\%\%\%\%\%\%\%\% Compressor to Burner Ducting $\% \% \% \% \% \% \% \% \% \% \% \% \% \% \% \% \% \% \% \% \% \% \% \% \% \% \%$

Po21 $=$ Po2.* $(1-$ CompToBurn_Delta_P $) ; \quad \%$ Stagnation Pressure at $21 \quad[\mathrm{kPa}]$

$\%$ Note that To2 21 is assumed to be equal to the To2 because we are assuming

$\%$ no heat loss between the Compressor and the Burner. This is an

$\%$ approximation and should be corrected with an accurate value for To21.

$\mathrm{To} 21=\mathrm{To} 2 ; \quad \%$ Stagnation Temperature at $21[\mathrm{~K}]$

$\mathrm{m} 21=\mathrm{m} 2 ; \quad$ \% Mass Flow Rate at $21 \quad[\mathrm{~kg} / \mathrm{s}]$

$\% \% \% \% \% \% \% \% \% \% \% \% \% \% \% \% \% \% \% \%$ Combustion Chamber (Burner) Calculations

$\% \% \% \% \% \% \% \% \% \% \% \% \% \% \% \% \% \% \%$

$\%$ Note that To3 is assumed to be equal to the TIT because we are assuming 
$\%$ no heat loss between the burner and the HP turbine. This is an

$\%$ approximation and should be corrected with an accurate value for To3.

To3 = TIT now;

\% Part Load Burner Efficency Calculation (From Walsh \& Fletcher) p.251

Load $=\left(\mathrm{m} 21 . /\left(\left((\text { Po2 1./101.325 })^{\wedge} 1.8 .{ }^{*}\right.\right.\right.$ Vcomb $) .{ }^{*} 10 . \wedge\left(0.00145 .{ }^{*}(\right.$ To2 $\left.\left.\left.1-400)\right)\right)\right) ; \%\left[\mathrm{~kg} / \mathrm{s} \mathrm{atm}^{\wedge} 1.8 \mathrm{~m}^{\wedge} 3\right]$

$\mathrm{Bn}=$ PartLoad_Bn(Load);

FuelFlow $=\left(m 21 . *\left(h \_a i r(T o 3)-h \_a i r(T o 21)\right)\right) . /\left(H V .{ }^{*} B n-\left(h \_a i r(T o 3)\right)\right) ; \%[k g / s]$

$\%$ Part Load Burner Pressure loss Calculation (From Walsh \& Fletcher)

DPhot $=$ Khot. ${ }^{*}$ Po2 1.* $\left(\left(m 21 .{ }^{*}\right.\right.$ sqrtt(To21)./Po21).^2).*((To3./To21)-1);

Po3 = Po21-DPhot; $\quad \%$ Stagnation Pressure at $3 \quad[\mathrm{kPa}]$

$\mathrm{m} 3=\mathrm{m} 21+$ FuelFlow; $\quad \%$ Mass Flow Rate at $3 \quad[\mathrm{~kg} / \mathrm{s}]$

$\% \% \% \% \% \% \% \% \% \% \% \% \% \% \% \% \% \% \% \%$ Burner to HP Turbine Ducting (Plenum)

$\% \% \% \% \% \% \% \% \% \% \% \% \% \% \% \% \% \% \%$

To31 = To3; $\quad$ \% Stagnation Temperature at $31[\mathrm{~K}]$

\% Part Load Plenum Pressure loss Calculation (From GasTurb 10 manual)

LossPlenum $=1$ - (Plenum_des .*((m3.* sqrt(To3.*Ra)./(Po3.*1000))./non_m3_des).^2);

Po31 = Po3. ${ }^{*}$ LossPlenum; $\quad \%$ Stagnation Pressure at $31 \quad[\mathrm{kPa}]$

corr_m31_calc $=$ m3. ${ }^{*}$ sqrt $\left(\left(\right.\right.$ To31. ${ }^{*}$ Ra).$/\left(\right.$ Tstd. ${ }^{*}$ Rstd $\left.)\right) . /($ Po31./Pstd $)$;

\%\%\%\%\%\%\%\%\%\%\%\%\%\%\%\%\%\%\%\%\%\%\% Auxiliaries Calculations

$\% \% \% \% \% \% \% \% \% \% \% \% \% \% \% \% \% \% \% \% \% \% \% \% \% \% \% \% \%$

Aux $=$ Control_Power + FuelPump_Power + OilPump_Power; \% Auxiliaries Power $[\mathrm{kW}]$

$\% \% \% \% \% \% \% \% \% \% \% \% \% \% \% \% \% \% \% \% \% \% \% \% \% \% \% \%$ HPT urbine Calculations

$\% \% \% \% \% \% \% \% \% \% \% \% \% \% \% \% \% \% \% \% \% \% \% \% \% \% \% \% \%$

$\%$ note that $\mathrm{m} 4$ is assumed to be equal to $\mathrm{m} 31$ since no cooling is required

$\%$ for this design

relN_turb $=(\mathrm{N} . / \operatorname{sqrt}($ To31 $)) . /\left(\mathrm{N} \_G G . / s q r t\left(T o 31 \_d e s\right)\right) ; \%$ Gas Turbine relative speed

$\% \% \% \% \% \% \% \% \% \% \% \% \% \% \% \% \% \% \% \% \% \% \%$ Retrive HP Turbine Map Info

$\% \% \% \% \% \% \% \% \% \% \% \% \% \% \% \% \% \% \% \% \% \% \% \%$

[TPR row TPR col] $=$ size(TPR);

[TMF_row $T M \bar{F}_{-}$col] $=$size $(\mathrm{TMF})$;

$\left[\mathrm{TEFF}\right.$ _row $\mathrm{TEFF} \bar{F}_{-}$col $]=$size $(\mathrm{TEFF})$;

HPTPR $=$

interp2(TPR(1,2:TPR_col),TPR(2:TPR_row,1),TPR(2:TPR_row,2:TPR_col),BetaT,relN_turb,"*spline');

corr_m31_map =

interp2(TMF(1,2:TMF_col),TMF(2:TMF_row,1),TMF(2:TMF_row,2:TMF_col),BetaT,relN_turb,'*spline') ; 


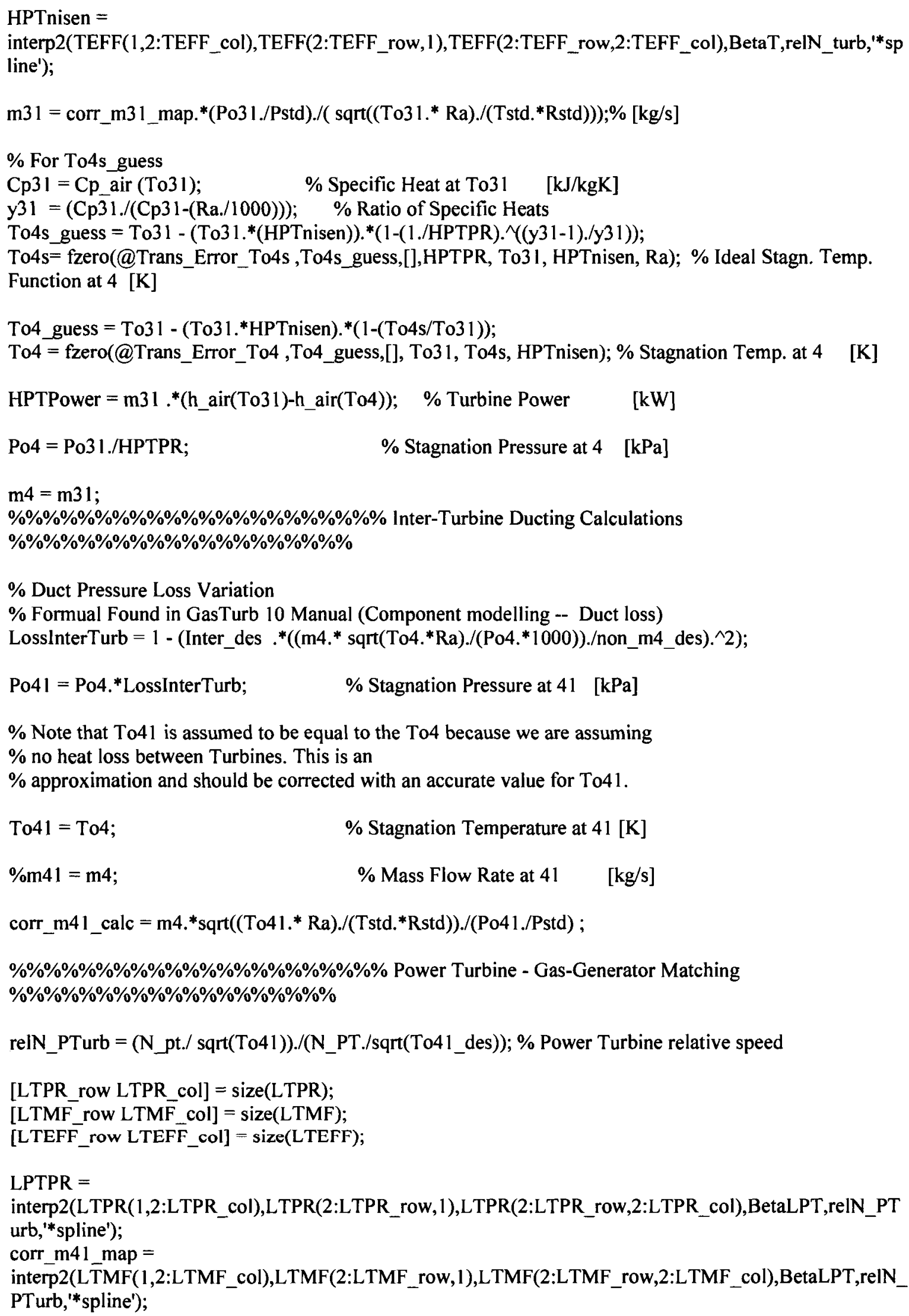




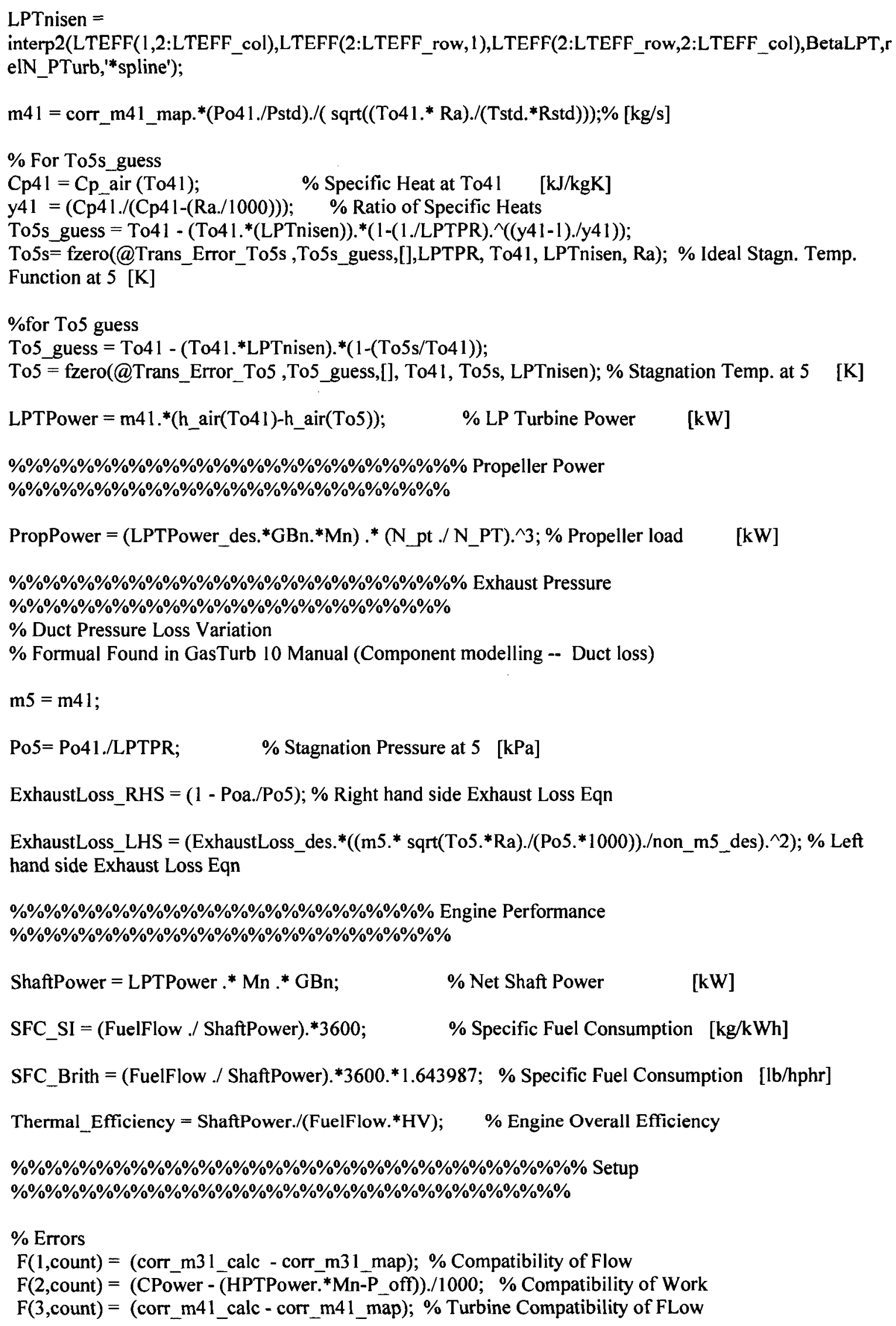


$\mathrm{F}(4$, count $)=($ ExhaustLoss_LHS - ExhaustLoss_RHS $)$;

$F(5$, count $)=($ PropPower - ShaftPower $) . / 1000$;

$\mathrm{F}(6$, count $)=($ FuelFlow - Fuel_Limit $)$;

end

$\mathrm{f}=\mathrm{F}(:, 1)$

$\% \%$ Setup Jacobian

for count $1=1: \operatorname{size}($ xguess, 1$)-1$

for count2 $=1$ :size(xguess, 1$)-1$;

$\mathrm{dF}($ count 1, count 2$)=(\mathrm{F}($ count $1,($ count $2+1))-\mathrm{F}(\operatorname{count} 1,1)) . /(\mathrm{ep}($ count 2$)) ;$ end

end

$\mathrm{J}=\mathrm{dF}$

\%\%\%\%\%\%\%\%\%\%\%\%\%\%\%\%\%\%\%\%\%\%\%\% End \%\%\%\%\%\%\%\%\%\%\%\%\%\%\%\%\%\%\%\%\%\%\%\%\%

$\% \% \% \% \% \% \% \% \% \% \% \% \% \% \% \% \%$ MP_RPMLimit.m $\% \% \% \% \% \% \% \% \% \% \% \% \% \% \% \% \%$

$\%$ This script calculates off design performance parameters along a

$\%$ Constant Maximum and Minimum speed lines.

$\%$ This data will be used to detemine the RPM fuel limits

$\%$ note that to get this data, we are using a modified version of

$\%$ MP_OffDesign_load. A PowerOfftake term has been added to the calculations.

Max_RPM = N_GG + (N_GG.*OverSpeed);

\%Maximum and Minimum RPM Limits

fprintf(1,'ln -----.--- Gas Generator Spool Speed Limiters -----.---')

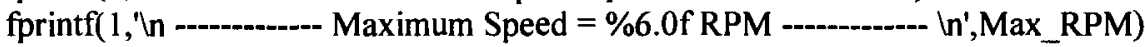

$\% \% \% \%$ Max RPM Protective Control \%\%\%\%

$\%$ Usually when maximum Spool Speed is reached a control system would shutdown

$\%$ the engine this is called a Shutdown control

$\%$ On the other hand a modulating control senses an upcoming malfunction and

$\%$ eliviates the problem by reducing the input (Fuel FLow or RPM demand)

$\%$ we will be using a Modualting control

$\%$ since the engine is protected by a fuel schedule from Ngg idle to N_GG we

$\%$ only need to protect from N_GG to Max_RPM 
Max_GG_RPM_protect $=[$ Ngg_idle N_GG Max_RPM Max_RPM+500]; \% [K]

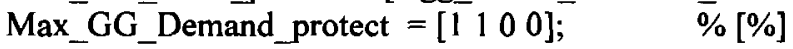

Max_GG_RPM_range $=\left[\mathrm{Ngg}\right.$ idle: $\left.10: \mathrm{Max} \_\mathrm{RPM}+500\right]$;

Max_GG_Demand Control $=$

Interp1(Max_GG_RPM_protect,Max_GG_Demand_protect,Max_GG_RPM_range,'pchip');

$\% \% \% \%$ MaxRPM Fuel Limit \%\%\%\%

[dummy,loc_max] =max(OffDesign_Data_load(:,8)<=Max_RPM);

BetaC_guess = OffDesign_Data_load(loc_max, 10);

BetaT_guess = OffDesign_Data_load(loc_max,26);

BetaPT_guess = OffDesign_Data_load(loc_max,37);

TIT_guess = OffDesign_Data_load(loc_max, 17);

Npt_guess = OffDesign_Data_load(loc_max,36);

$\mathrm{m}$ _guess $=$ OffDesign_Data_load(loc_max,4);

$\mathrm{x} \_$guess $=\left[\right.$BetaC_guess BetaT_guess $T I T \_g u e s s$ BetaPT_guess Npt_guess $\left.1 \mathrm{~m} \_g u e s s\right]$;

Tol_now $=$ OffDesign_Data_load(loc_max,5);

relN_max $=($ Max_RPM./sqrt(To1_now $)) . /\left(\mathbb{N}_{-}\right.$GG./sqrt(To1_des) $)$;

BetaC $=[1:-0.05: 0]$

for $\mathrm{jj}=1: \operatorname{size}(B e t a C, 2)$

BetaC now = BetaC(ij);

fprintf( 1 ,'In Calculating BetaC $=\% 4.2 \mathrm{f}^{\prime}, \mathrm{BetaC} \_$now $)$

Newton $=$ MP_NewtonRap5(relN_max,x_guess,BetaC_now);

$\mathbf{x}$ _guess $=[$ Newton $(1: 7)]$

\%rearrange matirx to add TIT and relN

A =[relN_max Newton(1:8)]; \%[BetaC BetaT TIT relN BetaLPT ma_guess Error]

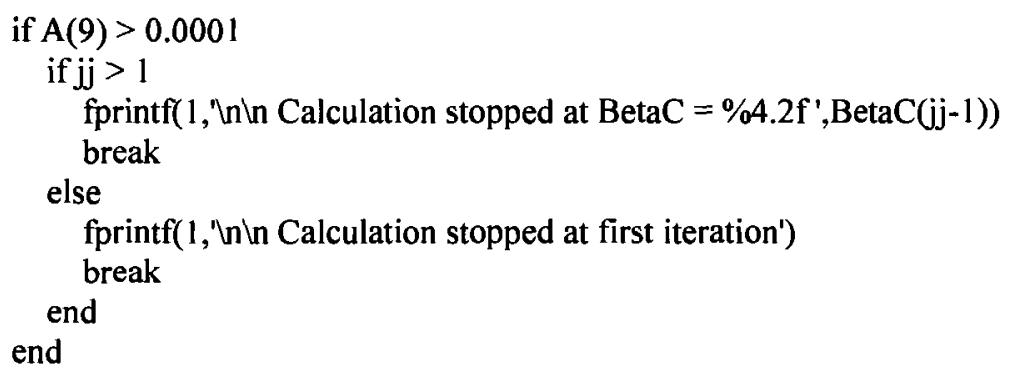

Max_RPMLimit_Data(jj,:) $=$ MP_Calc_RPMLimit(A);

$\% \quad$ Max_RPMLimit_Data $=[$ Toa Poa corr $\mathrm{ml} \mathrm{m1} \mathrm{Tol} \mathrm{Pol} \mathrm{Cnisen} \mathrm{N} \mathrm{relN} \mathrm{BetaC} \mathrm{PRc} \mathrm{m2} \mathrm{To2} \mathrm{Po2}$ CPower m3 To3 Po3...

$\% \quad$ Bn FuelFlow corr_m31_calc m31 Po31 HPTnisen relN_turb BetaT HPTPR HPTPower m4 To4 Po4...

$\% \quad$ m4 1 To41 Po41 corr_m41_calc N_pt relN_PTurb BetaLPT LPTPR LPTnisen m5 To5 Po5

LPTPower PropPower ShaftPower SFC_SI...

$\%$ Thermal_Efficiency Error_square $P_{-}$off];

end 
Min_RPM = Ngg_idle - (Ngg_idle. ${ }^{*}$ LowerSpeed);

fprintf( $(1, \ln \backslash n$ -

$\% \% \% \%$ Min RPM Protective Control \%\%\%\%

$\%$ Usually when minimum Spool Speed is reached a control system would shutdown

$\%$ the engine this is called a Shutdown control

$\%$ On the other hand a modulating control senses an upcoming malfunction and

$\%$ eliviates the problem by reducing the input (Fuel FLow or RPM demand)

$\%$ we will be using a Modualting control

$\%$ since the engine is protected by a fuel schedule from N_GG to N_idle we

$\%$ only need to protect from $\mathrm{N}$ _idle to Min_RPM

Min_GG_RPM_protect $=[$ Min_RPM-500 Min_RPM Ngg_idle N_GG]; \% [K]

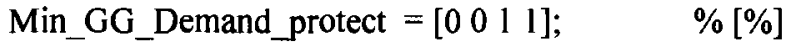

Min_GG_RPM_range $=[$ Min_RPM-500:10:N_GG];

Min_GG_Demand_Control $=$

Interp1(Min_GG_RPM_protect,Min_GG_Demand_protect,Min_GG_RPM_range,'pchip');

$\% \% \% \%$ MinRPM Fuel Limit \%\%\%\%

\% locate Min RPM

[dummy,loc_min] $=\max ($ OffDesign_Data_load(:,8)<=Min_RPM);

BetaC guess $=$ SurgeLimit Data $($ loc $\min , 10)$

BetaT_guess = SurgeLimit_Data(loc_min,26);

BetaPT_guess = SurgeLimit_Data(loc_min,37);

TIT_guess = SurgeLimit_Data(loc_min, 17);

Npt_guess $=$ SurgeLimit_Data(loc_min,36);

$\mathrm{m} \_$guess $=$SurgeLimit_Data(loc_min,4);

Poff_guess $=$ SurgeLimit_Data(loc_min, 50$)$;

$\mathrm{x}$ guess $=[$ BetaC guess BetaT guess TIT guess BetaPT guess Npt guess $1 \mathrm{~m}$ guess $]$;

To1_now = OffDesign_Data_load(loc_min,5);

reIN_min $=($ Min_RPM./sqrt $($ Tol_now $)) . /\left(\right.$ N_GG. $\left._{\text {sqrtt(Tol_des })}\right)$;

for $\mathrm{jj}=1: \operatorname{size}(\operatorname{BetaC}, 2)$

BetaC now = BetaC(jij);

fprintf( $\left(1\right.$, 'n Calculating BetaC $=\% 4.2 \mathrm{f}^{\prime}, \mathrm{BetaC} \_$now)

Newton $=$ MP_NewtonRap5(relN_min, $\mathbf{x} \_$guess,BetaC_now);

$\mathbf{x}$ _guess $=[$ Newton $(1: 7)]$;

$\%$ rearrange matirx to add TIT and relN

$A=[$ relN_min Newton(1:8)]; \% [BetaC BetaT TIT relN BetaLPT ma_guess Error]

if $A(9)>0.0001$

if $\mathrm{jj}>1$

fprintf( $\left(1,,^{\prime} \ln \ln\right.$ Calculation stopped at BetaC $=\% 4.2 \mathrm{f}^{\prime}$, BetaC(ij-1))

break

else

fprintf( $1,(\ln \ln$ Calculation stopped at first iteration') 


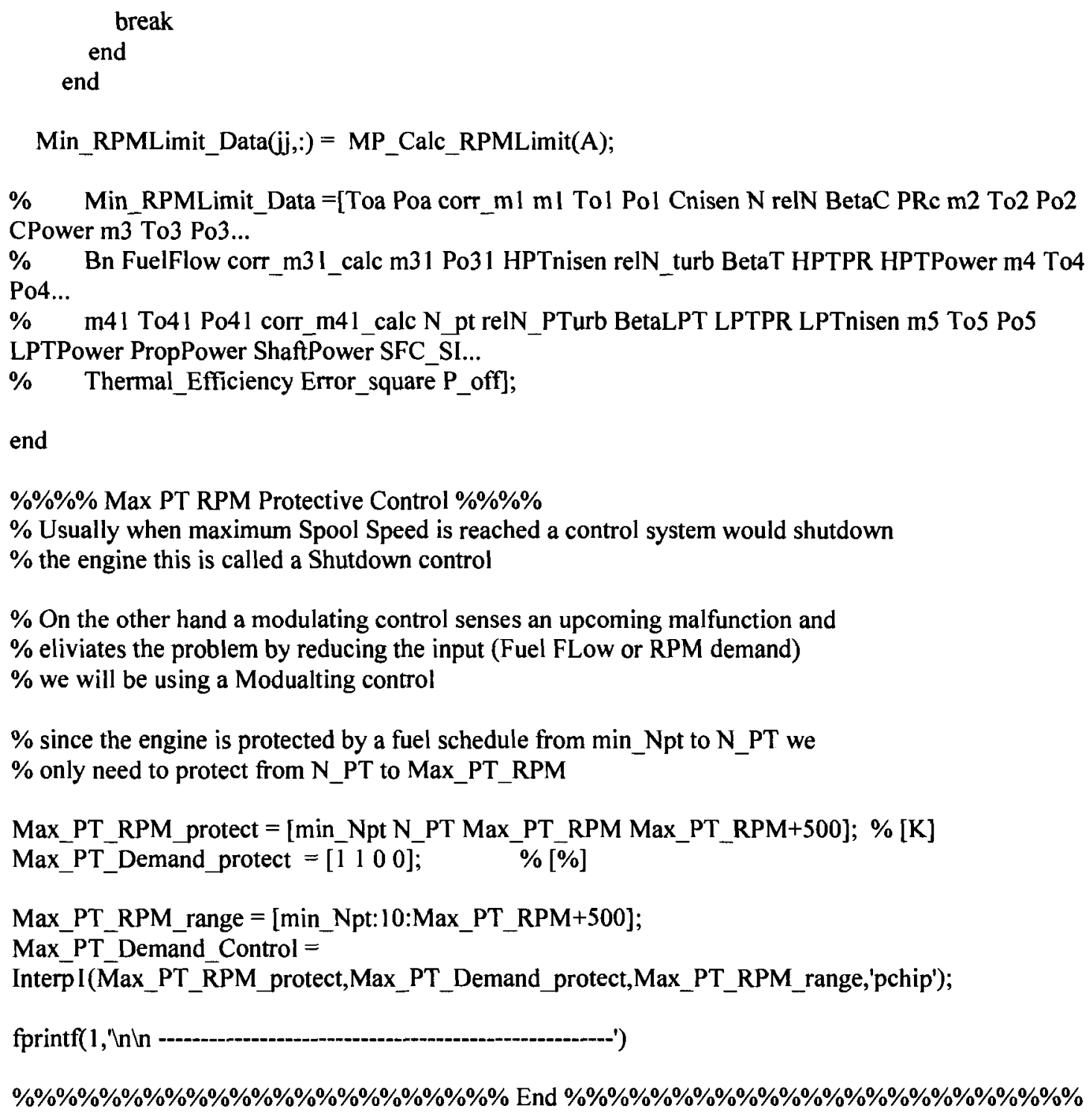


$\%$ TIT_now $=$ Turbine inlet Temperature $[\mathrm{K}]$

\%\%\%\%\%\%\%\%\%\%\%\%\%\%\%\%\%\%\%\%\%\%\%\%\%\%\%\%\%\%\% OUTPUTS

\%\%\%\%\%\%\%\%\%\%\%\%\%\%\%\%\%\%\%\%\%\%\%\%\%\%\%\%\%\%\%\%

$\%$ AMatrix $=[$ BetaC BetaT ma $]$

\%\%\%\%\%\%\%\%\%\%\%\%\%\%\%\%\%\%\%\%\%\%\%\%\%\%\%\%\% Calculations \%\%\%\%\%\%\%\%\%\%\%\%\%\%\%\%\%\%\%\%\%\%\%\%\%\%\%\%\%\%

function AMatrix $=$ MP_NewtonRap5(relN,x_guess,BetaC_now)

F_old $=0$;

$\mathrm{k}=1$;

\% Initial Guess [BetaC BetaT TIT BetaLPT N_pt P_off ma_guess]

$\mathrm{x}=\left[\mathrm{x} \_\right.$guess $\left.(1: 6)\right]$;

ma_guess $=x \_$guess $(7)$;

\% Outer Loop used in case the simulation diverges

while $\mathrm{k}<75$

$\mathbf{k}=\mathbf{k}+1$

\%\%\%\%\%\%\%\%\%\%\%\%\%\%\%\%\%\%\%\%\%\%\%\%\%\%\% Jacobian matrix \%\%\%\%\%\%\%\%\%\%\%\%\%\%\%\%\%\%\%\%\%\%\%\%\%\%\%\%

$\%$ Setup of the Jacobian Matrix

$[\mathrm{F}, \mathrm{J}, \mathrm{m} 1]=\mathrm{MP} \_J a c o b 5\left(\mathrm{relN}, \mathrm{x}, \mathrm{ma} \_\right.$guess, BetaC_now);

\% Solve using Gauss Elimination (in MatLab this is donw using "।")

$\mathrm{dx}=(J \mathrm{~F})$;

\%\%\%\%\%\%\%\%\%\%\%\%\%\%\%\%\%\%\%\%\%\%\%\%\%\%\%\%\%\%\%\%\%\%\% Damping $\% \% \% \% \% \% \% \% \% \% \% \% \% \% \% \% \% \% \% \% \% \% \% \% \% \% \% \% \% \% \% \% \% \%$

ma_guess $=\mathrm{ml}$;

$\%$ this process is used to enable better conevergence

if $(\operatorname{norm}(\operatorname{abs}(F)))>($ norm(abs(F_old $)))$

$$
\mathrm{dx}=\mathrm{dx} . / 5
$$

end

F_old $=F$;

\%\%\%\%\%\%\%\%\%\%\%\%\%\%\%\%\%\%\%\%\%\%\%\%\%\%\%\%\% Calculations

\%\%\%\%\%\%\%\%\%\%\%\%\%\%\%\%\%\%\%\%\%\%\%\%\%\%\%\%\%\%

$\mathrm{x}=\mathrm{x}-\mathrm{dx}$

Error_square $=(\operatorname{sum}(F . \wedge 2))$;

\%\%\%\%\%\%\%\%\%\%\%\%\%\%\%\%\%\%\%\%\%\%\%\%\%\%\%\%\%\%\%\% Convergence Tolerances $\% \% \% \% \% \% \% \% \% \% \% \% \% \% \% \% \% \% \% \% \% \% \% \% \% \% \% \% \% \%$ 


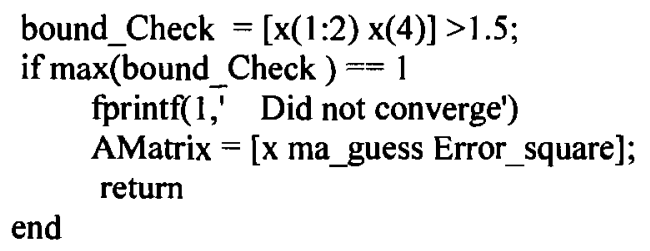

end

fprintf( 1, 'Maximum iterations reached, Did not converge')

AMatrix $=[x$ ma_guess Error_square $]$;

\%\%\%\%\%\%\%\%\%\%\%\%\%\%\%\%\%\%\%\%\%\%\% End \%\%\%\%\%\%\%\%\%\%\%\%\%\%\%\%\%\%\%\%\%\%\%\%\%

$\% \% \% \% \% \% \% \% \% \% \% \% \% \% \% \% \%$ MP_Jacob5.m $\% \% \% \% \% \% \% \% \% \% \% \% \% \% \% \% \% \% \% \%$

\% Off Design Operating line calculation

\%\%\%\%\%\%\%\%\%\%\%\%\%\%\%\%\%\%\%\%\%\%\%\%\%\%\%\%\%\%\%\%\%\%\%\% NOTES

\%\%\%\%\%\%\%\%\%\%\%\%\%\%\%\%\%\%\%\%\%\%\%\%\%\%\%\%\%\%\%\%\%\%\%\%\%

$\%$ Setup the Jacobian matrix for use in the Generalized Newton's Method $\%$ Source: Turns

$\%$ PT with load

\section{\%\%\%\%\%\%\%\%\%\%\%\%\%\%\%\%\%\%\%\%\%\%\%\%\%\%\%\%\%\%\% OUTPUTS}

\%\%\%\%\%\%\%\%\%\%\%\%\%\%\%\%\%\%\%\%\%\%\%\%\%\%\%\%\%\%\%\%

$\% \mathrm{f}=$ system of nonlinear equations

$\% \mathrm{~J}=\mathrm{Jacobian}$ of the system of equations

\%\%\%\%\%\%\%\%\%\%\%\%\%\%\%\%\%\%\%\%\%\%\%\%\%\%\%\%\% Calculations \%\%\%\%\%\%\%\%\%\%\%\%\%\%\%\%\%\%\%\%\%\%\%\%\%\%\%\%\%\%

function $[f, J, m 1]=$ MP_Jacob5(relN,x,ma_guess,BetaC_now)

warning off MATLAB:fzero:UndeterminedSyntax 


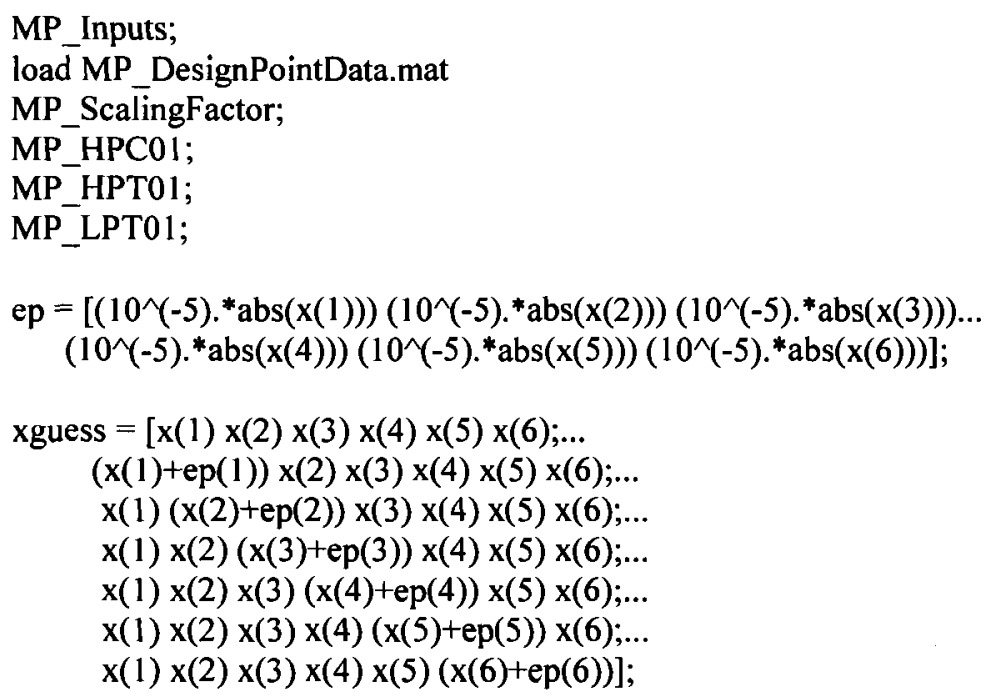

$\left[\mathrm{MF} \_\right.$row $\mathrm{MF} \_$col $]=\operatorname{size}(\mathrm{MF})$;

$[\mathrm{PR}$ row $\mathrm{PR}$ col $]=\operatorname{size}(\mathrm{PR})$;

$\left[E F \bar{E}\right.$ row $E \overline{F F} \_$col $]=\operatorname{size}(E F F)$;

PRc = interp2(PR(1,2:PR_col),PR(2:PR_row,1),PR(2:PR_row,2:PR_col),BetaC,relN,'*spline'); 
corr_ml = interp2(MF(1,2:MF_col),MF(2:MF_row,1),MF(2:MF_row,2:MF_col),BetaC,relN,'*spline');

Cnisen = interp2(EFF(1,2:EFF_col),EFF(2:EFF_row,1),EFF(2:EFF_row,2:EFF_col),BetaC,relN, ${ }^{\prime *}$ spline');

$\% \% \% \% \% \% \% \% \% \% \% \% \% \% \% \% \% \% \% \% \% \% \%$ Engine Intake Conditions

$\% \% \% \% \% \% \% \% \% \% \% \% \% \% \% \% \% \% \% \% \% \% \% \%$

Tol $=$ Toa; $\quad \%$ Stagnation Temperature at $1[\mathrm{~K}]$

$\mathrm{N}=($ relN .* (N_GG./sqrt(Tol_des))).*sqrt(To1); \% Gas Turbine speed [RPM]

\% Part Load Intake Pressure loss Calculation (From GasTurb 10 manual)

Losslntake $=1$ - (IntakeLoss_des.*((ma_guess.* sqrt(Toa.*Ra)./(Poa.*1000))./non_ma_des).^2);

PoI $=$ LossIntake.$^{*}$ Poa;

$\mathrm{m} 1$ = corr_m1 .* ((Pol./Pstd)./ sqrt((Tol.* Ra)./(Tstd.*Rstd)));

\%\%\%\%\%\%\%\%\%\%\%\%\%\%\%\%\%\%\%\%\%\%\% Compressor Calculations

$\% \% \% \% \% \% \% \% \% \% \% \% \% \% \% \% \% \% \% \% \% \% \% \%$

To2s_guess $=$ To1 $+($ To1./(Cnisen) $) . *(P R c . \wedge(($ yamb-1)./yamb)-1);

To2s=fzero(@Trans_Error_To2s ,To2s_guess,[],PRc, To1, Cnisen, Ra);\% Ideal Stagn. Temp. Function at $2[\mathrm{~K}]$

To2_guess $=$ To1 $+($ To1./Cnisen $){ }^{*}(($ To2s. $/$ To1 $)-1) ;$

To2 = fzero(@Trans_Error_To2 ,To2_guess,[], To1, To2s, Cnisen); \% Real Stagn. Temp Function at 2 [K]

Po2 = Po1.*PRc; $\quad$ \% Stagnation Pressure at $2 \quad[\mathrm{kPa}]$

$\mathrm{m} 2=\mathrm{ml} .^{*}(1-\mathrm{Bc}) ; \quad \quad \%$ Compressor Discharge Mass Flow Rate

CPower $=m 1 . *\left(h \_a i r(T 02)-h \_a i r(T o 1)\right) ; \quad \%$ Compressor Power $\quad[k W]$

\%\%\%\%\%\%\%\%\%\%\%\%\%\%\%\%\%\%\%\%\%\%\%\%\%\%\%\%\%\%\% Compressor to Burner Ducting $\% \% \% \% \% \% \% \% \% \% \% \% \% \% \% \% \% \% \% \% \% \% \% \% \% \%$

Po21 $=$ Po2.* $(1-$ CompToBurn_Delta_P $) ; \quad \%$ Stagnation Pressure at $21 \quad[\mathrm{kPa}]$

$\%$ Note that To21 is assumed to be equal to the To2 because we are assuming $\%$ no heat loss between the Compressor and the Burner. This is an $\%$ approximation and should be corrected with an accurate value for To21.

To21 $=$ To2; $\quad$ \% Stagnation Temperature at $21[\mathrm{~K}]$

$\mathrm{m} 21=\mathrm{m} 2 ; \quad \quad \%$ Mass Flow Rate at $21 \quad[\mathrm{~kg} / \mathrm{s}]$

\%\%\%\%\%\%\%\%\%\%\%\%\%\%\%\%\%\%\%\% Combustion Chamber (Burner) Calculations $\% \% \% \% \% \% \% \% \% \% \% \% \% \% \% \% \% \%$

$\%$ Note that To 3 is assumed to be equal to the TIT because we are assuming $\%$ no heat loss between the burner and the HP turbine. This is an

$\%$ approximation and should be corrected with an accurate value for To3.

To3 = TIT_now; 
\% Part Load Burner Efficency Calculation (From Walsh \& Fletcher)

Load $=\left(\mathrm{m} 21 . /\left((\text { Po21./101.325 })^{\wedge} 1.8 .{ }^{*}\right.\right.$ Vcomb $) .{ }^{*} 10 . \wedge\left(0.00145 .{ }^{*}(\right.$ To21-400 $\left.\left.\left.)\right)\right)\right) ; \%\left[\mathrm{~kg} / \mathrm{s} \mathrm{atm}{ }^{\wedge} 1.8 \mathrm{~m}^{\wedge} 3\right]$

$\mathrm{Bn}=$ PartLoad_Bn(Load);

FuelFlow $=($ m21.*(h_air(To3)-h_air(To21)))./(HV.*Bn - (h_air(To3))); \% [kg/s $]$

FA_now $=$ FuelFlow. $/ \mathrm{m} 21 ; \%$ Fuel Flow based on required Transient Fuel to air ratio

$\%$ Part Load Burner Pressure loss Calculation (From Walsh \& Fletcher)

DPhot $=$ Khot. ${ }^{*}$ Po21.*((m21.*sqrt(To21)./Po21).^2).*((To3./To21)-1);

Po3 $=$ Po21- DPhot; $\quad \%$ Stagnation Pressure at $3 \quad[\mathrm{kPa}]$

$\mathrm{m} 3=\mathrm{m} 21+$ FuelFlow; $\quad \%$ Mass Flow Rate at $3 \quad[\mathrm{~kg} / \mathrm{s}]$

\%\%\%\%\%\%\%\%\%\%\%\%\%\%\%\%\%\%\%\% Burner to HP Turbine Ducting (Plenum)

$\% \% \% \% \% \% \% \% \% \% \% \% \% \% \% \% \% \% \%$

To31 = To3; $\quad$ \% Stagnation Temperature at $31[\mathrm{~K}]$

\% Part Load Plenum Pressure loss Calculation (From GasTurb 10 manual)

LossPlenum $=1$ - $\left(\right.$ Plenum_des .* $\left(\left(\mathrm{m} 3 .{ }^{*} \operatorname{sqrt}\left(\mathrm{To} 3 .{ }^{*} \mathrm{Ra}\right) . /\left(\mathrm{Po} 3 .{ }^{*} 1000\right)\right) . /\right.$ non_m3_des $\left.) . \wedge 2\right)$;

Po31 = Po3. ${ }^{*}$ LossPlenum; $\quad \%$ Stagnation Pressure at $31 \quad[\mathrm{kPa}]$

corr_m31_calc $=$ m3. ${ }^{*}$ sqrt $\left(\left(\right.\right.$ To31. ${ }^{*}$ Ra) $) /\left(\right.$ Tstd. ${ }^{*}$ Rstd $\left.)\right) . /($ Po31./Pstd $)$;

\%\%\%\%\%\%\%\%\%\%\%\%\%\%\%\%\%\%\%\%\%\%\% Auxiliaries Calculations

\%\%\%\%\%\%\%\%\%\%\%\%\%\%\%\%\%\%\%\%\%\%\%\%\%\%\%\%\%

Aux $=$ Control_Power + FuelPump_Power + OilPump_Power; \% Auxiliaries Power $[\mathrm{kW}]$

\%\%\%\%\%\%\%\%\%\%\%\%\%\%\%\%\%\%\%\%\%\%\%\%\%\%\%\% HPTurbine Calculations

\%\%\%\%\%\%\%\%\%\%\%\%\%\%\%\%\%\%\%\%\%\%\%\%\%\%\%

$\%$ note that $\mathrm{m} 4$ is assumed to be equal to $\mathrm{m} 31$ since no cooling is required

$\%$ for this design

relN_turb $=(\mathrm{N} . / \operatorname{sqrt}($ To31 $)) . /\left(\mathrm{N} \_G G . / s q r t\left(T o 31 \_d e s\right)\right) ; \%$ Gas Turbine relative speed

$\% \% \% \% \% \% \% \% \% \% \% \% \% \% \% \% \% \% \% \% \% \% \%$ Retrive HP Turbine Map Info

$\% \% \% \% \% \% \% \% \% \% \% \% \% \% \% \% \% \% \% \% \% \% \% \%$

[TPR_row TPR_col] $=$ size(TPR);

$\left[T M F_{-}\right.$row $T M \bar{F}_{-}$col] $=\operatorname{size}(T M F)$;

$\left[T E F F \_\right.$row $T E F \bar{F} \_$col $]=\operatorname{size}(T E F F)$;

HPTPR $=$

interp2(TPR(1,2:TPR_col),TPR(2:TPR_row,1),TPR(2:TPR_row,2:TPR_col),BetaT,relN_turb,'*spline'); corr_m31_map =

interp2(TMF(1,2:TMF_col),TMF(2:TMF_row, 1),TMF(2:TMF_row,2:TMF_col),BetaT,relN_turb,'*spline') ;

HPTnisen $=$

interp2(TEFF(1,2:TEFF_col),TEFF(2:TEFF_row,1),TEFF(2:TEFF_row,2:TEFF_col),BetaT,relN_turb,'*sp line'); 
m31 = corr_m31_map.*(Po31./Pstd)./( sqrt((To31.*Ra)./(Tstd.*Rstd)));\%[kg/s]

$\%$ For To4s guess

$\mathrm{Cp} 31=\mathrm{Cp}$ air $(\mathrm{To} 31) ; \quad$ \% Specific Heat at To31 $\quad[\mathrm{kJ} / \mathrm{kgK}]$

y31 $=(\mathrm{Cp} 31 . /(\mathrm{Cp} 31-(\mathrm{Ra} . / 1000))) ; \quad \%$ Ratio of Specific Heats

To4s_guess $=$ To31 $-($ To31.*(HPTnisen $)) \cdot{ }^{*}\left(1-(1 . /\right.$ HPTPR $\left.) \cdot{ }^{\wedge}((y 31-1) . / y 31)\right)$;

To4s=fzero(@Trans_Error_To4s,To4s_guess,[],HPTPR, To31, HPTnisen, Ra); \% Ideal Stagn. Temp.

Function at $4[\mathrm{~K}]$

To4_guess $=$ To31 $-($ To31.*HPTnisen $) . *(1-(T o 4 s / T o 31)) ;$

To4=fzero(@Trans_Error_To4,To4_guess,[], To31, To4s, HPTnisen); \% Stagnation Temp. at 4 [K]

HPTPower $=m 31 . *\left(h \_a i r(T o 31)-h \_a i r(T o 4)\right) ; \quad \%$ Turbine Power $\quad[k W]$

Po4 = Po31./HPTPR; $\quad$ \% Stagnation Pressure at $4 \quad[\mathrm{kPa}]$

$\mathrm{m} 4=\mathrm{m} 31$;

$\% \% \% \% \% \% \% \% \% \% \% \% \% \% \% \% \% \% \% \% \% \%$ Inter-Turbine Ducting Calculations

$\% \% \% \% \% \% \% \% \% \% \% \% \% \% \% \% \% \% \% \%$

$\%$ Duct Pressure Loss Variation

\% Formual Found in GasTurb 10 Manual (Component modelling -- Duct loss)

LossInterTurb $=1$ - (Inter_des .*((m4.* $\operatorname{sqrt}\left(\mathrm{To} 4 .{ }^{*} \mathrm{Ra}\right) . /\left(\right.$ Po4. $\left.\left.{ }^{*} 1000\right)\right) . /$ non_m4_des $\left.) . \wedge 2\right)$;

Po41 = Po4. ${ }^{*}$ LossInterTurb; $\quad$ \% Stagnation Pressure at $41 \quad[\mathrm{kPa}]$

$\%$ Note that To41 is assumed to be equal to the To4 because we are assuming

$\%$ no heat loss between Turbines. This is an

$\%$ approximation and should be corrected with an accurate value for To4l.

To41 = To4; $\quad \%$ Stagnation Temperature at $41[\mathrm{~K}]$

$\% \mathrm{~m} 4 \mathrm{l}=\mathrm{m} 4 ; \quad$ \% Mass Flow Rate at $41 \quad[\mathrm{~kg} / \mathrm{s}]$

corr_m41_calc $=$ m4. ${ }^{*}$ sqrtt((To41.* Ra)./(Tstd.*Rstd))./(Po41./Pstd) ;

$\% \% \% \% \% \% \% \% \% \% \% \% \% \% \% \% \% \% \% \% \% \%$ Power Turbine - Gas-Generator Matching

$\% \% \% \% \% \% \% \% \% \% \% \% \% \% \% \% \% \% \%$

relN_PTurb $=\left(\mathrm{N} \_\right.$pt./sqrt(To41))./(N_PT./sqrt(To41_des)); \% Power Turbine relative speed

[LTPR_row LTPR_col] $=\operatorname{size}($ LTPR);

[LTMF_row LTMF_col] = size $(\mathrm{LTMF})$;

[LTEFF_row LTEFF_col] = size $($ LTEFF);

LPTPR =

interp2(LTPR(1,2:LTPR_col),LTPR(2:LTPR_row,1),LTPR(2:LTPR_row,2:LTPR_col),BetaLPT,relN_PT

urb,'*'spline');

corr_m41_map =

interp2(LTMF(1,2:LTMF_col),LTMF(2:LTMF_row,1),LTMF(2:LTMF_row,2:LTMF_col),BetaLPT,relN_ PTurb,'*spline');

LPTnisen =

interp2(LTEFF(1,2:LTEFF_col),LTEFF(2:LTEFF_row,1),LTEFF(2:LTEFF_row,2:LTEFF_col),BetaLPT,r elN_PTurb,'*spline'); 
m41 = corr_m41_map.*(Po41./Pstd)./( sqrt((To41.*Ra)./(Tstd.*Rstd)));\%[kg/s]

$\%$ For To5s guess

Cp41 = Cp_air (To41); \% Specific Heat at To4l [kJ/kgK]

$\mathrm{y} 41=(\mathrm{Cp} 41 . /(\mathrm{Cp} 41-(\mathrm{Ra} . / 1000))) ; \quad \%$ Ratio of Specific Heats

To5s_guess $=$ To41 - $($ To41.*(LPTnisen)).*(1-(1./LPTPR). $((y 41-1) . / y 41))$;

To5s=fzero(@Trans_Error_To5s,To5s_guess,[],LPTPR, To41, LPTnisen, Ra); \% Ideal Stagn. Temp.

Function at $5[\mathrm{~K}]$

$\%$ for To5 guess

To5_guess $=$ To4 $1-\left(\right.$ To41. ${ }^{*}$ LPTnisen $) . *(1-($ To5s/To41) $)$

To5=fzero(@Trans_Error_To5,To5_guess,[], To41, To5s, LPTnisen); \% Stagnation Temp. at 5 [K]

LPTPower $=m 41 . *\left(h \_a i r(T 041)-h \_a i r(T o 5)\right) ; \quad \%$ LP Turbine Power $\quad[k W]$

\%\%\%\%\%\%\%\%\%\%\%\%\%\%\%\%\%\%\%\%\%\%\%\%\%\%\% Propeller Power

\%\%\%\%\%\%\%\%\%\%\%\%\%\%\%\%\%\%\%\%\%\%\%\%\%\%

PropPower $=\left(\right.$ LPTPower_des. $\left.{ }^{*} \mathrm{GBn} .{ }^{*} \mathrm{Mn}\right) .^{*}\left(\mathrm{~N} \_\right.$pt.$\left./ \mathrm{N} \_\mathrm{PT}\right) .{ }^{\wedge} 3 ; \%$ Propeller load

$[\mathrm{kW}]$

\%\%\%\%\%\%\%\%\%\%\%\%\%\%\%\%\%\%\%\%\%\%\%\%\%\%\% Exhaust Pressure

$\% \% \% \% \% \% \% \% \% \% \% \% \% \% \% \% \% \% \% \% \% \% \% \% \% \%$

$\%$ Duct Pressure Loss Variation

\% Formual Found in GasTurb 10 Manual (Component modelling -- Duct loss)

$\mathrm{m} 5=\mathrm{m} 41$

Po5= P041./LPTPR; \% Stagnation Pressure at $5 \quad[\mathrm{kPa}]$

ExhaustLoss_RHS $=(1$ - Poa./Po5 $) ; \%$ Right hand side Exhaust Loss Eqn

ExhaustLoss_LHS $=\left(\right.$ ExhaustLoss_des. ${ }^{*}\left(\left(\mathrm{~m} 5 .{ }^{*}\right.\right.$ sqrt(T05.*Ra)./(Po5.*1000))./non_m5_des $\left.) . \wedge 2\right) ; \%$ Left hand side Exhaust Loss Eqn

\%\%\%\%\%\%\%\%\%\%\%\%\%\%\%\%\%\%\%\%\%\%\%\%\% Engine Performance

\%\%\%\%\%\%\%\%\%\%\%\%\%\%\%\%\%\%\%\%\%\%\%\%\%\%

ShaftPower $=$ LPTPower ${ }^{*} \mathrm{Mn} .{ }^{*} \mathrm{GBn}$;

$\%$ Net Shaft Power

$[\mathrm{kW}]$

SFC_SI $=\left(\right.$ FuelFlow $/$ ShaftPower). ${ }^{* 3600 ;} \quad \%$ Specific Fuel Consumption $[\mathrm{kg} / \mathrm{kWh}]$

SFC_Brith $=($ FuelFlow.$/$ ShaftPower $) .{ }^{*} 3600 .{ }^{*} 1.643987$; \% Specific Fuel Consumption $[\mathrm{lb} / \mathrm{hphr}]$

Thermal_Efficiency $=$ ShaftPower./(FuelFlow. $\left.{ }^{*} H V\right) ; \quad$ \% Engine Overall Efficiency

\%\%\%\%\%\%\%\%\%\%\%\%\%\%\%\%\%\%\%\%\%\%\%\%\%\%\%\%\%\%\%\%\%\% Setup

\%\%\%\%\%\%\%\%\%\%\%\%\%\%\%\%\%\%\%\%\%\%\%\%\%\%\%\%\%\%\%\%\%

$\%$ Errors

$\mathrm{F}(1$, count $)=$ (corr_m31_calc - corr_m31_map); \% Compatibility of Flow

$\mathrm{F}(2$, count $)=\left(\right.$ CPower $-\left(\right.$ HPTPower. ${ }^{*}$ Mn-P_off $\left.)\right) . / 1000 ; \%$ Compatibility of Work

$\mathrm{F}(3$, count $)=$ (corr_m41_calc - corr_m41_map); \% Turbine Compatibility of FLow

$\mathrm{F}(4$, count $)=($ ExhaustLoss_LHS - ExhaustLoss_RHS $)$;

$\mathrm{F}(5$, count $)=($ PropPower - ShaftPower $) . / 1000$;

$\mathrm{F}(6$, count $)=$ (BetaC-BetaC_now); 
end

$f=F(:, 1)$

$\% \%$ Setup Jacobian

for $\operatorname{count} 1=1: \operatorname{size}(x g u e s s, 1)-1$

for count2 = 1:size $(x g u e s s, 1)-1$

$\mathrm{dF}($ count 1, count 2$)=(F($ count $1,($ count $2+1))-F($ count 1,1$)) . /(e p($ count 2$)) ;$

end

end

$\mathrm{J}=\mathrm{dF}$

\%\%\%\%\%\%\%\%\%\%\%\%\%\%\%\%\%\%\%\%\%\%\% End \%\%\%\%\%\%\%\%\%\%\%\%\%\%\%\%\%\%\%\%\%\%\%\%\%\%

\%\%\%\%\%\%\%\%\%\%\%\%\%\%\%\%\%\%\%\% MP_AccSched.m \%\%\%\%\%\%\%\%\%\%\%\%\%\%\%\%\%\%\%\%\% $\%$ This script used data from Limiters to establish a safe Fuel Flow

$\%$ Acceleration schedule

fprintf(1,'In ------ Establishing Acceleration Fuel Schedule --.----|n')

$\% \% \% \%$ Surge Line Limit Fuel FLow \%\%\%\%

SurgeLimit_Fuel = SurgeLimit_Data(:,20);

SurgeLimit_Ngg = SurgeLimit_Data(:,8);

SurgeLimit_Po2 = SurgeLimit_Data(:,14);

$\%$ note that refered Fuel $=\mathrm{Wf} . / \mathrm{Po} 2 \mathrm{sqrt}(\mathrm{To} 2)$ but in practice To2 is omitted as it only has a secondary

Effect

$\%$ Walsh \& Fletcher p.462

Rfd_SurgeLimit_Fuel = SurgeLimit_Fuel./SurgeLimit_Po2;

$\% \% \% \%$ Constant TIT Limit Fuel FLow \%\%\%\%

TITLimit Fuel $=$ TITLimit_Data(:,20);

TITLimit_Ngg = TITLimit_Data(:,8);

TITLimit_Po2 = TITLimit_Data(:,14);

$\%$ note that refered Fuel $=\mathrm{Wf} . / \mathrm{Po} 2$ sqrt(To2) but in practice To2 is omitted as it only has a secondary Effect

$\%$ Walsh \& Fletcher p.462

Rfd_TITLimit_Fuel $=$ TITLimit_Fuel./TITLimit_Po2;

$\% \% \% \%$ Constant Design Point TIT Fuel FLow \%\%\%\%

TITDesign_Fuel = TITDesign_Data(:,20);

TITDesign Ngg = TITDesign Data(:,8);

TITDesign P02 = TITDesign_Data(:,14);

$\%$ note that refered Fuel $=\mathrm{Wf} . / \mathrm{Po} 2 \mathrm{sqrt}(\mathrm{To} 2)$ but in practice $\mathrm{To} 2$ is omitted as it only has a secondary Effect

$\%$ Walsh \& Fletcher p.462 
Rfd_TITDesign_Fuel = TITDesign_Fuel./TITDesign_Po2;

$\% \% \% \%$ Maximum Limit $\% \% \% \%$

$\%$ We need to perform a minimum test between Surge and TIT Fuel Flows to set

$\%$ the maximum limit so both limiter can be satisfied.

$\%$ note that the schedule is defined between idle speed and Design point speed

$\%$ the location of Idle Spool speed depends on many factor such as combustor

$\%$ stability, engine temperatures and surge margin.

$\%$ Here the Idle spool speed will be chosen based on combustor stability

$\%$ Therefore Idle spool speed will be located at the minimum Steady state

$\%$ Fuel air Ratio

for $\mathrm{ii}=1: \operatorname{size}($ Ngg_range, 2$)$

Ngg_now = Ngg_range(ii);

Surge_F = interpl(SurgeLimit_Ngg,Rfd_SurgeLimit_Fuel,Ngg now,'pchip');

TIT $\bar{F}=$ interp1(TITLimit_Ngg,Rfd_TITLimit_Fuel,Ngg_now,'pchip');

Rfd_Max_Fuel(ii) $=\min ([$ Surge_F TIT_F] $) ; \%$ Maximum allowable Reffered Fuel to satify both limiters

$\%$ This next part check is Design Point TIT line is located below the limiters

TIT_D = interp1(TITDesign_Ngg,Rfd_TITDesign_Fuel,Ngg_now,'pchip');

DesignTIT_Fuel(ii) $=\min \left(\left[\mathrm{Rfd}_{-}\right.\right.$Max_Fuel(ii) TIT_D $]$;

end

$\% \% \% \%$ Setup Acceleration Fuel Schedule \%\%\%\%

$\%$ Since the engine is usually sluggish close to idle speed we want the fuel

$\%$ schedule to be close to the TIT Limit to allow for greater acceleration but

$\%$ without letting the engine operate for long periods of time above Design Point TIT

$\%$ To make sure that the engine doesn't run above design Point TIT for long

$\%$ periods of time we will set the Fuel Schedule to follow the Constant

$\%$ Design Point TIT line.

$\%$ For Regions closer to the design point the fuel schedule we will allow

$\%$ the engine to run closer to maximum TIT.

fprintf(1,'nn Mapping Acceleration Fuel Schedule

for $\mathrm{kk}=\mathrm{I}$ : size(Ngg_range, 2$)$

Ngg now $=$ Ngg range(kk);

if Ngg now $<\left(0.8 .^{*} \mathrm{~N}\right.$ GG $)$

AccFuelSched(kk) = DesignTIT_Fuel(kk);

else if Ngg_now $>=\left(0.8 .{ }^{*} \mathrm{~N} \_G G\right) \&$ Ngg_now $<\left(0.95 .{ }^{*}\right.$ N_GG $)$

Rfd_FueI_Diff=(interp 1(Ngg_range,Rfd_Max_Fuel, $\left(0 . \overline{95} .^{*}\right.$ N_GG),'pchip'))-

(interpl(Ngg_range,DesignTIT Fuel, $\left.\left(0.95 .^{*} \mathrm{~N}^{-} \mathrm{GG}\right)\right)^{-}$'pchip'));

AccFuelSched $(\mathbf{k k})=$ DesignTIT_Fuel $(\mathbf{k k})+($ Rfd_Fuel_Diff $) .{ }^{*}\left(\left(\mathrm{Ngg} \_n o w-\left(0.8 .^{*} \mathrm{~N}_{-} \mathrm{GG}\right)\right) \cdot /((0.95 . *\right.$

N_GG)-(0.8.*N_GG))).^1;

else

Rfd_Fuel = [interp1(Ngg_range,Rfd_Max_Fuel, $\left(0.95 .^{*}\right.$ N_GG),'pchip')

interpl(Ngg range,DesignTIT_Fuel,N_GG,'pchip')];

$R P M=\left[\left(0.95 *^{*} \mathrm{~N} G \bar{G}\right) \mathrm{N} G \bar{G}\right]$

AccFuelSched(kk) = interpl(RPM ,Rfd_Fuel,Ngg_now,'pchip'); end 


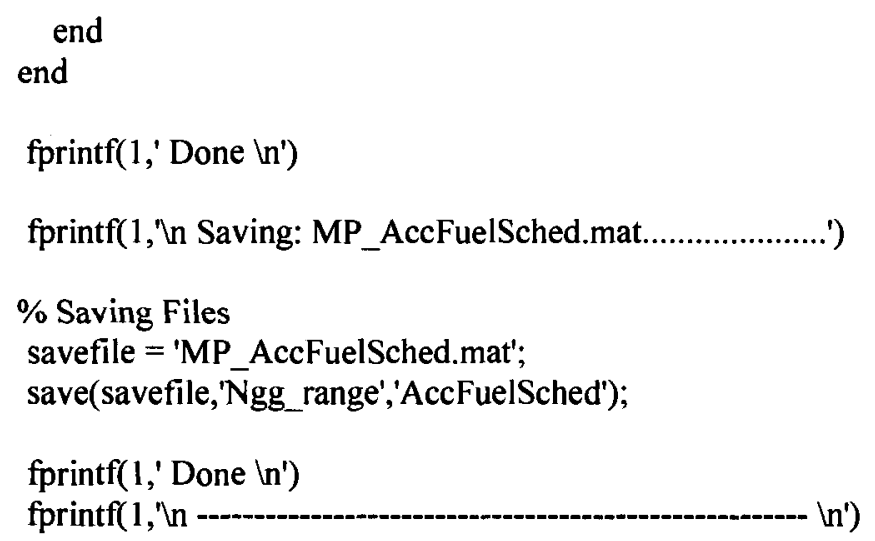

\%\%\%\%\%\%\%\%\%\%\%\%\%\%\%\%\%\%\%\%\%\% End \%\%\%\%\%\%\%\%\%\%\%\%\%\%\%\%\%\%\%\%\%\%\%\%\%\%

\%\%\%\%\%\%\%\%\%\%\%\%\%\%\%\% MP_DecSched.m \%\%\%\%\%\%\%\%\%\%\%\%\%\%\%\%\%\%\%

$\%$ This script used data from Limiters to establish a safe Fuel Flow

$\%$ Deceleration schedule

fprintf(1,' In ------ Establishing Deceleration Fuel Schedule -------- $\mid n ')$

$\% \% \%$ Note $\% \% \%$

$\%$ As explained in Walsh \& Fletcher "Gas Turbine Performance" p.456

$\%$ Combustion Stability is the main concern when the engine is decelerating

$\%$ They state that to facilitate engine deceleration the fuel flow should be

$\%$ reduced relative to that of the Steady state operating line by about

$\% 20-50 \%$

$\%$ Since the occurence of a rapid loss of load (Propeller out of water)

$\%$ is possible a rapid deceleration schedule is required as a result, we

$\%$ choose to reduce the steady state fuel flow by $30 \%$

Fuel_Reduction $=0.3$

$\%$ Also the give a rule of thumb

$\%$ Transient FA ratio should always be greater than 0.008

$\% \% \% \%$ Surge Line Limit Fuel FLow $\% \% \% \%$

OFFDesign_load Fuel = OffDesign_Data load(:,20);

OFFDesign load Ngg = OffDesign Data load(:,8);

OFFDesign_load_Po2 = OffDesign_Data_load(:,14);

$\%$ note that refered Fuel $=\mathrm{Wf} . / \mathrm{Po} 2 \operatorname{sqrt}\left(\mathrm{T}_{0}\right)$ but in practice $\mathrm{To} 2$ is omitted as it only has a secondary

Effect

$\%$ Walsh \& Fletcher p.462

Rfd_OFFDesign_load_Fuel=OFFDesign_load_Fuel./OFFDesign_load_Po2;

$\% \% \% \%$ FlameOut Limit Fuel FLow \%\%\%\%

FlameOutLimit Fuel $=$ FlameOutLimit $\_$Data(:,20);

FlameOutLimit_Ngg = FlameOutLimit_Data(:,8); 
FlameOutLimit_Po2 = FlameOutLimit_Data(:,14);

$\%$ note that refered Fuel $=$ Wf.$/$ Po2 sqrt(To2) but in practice To2 is omitted as it only has a secondary Effect

$\%$ Walsh \& Fletcher $p .462$

Rfd_FlameOutLimit_Fuel = FlameOutLimit_Fuel./FlameOutLimit_Po2;

$\% \% \%$ Minimum Limit \%\%\%\%

$\%$ We need to perform a maximum test between desired Fuel Schedule and $0.008 \mathrm{FA}$ line

$\%$ to ensure the Fuel Shedule satifies this limiter.

$\%$ note that the schedule is defined between idle speed and Design point speed

$\%$ the location of Idle Spool speed depends on many factor such as combustor

$\%$ stability, engine temperatures and surge margin.

$\%$ Here the Idle spool speed will be chosen based on combustor stability

$\%$ Therefore ldle spool speed will be located at the minimum Steady state

$\%$ Fuel air Ratio

fprintf(1, In Mapping Deceleration Fuel Schedule ')

min_Ngg = Ngg_idle; \% Schedule minimum speed

max_Ngg = N_GG; \% Schedule maximum speed

Ngg_range $=\left[\right.$ min_Ngg: $\left.: 100: \max \_N g g\right]$;

for ii $=1$ :size(Ngg_range, 2$)$

Ngg_now = Ngg_range(ii);

OffDesign_Rfd = interpl(OFFDesign_load_Ngg,Rfd_OFFDesign_load_Fuel,Ngg_now,'pchip');

FlameOut_Rfd = interpI(FlameOutLimit_Ngg,Rfd_FlameOutLimit_Fuel ,Ngg_now,'pchip');

DecFuelSched(ii) = OffDesign_Rfd - OffDesign_Rfd.*Fuel_Reduction.*((Ngg_now-

$\left.\min \_\mathrm{Ngg}\right) .\left(\left(\max \_N g g-\min \_\mathrm{Ngg}\right)\right)^{-} \wedge \mathbf{l}$;

end

fprintf(1,' Done $\ln$ ')

fprintf(I,'nn Saving: MP_DecFuelSched.mat.

$\%$ Saving Files

savefile = 'MP DecFuelSched.mat';

save(savefile,'Ngg_range','DecFuelSched');

fprintf( 1, ' Done $(n ')$

fprintf( 1, 'n

\%\%\%\%\%\%\%\%\%\%\%\%\%\%\%\%\%\%\%\%\%\%\%\% End \%\%\%\%\%\%\%\%\%\%\%\%\%\%\%\%\%\%\%\%\%\%\%\%

$\% \% \% \% \% \% \% \% \% \% \% \% \% \% \% \% \%$ MP_StepResponse.m \%\%\%\%\%\%\%\%\%\%\%\%\%\%\%\%\%

$\%$ This script calculates Transient performance based on the Intercomponent Volumes Approach

$\%$ described in the paper SAE 710550 by Saravanamuttoo

$\%$ The basic assumption in this approach is that flow and work mismatch

$\%$ occur during transients

$\%$ load Off design steady state performance data. this will be used as 
$\%$ initial conditions for the transient modeling

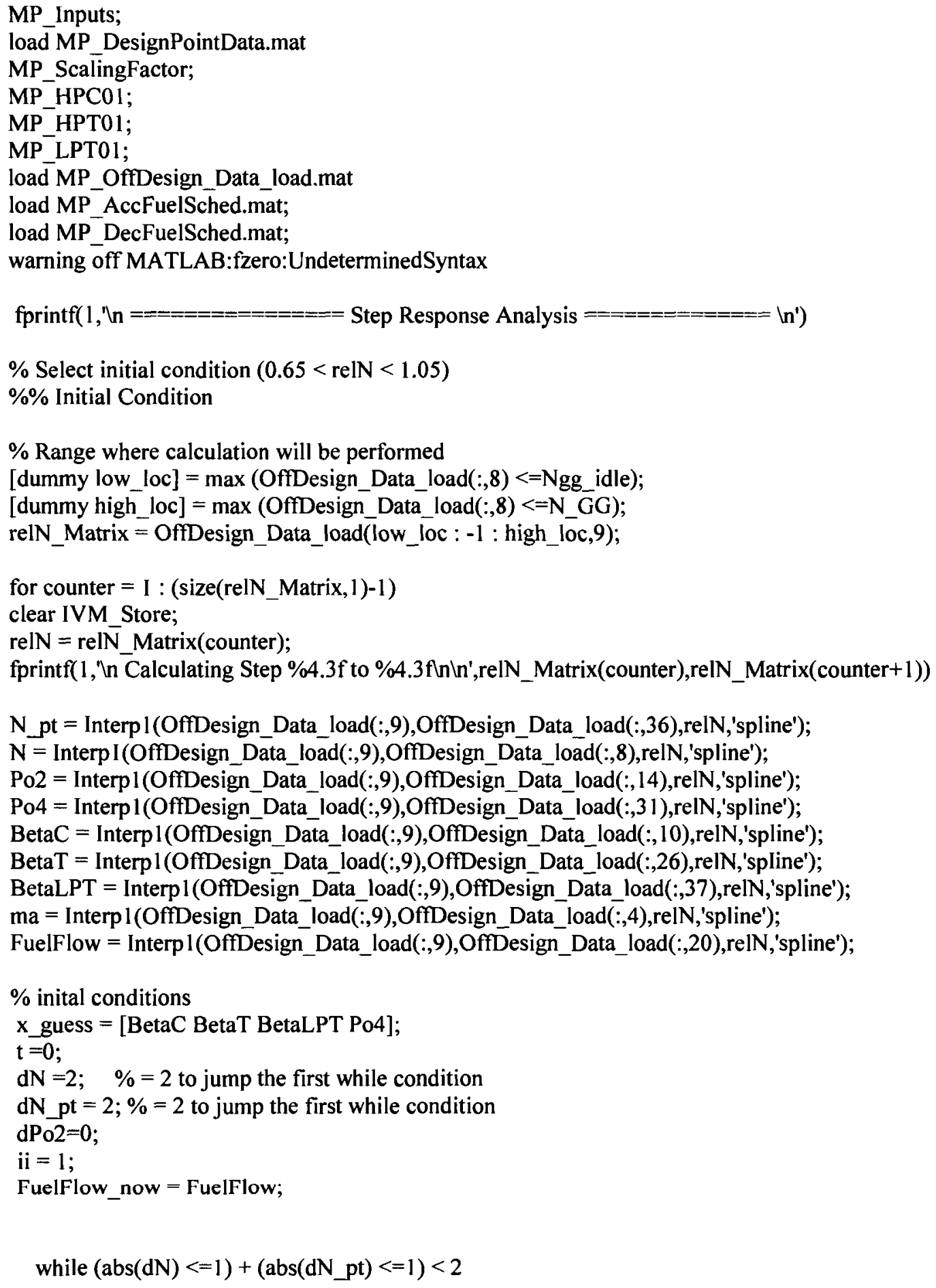


$\%$ calculate new conditons based on fuel step

[IVM_Newton, IVM_Matx] = MP_IVM_NewtonRap(N,N_pt,FuelFlow_now,Po2,x_guess,ma);

$\%$ IVM_Newton $=[$ BetaC BetaT BetaLPT Po4 ma_guess Error_square $]$

$\mathbf{x}$ guess $=[$ IVM_Newton(1:4)];

$\mathrm{ma}=\mathrm{IVM}$ Newton(5);

$\% \% \% \% \% \% \% \% \% \% \% \% \% \% \% \% \% \%$ Rate of Change of Speed $\% \% \% \% \% \% \% \% \% \% \% \% \% \% \%$ $\%$ we know that $\mathrm{dN} / \mathrm{dt}=60(\mathrm{Gt}-\mathrm{Gc}) /(2 \mathrm{piIg})$

$\%$ Since Torque is in $\mathrm{kNm}$ we get $\mathrm{dN} / \mathrm{dt}=60^{*} 1000(\mathrm{Gt}-\mathrm{Gc}) /(2 \mathrm{pilg})$

$\mathrm{dN}=60 .{ }^{*} 1000 . *\left(\left(\mathrm{IVM} \_\operatorname{Matx}(30) .{ }^{*} \mathrm{Mn}\right)-\mathrm{IVM} \_\operatorname{Matx}(16)\right) . /\left(2 .{ }^{*} \mathrm{pi} .{ }^{*} \mathrm{Ig}\right) ; \%[\mathrm{RPM} / \mathrm{s}]$

$\%$ and for the Power Turbine

$\mathrm{dN} \_\mathrm{pt}=60 .{ }^{*} 1000 .{ }^{*}\left(\left(\mathrm{IVM} \_\operatorname{Matx}(47) .{ }^{*} \mathrm{Mn} .{ }^{*} \mathrm{GBn}\right)-\mathrm{IVM} \_\operatorname{Matx}(49)\right) . /\left(2 .{ }^{*} \mathrm{pi} .{ }^{*} \mathrm{Ig} \_\mathrm{pt}\right) ; \%[\mathrm{RPM} / \mathrm{s}]$

$\% \% \% \% \% \% \% \% \% \% \%$ Rate of Change of Pressure in a Volume \%\%\%\%\%\%\%\%\%\%\%\%\%\%\%

$\%$ we know that $\mathrm{dP} / \mathrm{dt}=\left(\mathrm{m}\right.$ in $-\mathrm{m}_{-}$out $) *((\mathrm{~T} * \mathrm{Ra}) /$ Volume $)$

$\%$ therfore for the combustor we have: $\mathrm{dPo} / \mathrm{dt}=(\mathrm{m} 2+$ FuelFlow $-\mathrm{m} 31) *(\mathrm{To} 2 * \mathrm{Ra}) /(\mathrm{Vcomb}+$ Vplenum)

dPo2 $=(($ IVM_Matx(12)+IVM_Matx(21)-IVM_Matx(23)).*((IVM_Matx(13) .*Ra)./(Vcomb + Vplenum)))./1000; $\%[\mathrm{kPa} / \mathrm{s}]$

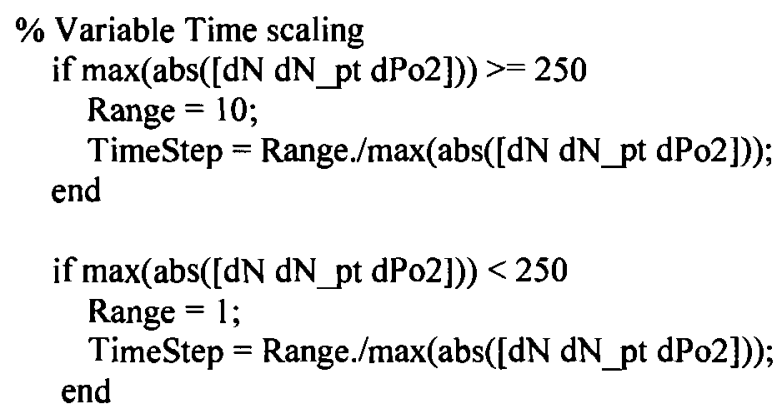

TimeStep $=0.01$;

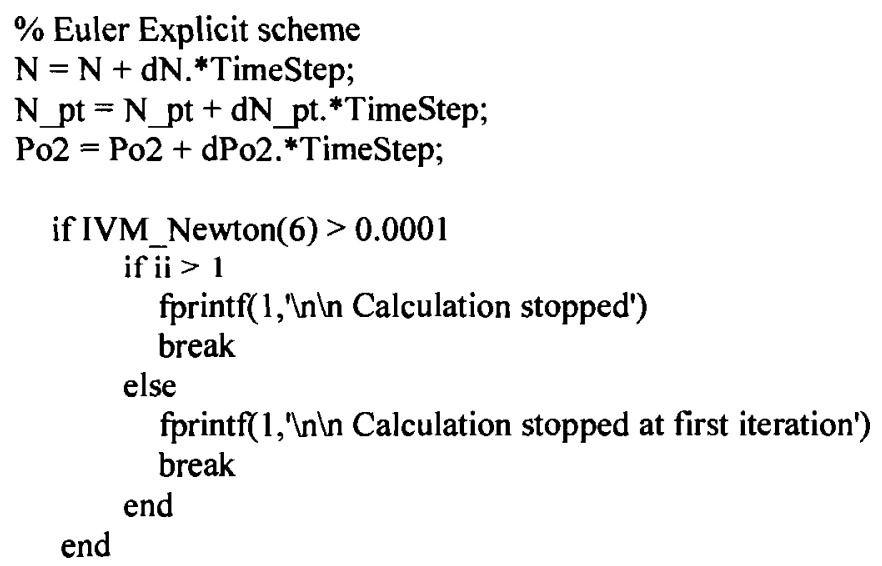


$\%$ Thermodynamic Cycle Data

IVM_Store(ii,:)=[t IVM_Matx dN dN_pt dPo2 TimeStep IVM_Newton(6)];

$\% \quad$ Note that: IVM_Store $=[t$ Toa Poa corr_m1 m1 To1 Pol Cnisen N relN BetaC PRc m2 To2 Po2 CPower Ge m3 To3 Po3...

$\% \quad$ Bn FuelFlow corr_m3 I_calc m31 Po31 HPTnisen relN_turb BetaT HPTPR HPTPower Gt m4 To4 Po4...

$\% \quad$ m41 To41 Po41 corr_m41_calc N_pt relN_PTurb BetaLPT LPTPR LPTnisen m5 To5 Po5

LPTPower Gpt ShaftPower Gprop SFC__SI...

$\% \quad$ Thermal_Efficiency PropPower $\mathrm{dN} d \mathrm{~N} \_p t \mathrm{dPo} 2$ TimeStep Error_square]

$\mathbf{t}=\mathbf{t}+$ TimeStep;

$\mathrm{ii}=\mathrm{ii}+1$;

fprintf $\left(1,{ }^{\prime} t=\% 6.4 \mathrm{f} \quad\right.$ TimeStep=\%6.4fin $\mathrm{N}=\% 5.0 \mathrm{f} \quad \mathrm{dN}=\% 6.2 \mathrm{fln} \mathrm{N} \_\mathrm{pt}=\% 5.0 \mathrm{f} \quad \mathrm{dN} \_\mathrm{pt}=$

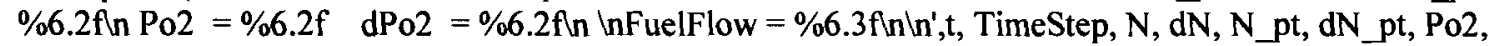
dPo2,FuelFlow_now)

end

fprintf(1, In Calculating Process and Controller Gains. ..')

Time = IVM_Store(:,1);

N_gg = IVM_Store(:,9);

N_pt $=$ IVM_Store $(:, 39)$;

\% Control variable Variations (Fuel Flow)

Delta_m $=\max ($ IVM_Store $(:, 22))$ -

Interp I(OFffDesign_Data_load(:,8),OffDesign_Data_load(:,20),min(N_gg),'spline');

$\%$ Output variable Variations

Delta_N_gg $=\max \left(\mathrm{N} \_g g\right)-\min \left(\mathrm{N} \_g g\right)$;

Delta_N_pt $=\max \left(N \_\right.$pt $)-\min \left(N \_\right.$pt $)$;

$\%$ Process Gains

K_gg = Delta_N_gg./Delta_m;

$\mathrm{K} \_\mathrm{pt}=$ Delta_N_pt./Delta_m;

$\%$ Time Delays

$\%$ First locate point of inflection and slope of tangent line

[Slope_gg,loc_gg] $=\max \left(\operatorname{diff}\left(\mathrm{N} \_g g\right) . / \operatorname{diff}(T i m e)\right)$;

[Slope_pt,loc_pt] $=\max \left(\operatorname{diff}\left(\mathrm{N} \_p t\right) . / \operatorname{diff}(\mathrm{Time})\right)$;

$\%$ then locate where the tangent line crosses the $\mathrm{x}$-axis $(\mathrm{L}=(\mathrm{min}-\mathrm{b}) / \mathrm{m})$

b_gg = N_gg(loc_gg) - Slope_gg * Time(loc_gg);

b_pt $=N \_p t\left(l o c \_p t\right)-S l o p e \_p t *$ Time $\left(l o c \_p t\right)$;

L_gg $=\left(\min \left(\mathrm{N} \_g g\right)-b \_g g\right) . / S l o p e \_g g ;$

$\mathrm{L} \_\mathrm{pt}=\left(\min \left(\mathrm{N} \_\mathrm{pt}\right)-\mathrm{b} \_\mathrm{pt}\right) /$ /Slope $\_$pt;

\% Time Constants (time to achieve $63.2 \%$ rise) 
$\%$ Time Constant calculation (T_1 = TotalTime - DeadTime)

$\%$ Looking to find elapse time required to reach $63.2 \%$ of Delta_c

$\%$ This method is a more accurate reprensentation of the dominet time constant

$\%$ see "Feedback Controllers for the Process Industries" by F.G.Shinskey

Percent $N \_g g=\left(N \_g g-\min \left(N \_g g\right)\right) . / D e l t a \_N \_g g ;$

$\mathrm{T} \_g g=$ interp 1 (Percent_N_gg, Time ,0.632,'pchip')-L_gg;

Percent $\mathbf{N} \_p t=\left(\mathbb{N} \_p t-\min \left(\mathbf{N} \_p t\right)\right) . /$ Delta $N \_p t$

$T \_p t=$ interpl(Percent_N_pt, Time ,0.632,'pchip')-L_pt;

\% Controller Gains (K1, K2, K3)

$\mathrm{K} 1=(1 . /$ Delta_N $\mathrm{N}$ pt $)$

$\mathrm{K} 2=($ Delta_N_gg);

$\mathrm{K} 3=($ Delta_m/Delta_N_gg $)$;

\% PI Gains (Kp, Ti)

$\%$ Based on the characteristic eqn

$\%$ Design requirements: Settling time $(2 \%$ criteron $)=2.5 \mathrm{~s}$

$\% \quad$ Max Overshoot $=10 \%$

$\%$

$\%$ Characteristic Eqn $=1+$ Controller * Plant

$\%$ Charc. Eqn $=s^{\wedge} 2+\left(1 / T \_p t+\left(1 / T \_p t\right)^{*} K p\right)+\left(1 / T \_p t\right)^{*}(K p / T i)$

$\%$

$\%$ Notice Charc Eqn. has the form of $s^{\wedge} 2+2 * z e t a * w n+w n^{\wedge} 2$

$\%$

$\%$ Therefore $\left(1 / \mathrm{T} \_\mathrm{pt}+\left(1 / \mathrm{T} \_\mathrm{pt}\right)^{*} \mathrm{Kp}\right)=2^{*} \mathrm{zeta}^{*} \mathrm{wn}$

$\%$ and $\left(1 / \mathrm{T} \_\mathrm{pt}\right)^{*}(\mathrm{Kp} / \mathrm{Ti})=\mathrm{wn}^{\wedge} 2$

$\%$

$\%$ we know that Damping Ratio zeta $=$

sqrt((log(MaxOverShoot)./pi).^2./(1+(log(MaxOverShoot)./pi).^2));

$\%$ and Undamped Natural Frequency is $w n=4 . /\left(\right.$ ts. ${ }^{*}$ zeta) for $2 \%$ criterion

$\%$

\% Rearrange to get $\mathrm{Kp}$ and $\mathrm{Ti}$

$\% \quad \mathrm{M}=0.1$

$\% \quad$ ts $=2$

$\% \quad$ zeta(i) $=\operatorname{sqrt}\left((\log (\mathrm{M}) \cdot / \mathrm{pi}) \cdot{ }^{\wedge} 2 . /\left(1+(\log (\mathrm{M}) . / \mathrm{pi}) \cdot{ }^{\wedge}\right)\right)$;

$\% \quad \operatorname{wn}(\mathrm{i})=4 . /\left(\right.$ ts. ${ }^{*}$ zeta(i));

$\% \quad \mathrm{Kp}(\mathrm{i})=\left(2 . *\right.$ zeta(i) $\left..^{*} \mathrm{wn}(\mathrm{i})-1 . / \mathrm{T} \_\mathrm{pt}(\mathrm{i})\right) . /\left(1 . / \mathrm{T} \_\mathrm{pt}(\mathrm{i})\right)$;

$\% \quad \mathrm{Ti}(\mathrm{i})=\left(1 . / \mathrm{T} \_\mathrm{pt}(\mathrm{i})\right) .^{*} \mathrm{Kp}(\mathrm{i}) . /(\mathrm{wn}(\mathrm{i})) .^{\wedge} 2$

$\% \% \% \%$ Acceleration Gains $\% \% \% \%$

MaxFuel = interp1(Ngg range, AccFuelSched, $\min \left(\mathrm{N} \_g g\right)$, 'pchip').* $^{*}$

Interpl(OffDesign_Data_load(:,8),OffDesign_Data_load(:, 14),min(N_gg),'spline');

RefFuel = Interpl (OffDesign_Data_load(:,8), OffDesign_Data_load(:,20),min(N_gg),'spline');

RefNgg $=\min \left(\mathrm{N} \_g g\right)$;

if RefNgg $<0.9 . * \mathrm{~N} \_\mathrm{GG}$

$\mathrm{M}=0.05$;

ts $=2$

else 


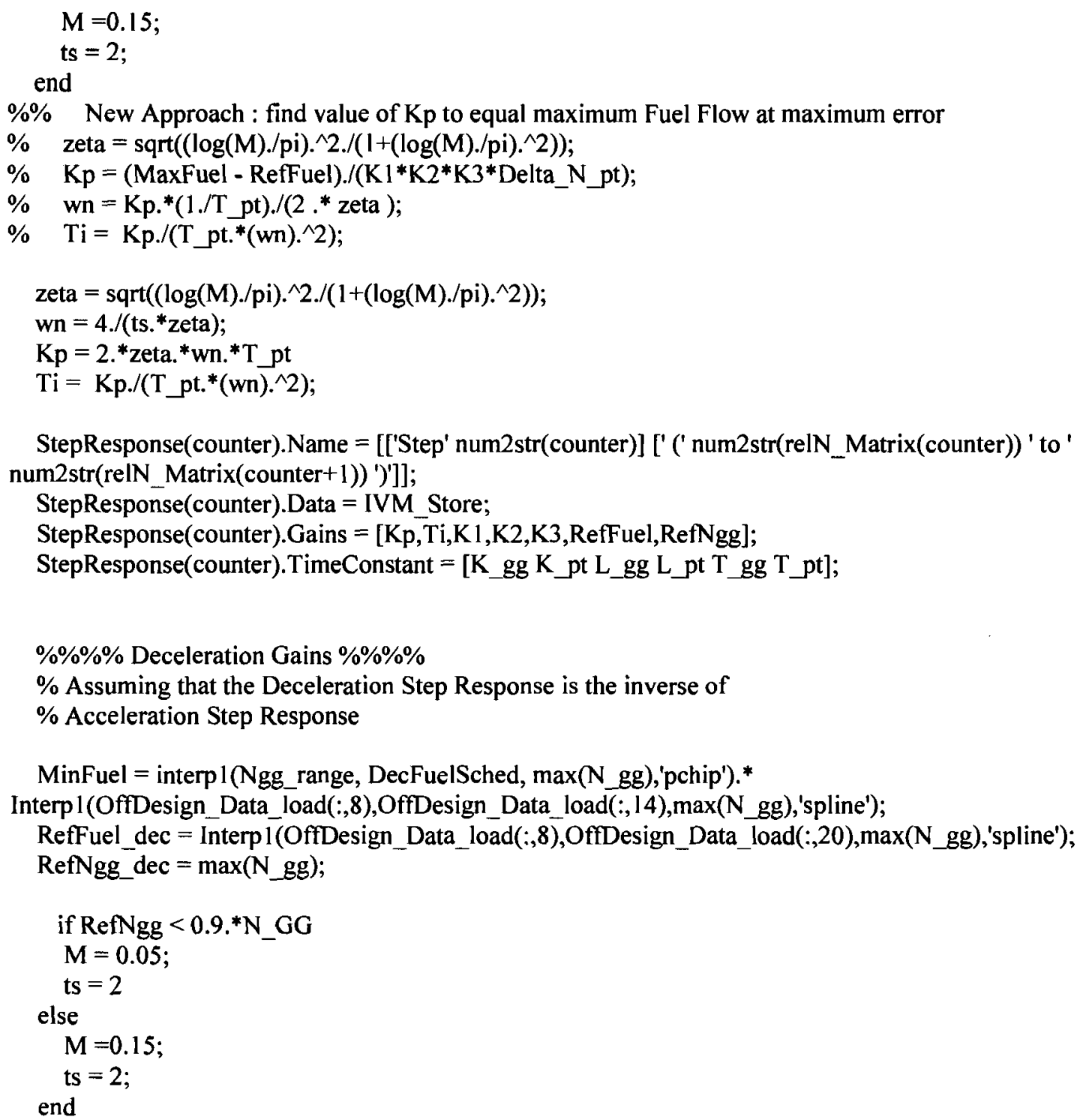

$\%$ New Approach : find value of $\mathrm{Kp}$ to equal maximum Fuel Flow at maximum error

$\% \quad$ zeta $=\operatorname{sqrt}((\log (\mathrm{M}) . / \mathrm{pi}) . \wedge 2 . /(1+(\log (\mathrm{M}) . / \mathrm{pi}) . \wedge 2))$;

$\% \quad$ Kp_dec $=($ RefFuel_dec-MinFuel)./(K1*K2*K3*Delta_N_pt);

$\% \quad \mathrm{wn}=\mathrm{Kp} \_$dec. ${ }^{*}(1 . / \mathrm{T}$ pt $) . /\left(2 .{ }^{*}\right.$ zeta $)$;

$\% \quad \mathrm{Ti}$ dec $=\mathrm{Kp} \_$dec./(T_pt.*(wn).^2);

zeta $=\operatorname{sqrt}\left((\log (M) \cdot / \mathrm{pi}) \cdot{ }^{\wedge} 2 . /(1+(\log (\mathrm{M}) \cdot / \mathrm{pi}) . \wedge 2)\right) ;$

wn $=4 . /\left(\right.$ ts. ${ }^{*}$ zeta);

$\mathrm{Kp} \_$dec $=2 .{ }^{*}$ zeta. $^{*} \mathrm{wn} .{ }^{*} \mathrm{~T} \_\mathrm{pt}$

Ti_dec $=$ Kp_dec./(T_pt. $\left.{ }^{*}(w n) .^{\wedge} 2\right)$;

StepResponse(counter).Gains_Dec $=\left[\mathrm{Kp} \_\right.$dec,Ti_dec,K1,K2,K3,RefFuel_dec,RefNgg_dec];

$\%$ Data and Time Constant will be the same as Acceleration

fprintf(1,' Done $\left.\backslash n^{\prime}\right)$

end

fprintf( 1 ,'In'n Saving: MP_StepResponse.mat. .') 
\%savefile = 'MP_StepResponse.mat';

savefile $=$ ' $C:$ Documents and Settings $\backslash$ Steve Locas $\backslash$ BureaulNouveau dossierlMP_StepResponse.mat'; save(savefile,'StepResponse');

fprintf(1,' Done $\left.\backslash n^{\prime}\right)$

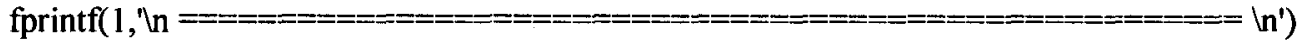

\%\%\%\%\%\%\%\%\%\%\%\%\%\%\%\%\%\%\%\%\%\%\%\%\% End \%\%\%\%\%\%\%\%\%\%\%\%\%\%\%\%\%\%\%\%\%\%\%

$\% \% \% \% \% \% \% \% \% \% \% \% \% \% \% \% \%$ MP_IVM_NewtonRap.m $\% \% \% \% \% \% \% \% \% \% \% \% \%$

$\%$ Transient BetaLPT and Po4 calculation

\%\%\%\%\%\%\%\%\%\%\%\%\%\%\%\%\%\%\%\%\%\%\%\%\%\%\%\%\%\%\% NOTES

\%\%\%\%\%\%\%\%\%\%\%\%\%\%\%\%\%\%\%\%\%\%\%\%\%\%\%\%\%\%\%\%\%\%

\% Source: Turns " An Intoduction To Combustion

$\%$ 2nd edition " Appendix E

$\%$ Also " Numerical Methods with Matlab" sec 8.5

\%\%\%\%\%\%\%\%\%\%\%\%\%\%\%\%\%\%\%\%\%\%\%\%\%\%\%\%\%\%\% OUTPUTS

\%\%\%\%\%\%\%\%\%\%\%\%\%\%\%\%\%\%\%\%\%\%\%\%\%\%\%\%\%\%\%\%

$\%$ AMatrix $=[$ BetaC BetaT BetaLPT Po4 ma Error $]$

$\% \% \% \% \% \% \% \% \% \% \% \% \% \% \% \% \% \% \% \% \% \% \% \% \% \% \% \% \%$ Calculations

\%\%\%\%\%\%\%\%\%\%\%\%\%\%\%\%\%\%\%\%\%\%\%\%\%\%\%\%\%\%

function [AMatrix,BMatrix ] =

MP_IVM_NewtonRap(N,N_pt,FuelFlow_now,Po2_now,X_guess,ma_guess)

F_old $=0$;

$\mathrm{k}=1$;

\% Initial Guess [BetaC BetaT BetaLPT Po4]

$\mathrm{x}=\left[\mathbf{x} \_\right.$guess $]$

$\%$ Outer Loop used in case the simulation diverges

while $\mathrm{k}<50$

$\mathrm{k}=\mathrm{k}+1$

$\% \% \% \% \% \% \% \% \% \% \% \% \% \% \% \% \% \% \% \% \% \% \% \% \% \% \%$ Jacobian matrix

\%\%\%\%\%\%\%\%\%\%\%\%\%\%\%\%\%\%\%\%\%\%\%\%\%\%\%\%

$\%$ Setup of the Jacobian Matrix

$[F, J, m l, M a t x]=M P \_I V M \_J a c o b\left(N, N \_p t, F u e l F l o w \_n o w, P o 2 \_n o w, x, m a \_g u e s s\right) ;$

\% Solve using Gauss Elimination (in MatLab this is donw using "l")

$\mathrm{dx}=(\mathrm{JF})$ 


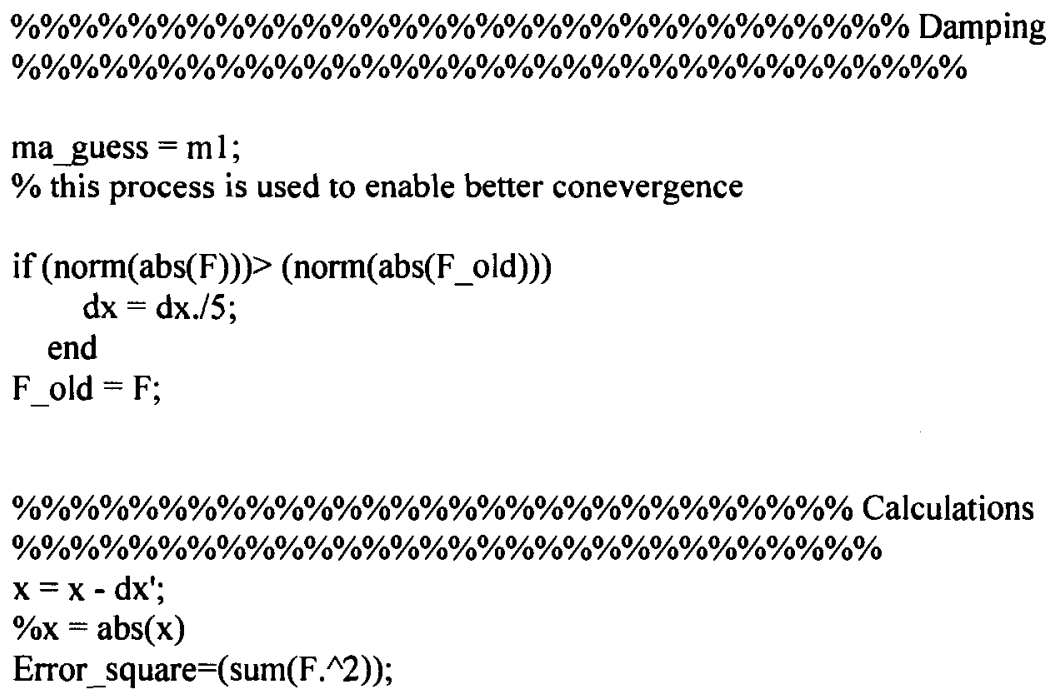

end

fprintf(1,'Maximum iterations reached! Search did not converge for $\mathrm{N}=\% 6.2 \mathrm{ftn}, \mathrm{N})$ AMatrix $=[\mathrm{x}$ ma_guess Error_square $]$;

BMatrix = Matx; 
$\% \% \% \% \% \% \% \% \% \% \% \% \% \%$ MP_IVM_Jacob.m \%\%\%\%\%\%\%\%\%\%\%\%\%\%\%\%\%

$\%$ Transient calculations based on Inter Component volume approach (IVM)

\%\%\%\%\%\%\%\%\%\%\%\%\%\%\%\%\%\%\%\%\%\%\%\%\%\%\%\%\%\%\% NOTES

\%\%\%\%\%\%\%\%\%\%\%\%\%\%\%\%\%\%\%\%\%\%\%\%\%\%\%\%\%\%\%\%\%\%

$\%$ Setup the Jacobian matrix for use in the Generalized Newton's Method $\%$ Source: Turns

$\%$ Note that only the combustor+plenum intercompent volume is being considered...

$\%$ we are assuming that the volume between turbines is small

\%\%\%\%\%\%\%\%\%\%\%\%\%\%\%\%\%\%\%\%\%\%\%\%\%\%\%\%\%\%\%\%\%\%\%\% OUTPUTS

\%\%\%\%\%\%\%\%\%\%\%\%\%\%\%\%\%\%\%\%\%\%\%\%\%\%\%\%\%\%\%\%\%\%\%

$\% \mathrm{f}=$ system of nonlinear equations

$\% \mathrm{~J}=$ Jacobian of the system of equations

$\% \% \% \% \% \% \% \% \% \% \% \% \% \% \% \% \% \% \% \% \% \% \% \% \% \% \% \% \% \% \%$ Calculations

$\% \% \% \% \% \% \% \% \% \% \% \% \% \% \% \% \% \% \% \% \% \% \% \% \% \% \% \% \% \% \% \%$

function $[f, J, m 1, M a t x]=M P \_I V M \_J a c o b\left(N, N \_p t, F u e l F l o w \_n o w, P o 2 \_n o w, x, m a \_g u e s s\right)$

ep $=\left[\left(10^{\wedge}(-5) \cdot{ }^{*} \operatorname{abs}(x(1))\right)\left(10^{\wedge}(-5) \cdot{ }^{*} \operatorname{abs}(x(2))\right)\left(10^{\wedge}(-5) \cdot{ }^{*} \operatorname{abs}(x(3))\right)\left(10^{\wedge}(-5) \cdot{ }^{*} \operatorname{abs}(x(4))\right)\right]$

$\mathrm{xguess}=[\mathrm{x}(1) \mathrm{x}(2) \mathrm{x}(3) \mathrm{x}(4) ; \ldots$

$(\mathrm{x}(1)+\mathrm{ep}(1)) \times(2) \times(3) \times(4) ; \ldots$

$\mathrm{x}(1)(\mathrm{x}(2)+\mathrm{ep}(2)) \mathrm{x}(3) \mathrm{x}(4) ; \ldots$

$\mathrm{x}(1) \mathrm{x}(2)(\mathrm{x}(3)+\mathrm{ep}(3)) \mathrm{x}(4) ; \ldots$

$\mathrm{x}(1) \mathrm{x}(2) \mathrm{x}(3)(\mathrm{x}(4)+\mathrm{ep}(4))]$;

for count $=1$ :size(xguess, 1 )

BetaC $=$ xguess $($ count, 1$)$;

BetaT $=$ xguess(count,2);

BetaLPT = xguess $($ count, 3$)$;

Po4_now $=$ xguess $($ count, 4$)$;

$\% \% \%$ Thermo. Calculations for Simple Cycle Twin-Shaft 1 MW Gas Turbine \%\%\%

$\%$ note that there is no disc cooling, customer bleeds, blade cooling, NGV cooling and leakage

$\%$ considered in this code.

$\%$ Also note that Dry Air is assumed for calculation

MP Inputs;

load MP_DesignPointData.mat

MP ScalingFactor;

MP_HPCOI; 


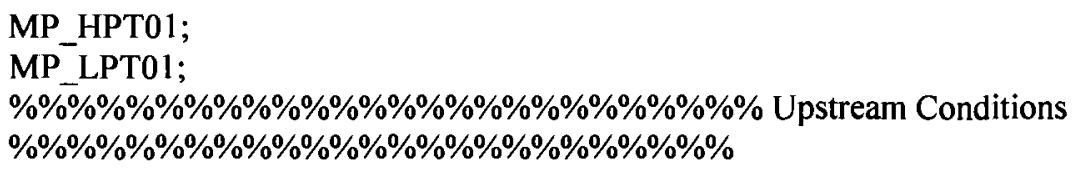

\% Part Load Intake Pressure loss Calculation (From GasTurb 10 manual)

Losslntake $=1$ - (IntakeLoss_des .*((ma_guess.* sqrt(Toa.*Ra)./(Poa.*1000))./non_ma_des).^2);

Pol $=$ LossIntake $\cdot^{*}$ Poa;

Tol $=$ Toa; $\quad$ \% Stagnation Temperature at $1[\mathrm{~K}]$

\%\%\%\%\%\%\%\%\%\%\%\%\%\%\%\%\%\%\%\%\%\%\% Retrive Compressor Map lnfo $\% \% \% \% \% \% \% \% \% \% \% \% \% \% \% \% \% \% \% \% \% \% \% \%$

relN = (N ./sqrt(To1))./(N_GG./sqrt(To1_des)); \% Relative Spool Speed

PRc_calc $=$ Po2_now./Po1;

$\%$ use a newton-raphson search method to find BetaC based on given relN and PRc

[MF_row MF_col] $=\operatorname{size}(\mathrm{MF})$;

$\left[E F \bar{F}\right.$ _row $E \bar{F} \bar{F}_{-}$col $]=\operatorname{size}(\mathrm{EFF})$;

$\left[P R \_\right.$row PR_col] $=$size $(P R)$;

PRc_map $=$ interp2 $\left(\mathrm{PR}\left(1,2: \mathrm{PR} \_\right.\right.$col),PR(2:PR_row, $), \mathrm{PR}\left(2: \mathrm{PR}\right.$ row,2:PR_col),BetaC,relN, ${ }^{\prime *}$ spline'); corr_m1 = interp2(MF(1,2:MF_col),MF(2:MF_row, 1$), \mathrm{MF}(2: \mathrm{MF}$ row, $2: \overline{\mathrm{MF}}$ col),BetaC, relN, '* spline');

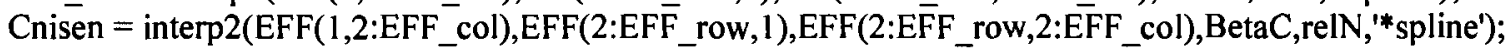

$\mathrm{ml}=$ corr_ml .*((Pol./Pstd)./sqrt((Tol.*Ra)./(Tstd.*Rstd)));

$\% \% \% \% \% \% \% \% \% \% \% \% \% \% \% \% \% \% \% \% \% \% \% \% \%$ Compressor Calculations $\% \% \% \% \% \% \% \% \% \% \% \% \% \% \% \% \% \% \% \% \% \% \% \%$

To2s_guess $=$ Tol $+($ Tol. $/($ Cnisen $)) \cdot{ }^{*}\left(\right.$ PRc_map..$^{\wedge}(($ yamb-1)./yamb $)-1)$

To2s=fzero(@Trans_Error_To2s ,To2s_guess,[],PRc_map, To1, Cnisen, Ra);\% Ideal Stagn. Temp. Function at $2[\mathrm{~K}]$

To2_guess $=$ Tol $+($ Tol.$/$ Cnisen $) .((T o 2 s . / T o l)-1) ;$ 
To2=fzero(@Trans_Error_To2,To2_guess,[], To1, To2s, Cnisen); \% Real Stagn. Temp Function at 2 [K]

$\mathrm{m} 2=\mathrm{ml} . *(1-\mathrm{Bc}) ; \quad \quad \%$ Compressor Discharge Mass Flow Rate

CPower $=\mathrm{m} 1 . *\left(\mathrm{~h} \_\right.$air(To2)-h_air(Tol)); \% Compressor Power $\quad[\mathrm{kW}]$

$\mathrm{Gc}=\mathrm{CPower} . /\left(\mathrm{N} .{ }^{*}\left(2 .{ }^{*} \mathrm{pi}\right) . / 60\right) ; \%$ Compressor Torque $[\mathrm{kNm}]$

\%\%\%\%\%\%\%\%\%\%\%\%\%\%\%\%\%\%\%\%\%\%\%\%\%\%\% Compressor to Burner Ducting $\% \% \% \% \% \% \% \% \% \% \% \% \% \% \% \% \% \% \% \% \% \% \% \% \%$

Po21 $=$ Po2_now. ${ }^{*}(1-$ CompToBurn_Delta_P $) ; \quad \%$ Stagnation Pressure at $21 \quad[\mathrm{kPa}]$

$\%$ Note that To21 is assumed to be equal to the To2 because we are assuming

$\%$ no heat loss between the Compressor and the Burner. This is an

$\%$ approximation and should be corrected with an accurate value for To21.

To21 $=$ To2; $\quad$ \% Stagnation Temperature at $21[\mathrm{~K}]$

$\mathrm{m} 21=\mathrm{m} 2 ; \quad$ \% Mass Flow Rate at $21 \quad[\mathrm{~kg} / \mathrm{s}]$

\%\%\%\%\%\%\%\%\%\%\%\%\%\%\%\%\%\%\%\% Combustion Chamber (Burner) Calculations $\% \% \% \% \% \% \% \% \% \% \% \% \% \% \% \% \% \%$

$\%$ Note that To 3 is assumed to be equal to the TIT because we are assuming

$\%$ no heat loss between the burner and the HP turbine. This is an

$\%$ approximation and should be corrected with an accurate value for To3.

$\%$ Part Load Burner Efficency Calculation (From Walsh \& Fletcher)

Load $=\left(\mathrm{m} 21 . /\left(\left((\mathrm{Po} 21 . / 101.325)^{\wedge} 1.8 .{ }^{*} \mathrm{Vcomb}\right) .{ }^{*} 10 . \wedge\left(0.00145 .{ }^{*}(\mathrm{To} 21-400)\right)\right)\right) ; \%\left[\mathrm{~kg} / \mathrm{s} \mathrm{atm}^{\wedge} 1.8 \mathrm{~m}^{\wedge} 3\right]$

$\mathrm{Bn}=$ PartLoad_Bn(Load);

To3_guess $=1000$

To3=fzero(@Trans_Error_To3,To3_guess,[],To21, m21, HV, Bn, FuelFlow_now);

$\%$ Part Load Burner Pressure loss Calculation (From Walsh \& Fletcher)

DPcold $=$ Kcold. ${ }^{*}$ Po2 1. ${ }^{*}\left(\left(\mathrm{~m} 21 .{ }^{*}\right.\right.$ sqrt(To21)./Po21).^2);

Po3 = Po21- DPcold; $\quad$ \% Stagnation Pressure at $3 \quad[\mathrm{kPa}]$

$\mathrm{m} 3=\mathrm{m} 21+$ FuelFlow; $\quad$ \% Mass Flow Rate at $3 \quad[\mathrm{~kg} / \mathrm{s}]$

\%\%\%\%\%\%\%\%\%\%\%\%\%\%\%\%\%\%\%\% Burner to HP Turbine Ducting (Plenum)

$\% \% \% \% \% \% \% \% \% \% \% \% \% \% \% \% \% \% \%$

To31 $=$ To3; $\quad \%$ Stagnation Temperature at $31[\mathrm{~K}]$

\% Part Load Plenum Pressure loss Calculation (From GasTurb 10 manual)

LossPlenum $=1$ - (Plenum_des .*((m3.* $\operatorname{sqrt}\left(\right.$ To3. ${ }^{*}$ Ra)./(Po3.*1000))./non_m3_des).^2);

Po31 = Po3. ${ }^{*}$ LossPlenum; $\quad \%$ Stagnation Pressure at $31 \quad[\mathrm{kPa}]$

\%\%\%\%\%\%\%\%\%\%\%\%\%\%\%\%\%\%\%\%\%\%\%\%\%\%\%\% HPTurbine Calculations

\%\%\%\%\%\%\%\%\%\%\%\%\%\%\%\%\%\%\%\%\%\%\%\%\%\%\% 
$\%$ note that $\mathrm{m} 4$ is assumed to be equal to $\mathrm{m} 31$ since no cooling is required $\%$ for this design

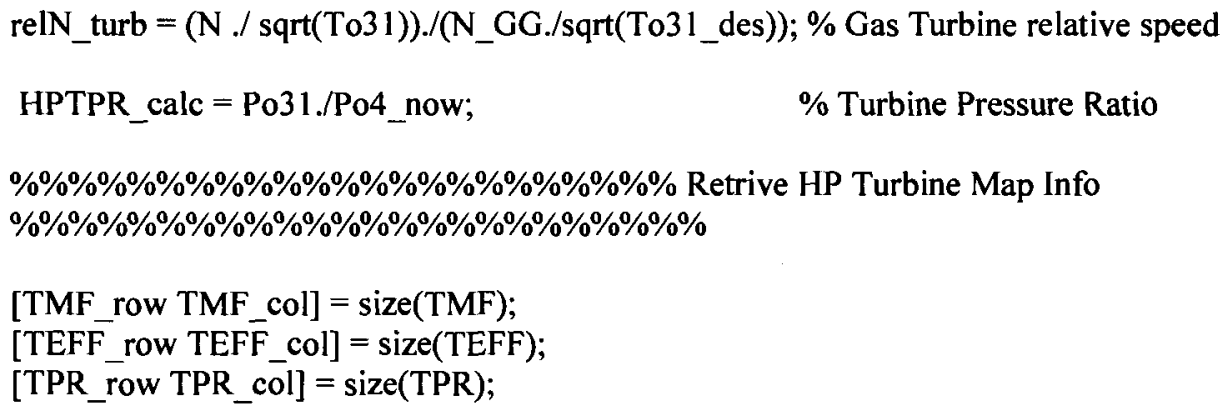

[TMF_row TMF_col] = size (TMF);

$\left[T E F F_{-}\right.$row $T E F \bar{F} \_$col] $=$size $(\mathrm{TEFF})$;

[TPR_row TPR_col] = size $(T P R)$;

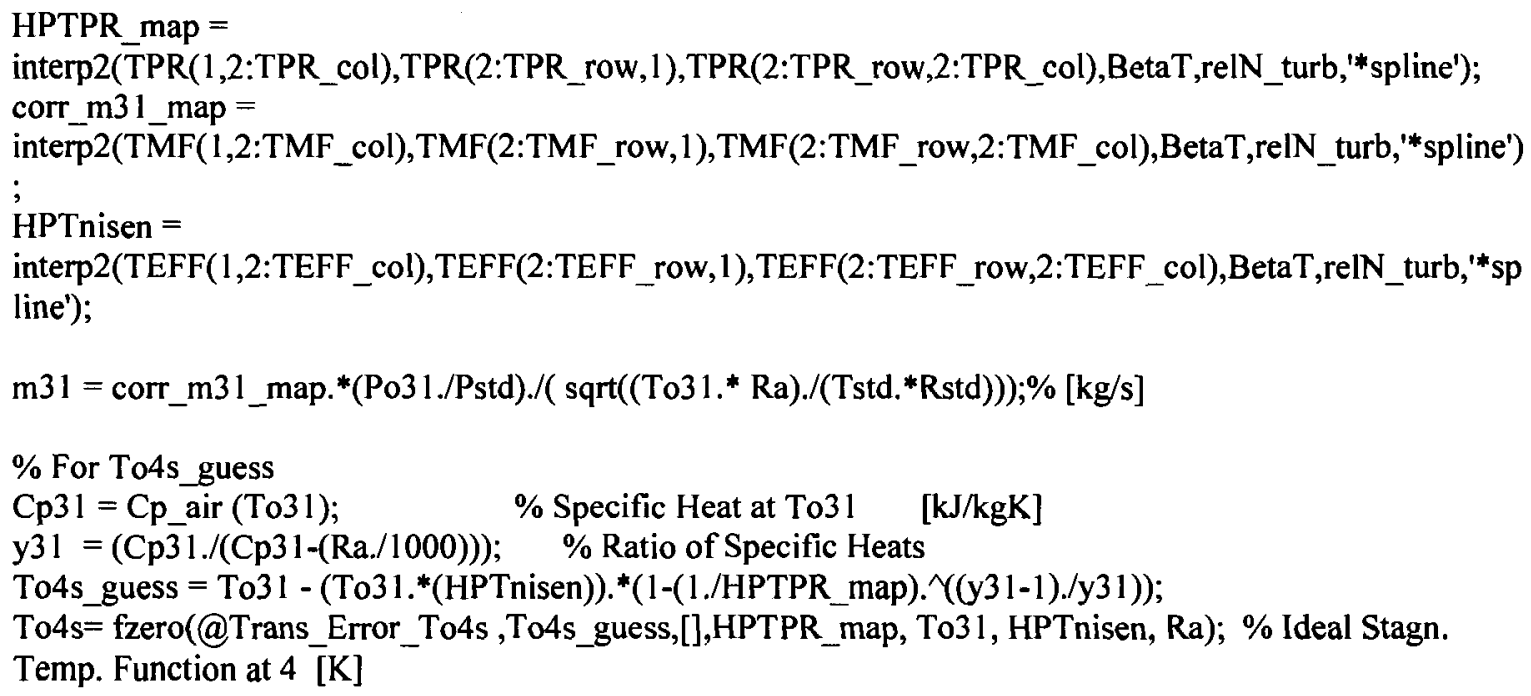

To4_guess $=$ To31 $-\left(\right.$ To31. ${ }^{*}$ HPTnisen $) . *(1-($ To4s/To31));

To4=fzero(@Trans_Error_To4,To4_guess,[], To31, To4s, HPTnisen); \% Stagnation Temp. at 4 [K]

HPTPower $=m 31 . *\left(h \_a i r(T o 31)-h \_a i r(T o 4)\right) ; \quad \%$ Turbine Power $\quad[\mathrm{kW}]$

$\mathrm{Gt}=\mathrm{HPTPower} . /\left(\mathrm{N} .{ }^{*}\left(2 .{ }^{*} \mathrm{pi}\right) . / 60\right) ; \%$ Turbine Torque $[\mathrm{kNm}]$

$\mathrm{m} 4=\mathrm{m} 31$

$\% \% \% \% \% \% \% \% \% \% \% \% \% \% \% \% \% \% \% \% \% \%$ Inter-Turbine Ducting Calculations $\% \% \% \% \% \% \% \% \% \% \% \% \% \% \% \% \% \% \% \%$

$\%$ Duct Pressure Loss Variation

\% Formual Found in GasTurb 10 Manual (Component modelling -- Duct loss)

LossInterTurb $=1$ - (Inter_des $.{ }^{*}\left(\left(\mathrm{~m} 4 .{ }^{*}\right.\right.$ sqrt(To4. ${ }^{*}$ Ra) $) /\left(\right.$ Po4_now. $\left.\left.{ }^{*} 1000\right)\right) . /$ non_m4_des $\left.) .{ }^{\wedge} 2\right)$;

Po41 = Po4_now. ${ }^{*}$ LossInterTurb; $\quad$ \% Stagnation Pressure at $41 \quad[\mathrm{kPa}]$

$\%$ Note that To41 is assumed to be equal to the To4 because we are assuming $\%$ no heat loss between Turbines. This is an

$\%$ approximation and should be corrected with an accurate value for To41.

To41 = To4; $\quad \%$ Stagnation Temperature at $41[\mathrm{~K}]$ 


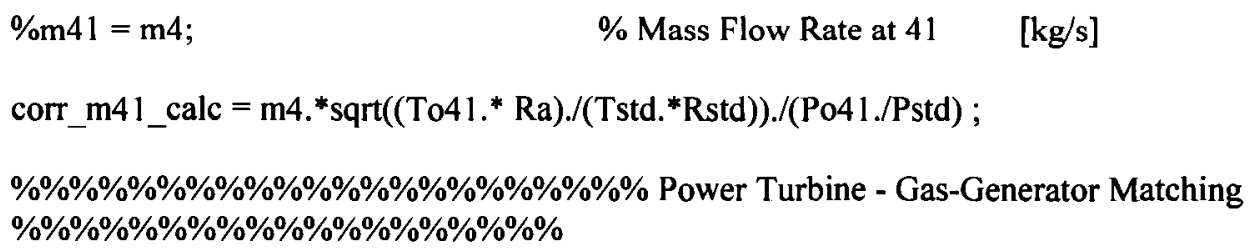

relN_PTurb $=\left(\mathrm{N} \_\right.$pt./ sqrt $($To41 $\left.)\right) . /\left(\mathrm{N} \_P T . /\right.$ sqrt $\left.\left(T o 41 \_d e s\right)\right) ; \%$ Power Turbine relative speed

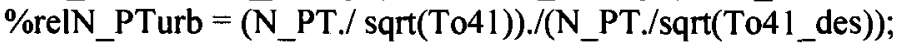

[LTPR_row LTPR_col] = size(LTPR);

[LTMF_row LTMF_col] $=\operatorname{size}($ LTMF);

$[\mathrm{LTEFF}$ _row LTEFF_col] $=\operatorname{size}(\mathrm{LTEFF})$;

LPTPR $=$

interp2(LTPR(1,2:LTPR_col),LTPR(2:LTPR_row, 1),LTPR(2:LTPR_row,2:LTPR_col),BetaLPT,relN_PT urb,'*spline');

corr_m41_map $=$

interp2(LTMF(1,2:LTMF_col),LTMF(2:LTMF_row,1),LTMF(2:LTMF_row,2:LTMF_col),BetaLPT,relN_ PTurb,'*spline');

LPTnisen $=$ interp2(LTEFF(1,2:LTEFF_col),LTEFF(2:LTEFF_row,1),LTEFF(2:LTEFF_row,2:LTEFF_col),BetaLPT,r elN_PTurb,'*spline');

m41 = corr_m41_map.*(Po41./Pstd)./( sqrt((To41.* Ra)./(Tstd.*Rstd)));\% [kg/s]

$\%$ For To5s_guess

Cp41 = Cp_air (To41); \% Specific Heat at To41 [kJ/kgK]

y41 $=(\mathrm{Cp} 41 . /(\mathrm{Cp} 41-(\mathrm{Ra} . / 1000))) ; \quad \%$ Ratio of Specific Heats

To5s_guess = To41 - (To41.*(LPTnisen)).*(1-(1./LPTPR).^((y41-1)./y41));

To5s=fzero(@Trans_Error_To5s,To5s_guess,[],LPTPR, To41, LPTnisen, Ra); \% Ideal Stagn. Temp.

Function at $5[\mathrm{~K}]$

$\%$ for To5 guess

To5_guess = To41 - (To41.*LPTnisen).*(1-(To5s/To41));

To5=fzero(@Trans_Error_To5,To5_guess,[], To41, To5s, LPTnisen); \% Stagnation Temp. at 5 [K]

LPTPower $=$ m41.*(h_air(To41)-h_air(To5)); $\quad \%$ LP Turbine Power $\quad$ [kW]

Gpt $=$ LPTPower./(N pt.*(2.*pi)./60); \% Power Turbine Torque [kNm]

$\%$ Gpt $=$ LPTPower./(N PT.*(2. ${ }^{*}$ pi). $\left./ 60\right)$;

\%\%\%\%\%\%\%\%\%\%\%\%\%\%\%\%\%\%\%\%\%\%\%\%\%\%\%\%\%\% Propeller Power

\%\%\%\%\%\%\%\%\%\%\%\%\%\%\%\%\%\%\%\%\%\%\%\%\%\%\%\%\%

PropPower $=($ LPTPower_des.*GBn.*Mn) .* (N_pt ./ N_PT).^3; \% Propeller load

$\%$ PropPower $=\left(\right.$ LPTPower_des.*GBn.*Mn) $.^{*}\left(\mathrm{~N}_{-} \mathrm{PT} . \overline{\mathrm{I}} \mathrm{N}\right.$ PT $) .^{\wedge} 3$;

$[\mathrm{kW}]$

Gprop $=$ PropPower .* $60 . /\left(\mathrm{N} \_\mathrm{pt} .{ }^{*} 2 .^{*} \mathrm{pi}\right) ; \%$ Propeller Torque $[\mathrm{kNm}]$

$\%$ Gprop $=$ PropPower $* 60 . /\left(\mathrm{N} \_\right.$PT $* 2 . *$ pi);

$\% \% \% \% \% \% \% \% \% \% \% \% \% \% \% \% \% \% \% \% \% \% \% \% \% \% \%$ Exhaust Pressure

$\% \% \% \% \% \% \% \% \% \% \% \% \% \% \% \% \% \% \% \% \% \% \% \% \% \% \%$

$\%$ Duct Pressure Loss Variation

\% Formual Found in GasTurb 10 Manual (Component modelling -- Duct loss) 
$\mathrm{m} 5=\mathrm{m} 41$

Po5 = Po41./LPTPR; $\quad$ \% Stagnation Pressure at $5 \quad[\mathrm{kPa}]$

ExhaustLoss_RHS = (1 - Poa./Po5); \% Right hand side Exhaust Loss Eqn

ExhaustLoss_LHS $=\left(\right.$ ExhaustLoss_des.*$\left(\left(m 5 .{ }^{*}\right.\right.$ sqrt(To5.*Ra)./(Po5.*1000))./non_m5_des).^2); \% Left hand side Exhaust Loss Eqn

\%\%\%\%\%\%\%\%\%\%\%\%\%\%\%\%\%\%\%\%\%\%\%\%\% Engine Performance

$\% \% \% \% \% \% \% \% \% \% \% \% \% \% \% \% \% \% \% \% \% \% \% \% \% \%$

ShaftPower $=$ LPTPower ${ }^{*}$ Mn * GBn; $\quad$ \% Net Shaft Power

$[\mathrm{kW}]$

SFC_SI $=($ FuelFlow.$/$ ShaftPower $) * 3600 ; \quad \%$ Specific Fuel Consumption $\quad[\mathrm{kg} / \mathrm{kWh}]$

Thermal_Efficiency $=$ ShaftPower./(FuelFlow.*HV); \% Engine Overall Efficiency

Matx $=[$ Toa Poa corr_ml m1 To1 Po] Cnisen N relN BetaC PRc_map m2 To2 Po2_now CPower Gc m3 To3 Po3...

Bn FuelFlow_now corr_m31_map m31 Po31 HPTnisen relN_turb BetaT HPTPR_map HPTPower Gt m4 To4 Po4_now...

m41 To41 Po41 corr_m41_map N_pt relN_PTurb BetaLPT LPTPR LPTnisen m5 To5 Po5 LPTPower Gpt ShaftPower Gprop SFC_SI...

Thermal_Efficiency PropPower];

\%\%\%\%\%\%\%\%\%\%\%\%\%\%\%\%\%\%\%\%\%\%\%\%\%\%\%\%\%\%\%\%\%\% Setup

\%\%\%\%\%\%\%\%\%\%\%\%\%\%\%\%\%\%\%\%\%\%\%\%\%\%\%\%\%\%\%\%\%

$\%$ Errors

$\mathrm{F}(1$, count $)=($ PRc_calc $-\mathrm{PRc}$ map $)$;

$F(2$, count $)=$ (HPTPR_calc - HPTPR_map);

$\mathrm{F}(3$, count $)=$ (corr_m41_calc - corr_m 41 map) $) \%$ Turbine Compatibility of FLow

$\mathrm{F}(4$, count $)=($ ExhaustLoss_LHS - ExhaustLoss_RHS $)$;

end

$f=F(:, 1)$

$\% \%$ Setup Jacobian

for count $1=1$ :size $($ xguess, 1$)-1$

for count $2=1: \operatorname{size}($ xguess, 1$)-1$;

end

$\mathrm{dF}($ count 1, count 2$)=(\mathrm{F}($ count $1,($ count $2+1))-\mathrm{F}(\operatorname{count} 1,1)) /(\mathrm{ep}(\operatorname{count} 2))$;

end

$\mathrm{J}=\mathrm{dF}$; 
$\%$ This script calculates Transient performance based on the Intercomponent Volumes Approach $\%$ described in the paper SAE 710550 by Saravanamuttoo

$\%$ The basic assumption in this approach is that flow and work mismatch

$\%$ occur during transients

$\%$ load Off design steady state performance data. this will be used as

$\%$ initial conditions for the transient modeling

clear IVM_Store;

clear Error;

clear Gains;

MP_Inputs;

load MP_DesignPointData.mat

MP_ScalingFactor;

MP_HPCOI;

MP_HPT01;

MP_LPT01;

load MP_OffDesign_Data_load.mat

load MP_AccFuelSched.mat;

load MP_DecFuelSched.mat;

load MP_StepResponse;

load MP_LimiterData.mat;

warning off MATLAB:fzero:UndeterminedSyntax

$\% \% \% \% \% \% \% \% \% \% \% \% \% \% \% \% \% \% \% \%$ Select initial condition (Idle Speed) \%\%\%\%\%\%\%\%\%\%\%\%\%\%

$\% \mathrm{~N}=\mathrm{N} \_\mathrm{GG}$

$\mathrm{N}=$ Ngg_idle;

N_pt = Interp I(OffDesign_Data_load(:,8),OffDesign_Data_load(:,36),N,'spline');

relN = Interpl(OffDesign_Data_load(:,8),OffDesign_Data_load(:,9),N,'spline');

Po2 = Interp 1(OffDesign_Data_load(:,8),OffDesign_Data_load(:,14),N,'spline');

Po4 = Interp l(OffDesign_Data_load(:,8),OffDesign_Data_load(:,31),N,'spline');

BetaC = Interp l(OffDesign_Data_load(:,8),OffDesign_Data_load(:,10), N,'spline');

BetaT = Interpl(OffDesign_Data_load(:,8),OffDesign_Data_load(:,26),N,'spline');

BetaLPT = Interpl(OffDesign_Data_load(:,8),OffDesign_Data_load(:,37), N,'spline');

$\mathrm{ma}=$ Interp 1 (OffDesign_Data_load(:,8),OffDesign_Data_load(:,4),N,'spline');

FuelFlow = Interpl(OffDesign_Data_load(:,8),OffDesign_Data_load(:,20),N,'spline');

$\mathrm{TIT}=$ Interpl(OffDesign_Data_load(:,8),OffDesign_Data_load(:,17), $\mathrm{N}$, 'spline');

$\mathrm{m} 21$ = Interpl(OffDesign_Data_load(:,8),OffDesign_Data_load(:,12),N,'spline');

$\operatorname{Trq}=0$;

sumError $=0$;

PLA_old $=0$;

Move $=0$;

dN_old $=0$;

dN_pt_old $=0$;

$\mathbf{x}$ guess $=[$ BetaC BetaT BetaLPT Po4 $] ;$

$\mathrm{t}=0$;

$\mathrm{dPo}=0$;

ii $=1$; 


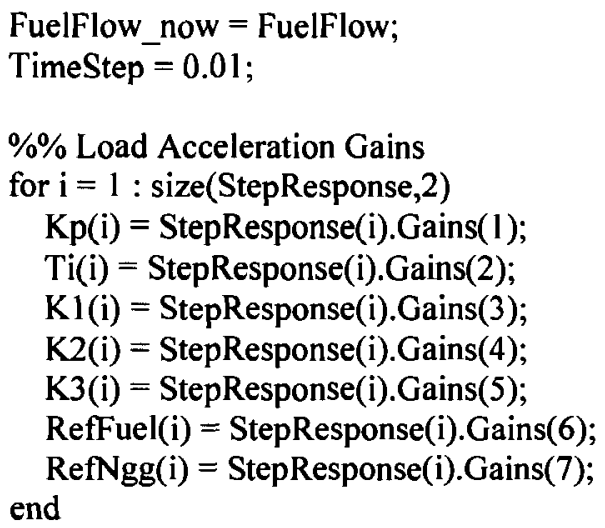

$\% \%$ Load Decelaration Gains

for $\mathrm{i}=1: \operatorname{size}($ StepResponse,2)

Kp_dec(i) = StepResponse(i).Gains_Dec(1);

Ti_dec(i) = StepResponse(i).Gains_Dec(2);

K1__dec(i) = StepResponse(i).Gains_Dec(3);

K2_dec(i) = StepResponse(i).Gains_Dec(4);

K3_dec(i) = StepResponse(i).Gains_Dec(5);

RefFuel_dec(i) = StepResponse(i).Gains_Dec(6);

RefNgg_dec(i) = StepResponse(i).Gains_Dec(7); end

\% Inital PI Controller Gains

Kp_now = interpl(RefNgg,Kp,N,'pchip');

Ti_now = interpl(RefNgg,Ti,N,'pchip');

$\mathrm{K}$ 1_now = interpl(RefNgg,K1,N,'pchip');

K2_now = interp l(RefNgg,K2,N,'pchip');

K3_now = interpl(RefNgg, K3,N,'pchip');

RefFuel_now = interpl(RefNgg,RefFuel,N,'pchip');

RefNgg_now = interpl(RefNgg,RefNgg,N,'pchip');

$\% \% \%$ Only use for starting simulation at N_GG

$\% \%$ Inital PI Controller Gains

$\% \quad K p \_n o w=$ interp $1(\operatorname{RefNgg}$ dec,Kp_dec,N,'pchip');

$\%$ Ti_now = interp $1(\operatorname{RefNgg}$ dec,Ti_dec,N,'pchip');

$\% \quad \mathrm{~K} 1$-now $=$ interpl $(\mathrm{RefNgg}$ dec,K1_dec,N,'pchip');

$\% \quad \mathrm{~K} 2 \_$now $=$interpl(RefNgg_dec,K2_dec,N,'pchip');

$\% \quad$ K3_now $=$ interpl $($ RefNgg_dec,K3_dec,N,'pchip');

$\%$ RefFuel now $=$ interpl(RefNgg_dec,RefFuel_dec,N,'pchip');

$\% \quad$ RefNgg_now = interpl $($ RefNgg_dec,RefNgg_dec,N,'pchip');

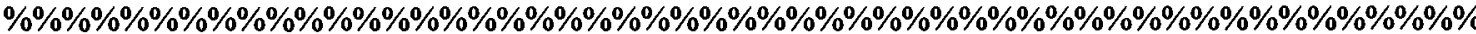
$\% \% \% \% \% \% \% \% \% \% \% \% \% \% \% \% \% \% \% \% \% \% \% \%$

$\% \% \%$ User Inputs \%\%\%\%

$\%$ User Inputs are usally PLA vs Time

$\%$ note that PLA inputs vary between 0 and 10 nly !

$P L A=[00.1072]$

for counter $=1: \operatorname{size}(\mathrm{PLA}, 2)$ 
PLA_now $=$ PLA(counter);

N_pt_req =interp 1 ([0 1 1$],\left[\min \_N p t\right.$ N_PT],PLA_now,'pchip')

$\mathrm{dN}=2 ; \%=2$ to jump the first while condition

$\mathrm{dN} \_\mathrm{pt}=2 ; \%=2$ to jump the first while condition

while $(\operatorname{abs}(\mathrm{dN})<=1)+\left(\operatorname{abs}\left(\mathrm{dN} \_\right.\right.$pt $\left.)<=1\right)<2$

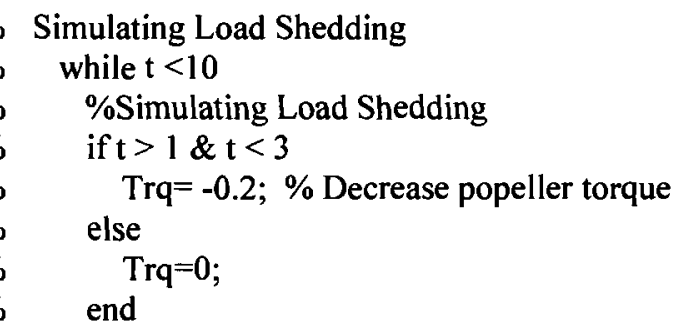

MP_ControlModule;

PLĀ old = PLA_now;

$\left[I V M \_N e w t o n, I V M \_M a t x\right]=M P \_I V M \_N e w t o n R a p\left(N, N \_p t, F u e I F l o w \_n o w, P o 2, x \_g u e s s, m a\right)$;

$\%$ IVM_Newton $=[$ BetaC BetaT BetaLPT Po4 ma_guess Error_square $]$

$x$ _guess $=[$ IVM_Newton(1:4)];

ma $=$ IVM_Newton(5);

TIT = IVM_Matx(18);

$\mathrm{m} 21$ = IVM_Matx(12);

$\% \% \% \% \% \% \% \% \% \% \% \% \% \% \% \% \% \%$ Rate of Change of Speed $\% \% \% \% \% \% \% \% \% \% \% \% \% \% \%$ $\%$ we know that $\mathrm{dN} / \mathrm{dt}=60(\mathrm{Gt}-\mathrm{Gc}) /(2 \mathrm{piIg})$

$\%$ Since Torque is in $\mathrm{kNm}$ we get $\mathrm{dN} / \mathrm{dt}=60 * 1000(\mathrm{Gt}-\mathrm{Gc}) /(2 \mathrm{pilg})$

$\mathrm{dN}=60 .{ }^{*} 1000 . *\left(\left(I V M \_M a t x(30) .{ }^{*} \mathrm{Mn}\right)-I V M \_M a t x(16)\right) . /\left(2 .{ }^{*} \mathrm{pi} .{ }^{*} \mathrm{Ig}\right) ; \%[\mathrm{RPM} / \mathrm{s}]$

$\%$ and for the Power Turbine

$\% \operatorname{Trq}=$ torque change... used to simulate sudden load variations $[\mathrm{RPM} / \mathrm{s}]$

$\mathrm{dN} \_\mathrm{pt}=60 .{ }^{*} 1000 .{ }^{*}\left(\left(\mathrm{IVM} \_\operatorname{Matx}(47) .{ }^{*} \mathrm{Mn} .{ }^{*} \mathrm{GBn}\right)-\left(\operatorname{IVM} \_\operatorname{Matx}(49)+\operatorname{Trq}\right)\right) . /\left(2 .{ }^{*} \mathrm{pi} .{ }^{*} \operatorname{Ig} \_\mathrm{pt}\right) ; \%$

$\% \% \% \% \% \% \% \% \% \% \% \% \% \% \% \% \% \%$ Rate of Change of Pressure in a Volume $\% \% \% \% \% \% \% \% \% \% \% \% \% \% \%$

$\%$ we know that $\mathrm{dP} / \mathrm{dt}=\left(\mathrm{m} \text { in }-\mathrm{m} \_ \text {out }\right)^{*}((\mathrm{~T} * \mathrm{Ra}) /$ Volume $)$

$\%$ therfore for the combustor we have: $\mathrm{dPo} 2 / \mathrm{dt}=(\mathrm{m} 2+\text { FuelFlow }-\mathrm{m} 31)^{*}(\mathrm{To} 2 * \mathrm{Ra}) /(\mathrm{Vcomb}+$ Vplenum)

dPo2 $=\left(\left(I V M \_M a t x(12)+I V M \_M a t x(21)-I V M \_M a t x(23)\right) . *\left(\left(I V M \_M a t x(13) . * R a\right) . /(V c o m b+\right.\right.$ Vplenum)))./1000; $\%[\mathrm{kPa} / \mathrm{s}]$

$\%$ Euler Explicit scheme

$\mathrm{N}=\mathrm{N}+\mathrm{dN} .{ }^{*}$ TimeStep;

$\mathrm{N} \_\mathrm{pt}=\mathrm{N} \_\mathrm{pt}+\mathrm{dN} \_$pt.* TimeStep;

$\mathrm{P} 02=\mathrm{Po} 2+\mathrm{dPo} 2{ }^{*}$ TimeStep;

\% Thermodynamic Cycle Data

IVM_Store(ii,:) =[t IVM_Matx dN dN_pt dPo2 TimeStep IVM_Newton(6) PLA_now Trq];

Error(ii,:) $=[$ Error_N_pt Error_N Delta_Npt_p Delta_Npt_I $]$; 
Gains(ii,:) $=\left[\mathrm{Kp} \_\right.$now Ti_now K1_now K2_now K3_now];

$\% \quad$ Note that: IVM_Store $=[\mathrm{t}$ Toa Poa corr_m1 m1 To1 Po1 Cnisen N relN BetaC PRc $\mathrm{m} 2$ To2 Po2 CPower Ge m3 To3 Po3...

$\%$ Bn FuelFlow corr_m31_calc m31 Po31 HPTnisen relN_turb BetaT HPTPR HPTPower Gt m4 To4 Po4...

$\% \quad$ m41 To41 Po41 corr_m41_calc N_pt relN_PTurb BetaLPT LPTPR LPTnisen m5 To5 Po5 LPTPower Gpt ShaftPower Gprop SFC

$\% \quad$ Thermal_Efficiency PropPower $\mathrm{dN} d \mathrm{~N} \_p t \mathrm{dPo} 2$ TimeStep Error_square PLA_now Trq]

$\mathrm{t}=\mathrm{t}+$ TimeStep;

$\mathrm{ii}=\mathrm{ii}+1$;

fprintf $\left(1,,^{\prime} t=\% 6.4 \mathrm{f} \quad\right.$ TimeStep=\%6.4fn $\mathrm{N}=\% 5.0 \mathrm{f} \quad \mathrm{dN}=\% 6.2 \mathrm{fn} \mathrm{N} \_\mathrm{pt}=\% 5.0 \mathrm{f} \quad \mathrm{dN} \_\mathrm{pt}=$ $\% 6.2 \mathrm{fln}$ Po2 $=\% 6.2 \mathrm{f} \quad \mathrm{dPo} 2=\% 6.2 \mathrm{fn}$ ',t, TimeStep, $\mathrm{N}, \mathrm{dN}, \mathrm{N}$ pt, dN pt, Po2, dPo2)

fprintf(1,"nAcc_FuelFlow $=\% 6.4 \mathrm{f}$ ',Acc_FuelFlow_sched);

fprintf( 1, "nFueiFlow $=\% 6.4 \mathrm{f}$, FuelFlow_now);

fprintf( 1 ,' 'nDec_FuelFlow $=\% 6.4$ fin $\backslash n$ ',Dec_FuelFlow_sched $)$;

end

end

savefile = 'MP_SmallStep.mat';

save(savefile,'IVM_Store','Error','Gains');

\%\%\%\%\%\%\%\%\%\%\%\%\%\%\%\%\%\%\%\%\%\%\% End \%\%\%\%\%\%\%\%\%\%\%\%\%\%\%\%\%\%\%\%\%\%\%\%\%\%

$\% \% \% \% \% \% \% \% \% \% \% \% \% \% \% \%$ MP_ControlModule.m $\% \% \% \% \% \% \% \% \% \% \% \% \% \% \% \%$

$\%$ PI controller with gain scheduling

$\% \% \% \%$ Controls $\% \% \% \%$

$\%$ Power Turbine SetPoint Error

Error_N_pt $=\mathrm{K} 1 \_$now. ${ }^{*}\left(\mathrm{~N} \_\mathrm{pt} \_\right.$req $\left.-\mathrm{N} \_\mathrm{pt}\right)$;

$\%$ Proportional term

Delta_Npt_p $=$ Kp_now.$^{*}$ Error_N_pt;

$\%$ Integral Term

if $\mathrm{Ti}$ now $==0$

Delta_Npt_I $=0$;

else

Delta Npt $\mathrm{I}=(\mathrm{Kp}$ now. $/ \mathrm{Ti}$ now $) .^{*}$ (sumError + Error_N_pt.* TimeStep);

sumError $=$ (sumError + Error_N_pt.* TimeStep $)$; end

Ngd $1=\left(\right.$ Delta_Npt $\_$p Delta_Npt_I ${ }^{*}$ K2_now

\%\%\%\%\%\%\%\%\%\%\%\%\%\%\%\%\% Over-Speed and Over-Temp Protection

$\% \% \% \% \% \% \% \% \% \% \% \% \% \% \% \% \%$ 
$\% \% \% \%$ Over Temperature Protection $\% \% \% \%$

MaxTIT_Demand = Interp1(TIT_range,Demand_Control,TIT,'pchip'); \% [\%]

Ngd2 = Ngd1 .*MaxTIT_Demand;

$\% \% \% \%$ Gas Generator Over-Speed Protection \%\%\%\%

MaxRPM_Demand = Interp1(Max_GG_RPM_range,Max_GG_Demand_Control,N,'pchip'); \% [\%]

Ngd3 = Ngd1 .* MaxRPM_Demand;

$\% \% \% \%$ PT Over-Speed Protection \%\%\%\%

Max_PT_RPM_Demand = Interpl(Max_PT_RPM_range,Max_PT_Demand_Control,N_pt,'pchip'); \% [\%]

Ngd $4=$ Ngdl .* Max_PT_RPM_Demand;

$\% \% \% \%$ Low Select $\% \% \% \%$

$\%$ Select lowest Ngg demand to ensure all Limiters are satified

$\mathrm{Ngd}=\min ([\mathrm{Ngd} 1 \mathrm{Ngd} 2 \mathrm{Ngd} 3 \mathrm{Ngd} 4])$;

\%\%\%\%\%\%\%\%\%\%\%\%\%\%\%\%\%\%\%\%\%\%\%\%\%\%\%\%\%\%\%\%\%\%\%\%\%\%\%\%\%\%\%\%\%\%\%\%\%\%\%

$\% \% \% \% \% \% \% \% \% \% \% \% \% \% \% \% \% \% \%$

$\%$ GG Spool Speed SetPoint Error

N_req $=$ RefNgg_now + Ngd;

Error_N $=\mathrm{N} \_$req $-\mathrm{N}$;

$\%$ PI Control Fuel Demand

Delta_mf_l $=($ K3_now.* Error_N $)$;

$\% \% \% \% \% \% \% \% \% \% \% \% \% \% \% \%$ Minimum Speed and FlameOut Protection

$\% \% \% \% \% \% \% \% \% \% \% \% \% \% \% \% \%$

$\% \% \% \%$ Minimum GG Spool Speed \%\%\%\%

MinRPM_Demand = Interpl(Min_GG_RPM_range,Min_GG_Demand_Control,N,'pchip'); \% [\%]

Delta_mf_2 $=$ Delta_mf_1 .* MinRPM_Demand;

$\% \% \% \%$ FlameOut \%\%\% $\%$

$\%$ Fuel to air ratio should be greater than 0.008 during transient

\%operations (Walsh \& Fletcher Gas Turbine Performance Page 456)

$\%$ FA_Limit $=($ Delta_mf_3 + RefFuel_now $) . / \mathrm{m} 21$

Delta_mf_3 $=\left(\right.$ FA_Limit ${ }^{*}$ m21)-RefFuel_now;

$\% \% \% \%$ High Select \%\%\%\%

$\%$ Select Highest Delta_mf demand to ensure all Limiters are satified

Delta_FuelFlow $=\max ([$ Delta_mf_1 Delta_mf_2 Delta_mf_3]);

\%\%\%\%\%\%\%\%\%\%\%\%\%\%\%\%\%\%\%\%\%\%\%\%\%\%\% Fuel Schedules

\%\%\%\%\%\%\%\%\%\%\%\%\%\%\%\%\%\%\%\%\%\%\%\%\%\%\%

$\% \% \% \%$ Accel Fuel Schedule $\% \% \% \%$

Acc_relFuel_now =interp 1(Ngg_range,AccFuelSched,N,'pchip');

Acc_FuelFlow_sched $=$ Acc_relFuel_now. ${ }^{*}$ Po2;

$\% \% \% \%$ Decel Fuel Schedule \%\%\%\%

Dec_relFuel_now =interpl(Ngg_range,DecFuelSched,N,'pchip');

Dec_FuelFlow_sched $=$ Dec_relFuel_now. ${ }^{*}$ Po2 ; 
\%\%\%\%\%\%\%\%\%\%\%\%\%\%\%\%\%\%\%\%\%\% OverAll Fuel Flow Demand $\% \% \% \% \% \% \% \% \% \% \% \% \% \% \% \% \% \% \% \% \% \% \% \%$

$\%$ During Acceleration select lowest fuel flow setting

$\%$ (Fuel Flow Demand vs Acc Fuel Flow)

FuelFlow_Demand $=\min (($ Delta_FuelFlow + RefFuel_now $)$, Acc_FuelFlow_sched $)$

$\%$ During Deceleration select Highest fuel flow setting

\% (Fuel Flow Demand vs Dec Fuel Flow)

FuelFlow_now $=\max ($ FuelFlow_Demand, Dec_FuelFlow_sched);

$\% \% \% \% \% \% \% \% \% \% \% \% \% \% \% \% \% \% \% \% \% \% \% \%$ Gain Scheduling

$\% \% \% \% \% \% \% \% \% \% \% \% \% \% \% \% \% \% \% \% \% \% \% \% \% \% \% \% \% \% \% \%$

$\% \%$ Check if engine is stable (not accelerating or decelerating)

$\%$ Checking if engine is accelerating or decelerating without user

$\%$ input(loss off load for example)

if $\operatorname{abs}\left(\mathrm{dN} \_\mathrm{pt}-\mathrm{dN} \_\mathrm{pt} \_\right.$old $)>1000 \& \mathrm{abs}(\mathrm{dN}-\mathrm{dN}$ _old $)<=10 \& \mathrm{abs}(\mathrm{PLA}$ _now $-\mathrm{PLA}$ _old $)<=0.1$

$\%$ if engine is accelerating without user input, the controller will be

$\%$ switch to decel mode (Move $=-1$ )

if $\mathrm{dN} \_\mathrm{pt}>0$

Move $=-1$;

Kp_now $=$ interpl $($ RefNgg_dec,Kp_dec,N,'pchip');

Ti now = interp 1(RefNgg_dec,Ti_dec,N,'pchip');

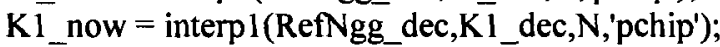

K2_now = interpl(RefNgg_dec,K2_dec, N,'pchip');

K3_now = interpl(RefNgg_dec,K3_dec,N,'pchip');

RefFuel_now = interp1(RefNgg_dec,RefFuel_dec,N,'pchip');

RefNgg_now = interpl(RefNgg_dec,RefNgg_dec,N,'pchip'); end

$\%$ if engine is Decelerating without user input, the controller will be

$\%$ switch to accel mode $($ Move $=1)$

if $\mathrm{dN} \_\mathrm{pt}<0$

Move $=1$;

Kp_now $=$ interp $1($ RefNgg,Kp,N,'pchip');

Ti_now = interp l(RefNgg,Ti,N,'pchip');

$\mathrm{K} 1$ - now = interp l(RefNgg,K1,N,'pchip');

K2_now = interp $1($ RefNgg,K2,N,'pchip');

K3_now = interp 1(RefNgg,K3,N,'pchip');

RefFuel_now = interpl(RefNgg,RefFuel,N,'pchip');

RefNgg_now = interp1(RefNgg,RefNgg,N,'pchip');

end

end

$\mathrm{dN}$ _old $=\mathrm{dN}$;

$\mathrm{dN} \_$pt_old $=\mathrm{dN} \_\mathrm{pt}$

$\% \%$ Check if engine is accelerating (Move $=1$ ) or Decelerating (Move $=-1$ )

$\% \%$ using PLA

if PLA_now $>$ PLA_old 


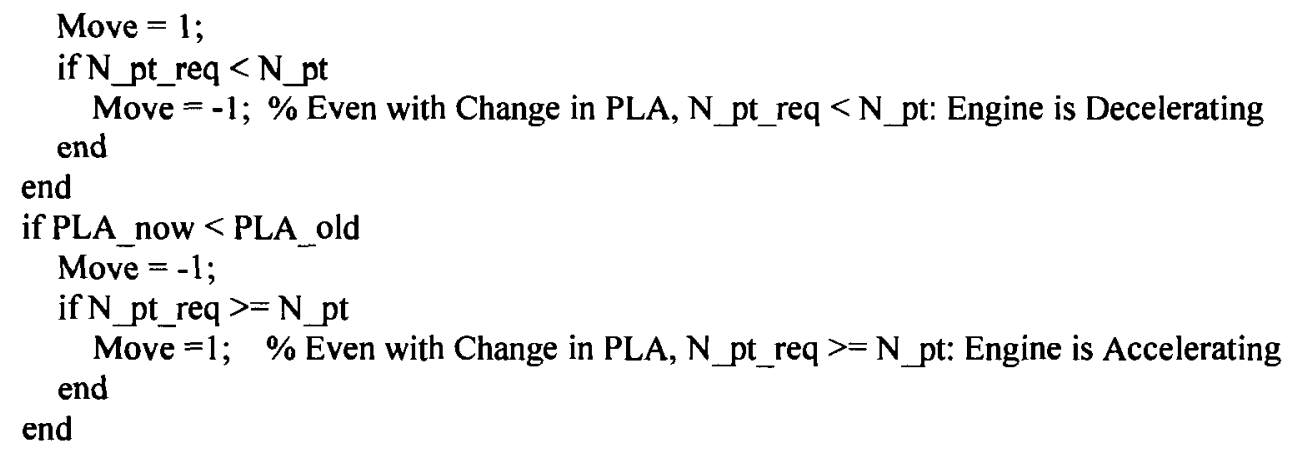

if Acc_FuelFlow_sched $<$ (Delta_FuelFlow + RefFuel_now) \& Move $>0$

Kp_now $=$ interp $1($ RefNgg,Kp,, ,'pchip');

Ti now $=$ interp $1($ RefNgg, Ti,N,'pchip');

K1_now = interpl $($ RefNgg,K1,N,'pchip');

K2_now = interp 1(RefNgg,K2,N,'pchip');

K3_now = interpl(RefNgg,K3,N,'pchip');

RefFuel_now = interp1(RefNgg, RefFuel,N,'pchip');

RefNgg_now = interpl(RefNgg,RefNgg,N,'pchip');

end

if Dec_FuelFlow_sched $>$ FuelFlow_Demand \& Move $<0$

Kp_now $=$ interpl $($ RefNgg_dec,Kp_dec,N,'pchip');

Ti now = interp 1 (RefNgg dec,Ti dec,N,'pchip');

Kİ_now = interpl(RefNgg_dec,K1_dec,N,'pchip');

K2_now = interpl(RefNgg_dec,K2_dec,N,'pchip');

K3_now $=$ interpl(RefNgg_dec,K3_dec,N,'pchip');

RefFuel now = interpl(RefNgg dec, RefFuel dec,N,'pchip');

RefNgg_now = interpl $($ RefNgg_dec,RefNgg_dec,N,'pchip');

end

if Acc_FuelFlow_sched $<$ (Delta_FuelFlow + RefFuel_now) $\mid$ Dec_FuelFlow_sched $>$ FuelFlow_Demand sumError $=0$;

end

\%\%\%\%\%\%\%\%\%\%\%\%\%\%\%\%\%\%\%\%\%\%\%\%\% End \%\%\%\%\%\%\%\%\%\%\%\%\%\%\%\%\%\%\%\%\%\%\%\%

$\% \% \% \% \% \% \% \% \% \% \% \% \% \% \% \% \% \% \%$ MP_Start.m $\% \% \% \% \% \% \% \% \% \% \% \% \% \% \% \% \% \%$

$\%$ This script calculates off design performance parameters and stores them

$\%$ in the file Starter.mat...

$\%$ Extrapolation Model ( As per Walsh and Fletcher "Gas turbine perfomance

\% book" P. 494

$\%$ Compressor Input and Turbine Output Power

$\%$ to get these values we will vary PowerOfftake to reach our limiter (TIT)

clear Start_Data;

clear Store;

MP_Inputs; 
load MP DesignPointData.mat

MP ScalingFactor;

MP_HPC01;

MP_HPT01;

MP_LPT01;

load MP_OffDesign_Data_load.mat

load MP LimiterData.mat

load MP_AccFuelSched.mat

warning off MATLAB:fzero:UndeterminedSyntax

$[$ relN loc] $=\min ($ TITLimit_Data(:,9));

TIT req = TIT Limit;

$\mathrm{N}$ lightOff $=$ relN LightOff. ${ }^{*} \mathrm{~N}$ GG;

N_ref = Interpl(TITLimit_Data(:,9),TITLimit_Data(:,8),relN,'spline');

N_pt = Interp I(TITLimit Data(:,9),TITLimit Data(:,36),relN,'spline');

BetaC = Interp I(TITLimit_Data(:,9),TITLimit_Data(:,10),relN,'spline');

BetaT = Interpl(TITLimit_Data(:,9),TITLimit_Data(:,26),relN,'spline');

BetaLPT = Interp1(TITLimit_Data(:,9),TITLimit_Data(:,37),reIN,'spline');

m_ref = Interp I(TITLimit_Data(:,9),TITLimit_Data(:,4),relN,'spline');

CPower_ref = Interp I(TITLimit_Data(:,9),TITLimit_Data(:,15),relN,'spline'); \% [kW]

HPTPower_ref = Interp1(TITLimit_Data(:,9),TITLimit_Data(:,28),relN,'spline'); \% [kW]

corrected_m_ref = Interp I(TITLimit_Data(:,9),TITLimit_Data(:,3),reIN,'spline');

PRc_ref $=$ Interp $1($ TITLimit_Data(:,9),TITLimit_Data(:, $\overline{1} 1)$,relN,'spline');

FuelFlow_ref = Interpl(TITLimit_Data(:,9),TITLimit_Data(:,20),relN,'spline');

Tol_now $=$ Interpl(OffDesign_Data_load(:,9),OffDesign_Data_load(:,5),relN,'spline');

Po2 = Interp1(TITLimit_Data(:,9),TITLimit_Data(:,14),relN,'spline');

Po4 = Interp 1 (TITLimit_Data(:,9),TITLimit_Data(:,31),relN,'spline');

$\%$ Basic Parasitic Losses

$\%$ Assume $=0$ for now

$P \_$parsitic $=0$;

\% Extrapolate Compressor Power using Cube Law (from ref to zero speed)

CPower start $=$ CPower ref. $*([0: \mathrm{N}$ ref $] . / \mathrm{N}$ ref $) .^{\wedge} 3 ; \%[\mathrm{~kW}]$

CTorque_start $=\left[0\left(\right.\right.$ CPower_start $\left(2: \operatorname{size}\left(\left[0: N \_r e f\right], 2\right)\right) . /\left(\left[1: N \_r e f\right] .{ }^{*}(2 *\right.$ pi./60) $\left.\left.)\right) *{ }^{*} 1000\right] ; \%[\mathrm{Nm}]$

\% Extrapolate Turbine Power using Cube Law (from ref to Light off speed

HPTPower_lightoff $=$ HPTPower_ref.*([N_lightOff:N_ref]./N_ref).^3; \% [kW]

HPTTorque_lightOff $=\left(\right.$ HPTPower_lightOff. $/\left(\left[\mathrm{N} \_\right.\right.$lightOff:N_ref $] .{ }^{*}\left(2^{*}\right.$ pi./60) $\left.)\right) .{ }^{*} 1000 ; \%[\mathrm{Nm}]$

$\%$ From Light off speed to zero speed

$\%$ Turbine Power is greatly reduced because it is proportional to TIT

$\%$ (walsh \& fletcher)

$\%$ They say that typically top of crank power $=25 \%$ Light off Power

$\%$ now extrapolate from this point to zero speed using this approach

HPTPower_crank $=\left(\right.$ HPTPower_lightOff(1). $\left.{ }^{*} 0.25\right) .{ }^{*}([0: \mathrm{N}$ lightOff-1]./N_lightOff $) . \wedge 3 ; \%[\mathrm{~kW}]$

HPTTorque_crank $=\left[0\right.$ (HPTPower_crank $\left(2: \operatorname{size}\left(\left[0: \mathrm{N} \_l i g h t O f f-I\right], 2\right)\right) . /\left(\left[\mathrm{I}: \mathrm{N} \_l i g h t O f f-\right.\right.$

1].*(2*pi./60))).*1000]; \%[Nm]

$\%$ Since parasitic losses have not been considered we will assume that

$\%$ the parasitic losses $=0$

HPTPower_start $=$ [HPTPower_crank HPTPower_lightOff]; 
HPTTorque_start $=[$ HPTTorque_crank HPTTorque_lightoff];

$\%$ Starter Motor Characteristic

MP_StarterMap;

N_StarterCutOff $=$ relN_StartCutOff. ${ }^{*}$ N_GG;

StarterTorque_CutOff $=$ interp 1(Starter_Speed,Starter_Torque,[0:N_StarterCutOff-1],'pchip');

StarterTorque_OFF $=0 . *[$ N_StarterCutOff:N_GG];

StarterTorque_start $=[$ StarterTorque_CutOff StarterTorque_OFF];

$\%$ Extrapolate Mass Flow Rates using Exponent Law (from ref to zero speed)

$\%$ Assuming that ratio of mass flow $=[\%$ Nnew $/ \%$ Nref $]$

corrected_m_start $=$ corrected_m_ref.* $\left(\left[0: N_{-}\right.\right.$ref $]$. $N_{-}$ref $)$;

$\mathrm{m}_{-}$start $=\mathrm{m}_{-}$ref. ${ }^{*}\left(\left[0: \mathrm{N} \_\right.\right.$ref $] . / \mathrm{N} \_$ref $)$;

$\%$ Extrapolate Pressure Ratio using Exponent Law (from ref to zero speed)

$\%$ Assume that ratio of ideal specific work $=[\% \text { Nnew } / \% \mathrm{Nref}]^{\wedge} 2$

$\%$ we know that (ideal spec work) $/ \mathrm{CpTo}=\left(1-(1 / \mathrm{PR})^{\wedge}((\mathrm{ycomb}-1) / \mathrm{ycomb})\right)=[\% \mathrm{Nnew} / \% \mathrm{Nref}]^{\wedge} 2$

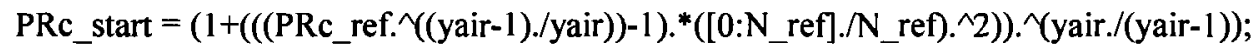

\% Collecting Data At Given TIT

Corr_m_Data $=$ [corrected_m_start $]$;

$m \_$Data $=\left[\mathrm{m} \_\right.$start $]$;

PRE_Data $=$ [PRc_start $]$;

StarterTorque_Data $=[$ StarterTorque_start $]$;

HPTTorque_Data $=$ [HPTTorque_start];

CTorque_Data $=[$ CTorque_start $]$;

$\%$ Start_Data $=$ [OffTake_Data];

$\% \% \%$ Start-up Fuel Schedule

$\%$ Assuming that Fuel Flow is Proportional to Power

$\%$ therefore Fuel flow will be proportional to speed cubed

$\%$ Note that Fuel Flow $=0$ Below Light off speed

$\%$ Start-up Fuel Schedule

$\%$ From Lightoff to RefSpeed

FuelFlow1_Start $=$ FuelFlow_ref.*([N_lightOff:N_ref-1]./N_ref).^3;

$\%$ From RefSpeed to Idle Speed (Schedule will reduce fuel to stop at

$\%$ Idle)

relN_range $=([\mathrm{N}$ ref: $100: \mathrm{Ngg}$ idle $] . / \mathrm{sqrt}($ Tol_now $)) . /\left(\mathrm{N} \_\mathrm{GG} . / \mathrm{sqrt}(\mathrm{Tol}\right.$ _des $\left.)\right)$;

FuelFlow_maxTiT $=$ Interpl(TITLimit_Data(:,9),TITLimit_Data(:,20),relN_range,'spline');

Delta_Fuel $=$ FuelFlow_maxTIT -

Interp 1(OffDesign_Data_load(:,9),OffDesign_Data_load(:,20),relN_range,'spline');

FuelFlow2_Start $=$ FuelFlow_maxTIT $-\left(\right.$ Delta_Fuel.* $\left[\left[N_{-}\right.\right.$ref: 100 :Ngg_idle]-N_ref]./(Ngg_idle-N_ref));

\% Total Startup Fuel Flow

FuelFlow_Start $=[$ FuelFlow1_Start FuelFlow2_Start $]$; 

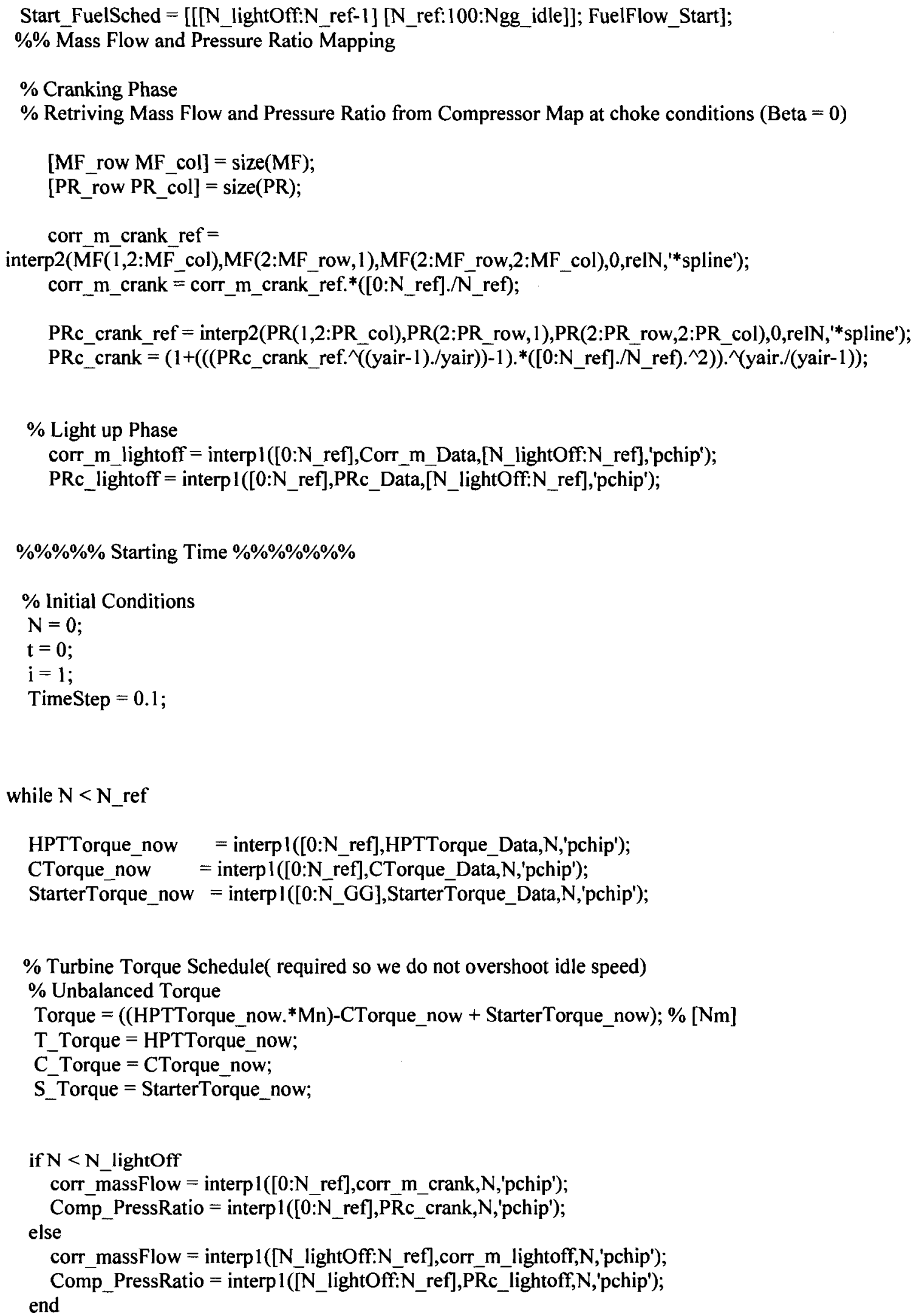


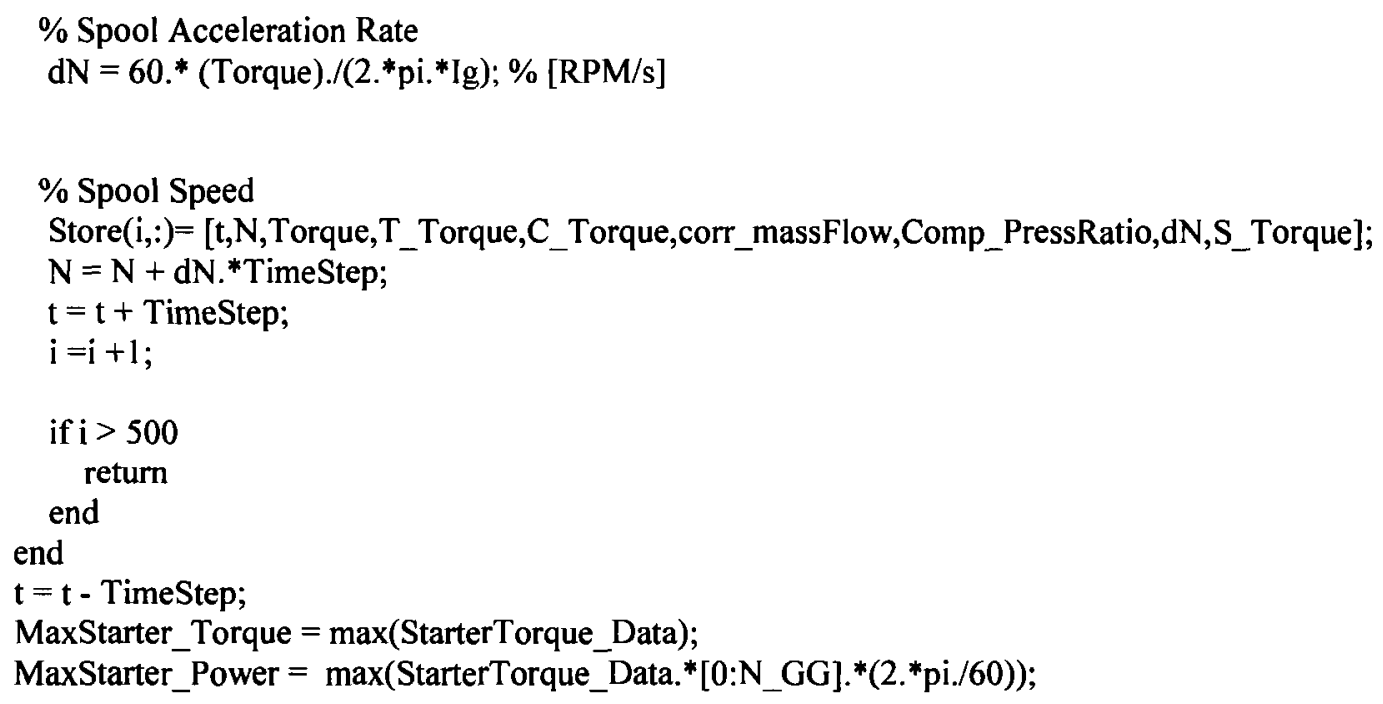

$\% \% \% \% \%$ Dynamic Modeling \%\%\%\%

$\%$ Using dynamic model from $\mathrm{N} \_$ref to $\mathrm{N} \_$idle $\%$ inital conditions

N_pt = Interp1(TITLimit_Data(:,8),TITLimit_Data(:36),N,'spline');

BetaC = Interp I(TITLimit_Data(:,8),TITLimit_Data(:, I0), N,'spline');

BetaT = Interp I(TITLimit_Data(:,8),TITLimit_Data(:,26),N,'spline');

BetaLPT = Interp 1(TITLimit_Data(:,8),TITLimit_Data(:,37),N,'spline');

ma = Interp 1(TITLimit_Data(:,8),TITLimit_Data(:,4),N,'spline');

FuelFlow = Interp1 (TITLLimit_Data(:,8),TITLimit_Data(:,20),N,'spline');

Po2 = Interp I(TITLimit_Data(:,8),TITLimit_Data(:,14),N,'spline');

Po4 = Interp 1(TITLimit_Data(:,8),TITLimit_Data(:,31),N,'spline');

$\mathrm{x}$ guess $=[$ BetaC BetaT BetaLPT Po4 $]$;

$\mathrm{ii}=1$;

dN_pt $=0$;

FuelFlow_now = FuelFlow;

while $(\operatorname{abs}(\mathrm{dN})<=1)+\left(\operatorname{abs}\left(\mathrm{dN} \_\right.\right.$pt $\left.)<=1\right)<2$

FuelFlow_now =interpl([[N_lightOff:N_ref-1] [N_ref:100:Ngg_idle]],FuelFlow_Start,N,'pchip');

StarterTorque_now = interpl $\left(\left[0: N \_G G\right]\right.$,StarterTorque_Data,N,'pchip');

$\%$ calculate new conditons based on fuel step

[IVM_Newton, IVM_Matx] = MP_IVM_NewtonRap(N,N_pt,FuelFlow_now,Po2,x_guess,ma);

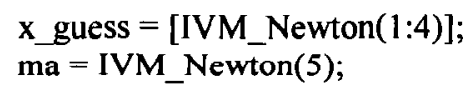

$\%$ and for the Power Turbine 
$\mathrm{dN} \_\mathrm{pt}=60 .{ }^{*} 1000 .{ }^{*}\left(\left(\mathrm{IVM} \_\operatorname{Matx}(47) .{ }^{*} \mathrm{Mn} .{ }^{*} \mathrm{GBn}\right)-\mathrm{IVM} \_\operatorname{Matx}(49)\right) . /\left(2 .{ }^{*} \mathrm{pi} .{ }^{*} \operatorname{Ig} \_\mathrm{pt}\right) ; \%[\mathrm{RPM} / \mathrm{s}]$

$\% \% \% \% \% \% \% \% \% \% \% \% \% \% \% \% \% \%$ Rate of Change of Pressure in a Volume $\% \% \% \% \% \% \% \% \% \% \% \% \% \% \%$

$\%$ we know that $\mathrm{dP} / \mathrm{dt}=\left(\mathrm{m}_{-} \text {in }-\mathrm{m}_{-} \text {out }\right)^{*}\left(\left(\mathrm{~T}^{*} \mathrm{Ra}\right) /\right.$ Volume $)$

$\%$ therfore for the combustor we have: $\mathrm{dPo} 2 / \mathrm{dt}=(\mathrm{m} 2+$ FuelFlow $-\mathrm{m} 31) *(\mathrm{To} 2 * \mathrm{Ra}) /(\mathrm{Vcomb}+\mathrm{Vplenum})$

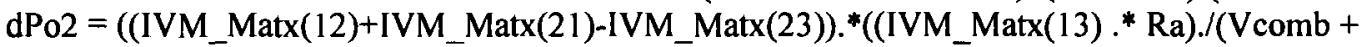
Vplenum) $)) . / 1000 ; \%[\mathrm{kPa} / \mathrm{s}]$

TimeStep $=0.005$;

$\%$ Euler Explicit scheme

$\mathrm{N}=\mathrm{N}+\mathrm{dN}$.*TimeStep;

$\mathrm{N} p \mathrm{pt}=\mathrm{N} \_\mathrm{pt}+\mathrm{dN}$ pt.*'TimeStep;

Po2 $=$ Po2 + dPo2. ${ }^{*}$ TimeStep;

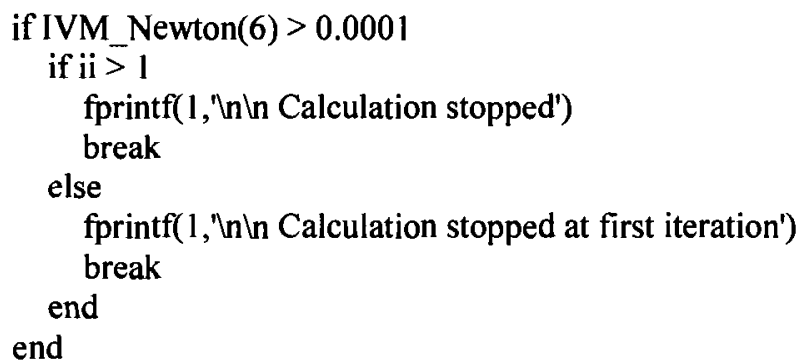

$\%$ Thermodynamic Cycle Data

Start_Data(ii,:)=[t IVM_Matx dN dN_pt dPo2 TimeStep IVM_Newton(6) StarterTorque_now];

\% Note that: IVM_Store $=[\mathrm{t}$ Toa Poa corr_m $1 \mathrm{~m} 1$ To1 Pol Cnisen N relN BetaC PRc $\mathrm{m} 2$ To2 Po2 CPower Gc m3 To3 Po3...

$\% \quad$ Bn FuelFlow corr_m31_calc m31 Po31 HPTnisen relN_turb BetaT HPTPR HPTPower Gt m4 To4 Po4...

$\% \quad$ m4l To4l Po4l corr_m41_calc N_pt relN_PTurb BetaLPT LPTPR LPTnisen m5 To5 Po5 LPTPower Gpt ShaftPower Gprop SFC_SI...

$\% \quad$ Thermal_Efficiency PropPower $\bar{d} \mathrm{~N} d N \_p t d P o 2$ TimeStep Error_square StarterTorque_now]

$\mathrm{t}=\mathbf{t}+$ TimeStep;

$\mathrm{ii}=\mathrm{ii}+1$;

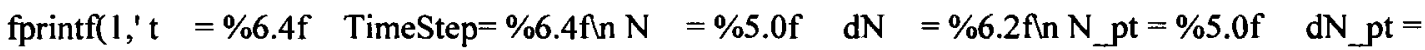
$\% 6.2 \mathrm{fln}$ Po2 $=\% 6.2 \mathrm{f} \quad \mathrm{dPo} 2=\% 6.2 \mathrm{fn}$ InFuelFlow $=\% 6.3 \mathrm{f} \ln \backslash n$ ',t, TimeStep, N, dN, N_pt, dN_pt, Po2, dPo2,FuelFlow_now)

end

end

\%\%\%\%\%\%\%\%\%\%\%\%\%\%\%\%\%\%\%\%\%End \%\%\%\%\%\%\%\%\%\%\%\%\%\%\%\%\%\%\%\%\%\%\%\%\%\%\% 
\%\%\%\%\%\%\%\%\%\%\%\%\%\%\% MP_StaterMap.m \%\%\%\%\%\%\%\%\%\%\%\%\%\%\%\%\%\%\%

$\%$ Nominal Starter Performance

$\%$ Series filed and open shunt windings at $77 \mathrm{deg} F$

$\% \%$ The starter assist curve is considered typicale for $28 \mathrm{~V}$ at 0 def $\mathrm{F}$

$\% \%$ Starter map found in a Paper by "R.K Agrawal and M.Yunis"

$\% \%$ " A Generalized Mathematical Model to Estimate Gas Turbine Starting

$\% \%$ Characterisitics "

$\%$ this map is only used as an example... in futur simulations the

$\%$ manufacturer's curves should be implemented in a similar fashion.

$\%$ image(imread('Starter Characteristic.jpg','jpg'))

$\%$ axis off

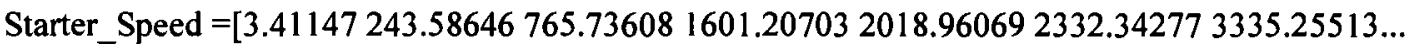
3847.243164380 .161625101 .232425383 .437996940 .92725 8979.25195]; \% [RPM]

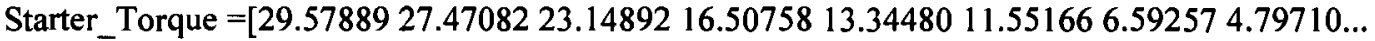
$3.211931 .624551 .410721 .392501 .36866] .^{*} 1.355817952 ; \%[\mathrm{Nm}]$ As per

OnlineConversion.com

$\% \% 800$ Amps Start Up

$\%$ Starter_Speed $=\left[\begin{array}{ll}14.957063732 .794923879 .002694046 .116214296 .841314652 .120125059 .66357 \ldots\end{array}\right.$

$\% \quad$ \% 5561.283695989 .793956449 .650886846 .826177432 .191418017 .556649000 .13379$] ; \%$

[RPM]

$\%$

$\%$ Starter_Torque $=\left[\begin{array}{ll}39.052439 .430028 .270427 .110575 .844484 .787693 .73029 & 2.671802 .14047 \ldots\end{array}\right.$

$\% \quad \quad \quad 1.503511 .183081 .176231 .169381 .15789] .{ }^{*} 1.355817952 ; \%[\mathrm{Nm}]$ As per

OnlineConversion.com

$\% 8$ Volts

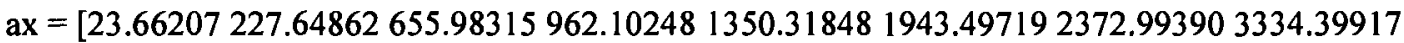

$4295.757815052 .572276463 .928227466 .195809000 .27930]$;

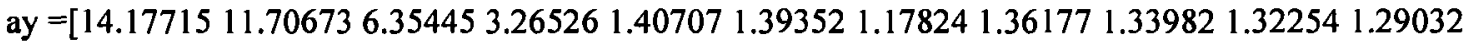
$1.267431 .23241]$.*1.355817952;

$\% 12$ Volts

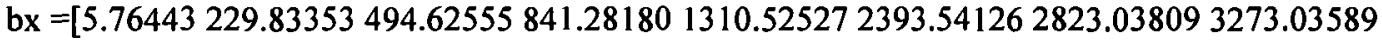

4275.25684 6320.65430 8898.00684];

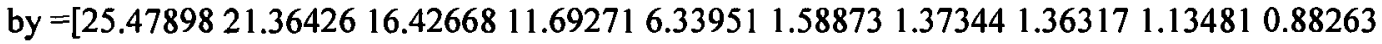

1.23474].* 1.355817952;

$\% 16$ Volts

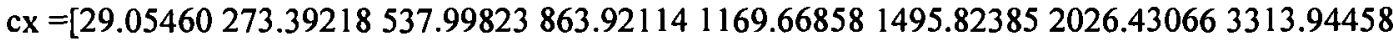

$3825.259285113 .935558938 .91602]$;

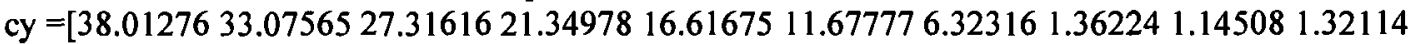

1.23381].*1.355817952;

$\% 20$ Volts 


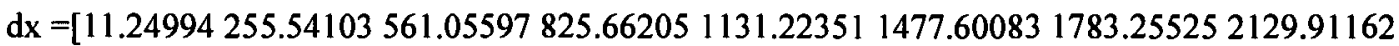
$2742.335944275 .349614848 .027837486 .650398938 .91602]$;

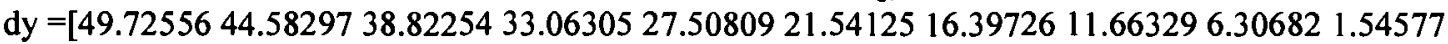
1.32721 1.26697 1.23381].* 1.355817952;

$\% 24$ Volts

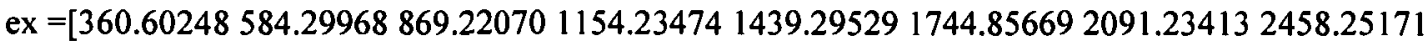

2845.81689 3478.74243 4255.36035 5134.38965 5850.29541 8938.91602];

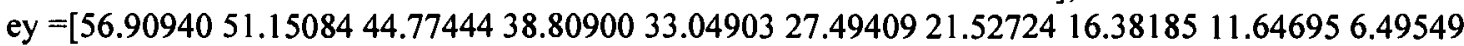

$3.601031 .320671 .304331 .23381] . * 1.355817952$;

$\% 28$ Volts

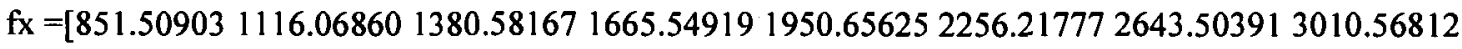

$3459.450204153 .738775196 .171396463 .975107016 .198248938 .91602]$;

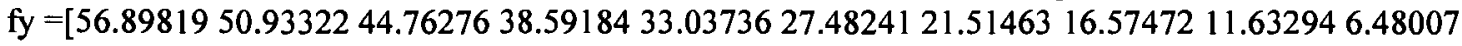

$3.168591 .495801 .277711 .23381] . * 1.355817952$;

$\mathrm{gx}=\left[\begin{array}{ll}0 & 1656.06982\end{array}\right]$

$\mathrm{gy}=[39.0526739 .03323] .^{*} 1.355817952 ; \% 800$ amps line

$\mathrm{hx}=\left[\begin{array}{lll}34.527512261 .01758 & \text {; }\end{array}\right.$

hy $=[27.4732627 .55248] .^{*} 1.355817952 ; \% 600$ amps line

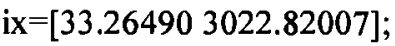

iy $=\left[\begin{array}{lll}16.52592 & 16.59621\end{array}\right] * 1.355817952 ; \% 400$ amps line

$\mathrm{jx}=[617.464484108 .78516]$;

$\mathrm{j} y=[6.413836 .68878] . * 1.355817952 ; \% 200$ amps line

\% Torque Vs RPM Eqn

Starter_eqn = interpl $($ Starter_Speed,Starter_Torque,[0:10000],'pchip');

$\operatorname{plot}([0: 10000]$, interp 1 (Starter_Speed,Starter_Torque,[0:10000],'pchip'),'r')

$\%$ hold on

$\% \%$ plot(Starter_Speed,Starter_Torque,'m')

$\%$

$\%$ plot(ax,ay,'b',bx,by,'b',cx,cy,'b',dx,dy,'b',ex,ey,'b',fx,fy,'b')

$\% \operatorname{plot}(g x, g y, ' k$ ',hx,hy,'k',ix,iy,'k',jx,jy,'k')

$\%$ hold off

\%\%\%\%\%\%\%\%\%\%\%\%\%\%\%\%\%\%\%\%\%\%\%\%\% End \%\%\%\%\%\%\%\%\%\%\%\%\%\%\%\%\%\%\%\%\%\%\%\% 